89/2012 Sb.

ACT

of 3 February 2012

the Civil Code

the Parliament has adopted the following Act of the Czech Republic:

BOOK ONE

\title{
GENERAL PROVISIONS
}

\author{
TITLE I
}

\section{SCOPE OF REGULATION AND ITS BASIC PRINCIPLES}

\section{Chapter 1}

\section{Private law}

\section{Section 1 [Recodification]}

(1) The provisions of the legal order governing the mutual rights and duties of persons together constitute private law. The application of private law is independent of the application of public law.

(2) Unless expressly prohibited by a statute, persons can stipulate rights and duties by way of exclusion from a statute; stipulations contrary to good morals, public order or the law concerning the status of persons, including the right to protection of personality rights, are prohibited.

\section{Section 2 [Recodification]}

(1) Each provision of private law may be interpreted only in accordance with the Charter of Fundamental Rights and Freedoms and the constitutional order in general, the principles underlying this Act, and considering at all times the values that it protects. Should the interpretation of a provision diverge from this imperative solely on the basis of its wording, the imperative prevails.

(2) Statutory provisions may not be given a meaning other than that which follows from the actual sense of the words in their mutual context and from the evident intention of the legislature; however, no one may invoke the wording of a legal regulation contrary to its sense.

(3) The interpretation and application of a legal regulation must not be contrary to good morals and must not lead to cruelty or inconsiderate behaviour offensive to ordinary human feelings.

\section{Section 3 [Recodification]}

(1) Private law protects the dignity and freedom of an individual and his natural right to pursue his own happiness and the happiness of his family or people close to him in a way that does not unreasonably harm others.

(2) Private law primarily relies on the following principles:

a) everyone has the right to protect his life and health, as well as freedom, honour, dignity and privacy,

b) family, parenthood and marriage enjoy special statutory protection,

c) no one may sustain unjustified harm due to insufficient age, mental capacity or dependency; however, no one may unreasonably benefit from his own inability to the detriment of others,

d) a promise is binding and contracts are to be executed,

e) right of ownership is protected by statutes, and only a statute can prescribe how the right of ownership is created and extinguished, and

f) no one may be denied what he is rightfully entitled to.

(3) Private law also stems from other generally recognised principles of justice and law.

\section{Section 4 [Recodification]}

(1) Every person having legal capacity is presumed to have the intellect of an average individual and the ability to use it with ordinary care and caution, and anybody can reasonably expect every such person to act in that way in legal transactions. 
(2) Where the legal order makes a specific consequence dependent on one's knowledge, it means knowledge reasonably acquired by a person knowledgeable of the case having considered the circumstances which must have been obvious to him in his capacity. This applies by analogy if the legal order connects a certain consequence with the existence of a doubt.

\section{Section 5 [Recodification]}

(1) A person who offers professional performance as a member of an occupation or profession, whether publicly or in dealings with another person, demonstrates his ability to act with the knowledge and care associated with his occupation or profession. If the person fails to act with such professional care, he bears the consequences.

(2) The nature or validity of a juridical act may not be challenged against the will of the person affected only because the person who made the act was not duly authorised or was prohibited to do so.

\section{Section 6 [Recodification]}

(1) Everyone is obliged to act fairly in legal transactions.

(2) No one may benefit from acting unfairly or unlawfully. Furthermore, no one may benefit from an unlawful situation which the person caused or over which he has control.

$$
\text { Section } 7 \text { [Recodification] }
$$

A person who acted in a certain way is presumed to have acted fairly and in good faith.

$$
\text { Section } 8 \text { [Recodification] }
$$

Evident abuse of a right does not enjoy legal protection.

\section{Chapter 2}

\section{Application of the rules of civil law}

\section{Section 9 [Recodification]}

(1) The Civil Code governs the personal status of persons.

(2) Private rights and duties of a personal and proprietary nature are governed by the Civil Code to the extent that they are not governed by other legal regulations. Usages may be considered where invoked by a statute.

\section{Section 10 [Recodification]}

(1) Where a legal case cannot be decided on the basis of an express provision, it is assessed under the provisions concerning the legal case which is, in terms of its content and purpose, the closest possible to the case under consideration.

(2) In the absence of such a provision, the legal case is to be assessed under the principles of fairness and the principles underlying this Act in order to arrive at a good arrangement of rights and duties, having regard to the practice of private life and taking into account the state of legal opinion and established decision-making practice.

\section{Section 11 [Recodification]}

General provisions concerning the creation, change and extinction of rights and duties arising from obligations under Book Four of this Act apply, with the necessary modifications, to the creation, change and extinction of other private rights and duties.

\section{Chapter 3}

\section{Protection of private rights}

\section{Section 12 [Recodification}

Anyone who feels that his rights have been prejudiced may claim the protection of a body executing public authority (hereinafter a "public body"). Unless otherwise provided by a statute, the public body is a court.

\section{Section 13 [Recodification]}

Anyone seeking legal protection may reasonably expect that his legal case will be decided similarly to another legal case that has already been decided and that coincides in essential aspects with his legal case; where the legal case has been decided differently, anyone seeking legal protection has the right to a persuasive explanation of the reasons for such a variance.

Section 14 [Recodification] 
(1) Anyone may, in a reasonable manner, help himself to his rights, if such rights are endangered and it is evident that public authority action would come too late.

(2) Where an unlawful interference with one's right is imminent, anyone so threatened may use effort and resources that a person in his position and under the given circumstances must consider appropriate to avert such encroachment. However, if self-help is only aimed at securing a right that would otherwise be frustrated, the person exercising self-help must, without undue delay, contact the competent public body.

\section{TITLE II}

\section{PERSONS}

\section{Chapter 1}

\section{General provisions}

\section{Section 15 [Recodification]}

(1) Legal personality is the capacity to have rights and duties within the legal order. juridical acts)

(2) Legal capacity is the capacity to acquire rights and assume duties for oneself by making juridical acts (to make

\section{Section 16 [Recodification]}

No one may surrender his legal personality and legal capacity, neither in full, nor in part; doing so is disregarded.

\section{Section 17}

(1) Only persons may have and exercise their rights. Duties may only be imposed upon and their performance enforced in relation to persons.

(2) If anyone creates a right or imposes a duty upon something other than a person, such a right or duty is attributed to the person to whom it belongs according to the legal nature of the case.

\section{Section 18}

There are either natural, or legal persons.

\section{Section 19 [Recodification]}

(1) Every individual has innate natural rights knowable by the very reason and feelings, and therefore is considered to be a person. A statute only provides for the limits of application and the manner of protection of the natural rights of an individual.

(2) Natural rights associated with the personality of an individual may not be alienated and may not be waived; should this occur, it is disregarded. The limitation of these rights to the extent contrary to a statute, good morals or public order is also disregarded.

\section{Section 20 [Recodification]}

(1) A legal person is an organised body whose legal personality is provided or recognised by a statute. A legal person may, without regard to its objects of activities, have rights and duties consistent with its legal nature.

(2) Legal persons governed by public law are subject to statutes under which they have been established; the provisions of this Act only apply if they are consistent with the legal nature of these persons.

\section{Section 21 [Recodification]}

Within private law, the State is considered to be a legal person. Another legal regulation provides for the manner in which the State makes juridical acts.

\section{Section 22 [Recodification]}

(1) A close person is a relative in the direct line, sibling and spouse or a partner under another statute governing registered partnership (hereinafter a "partner"); other persons in a familial or similar relationship shall, with regard to each other, be considered to be close persons if the harm suffered by one of them is perceived as his own harm by the other. Persons related by affinity and persons permanently living together are also presumed to be close persons.

(2) If a statute provides specific conditions or limitations for the protection of third persons regarding the transfer or encumbrance of property or the relinquishment of property to another for his use between close persons, these conditions and limitations shall also apply to similar juridical acts between a legal person and a member of its governing body or a person exercising substantial influence over the legal person as its member or based on an agreement or another fact. 


\section{Chapter 2}

\section{Natural persons}

\section{Division 1}

\section{General provisions}

\section{Section 23}

An individual has legal personality from birth to death.

\section{Section 24}

Every individual is responsible for his own actions, if he is able to assess and control them. A person who induces upon himself a self-inflicted condition which would otherwise preclude the responsibility for his actions is responsible for the actions taken under this condition.

\section{Section 25}

A conceived child is considered to be already born if it suits the child's interests. A child is presumed to have been born alive. However, if the child is not born alive, he is considered never to have existed.

\section{Section 26}

\section{Proof of death} prescribed.

(1) The death of an individual is proved by a public instrument issued after examining the dead body in a manner

(2) Where a dead body cannot be examined in the manner prescribed, a court shall, even of its own motion, declare the individual dead if the individual was involved in such an event that his death, given the circumstances, seems certain. In its decision, the court shall specify the date established as the date of death.

\section{Section 27}

If a legal consequence is dependent on an individual surviving another individual, and it is not certain which of them died first, they are all presumed to have died at the same time.

\section{Section 28}

(1) If it is not known where an individual died, he is presumed to have died where his body was found.

(2) The place where an individual declared dead last dwelled when he was alive is conclusively presumed to be the place where he died.

\section{Section 29 [Recodification]}

\section{Sex change}

(1) Sex change of an individual takes place by surgery while simultaneously disabling the reproductive function and transforming the genitalia. The date of the sex change is presumed to be the date indicated in the certificate issued by the health care provider.

(2) Sex change does not affect the personal status of an individual or his personal and property situation; however, marriage or registered partnership terminate. The rights and duties of a man and woman whose marriage terminated to their common child and their property rights and duties at the period following the termination of marriage are governed, by analogy, by the provisions on the rights and duties of divorced spouses to their common child and on their property rights and duties at the period following the divorce; a court shall decide, even of its own motion, on the care each of the parents will take of their common child thereafter.

\section{Section 30 [Recodification]}

\section{Age of majority}

(1) An individual acquires full legal capacity upon reaching the age of majority. The age of majority is reached upon reaching eighteen years of age.

(2) Before reaching the age of majority, full legal capacity is acquired by being granted legal capacity or by entering into marriage. Legal capacity acquired by entering into marriage is not terminated upon termination or invalidation of marriage. 


\title{
Section 31 [Recodification]
}

Any minor who has not yet acquired full legal capacity is presumed to be capable of making juridical acts which are, as to their nature, appropriate to the intellectual and volitional maturity of the minors of his age.

\section{Section 32 [Recodification]}

(1) Where, in accordance with the usages of private life, a legal representative has granted a minor who has not yet acquired full legal capacity his consent to make a particular juridical act or achieve a specific purpose, the minor is capable of making juridical acts within the consent so granted, unless specifically prohibited by a statute; the consent may be subsequently limited or withdrawn.

(2) Where there are multiple legal representatives, it is sufficient if at least one of them expresses his will towards a third person. However, if there are multiple representatives performing acts towards another person together and these acts are contradictory, their expressions of will are disregarded.

\section{Section 33 [Recodification]}

(1) If the legal representative of a minor who has not yet acquired full legal capacity grants his consent to the independent operation of a business enterprise or another similar gainful activity, the minor becomes capable of making acts related to this activity. The validity of the consent is subject to the leave of a court.

(2) The leave of a court substitutes the condition of a certain age, if required to perform a gainful activity by another legal regulation.

(3) The legal representative may withdraw his consent only with the leave of a court.

\section{Section 34}

Dependent work of minors under the age of fifteen years or minors who have not completed compulsory education is prohibited. These minors may perform only artistic, cultural, advertising or sporting activities under the conditions laid down in another legal regulation.

\section{Section 35 [Recodification]}

(1) A minor who has reached the age of fifteen years and completed compulsory education may undertake to perform dependent work under another legal regulation.

(2) The legal representative of a minor who has not reached the age of sixteen years may terminate the minor's employment or a job contract creating a similar obligation between an employee and the employer if it is necessary in the interests of upbringing, development or health of the minor, in the manner provided by another legal regulation.

\section{Section 36}

Notwithstanding the content of other provisions, a minor who has not acquired full legal capacity shall in no case have the capacity to act independently in the matters in which his legal representative would need the leave of a court.

\section{Section 37 [Recodification]}

\section{Granting legal capacity}

(1) If a minor without full legal capacity applies to a court to be awarded legal capacity, the court shall grant the application if the minor has reached the age of sixteen years, if his ability to provide for his maintenance and take care of his matters has been proved, and if the legal representative of the minor consents to such an application. In other cases the court shall grant the application if it is in the interest of the minor for serious reasons.

(2) Under the conditions set out in Subsection (1), the court shall also grant legal capacity to a minor on the application of his legal representative if the minor consents to the application.

\section{Division 2}

\section{Subsidiary measures in the case of disrupted capacity of an adult to make juridical acts}

\section{Declaration in anticipation of incapacity}

\author{
Section 38 [Recodification]
}

In anticipation of one's own lack of capacity to make juridical acts, an individual may express the will to have his matters managed in a certain way or by a certain person, or to have a specific person become his guardian.

\section{Section 39 [Recodification]}

(1) Unless the declaration has the form of a public instrument, it must be made by a private instrument dated and acknowledged by two witnesses; in the acknowledgement, the witness shall provide his personal information which allows the witness to be identified. 
(2) Only persons without any interest in the declaration and its contents who are not blind, deaf, mute or ignorant of the language in which the declaration is made may become witnesses. Witnesses must sign the declaration and be able to confirm the ability of the declarant to perform acts and the content of his declaration.

(3) Where the content of the declaration made by a public instrument determines who is to become the guardian, the person who wrote the public instrument shall record information about the identity of the person who made the declaration, the person who is selected to act as the guardian and the person who wrote the public instrument in a non-public list maintained under another statute.

\section{Section 40 [Recodification]}

(1) Where the declaration is made by a blind person or a person who cannot or is not able to read or write, the declaration must be read aloud to the person by a witness who did not write the declaration. A blind person or a person who cannot or is not able to read or write shall confirm before witnesses that the instrument contains his true will.

(2) Where a declaration is made by a person with a sensory disability who cannot read or write, the contents of the instrument must be interpreted to the person in the way of communication of his choosing and by a witness who did not write the declaration; all witnesses must have command of the way of communication which is used to interpret the content of the instrument. The declarant shall acknowledge before witnesses in the way of communication of his choosing that the instrument contains his true will.

\section{Section 41 [Recodification]}

(1) Express withdrawal of the declaration requires the expression of will made in the form prescribed in Section 39(1).

(2) If the instrument containing the declaration is destroyed by the declarant, it has the effect of revocation.

\section{Section 42 [Recodification]}

Where the declaration concerns matters other than selecting a person to act as a guardian and its effectiveness is conditional, the fulfilment of the condition is decided by a court.

\section{Section 43 [Recodification]}

If the circumstances evidently change in such a substantial way that, under such circumstances, the declarant would not have made the declaration or would have made a declaration with different contents, a court shall amend or cancel the declaration if the declarant were otherwise under a threat of serious harm. Before making any decision, the court shall make the necessary effort to obtain the opinion of the individual whose declaration is subject to the court's decision, also using the way of communication of the individual's choosing.

\section{Section 44 [Recodification]}

If the declaration or its revocation is invalid, the court shall take it into account, unless there is cause to doubt the will of the declarant.

\section{Assistance in decision-making}

\section{Section 45 [Recodification]}

If an individual needs assistance in decision-making due to complications resulting from his mental disorder, even where his legal capacity has not been limited, he and the assisting person may agree on the provision of assistance; there may be multiple assisting persons.

\section{Section 46 [Recodification]}

(1) By concluding a contract for assistance, the assisting person undertakes, subject to the consent of the person receiving assistance, to be present at his legal proceedings, provide him with the necessary information and communications and assist him by giving advice.

(2) The contract becomes effective on the date on which it is approved by a court. Unless the contract has been executed in writing, the parties are required to express their will to execute the contract before a court. If the interests of the assisting person are contrary to the interests of the person receiving assistance, the court shall not approve the contract.

\section{Section 47 [Recodification]}

(1) The assisting person must not jeopardise the interests of the person receiving assistance by exerting improper influence or unjustly enrich himself at the expense of the person receiving assistance.

(2) In carrying out his duties, the assisting person shall proceed in accordance with the decisions of the person receiving assistance. If the person receiving assistance makes a juridical act in writing, the assisting person may affix his signature, indicating his position and, where applicable, the support provided to the person receiving assistance; the assisting person may also invoke the invalidity of the juridical act made by the person receiving assistance. 
On the application of the person receiving assistance or the assisting person, a court shall remove the assisting person; the court shall also remove him, even of its own motion, if the assisting person commits a substantial breach of his duties.

\title{
Representation by a household member
}

\author{
Section 49 [Recodification]
}

(1) If a mental disorder prevents an adult who has no other representative to make juridical acts, he may be represented by his descendant, ancestor, sibling, spouse or partner, or a person who had lived with the person represented in a common household before the creation of representation for at least three years.

(2) The representative shall inform the person represented that he will represent him, and shall clearly explain to him the nature and consequences of representation. If the person to be represented refuses that, the representation is not created; the ability to make a wish is sufficient to express the refusal.

\section{Section 50 [Recodification]}

The creation of representation must be approved by a court. Before making any decision, the court shall make the necessary effort to obtain the opinion of the person represented, also using the way of communication chosen by the person represented.

\section{Section 51 [Recodification]}

The representative shall ensure the protection of the interests of the person represented and the exercise of his rights as well as make sure that his way of life is not in conflict with his abilities and that, unless it can be reasonably challenged, it corresponds to the specific ideas and wishes of the person represented.

\section{Section 52 [Recodification]}

(1) Representation covers ordinary matters, as is consistent with the life circumstances of the person represented. However, the representative may not give consent to an interference in mental or physical integrity of the individual with permanent consequences.

(2) The representative may dispose of the income of the person represented to the extent necessary to arrange ordinary matters, as is consistent with the life circumstances of the person represented; however, the representative may dispose of the funds deposited in the account of the person represented only to the extent which does not exceed the amount of monthly level for an individual under another legal regulation.

\section{Section 53 [Recodification]}

If the person represented has multiple representatives, an act of one of them shall suffice. However, if there are multiple representatives performing acts towards another person together and these acts are contradictory, their expressions of will are disregarded.

\section{Section 54 [Recodification]}

(1) Representation is extinguished if waived by the representative, or if the person represented refuses to be further represented by the representative; the ability to make a wish is sufficient to express the refusal. Representation is also extinguished if a court appoints a guardian of the person represented.

(2) If a contract for assistance in decision-making is concluded, representation is extinguished on the effective date of the contract to the extent in which the person represented is capable of making juridical acts.

\section{Limitation of legal capacity}

\section{Section 55 [Recodification]}

(1) Legal capacity may only be limited in the interests of the individual concerned, after he has been seen by a court and with full recognition of his rights and his personal uniqueness. In so doing, the extent and degree of the individual's inability to take care of his own matters must be carefully taken into account.

(2) An individual's legal capacity may only be limited if he were otherwise under a threat of serious harm and unless milder and less restrictive measures suffice to protect his interests.

\section{Section 56 [Recodification]}

(1) An individual's legal capacity may only be limited by a court.

The court shall take all the necessary steps to obtain the opinion of the individual whose legal capacity is subject to the court's decision also using the way of communication of the individual's choosing.

\section{Section 57 [Recodification]}

(1) A court may limit the legal capacity of an individual to the extent to which the individual is unable to make juridical acts due to a mental disorder which is not only temporary, and shall define the extent to which it has limited the capacity of the 
individual to make independent juridical acts.

(2) If an individual has difficulty to communicate, this is not in itself a reason to limit his legal capacity.

\section{Section 58 [Recodification]}

During the proceedings on the limitation of legal capacity, a court may entrust a third person with making certain individual juridical acts or administering property, if it is necessary to prevent serious harm.

\section{Section 59 [Recodification]}

A court may limit legal capacity in connection with a certain matter for a period necessary to arrange such matter, or for an otherwise defined definite period not exceeding three years; legal effects of the limitation are extinguished upon the expiry of that period. However, if proceedings to extend the period of limitation are initiated within this period, the legal effects of the original decision shall last until a new decision has been made, but no longer than one year.

\section{Section 60 [Recodification]}

If the circumstances change, a court shall, even of its own motion, change or cancel its decision without delay.

\section{Section 61 [Recodification]}

If a court decides to limit the legal capacity of an individual, the person selected by the court to act as a guardian may apply for appointment as a guardian; if he does not file such an application, the court shall obtain his opinion. If this person is eligible to become a guardian, the court shall, with his consent, appoint the person as a guardian.

\section{Section 62 [Recodification]}

In its decision to limit the legal capacity of an individual, a court shall appoint a guardian for the individual. When choosing a guardian, the court shall take into account the wishes of the ward, his needs as well as the suggestions of close persons of the ward, provided that they pursue his well-being, and ensure that by choosing a guardian the court does not establish a relationship of mistrust of the ward towards the guardian.

\section{Section 63 [Recodification]}

A person lacking legal capacity, or a person whose interests are contrary to the interests of the ward, or the operator of a facility where the ward stays or which provides him with services, or a person dependent on such a facility, may not be appointed as a guardian.

\section{Section 64 [Recodification]}

The decision to limit the legal capacity does not deprive an individual of the right to individually make juridical acts in ordinary matters of everyday life.

\section{Section 65 [Recodification]}

(1) If the ward acted on his own without being allowed to act without a guardian, his juridical act may only be declared invalid if it has caused him harm. However, if a change of scope of the duties of the ward is sufficient as a remedy, the court shall do so without being bound by the parties' motions.

(2) If the ward acted on his own without being allowed to act without a guardian, the act of the former is considered to be valid if approved by the guardian. This also applies if the person acting approved such a juridical act himself after acquiring legal capacity.

\section{Division 3}

\section{Absent persons}

\section{Section 66 [Recodification]}

(1) A court may declare an individual having legal capacity who has left his residence, has not provided any information about himself and whose whereabouts are unknown to be an absent person. In its decision, a court shall state the day on which the declaration of absence became effective.

(2) A person may be declared absent on the application of a person with a legal interest in such a declaration, in particular a spouse or another close person, a co-owner, employer or a corporation in which the individual has interest.

\section{Section 67 [Recodification]}

(1) In assessing the acts which otherwise require the granting of consent, permission, casting a vote or another action by the person declared absent, this requirement is disregarded; however, this does not apply if it concerns matters of personal status. A person who performs acts concerning the matters of an absent person must do so with regard to his interests.

(2) A juridical act which was made without the consent or another necessary expression of will of the absent person after he left his residence, but before he was declared to be absent, even though the declaration was applied for without undue 
delay, is considered to have been made with a suspensive condition of issuing a decision declaring the person absent.

\section{Section 68 [Recodification]}

If an individual declared absent returns or appoints an administrator for his assets and liabilities, the declaration of the person's absence shall cease to be effective. The declaration shall also cease to be effective on the date established as the date of death of the absent person.

\section{Section 69 [Recodification]}

A person who has been declared absent may not invoke invalidity or ineffectiveness of a juridical act made in his absence while such a declaration was in effect, because his expression of will was not required for such an act.

\section{Section 70 [Recodification]}

If a person who designated an administrator for his property is declared absent, it does not affect the rights and duties of the designated administrator. This does not apply if the administrator is unknown, refuses to act in the interest of the absent person, neglects his acts in the interest of the absent person or is unable to act at all.

\section{Division 4}

\section{Presumption of death}

Section 71

(1) On the application of a person with a legal interest in declaring an individual dead, a court shall declare the death of an individual who may be reasonably presumed to have died, and shall determine the date established as the date of his death.

(2) An individual who has been declared dead is considered to have died. Declaration of death of a spouse shall terminate marriage as of the date established as the date of his death; the same applies to registered partnership.

\section{Section 72 [Recodification]}

If an individual has been declared absent and the circumstances give rise to serious doubts as to whether he is still alive, although his death is not beyond doubt, a court may declare him dead on the application of a person with a legal interest in such a declaration, and shall determine the date which the absent person apparently did not survive. This date is presumed to be the date of death of the absent person.

\section{Section 73 [Recodification]}

An individual who has been declared absent may be declared dead no sooner than after five years from the end of the year in which he was declared absent. However, this may not be done if, during this period, information is obtained which may lead to believe that the absent person is still alive. In this case the procedure under Section 74 or 75 applies.

\section{Section 74 [Recodification]}

(1) An individual who became absent by leaving his residence, not providing any information about himself, and whose whereabouts are unknown, but who has not been declared absent, may be declared dead no sooner than after seven years from the end of the year in which the last information was obtained which may lead to believe that he was still alive.

(2) An individual who became absent before the age of eighteen may not be declared dead before the end of the year in which twenty-five years since his birth have elapsed.

\section{Section 75}

An individual who became absent as a participant to an event which posed a threat to life to a larger number of persons may be declared dead no sooner than after three years from the end of the year in which last information was obtained which leads to believe that he was still alive in the course of these events.

\section{Section 76}

(1) If an individual has beendeclared dead, this does not exclude evidence that he died before or after that, or that he is still alive. If he is found to be alive, the declaration of death is disregarded; however, marriage or registered partnership is not reinstated.

(2) If an erroneous proof of death was made, Subsection (1) applies by analogy.

\section{Division 5}

Name and residence of an individual

Name of an individual and its protection 
(1) The name of an individual is composed of his given name and surname and his other names, where applicable, and surname at birth which pertain to him on the basis of a statute. Every individual has the right to use his name in legal transactions, as well as the right to the protection of and respect for his name.

(2) An individual using a name other than his own in legal transactions bears the consequences of any mistakes and injuries arising therefrom.

\section{Section 78 [Recodification]}

(1) An individual who is affected by having the right to his name disputed or who has suffered harm due to an unlawful interference with this right, in particular by unauthorised use of the name, may claim that the unlawful interference be refrained from or its consequence remedied.

(2) If the individual affected is absent or if he is absent, lacking legal capacity or unable to assert the right to the protection of his name due to other reasons, the right may be asserted by his spouse, descendant, ancestor or partner, unless the individual affected, although he has legal capacity, has made expressly clear his intention to the contrary.

(3) If an unlawful interference concerns a surname and if there is a reason for this consisting in an important interest in protecting the family, protection may be individually claimed by the spouse or another close person of the individual affected, even though the right to his name was not affected directly.

\section{Section 79}

\section{Assumed name}

(1) An individual may assume a name for a certain area of his activity or for personal interactions in general. A juridical act made under the assumed name does not affect its validity if it is evident who made the act and the other party can have no doubts about the identity of the person acting.

(2) If an assumed name becomes known, it shall enjoy the same protection as a name.

$$
\text { Section } 80 \text { [Recodification] }
$$

\section{Place of residence}

(1) The place where an individual stays with the intention to live there permanently is his place of residence, subject to changes in circumstances; such intention may be evident from his declarations or from the circumstances of the case. If an individual states a place of residence other than his actual place of residence, anyone may also invoke his actual place of residence. No one may claim to have his actual place of residence elsewhere against anyone who, in good faith, invokes the actual place of residence.

(2) An individual with no place of residence is considered to reside at the place where he lives. If such a place cannot be determined or if it can be determined only with disproportionate difficulties, the place where an individual has property or the place of his last residence is considered to be his place of residence.

\section{Division 6}

\section{Personality rights of an individual}

\section{Subdivision 1}

\section{General provisions}

\section{Section 81}

(1) Personality of an individual including all his natural rights are protected. Every person is obliged to respect the free choice of an individual to live as he pleases.

(2) Life and dignity of an individual, his health and the right to live in a favourable environment, his respect, honour, privacy and expressions of personal nature enjoy particular protection.

\section{Section 82 [Recodification]}

(1) An individual whose personality rights have been affected has the right to claim that the unlawful interference be refrained from or its consequence remedied.

(2) After the death of an individual, the protection of his personality rights may be claimed by any of his close persons.

$$
\text { Section } 83 \text { [Recodification] }
$$

(1) If an unlawful interference with the personality rights of an individual is associated with his activities in a legal person, the right to the protection of his personality rights may also be asserted by that legal person; however, during his life, the legal person may do so only in the name of the individual and with his consent. If an individual is unable to express his will 
due to his absence of or inability to reason, consent is not required.

(2) After the death of an individual, a legal person may claim that the unlawful interference be refrained from and its consequences remedied.

\title{
Subdivision 2
}

\section{Image and privacy}

Section 84 [Recodification]

Capturing the image of an individual in any way that would allow his identity to be determined is only possible with his consent.

\section{Section 85 [Recodification]}

(1) The image of an individual may only be distributed with his consent.

(2) If anyone consents to having his image captured under circumstances which make it evident that the image will be distributed, he is conclusively presumed to also consent to its reproduction and distribution in the usual way, as he could reasonably expect under the circumstances.

\section{Section 86 [Recodification]}

No one may interfere in the privacy of another without a lawful reason. Without an individual's consent, it shall in particular be prohibited to intrude into his private premises, watch or record his private life on audio or video recordings, use such or other recordings made by a third person about the private life of an individual, or distribute such recordings about his private life. Private documents of personal nature are protected to the same extent.

\section{Section 87 [Recodification]}

(1) A person who consented to the use of documents of a personal nature, portraits or audio or video recordings relating to an individual or his expressions of personal nature may withdraw his consent, even where granted for a definite period.

(2) If consent granted for a definite period is withdrawn without it being justified by a substantial change in circumstances or any other reasonable cause, the withdrawing person shall compensate the person to whom he granted the consent to the resulting damage.

\section{Section 88 [Recodification]}

(1) The consent is not required if the image, or audio or video recording is made or used to exercise or protect other rights or legally protected interests of others.

(2) The consent is also not required where an image, document of a personal nature or audio or video recording is made or used by means of a statute for official purposes, or where someone performs a public act in matters of public interest.

\section{Section 89}

An image, or audio or video recording may, without the consent of an individual, also be reasonably made or used for scientific or artistic purposes and for print, radio, television or similar coverage.

\section{Section 90}

Lawful reasons for interference with the privacy of another or for the use of his image, documents of personal nature or audio or video recordings may not be used unreasonably in conflict with the legitimate interests of the individual.

\section{Subdivision 3}

\section{Right to mental and physical integrity}

\author{
Section 91
}

An individual is inviolable.

\section{Section 92}

(1) The human body remains under legal protection even after the death of an individual. Disposing of a human corpse and human remains left after burial in a manner undignified for the deceased is prohibited.

(2) Unless human remains left after burial are buried in a public cemetery, the person specifically designated by the individual before his death is entitled to claim them; otherwise they may be claimed by the spouse, child or parent, in the given order, and in the absence of all such persons, or if they refuse to take over the remains, they are taken over by his heir. 
(1) Except as provided by a statute, no one may interfere with the integrity of another individual without his consent granted with the knowledge of the nature of the interference and its possible consequences. If a person consents to serious harm being caused to him, it is disregarded; this does not apply if the interference is, given all the circumstances, necessary in the interest of the life or health of the individual concerned.

(2) The legal representative may give consent to the interference with the integrity of the person represented if it is for the direct benefit of the person who is unable to give the consent himself.

\title{
Section 94 [Recodification]
}

(1) A person who wishes to perform an intervention on another individual shall clearly explain the nature of this intervention. Explanation is duly provided if it can be reasonably assumed that the other party has understood the nature and purpose of the intervention, including the expected consequences and possible dangers to his health, as well as whether or not a different approach is possible.

(2) If the consent is given on behalf of someone by his legal representative, explanation shall also be provided to the person who is to be subjected to the intervention, if the person is capable of judgement, in a manner appropriate to his ability to understand the explanation.

\section{Section 95 [Recodification]}

A minor without full legal capacity may, in usual matters, also give his consent to an intervention on his body himself, if this is adequate to the intellectual and volitional maturity of minors of his age, and if it is an intervention not resulting in any permanent or serious consequences.

\section{Section 96 [Recodification]}

(1) The consent to an interference with the integrity of an individual must be in writing where a body part which will not regrow is to be separated.

(2) Written form is also required for the consent to:

a) a medical experiment on an individual, or

b) an intervention which is not required with respect to the health condition of an individual; this does not apply in the case of cosmetic intervention not resulting in any permanent or serious consequences.

\section{Section 97 [Recodification]}

(1) The consent granted may be withdrawn in any form, even where the consent must be granted in writing.

(2) Unless the consent must be granted in writing, it is presumed to have been granted. In the case of uncertainty about whether consent was withdrawn in a form other than in writing, it is presumed not to have been withdrawn.

\section{Section 98 [Recodification]}

(1) If a person cannot give consent due to the inability, even temporary, to express his will, and has no legal representative, consent of the present spouse, parent or close person is required. If none of these persons is present, consent of the spouse is required, and in his absence, the consent of a parent or another close person if they can be easily identified and contacted and if it is evident that there is no danger in delay. If consent cannot be obtained in any of the above ways, it may be granted by another person present who has demonstrated extraordinary interest in the individual concerned.

(2) In an intervention as well as when granting consent, account is taken of previously expressed wishes of the individual whose integrity is to be interfered with.

\section{Section 99 [Recodification]}

If an individual's life gets into a sudden and apparent danger and consent cannot be obtained even in a form other than the one prescribed, immediate intervention may be carried out if it is necessary for the benefit of the health of the individual concerned.

\section{Section 100 [Recodification]}

(1) In the event of interfering with the integrity of a minor who has reached at least the age of fourteen years and has not acquired full legal capacity, and who seriously objects to the intervention, although his legal representative consents to it, the intervention may not be performed without court approval. This also applies where an intervention is carried out on an adult person without full legal capacity.

(2) If the legal representative does not consent to an interference with the integrity of a person under Subsection (1), although the person so wishes, the intervention may be performed on the application of the person concerned or his close person only with court approval.

\author{
Section 101 [Recodification]
}


If the integrity of an individual incapable of judgement is to be interfered with in a way resulting in permanent, irreversible and serious consequences or a way associated with a serious threat to his life or health, the intervention may only be carried out with the leave of a court. This does not affect the provision of Section 99.

\section{Section 102 [Recodification]}

A court shall sanction an intervention under Sections 100 or 101 if, upon reasonable consideration, it is to the benefit of the person concerned, after the person has been seen by a court and with full recognition of his personality rights.

\section{Section 103 [Recodification]}

In the event of having interfered with the integrity of an individual who was in a condition which prevented him from assessing what was happening to him and if the individual did not consent to the intervention himself, he must, as soon as his condition allows it, be given an explanation, in a way that he can understand, of what intervention was performed on him, and he must be advised of the possible consequences as well as the risk of not performing the intervention.

\section{Subdivision 4}

\section{The rights of an individual admitted to a health care facility without his consent}

\section{Section 104}

A person may be admitted to or kept in a facility providing health care without his consent only on grounds provided by a statute and provided that no milder and less restrictive measure can be taken to provide for the necessary care of the person. Filing an application to limit the legal capacity does not in itself constitute a reason for the person to be admitted to or kept in such a facility without his consent.

\section{Section 105 [Recodification]}

(1) If an individual is admitted to or kept in a facility providing health care, the health care provider shall immediately inform his legal representative, guardian or assisting person and his spouse or another close person; however, the health care provider may not inform his spouse or another close person, if prohibited to do so.

(2) Admitting an individual to a facility providing health care is notified by the health care provider to a court within 24 hours; the same shall also apply if the person is detained in such a facility. The court will decide on the measure to be taken within seven days.

\section{Section 106}

(1) The health care provider shall ensure that the individual admitted to or detained in a facility providing health care is given, without undue delay, appropriate explanation of his legal status, lawful reason for the measure taken and the possibility of legal protection, including the right to choose an agent or a fiduciary.

(2) Explanation is given so that the individual may sufficiently understand and realise the nature of the measure taken and its consequences; if such an individual has a legal representative, guardian or assisting person, the explanation shall, without undue delay, also be given to him.

\section{Section 107}

(1) If an individual has an agent or a fiduciary, the health care provider shall notify the agent or fiduciary of the measures taken without undue delay after becoming aware of them.

(2) A fiduciary may, in his own name and for the benefit of the individual, assert all rights of the individual created in connection with his admission to or detention in such a facility. An assisting person has the same rights as a fiduciary.

\section{Section 108}

An individual who has been admitted to or detained in a facility providing health care has the right to discuss with his representative, fiduciary or assisting person his own matters in a personal conversation and without the presence of third persons.

\section{Section 109}

(1) An individual admitted to or detained in a facility providing health care has the right to have his health condition, medical records or the attending physician's statement regarding his inability to reason and express wishes independently reviewed by a physician independent of the health care provider in this facility and its operator. A fiduciary or assisting person has the same right.

(2) If the right to review is asserted before a court decides pursuant to Section 105(2), its exercise must be allowed so that the court may consider the results of the review in the proceedings on the admissibility of the measure taken.

\section{Section 110}

If the court rules that the measure taken is admissible, the involuntary stay at a facility providing health care shall thereby be approved; however, this does not exclude the right to refuse a certain intervention or medical procedure.

\section{Subdivision 5}




\section{Disposing of human body parts}

Section 111 [Recodification]

(1) An individual whose body part has been removed has the right to know how it has been disposed of. Disposing of removed body parts in a way which is undignified for the individual or which endangers public health is prohibited.

(2) A removed part of an individual's body may, with his consent, be used during his lifetime for medical, scientific or research purposes. Using a removed body part of an individual for a purpose of an unusual nature always requires his express consent.

(3) What applies to human body parts shall also apply, by analogy, to anything that proceeds from the human body.

\section{Section 112 [Recodification]}

An individual may leave a part of his body to another only under conditions laid down by other legal regulations. This does not apply in the case of hair or similar parts of the human body, which can be painlessly removed without anaesthesia and which are naturally restored; they may be relinquished to another, even for remuneration, and are considered to be a movable thing.

\section{Subdivision 6}

\section{Protection of human body after the death of an individual}

Section 113 [Recodification]

(1) An individual has the right to decide how his body will be disposed of after his death.

(2) Performing an autopsy or using the human body after the death of an individual for the purposes of medical science, research or teaching purposes without the consent of the deceased is possible only where provided by another statute.

\section{Section 114 [Recodification]}

(1) An individual may decide on the form of his funeral. In the absence of an individual's express decision, the form of funeral is decided by the spouse of the deceased, and, in the absence of a spouse, by the children of the deceased; in the absence of children, it is decided by parents and in their absence by the siblings of the deceased; if they are not alive, it is decided by their children and in the absence of their children by any close person; in the absence of any of these persons it is decided by the municipality in whose territory the individual died.

(2) The costs of the funeral and cemetery arrangements are paid from the decedent's estate. If decedent's estate is insufficient to cover the costs of the form of the funeral the deceased wished, he must be at least buried in a decent manner according to local usages.

(3) Another legal regulation provides how and at whose expense to bury an individual whose decedent's estate is insufficient to cover the funeral costs if no one is willing to pay funeral costs voluntarily.

\section{Section 115 [Recodification]}

If an individual dies without expressing consent to an autopsy or the use of his body after death in the manner under Section 113 , he is conclusively presumed to have disagreed with an autopsy or such use of his body.

\section{Section 116 [Recodification]}

A person who consents to have his body subjected to an autopsy or used in the manner under Section 113 after his death shall write his statement in the register maintained under another legal regulation; this consent may also be expressed in a public instrument or with respect to a health care provider with effect towards that provider.

\section{Section 117 [Recodification]}

The consent to autopsy or the use of one's body after death for the purpose of medical science, research or teaching purposes may be withdrawn. If an individual withdraws his consent in a health care facility, he may do so by a declaration in writing.

\section{Chapter 3}

\section{Legal persons}

\section{Division 1}

\section{General provisions}

Section 118 [Recodification]

A legal person has legal personality from its incorporation to its termination. 
Legal persons shall maintain reliable records of their property situation, even if they are not obliged to keep accounts under another legal regulation.

\section{Public registers of legal persons}

\section{Section 120 [Recodification]}

(1) A public register of legal persons shall indicate at least the day of incorporation, the day of dissolution including the legal cause, and the day of termination of a legal person, as well as its name, address of the registered office and the objects of activities, name and address of residence of each of the members of the governing body including the manner in which the body represents the legal person, and the date of their appointment to or extinction of their office.

(2) Another legal regulation provides the public registers of legal persons, what legal persons are to be registered in them and how, or what other information about legal persons is to be registered in them and how it is deleted and, where applicable, whether or not the public register contains a collection of instruments. Public registers of legal persons are accessible to anyone; anyone may search them and make extracts, duplicates or copies.

(3) Whenever a recorded fact changes, the registered person or the person obliged to do so on the basis of a statute shall, without undue delay, notify the person maintaining the public register of the change, and the latter person shall record the change in the public register without undue delay.

\section{Section 121 [Recodification]}

(1) A person concerned by a record registered in a public register on which another person making a juridical act relies may not invoke against such other person that the record does not correspond to reality.

(2) If a record entered in a public register is published, no one may, after fifteen days from its publication, claim that he could not have known about the published record. Where a published record does not correspond to that registered in the register, a person concerned by the record may not invoke the published record against another person; however, if he demonstrates that the other person was aware of the registered record, he may object against that person a discrepancy between the published and registered record.

\section{Creation and incorporation of a legal person}

\section{Section 122 [Recodification]}

A legal person may be created by a forming juridical act, by a statute, by a decision of a public body, or in another manner provided by another legal regulation.

\section{Section 123}

(1) The forming juridical act determines at least the legal person's name, registered office, objects of activities, the type of governing body and the manner of its establishment, unless directly provided by a statute. It shall also specify the first members of the governing body.

(2) The forming juridical act must be in writing.

\section{Section 124}

If the time for which a legal person is formed has not been provided, it is conclusively presumed to have been created for an indefinite period.

\section{Section 125}

(1) Several founders form a legal person by adopting the articles of association or by entering into another contract.

(2) A statute provides for cases in which a legal person may also be formed by the juridical act of one person contained in the formation charter.

\section{Section 126}

(1) A legal person is incorporated upon registration in a public register.

(2) If a legal person is established by a statute, it becomes incorporated upon the effective date of the statute, unless a later date is provided by a statute.

(3) A statute provides for other cases in which the registration in a public register is not required for a legal person to become incorporated. A statute provides for the cases in which the decision of a public body is needed for the formation or incorporation of a legal person.

\section{Section 127 [Recodification]}

Acts in the name of a legal person may even be performed prior to its incorporation. A person who performs such acts 
is the only person entitled and obliged under these acts; where the acts are performed by several persons, these persons are entitled and obliged jointly and severally. A legal person may assume the effects of these acts for itself within three months from its incorporation. In this case, it is conclusively presumed to have been entitled and obliged under these acts from the beginning. If the legal person assumes these effects, it shall notify other involved parties accordingly.

\section{Section 128}

After the incorporation of a legal person, no one may seek the determination that it was not incorporated, and its registration in a public register cannot be cancelled on those grounds.

\section{Section 129 [Recodification]}

(1) After the incorporation of a legal person, a court shall declare it invalid, even of its own motion, if:

a) there is no forming juridical act,

b) the forming juridical act lacks an essential element necessary for the legal existence of a legal person,

c) the forming juridical act contradict Section 145, or

d) a legal person has been formed by fewer persons than required by a statute.

(2) On the date of the declaration of its invalidity, a legal person shall enter into liquidation.

\section{Section 130 [Recodification]}

Before the decision under Section 129 is made, the court shall provide a legal person with reasonable time limit to remedy the situation, provided that the defect can be removed.

\section{Section 131 [Recodification]}

Declaration of invalidity of a legal person does not affect the rights and duties it acquired.

\section{Name}

\section{Section 132}

(1) A legal person is designated by its name. misleading.

(2) The name must differentiate a legal person from another person and indicate its legal form. The name must not be

\section{Section 133 [Recodification]}

(1) The name may include the name of an individual to whom the legal person has a special relationship. The name of a living individual may only be used in the name of a legal person with his consent; if he dies without having given his consent, the consent of his spouse is required, and in the absence of a spouse the consent of an adult descendant, and in the absence of an adult descendant the consent of an ancestor.

(2) If a surname has been used in the name of a legal person and if it is justified by an important interest in the protection of family, Section 78(3) applies by analogy.

(3) A person who has the right to give consent to the use of a name of an individual in the name of a legal person has the right to withdraw the consent at any time, even if it was granted for a definite period; a stipulation to the contrary is disregarded if the withdrawal of the consent is justified by a substantial change in circumstances or another reasonable cause. If consent granted for a definite period is withdrawn without being justified by a substantial change in circumstances or any other reasonable cause, the withdrawing person shall compensate the legal person for the resulting damage.

\section{Section 134}

(1) The name of a legal person may contain a distinctive element of a name of another legal person, if it is justified on the basis of their mutual relationship. Even in this case, the public must be able to sufficiently distinguish between the two names.

(2) A characteristic part of a name of another legal person may not be used in a name without its consent. Section 133(3) applies by analogy.

\section{Section 135}

(1) A legal person which has been affected by having its right to a name disputed or which has suffered harm due to unlawful interference with that right, or which is under threat of such harm, in particular by unauthorised use of the name, may claim that such unlawful interference be refrained from and its consequence remedied.

(2) A legal person enjoys the same protection against anyone who, without a lawful reason, interferes with its reputation or privacy, unless for artistic or scientific purposes or for print, radio, television or similar coverage; however, neither 
such an interference may be in conflict with the legitimate interests of the legal person.

Section 136 [Recodification]

\section{Registered office}

(1) When a legal person is created, its registered office is determined. Unless it disturbs the peace and order in the building, the registered office may also be in an apartment.

(2) If a legal person is subject to registration in a public register, it is sufficient if the forming juridical act specifies the name of the municipality where the registered office of the legal person is located; however, in the application for registration in the public register, the legal person shall indicate the full address of its registered office.

\section{Section 137 [Recodification]}

(1) Anyone may invoke the real registered office of a legal person.

(2) A legal person may not claim to have its registered office elsewhere against anyone who invokes the registered office entered in a public register.

\section{Transfer of registered office}

\section{Section 138 [Recodification]}

(1) A legal person having its registered office abroad may transfer its registered office to the Czech Republic. This does not apply if it is not allowed under the legal order of the state in which the legal person has its registered office or if a legal person prohibited under Section 145 is involved.

(2) A legal person who intends to transfer its registered office to the Czech Republic shall attach to its application for registration in the public register the decision regarding the selected legal form of a Czech legal person, as well as the forming juridical act required by the legal order of the Czech Republic for the legal form.

(3) After transferring its registered office to the Czech Republic, internal legal relations within a legal person are governed by the laws of the Czech Republic. The liability of its members and the members of its bodies for the debts of the legal person incurred after the effective date of the transfer of the registered office to the Czech Republic is also governed by the legal order of the Czech Republic.

\section{Section 139 [Recodification]}

A legal person having its registered office in the Czech Republic may transfer its registered office abroad, unless it is contrary to public order and if permitted by the legal order of the state to which the registered office of the legal person is to be transferred.

\section{Section 140 [Recodification]}

(1) A legal person that intends to transfer its registered office abroad shall publish this intention, indicating the address of the new registered office and the legal form after transferring the registered office, at least three months before the date of the anticipated transfer. Creditors have the right to require sufficient security for their claims which are yet to become due within two months of publication if, after the transfer of the registered office, the recoverability of their claims in the Czech Republic deteriorates.

(2) In the absence of an agreement on the nature and extent of security, sufficient security and its extent is decided by a court with regard to the type and amount of the claim. If a legal person fails to provide the security according to the decision of the court, the liability for unsecured debts is assumed by the members of the governing body, except those who prove that they made sufficient effort to comply with the decision.

\section{Section 141 [Recodification]}

(1) A member of a legal person who disagreed with transferring the registered office abroad has the right to end his membership in the legal person with effect from the date of the transfer. If, upon the end of his membership, a member of a legal person is entitled to a settlement, the legal person shall provide him with the performance no later than on the effective date of the transfer. Members of the governing body are liable for the discharge of this obligation.

(2) Members of a legal person and its governing body are liable for debts incurred prior to the effective date of the transfer of registered office in the same way as before the transfer of registered office abroad.

\section{Section 142 [Recodification]}

Transfer of registered office becomes effective on the date of registration of its address in the relevant public register.

\section{Section 143 [Recodification]}

The establishment and transfer of branches of legal persons are governed by Sections 138 to 142 by analogy. 


\section{Section 144 [Recodification]}

legal person.

(1) A legal person may be created in public or private interest. Its nature is derived from the primary activity of the

(2) A statute provides for the purposes for which a legal person may only be created after meeting specific conditions.

\section{Section 145 [Recodification]}

(1) It is forbidden to form a legal person whose purpose is to violate the law or achieve a goal in an unlawful manner, in particular if its purpose includes:

a) denial or limitation of personal, political or other rights of persons on the grounds of nationality, gender, race, origin, political or other views, religion and social status,

b) incitement of hatred and intolerance,

c) promotion of violence, or

d) control over a public body or public administration without statutory authorisation.

(2) It is forbidden to form a legal person which is armed or has armed forces, unless the legal person was established by a statute and expressly permitted or obliged by the statute to be armed or create armed forces; or a legal person which disposes of weapons in connection with its business activities under a special legal regulation; or a legal person whose members hold or use guns for sporting or cultural purposes, for hunting or for the performance of duties under a special legal regulation.

\section{Publicly beneficial status}

\section{Section 146 [Recodification]}

A publicly beneficial legal person is a legal person whose mission is to carry out its own activities to contribute, in accordance with the forming juridical act, to achieving common welfare, if the decision-making of the legal person is significantly influenced only by persons with no criminal record, if it has acquired its property from fair sources, and if it uses its assets and liabilities economically for a publicly beneficial purpose.

\section{Section 147 [Recodification]}

A publicly beneficial legal person is entitled to register the publicly beneficial status in a public register if it meets the conditions set forth by a special legal regulation.

\section{Section 148 [Recodification]}

If publicly beneficial status is registered in a public register and if its publicly beneficial status is waived by the legal person or revoked by a court, it is deleted by the administrator of the public register. Publicly beneficial status is extinguished upon deletion from a public register.

\section{Section 149 [Recodification]}

A court shall decide on the revocation of the publicly beneficial status on the application of a person with a legal interest therein, or even of its own motion if the legal person ceases to meet the conditions for its acquisition and even fails to remove the defect upon the request of the court within a reasonable time limit.

\section{Section 150 [Recodification]}

Only a legal person whose publicly beneficial status is registered in a public register has the right to specify the publicly beneficial status in its name.

\section{Bodies of a legal person}

\section{Section 151 [Recodification]}

(1) A statute provides, or the forming juridical act determines, the manner and scope in which members of a legal person make decisions for and replace the will of the legal person.

(2) Good faith of the members of the bodies of a legal person is attributed to the legal person.

\section{Section 152 [Recodification]}

(1) A legal person establishes bodies comprised of one member (individual) or several members (collective).

(2) A natural person who is an elected, appointed or otherwise selected member of a legal person's body (hereinafter a "member of an elected body") must have full legal capacity. This also applies to a representative of a legal person which is itself a member of an elected body of another legal person. 
(3) If the primary activity of a legal person concerns minors or persons with limited legal capacity and if the primary purpose of the legal person is not business activity, the forming juridical act may determine that even a minor or a person with limited legal capacity may become a member of an elected collective body of the legal person.

\section{Section 153 [Recodification]}

(1) A person whose insolvency has been proved may become a member of an elected body if the person notified the person who selects him for office accordingly in advance; this does not apply if at least three years have elapsed since the end of the insolvency proceedings.

(2) If insolvency of a person who is a member of an elected body has been proved, such a person shall, without undue delay, notify the person who selects him for office accordingly.

(3) If no notification is made, any person with a legal interest therein may claim that a court remove that member of the elected body. This does not apply if the person who selected the member of the elected body, after becoming aware of the proof of insolvency of the person, has decided that the person should remain in office.

\section{Section 154 [Recodification]}

If another legal person is a member of an elected body of a legal person, the former shall authorise a natural person to represent it in the body; otherwise, the legal person is represented by a member of its governing body.

\section{Section 155 [Recodification]}

(1) If a person selected to act as a member of an elected body lacks the statutory legal capacity to hold his office, he is considered never to have been selected for office. If, after being selected for office, a member of an elected body loses his statutory capacity to be a member of an elected body, his office is extinguished; he shall inform the legal person of the extinction of office without undue delay.

(2) Where a member of an elected body is considered never to have been selected for office, or if the selection is invalid, it shall not affect any rights acquired in good faith.

\section{Section 156 [Recodification]}

(1) If a body is collective, matters concerning the legal person are decided collectively. It has a quorum if a majority of its members is present or otherwise in attendance, and decisions are made by a majority of votes of the attending members.

(2) Where the competence of the individual members of a body is divided by certain fields, the provision of Subsection (1) does not apply. The division of competence does not relieve other members of their duty to supervise how matters of the legal person are administered.

\section{Section 157 [Recodification]} at his request.

(1) If a decision is adopted, a differing opinion of a member of an elected body who opposed the proposal is recorded

(2) If a proposal has been adopted in the absence of a member, that member is entitled to know the contents of the decision.

\section{Section 158 [Recodification]}

(1) The forming juridical act may provide a higher number of attendees for a body to have a quorum, require a higher number of votes for a decision, or provide a procedure which can be used to change the manner of decision-making of a body.

(2) Forming juridical act may also allow a body to make out-of-session decisions by correspondence or using technical means.

(3) Forming juridical act may specify that the chairman has the casting vote in the event of a tied vote in the decisionmaking of an elected body of a legal person.

\section{Section 159 [Recodification]}

(1) A person who accepts the office of a member of an elected body undertakes to discharge the office with the necessary loyalty as well as with the necessary knowledge and care. A person who is unable to act with due managerial care although he must have become aware thereof upon accepting or in the discharge of the office and fails to draw conclusions for himself is presumed to act with negligence.

(2) A member of an elected body shall discharge his office personally; however, this does not prevent a member from authorising, on a case-case basis, another member of the same body to vote for him in his absence.

(3) If a member of an elected body fails to compensate the legal person for damage caused by breaching his duties in the discharge of his office, although he was obliged to compensate the damage, he is liable to a creditor of the legal person for its debt to the extent to which he failed to compensate the damage, if the creditor is unable to recover the performance from the legal person. 
If a member of an elected body resigns from his office by a declaration which reached the legal person, the office terminates two months after the declaration reached the legal person.

\section{Acting on behalf of a legal person}

\section{Section 161 [Recodification]}

A person representing a legal person shall demonstrate his entitlement to do so, unless it is already evident from the circumstances. The person signing on behalf of a legal person shall affix his signature and, where applicable, also indicate his office or position opposite the name of the legal person.

\section{Section 162 [Recodification]}

If a legal person is represented by a member of its body in a manner registered in a public register, no one may invoke that the legal person failed to adopt the necessary resolution, that the resolution was defective, or that a member of the body breached the resolution adopted.

\section{Section 163 [Recodification]}

A governing body has all competence that is not entrusted to another body of the legal person by any forming juridical act, a statute or decision of a public body.

\section{Section 164 [Recodification]}

(1) A member of a governing body may represent the legal person in all matters.

(2) Where the competence of the governing body is entrusted to several persons, they form a collective governing body. If the forming juridical act does not determine the way in which its members represent the legal person, each member shall do so individually. If the forming juridical act requires the members of a governing body to act jointly, a member may individually represent the legal person as an agent only if he has been authorised to make a specific juridical act.

(3) If a legal person with a collective governing body has employees, it shall authorise one member of the governing body to make juridical acts with respect to the employees; otherwise, this competence is exercised by the chairman of the governing body.

\section{Section 165 [Recodification]}

(1) If the governing body does not have a sufficient number of members needed to make a decision, a court, on the application of the person who proves a legal interest, shall appoint the missing members for a period until new members are selected through the procedure set out in the forming juridical act; otherwise, a court shall appoint the legal person's guardian, even of its own motion, whenever it learns of it in the course of its activity.

(2) The court shall, even of its own motion, appoint a guardian of a legal person if the interests of its governing body are contrary to the interests of the legal person, and in the absence of another member of a body of the legal person capable of representing it.

\section{Section 166 [Recodification]}

(1) A legal person is represented by its employees to the extent typical with respect to their position or title, the decisive aspect being how they are perceived by the public. Provisions on the representation of a legal person by an employee apply by analogy to the representation of a legal person by its member or a member of another body not registered in a public register.

(2) Limitation of the authority to represent by an internal regulation of a legal person has effect against a third person only if the person must have been aware of it.

\section{Section 167 [Recodification]}

A legal person is liable for an unlawful act committed in the performance of its duties by a member of an elected body, employee or another representative against a third person.

\section{Dissolution of a legal person}

Section 168

(1) A legal person is dissolved by making a juridical act, by expiry of period, by a decision of a public body or by achieving the purpose for which it was created, as well as for other reasons provided by a statute.

(2) A voluntary dissolution of a legal person is decided by its competent body.

\section{Section 169 [Recodification]}

(1) After its dissolution, a legal person must be liquidated, unless its entire assets and liabilities are acquired by a legal successor, or unless otherwise provided by a statute. 
(2) If it is not evident from the juridical acts concerning the dissolution of a legal person whether it is dissolved with or without liquidation, it is conclusively presumed to be dissolved with liquidation.

\section{Section 170 [Recodification]}

The person who decided on the dissolution of a legal person with liquidation may change the decision if the purpose of liquidation has not yet been achieved.

\section{Section 171 [Recodification]}

A legal person is dissolved with liquidation:

a) if the period for which it was formed has expired,

b) if the purpose for which it was formed has been achieved

c) as of the date specified by a statute or by the juridical act concerning the dissolution of the legal person, or otherwise on its effective date, or

d) as of the date when a decision of a public body becomes final and absolute, unless a later date is determined in the decision.

\section{Section 172 [Recodification]}

(1) On the application of a person who demonstrates a legal interest, or even of its own motion, a court shall dissolve a legal person and order its liquidation where:

a) the legal person carries out illegal activities to such an extent that it seriously disrupts public order,

b) the legal person no longer meets the statutory requirements for the incorporation of a legal person,

c) the legal person has not had a governing body able to constitute a quorum for more than two years, or

d) provided by a statute.

(2) If a statute allows a court to dissolve a legal person on grounds which may be remedied, the court shall, before making its decision, provide a reasonable time limit for the legal person to remove the deficiencies.

\section{Section 173 [Recodification]} transformation.

(1) If a legal person is dissolved upon transformation, it is dissolved without liquidation on the effective date of the

(2) If insolvency of a legal person has been proved, it is dissolved without liquidation by cancelling the bankruptcy after fulfilling a resolution on the distribution of property, or by cancelling the bankruptcy due to absolutely insufficient property; however, it shall enter into liquidation if any property is found after the end of the insolvency proceedings.

\section{Transformation of a legal person}

\section{Section 174 [Recodification]}

(1) Transformation of a legal person means a merger, de-merger or change of its legal form.

(2) A legal person may change its legal form only where provided by a statute.

\section{Section 175 [Recodification]}

(1) A person who decided on the transformation of a legal person may change the decision until the transformation has become effective.

(2) If the transformation of a legal person becomes effective, it is no longer possible to decide that it never occurred, or declare the invalidity of the juridical act leading to the transformation, and the registration of the transformation into a public register cannot be cancelled.

\section{Section 176 [Recodification]}

(1) With respect to transformation, the decisive date must be set from which the acts of the terminating legal person, for accounting purposes, are considered to be made on the account of the successor legal person.

(2) As of the day preceding the decisive date, the terminating legal person or legal person being de-merged by spinoff shall prepare the final financial statements. As of the decisive date, the successor legal person or legal person being demerged by spin-off shall draw up the opening balance sheet.

\section{Section 177 [Recodification]}

(1) The transformation of a legal person which is subject to registration in a public register becomes effective on the date of registration in a public register. In this case, the decisive date is set as a date not preceding the date of the application to 
register the transformation in a public register by more than twelve months.

(2) If the participating persons are entered in a public register in different districts, the application to register the transformation is filed in any of them, and the public body shall register in the public register all the registered facts as of the same day.

\section{Section 178 [Recodification]}

(1) A merger takes place if at least two participating legal persons merge by acquisition or merge by the formation of a new legal person. Merger by acquisition or merger by the formation of a new legal person is considered to be a transfer of the activities of the employer.

(2) Upon merger by acquisition, at least one of the participating persons terminates; the rights and duties of the terminating persons pass to only one of the participating persons as the successor legal person.

(3) Upon merger by the formation of a new legal person, all participating persons terminate and a new legal person is created in their place as the successor legal person; the rights and duties of all the terminating persons pass to the successor legal person.

\section{Section 179 [Recodification]}

(1) A legal person de-merges by spinning off with the formation of new legal persons or de-merges while being acquired by other legal persons (hereinafter a "de-merger by acquisition"). A legal person may also be formed by spin-off or by combining multiple methods of de-merging. De-merger by acquisition, spin-off as well as other forms of de-merger are considered to be a transfer of the activities of the employer.

(2) If, upon a de-merger, the de-merged legal person terminates and its rights and duties pass to several successor legal persons, the following applies:

a) if the successor legal persons are involved in the de-merger as already existing persons, it is considered a de-merger by acquisition,

b) if the successor legal persons are yet to be created by the de-merger, it is considered a de-merger with the formation of new legal persons.

(3) Upon de-merger of a legal person by spin-off, the de-merged legal person is neither dissolved, nor terminated; however, a designated part of its rights and duties passes to an existing or newly formed successor person.

\section{Section 180}

In the cases under Section 179 (2) and (3), the competent body of a legal person shall decide which employees of the terminating legal person will become employees of the individual successor legal persons.

\section{Section 181}

Legal persons of different legal forms may merge and de-merge only where provided by a statute.

Section 182

Where, upon its transformation, the assets and liabilities of a legal person pass to the successor legal person and the approval of a public body is required under another legal regulation to transfer the rights and duties, such an approval is also required for the transformation of the legal person.

\section{Section 183}

(1) A change in legal form does not lead to the dissolution or termination of a legal person whose legal form changes, but merely to a change in its legal situation and, in the case of a corporation, also the legal status of its members.

(2) If the date on which a draft contract or decision to change the legal form was prepared is not the date of preparation of balance sheet under a special legal regulation, a legal person shall prepare interim financial statements as at that date. The information used to prepare the financial statements as at the date on which the document changing the legal form is prepared may not precede the date of the legal person's decision to change its legal form by more than three months.

\section{Section 184}

(1) A decision on the transformation of a legal person established by a statute may be made where expressly provided by a statute.

body.

(2) The decision on the transformation of a legal person established by a decision of a public body is made by that

\section{Termination of a legal person}

Section 185

A legal person registered in a public register terminates on the date of its deletion from the public register. 
A legal person which is not subject to registration in a public register terminates upon the end of its liquidation.

\section{Liquidation}

\section{Section 187 [Recodification]}

(1) Liquidation aims to settle the property of the terminating legal person (liquidation estate), to pay the debts to the creditors and dispose of the net property balance resulting from the liquidation (with liquidation balance) according to a statute.

(2) A legal person enters into liquidation on the date it is dissolved or declared invalid. If a legal person registered in a public register enters into liquidation, the liquidator shall, without undue delay, apply for the registration of the entry into liquidation in a public register. During liquidation, a legal person uses its name plus the words "v likvidaci" (in liquidation).

\section{Section 188}

If a legal person enters into liquidation, no one may make juridical acts on behalf of the legal person beyond the scope specified in Section 196 from the moment he became aware, or should have and could have become aware of its entry into liquidation.

\section{Section 189 [Recodification]}

(1) Upon entering into liquidation, the competent body shall select a liquidator for the legal person; the liquidator must be a person eligible to be a member of a governing body. If the office of a liquidator is extinguished before the termination of a legal person, the competent body shall, without undue delay, select a new liquidator for the legal person.

(2) If a legal person is in liquidation and no liquidator has been selected, his competence is exercised by all members of the governing body.

\section{Section 190}

If several liquidators have been selected to liquidate a legal person, they shall form a collective body.

\section{Section 191}

(1) Where a legal person has entered into liquidation without a liquidator being selected under Section 189, the liquidator is appointed by a court, even of its own motion. A court shall appoint a liquidator even where the court itself decided on the dissolution of the legal person.

(2) On the application of the person who demonstrates his legal interest therein, a court shall remove a liquidator who fails to properly discharge his duties, and appoint a new liquidator.

(3) If no other application has been filed or if an application cannot be granted, a court may, in accordance with the procedure under Subsection (1) or (2), appoint a member of the governing body to act as the liquidator, even without his consent. Such a liquidator may not resign his office. However, he may move the court to relieve him of office if he proves that he may not be reasonably required to perform his office.

(4) If the liquidator cannot be appointed even pursuant to Subsection (3), he is chosen by a court from the persons in the list of insolvency administrators.

\section{Section 192}

If the liquidator has been appointed by a court, third persons shall assist the liquidator to the same extent as the insolvency administrator.

\section{Section 193 [Recodification]}

Upon his selection, a liquidator acquires the competence of a governing body. A liquidator is responsible for the proper performance of his office in the same way as a member of the governing body.

\section{Section 194}

Only the court which appointed the liquidator may remove him from office.

Section 195

The liquidator's remuneration and the method of its payment is determined by the person who selected him.

\section{Section 196} liquidation.

(1) The activities of a liquidator may only aim to achieve the purpose which corresponds to the nature and objective of 
(2) Where a legal person has acquired inheritance or legacy with a condition, determination of time or a mandate, the liquidator shall comply with such restrictions. However, if a legal person has received funds designated for a specific purpose from public budgets, the liquidator shall use these funds in accordance with the decision of the body which provided them; the liquidator shall proceed by analogy if a legal person received funds designated to achieve a charitable purpose.

\section{Section 197} insolvency.

During liquidation, a liquidator shall satisfy the claims of employees first; this does not apply if the legal person is in

\section{Section 198}

(1) A liquidator shall notify all known creditors that the legal person is in liquidation.

(2) A liquidator shall, without undue delay, publish, at least twice in a row and with at least a two-week interval, the notification under Subsection (1), together with a call upon the creditors to register their claims within a time limit of no less than three months from the second publication.

\section{Section 199}

(1) As of the date of entry of a legal person into liquidation, the liquidator shall compile the opening balance sheet and an inventory of assets and liabilities of the legal person.

(2) The liquidator shall, against the payment of the related costs, provide the inventory of assets and liabilities to any creditor who so requests.

\section{Section 200}

If, in the liquidation process, a liquidator finds the legal person to be insolvent, it shall, without undue delay, file an insolvency petition, unless it is a case under Section 201.

\section{Section 201}

(1) If it is a case under Section 173(2) and the liquidation estate do not suffice to discharge all debts, the liquidator shall use the proceeds to pay the costs of liquidation in the first rank, the employees' claims in the second rank and then other creditors' claims in the third rank.

(2) If it is not possible to fully settle claims within the same rank, they are satisfied proportionately.

Section 202

(1) In the case of failure to sell all the liquidation estate within a reasonable period, the liquidator shall use the partial proceeds to settle, as a matter of priority, the first-ranking and then the second-ranking costs and claims, where possible; this does not affect Section 201(2). Subsequently, the liquidator shall offer the third-ranking creditors to take over the liquidation estate to pay their debts.

(2) If the liquidation estate or even part thereof cannot be sold within a reasonable period, or if the partial proceeds are insufficient to fully settle the first- and second-ranking claims, the liquidator shall offer all creditors to take over the liquidation estate.

(3) The creditor who was offered the liquidation estate under Subsection (1) or (2) and who did not respond to the offer within two months is conclusively presumed to have accepted the offer; this effect only occurs if the liquidator advised him to do so in the offer.

\section{Section 203}

(1) Creditors who take over the liquidation estate shall each be entitled to a share defined by the ratio of the amount of their claims; the remaining part of their claims is extinguished.

(2) If any of the creditors refuses to participate in taking over the liquidation estate, his claim is considered to be extinguished. This does not apply if a previously unknown property of the legal person is subsequently found.

\section{Section 204}

(1) If all creditors refuse to take over the liquidation estate, it passes to the State on the date of termination of the legal person; the liquidator shall, without undue delay, notify the body competent under another statute accordingly.

(2) Notwithstanding Sections 201 to 203, the creditor who is a secured creditor under another statute is entitled to have his claim satisfied from the security securing his claim. If this does not fully settle the claim of the secured creditor, he is entitled to the performance under Sections 201 to 203 for the balance of his claim.

\section{Section 205 [Recodification]}

(1) As soon as the liquidator completes everything that precedes the disposal of the liquidation balance or the handover of the liquidation estate under Section 202 or notification under Section 204, he shall prepare a final report on the course of the liquidation, which shall at least specify the manner in which the liquidation estate was disposed of and, where 
applicable, a proposal to use the liquidation balance. On the same day the liquidator shall compile financial statements. The liquidator shall also affix his signature, certificated electronic signature and a similar demonstrative accounting record to the financial statements.

(2) The liquidator shall submit the final report, proposal to use the liquidation balance and financial statements for approval to the person that selected him for office. A person who became a liquidator under Section 189(1) shall submit a final report, a proposal to use the liquidation balance and the financial statements to the body of the legal person which has the authority to remove him from office, or to supervise him, where applicable. In the absence of any such body, the liquidator shall submit these documents and proposals to a court for approval.

(3) Deletion of a legal person from a public register is not precluded by the failure to approve the documents under Subsection (1)

\section{Section 206}

(1) Until the rights of all creditors who registered their claims in time under Section 198 have been satisfied, no share of the liquidation balance, even in the form of an advance payment, may be paid out or otherwise used.

(2) If a claim has been disputed or if it is yet to become due, the liquidation balance may only be used if the creditor has been provided with sufficient security.

\section{Section 207 [Recodification]}

Liquidation ends by using the liquidation balance, by the creditors taking over the liquidation estate or by its rejection. The liquidator shall, within thirty days from the end of liquidation, submit an application to delete the legal person from the public register

\section{Section 208 [Recodification]}

If, before its deletion from a public register, previously unknown property of a legal person is found, or if there is need for other necessary measures, liquidation will not end and the liquidator shall settle and adjust the property or take further necessary action. After completing these acts, he shall proceed in accordance with Sections 205 to 207; the provision of Section 170 does not apply.

\section{Section 209 [Recodification]}

(1) If unknown property of a legal person is found after its deletion from a public register or if another interest worthy of legal protection appears, a court shall, on the application of the person who demonstrates a legal interest, cancel the deletion of the legal person, decide on its liquidation and appoint a liquidator. The person that maintains the public register shall, in accordance with this decision, register the restoration of the legal person, its liquidation status and information about the liquidator. From its restoration, the legal person is considered never to have terminated.

(2) If a legal person has been restored due to unknown property having been found, the unsettled claims of its creditors is restored.

\section{Division 2}

\section{Corporations}

\section{Subdivision 1}

\section{Corporations in general}

Section 210 [Recodification]

(1) A corporation is created as a legal person by a community of persons.

(2) A legal person composed of a sole member is considered to be a corporation.

\section{Section 211 [Recodification]}

(1) A corporation may have a sole member, if permitted by a statute. In this case, the sole member of the corporation may not end its membership on its own initiative unless, as a result, a new person takes his place.

(2) If the number of members of a corporation drops below that provided by a statute, a court shall, even of its own motion, dissolve it and decide on its liquidation. First, however, the court shall provide the corporation with reasonable time limit to remedy the situation.

\section{Section 212 [Recodification]}

(1) By accepting membership in a corporation, a member undertakes to act, with respect to the corporation, with integrity and comply with its internal order. A corporation may not unreasonably discriminate in favour or against its member and must protect his membership rights as well as legitimate interests.

(2) If a member of a private corporation abuses his right to vote to the detriment of the whole, a court shall, on the 
application of the person who has demonstrated legal interest, decide that the vote of that member is disregarded in a particular case. This right is extinguished, unless the application is filed within three months from the day on which the right to vote was abused.

\section{Section 213 [Recodification]}

If damage to the corporation is caused by its member or a member of its body in a way which creates his duty to provide compensation for damage and which also damaged another member of the corporation in the value of his participation, and if compensation for damage is sought by that member only, the court may, even of its own motion, impose upon the tortfeasor the duty to provide compensation for damage only to the corporation, if it is justified by the circumstances of the case, especially if it is sufficiently evident that such a measure will compensate the damage of the devalued participation.

\section{Subdivision 2}

\section{Association}

\section{Section 214 [Recodification]}

(1) At least three persons driven by a common interest may implement this interest by forming an association as a self-governing and voluntary group of members to associate with each other.

(2) Where associations implement their common interest by founding a new association as their union, they shall express its union nature in the name of the new association.

Section 215

(1) No one may be forced to participate in an association, and no one may be prevented from withdrawing from it.

(2) Members of an association are not liable for its debts.

\section{Section 216}

The name of an association must contain the word "spolek" (association) or "zapsaný spolek" (registered association), but the abbreviation "z. s." will suffice.

\section{Section 217}

(1) The primary activity of an association may only involve satisfying and protecting those interests it was formed to implement. The primary activity of an association may not involve business or other gainful activities.

(2) In addition to the primary activity, an association may also pursue secondary economic activity consisting in business or other gainful activities if their purpose is to support the primary activity or for the economical use of the association's property. association

(3) Profits from the association's activities may only be used for its activities, including the administration of the

\section{Formation of an association}

\section{Section 218 [Recodification]}

Founders form an association if they agree on the contents of the articles of association; these shall contain at least:

a) the name and address of the association,

b) the purpose of the association,

c) the rights and duties of members with respect to the association, or specification of how their rights and duties will be created,

d) the determination of the governing body.

\section{Section 219 [Recodification]}

The articles of association may form a subsidiary association as an organisational unit of the association, or determine how the subsidiary association is formed and which body decides on forming, dissolving or transforming the subsidiary association.

\section{Section 220}

(1) If the articles of association provide various kinds of membership, they shall also define the rights and duties associated with each type of membership.

(2) It is only possible to limit the rights and extend the duties associated with a specific type of membership under the conditions set forth in advance in the articles of association; otherwise the consent of a majority of members is needed. This does not apply if the association has a just cause to limit the rights or extend the duties. 
Section 221

The articles of association must be kept in full at the registered office of an association.

\section{Constituting meeting}

\section{Section 222}

(1) An association may also be formed by a resolution of the constituting meeting of the association being formed. The provisions on members' meetings apply by analogy to the constituting meeting.

(2) The convener shall draft the articles of association and appropriately convene other persons interested in forming the association to a constituting meeting. The convener or his delegate shall check the accuracy and completeness of the attendee list.

\section{Section 223}

Anyone who arrives at the constituting meeting and meets the conditions for membership in the association shall register in the attendee list and attach his signature to his name and residence or registered office. The convener or his delegate shall check the attendee list for accuracy and completeness. The persons registered in the attendee list are conclusively presumed to have submitted a proper application to the association.

\section{Section 224}

(1) The convener or his delegate shall open the constituting meeting. He shall inform the constituting meeting of the number of attendees and familiarise them with the acts already performed by the convener in the interests of the association. $\mathrm{He}$ shall also propose the rules of order of the constituting meeting and the election of the chairman as well as any other officials.

(2) The constituting meeting elects the members of the bodies required by a statute and the articles of association.

(3) The constituting meeting adopts resolutions by a majority vote of the attendees present at the time of voting.

(4) A person who voted against the acceptance of the draft articles of association may withdraw his application to the association. This must be recorded in the attendee list and the record signed by the withdrawing person and by the person who made the record.

\section{Section 225} adopted.

If the constituting meeting is attended by at least three persons, the articles of association under Section 218 may be

\section{Incorporation of an association}

\section{Section 226 [Recodification]}

(1) An association is incorporated upon registration in a public register.

(2) The founders or a person designated by the constituting meeting shall file the application for registration of an association in a public register.

(3) If an association is not registered in a public register within thirty days after filing the application for registration, and no decision rejecting the registration is issued within that time limit, the association is considered registered in the public register on the thirtieth day after filing the application.

\section{Section 227 [Recodification]}

If an association continues its activities even after its registration in a public register has been rejected, the provisions on a partnership apply.

\section{Subsidiary association}

\section{Section 228 [Recodification]}

(1) The legal personality of a subsidiary association derives from the legal personality of the principal association. A subsidiary association may have rights and duties and acquire them to the extent specified by the articles of association and recorded in a public register.

(2) The name of a subsidiary association must contain a characteristic element of the name of the principal association and express its nature of a subsidiary association.

\section{Section 229 [Recodification]}

(1) A subsidiary association is incorporated upon registration in a public register. 
(2) The principal association shall file the application for registration of a subsidiary association in a public register.

(3) Unless the decision on or refusal of the registration is issued within thirty days from filing the application for registration, a subsidiary association is considered to have been registered in a public register.

(4) Juridical acts of the subsidiary association made before the date of its registration in a public register shall entitle and oblige the principal association jointly and severally with the subsidiary association. From the date of registration of a subsidiary association in the public register, the principal association is liable for the debts of the subsidiary association to the extent determined by the articles of association.

\section{Section 230 [Recodification]}

(1) The dissolution of the principal association shall also dissolve the subsidiary association.

(2) The principal association does not terminate before the termination of all subsidiary associations.

\section{Section 231 [Recodification]}

By acquiring publicly beneficial status by the principal association, the status is also acquired by the subsidiary associations. If the principal association waives its publicly beneficial status or if it is revoked, subsidiary associations shall also lose their publicly beneficial status.

\section{Membership}

\section{Section 232}

(1) Unless otherwise provided by the articles of association, the membership in an association is linked to the member personally and does not pass to his legal successor.

(2) If a legal person is a member of an association, it is represented by its governing body unless the legal person designates another representative.

\section{Section 233}

(1) After an association has been incorporated, membership in the association may be created by being accepted as a member or otherwise as provided by the articles of association.

(2) A person who is applying for membership in an association thereby expresses his will to be bound by the articles of association from the moment he becomes a member of the association.

(3) The acceptance of members is decided by the body provided by the articles of association, or otherwise by the supreme body of the association.

\section{Section 234}

Membership created in a subsidiary association is presumed to also create membership in the principal association; this also applies to the extinction of membership.

\section{Section 235}

The articles of association may determine the amount and due date of a membership fee, or determine the body of the association which is to determine the amount and due date of a membership fee and the manner in which the body is to do so.

\section{Section 236 [Recodification]}

\section{List of members}

(1) Where an association keeps a list of its members, the articles of association shall determine how it shall make records in the list of members relating to the membership of persons in the association. The articles shall further determine how the list of members will be made available, or that it will not be made available.

(2) Each member, including former members, will, upon his request, receive from the association, at the association's expense, a confirmation with an extract from the list of members containing information concerning him, or a confirmation that the information has been deleted. Instead of a deceased member, the confirmation may be requested by his spouse, child or parent, and in the absence of spouse, child or parent by another close person or an heir, if they demonstrate an interest worthy of legal protection.

(3) A list of members may be published with the consent of all members listed in it; when publishing an incomplete list of members, it must be evident from the list that it is incomplete.

\section{Extinction of membership}


Membership in an association is extinguished upon resignation, expulsion or other means provided by the articles of association or by a statute.

\section{Section 238}

Unless otherwise provided by the articles of association, membership is extinguished if a member fails to pay the membership fee within a reasonable additional time limit specified by the association in a request for payment, despite having been informed of such consequence in the request.

\section{Section 239}

(1) Unless otherwise provided by the articles of association, an association may expel a member who has seriously breached the duties under the membership and failed to remedy the situation within a reasonable time limit even after being requested to do so by the association. No request is required where the breach of duty cannot be remedied or where the association has suffered a particularly severe harm.

(2) The decision on expulsion is delivered to the expelled member.

\section{Section 240}

body.

(1) Unless the articles of association specify another body, the decision to expel a member is made by the governing

(2) Unless otherwise provided by the articles of association, a proposal to expel a member may be submitted in writing by any member; the proposal shall state the circumstances demonstrating the grounds for exclusion. A member concerned by the proposal must have an opportunity to become familiar with the proposal to expel him, ask for an explanation of the proposal, and state and document everything that is in his favour.

\section{Section 241}

(1) A member may, within fifteen days from the delivery of the decision in writing, propose that the decision to expel him be reviewed by an arbitration committee, unless another body is provided by the articles of association.

(2) The competent body shall cancel the decision to expel a member if such expulsion is contrary to a statute or the articles of association; the decision to expel a member may also be revoked in other justified cases.

\section{Section 242}

An expelled member may, within three months from the delivery of the final decision of the association to expel him, apply to the court for a decision on the invalidity of such expulsion; otherwise, this right is extinguished. If the decision has not been delivered to him, the member may file an application within three months from the date on which he learned of it, but no later than one year from the date on which, after issuing the decision, the extinction of his membership by expulsion was entered in the list of members; otherwise, this right is extinguished.

\section{Organisation of an association}

\section{Section 243 [Recodification]}

The bodies of an association are the governing body and the supreme body and, where applicable, the supervisory committee, arbitration committee and other bodies provided by the articles of association. Articles of association may name the association's bodies at will, unless the names give a misleading impression as to their nature.

\section{Section 244}

Articles of association shall determine if a governing body is collective (a committee) or individual (chairman). Unless otherwise provided by the articles of association, the members of the governing body are elected and removed by the supreme body of the association.

\section{Section 245}

The resolution of a members' meeting or another body which is contrary to good morals or which amends the articles of association in a way that renders their content contrary to compelling provisions of a statute is considered not to have been adopted. This also applies where a resolution was adopted in a matter outside the body's decision-making competence.

Section 246

(1) Unless the articles of association provide a term of office of the members of the association's elected bodies, the term is five years.

(2) Unless otherwise provided by the articles of association, the members of elected bodies of an association whose number has not dropped below half may co-opt substitute members until the next meeting of the body competent to vote.

(3) Unless otherwise provided by the articles of association, sections 156 and 159(2) and, with the necessary modifications, also the provisions on members' meetings apply to convening and conducting meetings and decision-making of an association's collective bodies. 


\section{Supreme body of an association}

(1) The articles of association shall specify which body is the supreme body of the association; its competence generally includes determining the primary focus of the association, deciding on amendments to the articles of association, approving the economic results of the association, evaluating the activities of other bodies of the association as well as their members and deciding on the dissolution of the association with liquidation or on its transformation.

(2) If, under the articles of association, the governing body is also the supreme body of the association and it has not been capable of exercising its competence for more than one month, at least one fifth of the members of the association may convene a meeting of all members of the association; the meeting assumes the competence of the supreme body of the association. This does not apply if the articles of association provide otherwise.

(3) Unless otherwise provided by the articles of association, the members' meeting is the supreme body of an association; the provisions of Sections 248 to 257 apply to members' meetings, unless otherwise provided by the articles of association.

\section{Members' meeting}

Section 248

(1) A members' meeting is convened by the governing body of an association at least once a year.

(2) The governing body of an association shall convene a member's meeting upon request of at least a third of the members of the association or the supervisory body of the association. Unless the governing body of the association convenes the members' meeting within thirty days from the delivery of the request, the person who filed the request may, at the expense of the association, convene the members' meeting himself.

\section{Section 249}

(1) The members' meeting is convened in an appropriate manner within the time limit specified in the articles of association, or otherwise at least thirty days before the meeting. The invitation must clearly specify the place, time and agenda of the meeting.

(2) If a meeting is convened pursuant to Section 248 , the agenda of the meeting may be changed, as compared to the proposal set out in the initiative, only with the consent of the person who filed the initiative.

(3) The place and time of the meeting is determined so as to minimise the members' opportunity to participate in it.

\section{Section 250}

(1) The person who convened the meeting may cancel or postpone it in the same manner in which it was convened. If this happens less than a week before the announced date of the meeting, the association shall reimburse the members who arrived at the meeting according to the invitation for reasonably incurred costs.

(2) If a meeting is convened under Section 248, it may be cancelled or postponed only on a proposal or with the consent of the person who requested it.

\section{Section 251}

Each member is entitled to attend the meeting and require and be given explanation of matters concerning the association, if the required explanation is related to the subject of the members' meeting. If, at the meeting, a member requests the disclosure of facts whose disclosure is prohibited by a statute or would cause serious harm to the association, such request may not be granted.

\section{Section 252}

(1) A members' meeting has a quorum if the majority of the association's members are present. Resolutions are adopted by a majority vote of the members present at the time of voting; each member has one vote.

(2) If, in the provisions governing various types of membership in the association, the articles of association provide that a specific type of membership allows acting in advisory capacity only, such votes shall, for the purposes of Subsection (1), be disregarded.

\section{Section 253}

(1) A person who opens the meeting shall check whether the members' meeting has a quorum. Then, he shall provide for the election of the meeting's chairman and any other officials, if required by the articles of association.

(2) The chairman conducts the meeting in line with the announced agenda, unless the members' meeting decides to end the meeting early.

(3) A matter not included in the agenda of the meeting upon its announcement may be decided only with the participation and consent of all members of the association entitled to vote on it. 
(1) The governing body of the association shall ensure that the minutes of the meeting be prepared within thirty days of its end. If this is not possible, the minutes of meeting are prepared by the person who chaired the meeting, or who was authorised to do so by the members' meeting.

(2) The minutes must clearly indicate who convened the meeting and how, when it was held, who opened it, who chaired it, what other officials were elected and the resolutions adopted at the members' meeting and when the minutes were prepared.

(3) Each member of the association may inspect the minutes of the meeting under the conditions provided by the articles of association. Unless otherwise provided by the articles of association, this right can be exercised at the association's registered office.

Section 255

\section{Partial members' meeting}

Articles of association may provide that a members' meeting is to be held in the form of partial members' meetings and, as applicable, which matters may not be decided in this way. If articles of association admit partial members' meetings, they shall also specify the period of time in which all the meetings must be held. In order to have a quorum and to adopt resolutions, both the attending members, and the votes cast are added together.

\section{Section 256}

\section{Assembly of delegates} meeting.

(1) Articles of association may determine that the assembly of delegates acts in the capacity of the members'

(2) The same number of votes must be cast in the election of each delegate. If this is not reasonably possible, the articles of association may determine a reasonable variation for the election of delegates.

\section{Section 257}

\section{Alternate session of members' meeting}

(1) If, at its session, a member's meeting is unable to reach a quorum, the governing body or the person who convened the original meeting may, within fifteen days from the previous meeting, dispatch a new invitation to convene an alternate session of member's meeting. The invitations must clearly indicate that it is an alternate session of members' meeting. The alternate session of members' meeting must be held no later than six weeks after the date for which the previous members' meeting was convened.

(2) At its alternate session, the members' meeting may only consider matters included in the agenda of the previous meeting. Any number of attendees is sufficient for the member's meeting to reach a quorum, unless otherwise provided by the articles of association.

(3) If the members make decisions at partial members' meetings or if the assembly of delegates makes the decision in its capacity, the procedure under Subsections (1) and (2) apply by analogy.

\section{Invalidity of a decision of an association's body}

\section{Section 258 [Recodification]}

Each member of the association or anyone having an interest worthy of legal protection may apply to a court for a decision on the invalidity of a decision of an association's body due to its conflict with a statute or with the articles of association, unless the invalidity can be invoked before the association's bodies.

\section{Section 259 [Recodification]}

The right to invoke the invalidity is extinguished within three months from the date on which the applicant learnt or should have learnt of the decision, but no later than one year from the decision.

\section{Section 260 [Recodification]}

(1) A court shall not declare a decision invalid if a statute or articles of association have been violated without it having any adverse legal consequences, and if not declaring the decision invalid is in the association's interest deserving legal protection. in good faith.

(2) The court shall also not declare a decision invalid if it would substantially affect the rights of third persons acquired

\section{Section 261 [Recodification]}

(1) Where an association has gravely violated a fundamental right of a member, the member is entitled to reasonable 
(2) If objected by the association, a court shall not grant the association's member the right to satisfaction unless it was asserted:

a) at the period specified for filing the application to declare the invalidity of the decision, or

b) within three months from the date on which the decision on dismissing the application becomes final and absolute, if the application was dismissed pursuant to Section 260.

\section{Supervisory committee}

\section{Section 262}

(1) If the articles of association establish a supervisory committee, it must have at least three members. Unless otherwise provided by the articles of association, the members of the supervisory committee are elected and removed by the members' meeting. If the articles of association specify that the members of the supervisory committee are appointed or removed by the governing body, it is disregarded.

(2) Unless other restrictions are provided by the articles of association, membership in the supervisory committee is incompatible with membership in the governing body of the association and with the office of liquidator.

\section{Section 263}

The supervisory committee ensures that the association's matters are handled properly and that the association carries out its activities in accordance with the articles of association and legal regulations, unless articles of association entrust it with additional powers. If the supervisory committee finds deficiencies, it shall notify the governing body as well as other bodies as provided by the articles of association.

\section{Section 264}

Within the competence of the supervisory committee, its authorised member may inspect the documents of the association and require the members of other bodies or employees of the association to provide explanations on various issues.

\section{Arbitration committee}

\section{Section 265}

If an arbitration committee is established, it shall decide disputed matters falling within the association's selfgovernance to the extent determined by the articles of association; if the articles of association do not provide the scope of competence of the arbitration committee, it shall resolve disputes between the members and the association concerning the payment of membership fees and review the decisions to expel a member from the association.

\section{Section 266 [Recodification]}

(1) Unless otherwise provided by the articles of association, an arbitration committee consists of three members, who are elected and removed by the members' meeting or the assembly of the association's members.

(2) Only an adult person with full legal capacity with no criminal record who does not act in the association in the capacity of a member of the governing body or supervisory committee may become a member of the arbitration committee. If no one has proposed that the election of a member of the arbitration committee be declared invalid due to the member having a criminal record, the person elected is conclusively presumed to have no criminal record, subject to change in circumstances.

(3) A member who, given the circumstances of the case, is or could be prevented from making unbiased decisions, is excluded from the activities of the arbitration committee.

\section{Section 267}

Proceedings before the arbitration committee are governed by another legal regulation.

\section{Section 268 [Recodification]}

\section{Dissolution of an association}

(1) The court shall dissolve an association with liquidation on the application of a person with a lawful interest, or of its own motion if the association, despite being advised by the court accordingly:

a) pursues an activity prohibited under Section 145 ,

b) pursues an activity contrary to Section 217 ,

c) forces third persons to become members in the association, to participate in its activities or to support it, or

d) prevents members from withdrawing from the association.

(2) Section 172 is not affected. 


\section{Liquidation of an association}

Section 269 [Recodification]

(1) When dissolving an association with liquidation, a liquidator shall make an inventory of assets and liabilities and make it available to all members at the registered office of the association. so requests.

(2) The liquidator shall, upon payment of the costs, provide the inventory of assets and liabilities to any member who

\section{Section 270 [Recodification]}

(1) Unless a liquidator may be selected otherwise, a court shall appoint a member of the governing body as the liquidator, even without his consent. If this is not possible, the court shall appoint a member of the association as the liquidator, even without his consent.

(2) The liquidator appointed under Subsection (1) may not resign, but may apply to the court to be relieved from office if he proves that he may not be reasonably required to perform the office.

\section{Section 271 [Recodification]} association.

The liquidator shall sell the liquidation estate only within the scope necessary to discharge the debts of the

\section{Section 272 [Recodification]}

(1) The liquidator disposes of the liquidation balance according to the articles of association. If the articles of association of an association with publicly beneficial status provide that the liquidation balance is to be used for a purpose other than a publicly beneficial one, the relevant provisions are disregarded.

(2) If the liquidation balance cannot be disposed of according to the articles of association, the liquidator shall offer the liquidation balance to an association with a similar purpose. If this is not possible, the liquidator shall offer the liquidation balance to the municipality in whose territory the association's registered office is located. If the municipality does not accept the offer within two months, the liquidation balance is acquired by the region in whose territory the association's registered office is located. If the liquidation balance is acquired by the municipality or region, they may only use it for publicly beneficial purposes.

\section{Section 273 [Recodification]}

If an association acquired funds designated for a specific purpose from a public budget, the provision of Section 272 does not apply and the liquidator shall dispose of the relevant part of the liquidation balance as decided by the competent body.

\section{Merger of associations}

\section{Section 274 [Recodification]}

Participating associations may conclude a merger agreement in the form of an agreement on merger of associations by acquisition or on merger of associations by the formation of a new association.

\section{Section 275}

A merger agreement shall contain at least the name, address and identification data of each of the participating associations, indicating the association being terminated and successor association and the decisive date.

\section{Section 276}

(1) An agreement on merger of associations by the formation of a new association also contains a stipulation on the articles of association of the successor association.

(2) If, during the merger by acquisition, the articles of association of the successor association are amended, the stipulation on merger by acquisition shall also contain a stipulation on the amendment.

\section{Section 277}

(1) Together with the draft merger agreement, the members of the governing bodies of the participating associations shall prepare a report explaining the economic and legal grounds and consequences of the merger. A report common to all participating associations may also be prepared.

(2) The report explaining the economic as well as legal grounds and consequences of the merger is not required if all members of the participating association are members of its governing or supervisory body or if so agreed by all members of the participating associations.

\section{Section 278}

The members' meeting to which the draft merger agreement will be submitted for approval must be announced by the person who convenes it at least thirty days before the meeting. Within this time limit, the following must be made available to all members: 
a) the draft merger agreement,

b) the articles of association of the successor association,

c) a statement of assets and liabilities of all participating associations no older than six months, and

d) the report explaining the economic and legal grounds and consequences of the merger, if its preparation is required.

\section{Section 279}

(1) The participating associations shall, at least thirty days before the members' meeting, publish a joint notification stating what associations are concerned by the merger and what association is to become the successor association.

(2) If the association is not a recipient of funds from a public budget, has a negligible number of creditors and the total amount of its debt is negligible, delivering the notification to the known creditors shall suffice.

\section{Section 280}

If a creditor of a participating association registers a claim within six months from the date on which the registration of the merger became effective with respect to the creditor, he is entitled to sufficient security in case the recoverability of his claim deteriorates. If a creditor proves that the merger will lead to a significant deterioration of the recoverability of his claim, he is entitled to sufficient security even prior to the registration of the merger in a public register.

\section{Section 281}

(1) The draft merger agreement is approved by the members' meetings of the participating associations. The members' meetings may only approve or reject the draft merger agreement.

(2) The participating associations may also convene a joint members' meeting. In such a case the members' meetings of the participating associations vote on the draft merger agreement separately. However, if, following the approval of the draft merger agreement, the members of the bodies of the successor association are elected, the members' meetings of the participating associations may decide to vote on these members together.

\section{Section 282}

The person who signs the draft merger agreement on behalf of the participating association shall, in addition to other elements, also attach to his signature the information that the draft agreement was approved by the members' meeting of the association and when it was approved. A merger agreement is approved upon the resolution of the members' meeting of the last participating association on the approval of the draft merger agreement and its signing on behalf of the association.

\section{Section 283}

A proposal to declare a merger agreement invalid may only be made together with a proposal to declare invalidity of the resolution of the members' meeting approving the agreement. Only a participating association or a person authorised to propose the declaration of invalidity of the members' meeting is entitled to claim invalidity.

\section{Section 284}

(1) An application for registration of a merger in a public register is filed jointly by all participating associations. In the case of merger by the formation of a new association, the application is also signed by the members of the governing body of the successor association.

(2) On the basis of the application, the competent body shall register the merger by deleting in the public register, on the same date, the association being terminated, noting their legal successor, and in the case of a merger:

a) by acquisition, it shall, for the successor association, note the effective date of the merger and the names, registered office addresses and identification data of the associations which merged with the successor association, and any other changes for the successor association that may have occurred as a result of the merger,

b) by the formation of a new association, it shall register the successor association and note the names, registered office addresses and identification data of the associations which are its legal predecessors.

\section{Section 285}

After registering a merger in the public register, the merger agreement may not be amended or cancelled.

\section{Section 286} association.

Upon registering the merger, the members of the association being terminated become members of the successor

\section{Section 287}

(1) If the participating associations fail to apply for the registration of the merger within six months from the date on which the merger agreement was concluded, the participating association which was prepared to file the application may 
withdraw from the merger agreement. Withdrawal from the agreement by even one party extinguishes the obligation of all parties arising from the agreement.

(2) If the participating associations fail to apply for registration of the merger within one year from the date on which the merger agreement was concluded, all the participating associations are conclusively presumed to have withdrawn from the agreement.

The members of the governing body of an association that is responsible for not applying for the registration of the merger in time shall, jointly and severally with the person involved, compensate other associations for the resulting damage; this does not apply to those members who prove that they made sufficient efforts to file the application in time.

\section{De-merger of an association}

\section{Section 288 [Recodification]}

(1) In case of a de-merger by acquisition, the participating associations conclude a de-merger agreement.

(2) The de-merger agreement shall contain at least:

a) the name, registered office and identification data on the participating associations indicating the terminating and successor associations,

b) determination of the property and debts of the association being terminated assumed by the successor associations,

c) determination of the employees of the association being terminated who become employees of the successor associations,

d) the decisive date.

(3) If a de-merger by acquisition results in an amendment to the articles of association of any of the successor associations, the de-merger agreement shall also contain an agreement on the amendment.

(4) Unless otherwise stipulated by the de-merger agreement, each member of the association being terminated shall, as of the effective date of the de-merger, become a member of all successor associations.

Section 289

project.

(1) When de-merging by the formation of new associations, the de-merged association shall prepare a de-merger

(2) The project shall contain at least:

a) the name, registered office and identification data on the participating associations indicating the association being terminated and successor association,

b) determination of the property and debts of the association being terminated assumed by the successor associations,

c) determination of the employees of the association being terminated who become employees of the successor associations,

d) the draft articles of association of the successor associations,

e) the decisive date.

(3) Unless otherwise provided by the de-merger project, each member of the association being terminated shall, as of the effective date of the de-merger, become a member in all successor associations.

\section{Section 290}

(1) Unless it is evident from the de-merger agreement or the de-merger project what property passes from the demerged association to the successor associations, the successor associations are conclusively presumed to be co-owners of such property.

(2) Unless it is evident from the de-merger agreement or the de-merger project what debt pass from the de-merged association to the successor associations, the successor associations are conclusively presumed to be jointly and severally liable for the debt.

\section{Section 291}

(1) The provisions on mergers apply by analogy to de-merger by acquisition.

(2) When de-merging by the formation of new associations, the governing body of the de-merged association shall, together with the de-merger project, also prepare a report explaining the economic and legal grounds and consequences of the de-merger. The preparation of the report is not required if all members of the association are members of its governing body, or if so agreed by all members of the association. 
(1) The members' meeting to which the de-merger agreement or de-merger project will be submitted for approval must be announced by the person who convenes it at least thirty days before the meeting.

(2) Within the time limit under Subsection (1), the association shall, at its registered office, make available to all members the report of the governing body explaining the economic and legal grounds and consequences of the de-merger, if its preparation is required. The report must contain:

a) in the case of de-merger by acquisition the draft de-merger agreement, the articles of association of the successor association and a statement of assets and liabilities of all participating associations not older than six months, or

b) in the case of de-merger by the formation of new associations the de-merger project, a statement of assets and liabilities of the de-merged association, as well as the opening balance sheet and draft articles of association of the successor associations.

\section{Section 293}

(1) At least thirty days before the members' meeting, the de-merging association shall publish a notice specifying the association concerned by the de-merger and the associations which will become its successor associations. In the notice, the de-merging association shall also notify the creditors of their right under Section 301.

(2) If the association is not a recipient of funds from a public budget, has a negligible number of creditors and the total amount of debt is negligible, delivering the notice to known creditors suffices.

\section{Section 294}

(1) The de-merger agreement is approved by the members' meetings of the participating associations. Section 282 applies by analogy.

(2) The de-merger project is approved by the members' meeting of the de-merging association.

(3) The members' meeting may only approve or reject a de-merger agreement or de-merger project.

\section{Section 295}

(1) A de-merging association shall apply for the registration of the de-merger in a public register. In case of a demerger by acquisition, the de-merging and the successor associations shall file a joint application.

(2) On the basis of the application, the competent body shall register the de-merger by deleting in the public register, on the same date, the association being terminated, noting its legal successor, and in the case of a de-merger:

a) by acquisition, it shall, for the successor association, note the effective date of the de-merger by acquisition and the name, registered office address and identification data of the association which merged with the successor association, and any other changes for the successor association that may have occurred as a result of the de-merger,

b) by the formation of new associations, it shall register the successor associations and note with the registration the name, registered office address and identifying data of the association which is its legal predecessor.

\section{Section 296}

After the registration of the de-merger in a public register the de-merger agreement and the de-merger project may not be amended or cancelled.

\section{Section 297}

(1) If, when de-merging by acquisition, the participating associations fail to apply for the registration of the de-merger within six months from the date on which the de-merger agreement was concluded, the participating association which was prepared to file the application may withdraw from the de-merger agreement. Withdrawal from the agreement by even one party extinguishes the obligations of all parties arising from the agreement.

(2) If, when de-merging by acquisition, the participating associations fail to apply for registration of the de-merger within one year from the date on which the de-merger agreement was concluded, all the participating associations are conclusively presumed to have withdrawn from the agreement.

The members of the governing body of an association that is responsible for not applying for the registration of the demerger in time shall, jointly and severally with the person involved, compensate other associations for the resulting damage; this does not apply to those members who prove that they made sufficient efforts to file the application in time.

\section{Section 298}

If, while de-merging by the formation of new associations, the de-merged association fails to apply for registration of the de-merger within one year from the date on which the decision on the de-merger was adopted, the decision on the demerger is cancelled upon the expiry of the time limit.

\section{Section 299}

(1) Each of the successor associations is liable jointly with the other associations for the debts passed from the demerging association to another successor association. 
(2) If the de-merging association has its assets and liabilities valuated by a report of an expert appointed by the court under another statute, including a separate valuation of assets and liabilities which pass to the individual successor associations, and fulfils the duty to disclose under Section 269, each successor association is liable for the debt under Subsection (1) only up to the amount of the net assets and liabilities acquired by the de-merger.

(3) The right arising from liability under Subsections (1) and (2) may not be asserted by creditors that have acquired security under Section 300 .

\section{Section 300}

If a creditor of a participating association registers a claim within six months from the date on which the registration of the de-merger became effective with respect to the creditor, he is entitled to sufficient security if he proves that this will deteriorate the recoverability of his claim. If a creditor proves that the de-merger leads to a significant deterioration of the recoverability of his claim, he is entitled to sufficient security even before the registration of the de-merger in a public register.

\section{Section 301}

(1) Any person whose legal interests are affected by the de-merger has the right to be informed within one month from the delivery of the request by any of the participating associations of the assets and liabilities passed to each successor association as a result of the de-merger.

(2) If a debtor of a terminated association is not informed about the identity of his creditor after the association's demerger, he may perform to any of the successor associations. If a creditor of a terminated association is not informed about the identity of the debtor after the association has de-merged, he may require a performance from any of the successor associations.

\section{Section 302}

If the articles of association provide that the decision on a merger or de-merger of an association is made by a body other than the members' meeting, the part of the provisions on mergers or de-mergers of associations which concern members' meetings applies to the decision-making of such a body with the necessary modifications.

\section{Division 3}

\section{Endowed institutions}

\section{Subdivision 1}

\section{Endowed institutions in general}

\section{Section 303 [Recodification]}

An endowed institution is a legal person created using property designated for a specific purpose. Its activities are linked to the purpose for which it has been established.

\section{Section 304 [Recodification]}

An endowed institution is created by the forming juridical act or by a statute, which must also specify its property security and its purpose.

\section{Section 305 [Recodification]}

Internal arrangements of an endowed institution are governed by its by-laws.

\section{Subdivision 2}

\section{Foundations}

\section{Section 306 [Recodification]}

(1) A founder forms a foundation to permanently serve a socially or economically beneficial purpose. A foundation may have a publicly beneficial purpose if it aims to promote common welfare, as well as a charitable purpose if it aims to support a specific group of persons defined individually or otherwise.

(2) It is prohibited to form a foundation to support political parties and movements or to otherwise participate in their activities. It is prohibited to form a foundation exclusively serving profitable purposes. If a foundation serves a prohibited purpose, a court shall, even of its own motion, dissolve it and order its liquidation.

\section{Section 307 [Recodification]}

(1) A foundation may pursue business activities if they are merely secondary and their proceeds are solely used to support its purpose; however, a foundation may not pursue business activities if excluded by the founder in the foundation charter. Under the same conditions, a foundation may take over the management of a company. 
(2) A foundation may not be a partner of a company who has unlimited liability.

\section{Section 308 [Recodification]}

(1) The name of a foundation shall include the word "nadace" (foundation).

(2) As a rule, an indication referring to the purpose of a foundation forms part of its name.

\section{Formation of a foundation}

\section{Section 309}

(1) A foundation is formed by a foundation charter, which may be in the form of a formation deed or disposition mortis causa.

(2) A formation deed is prepared by one or more persons.

(3) Where a foundation is formed by multiple persons, they are considered to be a single founder and must act unanimously with respect to the matters of the foundation; if any of these persons refuses to give his consent without a serious reason, he is replaced by the decision of a court on the application of any of the other forming persons.

(4) A foundation charter requires the form of a public instrument.

Section 310

A formation deed shall contain at least:

a) the name and address of the foundation,

b) the name of the founder and his place of residence or registered office,

c) the scope of the purpose for which the foundation is formed,

d) the amount of the contribution of each founder,

e) the amount of the foundation capital,

f) the number of members of the foundation board, the names and addresses of residence of its first members, and how the members of the foundation board act on behalf of the foundation,

g) the number of members of the supervisory board and the names and addresses of residence of its first members, or in case no supervisory board is established, the name and address of residence of the first inspector,

h) the appointment of the administrator of contributions and

i) the conditions for the provision of foundation grants or, where appropriate, the persons to whom they may be provided, or the range of activities that the foundation may pursue with respect to its purpose, or a provision that these requirements are determined by the foundation's by-laws.

\section{Section 311 [Recodification]}

(1) Where a foundation is formed by a disposition mortis causa, the endowment is contributed to the foundation by designating the foundation as an heir or by ordering legacy. In that case, the formation of a foundation becomes effective upon the death of the decedent.

(2) If a foundation charter is included in the disposition mortis causa, it shall contain at least:

a) the name of the foundation,

b) the scope of the purpose for which the foundation is being formed,

c) the amount of the contribution,

d) the amount of the endowment capital and

e) the conditions for providing foundation grants or, where appropriate, the persons to whom they may be provided, or a provision that these requirements are determined by the foundation's by-laws.

Section 312

(1) If the disposition mortis causa does not contain other elements pursuant to Section 310, they are decided by the person appointed in the disposition, or otherwise by the executor of testament; this also applies if the decedent appointed the members of the foundation board or the supervisory board and one of them died, lacks the legal capacity to hold the office or rejects it. 
(2) The decision under Subsection (1) requires the form of a public instrument.

Section 313

(1) Unless the foundation charter specifies the subject of contribution, the duty to contribute is conclusively presumed to be performed in money.

(2) If the foundation charter specifies that the duty to contribute is fulfilled by depositing a non-pecuniary thing, and if that is not possible or if, upon fulfilling the duty to contribute, the value of the contribution does not reach the amount specified in the foundation charter, the contributor is presumed to settle the difference in money.

\section{Section 314}

\section{By-laws of a foundation}

(1) The by-laws of a foundation shall at least regulate:

a) the manner in which the bodies of the foundation act, and

b) the conditions for the provision of foundation grants, and, where appropriate, the persons to whom they can be provided.

(2) If the by-laws of a foundation have not been issued by the founder together with the foundation charter, it is issued by the foundation board within one month from the date the foundation was formed, subject to prior approval by the supervisory board. Unless precluded by the foundation charter, the decision to amend the by-laws is made by the foundation board, subject to prior approval by the supervisory board.

(3) The foundation shall publish the by-laws by filing them in the collection of instruments. Anyone can inspect the bylaws in the public register and make extracts, duplicates or copies thereof. The same right can also be asserted at the foundation's registered office.

\section{Section 315 [Recodification]}

\section{Incorporation of a foundation}

(1) A foundation is incorporated upon registration in a public register.

(2) The founder shall apply for registration of a foundation in a public register; if it is not possible and unless the founder has specified otherwise, the foundation board shall apply for registration in the name of the foundation.

Section 316

\section{Change of registered office of the foundation}

Unless precluded by the foundation charter, the foundation board, subject to a prior statement of the supervisory board, may change the registered office of the foundation. The decision to transfer the registered office of the foundation abroad requires approval by court; the court shall not approve a transfer of the registered office if there is no serious reason for the transfer or if the change of the registered office would endanger the legitimate interests of persons who are to be provided with foundation grants.

\section{Amendment to the foundation charter}

\section{Section 317 [Recodification]}

After the incorporation of a foundation, the foundation charter may be amended to the extent and in the manner expressly reserved in the foundation charter by the founder for himself or for one of the bodies of the foundation.

\section{Section 318 [Recodification]}

(1) If, after the foundation has been incorporated, the circumstances change to such an extent that they induce, in the interest of the foundation, a reasonable need to change its internal relations, the founder may amend the foundation charter even without having reserved such a right in the foundation charter; the amendment is valid if approved by the foundation board and if it does not affect the rights of third persons.

(2) A foundation shall publish an amendment to the foundation charter; the amendment becomes effective three months after the date of publication. If a person who claims that his rights have been affected by an amendment to the foundation charter applies to a court for a decision on the invalidity of the amendment within this time limit, the court may decide that the effect of the amendment to the foundation charter be postponed until the court's decision.

(3) The provisions of Subsections (1) and (2) do not apply if the amendment to the foundation charter concerns a part that has been defined by the founder in the foundation charter as unamendable.

\section{Section 319 [Recodification]}

(1) If the founder no longer exists and if, after incorporation, the circumstances change to such an extent that they induce, in the interest of the foundation, a reasonable need to change its internal relations, the decision to amend the foundation charter may, on the application of the foundation, be made by court; filing the application must be agreed by the foundation 
board.

(2) The court shall grant the application unless the application to amend the foundation charter affects the rights of third persons; simultaneously, the intention of the founder evident from the foundation charter must, insofar as is possible, be protected, and any conditions provided by the founder in the foundation charter for such a case must be met.

(3) When deciding to amend the foundation charter, a court shall consider the opinion of the supervisory board, taking into account the interests of third persons deserving legal protection.

\section{Section 320 [Recodification]}

If the founder expressly provides in the foundation charter that the foundation charter or a specific part thereof may not be amended, it may not be amended even by the decision of a court.

\section{Special provisions on changing the purpose of a foundation}

\section{Section 321 [Recodification]}

(1) If the foundation charter does not create the right of the founder or a body of the foundation to change its purpose, the purpose may be changed by court on the application of the foundation, subject to approval by the foundation board and supervisory board. However, if such a change is opposed by the founder or a person designated in the foundation charter, the court shall dismiss the application.

(2) The foundation shall, without undue delay after filing the application, publish the notification of the application for change. Anyone with a legal interest in doing so may challenge the application in court within one month from the date on which the notification was published.

\section{Section 322 [Recodification]}

If achieving the purpose of a foundation is impossible or difficult due to causes unknown or unpredictable to the founder, the court shall, on the application of the founder or a person with a legal interest therein, replace the current purpose of the foundation with a similar purpose, unless otherwise provided by the foundation charter.

\section{Section 323 [Recodification]}

If the founder and even the person in whose favour the founder has created the right to approve or reject a change of the foundation's purpose, where applicable, no longer exist, the court shall, when deciding on the change of the purpose of the foundation, take into account the founder's known intentions and wishes, even if they are not evident from the foundation charter.

\section{Section 324 [Recodification]}

A decision to change a foundation's purpose from a publicly beneficial to a charitable purpose may only be made by a court and only where justified by a particularly compelling reason, and not precluded by the foundation charter.

\section{Section 325 [Recodification]}

When the purpose of a foundation changes, the gifts provided in favour of the original purpose and the yields therefrom must be used to provide foundation grants in accordance with the original purpose, unless the donor wishes otherwise.

\section{Section 326 [Recodification]}

If a court changes the purpose of a foundation, it may, even of its own motion, also simultaneously decide to what extent and for how long the foundation may use the yields from the endowment principal to provide foundation grants in accordance with the original purpose. The court shall specify such extent and period whenever it is required by the lawful interest of persons identified as recipients of foundation grants with regard to the original purpose of the foundation. If the court changes the purpose of a foundation from a publicly beneficial to charitable purpose and does not determine such extent and period, the foundation is conclusively presumed to use four fifths of the yields to provide foundation grants in accordance with the original purpose for a period of five years from the date on which the change became effective.

\section{Contributions to a foundation}

\section{Section 327}

(1) The amount of a non-pecuniary contribution may not be set higher than the amount determined by an expert opinion as the value of the subject of contribution.

(2) If the subject of contribution to a foundation is of non-pecuniary nature, it must meet the requirement of providing permanent yield, and may not be used as a security.

\section{Section 328}

(1) If the subject of contribution is an investment security or money market instrument under the statute regulating business activities on the capital market, its value may also be determined as a weighted average of the prices at which the security or regulated market instrument was traded six months before the contribution was paid. 
(2) Subsection (1) does not apply if the amount of the subject of contribution determined under Subsection (1) is affected by exceptional circumstances that would lead to significant change in its value as of the date on which the duty to contribute is fulfilled.

\section{Section 329}

(1) If the subject of contribution is a thing other than an investment security or money market instrument under the statute regulating business activities on the capital market, its value may also be determined as:

a) the market value of the thing determined by a generally recognised independent expert using generally accepted procedures and valuation principles no earlier than six months before the duty to contribute is fulfilled, or

b) the value of the thing specified in the financial statements for the accounting period immediately preceding the creation of the duty to contribute, if the thing is valued at fair value under another legal regulation and the financial statements have been approved by an auditor without reservations.

(2) Subsection (1) does not apply if new circumstances occur that could significantly change the value of the contribution as of the date the duty to contribute is fulfilled.

\section{Section 330 [Recodification]}

(1) Before the incorporation of a foundation, the aggregate amount of the contributions reaches at least CZK 500,000 to fulfilled the duty to contribute.

(2) Contributions to the foundation before its incorporation are taken over by the person appointed by the foundation charter as the administrator of contributions. If his office is extinguished, the founder or, where appropriate, the executor of testament or another authorised person shall, without undue delay, select a new administrator of contributions; if it is not possible, new administrators of contributions are selected by the foundation board. The rights and duties of the administrator are governed, by analogy, by the provisions on the rights and duties of the members of the bodies of legal persons.

\section{Section 331}

(1) The duty to contribute is fulfilled by handing over the subject of contribution to the administrator of contributions. A foundation acquires the right of ownership in the subject of contribution on the day of its incorporation; however, if a statute makes the acquisition of the right of ownership conditional upon the registration in a public register, the foundation shall acquire the right of ownership in the subject of contribution only upon such registration.

(2) If the subject of contribution is in money, the administrator of contributions shall deposit it in a special account opened by the administrator with a bank or a savings and loan cooperative for the foundation in its name. The person who manages the account shall, up until the incorporation of the foundation, not allow the account balance to be used for payments, unless the foundation's formation is proved to be invalid; if the foundation was formed by disposition mortis causa, the invalidity of its formation must be decided by court.

(3) Where the subject of contribution is a thing registered in a public register, the contributor shall also hand over a statement of contribution deposit to the administrator of contributions; after the foundation is incorporated, its right of ownership is registered in the public register on the basis of this statement. The contributor's signature on the statement must be authenticated.

Section 332

The administrator of contributions shall provide the person who applies for the registration of a foundation in a public register with a written confirmation of the person who fulfilled the duty to contribute, the time when it occurred, the subject of contribution and the total amount of contributions. If the administrator of contributions confirms a higher performance than corresponds to the reality, he is liable, with respect to the creditors, for the debts of the foundation up to the amount of the difference for a period of five years from the date the foundation was incorporated.

\section{Section 333}

(1) The administrator of contributions shall, without undue delay after the foundation has been incorporated, hand over the accepted subject of contribution to the foundation.

(2) If the foundation has not been incorporated, the administrator of contributions shall return the subject of contribution to the person who paid it up or deposited it. Juridical acts made by the administrator in administering the subject is also binding upon that person.

\section{Section 334}

(1) After a foundation has been incorporated, its endowment principal can be extended by endowment gifts or by a decision to increase the endowment capital

(2) If a non-pecuniary gift meets the requirement of permanent yield and unless it is used as a security, the gift is presumed to extend the endowment principal. 
Section 335

The property of a foundation consists of the endowment principal and other property.

Section 336

(1) The endowment principal consists of a set of the subjects of contribution to the foundation or, where appropriate, also endowment gifts.

(2) An endowment principal must have has a total value equivalent at least to CZK 500,000.

\section{Section 337}

Monetary expression of the endowment principal is the endowment capital. The amount of the endowment capital is subject to registration in a public register.

\section{Section 338}

(1) A foundation uses its property in accordance with the purpose specified in the foundation charter and in the bylaws and under the conditions set forth therein for providing foundation grants, providing for its own activities fulfilling its purpose and paying the cost of increasing the value of the endowment principal and the cost of its own administration.

(2) Juridical acts whereby a foundation assumes unlimited liability for another person are disregarded.

\section{Section 339 [Recodification]}

(1) Items constituting the endowment principal may not be pledged or otherwise used to secure a debt. This does not apply if the foundation operates a business enterprise to the extent necessary for its smooth operation.

(2) Nothing may be alienated from the endowment principal if it is contrary to the will of the person who provided the gift to the foundation or fulfilled the duty to contribute. Otherwise, nothing may be alienated from the endowment principal, unless for consideration to be included in the endowment principal, or if the need to alienate something was caused by a change in circumstances which could not have been foreseen and which may not be otherwise dealt with, even if acting with due managerial care.

\section{Section 340 [Recodification]}

A foundation disposes of the endowment principal with the degree of care prescribed by this Act for the administration of property of others. Where, under the provisions on simple administration of property of others, the consent of the beneficiary is required for certain juridical acts, such acts shall require the prior consent of the persons designated in the foundation charter; if no such person is designated, the prior approval of the supervisory board is required.

\section{Section 34}

(1) If, in the last accounting period, the endowment capital or the turnover of the foundation reached an amount at least ten times the amount provided for under Section 330(1), the ordinary financial statements, extraordinary financial statements and consolidated financial statements are subject to an audit by an auditor.

(2) Financial statements are subject to an audit by an auditor also where they are used as a basis for a decision to increase or decrease the endowment capital or to transform the foundation.

\section{Increase in endowment capital}

\section{Section 342}

(1) Upon approval of the financial statements, the foundation board may, within one year from the date on which the data used to compile the financial statements were obtained, decide to extend the endowment principal and increase the endowment capital:

a) provided that the increase in the endowment capital is not greater than the difference between the amount of its own resources of financing of the foundation's property reported in the balance sheet as liabilities and the endowment capital, and

b) provided that the increase in the endowment capital is not financed from its own resources, which are designated for a specific purpose and whose purpose may not be changed by the foundation.

(2) A decision to extend the endowment principal and increase the endowment capital shall specify the amount whereby the endowment capital increases, and an indication of the resource which is used to increase the endowment capital, according to the structure of its own resources of financing the foundation's property in the financial statements.

(3) If the foundation learns from any subsequent financial statements of a reduction of its own resources, it shall rely on these financial statements when deciding to increase the endowment capital.

\section{Section 343}

(1) If a foundation increases its endowment capital by the amount of a gift consisting in a thing which is fit to constitute a contribution to the foundation, the increase of the endowment capital may not be higher than its determined value. 
(2) A decision to increase the endowment capital shall specify the amount whereby the endowment capital increases, and a description of the thing that extends the endowment principal, together with an indication of the value of the thing and how that value was determined.

\section{Decrease in endowment capital}

\section{Section 344}

(1) Unless prohibited by the foundation charter, the foundation may decrease the endowment capital by reducing the capital principal, if it is required in the interests of a more efficient fulfilment of its purpose. Endowment capital can be decreased by an amount equivalent to no more than one fifth of the endowment capital over five years. Decreasing the foundation capital may not directly or indirectly cover the costs of the foundation's administrator.

(2) A decision to decrease endowment capital shall specify the amount whereby the endowment capital decreases, and the reason why it is decreased.

\section{Section 345}

It is prohibited to decrease the endowment capital to less than CZK 500,000

\section{Section 346}

If the foundation loses a part of its endowment principal or if its value drops significantly, the foundation shall supplement the endowment principal without undue delay; if it is not reasonably possible, the foundation shall decrease the endowment capital to the extent of the loss.

\section{Common provisions}

Section 347

The decision to increase or decrease the endowment capital is made by the foundation board subject to prior approval of the supervisory board.

Section 348

An increase or decrease of endowment capital becomes effective upon registration in a public register.

\section{Affiliated fund}

\section{Section 349 [Recodification]}

(1) By a contract, a foundation may be entrusted with the administration of property fit for contribution to the foundation in the form of an affiliated fund, and authorised to use this property for a stipulated purpose if it is related to the mission of the foundation; it must not be used to support a political party or political movement.

(2) The contract must be in writing.

\section{Section 350 [Recodification]}

If it has been stipulated that the foundation will administer the affiliated fund under a special designation, the designation must include the words "přidružený fond" (affiliated fund). The designation must be specified together with the name of the foundation which administers the affiliated fund.

\section{Section 351 [Recodification]}

A foundation is presumed to carry out a simple administration of property in the affiliated fund and to carry it out for consideration usually required in similar cases.

\section{Section 352 [Recodification]}

(1) The disposal of an affiliated fund creates rights and duties only of the administering foundation. A foundation records the property in the affiliated fund separately from its own property.

(2) If the foundation is dissolved, the liquidator shall dispose of the affiliated fund in a way so that its legal nature and purpose are preserved.

\section{Foundation grant}

\section{Section 353 [Recodification]}

(1) The foundation must not provide a foundation grant to a person who is a member of one of its bodies or who is employed by the foundation, or to a close person of the body or foundation.

(2) Unless there are reasons deserving special consideration caused on the part of the founder by a change in circumstances, the foundation may not provide a foundation grant to its founder; if there are such reasons, the foundation board 
shall decide after consulting the supervisory board or inspector. This also applies if the foundation grant is provided to a close person of the founder, unless the foundation was established to support persons close to the founder.

\section{Section 354}

A person who has received a foundation grant may only use it in accordance with the stipulated conditions; upon request by the foundation he shall demonstrate how it was used. A person who used a foundation grant contrary to the stipulated conditions shall return it to the foundation as an unjust enrichment.

\section{Section 355}

(1) A foundation may not provide foundation grants if the amount of its own resources of financing the foundation's property reported in the balance sheet as liabilities is less than the amount of the endowment capital set out under Subsection (2), or if it were less than the adjusted amount of the endowment capital due to the provision of foundation grants.

(2) For the purposes set out in Subsection (1), the following amounts are added to the amount of the endowment capital:

a) an increase in the endowment capital as a result of receiving endowment capital or adopting a decision, even if it has not yet been registered in a public register, and

b) its own resources that are designated for a specific purpose and whose purpose may not be changed by the foundation. the donor.

(3) The provisions of Subsections (1) and (2) do not apply to providing grants from gifts determined for this purpose by

\section{Section 356} to return it.

A person who, acting in good faith, has accepted a foundation grant provided in violation of Section 355 is not obliged

\section{Section 357}

\section{Costs of administration}

A foundation shall keep separate accounts of foundation grants, other activities to fulfil the purpose of the foundation and the costs of its administration.

\section{Annual report}

Section 358

(1) A foundation shall prepare an annual report within six months from the end of the previous accounting period.

(2) The annual report shall include the financial statements and an overview of all the activities of the foundation, including the assessment of these activities.

(3) In its annual report, the foundation shall at least provide:

a) an overview of its own property and obligations,

b) for individual endowment gift, an overview of the persons who provided an endowment gift of more than CZK 10,000,

c) an overview of how the property of the foundation has been used,

d) an overview of persons who have been provided with a foundation grant worth more than CZK 10,000,

e) an assessment of whether, in its business management, the foundation complied with the rules for the provision of foundation grants under Sections 353 to 356 , and an overview of the costs of its own administration, and

f) an evaluation of the basic data of annual financial statements and the auditor's report, if the foundation is required to have their financial statements audited by an auditor.

(4) If, after the publication of the report, a fact becomes known that justifies a correction of the report, the foundation shall make the correction and publish it without undue delay.

\section{Section 359}

(1) If requested by a donor, a foundation shall not disclose the information about the donor in its annual report. A recipient of a foundation grant has the same right. When providing a foundation grant worth more than CZK 10,000, only a person who received the foundation grant for humanitarian reasons, in particular for health reasons, may request to remain anonymous.

(2) The foundation shall preserve anonymity if the entitled persons delivered their requests before the approval of the annual report. However, a person who received a foundation grant for humanitarian reasons may assert his right to anonymity at any time if the foundation failed to advise him of his right upon the provision of the grant; the advice is presumed not to have 
been provided.

\section{Section 360}

(1) A foundation shall publish its annual report within thirty days of its approval by the foundation board and also make it available at its registered office. Unless the foundation is established as having publicly beneficial status, it is sufficient to make the annual report available at its registered office.

(2) If the foundation board fails to approve the annual report, the foundation shall publish the annual report in the manner provided in Subsection (1) no later than by the end of the immediately following accounting period and shall state that the annual report was not approved and for what reasons.

Section 361

Anyone can inspect the annual report in the public register and make extracts, duplicates and copies. The same right may also be asserted at the foundation's registered office.

\section{Foundation board}

Section 362 [Recodification]

A foundation board is the foundation's governing body.

Section 363

Unless the foundation charter provides additional restrictions, the persons not eligible to be members of the foundation board shall include any person who:

a) is a member of the supervisory board of the foundation,

b) is employed by the foundation, or

c) has a criminal record related to the purpose of the foundation.

Section 364

Unless the foundation charter provides another term of office of a member of the foundation board, the term is five years. Unless precluded by the foundation charter, a board member may be re-elected.

Section 365

(1) Unless otherwise provided by the foundation charter, the foundation board elects and removes its members itself.

(2) The foundation charter may provide that a certain number of board members must be elected from among candidates nominated to the foundation board by the persons designated in the foundation charter or by persons designated in the manner laid down therein.

\section{Section 366}

Unless other reasons are provided by the foundation charter, the foundation board shall remove from office a member who seriously or repeatedly violated the foundation charter or by-laws, or who violated a statute in a way that evidently damages the reputation of the foundation. If the foundation board fails to do so within one month from the date on which it learned of the reason for the removal from office, but no later than six months from the date on which the reason emerged, the member of the foundation board shall, on the application of a person who can demonstrate a legal interest, be removed from office by court; the right to seek the removal of a member of foundation board is extinguished unless asserted within one year from the date on which the reason for removal emerged.

Section 367

(1) If a membership in the foundation board is extinguished, the foundation board shall elect a new member within three months. If the foundation board fails to do so, a new member of the foundation board is appointed by court on the application of the supervisory board or a person who can demonstrate legal interest, for the time until the foundation board elects a new member.

(2) The court shall appoint a new member of the foundation board, even of its own motion, if the foundation board is unable to decide on a new vote due to a decrease in the number of its members.

\section{Supervisory board}

\section{Section 368 [Recodification]}

(1) The supervisory board is the supervisory and revision body of a foundation; it has at least three members.

(2) The supervisory board must be established if the endowment capital reaches at least ten times the amount under Section 330(1). 
Unless the foundation charter provides additional restrictions, the persons not eligible to be members of the supervisory board shall include any person who:

a) is a member of the foundation board or the liquidator,

b) is employed by the foundation, or

c) has a criminal record related to the purpose of the foundation.

\section{Section 370}

(1) Unless the foundation charter or, within the scope provided therein, the by-laws of the foundation grant the supervisory board additional powers, the supervisory board:

a) ensures that the foundation board exercises its competence according to statutes and in accordance with the foundation charter and the by-laws,

b) checks compliance with the conditions laid down for the provision of foundation grants,

c) notifies the foundation board of the ascertained deficiencies and submits proposals to remove them,

d) checks how accounts are kept and reviews the annual, extraordinary and consolidated financial statements,

e) comments on the annual report, and

f) at least once a year it submits a report in writing to the foundation board on its supervisory activities.

(2) The supervisory board represents the foundation against a member of the foundation board, as well as in any matter where the interest of the members of the foundation board is contrary to the interests of the foundation. For this purpose, the supervisory board shall appoint one of its members.

\section{Section 371}

(1) The supervisory board shall convene a meeting of the foundation board, unless convened by the chairman of the foundation board on a proposal by the supervisory board.

(2) Within the competence of the supervisory board, its authorised member may inspect the documents of the foundation and require the members of other bodies or employees of the foundation to provide explanations on various issues.

\section{Section 372}

Unless otherwise provided by the foundation charter, the supervisory board elects and removes its members itself. The provisions on a foundation board apply, by analogy, to the election and removal of members of the supervisory board and their term of office.

\section{Inspector}

\section{Section 373 [Recodification]}

(1) In the absence of a supervisory board, its competence is exercised by an inspector.

(2) The foundation charter or by-laws of a foundation may provide that the office of inspector is discharged by a legal person whose objects of activities allow the discharge of supervisory and revision activities, and that this office shall also be discharged for an indefinite period.

\section{Section 374}

(1) Section 369 applies, by analogy, to the capacity to be an inspector. If the inspector is a legal person, its rights and duties associated with the office of inspector may be discharged by its representative that meets the conditions set out in the first sentence.

(2) Unless the foundation charter provides a shorter term, the term of office of an inspector is five years. An inspector may also be re-elected, unless excluded by the foundation charter.

\section{Section 375}

(1) Unless the foundation charter provides differently, an inspector is elected and removed by the foundation board.

(2) Unless the foundation charter provides for other reasons, the foundation board shall remove an inspector who seriously or repeatedly violated the foundation charter or by-laws, or who violated a statute in a way that evidently damages the reputation of the foundation. If the foundation board fails to do so within one month from the date on which it learned of the reason for the removal from office, but no later than six months from the date on which the reason emerged, the inspector shall, on the application of a person who can demonstrate a legal interest, be removed from office by a court; the right to seek the 
removal of an inspector is extinguished unless asserted within one year from the date on which the reason for removal emerged.

\section{Dissolution of a foundation with liquidation}

Section 376 [Recodification]

If the purpose for which a foundation has been formed is achieved, the foundation is dissolved and the foundation board shall choose a liquidator.

\section{Section 377 [Recodification]}

(1) The court shall dissolve a foundation with liquidation on the application of a person with a legal interest therein, or even of its own motion, if:

a) the foundation pursues activities prohibited under Section 145 or acts in violation of Section 307,

b) the foundation becomes a business company's member with unlimited liability,

c) the foundation seriously or repeatedly violates the prohibition to provide a foundation grant to the person under Section 353 ,

d) the foundation provides foundation grants for more than two years without having a serious reason to do so,

e) the foundation disposes of the endowment principal in violation of Section 339,

f) the value of the endowment principal decreases below CZK 500,000, and that state lasts for more than one year from the end of the accounting period in which the decrease of the endowment principal occurred,

g) the endowment principal has not generated any yield for more than two years, or

h) it is not consistently possible for the foundation to continue to fulfil its purpose.

(2) This provision does not affect Section 172.

\section{Section 378 [Recodification]}

(1) The liquidator shall sell the liquidation estate to the extent necessary to settle the debts of the foundation. He shall dispose of the liquidation balance according to the foundation charter.

(2) If the foundation charter of a publicly beneficial foundation determines that the liquidated balance is to be used for a purpose other than a publicly beneficial one, is disregarded.

\section{Section 379 [Recodification]}

(1) If the foundation charter does not determine the way the liquidation balance is to be disposed of, the liquidator shall offer it to a foundation with a similar purpose. However, if there is a serious reason, the foundation board may decide that the liquidation balance is primarily offered to the municipality, region or State.

(2) If it is not reasonably possible to offer the liquidation balance to a foundation with a similar purpose, or if the offer made under Subsection (1) is rejected, the liquidator shall offer the liquidation balance to the municipality in whose territory the registered office of the foundation is located. If the municipality does not accept such offer within two months from the day it becomes effective, the liquidated balance is acquired by the region in which the registered office of the foundation is located.

\section{Section 380 [Recodification]}

If the liquidation balance is acquired by a municipality, region or State, they shall only use the liquidation balance for a publicly beneficial purpose.

\section{Section 381 [Recodification]}

If a foundation has acquired funds designated for a specific purpose from a public budget, the provision of Section 378 does not apply and the liquidator shall dispose of the relevant part of the liquidation balance according to the decision of a competent body.

\section{Transformation of a foundation}

\section{Section 382 [Recodification]}

(1) A transformation of a foundation may occur as a result of a merger by acquisition of another foundation or endowment fund, or a change of its legal form to an endowment fund.

(2) A foundation may merge by acquisition of another foundation or endowment fund, unless excluded by the foundation charter and the persons involved serve the same or a similar purpose. In the event of a merger by acquisition between a foundation and an endowment fund, the successor person must be a foundation. 
(1) The agreement on merger by acquisition shall specify at least:

a) the name, address and identifier of the persons involved indicating the acquired person and the successor person,

b) determination of the structure in which the successor person takes over the components of equity capital and debt capital of the terminating person which do not constitute liabilities,

c) the amount of endowment capital, if the successor person is a foundation,

d) an agreement to change the by-laws of the successor person, if such a change occurs as a result of merger by acquisition,

e) the decisive date.

(2) In the event of a merger by acquisition between foundations, the endowment capital under Subsection (1)(c) is the sum of the endowment capital of the foundations being merged by acquisition. In the event of a merger by acquisition between an endowment fund and a foundation as the successor person, the endowment capital may be increased under the conditions set out in Section 342; in that case, the agreement on merger by acquisition must include the elements set out in Section 342(2).

(3) An agreement on merger by acquisition requires the form of a public instrument.

\section{Section 384}

(1) Before entering into an agreement on merger by acquisition, the persons involved shall make their accounting records mutually available and provide additional information and documents necessary to assess the legal and economic implications of the merger by acquisition.

(2) A person who becomes familiar with the information under Subsection (1) shall keep confidential the facts whose disclosure is prohibited by a statute or may cause serious harm to a person involved.

\section{Section 385}

The supervisory board or inspectors of the persons involved shall review the accounts of each of the persons involved and prepare a report on the facts that are the subject of their accounts, including a statement on the draft agreement on merger by acquisition and a statement on the economic consequences of the merger by acquisition; a joint report of all the persons involved can also be prepared.

\section{Section 386}

(1) If a report is prepared under Section 385, the merger by acquisition is decided by the foundation boards of the persons involved. A meeting of the foundation board must be notified at least thirty days before it takes place; within this time limit, each member of the foundation board is provided with:

a) a draft agreement on the merger by acquisition,

b) its articles of association, if the merger by acquisition is to result in a change of the articles of association of the successor person,

c) the financial statements of all persons involved; if the financial statements are compiled from information as of the date from which more than six months have elapsed until the date of the preparation of the draft agreement on merger by acquisition, also interim financial statements of the relevant person,

d) the opening balance sheet of the successor person, and

e) a report under Section 385

(2) The foundation board may only accept or reject the draft agreement on merger by acquisition.

(3) If a joint foundation board meeting of the persons involved is convened, each foundation board votes on the draft agreement on merger by acquisition separately. However, if, after the approval of the agreement, members of bodies of the successor person are elected, the foundation boards of the parties involved may decide to vote on the members together.

\section{Section 387}

(1) The persons involved shall, at least thirty days before the meeting of the foundation board, publish a joint notification indicating the persons concerned by the merger and which of them will become the successor person.

(2) If a creditor of a person involved registers a claim within six months from the date on which the registration of the merger became effective with respect to the creditor, he is entitled to adequate security if he can prove that the recoverability of his claim deteriorates. If a creditor proves that the merger leads to a significant deterioration of the recoverability of his claim, he is entitled to adequate security even before registration of the de-merger in a public register.

Only a person involved, a member of the foundation board, a member of the supervisory board or an inspector has 
the right to seek invalidity of the agreement on merger by acquisition; this right is extinguished if the application is not filed within three months from the date of the meeting of the foundation board.

\section{Section 389}

(1) An application to register a merger in a public register is submitted jointly by all the parties involved; the application shall also be signed by the members of the governing body of the successor person.

(2) Based on the application, the merger is registered by deleting, on the same date, the terminating persons in the public register indicating their legal successor, and for the successor person indicating the effective date of the merger and the names, addresses of registered offices and identifiers of the persons who merged with the successor person as well as any other changes concerning the successor person that may have occurred as a result of the merger.

\section{Section 390}

(1) If the persons involved fail to file an application for the registration of the merger within six months from the date on which the agreement on merger by acquisition was concluded, any of the persons involved who was ready to file the application may withdraw from the agreement. Withdrawal from the agreement by even one party extinguishes the obligations of all parties arising from the agreement.

(2) If the persons involved fail to apply for registration of the merger within one year from the date on which the agreement on merger by acquisition was concluded, all the persons involved are conclusively presumed to have withdrawn from the agreement.

The members of the governing body of a person involved that is responsible for not applying for the registration of the merger by acquisition in time shall, jointly and severally with the person involved, compensate other persons involved for the resulting damage; this does not apply to those members who prove that they made sufficient efforts to file the application in time.

\section{Change of legal form of a foundation to an endowment fund}

\section{Section 391 [Recodification]}

(1) If expressly permitted by the foundation charter, the foundation board may, subject to a statement of the supervisory board or the inspector, decide to change the legal status of a foundation to an endowment fund, but only if the value of the endowment principal dropped below the amount under Section 330(1) for a period other than a transitional period.

(2) A decision to change the legal form must specify:

a) the designation of the foundation by its name, registered office and identifier,

b) the name of the endowment fund after the change of legal form,

c) the decisive date,

d) details of the members of the endowment fund's bodies which are subject to registration in a public register.

(3) The decision requires the form of a public instrument.

\section{Section 392 [Recodification]}

A decision to change the legal form becomes effective upon registration in a public register.

\section{Section 393 [Recodification]}

(1) At least thirty days before the meeting of the foundation board, a foundation shall publish a notification of its intention to adopt a decision to change the legal form.

(2) A creditor of a foundation who registers his claim within six months from the date the registration of change of legal form became effective against third persons may require sufficient security of his claim if the change of legal form leads to deterioration of its recoverability. If a creditor proves that a change of legal form has led to a substantial deterioration of recoverability of his claim, he is entitled to sufficient security before the change of legal status is registered in a public register.

\section{Subdivision 3}

\section{Endowment fund}

\section{Section 394 [Recodification]}

(1) A founder forms an endowment fund to serve a socially or economically useful purpose.

(2) The name of the endowment fund must contain the words "nadační fond" (endowment fund).

\section{Section 395 [Recodification]}

An endowment fund is formed by a formation deed or disposition mortis causa. 
(1) The forming juridical act contains at least:

a) the name and registered office of the endowment fund,

b) the name of the founder and his place of residence or registered office,

c) the definition of the purpose for which the endowment fund is formed,

d) an indication of the amount of contribution, or non-pecuniary contribution,

e) the number of members of the foundation board, the names and addresses of residence of its first members, and how the members of the foundation board act on behalf of the endowment fund,

f) the number of members of the supervisory board and the names and addresses of its first members, or the name and residence of the first inspector,

g) the appointment of the administrator of contributions, and

h) the conditions for the provision of grants from the property of the endowment fund or the specification of the types of activities permitted to be pursued by the endowment fund, given its purpose.

(2) If an endowment fund is formed by a disposition mortis causa and the founder has not determined even a method of appointment of the first members of the foundation board and supervisory board or the first inspector, they are appointed by the executor of testament; otherwise, they are appointed by a court on the application of a person who demonstrates a legal interest.

\section{Section 397 [Recodification]}

\section{Incorporation of an endowment fund}

An endowment fund is incorporated upon registration in a public register.

\section{Section 398 [Recodification]}

(1) The property of an endowment fund are made up of a set created from contributions and gifts, the subject of which need not fulfil the condition of generating a permanent yield. No item of the property of an endowment fund may be pledged or otherwise used to secure a debt; juridical acts in breach of this requirement are disregarded.

(2) The property of the endowment fund may be alienated if it is consistent with the purpose of the endowment fund. It can also be used for an investment which is considered to be prudent.

(3) An endowment fund does not create an endowment principal or endowment capital.

\section{Section 399 [Recodification]}

(1) If expressly permitted by the forming juridical act, the foundation board may, after a prior statement provided by the supervisory board or the inspector, decide to change the legal form of an endowment fund to a foundation. A decision to change the legal form must contain at least the identification of the endowment fund with its name, address and identifying information, and elements required for the foundation charter.

(2) The decision requires the form of a public instrument.

\section{Section 400 [Recodification]}

(1) At least thirty days before the meeting of the foundation board the endowment fund shall publish a notification of the intention to change the legal form.

(2) A creditor of an endowment fund who registers his claim within six months from the date the registration of change became effective against third persons may require sufficient security of his claim if the change of legal form leads to the deterioration of its recoverability. If a creditor proves that a change of legal form has led to a substantial deterioration of recoverability of his claim, he is entitled to sufficient security before the change of legal status is registered in a public register.

\section{Section 401 [Recodification]}

(1) If it is not consistently possible for an endowment fund to continue to fulfil its purpose, the foundation board shall decide to dissolve the endowment fund with liquidation and appoint a liquidator.

(2) If an endowment fund does not fulfil the purpose for which it was established, a court shall dissolve it on the application of a person who demonstrates a legal interest, and order its liquidation.

\section{Division 4}

\section{Institute}


An institute is a legal person created for the purpose of pursuing socially or economically useful activities using its personal and property resources. An institute pursues activities the results of which are equally available to everyone under predetermined conditions.

\section{Section 403 [Recodification]}

If an institute operates a business enterprise or another secondary activity, its operation must not be to the detriment of the quality, scope and availability of the services provided as the primary activity of the institute. An institute may only use its profit to support the activities for which it was formed, and to pay the costs of its own administration.

\section{Section 404 [Recodification]}

\section{Name of an institute} ú." will suffice.

The name of an institute must include the words "zapsaný ústav" (registered institute); however, the abbreviation "z.

\section{Section 405 [Recodification]}

\section{Formation of an institute} specify:

(1) An institute is formed by a formation deed or disposition mortis causa. The forming juridical act shall at least

a) the name of the institute and its registered office,

b) the purpose of the institute by defining the its objects of activities, or, where applicable, its objects of business,

c) an indication of the amount of contribution, or non-pecuniary contribution,

d) the number of members of the board of trustees and the names and places of residence of its first members, and

e) details of the internal organisation of the institute, unless reserved for the by-laws of the institute.

(2) If the forming juridical act establishes a supervisory board, it specifies the number of supervisory board members and the names and places of residence of its first members.

\section{Section 406 [Recodification]}

(1) The founder decides on amendments to the forming juridical act, even during the existence of the institute.

(2) If the founder cannot make decisions, his rights with respect to the institute are acquired by a person designated by the forming juridical act to the extent specified therein; otherwise they are acquired by the board of trustees; in that case, however, a decision of the board of trustees to alter the purpose of the institute or to dissolve it requires prior approval by a court.

\section{Section 407 [Recodification]}

\section{Incorporation of an institute}

An institute is incorporated upon registration in a public register.

\section{Section 408 [Recodification]}

\section{Director}

(1) The director is the governing body of an institute. The by-laws may provide another name for this body, provided that it is not misleading as to its nature.

(2) The director may not be a member of the board of trustees, and a member of the supervisory board or another body of a similar nature, if established. If a person convicted of an intentional criminal offence is elected as the director, the election is disregarded.

\section{Board of trustees}

\section{Section 409 [Recodification]}

(1) Unless otherwise provided by the forming juridical act, the members of the board of trustees are appointed and removed by the founder. If it is not possible, the members of the board of trustees are elected and removed by the supervisory board, if established; otherwise the board of trustees elects and removes its members on its own. 
(2) Unless otherwise provided by the forming juridical act, the term of office of a member of the board of trustees is three years. Unless it is excluded by the forming juridical act, a member of the board of trustees may be elected repeatedly; however, if the board of trustees elects and removes its members on its own, the same person may be repeatedly elected for no more than two consecutive terms.

(3) Where supervisory board has been established, the membership in the board of trustees is incompatible with the membership in the supervisory board.

\section{Section 410 [Recodification]}

The board of trustees elects and removes the director, supervises over the discharge of his powers and decides on the juridical acts of the institute against the director; unless otherwise provided, the chairman of the board of trustees expresses will on behalf of the institute in these juridical acts.

\section{Section 411 [Recodification]}

(1) The board of trustees approves the budget, ordinary and extraordinary financial statements and the annual report of the institute.

(2) The board of trustees makes a decision to start the operation of the business enterprise or other secondary activities of the institute, or to change its objects of activities, unless otherwise provided by the forming juridical act.

\section{Section 412 [Recodification]}

(1) Unless the forming juridical act imposes other limitations, the board of trustees grants its prior consent to juridical acts whereby the institute:

a) acquires or loses the right of ownership in an immovable thing,

b) encumbers its own immovable things,

c) acquires or loses a copyright or industrial right, or

d) forms another legal person or participates in such a person with a contribution.

(2) Unless otherwise provided by the forming juridical act, the board of trustees grants its prior consent to juridical acts whereby the institute acquires or loses the right of ownership in a movable thing whose value is greater than the value of a below-threshold contract under the statute regulating public procurement.

\section{Section 413 [Recodification]}

\section{By-laws of an institute}

(1) If provided by the forming juridical act or where appropriate, the board of trustees shall issue the institute's by-laws and set out the internal organisation of the institute and the details of its activities therein.

(2) An institute shall publish the by-laws by depositing them in the collection of instruments. Anyone can inspect the by-laws in the public register and make extracts, duplicates or copies thereof. The same right can also be asserted at the institute's registered office.

\section{Section 414 [Recodification]}

Unless the formation deed provides that the members of the institute's bodies are entitled to remuneration for the discharge of their office and how it is to be determined, the director is conclusively presumed to be entitled to a usual remuneration; the offices of the members of other bodies are presumed to be honorary. In such a case, the board of trustees determines the amount of the remuneration of the director or the manner of its determination.

\section{Section 415 [Recodification]}

(1) An institute accounts separately for costs and revenues associated with the primary objects of activities, the operation of a business enterprise or other secondary activities and the administration of the institute.

(2) Financial statements of the institute are audited by an auditor, if he is required to do so by the forming juridical act or by-laws, or if the amount of the institute's net turnover exceeds CZK 10,000,000. In such cases, the auditor also audits the annual report of the institute.

\section{Section 416 [Recodification]}

\section{Annual report}

(1) An annual report of an institute specifies, in addition to other requirements laid down in another legal regulation governing accounting, other relevant information about the activities and business management of the institute, including the amounts provided to members of the institute's bodies, and any amendments to the forming juridical act or changes in the membership in the institute's bodies.

(2) Unless the forming juridical act provides for additional methods of publication, an institute shall publish its annual 
report no later than six months after the end of the accounting period by depositing it in the collection of instruments. Anyone can inspect the by-laws in the public register and make extracts, duplicates or copies thereof.

\section{Section 417 [Recodification]}

If, in the long term, an institute fails to fulfil its purpose, it is dissolved by court on the application of a person who demonstrates a legal interest.

\section{Section 418 [Recodification]}

In other respects, the provisions on foundations apply, by analogy, to the legal relations of an institute; however, the provisions on endowment principal and endowment capital do not apply.

\section{Chapter 4}

\section{Consumer}

\section{Section 419 [Recodification]}

A consumer is any individual who, outside his trade, business or profession, enters into a contract or has other dealings with an entrepreneur.

\section{Chapter 5}

\section{Entrepreneur}

\section{Section 420 [Recodification]}

(1) A person who, on his own account and responsibility, independently carries out a gainful activity in the form of a trade or in a similar manner with the intention to do so consistently for profit is considered, with regard to this activity, to be an entrepreneur.

(2) For the purposes of consumer protection and for the purposes of Section 1963, any person who enters into contracts related to his own commercial, production or similar activities, or within his trade, business or profession, or a person acting in the name or on the account of an entrepreneur is considered to be an entrepreneur.

\section{Section 421 [Recodification]}

(1) A person registered in the commercial register is considered to be an entrepreneur. The conditions under which persons are subject to registration in the commercial register are provided by another statute.

(2) A person who is authorised to conduct his business activities on the basis of a trade or another licence under another statute is presumed to be an entrepreneur.

\section{Section 422 [Recodification]}

An entrepreneur who does not have a corporate name makes juridical acts within his business activities under his own name; if the entrepreneur adds to his name additions describing his business enterprise or person in more detail, these may not be misleading.

\section{Corporate name}

\section{Section 423}

(1) A corporate name is a name under which the entrepreneur is registered in the commercial register. An entrepreneur may not have several corporate names.

(2) The protection of the rights to the corporate name pertains to the first person to have lawfully used it. A person whose right to the corporate name has been affected has the same rights as in the case of protection against unfair competition.

\section{Section 424}

A corporate name must not be capable of being confused with another corporate name and must not give a misleading impression.

\section{Section 425}

(1) An individual shall register in the commercial register under the corporate name generally consisting of his name. If his name changes, his former name may continue to be used in the corporate name; however, he shall publish such a change of name.

(2) If an individual registers in the commercial register under a corporate name other than his own name, it must be evident that it is not a corporate name of a legal person. 


\section{Section 426}

If multiple business enterprises of several entrepreneurs join to form a business group, their names or corporate names may contain identical elements; however, they must be distinguishable to the public.

\section{Section 427}

(1) A person who acquires a corporate name has the right to use it subject to the consent of his predecessor or the legal successor thereof; however, he is required to attach to the corporate name information indicating legal succession.

(2) In the case of transformation of a legal person, the corporate name passes to the legal successor, subject to its consent; the consent of another person is not required. If a legal person has multiple legal successors and it has not been determined to which of them the name passes, the corporate name will pass to none of them.

\section{Section 428}

A person has the right to withdraw the consent to use his name in a corporate name of a legal person if he has such a serious reason to do so that he may not be fairly required to allow his name to be used in the corporate name; such a reason may especially be a change in the prevailing nature of business activities of the legal person or a change in the ownership structure of the business corporation. Under these conditions, a legal successor of the person who gave the consent has the same right.

\section{Section 429 [Recodification]}

\section{Registered office of an entrepreneur}

(1) A registered office of an entrepreneur is determined by an address registered in a public register. If a natural person is not subject to registration in a public register as an entrepreneur, his registered office is the place of his principal business enterprise or his residence.

(2) If an entrepreneur provides as his registered office a place other than his actual registered office, anyone may also invoke his actual registered office. An entrepreneur may not claim to have his registered office elsewhere against anyone who invokes the entrepreneur's registered office entered in a public register.

\section{Representation of an entrepreneur}

\section{Section 430 [Recodification]}

(1) If an entrepreneur authorises a person to carry out a certain activity within the operation of a business enterprise, that person represents the entrepreneur in all dealings that this activity typically involves.

(2) An entrepreneur is also bound by the acts of another person in his establishment if a third person is in good faith that the acting person was authorised to perform such acts.

\section{Section 431 [Recodification]}

If an entrepreneur's representative exceeds his authority to represent, the entrepreneur is bound by his juridical acts; this does not apply if a third person knew or must have known of the excess given the circumstances of the case.

\section{Section 432}

\section{Prohibition of competition}

(1) A person who acts as an entrepreneur's representative in the operation of a business enterprise may not perform any acts, on his own account or the account of another, that fall within the field of the business enterprise without the entrepreneur's consent. Should this be the case, the entrepreneur may demand that his representative refrain from acting so.

(2) If the agent acted on his own account, the entrepreneur may demand that the agent's acts be declared to have been made on the entrepreneur's account. If the agent acted on the account of another, the entrepreneur may demand that the right to compensation be assigned or a previously provided compensation be surrendered to the entrepreneur. These rights are extinguished if not asserted within three months from the date on which the entrepreneur learned of the acts, but no later than one year from the date on which the acts occurred.

(3) Instead of the right under Subsection (2), an entrepreneur may claim compensation for damage; however, this only applies if the representative should and could have known that his acts were to the detriment of the entrepreneur. If the person in whose favour the entrepreneur's representative performed unallowed acts should have and could have known that his acts were to the detriment of the entrepreneur, he is also liable to provide compensation for damage.

\section{Section 433 [Recodification]}

(1) A person who acts as an entrepreneur with respect to other persons in economic transactions may not abuse his expertise or economic position to create or take advantage of the dependence of the weaker party and to achieve a clear and unjustified imbalance in the mutual rights and duties of the parties.

(2) It is presumed that the person who, in economic transactions, acts with respect to the entrepreneur in a manner 
unrelated to his own business activities is always the weaker party.

\title{
Section 434
}

If an entrepreneur makes his place of business known to the public, he shall allow the public to engage with him in legal transactions in this place during the specified business hours; otherwise during usual hours.

\section{Section 435}

(1) Every entrepreneur must specify his name and registered office on business instruments and as part of the information made available to the public via remote access. An entrepreneur registered in the commercial register shall also specify information about this registration, including the section and inset on the business instrument; an entrepreneur registered in another public register shall provide information of his registration in the register; an entrepreneur not registered in a public register shall provide the information of his registration in another register. If an entrepreneur has been assigned an identifier, he shall specify it as well. impression.

(2) Additional information may be specified on the instrument under Subsection (1) unless it gives a misleading

\author{
TITLE III
}

\section{REPRESENTATION}

\section{Chapter 1}

\section{General provisions}

\section{Section 436}

(1) A person who is authorised to make juridical acts in the name of another is his representative; the person represented acquires rights and duties arising from representation directly. If it is not evident that a person acts on behalf of another, he is conclusively presumed to act in his own name.

(2) If a representative acts in good faith or if he must have known about a specific circumstance, the same is taken into account for the person represented; this does not apply in the case of a circumstance which the representative learned before the representation was created. If the person represented does not act in good faith, he may not invoke good faith of the representative.

\section{Section 437 [Recodification]}

(1) A person may not represent another if his interests are contrary to the interests of the person represented, unless, under the contractual representation, the person represented knew or must have known of such a contradiction.

(2) If a representative whose interest is contrary to the interests of the person represented had dealings with a third person and that person knew or must have known of that circumstance, this may be invoked by the person represented. A contradiction in the interests of the representative and the person represented is presumed to exist where the representative acts even for that third person, or if he acts in his own matter.

\section{Section 438 [Recodification]}

A representative acts personally. He may authorise another representative, if so agreed with the person represented or if required by an urgent need; however, he is responsible for the proper selection of the representative.

\section{Section 439 [Recodification]}

If a person represented has multiple representatives for the same matter, each of them is presumed to be entitled to act individually.

\section{Section 440}

(1) If a representative exceeds his authority to represent, the person represented is bound by the juridical acts if he approves such excess without undue delay. This applies even where a person acts on behalf of another without being authorised to do so.

(2) If a juridical act is not approved without undue delay, the person having made the juridical act for another is bound himself. A person that was dealt with and who acted in good faith may require the acting person to fulfil what was agreed, or to provide compensation for damage.

\section{Chapter 2}

\section{Contractual representation}

\section{Division 1}




\title{
General provisions
}

\author{
Section 441
}

(1) If so stipulated by the parties, one represents the other as an agent to the stipulated extent.

(2) The principal shall state the scope of the authority to represent in a power of attorney. Unless representation is only related to a particular juridical act, the power of attorney is granted in writing. Where a special form is required for juridical acts, the power of attorney is granted in the same form.

\section{Section 442 [Recodification]}

The principal may not waive his right to withdraw the authorisation; however, if the parties stipulate certain reasons for such withdrawal, the authorisation may not be withdrawn for another reason. This does not apply if the principal has a particularly serious reason to withdraw the authorisation.

\section{Section 443 [Recodification]}

Where authorisation is granted to a legal person, the exercise of the authority to represent falls within the scope of competence of its governing body. A person designated by the governing body is also authorised to exercise representation.

\section{Section 444 [Recodification]}

(1) A person who causes, by his own fault, a presumption in a third person that the former has authorised someone else to make juridical acts may not invoke the lack of authorisation if the third person acted in good faith and could have reasonably expected that the authorisation had been granted.

(2) If a principal indicated to another person that he had authorised an agent to make certain juridical acts, he may invoke with respect to that person that the authorisation was later extinguished only if the principal had notified the person thereof before the agent made the juridical act or if the person knew of the extinction at the time the agent made the juridical act.

\section{Section 445 [Recodification]}

If a person without the legal capacity to make independent juridical acts acted in the capacity of a representative, such act may not be invoked with respect to a person who did not know and could not have known of that fact.

\section{Section 446}

If an agent has exceeded his authority to represent and unless agreed by the principal, the principal shall, without undue delay after learning of the juridical act, notify the person with respect to whom the agent made the juridical acts. If he fails to do so, the principal is conclusively presumed to have approved the excess; this does not apply if the person with respect to whom the representative made juridical acts should have and could have realised, based on the circumstances and beyond any doubt, that the agent clearly exceeded his authority to represent.

\section{Section 447 [Recodification]}

If the instructions of a principal are contained in a power of attorney and if the person with respect to whom the agent made juridical acts must have been aware of these instructions, exceeding these instructions is considered to be a violation of the authority to represent.

\section{Section 448 [Recodification]}

(1) Authorisation is extinguished upon making the juridical act to which the representation was restricted; authorisation is also extinguished if revoked by the principal or terminated by the agent. Authorisation is extinguished by the death of the agent or principal or, where any of them is a legal person, upon its termination, unless stipulated otherwise.

(2) Until the agent becomes aware of the revocation, his juridical acts have the same effect as if the authorisation were still effective. This, however, may not be invoked by the party that knew or should and could have known of the revocation of the authorisation.

\section{Section 449 [Recodification]}

(1) If the principal dies or the agent terminates the authorisation, the agent shall still do everything that cannot be postponed to prevent any harm incurred by the principal or his legal successor. His juridical acts have the same effect as if the authorisation were still effective, unless it contradicts what the principal or his legal successor ordered.

(2) The agent shall, without undue delay after the termination of the authorisation, surrender everything the principal lent to him, or what he acquired for the principal. If the agent dies, anyone who has possession of those things has the same duty to the principal.

\section{Division 2}

\section{Corporate representation}


(1) By granting corporate representation, an entrepreneur registered in the commercial register authorises a corporate agent to make juridical acts associated with the operation of a business enterprise or a branch thereof, including those which otherwise require a special power of attorney. However, a corporate agent may alienate or encumber an immovable thing only if expressly provided.

(2) When granting corporate representation, the fact that it is corporate representation must be expressly provided. If an entrepreneur grants corporate representation to a branch of his business enterprise or to one of several of his business enterprises, he shall specifically identify the branch or business enterprise.

\section{Section 451 [Recodification]}

A corporate agent is not authorised to transfer the corporate representation to any other person or grant additional corporate representation; stipulations to the contrary are disregarded.

\section{Section 452 [Recodification]}

(1) It is prohibited to grant corporate representation to a legal person.

(2) If corporate representation has been granted to several persons, each of them represents the entrepreneur individually, unless otherwise determined when the corporate representation was granted.

\section{Section 453 [Recodification]}

Limitation of the corporate representation by internal guidelines has no effect on third persons, even if published.

\section{Section 454 [Recodification]}

A corporate agent shall perform his duties under corporate representation with due managerial care.

\section{Section 455 [Recodification]}

A corporate agent signs by affixing his signature and information indicating the corporate representation to the entrepreneur's corporate name; if corporate representation has been granted to an individual branch or one of several business enterprises, he shall also add information designating the branch or business enterprise.

\section{Section 456 [Recodification]}

Corporate representation is also extinguished upon the transfer or usufructuary lease of the business enterprise or branch for which it was granted. Corporate representation is not extinguished upon the death of the entrepreneur, unless stipulated otherwise.

\section{Chapter 3}

\section{Legal representation and guardianship}

\section{Division 1}

\section{General provisions}

Section 457

rights.

Legal representation and guardianship aim to protect the interests of the person represented and the fulfilment of his

\section{Section 458 [Recodification]}

A legal representative or guardian is not authorised to make juridical acts on behalf of the person represented in matters relating to the formation and termination of marriage, exercise of parental rights and duties, and the disposition mortis causa and declaration of disinheritance and their withdrawal.

\section{Section 459 [Recodification]}

A legal representative may not take a thing of sentimental value away from the person represented, unless it is justified by threat to life or health, or on the basis of other serious grounds if the person represented is a minor who lacks full legal capacity. A thing of sentimental value must be left in the possession of the person represented even if placed in a health care facility, social service facility, facility for social and legal protection of children or a similar facility.

\section{Section 460}

If there is a conflict between the interests of a legal representative or guardian and the interest of the person represented, or a conflict of interests of those who are represented by the same legal representative or guardian, or in case of a threat of such a conflict, a guardian ad litem is appointed by a court. 
(1) If a legal representative or a guardian administers the assets and liabilities of the person represented, he is entitled to carry out usual administration of such assets and liabilities. In case of a matter other than a usual matter, the disposition of the assets and liabilities of the person represented requires approval by a court.

(2) A gift, inheritance or legacy intended for the person represented on the condition that it will be administered by a third person is excluded from administration under Subsection (1). However, a legal representative or guardian may refuse to accept such a gift, inheritance or legacy; the rejection requires approval by a court.

\section{Section 462 [Recodification]}

A legal representative or guardian may not require remuneration for representation from the person represented. However, if he is obliged to administer assets and liabilities, remuneration for the administration may be granted. Its amount is determined by a court with regard to the cost of administration, the value of the property under administration and the yields therefrom, as well as the amount of time and work required for the administration.

\section{Section 463}

(1) A guardian is appointed by a court; the court shall also determine the scope of rights and duties of the guardian. The person for whom a court has appointed a guardian becomes a ward for the duration of the guardianship.

(2) The court shall remove a guardian upon his request; the court shall also remove a guardian if he fails to fulfil his duties. The court shall at the same time appoint a new guardian for the ward.

\section{Section 464 [Recodification]}

(1) Except in the case of administration of assets and liabilities, only one guardian may be appointed for a person. If a court appoints a special guardian to administer the assets and liabilities, or part thereof, of the person represented and also a guardian of the person, the latter is exclusively entitled to represent the person before the court, even where the matter relates to the assets and liabilities under administration.

(2) If a court appoints several guardians and does not decide on the matters in which each of them has the capacity to act individually on behalf of the person represented, the guardians are obliged to act jointly.

\section{Division 2}

\section{Guardianship of an individual}

\section{Section 465 [Recodification]}

(1) The court shall appoint a guardian for an individual if it is necessary to protect his interests, or if required by a public interest. A court shall in particular appoint a guardian for a person whose legal capacity has been limited by the court, for a person of unknown whereabouts, an unknown person participating in certain juridical acts or a person whose health condition is causing him difficulties in administering his assets and liabilities or defending his rights.

(2) If justified by the circumstances, the court may order a guardian to conclude insurance, to a reasonable extent, against harm he may cause to the ward or to another person in the performance of his function.

\section{Section 466}

(1) The duties of a guardian include maintaining contact with the ward in an appropriate manner and to the extent required, showing genuine interest in the ward, as well as taking care of his health condition, and ensuring the fulfilment of his rights and protection of his interests.

(2) When making a decision on the matters of a ward, the guardian shall clearly explain to him the nature and consequences of the decision.

\section{Section 467}

(1) In the performance of his duties, a guardian fulfils the legal declarations of the ward and respects his opinions, even if expressed previously, including his beliefs or creed, systematically takes them into account and arranges the matters of the ward accordingly. If this is not possible, the guardian shall proceed according to the interests of the ward.

(2) A guardian shall ensure that the way of life of the ward is not in conflict with his abilities and corresponds to the specific ideas and wishes of the ward, unless they can be reasonably opposed.

\section{Section 468 [Recodification]}

The death or removal of a guardian does not extinguish the guardianship, and until a court appoints a new guardian for the ward, it passes to a public guardian in accordance with another statute.

\section{Section 469 [Recodification]}

(1) On the application of an individual who has difficulty administering his assets and liabilities or defending his rights due to his health condition, a court shall appoint a guardian for such a person and, in accordance with such an application, 
determine the scope of competence of the guardian. On the application of the ward, the court shall also remove the guardian.

(2) A guardian usually acts jointly with the ward; if the guardian acts individually, he shall act in accordance with the will of the ward. If the will of the ward cannot be ascertained, the decision is made by a court on the application of the guardian.

\section{Section 470}

If a person provides for the administrator of his assets and liabilities himself, a guardian to administer his assets and liabilities may not be appointed. This does not apply if the administrator of assets and liabilities is unknown, refuses to act in the interests of the person represented or neglects this duty, or if he is unable to administer the assets and liabilities.

\section{Section 471 [Recodification]}

(1) When deciding on the appointment of a guardian for an individual, a court may do so only after having seen him, unless that is impossible due to an insurmountable obstacle; it must also hear his statement or otherwise obtain his opinion and rely on it.

(2) A court shall appoint the person proposed by the ward to be his guardian. If this is not possible, the court, in choosing the guardian, shall typically appoint a relative or another close person of the ward who demonstrates a long-term and serious interest in the ward and the ability to have such interest in the future. If this is not possible, the court shall, in choosing the guardian, appoint another person who meets the conditions for becoming a guardian or public guardian under another statute.

(3) The municipality in which the ward has his residence, or a legal person established by the municipality to perform the tasks of this kind, has the cpacity to become a public guardian; appointing a public guardian under another statute is not subject to the public guardian's approval.

\section{Guardianship council}

\section{Section 472 [Recodification]}

(1) If a guardian is appointed, the ward or any of his close persons may request the establishment of a guardianship council; the guardian shall convene a meeting of the persons close to the ward and his friends, if they are known to the guardian, so that the meeting may be held within thirty days after the receipt of the request. If the meeting is not convened in time or does not take place for any other reason, or if the guardianship council is not elected at the meeting, the meeting is convened by a court, even of its own motion.

(2) The meeting may be attended by the ward, any close person of the ward and any of his friends, even if uninvited; each of them has one vote. If the meeting is attended by at least five persons, the guardianship council may be elected.

\section{Section 473 [Recodification]}

(1) Persons present at the meeting shall elect the members of the guardianship council and their alternates, by a majority vote. In the election, a proportional representation of persons under Section 472 must be ensured, if possible.

(2) Only a person who demonstrates a long-term and serious interest in the ward and the ability to have such an interest in the future, and whose interests do not conflict with the interests of the ward, may become a member of the guardianship council. A guardian may not be a member of the guardianship council.

\section{Section 474 [Recodification]}

A guardianship council has at least three members. A majority of its members is required to have a quorum; however, if the guardianship council has three members, the presence of all of them is required. Guardianship council makes decisions by a majority vote of the members present.

\section{Section 475 [Recodification]}

The election of the members of the guardianship council and their alternates is recorded in minutes by a recorder appointed by the attendees. The minutes must clearly indicate when the meeting was held, who were the attendees, who was elected the recorder, a member of the guardianship council and an alternate and the number of votes they received, and whether someone objected to the course of the meeting and why. Objections submitted in written form must be attached to the minutes. The recorder shall deliver the minutes on the election of the members of the guardianship council to the guardian and the court which appointed the guardian.

\section{Section 476 [Recodification]}

(1) On the application of a guardian or any person entitled to attend the meeting, or even of its own motion, the court may declare an election invalid, if it involved a breach of a statute resulting in the ward being at risk of harm. In such a case, the court shall, without undue delay, order a new election.

(2) If justified by serious reasons, a court may, after initiating the proceedings, suspend the exercise of the rights of a member of a guardianship council until a decision on the invalidity of the election is made.

\section{Section 477 [Recodification]}

(1) A member of a guardianship council is elected for an indefinite period. A member may resign his office; resignation 
is effective upon the delivery of a written notice to the guardian and the court. He shall notify other members of the guardianship council of his resignation.

(2) The court may remove a member of a guardianship council on the application of a guardian or any of the persons entitled to attend the meeting, or of its own motion, if a member of the guardianship council seriously or repeatedly breaches his duties, loses the interest in the ward or his interests repeatedly conflict with the interests of the ward. Section 476(2) applies by analogy.

(3) Upon the termination of the office of a member of a guardianship council, the guardian or the chairman of the guardianship council shall arrange for the election of a new guardianship council member or his alternate. If the election is held without undue delay, the court shall proceed pursuant to Section 472(1), by analogy.

\section{Section 478 [Recodification]}

(1) A guardianship council shall meet at least once a year; it is convened by its chairman or the guardian, or otherwise by any member of the guardianship council, or the court on the application of a person who demonstrates a serious interest in the ward, or even of its own motion.

(2) A guardianship council shall invite the ward and the guardian to the meeting.

(3) The minutes of the guardianship council's meeting must clearly indicate when it was held, who the attendees were, what decisions were taken, who raised an objection and who recorded the minutes. If the minutes do not indicate who voted for or against a proposal, all present members of the guardianship council are presumed to have voted for the proposal. The chairman of the guardianship council shall deliver the minutes to the guardian and to the court which appointed the guardian.

\section{Section 479 [Recodification]}

(1) At its regular meeting, a guardianship council shall discuss the guardian's report on his activities in the matters of the ward, make a statement on the inventory of assets and liabilities of the ward and the account of its administration as well as on the account of any remuneration for the guardian for administering the assets and liabilities.

(2) If agreed by the guardianship council, its member authorised by a resolution shall file an application with a court to change the amount of remuneration for the guardian for administering the assets and liabilities of the ward.

(3) If agreed by the guardianship council, its authorised member shall file an application with a court to cancel the guardianship, or to remove a guardian and replace him with another person.

\section{Section 480 [Recodification]}

(1) Without the consent of the guardianship council, a guardian may not decide to:

a) change the residence of the ward,

b) place the ward in a closed institution or a similar facility unless evidently required by his health condition, or

c) interfere with the integrity of the ward, unless the interference is without serious consequences.

(2) Without the consent of the guardianship council, a guardian may not dispose of the property of the ward in the case of:

a) acquisition or alienation of property with a value exceeding one hundred times the minimum living level for an individual under another legal regulation,

b) acquisition or alienation of property exceeding one third of the property of the ward, unless such one third has only a negligible value, or

c) receipt or provision of a loan for consumption, credit or security in the values under paragraph (a) or (b), unless such a decision also requires court approval.

(3) If it is in the interests of the ward, the guardianship council may resolve on other decisions made by the guardian concerning the ward which are to be subject to its approval; such resolutions may not limit the guardian beyond what is reasonable given the circumstances.

\section{Section 481 [Recodification]}

A member of the guardianship council who did not vote for one of its decisions, the guardian or the ward may, within fifteen days from the receipt of the decision, apply to the court for the cancellation of the decision of the guardianship council and replace it with the court's own decision. Until the court decides, the decision of the guardianship council shall not become legally effective.

\section{Section 482 [Recodification]}

(1) If it is impossible to establish a guardianship council due to lack of interest of a sufficient number of persons under Section 472(1), or for other similar reasons, the court may, on the application of any of these persons, decide that the competence of the guardianship council be exercised by only one of these persons, and simultaneously decide on the 
appointment of such a person.

(2) If a guardianship council is not elected and the procedure under Subsection (1) is impossible, measures by the guardian concerning the ward or his assets and liabilities are decided by a court instead of the guardianship council.

\section{Section 483 [Recodification]}

(1) Unless approved by a court, the guardian may not consent to the change of the personal status of the ward.

(2) If the guardian administers the assets and liabilities of the ward and unless the court has decided on additional restrictions, court approval is required for him to:

a) oblige the ward to provide a performance to any of the guardianship council members or a close person of that member,

b) acquire an immovable thing or a share in it for the ward, or alienate or encumber an immovable thing of the ward or a share in it,

c) acquire a business enterprise, share in a business enterprise or a share in a legal person for the ward, or alienate or encumber such property; this does not apply in the case of acquisition of participation or similar securities ensuring a safe yield,

d) conclude a contract on behalf of the ward binding him to a continued or repeated performance for more than three years,

e) refuse inheritance or another performance from decedent's estate, or

f) oblige the ward to provide a gratuitous performance to another person, unless it is a gift provided on a usual occasion according to the principles of decency to a reasonable extent, and the ward is capable of judgement and consented to the gift.

(3) Notwithstanding the provision of Subsection (2), the guardian may not, unless approved by court, dispose of the property of the ward in the case of:

a) acquisition or alienation of property with a value exceeding five hundred times the minimum living level for an individual under another legal regulation,

b) acquisition or alienation of property exceeding one half of the property of the ward, unless this one half is of a negligible value and is a thing other than a thing of sentimental value for the ward, or

c) receipt or provision of a loan, credit or security in the values under paragraph (a) or (b).

(4) Before making a decision under Subsections (1) to (3), a court shall request the opinion of the guardianship council. If the guardianship council fails to provide the court with their opinion within a reasonable time limit, the court shall decide on its own.

\section{Section 484 [Recodification]}

(1) A legal person whose primary activity is the care of persons with disabilities and the protection of their interests has the right to propose that a meeting to establish a guardianship council be convened.

(2) A legal person whose primary activity is the care of persons with disabilities and the protection of their interests which has operated in the Czech Republic for at least three consecutive years and has been in regular contact with the ward for at least three months has the right to be a member of the guardianship council or attend its meetings and the meeting to establish the guardianship council, and apply to the court for a cancellation of a decision of the guardianship council and replace it with its own decision. However, if such a legal person asserts its rights in a manner other than in accordance with the interests of the ward, the court shall remove the rights from the legal person on the application of the ward, guardian or guardianship council members.

Section 485 [Recodification]

\section{Inventory of assets and liabilities and account of administration}

(1) A guardian who administers the assets and liabilities of the ward shall, within two months from his appointment, make an inventory of assets and liabilities under administration and deliver it to the court, the ward and the guardianship council.

(2) For the duration of the guardianship, the guardian shall prepare an annual account of the administration of assets and liabilities by 30th June of each year, unless he agrees with the members of the guardianship council to present the account earlier. If justified on the basis of serious grounds, the ward or the guardianship council may apply to the court to order the guardian to present an extraordinary account. The guardian shall deliver every account to the ward, guardianship council and the court.

(3) A guardian whose office is ending shall deliver the final account of the administration of the assets and liabilities to the ward, the guardianship council and the court and, where appropriate, also to another guardian or court commissioner appointed in succession proceedings. If a guardian dies, any person who has possession of instruments and other documents relating to the ward and his matters shall surrender these instruments and documents to the court which appointed him.

\section{Division 3}




\section{Guardianship of a legal person}

Section 486 [Recodification]

(1) A court shall appoint a guardian for a legal person that needs it to have its matters managed or its rights defended.

(2) When appointing a guardian, a court may only appoint a person who meets the conditions to be a member of a governing body. If a guardian no longer meets these conditions, he shall notify the court accordingly without undue delay. If the court becomes aware that a guardian no longer meets those conditions, he shall replace him without undue delay with a new guardian.

\section{Section 487 [Recodification]}

(1) The provisions on the rights and duties of members of a governing body apply, by analogy, to the rights and duties of a guardian of a legal person. The scope of competence of a guardian is governed by the provisions on the scope of competence of a governing body with the necessary modifications.

(2) The court shall order the guardian to seek, acting with professional care, proper restoration of activities of a governing body of a legal person; if necessary, the court shall further define the scope of competence of a guardian with regard to the scope of competence of other bodies of the legal person, or, where applicable, to the rights of shareholders.

\section{Section 488 [Recodification]}

If the forming juridical act specifies that a specific person is to be appointed as a guardian of a legal person, the court shall appoint such a person to be the guardian, provided that he has the capacity and consents to the appointment.

\section{TITLE IV}

\section{THINGS AND THEIR DIVISION}

\section{Chapter 1}

\section{General provisions}

Section 489 [Recodification]

A thing in a legal sense (hereinafter a "thing") is everything that is different from a person and serves the needs of people.

\section{Section 490}

A thing intended for public use constitutes a public thing.

\section{Section 491}

(1) A fruit is what a thing regularly provides by its inherent nature, as follows from and is appropriate to its usual intended purpose, whether or not as a result of the endeavour of man.

(2) Revenues are what a thing regularly provides by its legal nature.

\section{Section 492}

(1) The value of a thing, if it can be expressed in pecuniary terms, is its price. The price of a thing is determined as a usual price, unless otherwise agreed or provided by a statute.

(2) An extraordinary price of a thing is determined if its value is to be compensated, having regard to the particular circumstances or the of sentimental value caused by the random properties of the thing.

\section{Section 493 [Recodification]}

Human body and its parts, even if separated from the body, are not a thing.

\section{Section 494 [Recodification]}

A living animal has a special significance and value as a living creature endowed with senses. A living animal is not a thing, and the provisions on things apply, by analogy, to a living animal only to the extent in which they are not contrary to its nature.

\section{Section 495 [Recodification]}

The totality of what belongs to a person constitutes his property. Assets and liabilities of a person consist of the totality of his property and debts.

\section{Chapter 2}




\section{Division of things}

Section 496 [Recodification]

\section{Corporeal and incorporeal things}

(1) A corporeal thing is a controllable part of the external world having the character of an independent object.

(2) Incorporeal things are rights whose nature allows it, and other things without corporeal substance.

Section 497 [Recodification]

\section{Controllable forces of nature}

traded.

The provisions on corporeal things apply, with the necessary modifications, to controllable forces of nature which are Section 498 [Recodification]

\section{Immovable and movable things}

(1) Immovable things are tracts of land and underground structures with a separate intended purpose, as well as in rem rights therein and rights declared by a statute to be immovable things. If another legal regulation provides that a certain thing is not a component part of a tract of land, and such a thing cannot be transferred from place to place without violating its substance, such a thing is also an immovable thing.

(2) All other things, whether of a corporeal or incorporeal nature, are movable.

\section{Section 499}

\section{Fungible thing}

A movable thing that can be substituted with another thing of the same kind is fungible; other things are non-fungible. In the case of doubt, each case is considered relying on usages.

Section 500

\section{Consumable thing}

A consumable thing is a movable thing whose common use consists in its consumption, processing or alienation; movable things which belong to a stock or another set of things, if their common use consists in these things being sold individually, are also consumable things. Other things are non-consumable.

\section{Section 501}

\section{Collective thing (universitas rerum)}

A set of individual things belonging to the same person, regarded as one object and bearing a single designation as such, is regarded as a whole and constitutes a collective thing (universitas rerum).

\section{Section 502 [Recodification]}

\section{Business enterprise}

A business enterprise (hereinafter an "enterprise") is an organised set of assets and liabilities created by an entrepreneur which, based on his will, are used to pursue his activities. An enterprise is presumed to comprise everything that is typically used for its operation.

\section{Section 503 [Recodification]}

\section{Branch}

(1) A branch is part of an enterprise which is economically and functionally independent and which has been decided to be a branch by the entrepreneur.

(2) A branch registered in the commercial register is a registered branch; the same also applies to another organisational component if another legal regulation provides that it is to be registered in the commercial register. The head of a registered branch may represent the entrepreneur in all matters relating to the registered branch from the date on which he was registered in the commercial register as the head of the registered branch.

\section{Section 504}

\section{Business secrets}

Business secrets involve competitively significant, identifiable, valuable and in relevant business circles normally 
unavailable facts related to the enterprise, whose confidentiality is ensured by the owner in his own interest.

\section{Chapter 3}

\section{Component part of a thing and accessory to a thing}

\section{Component part of a thing}

\section{Section 505 [Recodification]}

Everything that pertains to a thing by its nature and cannot be separated from a thing without devaluing it is a component part of a thing.

\section{Section 506 [Recodification]}

(1) Component parts of a tract of land include the space above and below the surface, structures erected on the tract of land and other facilities (hereinafter a "structure"), except for temporary structures, including what is sunk into the tract of land and attached to walls.

(2) If an underground structure is not an immovable thing, it is a component part of the tract of land even if it extends under another tract of land.

\section{Section 507 [Recodification]}

Vegetation grown on a tract of land constitutes a component part of tract of land.

\section{Section 508 [Recodification]}

(1) A machine or other fixed equipment (hereinafter a "machine") is not a component part of an immovable thing registered in a public register if a reservation has been registered in the same register with the consent of its owner that he is not the owner of the machine. The reservation will be deleted if the owner of the immovable thing or another person authorised to do so according to a registration in a public register demonstrates that the owner of the immovable thing has become the owner of the machine.

(2) If such a machine is to replace a machine that is a component part of an immovable thing, the reservation may be registered in the public register unless challenged by a person registered in a more favourable order. However, a person whose right may not be prejudiced by registering the reservation or a person whose claim has been satisfied does not have the right of challenge; for this purpose, a claim yet to become due may also be satisfied.

\section{Section 509 [Recodification]}

Utility networks, especially water lines, sewer systems or power or other lines do not constitute a component part of a tract of land. Structures and technical facilities operationally related thereto are presumed to also form part of utility networks.

\section{Accessory to a thing}

\section{Section 510 [Recodification]}

(1) An owner's thing accessory to the principal thing constitutes its accessory, provided that the accessory thing is intended to be permanently used jointly with the principal thing within their economic purpose. Temporary separation of an accessory thing from the principal thing does not deprive it of the quality of an accessory.

(2) Juridical acts, and rights and duties related to the principal thing are presumed to also relate to its accessories.

\section{Section 511 [Recodification]}

In case of doubt whether something constitutes an accessory to a thing, the case is considered according to usages.

\section{Section 512 [Recodification]}

Where a structure is a component part of a tract of land, the owner's things accessory to the structure constitute accessory to the tract of land if they are intended to be permanently used with the structure or tract of land within their economic purpose.

\section{Section 513 [Recodification]}

Accessories to a claim include interest, default interest and costs of asserting the claim.

\section{Chapter 4}

\section{Securities}

\section{Division 1}

\section{General provisions}




\section{Section 514 [Recodification]}

Securities is an instrument incorporating a right in such a manner that after issuing the security the right cannot be asserted or transferred without the relevant instrument.

\section{Section 515}

Unless the issuer has issued the securities as a kind with elements specifically regulated by a statute, the instrument must, at least by reference to the terms of issue, specify the right which is attached to the securities, and information about the issuer.

\section{Section 516}

\section{Fungible securities}

(1) Securities of the same kind issued by the same issuer in the same form which create the same rights are fungible.

(2) The signature of an issuer on a fungible security may be replaced by its imprint if the instrument also uses security features against counterfeiting or tampering.

\section{Section 517}

If securities oblige a person other than the issuer and the person breaches his duty, the issuer shall compensate for the resulting damage.

\section{Section 518 [Recodification] \\ Form of securities}

(1) Securities may be in the form of bearer securities, securities to order or registered securities.

(2) Securities that indicate the name of the obligee are presumed to be securities to order. Securities that do not indicate the name of the obligee are conclusively presumed to be bearer securities.

\section{Section 519}

\section{Issue of securities}

(1) The date of issue of securities means the date on which securities may be issued to the initial acquirer. Unless otherwise provided, the date of issue of securities is set by the issuer.

(2) The terms of issue set out the rights and duties of the issuer and owners of the securities, as well as detailed information about the issue.

\section{Section 520}

\section{Delivery of securities}

(1) Securities are delivered on the date on which they meet the requirements provided by a statute or another legal regulation, and on which they become the property of the initial acquirer in the manner prescribed.

(2) The amount of money for which an issuer delivers securities is the issue rate of the securities.

\section{Section 521}

(1) If an acquirer acquired securities assuming in good faith that they have been duly delivered, they are delivered even if the requirements for the procedure in the delivery of the security have not been met or the security has not become the property of the initial acquirer in the manner prescribed.

(2) A person whose right has been affected by non-compliance with the requirements for the procedure in the delivery of securities or the securities have not become the property of the initial acquirer in the manner prescribed is entitled to compensation for damage against the issuer and against the person who acted in this matter in the name or on the account of the issuer, under the conditions provided by this Act.

\section{Section 522}

\section{Counterparts}

(1) If securities are delivered in multiple counterparts, the counterparts must be numbered in the text of the instrument; otherwise each copy is considered to be a separate security.

(2) If a performance has been provided with respect to one counterpart, the rights arising from all other counterparts are extinguished. 


\section{Coupon}

(1) If securities are associated with a right to yield, a coupon in the form of a bearer security can be delivered to assert this right; coupons are delivered in a coupon sheet. If a coupon sheet includes a talon, it constitutes the right of issue of a new coupon sheet; however, a talon is not a security.

(2) A coupon must contain at least the information on:

a) the kind and the issuer of the security for which it has been delivered; if the coupon has been delivered for a security, its numerical designation is also required,

b) the amount of yield or the method of its determination, and

c) the date and place the right to yield can be asserted.

\section{Section 524 [Recodification]}

\section{Global certificate}

(1) Fungible securities can be substituted by a global certificate. The issue and delivery of a global certificate is governed by the same conditions as the issue of individual securities. A global certificate contains at least the elements provided by a statute for individual securities, including its number.

(2) The owner of a global certificate has the right to exchange it for individual securities; if the issuer sets conditions for the exchange, the right is conditional upon the fulfillment of these conditions.

(3) By transferring a global certificate, the rights arising therefrom may not be divided into shares. This does not apply if securities have been immobilised in a collective deposit, in which case such a share must be equal to individual securities that are substituted by the global certificate.

\section{Division 2}

\section{Book-entry securities}

Section 525 [Recodification]

\section{Book-entry securities}

(1) If securities are replaced by a registration in a corresponding register and may not be transferred in a manner other than by changing the record in the register, they represent book-entry securities. Book-entry securities are fungible, if delivered by the same issuer and if they create the same rights.

(2) The provisions on securities shall also apply to book-entry securities, unless their applicability is excluded by their nature, this Act or any other legal regulation.

\section{Section 526 [Recodification]}

\section{Register of book-entry securities}

Book-entry securities are registered in property accounts; they are the owner's account or the clients' account.

\section{Section 527 [Recodification]}

\section{Owner's account}

(1) The owner's account is used to register book-entry securities of the person for whom the account has been set up.

(2) The owner of book-entry securities is presumed to be the person on whose owner's account the book-entry security is registered.

\section{Section 528 [Recodification]}

\section{Clients' account}

(1) The clients' account is used to register book-entry securities of persons who entrusted the book-entry security to the person for whom the clients' account has been set up.

(2) The person for whom the clients' account has been set up is not the owner of the book-entry securities registered in this account.

\section{Division 3}

Conversion of securities to book-entry securities and conversion of book-entry securities to securities 


\title{
Subdivision 1
}

\section{Conversion of securities to book-entry securities}

\author{
Section 529
}

(1) If an issuer has decided to convert securities to book-entry securities, he shall, without undue delay, publish his decision, including the time limit within which the owner of the securities shall deliver the securities to the issuer, and publish the decisions within the same time limit in a manner allowing remote access.

(2) The time limit for the delivery of the securities to the issuer may not be less than two months and more than six months from the date the decision is published.

(3) The issuer that is required by another legal regulation to maintain the register of the owners of securities shall dispatch a notice of conversion of the securities to book-entry securities to the person and to the address provided in the register.

\section{Section 530}

(1) The owner of securities shall, upon its delivery to the issuer, specify the account number in the relevant register in which the security is to be registered; if he fails to do so, the issuer shall provide to the owner an additional time limit of not less than two months.

(2) If the owner has submitted securities to the issuer without providing the account number in the relevant register in which the security is to be registered even within the additional time limit, the right of ownership in this security passes to the issuer on the date on which it will pay the owner a fair price.

\section{Section 531}

If the owner of securities is in default of the delivery of the security, the issuer shall determine an additional time limit for its submission as provided for in Section 529(1), and upon its publication he shall advise that the security which will not be submitted within this additional time limit will be declared invalid by the issuer.

\section{Section 532}

(1) At the request of the issuer, the central depository shall, similarly to the delivery of book-entry securities, register the book-entry securities into a central register and register the securities in property accounts specified in the request. The issuer shall file the application after the expiry of the time limit specified in Section 529(1) or even before, if all securities have been delivered to him, but not later than upon the expiry of the additional time limit.

(2) From filing the issuer's application for registration of book-entry securities to the central register to the registration of the entire issue, these securities may not be traded on a regulated European market.

\section{Section 533}

(1) Securities that have not been delivered are recorded by the central depository in a special technical account; the owner of the technical account is the issuer. Upon registration in this account, these securities are converted to book-entry securities.

(2) The right to yield from securities under Subsection (1) for the period from the end of the time limit under Section 529 (1) shall not mature before the owner of the security delivers the security to the issuer.

\section{Section 534}

(1) If the security is not delivered even within the additional time limit, the issuer shall declare it invalid.

(2) After declaring securities invalid, the issuer shall sell the book-entry security which replaces it with professional care. If the issuer decides to sell the book-entry security at a public auction, he shall publish the place, time and subject of the auction at least two weeks before it is held.

(3) The issuer shall pay the proceeds from the sale of the book-entry security to the person whose security was declared invalid after setting off claims incurred by the issuer for declaring the security invalid and for selling the book-entry security which replaces it.

\section{Section 535}

The provisions of Sections 529 and 531 to 533 apply, with the necessary modifications, to the securities which are converted to book-entry securities to be kept in a separate register.

\section{Subdivision 2}

\section{Conversion of book-entry securities to securities}


If the issuer has decided to convert book-entry securities to securities, he shall, without undue delay, publish his decision and within the same time limit, he shall publish his decision in a manner allowing remote access.

\section{Section 537}

(1) The central depository shall, within thirty days from the date on which it receives the issuer's notice of the conversion of book-entry securities to securities, hand over to the issuer an extract from the central and associated register containing information on the issue of the book-entry securities, the owners of the book-entry securities, whether the disposal of the book-entry securities has been suspended and whether the book-entry securities have been pledged, including the designation of the pledgee.

(2) The central depository or the owner of a clients' account may not, after making the extract, make in its register any record relating to the book-entry securities being converted to securities.

\section{Section 538}

(1) The central depository shall cancel the registration of book-entry securities as of the date specified by the issuer, but not before the date the extract under Section 537(1) is made, and no later than one month from the date on which the extract is made.

(2) Cancellation of registration of book-entry securities is notified by the central depository to the organiser of the European regulated market on which such book-entry securities are admitted to trading, to the central depository participants, who shall notify the owners of the book-entry securities accordingly, and to the owner of the clients' account.

(3) The owner of a clients' account shall cancel the registration of book-entry securities on the same date as the central depository.

\section{Section 539}

(1) On the date of the cancellation of registration of book-entry securities, the owner of the book-entry securities that were converted to securities becomes entitled to have the securities delivered by the issuer.

(2) The securities are submitted no earlier than on the date of the cancellation of registration.

\section{Section 540}

(1) If, as of the date of the cancellation of registration of book-entry securities, the disposal of the securities is suspended on the basis of a mandate given by a public body, the issuer shall deliver the securities to that body.

(2) If, as of the date on which the registration of book-entry securities is cancelled, the disposal of book-entry securities which was mandated by a person authorised to do so by the statute regulating business activities on the capital market is suspended, the owner of the book-entry securities becomes entitled to have the securities delivered only after the expiry of the period for which the disposal of the book-entry securities was suspended. This does not apply if the person who gave the mandate for such a suspension consents to the delivery of the securities to the owner.

\section{Section 541}

(1) If, as of the date of the cancellation of registration of book-entry securities, the book-entry securities are pledged, the effects of pledging remain unaffected; the pledgee becomes entitled to have the securities delivered to him. The issuer also fulfils his duty to deliver securities if, with the consent of the pledgee, he places the issued security in deposit for the benefit of the owner and hands over the original pledge agreement or a certified copy thereof to the depositary.

(2) In the case of a conversion of book-entry securities to securities to order, the issuer shall mark thereon a declaration of pledge of the securities.

\section{Section 542}

(1) After cancelling the registration of book-entry securities, the issuer shall, without undue delay, publish a call upon the owners of the securities from this issue to take over the securities, and publish the call within the same time limit in a manner allowing remote access. He shall specify the time limits to take over the securities, by analogy, according to Section 529(2) and Section 531.

(2) In the case of registered securities or securities to order, the issuer shall also dispatch the invitationto take over the securities to the address of the registered office or residence of the owner referred to in the relevant register.

\section{Section 543}

(1) If the owner does not take over the securities within the additional time limit, the issuer shall sell it with professional care. If the issuer decides to sell securities at a public auction, he shall publish the place, time and subject of the auction at least two weeks before it is held.

(2) The issuer shall pay the proceeds from the sale of the securities to the owner after setting off the claims incurred by the issuer in connection with its sale. 
Sections 536 to 543 apply to the book-entry securities maintained in a separate register with the necessary modifications.

\section{TITLE V \\ LEGAL FACTS \\ Chapter 1}

\section{Juridical acts}

Division 1

General provisions

Section 545 [Recodification]

Juridical acts produce legal consequences expressed in them, as well as legal consequences arising from a statute, good morals, usages and regular dealings of parties.

\section{Section 546}

Juridical acts can be made by act or omission; this may be done expressly or in another way raising no doubt about what the acting person wished to express.

\section{Section 547}

Juridical acts must, in terms of their content and purpose, be consistent with good morals and statutes.

\section{Conditions}

\section{Section 548}

(1) The creation, change or extinction of rights may be subject to a condition. If the extinction of a right or duty is based on an impossible condition, it is disregarded.

(2) A condition is suspensive if its fulfilment determines whether legal consequences of an act will occur. A condition is resolutive if its fulfilment determines whether already existing legal consequences will terminate.

(3) Unless a juridical act or its nature implies otherwise, a condition is presumed to be suspensive.

\section{Section 549}

(1) The fulfilment of a condition is disregarded if it is deliberately fulfilled by a person who is not authorised to do so and who benefits from the fulfilment of the condition.

(2) If a party benefiting from non-fulfilment of a condition deliberately frustrates the fulfilment of the condition without being authorised to do so, the condition is considered to have been fulfilled.

\section{Section 550}

\section{Determination of time}

If the time has been determined for a juridical act to become effective, Sections 548 and 549 on suspensive condition apply by analogy. If the effect of a juridical act are limited with a deadline, Sections 548 and 549 on resolutive condition apply by analogy.

\section{Putative juridical act}

\section{Section 551 [Recodification]}

No juridical act is made where there is an absence of will of the acting person.

\section{Section 552 [Recodification]}

No juridical act is made where a serious will has not been clearly manifested.

\section{Section 553 [Recodification]}

(1) No juridical act is made where indeterminacy or incomprehensibility prevents its contents to be ascertained, even by interpretation.

(2) If the expression of will between the parties has been subsequently clarified, its defect is disregarded and the 
juridical act is considered to have existed from the beginning.

\section{Section 554 [Recodification]}

Putative juridical acts are disregarded.

\section{Division 2}

\section{Interpretation of juridical acts}

Section 555 [Recodification]

(1) A juridical act is assessed according to its content.

(2) If a certain juridical act is intended to obscure another juridical act, the former is assessed according to its true nature.

\section{Section 556 [Recodification]}

(1) What is expressed by words or otherwise is interpreted according to the intention of the acting person if the other party was aware or must have known of such an intention. If the intention of the acting person cannot be ascertained, the expression of will is attributed the same meaning which would be typically attributed by a person in the position of the person against whom the will was expressed.

(2) When interpreting the expression of will, account is taken of the regular dealings of parties in legal transactions, what preceded the juridical act, as well as the manner in which the parties subsequently demonstrated what content and relevance they attach to the juridical act.

\section{Section 557 [Recodification]}

If a term is used which allows various interpretations, in the case of doubt it is to be interpreted to the detriment of the person who used the term first.

\section{Section 558 [Recodification]}

(1) In legal transactions with an entrepreneur, a term allowing different interpretations is attributed the meaning customarily used in such transactions. However, if the other party is not an entrepreneur, the person who invokes the meaning must demonstrate that the other party must have been aware of it.

(2) In legal transactions among entrepreneurs, account is taken of business usages maintained in general or in a given industry, unless excluded by an agreement between the parties or by a statute. Unless otherwise agreed, a business usage is conclusively presumed to take precedence over non-compelling provisions of a statute; otherwise, an entrepreneur may invoke a usage if he proves that the other party must have known a given usage and was aware that it would be followed.

\section{Division 3}

\section{Form of juridical acts}

\section{Section 559} by a statute.

Everyone has the right to choose any form of juridical act, unless the choice of form is restricted by an agreement or

\section{Section 560}

Written form is required for a juridical act creating or transferring a right in rem to an immovable thing, as well as a juridical act altering or extinguishing that right.

\section{Section 561}

(1) The validity of a juridical act made in written form requires the signature of the acting person. The signature may be replaced by mechanical means, where it is typical to do so. Another legal regulation provides how a document can be electronically signed when making juridical acts by electronic means.

(2) If several persons make an act, their expressions of will must be made on the same instrument in the case of a juridical act creating or transferring a right in rem to an immovable thing, or altering or extinguishing that right.

\section{Section 562 [Recodification]}

(1) Written form is also maintained in juridical acts made by electronic or other technical means which enable its contents to be captured and the acting person to be identified.

(2) The records of data on juridical acts in the electronic system are presumed to be reliable if they are recorded systematically and sequentially, and if they are protected against alterations. If a record has been made in the operation of an enterprise and the other party invokes it to his own advantage, the record is presumed to be reliable. 
(1) If a person making a juridical act in writing cannot read and write, but is able to familiarise himself with the content of the juridical act using devices or special aids or through another person of his choosing, he shall sign the instrument; if he is unable to do so, he shall, at least before two witnesses and by hand or otherwise, substitute his signature on the instrument with his own mark, to which one of the witnesses shall add the name of the acting person.

(2) Section 39 applies to the witnesses by analogy.

(3) If the procedure under Subsection (1) is not possible, an act of a person who cannot read and write requires the form of a public instrument. This form is also required where a statute provides that the expression of will of the acting person must be written on the instrument by his own hand. If the acting person is able to do so, he shall attach to the record his own mark affirming his juridical act.

\section{Section 564}

If a statute requires a juridical act to have a specific form, the content of the juridical act may be changed by an expression of will in the same or stricter form; if this form is only required on the basis of an agreement between the parties, the content of the juridical act may also be changed in another form, unless excluded by an agreement between the parties.

\section{Division 4}

\section{Private instrument and public instrument}

\section{Private instrument}

\section{Section 565 [Recodification]}

The burden of proving the authenticity and accuracy of a private instrument lies with the person who invokes it. If a private instrument is used against a person who has evidently signed the instrument or against his heir or against any person who has acquired assets and liabilities in the transformation of a legal person as its legal successor, the authenticity and accuracy of the instrument is presumed to have been acknowledged.

\section{Section 566 [Recodification]} claims it does.

(1) If a private instrument is not signed, the person who has used it must prove that it comes from the person he

(2) Documents relating to legal facts occurring during the normal operation of an enterprise, if invoked by the other party to its advantage, are presumed to demonstrate the facts contained in the particular instrument and that the instrument was issued at the time indicated therein; this applies even if the instrument has not been signed.

\section{Public instrument}

\section{Section 567 [Recodification]}

A public instrument is an instrument issued by a public body within the scope of its powers or an instrument declared to be a public instrument by a statute; this does not apply if it is vitiated by such defects that it is considered not to be a public instrument.

\section{Section 568 [Recodification]}

(1) Where a fact is confirmed in a public instrument, this constitutes, with respect to any person, a full proof that the instrument originates from the body or person that established it, a full proof of the time of drafting the instrument, as well as of a fact which the originator of the public instrument confirmed as having occurred or having been performed in his presence, until the contrary is proved.

(2) Where a public instrument contains the expression of will of a person making a juridical act and is signed by the acting person, it constitutes full proof of such expression of will with respect to any person. This also applies if the signature of the acting person has been substituted in a manner provided by a statute.

\section{Section 569 [Recodification]}

If a public instrument has been drafted to negate an earlier public instrument concerning a juridical act between the same persons, it becomes effective with respect to third persons if its content has been published in a public register or if it has been submitted to a third person.

\section{Division 5}

\section{Juridical acts with respect to a person that is not present}

\section{Section 570 [Recodification]}

(1) A juridical act has effects with respect to a person that is not present from the moment the expression of will reaches the person; if the party expressing its will intentionally frustrates the will reaching the person, it is conclusively presumed to have duly reached the person. 
(2) A juridical act becomes effective with respect to a person who lacks full legal capacity only when the expression of will reaches his legal representative or guardian. However, if a juridical act only aims to provide such a person with a legal benefit, the juridical act becomes effective when made with respect to that person.

\section{Section 571 [Recodification]}

If an expression of will reaches the destination in an altered form as a result of means used by the person who performed the act or other circumstances having occurred during carriage, the legal case is assessed under the provisions on errors.

\section{Section 572 [Recodification]}

A person acting in written form may withdraw his expression of will, provided that the withdrawal reaches the other party no later than simultaneously with the original expression of will.

\section{Section 573 [Recodification]}

\section{Presumption of the time of reaching}

A consignment which has reached the destination and which was dispatched using a postal service operator is presumed to have reached the destination on the third working day after it was dispatched; however, if it was dispatched to an address in another country, it is presumed to have reached the destination on the fifteenth working day after it was dispatched.

\section{Division 6}

\section{Invalidity of juridical acts}

\section{General provisions}

Section 574 [Recodification]

Juridical acts are to be preferably considered valid rather than invalid.

Section 575

If an invalid juridical act has the elements of another valid juridical act, the latter juridical act applies if the circumstances clearly show that it expresses the will of the acting person.

\section{Section 576}

If the grounds for the invalidity of a juridical act only concern a part of the juridical act that can be severed from its other content, only that part is invalid if it can be assumed that the juridical act would have occurred even without the invalid part, had the party ascertained the invalidity in time.

\section{Section 577 [Recodification]}

If the reason for invalidity only consists in an unlawful determining of quantitative, temporal spatial or other scope, a court shall change the scope so that it is consistent with an equitable arrangement of rights and duties of the parties; in doing so, the court is not bound by the parties' motions, but shall consider whether a party would have made the juridical act had the party ascertained its invalidity in time.

\section{Section 578}

Errors in writing or numbers do not prejudice the validity of a juridical act if its meaning is undoubted.

\section{Section 579}

(1) A person who has caused a juridical act to be invalid does not have the right to invoke its invalidity or claim for himself any benefit arising from the invalid juridical act.

(2) A person who has caused a juridical act to be invalid shall compensate the party that was unaware of the invalidity for the resulting damage.

\section{Main grounds for invalidity}

\section{Section 580 [Recodification]}

(1) A juridical act is also invalid if it is contrary to good morals or contrary to a statute, if so required by the sense and purpose of a statute.

(2) A juridical act is invalid if something impossible is to be performed thereunder.

\section{Section 581 [Recodification]}

If a person lacks full legal capacity, a juridical act which he is not eligible to make is invalid. Also invalid is the juridical 
act of a person acting under a mental disorder that makes him unable to make juridical acts.

\section{Section 582 [Recodification]}

(1) If a juridical act is not made in the form agreed by the parties or provided by a statute, it is invalid, unless the defect is subsequently remedied by the parties. If an expression of will includes several simultaneous juridical acts, the lack of form required for some of them shall not in itself cause the others to be invalid.

(2) Unless the form of a juridical act agreed by the parties is complied with, invalidity may only be invoked if no performance has been provided yet. This applies even where a particular form of a juridical act is required under the provisions of Book Four of this Act.

\section{Error}

\section{Section 583 [Recodification]}

Where a person made an act in error concerning a decisive circumstance and the error was caused by the other party, the juridical act is invalid.

\section{Section 584 [Recodification]}

(1) If an error concerns a secondary circumstance which neither party has declared decisive, the juridical act is valid, but the misled person is entitled to claim appropriate compensation from the person who caused the error.

(2) If a juridical act in error was made as a result of trickery, the juridical act is invalid, even where the error only concerns a secondary circumstance.

\section{Section 585 [Recodification]}

Where a person acted in error caused by a third person, his juridical act is valid. However, if the person with respect to whom the juridical act was made was involved in the act of the third person, or knew or at least must have known thereof, such a person is also considered the originator of the error.

\section{Consequences of invalidity}

\section{Section 586 [Recodification]} that person.

(1) If the invalidity of a juridical act is determined to protect the interest of a person, invalidity may only be invoked by

(2) Unless an entitled person invokes invalidity of a juridical act, the juridical act is considered valid.

\section{Section 587 [Recodification]}

(1) A person forced to make a juridical act under a threat of physical or mental violence inducing justified concern given the relevance and likelihood of danger as well as the personal characteristics of the person being threatened has the right to invoke invalidity of the juridical act.

(2) A person who used threat or trickery to cause another person to make a juridical act shall always compensate the resulting harm

\section{Section 588 [Recodification]}

A court shall, even of its own motion, take into account the invalidity of a juridical act which is manifestly against good morals or which is contrary to a statute and manifestly disrupting public order. This also applies in cases where a juridical act requires the provision of a performance which was impossible from the beginning.

\section{Division 7}

\section{Relative ineffectiveness}

\section{Section 589 [Recodification]}

(1) If a juridical act of a debtor prejudices the satisfaction of an enforceable claim of a creditor, the creditor is entitled to claim that a court declare the juridical act of the debtor legally ineffective with respect to the creditor. A creditor has this right even where the right of the third person is already enforceable or has already been satisfied.

(2) Ineffectiveness of a juridical act of a debtor is constituted by a court decision on a creditor's application which challenged a juridical act of the debtor (application to challenge a juridical act).

\section{Section 590 [Recodification]}

(1) A creditor may invoke ineffectiveness of a juridical act:

a) which a debtor performed in the last five years in order to impair the satisfaction of his creditors, if the other party was aware 
of such an intention,

b) whereby a debtor has impaired satisfaction of his creditors in the last two years if the other party must have been aware of the debtor's intention to impair satisfaction of his creditors, or

c) which impaired the creditor's satisfaction and which occurred in the last two years between the debtor and his close person, or which the debtor performed in favour of such a person, unless the other party was neither aware nor was required to be aware, at the time the act occurred, of the debtor's intention to impair satisfaction of his creditor.

(2) A creditor may invoke ineffectiveness of a contract of sale or contract of exchange concluded in the last year if the other party must have recognised that, by his act, the debtor squanders property, thereby impairing satisfaction of his creditor.

\section{Section 591 [Recodification]}

Ineffectiveness of a gratuitous juridical act of a debtor may be invoked by the creditor if it has occurred in the last two years. This does not apply in the case of:

a) fulfilment of a duty imposed by a statute,

b) common occasional gifts,

c) donation of a reasonable amount provided for a publicly beneficial purpose, or

d) a performance provided to satisfy a moral obligation or considerations of decency.

\section{Section 592 [Recodification]}

Omission whereby a debtor has lost a property right or caused the creation, maintenance or securing of another person's right of a proprietary nature against himself is assessed in the same manner as the juridical acts under Sections 590 and 591. This also applies where a debtor refused inheritance, unless it was over-indebted.

\section{Section 593 [Recodification]}

Where a creditor, before his claim becomes enforceable, reserves the right to invoke ineffectiveness of a juridical act by notifying the person against whom he may invoke the ineffectiveness of a juridical act of the reservation through a notary, private enforcement officer or court, the time limit for the creditor to invoke ineffectiveness of a juridical act begins only after the claim becomes enforceable.

\section{Section 594 [Recodification]}

(1) Ineffectiveness of a juridical act may be invoked against a person who made a juridical act with respect to a debtor or against a person who directly benefited from the juridical act or against his heir or against a person who acquired assets and liabilities in the transformation of a legal person as its legal successor.

(2) Ineffectiveness may only be invoked against another legal successor if:

a) the legal successor must have been aware of the circumstances for which a creditor could invoke ineffectiveness of a juridical act,

b) the legal successor acquired a right gratuitously, or

c) the legal successor is a close person, unless at the time he acquired the right from the predecessor he may not have been aware of the circumstances for which a creditor could invoke ineffectiveness of a juridical act.

Section 595

(1) Ineffectiveness of a juridical act creates a creditor's right to seek satisfaction of his claim also from what was lost from the debtor's property due to an ineffective juridical act. If not reasonably possible, the creditor is entitled to appropriate compensation.

(2) A person who is obliged to provide a performance is considered a possessor in bad faith; the same applies to his heir or another general legal successor only if he must have been aware of the circumstances for which a creditor could invoke ineffectiveness of a juridical act.

(3) A recipient in good faith who received a gratuitous performance shall satisfy the creditor from the performance to the extent in which he was enriched by that performance. This does not apply if a creditor could have invoked ineffectiveness of a juridical act even if it had been made for consideration.

\section{Section 596}

If a third person has acquired a right to a thing from which a creditor could have otherwise been satisfied and the right prevents ineffectiveness being invoked against the third person, the person against whom the creditor could have previously invoked ineffectiveness of a juridical act and under whose possession the right of the third person was created is obliged to provide compensation for damage to the creditor. 
(1) A person having a duty to a creditor under Section 595 or 596 may be released from such a duty by satisfying the creditor's claim against the debtor. He may do so even before the creditor invokes ineffectiveness.

(2) A person having a duty to the creditor under Section 595 or 596 may require that the parties return the mutual performance or discharge a claim, which was reactivated because the creditor invoked ineffectiveness.

\section{Section 598}

If several creditors invoke ineffectiveness of the same juridical act, the obligor may not be required to provide in aggregate more than what is provided under Sections 595 and 596.

\section{Section 599}

(1) If a creditor invokes ineffectiveness of a juridical act relating to a thing registered in a public register, he may, along with the submission of an application to challenge the juridical act and a proof of its submission, require that the body responsible for maintaining the register note in the register that ineffectiveness of the juridical act has been invoked.

(2) If a court grants the application, the judgment is also effective against persons who acquired a thing or a right to a thing registered in such a register after the date of the note.

\section{Chapter 2}

\section{Legal events}

Section 600

\section{General provision}

A statute provided what rights and duties are created, changed or extinguished as a result of legal facts beyond the control of a person. Such a consequence may also be determined by an agreement between parties.

\section{Meaning of time}

Section 601

(1) If a right is acquired or a duty created on a certain date, it is acquired or created at the start of that day; if a right or duty is extinguished on a certain day, it is extinguished at the end of that day. This does not apply if excluded by the nature of the legal case concerned.

(2) If two rights are interrelated and the creation of one right is conditional on the extinction of the other, both events occur at the same time. Unless otherwise agreed or provided, such a legal effect arises at the end of the day.

\section{Section 602}

If a right is to be exercised or duty fulfilled on or by a specific date, it is required to happen at a usual time of day, unless usages, regular dealings of the parties or the particular circumstances of the case indicate otherwise.

\section{Section 603}

Rights and duties are extinguished upon the expiry of the period for which they were limited.

\section{Section 604}

A change in the identity of a creditor or debtor does not affect the running of a period or time limit.

\section{Computation of time}

\section{Section 605 [Recodification]}

(1) A time limit or period specified in days begins on the day following the occurrence of the fact that is decisive for its commencement.

(2) A time limit or period specified in weeks, months or years shall end on the day whose name or number is identical to the day when the fact from which the time limit or period starts running occurred. If there is no such a day in the last month, the time limit or period shall end on the last day of the given month.

\section{Section 606 [Recodification]}

(1) Half-month is to be understood as fifteen days and the middle of month is the fifteenth day thereof.

(2) If a time limit or period is set for one or more months and a part of a month, the part of a month is computed last. 
If the last day of a time limit falls on a Saturday, Sunday or a public holiday, the immediately following working day is the last day of the time limit.

\section{Section 608 [Recodification]}

ends.

A time limit or period specified in time units shorter than days is computed from the moment it begins to the moment it

\section{Chapter 3}

\section{Statute of limitations and prescription}

Division 1

Statute of limitations

\section{Subdivision 1}

\section{General provisions}

\section{Section 609 [Recodification]}

If a right has not been exercised within a limitation period, it becomes time-barred and the debtor is not obliged to perform. However, if a debtor performed after the expiry of a limitation period, he may not claim that his performance be returned.

\section{Section 610 [Recodification]}

(1) A court shall only take into account the statute of limitations if the debtor invokes that the right has become timebarred. If a person waives his right to invoke statute of limitations in advance, the waiver is disregarded.

(2) If parties are obliged to mutually return what they acquired under an invalid contract or a extinguished obligation, the court shall take the defence of statute of limitations into account only if the statute of limitations could also be invoked by the other party. This also applies if a performance was provided on the basis of a putative juridical act.

\section{Section 611 [Recodification]}

All property rights are subject to limitation except as provided by a statute. Other rights are subject to limitation where provided by a statute.

\section{Section 612 [Recodification]}

In the case of the rights to life and dignity, name, health, respect, honour, privacy and similar personal rights, only the rights to remedy harm caused to these rights are subject to limitation.

\section{Section 613 [Recodification]}

The right to maintenance and support is not subject to limitation; however, the rights to individual repeated performances are subject to limitation.

\section{Section 614 [Recodification]}

The right of ownership or the right to claim the division of an undivided thing, the right to create the necessary passage and the right to redeem a real burden are not subject to limitation.

\section{Section 615 [Recodification]}

(1) If the discharge of a debt is secured by a pledge, the pledge does not become time-barred before the claim. Limitation of a claim does not prevent the pledgee from satisfying his claim from the pledged thing.

(2) A pledge shall not become time-barred as long as the pledgee has possession of the pledged movable thing, or a third person takes care of the pledged movable thing for the pledgee.

(3) Where a creditor has a retention right, Subsections (1) and (2) apply by analogy.

\section{Section 616 [Recodification]}

When a security is provided by transferring a right, limitation of the claim does not constitute grounds for transfer of the right back to the person who provided the security.

\section{Section 617 [Recodification]}

(1) Even after the expiry of a limitation period, a party may invoke his right when defending against a right asserted by the other party if both rights relate to the same contract or several contracts concluded in dependence on each other with respect to their purpose. 
(2) Even after the expiry of a limitation period, a party may invoke his right in the case of a set-off if the set-off could have been performed at any time before the expiry of the limitation period.

\section{Section 618 [Recodification]}

If a right registered in a public register or the pledge registry becomes time-barred, the time-barred right is deleted from that register by the person maintaining the public register or pledge registry on the application of the person with a legal interest in the deletion.

\section{Commencement of limitation period}

\section{Section 619 [Recodification]}

(1) Where a right is enforceable before a public body, the limitation period commence from the date on which the right could be asserted for the first time.

(2) A right may be asserted for the first time once the entitled person became aware of the circumstances decisive for the start of the limitation period or when he should and could have learnt thereof.

\section{Section 620}

(1) Circumstances decisive for the commencement of a limitation period for a right to compensation for damage include knowledge of the damage and the person liable to provide the compensation of damage. This also applies, by analogy, to the remedy of harm.

(2) Circumstances decisive for the commencement of a limitation period for a right to compensation for damage caused by a defective product under Section 2939 include knowledge of the damage, the defect and the identity of the producer.

\section{Section 621}

Circumstances decisive for the commencement of the limitation period for a right to restitution of unjust enrichment include knowledge of the occurrence of the unjust enrichment and of the person obliged to surrender it.

\section{Section 622 [Recodification]}

In the case of bodily harm to a minor lacking full legal capacity, the limitation period does not commence before the minor acquires full legal capacity. If he does not acquire full legal capacity, the limitation period shall not commence until his guardian is appointed upon the person reaching the age of majority.

\section{Section 623}

In the case of partial performances of a debt, the limitation period for each partial performance commences on the date of its maturity. If the entire debt becomes due because of a failure to execute any partial performance, the limitation period for the entire debt commences on the date the non-executed partial performance became due.

\section{Section 624}

In the case of the right to surrender funds deposited in an account or representing a deposit, the limitation period commences on the date on which the contractual obligation was extinguished.

\section{Section 625 [Recodification]}

In the case of a right created as a result of a complete destruction or loss of a transported thing, the limitation period commences on the date the consignment was to be delivered to the recipient. However, if the transported thing was only damaged or if it was delivered late, the limitation period commences on the date on which the consignment was delivered.

Section 626

In the case of a right to insurance indemnity, the limitation period commences one year after the insured event. This also applies if the aggrieved person becomes directly entitled to insurance indemnity against the insurer, or where the insured person requires the insurer to pay for what the insured person provided to the aggrieved person in the performance of the duty to compensate for the damage or other harm.

\section{Section 627 [Recodification]}

If, according to usage or practice mutually established between the parties, a claim is to be settled on the basis of an account presented at the end of a certain period, the limitation period commences on the day following the end of the period of time in which the account should have been presented.

\section{Section 628}

In the case of a right which must be first asserted with the relevant person, the limitation period commences on the date on which the right was so asserted with that person. 


\section{Subdivision 2}

\section{Length of limitation period}

\section{General provisions}

Section 629 [Recodification]

(1) The length of a limitation period is three years.

(2) A property right becomes time-barred no later than after ten years from the date on which it became due unless a statute specifically provides a different limitation period.

\section{Section 630 [Recodification]}

(1) The parties may stipulate a limitation period, computed from the date on which the right could have been asserted for the first time, shorter or longer than that provided by a statute, but with a minimum duration of one year and a maximum duration of fifteen years.

(2) If a shorter or longer limitation period is stipulated to the detriment of the weaker party, such a stipulation is disregarded. Moreover, a stipulation on a shorter limitation period is disregarded if it concerns a right to a performance arising from harm to freedom, life or health, or a right created as a result of wilful breach of duty.

\section{Special provisions}

\section{Section 631 [Recodification]}

Where a right has been registered in a public register, it becomes time-barred ten years after the date on which it could have been exercised for the first time.

\section{Section 632 [Recodification]}

Where a right that may be exercised continuously or repeatedly is registered in a public register, it becomes timebarred if not exercised for a period of ten years. However, if a right which is only exercised rarely is registered in a public register, it only becomes time-barred if the right holder has never exercised the right despite having had an opportunity to do so at least three times over ten years; if, over ten years, the person has had an opportunity to exercise the right less than three times, the limitation period is extended until three opportunities have occurred without the right being exercised.

\section{Section 633 [Recodification]}

(1) If an obligor obliged under an easement prevents the exercise of a right, the easement becomes time-barred if the obligee fails to assert his right within three years.

(2) The right to an individual performance under a real burden becomes time-barred as a claim.

\section{Section 634}

The right to request that a court determine the content of a future contract on the basis of a preliminary contract becomes time-barred one year after the last day of the time limit within which the future contract should have been concluded. This also applies where it has been stipulated that a certain essential element of a contract is determined by a third person or a court.

\section{Section 635}

(1) A right to insurance indemnity under life insurance becomes time-barred after ten years.

(2) A right to insurance indemnity under third-party liability insurance becomes time-barred no later than when the right to compensation for damage or harm covered by the insurance becomes time-barred.

\section{Section 636 [Recodification]}

(1) A right to compensation for damage or other harm becomes time-barred no later than ten years after the date the damage or harm was incurred.

(2) Where damage or harm has been caused intentionally, the right to its compensation becomes time-barred no later than fifteen years after the date on which the damage or harm occurred. This also applies in case of damage or harm resulting from a breach of a duty due to bribery consisting in offering, promising to provide or providing a bribe by a person other than the aggrieved person or in directly or indirectly soliciting a bribe from the aggrieved person.

(3) Subsections (1) and (2) do not apply to a right arising from harm to freedom, harm to life or bodily harm.

\section{Section 637}

The right to compensation for damage caused by a defective product under Section 2939 becomes time-barred no later than ten years after the date on which the producer placed the defective product on the market. 


\section{Section 638 [Recodification]}

(1) The right to restitution of unjust enrichment becomes time-barred no later than ten years after the date on which the unjust enrichment occurred.

(2) If unjust enrichment was acquired wilfully, the right to restitution of the unjust enrichment becomes time-barred no later than fifteen years after the date on which the unjust enrichment occurred.

\section{Section 639}

If a debtor acknowledged his debt, the right becomes time-barred ten years after the date on which the debt was acknowledged. However, if the debtor specifies in the acknowledgement a period within which he will discharge his debt, the right becomes time-barred ten years after the last day of the period specified.

\section{Section 640}

A right granted by a decision of a public body becomes time-barred ten years after the date on which the performance was to be provided under the decision.

\section{Section 641}

If acknowledgement of debt or a decision of a public body divides the performance into individual partial performances, the ten-year limitation period also applies to those partial performances and commences on the date on which each partial performance becomes due. If the entire debt becomes due because of a failure to execute any partial performance, the limitation period commences on the date on which the non-discharged partial performance became due.

\section{Section 642}

If a debt was acknowledged or a right was granted by a decision of a public body, the ten-year limitation period does not apply to interest and the recurrent performances which became due after the debt was acknowledged or the right granted.

\section{Section 643 [Recodification]}

(1) Where a duty passed to an heir, a limitation period shall expire no earlier than six months after the date on which the heir obtained a confirmation of the inheritance.

(2) Where a legal person has been restored, a limitation period for its creditors shall expire no earlier than six months after the date on which the registration of the legal person in a public register was restored.

\section{Section 644 [Recodification]}

If a pledgor discharges a debt to a creditor for a debtor, his right against the debtor becomes time-barred no earlier than six months after the debt has been fulfilled.

\section{Subdivision 3}

\section{Running of a limitation period}

\section{Section 645 [Recodification]}

Where a person is required to have a legal representative or a guardian, a limitation period for a right of or against such a person commences only on the day on which the legal representative or guardian of that person is appointed. A limitation period which has already begun shall continue to run, but shall end no earlier than one year after the obstacle is removed.

\section{Section 646 [Recodification]}

Between spouses, a limitation period neither commences nor runs while the marriage lasts. This applies, by analogy, to mutual rights of persons living in a common household, a person represented and his legal representative, a ward and his guardian and a person under tutorship and his tutor.

\section{Section 647 [Recodification]}

In the case of an agreement on out-of-court negotiations between the debtor and creditor concerning a right or a circumstance constituting a right, the limitation period only s after the creditor or debtor has expressly refused to continue such negotiations; where a limitation period commenced earlier, it is suspended for the duration of the negotiations.

\section{Section 648}

If, within a limitation period, a creditor asserts a right against a public body and continues in duly initiated proceedings, the statute of limitations is suspended. This also applies to an already enforceable right if an application for court enforcement or private enforcement has been filed with respect to the right. 
Where a creditor asserts a mutual right before a public body and both rights are related to the same contract or several contracts concluded in dependence on each other with respect to their purpose, a limitation period is suspended from the date on which proceedings on the right against which the mutual right is directed were initiated. In other cases, a limitation period is suspended from the date on which the mutual right was asserted.

\section{Section 650 [Recodification]}

A limitation period is suspended for a period for which a creditor is prevented from asserting his right by being threatened. This also applies where a creditor has not asserted a right due to having been misled by trickery committed by the debtor or a close person of the debtor.

\section{Section 651 [Recodification]}

A limitation period is suspended for the duration of an event of force majeure which prevented the creditor from asserting his right in the last six months of the limitation period.

\section{Section 652 [Recodification]}

If a limitation period continues to run after any of the obstacles provided under Sections 646 to 651 have been removed, the limitation period shall end no earlier than six months after the date on which it commenced again.

\section{Subdivision 4}

\section{Restoring a claim and running of a new limitation period}

\section{Section 653}

(1) If a right has been time-barred and the debtor has acknowledged his debt, a claim is renewed and a new limitation period commences on the date on which the debt was acknowledged. However, if the debtor specifies in the acknowledgement a period within which he will discharge his debt, the right becomes time-barred ten years after the last day of the period specified. analogy

(2) If a right, although already time-barred, has been granted by a decision of a public body, Subsection (1) applies by

\section{Division 2}

Prescription

\section{Section 654}

(1) If a right has not been exercised within the specified time limit, it is extinguished only in the cases expressly provided by a statute. The extinction of the right is taken into account by a court even if not invoked by the debtor.

(2) The provisions of this Act on the running of a limitation period apply by analogy to a prescription period.

\section{BOOK TWO}

\section{FAMILY LAW}

TITLE I

\section{MARRIAGE}

\section{Chapter 1}

\section{General provision}

\section{Section 655}

Marriage is a permanent union of a man and a woman formed in a manner provided by this Act. The primary purpose of marriage is the foundation of a family, proper upbringing of children and mutual support and assistance.

\section{Chapter 2}

\section{Formation of marriage}

Section 656

(1) Marriage is formed by free and full affirmative expressions of will by a man and woman (hereinafter "fiancés") having an intention to enter into marriage. 
(2) A wedding ceremony is public and festive; it is held in the presence of two witnesses.

\section{Section 657}

(1) Where fiancés express their will to enter into marriage in person before a public body performing the wedding ceremony in the presence of a registrar, it is a civil wedding.

(2) Where fiancés express their will to enter into marriage in person before a body of a church or religious society authorised to do so under another legal regulation (hereinafter an "authorised church"), it is a church wedding.

\section{Section 658} ceremony.

(1) In the case of a civil wedding, another legal regulation shall define the public body which performs the wedding church.

(2) In the case of a church wedding, a person authorised by the authorised church is the body of the authorised

\section{Section 659}

Marriage is entered into in such a manner that a person acting on behalf of a public body or a person acting on behalf of the body of an authorised church, acting in the capacity of a solemnising officer, shall ask the fiancés whether they wish to enter into marriage; upon a positive response from each of them, the marriage is formed. Marriage may also be formed in a different manner if it is clear that the fiancés express their will to enter into marriage.

\section{Section 660}

During a wedding ceremony, fiancés shall declare that:

a) the surname of one of them will be their common surname,

b) they will both keep their respective surnames, or

c) the surname of one of them will be their common surname, and the person whose surname is not to become the common surname will add his existing surname after the common surname as his second surname.

\section{Section 661}

(1) If fiancés keep their existing surnames, they shall also declare at the wedding ceremony which of their surnames is to become the surname of their common children.

(2) If spouses have kept their existing surnames, they may, even later, declare before a public body that they have agreed on a common surname of one of them.

\section{Section 662}

(1) Where, in the case of the option under Section 660(c), a fiancé whose surname is not to become the common surname already has a second surname, he may only choose the first surname to be the new second surname.

(2) The option under Section 660(c) may not be used if a fiancé whose surname is to become the common surname already has a second surname.

\section{Section 663}

(1) In the case of a civil wedding, a wedding ceremony is held at a place designated by the public body performing the wedding ceremony, while also considering the will of the fiancés.

(2) In the case of a church wedding, a wedding ceremony is held at a place designated by the internal regulations of the authorised church.

\section{Section 664}

(1) Fiancés shall apply to the public body in whose jurisdiction the marriage is to be solemnised to perform the wedding ceremony, and submit documents proving their identity and capacity to enter into marriage; another legal regulation provides the documents required to be submitted.

(2) A public body may waive the submission of the required documents if obtaining them is associated with an obstacle which is difficult to overcome.

\section{Section 665}

During a wedding ceremony, fiancés shall, before expressing their will to enter into marriage, state that they are not aware of any obstacles preventing them from entering into marriage, that they are aware of each other's health condition and that they have considered the arrangement of future property situation, their housing and material security after entering into marriage. 
(1) If a church marriage is to be entered into, fiancés must first submit to the solemnising officer a certificate issued by the registry of births, deaths and marriages in whose jurisdiction the marriage is to be solemnised. The certificate must contain a confirmation that the fiancés have met all statutory requirements for entering into marriage. The certificate may not be issued earlier than six months before the wedding ceremony.

(2) If a church marriage has been entered into, the solemnising officer shall, within three working days after the marriage has been entered into, deliver to the registry of births, deaths and marriages in whose jurisdiction the marriage was solemnised a certificate of marriage including the facts provided by another legal regulation.

\section{Section 667}

(1) If the life of a fiancé is directly threatened, a wedding ceremony may be performed by any body pursuant to Section 658 , or another body provided by another legal regulation, at any place; the same applies to a church wedding. Outside the territory of the Czech Republic, a wedding ceremony may also be performed by a commander of a naval vessel sailing under the national flag of the Czech Republic or a commander of an aircraft registered in the Czech Republic, and if at least one of the fiancés is a citizen of the Czech Republic, also by a commander of a military unit of the Czech Republic abroad.

(2) The cases under Subsection (1) shall not require the submission of documents otherwise required; the presence of a registrar is not required.

\section{Section 668}

Outside the territory of the Czech Republic, a citizen of the Czech Republic may also enter into marriage before a diplomatic mission or consular office of the Czech Republic.

\section{Section 669}

(1) Where justified by important reasons, the regional office in whose jurisdiction the marriage is to be solemnised may, upon request of the fiancés, allow the expression of will of one of the fiancés concerning entering into marriage to be made by a proxy on his behalf.

(2) The power of attorney must contain information proving identity and other decisive facts relating to both fiancés and to the proxy, and a declaration concerning the surname. It must also state that the fiancés are not aware of any obstacles preventing them from entering into marriage, that they are aware of each other's health condition and that they have considered the arrangement of future property situation, their home and material security after entering into marriage. The power of attorney must be in writing and the signature thereon must be authenticated.

(3) Withdrawal of the power of attorney is effective only if the other fiancé learns of it before expressing his will concerning entry into marriage.

\section{Section 670}

(1) If a civil marriage has been entered into, no subsequent religious ceremonies have any legal consequences.

(2) Entering into a church wedding precludes subsequent entering into a civil marriage.

\section{Section 671}

\section{Capacity to enter into marriage} 672 to 676 .

Marriage may be entered into by anyone unless prevented from doing so by a legal impediment pursuant to Sections

\section{Legal impediments to marriage}

\section{Section 672 [Recodification]}

(1) Marriage may not be entered into by a minor lacking full legal capacity.

(2) A court may, in exceptional cases, allow a minor who lacks full legal capacity and has reached sixteen years of age to enter into marriage, if justified by important grounds.

\section{Section 673 [Recodification]}

A person whose legal capacity to enter into marriage has been limited may not enter into marriage.

\section{Section 674 [Recodification]}

Marriage may not be entered into by a person who has previously entered into marriage or a person who has previously entered into a registered partnership or another similar union abroad while this marriage, registered partnership or other similar union entered into abroad still lasts. 
Marriage may not be entered into between ancestors and descendants or between siblings; the same applies to individuals whose family relationship was created by adoption.

\section{Section 676 [Recodification]}

Marriage may not be entered into between a tutor and person under tutorship, between a child and the person to whose care the child has been entrusted, or between a foster parent and the child placed in foster care.

\section{Chapter 3}

\section{Ostensible marriage and invalidity of marriage}

Division 1

\section{Ostensible marriage}

\section{Section 677 [Recodification]}

(1) A marriage is not formed if, regarding at least one of the persons who intended to enter into marriage, the elements in the expression of will to enter into marriage, or in or in connection with a wedding ceremony, have not been fulfilled and the fulfilment of such elements must be unconditionally insisted on for the marriage to be formed.

(2) In the case of a church wedding, these elements also include the requirement of entering into marriage before a body of an authorised church. In the absence of a wedding ceremony due to direct threat to life of one of the fiancés, these facts also include a certificate of the registry of births, deaths and marriages proving that the fiancés have met all statutory requirements for entering into marriage and that the certificate has not been issued more than six months before the entering into marriage.

\section{Section 678 [Recodification]}

A court may determine a marriage to be non-existent, even of its own motion.

\section{Section 679 [Recodification]}

(1) Immediately after a court determines that a marriage is non-existent, a court shall decide on the paternity of a common child as well as the parents' rights and duties in respect of the child.

(2) Property rights and duties of a man and woman are assessed individually according to the nature of such rights and duties. Where no other procedure is possible, the provisions on unjust enrichment apply. In these matters, account must be taken of the man or woman acting in good faith, as well as of the rights and legal interests of the common children and third persons.

\section{Division 2}

\section{Invalidity of marriage}

\section{Section 680 [Recodification]}

If a marriage has been entered into despite the existence of a legal impediment, the court shall declare the marriage invalid on the application of anyone having a legal interest therein, unless the marriage was impeded by limited legal capacity.

\section{Section 681 [Recodification]}

A marriage is considered valid until declared invalid. If a marriage has been declared invalid, it is considered never to have been entered into.

\section{Section 682 [Recodification]}

A marriage may not be declared invalid if it has terminated or if the defects have already been remedied.

\section{Section 683 [Recodification]}

A marriage may not be declared invalid if it was entered into by a minor lacking full legal capacity or a person whose legal capacity has been limited in this area and a child was conceived and born alive.

\section{Section 684 [Recodification]}

(1) A court shall declare a marriage invalid on the application of a spouse whose will to enter into marriage was expressed under duress consisting in the use or threat of violence, or whose will to enter into marriage was expressed as a result of error regarding the identity of the fiance or the nature of the juridical act constituting a wedding. The application may be submitted no later than one year from the date on which the spouse could have done so under the circumstances, or on which he learned of the real state of affairs.

(2) In the case provided in Subsection (1), a court shall declare a marriage invalid even where it terminated by the death of a spouse before the proceedings on the invalidity of the marriage initiated by the other spouse were completed, or if the 
descendants of the spouse who filed the application to declare the marriage invalid apply, within one year after his death, to the court to declare the marriage invalid.

\section{Section 685 [Recodification]}

A court shall declare a marriage invalid, even of its own motion, even where it has terminated, if it was entered into:

a) by a person who has previously entered into marriage, or who has previously entered into a registered partnership or another similar union abroad, if such a marriage, partnership or another similar union still lasts,

b) between an ancestor and a descendant, between siblings or between persons whose family relationship was created by adoption.

\section{Section 686 [Recodification]}

(1) The rights and duties of a man and woman whose marriage has been declared invalid to a common child and their property rights and duties at the time after the marriage has been declared invalid are governed, by analogy, by the provisions on the rights and duties of divorced spouses to a common child and on their property rights and duties at the time after the divorce.

(2) If a marriage has been declared invalid under Section 684, account must be taken of the person who acted in good faith when deciding on property rights and duties.

\section{Chapter 4}

\section{Rights and duties of spouses}

\section{Division 1}

\section{General provisions}

Section 687

(1) Spouses have equal rights and duties.

(2) Spouses are obliged to respect each other, they are obliged to live together, be faithful to each other, respect each other's dignity, support each other, maintain the family community, create a healthy family environment and jointly care of children.

\section{Section 688}

A spouse has the right be given, by the other spouse, information on his income and amount of his assets and liabilities, as well as on his existing and planned work, study and similar activities.

\section{Section 689}

When choosing his work, study and similar activities, a spouse shall take into account the interests of the family, the other spouse and a minor child who has not yet acquired full legal capacity and lives in the family household with the spouses, and the interests of other family members, where applicable.

\section{Section 690 [Recodification]}

\section{Satisfying family needs}

Each spouse shall contribute to the needs of family life and the needs of the family household according to his personal and property situation, abilities and potential so that in principle the standard of living of all family members is comparable. Contributing property has the same relevance as personal care of the family and its members.

\section{Section 691 [Recodification]}

(1) If spouses do not have a family household, each of them bears the costs of his respective household; this does not relieve them of the duty to help and support each other.

(2) Where a common child of spouses to whom both spouses have a duty to maintain and support, or a minor child who has not yet acquired full legal capacity and has been entrusted to the care of both or one of spouses, lives with one of the spouses and the other spouse leaves the family household without having a reason deserving special consideration and refuses to return, the latter must also contribute to the costs of the family household. The reason for leaving the family household or refusing to return is assessed by a court according to the principles of decency and good morals.

\section{Section 692}

\section{Deciding on family matters}

(1) Family matters, including the choice of the place of the family household or, where applicable, the household of one of the spouses and other family members, in particular children who have not yet acquired full legal capacity, and the way 
of life of the family, is to be agreed by spouses.

(2) If spouses fail to agree on a substantial family matter, a court may, on the application of one of the spouses, substitute the consent of the other spouse by its decision if the spouse refuses to give his consent in such a matter of family life without a serious reason and contrary to the interests of the family, or if he is unable to express his will. However, the court shall primarily encourage the spouses to reach an agreement.

\section{Providing for family matters}

Section 693

Family matters are provided for by spouses jointly, or by one of them.

\section{Section 694}

(1) In usual family matters, a juridical act made by one of the spouses obliges and entitles both spouses jointly and severally; this does not apply if the spouse who did not make the juridical act informed a third person in advance that he disagreed with the juridical act. Also a court may, on the application of a spouse, exclude the spouse from the effects of future juridical acts made by the other spouse with respect to third persons. Such measures do not apply to juridical acts whereby a spouse provides for usual life necessities of the family and its members, especially children who have not yet acquired full legal capacity.

(2) In other family matters, a juridical act of one of the spouses obliges and entitles both spouses jointly and severally if the other spouse gave his consent to the former's juridical act; Section 692(2) applies by analogy. However, if a spouse who does not consent to a juridical act of the other spouse has not managed to obtain help from a court in advance, he may invoke the invalidity of such a juridical act.

(3) If spouses do not live together in a situation under Section 691(2), a juridical act of one of the spouses in family matters does not oblige or entitle the other spouse without his consent.

\section{Section 695}

Sections 693 and 694 do not apply to matters governed by the provisions on matrimonial property law.

Section 696

\section{Mutual representation of spouses}

(1) A spouse has the right to represent the other spouse in usual matters.

(2) A spouse does not have the right under Subsection (1) if the spouse to be represented informs in advance the person with respect to whom his spouse is to or intends to make a juridical act, that he does not consent to being represented, or if a court, on the application of a spouse, extinguishes the spouse's right of representation.

(3) Moreover, a spouse does not have the right under Subsection (1) if the spouses do not live together in a situation under Section 691(2).

Section 697

\section{Maintenance and support between spouses}

(1) Spouses have a duty to maintain and support each other to such an extent that, in principle, ensures the same material and cultural standard for both of them. The duty to maintain and support between spouses takes precedence over the children's or parents' duty to maintain and support.

(2) In other respects, the duty to maintain and support between spouses is governed by the general provisions on maintenance and support.

\section{Usual family household equipment}

\section{Section 698 [Recodification]}

(1) Usual family household equipment consists of a set of movable things which normally serve for usual essential needs of life of the family and its members; whether individual things belong to both spouses or just one of them is not decisive.

(2) A spouse needs the consent of the other spouse to dispose of a thing which is a part of the usual equipment of a family household; this does not apply to things of negligible value.

(3) A spouse may invoke invalidity of a juridical act whereby the other spouse disposed of a thing that is part of the usual equipment of the family household without his consent.

\section{Section 699 [Recodification]}

(1) If a spouse leaves the family household with the intention to do so permanently and refuses to return, he may request that his spouse surrender to him what belongs to the usual equipment of a family household and belongs exclusively to him. What spouses own jointly is divided equally between them, unless excluded by the nature of the thing; in that case, the 
general provisions of this Act on cancellation and settlement of co-ownership apply.

(2) If a spouse needs what belongs to the usual equipment of a family household, in particular also for a common minor child of the spouses who has not yet acquired full legal capacity and with respect to whom both have the duty to maintain and support, or a minor child who has not yet acquired full legal capacity was entrusted to the joint care of the spouses living in a family household and has remained in the family household, Subsection (1) does not apply.

\section{Family enterprise}

\section{Section 700 [Recodification]}

(1) A family enterprise is considered to be an enterprise in which the spouses, or at least one of the spouses with their relatives up to the third degree or persons in an in-law relationship with the spouses up to the second degree work together and which is owned by one of these persons. Those of them who constantly work for the family or for the family enterprise are considered to be family members participating in the operation of the family enterprise.

(2) The provisions on the rights and duties of family members participating in the operation of a family enterprise do not apply in cases where these rights and duties are governed by a memorandum of association, including the forming juridical act on forming a company or cooperative, silent partnership contract, or a contract and provisions of another statute on employment, or, where applicable, another similar contract. Where the family members participating in the operation of a family enterprise are spouses, the provisions of this Act on matrimonial property law take precedence over the provisions on family enterprises.

\section{Section 701 [Recodification]}

Family members participating in the operation of a family enterprise are entitled to a share in its profits and the things acquired from the profits, as well as in the accessions to the enterprise to an extent corresponding to the amount and type of their work. Only a person having full legal capacity may waive this right by a personal declaration; the declaration requires the form of a public instrument.

\section{Section 702 [Recodification]}

Decisions on the use of profits from a family enterprise or its accessions, as well as decisions on matters beyond usual business management, including changes in the fundamental principles of operation or the cessation of operation of an enterprise, are adopted by a majority vote of the family members participating in the operation of the family enterprise. If they include a person lacking full legal capacity, he is represented in voting by a legal representative, if a minor; otherwise, by a guardian.

\section{Section 703 [Recodification]}

Participation in the operation of a family enterprise is bound to a family member personally and cannot be transferred to another, unless the person is a family member under Section 700(1) and all family members who already participate in the operation of the family enterprise have consented to the transfer.

\section{Section 704 [Recodification]}

(1) Where a family enterprise is to be divided upon division of decedent's estate by a court, a family member participating in its operation has a priority right to the family enterprise.

(2) Where a family enterprise is to be alienated, a family member participating in its operation has a pre-emptive right to the family enterprise, unless stipulated otherwise. This also applies in the case of alienation of a co-ownership share in a family enterprise or alienation of a thing intended, given its nature and the current purpose, to permanently serve the operation of the family enterprise.

\section{Section 705 [Recodification]}

(1) Upon the alienation of a family enterprise, participation in the operation of the family enterprise terminates.

(2) Participation of a family member in the operation of a family enterprise is also extinguished if he ceases to work for the family or in the family enterprise, or if the legal cause on which he continues to work in the family enterprise change.

\section{Section 706 [Recodification]}

If participation in the operation of a family enterprise terminates, a payment to a family member who is still participating in the operation of the enterprise may be split into instalments, if so agreed upon or if approved by a court. In the absence of reasonable grounds to split payments into instalments, a court shall not approve the payment in instalments or, where appropriate, shall declare the stipulation on instalments invalid.

\section{Section 707 [Recodification]}

Family communities formed to operate a family enterprise without the express stipulation of the family members are governed by usages and practice established therein, unless contrary to Sections 700 to 706 .

\section{Division 2}

\section{Matrimonial property law}




\section{Section 708}

(1) What belongs to spouses, has property value and is not excluded from the legal relations forms part of the community property of the spouses (hereinafter "community property"). This does not apply if community property is extinguished by means of a statute during the marriage.

(2) Community property is subject to a statutory regime, contractual regime or a regime formed by the decision of a court.

\section{Statutory regime}

\section{Section 709 [Recodification]}

(1) Community property includes what was acquired during the marriage by one of the spouses individually or both spouses jointly, except for what:

a) serves the personal needs of one of the spouses,

b) was acquired as a gift, inheritance or legacy by only one of the spouses, unless the donor in the donation or decedent in the disposition mortis causa expressed a different intention,

c) was acquired by one of the spouses as compensation for non-pecuniary harm to his natural rights,

d) was acquired by one of the spouses by a juridical act relating to his separate property,

e) was acquired by one of the spouses as compensation for damage, destruction or loss of his separate property.

(2) Community property includes profits from what belongs exclusively to one of the spouses.

(3) Community property also includes a spouse's share in a company or cooperative if, during the marriage, a spouse becomes a shareholder in a company or a member of a cooperative. This does not apply if one of the spouses has acquired the share in a manner constituting his separate property under Subsection (1).

\section{Section 710 [Recodification]}

Community property includes debts assumed during the marriage, unless:

a) they relate to property that belongs exclusively to one spouse, to the extent which exceeds the profits from such property, or

b) they were assumed by only one spouse without the consent of the other except for debts incurred to provide for the everyday or usual needs of the family.

\section{Section 711}

(1) Acquisition and loss of individual items of community property is governed by the general provisions of this Act.

(2) The amounts of earnings, salary, wage, profit and other values for work and other gainful activities become part of community property when the spouse who contributed to obtaining them became able to dispose of them.

(3) Claims under the separate property of only one of the spouses that are to become part of the community property become part thereof on the due date.

\section{Section 712 [Recodification]}

Unless otherwise provided by this Book of this Act, the provisions of this Act on a partnership or, where applicable, on co-ownership apply by analogy to community property.

\section{Administration under the statutory regime}

\section{Section 713}

(1) Both or one of the spouses use, take the fruits and revenues of, maintain, dispose of, manage and administer the community property as agreed. severally.

(2) Rights and duties associated with community property or parts thereof pertain to both spouses jointly and

(3) Juridical acts relating to community property or parts thereof oblige and entitle both spouses jointly and severally.

\section{Section 714 [Recodification]}

(1) In matters relating to community property and parts thereof which cannot be considered common, the spouses make juridical acts jointly, or one of the spouses acts with the consent of the other. If one of the spouses refuses to give consent without a serious reason and contrary to the interests of the spouses, family or family household or is unable to express his will, the other spouse may apply to a court to substitute the consent of his spouse. 
(2) If a spouse makes a juridical act without the consent of the other spouse where consent is required, the latter may invoke invalidity of such a juridical act.

\section{Section 715 [Recodification]}

(1) If part of the community property is to be used for business activities of one of the spouses and the property value of what is to be used exceeds a level appropriate to the property situation of the spouses, consent of the other spouse is required upon the first such use. If the other spouse has been omitted, he may invoke invalidity of such an act.

(2) If part of the community property is to be used for the acquisition of a share in a company or cooperative, or if the acquisition of a share results in liability for the debts of the company or cooperative to the extent exceeding a level appropriate to the property situation of the spouses, Subsection (1) applies by analogy.

\section{Contractual regime}

\section{Section 716}

(1) Fiancés and spouses may agree on a matrimonial property regime different from the statutory regime. If contractual regime has been agreed by spouses, they typically provide for their rights and duties relating to existing community property. If a contractual regime has been agreed as retroactive, it is disregarded.

(2) A contract on matrimonial property regime must be in the form of a public instrument.

\section{Section 717}

(1) Contractual regime may consist in a separate property regime, a regime reserving the creation of community property as of the date the marriage terminates, as well as a regime constituting an extension or reduction of the scope of the statutory regime of community property. The provisions on a separate property regime apply by analogy under the regime reserving the creation of community property as of the date on which the marriage terminates.

(2) A contractual regime may be changed by agreement of the spouses or a court decision; such a change requires agreement of the spouses or a court decision on the parts of the community property in the existing regime.

\section{Section 718 [Recodification]}

(1) The contract may contain any stipulation and relate to any matter, unless prohibited by a statute; it may relate in particular to the scope, content and time of creation of the statutory or other community property regime, as well as individual things and sets thereof. The contract may also change the classification of the existing as well as modify the classification of the future parts of assets and liabilities differently from the statutory regime.

(2) The contract may also specify property situation in the case of termination of marriage; where the contract stipulates arrangements in the case of termination of marriage by death, the relevant part of the contract is considered to be an inheritance contract, if it contains its elements.

(3) The contract may not exclude or change the provisions on usual family household equipment, unless one of the spouses has permanently left the household and refuses to return.

\section{Section 719 [Recodification]}

(1) The consequences of a contract on matrimonial property regime may not exclude a spouse's ability to provide for the family.

(2) The content or purpose of a contract on matrimonial property regime may not affect the rights of a third person, unless the third person has consented to the contract; such a contract concluded without the consent of the third person has no legal effects with respect to the third person.

\section{Section 720}

(1) A contract of fiancés on matrimonial property regime becomes effective upon entering into marriage. If the contract relates to an already existing thing registered in a public register, the change may be registered in the register only after the marriage has been entered into.

(2) If a contract between the spouses on matrimonial property regime relates to an already existing thing registered in a public register, the contract shall, in this part, become effective with respect to third persons upon registration in that register, unless otherwise provided by this Act.

\section{Section 721 [Recodification]}

(1) A contract on matrimonial property regime is registered in a public register if so stipulated therein, or otherwise at the request of both spouses. Everything that changes the statutory property regime of the spouses is registered in the register.

(2) The registration is made without undue delay by the person who prepared the contract, and if this is not possible, by the person who maintains the register. 


\section{Section 722}

(1) Fiancés and spouses may conclude a contract for the administration of what is part of their community property which derogates from the provisions of Section 713 and 714; the provisions of Sections 719 and 720 also apply to this contract.

(2) The contract under Subsection (1) stipulates which of the spouses will administer the community property or part thereof, and how.

\section{Section 723 [Recodification]}

(1) The spouse who administers community property makes juridical acts independently in matters relating to the community property, even in judicial or other proceedings, unless otherwise provided below. other spouse:

(2) The spouse who administers the entire community property may make juridical acts only with the consent of the

a) when disposing of community property as a whole,

b) when disposing of the dwelling in which the family household of the spouses is located, if the dwelling is part of community property, or a dwelling of one of the spouses or a dwelling of a minor child who has not yet acquired full legal capacity and is in the care of the spouses, as well as when stipulating a permanent encumbrance of an immovable thing which is part of community property.

(3) Section 714(2) applies by analogy.

\section{Regime established by a court decision}

\section{Section 724 [Recodification]} existing scope.

(1) In case of a serious reason, a court shall, on the application of a spouse, cancel community property or reduce its

(2) A serious reason shall always mean the fact that a spouse's creditor requires his claim to be secured to an extent exceeding the value of what belongs exclusively to that spouse, that a spouse may be considered prodigal, or that the spouse constantly or repeatedly takes unreasonable risks. The fact that a spouse has started pursuing business activities or become a partner of a legal person with unlimited liability may also be considered to be a serious reason.

\section{Section 725 [Recodification]}

A regime established by a court decision may be changed by a contract between the spouses or a court decision.

Section 726

(1) A court may renew community property after having cancelled it; a court shall decide so especially where the reasons to cancel community property have ceased to exist. This applies even where a spouse applies to a court to extend community property whose scope was restricted to the statutory scope.

(2) If community property has been extinguished by means of a statute, a court shall, on the application of a spouse, renew it if it is in the interest of both spouses.

\section{Section 727 [Recodification]}

(1) A court decision may not exclude or amend provisions governing usual family household equipment.

(2) The consequences of a court decision on the change, cancellation or renewal of community property must not exclude the ability of a spouse to provide for the family, and its content or purpose may not affect the rights of a third person, unless the third person has consented to the decision.

\section{Section 728}

\section{Administration under the regime formed by the decision of a court}

If, when administering community property, a spouse acts in a manner which is clearly contrary to the interests of the other spouse, family or family household and the fiancés or spouses have not concluded a contract governing the administration of what forms part of community property, a court may, on the application of the other spouse, decide how community property will be administered.

\section{Separate property regime}

Section 729

In the separate property regime, a spouse may dispose of his property without the consent of the other spouse. 
If, under the separate property regime, spouses pursue business activities jointly or one of the spouses pursues business activities with the help of the other spouse, they shall divide the income from business activities as agreed earlier in writing; otherwise, the income is divided equally.

\section{Protection of third persons}

\section{Section 731 [Recodification]}

If only one of the spouses incurred debt during the existence of community property, a creditor may, in the framework of enforcement of a decision, satisfy his claims from community property.

\section{Section 732 [Recodification]}

If debt was incurred by only one of the spouses against the will of the other spouse who expressed his disagreement to the creditor without undue delay after becoming aware of the debt, community property may only be affected up to the amount equalling to a share that would belong to the debtor were community property cancelled and settled pursuant to Section 742. This also applies to a spouse's duty to provide maintenance and support or to debt arising from an unlawful act of only one of the spouses, or where debt was incurred by only one of the spouses before entering into marriage.

\section{Section 733}

If one of the spouses assumed an obligation at a period within six months before the statutory property regime was changed or excluded, either by a contract between spouses or a court decision, the claim of his creditor may be satisfied from anything that would have been part of community property but for the contract between spouses or the court decision.

\section{Section 734}

If a contract between spouses or a court decision changing or excluding the statutory property regime affects a right of a third person, in particular of a creditor, the person concerned may assert his right on the occasion of the settlement of what was formerly part of community property in the same manner as if no contract between spouses has been concluded or court decision made; in this context, Section 742 applies.

\section{Section 735}

\section{Special provisions}

Unless spouses who intend to divorce in a manner set out in Section 757 conclude an agreement on the arrangement of property rights and duties in the event of a divorce, in which, under the condition that the marriage is divorced, they also stipulate the manner in which they will acquire rights and assume duties during separate management, the provisions on community property apply to the period of separate management with the necessary modifications, unless otherwise provided by this Act.

\section{Settlement of community property}

\section{Section 736 [Recodification]}

If community property is cancelled or extinguished or their current scope is reduced, the common rights and duties are liquidated by means of a settlement. Until community property which is reduced, cancelled or extinguished has been settled, it is governed by the provisions on community property with the necessary modifications.

\section{Section 737}

(1) Settlement of assets and liabilities must not affect any right of a third person. If a right of a third person has been affected by a settlement, the third person may claim that a court declare the settlement ineffective with respect to this third person.

(2) Settlement of debts is effective between spouses only.

\section{Section 738 [Recodification]}

(1) A settlement agreement is always effective as from the date on which the community property was reduced, cancelled or extinguished, regardless of whether the agreement was concluded before or after the reduction, cancellation or extinction of the community property. However, if the settlement concerns a thing which is subject to registration in a public register, the part of the agreement concerning this thing becomes legally effective upon its registration in the public register.

(2) The validity of a settlement agreement is not impeded if it concerns only a part of the common rights and duties relating to property.

\section{Section 739}

(1) A settlement agreement must be in writing if it is concluded during marriage or if the settlement concerns a thing for which an agreement on transfer of the right of ownership is also required in writing.

(2) If the settlement agreement is not required in writing and if requested by one of the spouses, the other spouse shall deliver to the former a confirmation of the contents of their settlement. 
If spouses fail to agree on a settlement, any of them may apply to a court for a decision. The settlement is decided on by a court based on the state existing at the time when the reduction, cancellation or extinction of community property became effective.

\section{Section 74}

If, within three years from reduction, cancellation or extinction of community property, no settlement of what was formerly part of the community property takes place, even by agreement, and no application for settlement by a court decision is filed, the spouses or former spouses are conclusively presumed to have settled as follows:

a) corporeal movable things are owned by the spouse who uses them exclusively as an owner for his own needs or the needs of his family or family household,

b) other corporeal movable things and immovable things are under undivided co-ownership of both spouses; their shares are equal,

c) other property rights, claims and debts belong to both spouses jointly; their shares are equal.

\section{Section 742}

(1) Unless the spouses or former spouses agree otherwise or if Section 741 does not apply, the settlement is governed by the following rules:

a) the shares of both spouses on the assets and liabilities being settled are the same,

b) each of the spouses shall reimburse the part of the common property which was expended on his exclusive property,

c) each of the spouses has the right to request that he be reimbursed for the part of his exclusive property which he expended on the common property,

d) account is taken of the needs of dependent children,

e) account is taken of the way each of the spouses cared for the family, in particular how he took care of the children and the family household,

f) account is taken of the way each of the spouses contributed to the acquisition and maintenance of property values pertaining to the community property.

(2) When settling community property, the value of the part of the community property which was expended on exclusive property of a spouse, as well as the value of the part of the exclusive property of a spouse which was expended on community property, is included after having been increased or decreased depending on the increase or decrease in the value of the part of the property on which the cost was incurred in a period from the date the property was expended until the date the community property was reduced, cancelled or extinguished.

\section{Certain provisions on the housing of spouses}

\section{Section 743 [Recodification]}

(1) A family household is at the place of the dwelling of the spouses.

(2) If a spouse requests, for serious reasons, that the family household be relocated, the other spouse should accommodate such a request unless the reasons for staying outweigh the reasons for such a change.

(3) Spouses may agree to permanently live separately. An agreement of spouses on separate housing has the same legal effect as leaving the family household with the intent to live permanently elsewhere.

\section{Section 744 [Recodification]}

If the dwelling of spouses is a building or an apartment to which one of the spouses has an exclusive right allowing him to live in the building or apartment other than a right arising from an obligation, the other spouse shall acquire a right of residence upon entering into marriage. If such an exclusive right of one of the spouses is created during marriage, the other spouse acquires thereby a right of residence.

\section{Section 745 [Recodification]}

(1) If the dwelling of spouses is a building or an apartment which one of the spouses uses on the basis of a lease as of the date on which the marriage was entered into, both spouses shall acquire joint lease of the building or apartment upon entering into marriage; if a lease contract is concluded at a later time, joint lease of both spouses is created upon the effective date of the contract. This also applies, by analogy, to other similar rights arising from an obligation.

(2) Subsection (1) does not apply if spouses agree otherwise. 
(1) Spouses having a joint lease of a building or an apartment are entitled and obliged jointly and severally.

(2) A spouse having the right of residence is in the position of a surety for his spouse.

\section{Section 747 [Recodification]}

(1) If at least one of the spouses has a right to dispose of a building or apartment in which the family household of the spouses or the family is located and the building or apartment is essential for the residence of the spouses or family, he must refrain from and avoid all that may prevent or endanger such residence. Without the consent of the other spouse, a spouse may not, in particular, alienate such a building or an apartment or create such a right to the building, its part or the whole apartment the exercise of which is incompatible with the housing of the spouses or family, unless he provides his spouse or family with housing which is in all respects similar to the existing one.

(2) If a spouse acts without the consent of the other spouse contrary to Subsection (1), the spouse may invoke invalidity of such a juridical act.

\section{Section 748 [Recodification]}

(1) If spouses have a joint lease of a building or an apartment in which the family household of the spouses or family is located, first sentence of Section 747(1) applies by analogy. Without the consent of the other spouse, a spouse may not end the lease or limit the lease by a right, the exercise of which is incompatible with the housing of the spouses or family.

(2) If a spouse acts without the consent of the other spouse contrary to Subsection (1), the spouse may invoke invalidity of such a juridical act.

\section{Section 749 [Recodification]}

The consent of a spouse under Sections 747 and 748 must be in writing.

\section{Section 750 [Recodification]}

(1) If spouses or fiancés agree by way of derogation from Sections 747 and 748 , such an agreement may not deteriorate the position of their common minor child who has not acquired full legal capacity and lives with them in the family household, and to which they have the duty to maintain and support, or a minor child who has not acquired full legal capacity and has been placed in the joint care of both or one of the spouses; furthermore, the agreement may not affect the rights of third persons, unless they have consented to such an agreement.

(2) The agreement and consent of third persons under Subsection (1) must be in writing.

\section{Special provisions against domestic violence}

\section{Section 751 [Recodification]}

(1) If further cohabitation of spouses in a building or an apartment in which the family household is located becomes unbearable for one of the spouses due to physical or mental violence committed against him or another person living with the spouses in the family household, a court may, on the application of the affected spouse, limit or even exclude the right of the other spouse to reside in the building or apartment for a determined period.

(2) The same procedure as under Subsection (1) may be applied to divorced spouses, as well as to spouses or divorced spouses living together at a place other than the family household.

\section{Section 752 [Recodification]}

A court shall limit or exclude a spouse's right to reside in a building or apartment for a maximum period of six months. The court shall, on the application, decide again if justified by particularly serious reasons.

\section{Section 753 [Recodification]}

Any other person who lives with the spouses or divorced spouses in the family household also has the right to seek protection against domestic violence.

\section{Chapter 5}

\section{Termination of marriage}

\section{Division 1}

\section{General provision}

Section 754

A marriage only terminates on the grounds provided by a statute. 


\section{Divorce}

Section 755

(1) A marriage may be divorced if the married life of the spouses has deeply, permanently and irreversibly broken down and its restoration cannot be expected. contrary to:

(2) Even where the married life of the spouses has broken down, a marriage may not be divorced if the divorce is

a) the interest of a minor child of the spouses who has not yet acquired full legal capacity, which is based on special reasons; the court shall also ascertain the interest of the child in the continuation of the marriage by asking the guardian appointed by a court for the proceedings to provide for the relationships to the child for the time after the divorce, or

b) the interest of the spouse who has not predominantly contributed to the breakdown by breaching marital duties and who would incur particularly serious harm; extraordinary circumstances are an indication in favour of preserving the marriage, unless the spouses have not lived together for at least three years.

(3) If spouses have a minor child who has not yet acquired full legal capacity, the court shall not divorce the marriage until it decides on the situation of the child at the period after the divorce.

\section{Section 756}

A court which decides on a divorce shall ascertain the existence of breakdown of the marriage, and, in doing so, investigate the causes, unless otherwise provided below.

\section{Section 757 [Recodification]}

(1) If a spouse joins the petition for divorce filed by the other spouse, the court will grant the divorce without investigating the cause of breakdown of marriage if it concludes that the concurring statement of the spouses in relation to the breakdown of the marriage and the intention to get a divorce is true, and if:

a) by the date on which divorce proceedings are initiated the marriage has lasted at least one year, and the spouses have not lived together for more than six months,

b) the spouses who are parents of a minor child which has not yet acquired full legal capacity have agreed to provide for the arrangements in respect of the child for the time after the divorce and the court has approved the agreement,

c) the spouses have agreed to provide for their property situation, their housing and, where appropriate, the maintenance and support for the period after this divorce.

(2) The agreements referred to in Subsection (1) (c) must be in writing and the signatures must be authenticated.

\section{Section 758 [Recodification]}

Spouses are deemed not to live together if they do not form marital or family community, regardless of whether they have or maintain a family household, and at least one of the spouses clearly lacks the will to renew the marital community.

\section{Division 3}

\section{Consequences of termination of marriage}

Section 759

\section{Surname of a divorced spouse}

A spouse who adopted the surname of the other spouse may, within six months after the divorce, notify the registry of births, deaths and marriages that he assumes back his former surname. This applies even where a spouse who has adopted the surname of the other spouse with the intention to annex to the common surname his existing surname or the first of his surnames henceforth only intends to use his former surname.

\section{Maintenance and support of a divorced spouse}

\section{Section 760 [Recodification]}

(1) If a divorced spouse is unable to provide for himself and his inability originated in or in connection with the marriage, his former spouse shall, to a reasonable extent, have the duty to maintain and support the spouse if he can be reasonably required to do so, in particular with regard to the age and health condition of the divorced spouse at the time of the divorce or the end of the care for a common child of the divorced spouses.

(2) When deciding on the maintenance and support or its amount, a court shall take into account the duration of the divorced marriage and how long it has been divorced, as well as whether:

a) the divorced spouse has not found an appropriate job without being prevented to do so by a serious obstacle,

b) the divorced spouse could have provided for his own maintenance by duly managing his own property, 
c) the divorced spouse contributed to the care of the family household during the marriage,

d) the divorced spouse has committed an act having a nature of criminal offence against the former spouse or his close person, or

e) there is another similarly serious reason.

(3) The duty of the divorced spouses to maintain and support is governed, by analogy, by the general provisions on maintenance and support.

\section{Section 761 [Recodification]}

(1) The scope of the duty to maintain and support and the way maintenance and support is provided are governed by an agreement of the spouses or divorced spouses; if they stipulate that maintenance and support is replaced by a lump-sum payment, the right of the divorced spouse to maintenance and support is extinguished upon the provision of the lump-sum payment.

(2) If the divorced spouses fail to agree on maintenance and support, the former spouse having the need may apply to a court for a decision on the duty of the other spouse to maintain and support.

\section{Section 762 [Recodification]}

(1) If spouses or divorced spouses fail to agree on the maintenance and support, the spouse who has not predominantly caused the breakdown of the marriage or who disagreed with the divorce, and who incurred serious harm as a result of the divorce, may apply to a court to determine that the former spouse has the duty to maintain and support also to an extent ensuring that the divorced spouses have essentially the same standard of living. The right of a divorced spouse to maintenance and support may in this case be considered justified only for a period appropriate to the circumstances, but not longer than for three years after the divorce.

(2) A former spouse who committed an act against the other spouse that constitutes domestic violence is not entitled to maintenance and support under Subsection (1), even where he would otherwise meet the conditions to be granted the right to maintenance and support.

\section{Section 763 [Recodification]}

The right of a divorced spouse to maintenance and support is extinguished if the entitled divorced spouse remarries or enters into a registered partnership.

\section{Property rights and duties upon termination of marriage}

\section{Section 764}

(1) If a marriage terminates by a spouse's death, the property rights and duties of the former spouses are assessed under succession proceedings according to the property regime which existed between the spouses, or, where applicable, according to the instructions which the deceased spouse gave during his life regarding his property upon death; otherwise, the rules under Section 742, with the exception of Section 742(1)(c) apply, unless the surviving spouse agrees with the heirs on the settlement otherwise.

(2) If a spouse has been declared dead, his property rights and duties are assessed as of the day which is established as the date of his death in the decision on the declaration of death.

\section{Section 765}

(1) If a marriage terminates by divorce, the property rights and duties of the divorced spouses are administered under the agreement of the spouses or divorced spouses. decision.

(2) Unless divorced spouses agree on a settlement, a former spouse may file an application for settlement by a court

\section{Housing after the termination of marriage}

\section{Section 766 [Recodification]}

(1) If a marriage terminates upon the death of a spouse and the spouses had a common lease of a building or apartment in which their family household was located, the surviving spouse shall continue to be the lessee. If the spouses jointly possessed another right to a building or an apartment arising from an obligation, the surviving spouse remains the obligee.

(2) If a marriage terminates upon the death of a spouse and only one of them is the lessee of a building or an apartment in which the family household was located, the provisions on apartment lease apply.

\section{Section 767 [Recodification]}

(1) If a marriage terminates upon the death of a spouse who had an exclusive right (other than a right arising from an obligation) to live in a building or an apartment in which the family household of the spouses was located, while the other 
spouse had a right of residence in the building or apartment, the right of residence of the spouse is extinguished if the exclusive right of the deceased spouse passed to a person other than the surviving spouse. This does not apply if the surviving spouse cannot be reasonably required to leave the building or apartment.

(2) If appropriate to the circumstances of the surviving spouse, in particular because he takes care of a minor child who has not yet acquired full legal capacity and for whom the spouses cared, or a minor child who has not yet acquired full legal capacity and whose parent is the deceased spouse, or a dependent child living with the surviving spouse, a court may, on the application of the surviving spouse, create a right for his benefit corresponding to a housing easement according to the circumstances of the case, but only until such time as the child becomes permanently able to provide for himself, and for a consideration comparable to the rent usual to the place; this right is not extinguished if the child becomes able to provide for himself only temporarily.

(3) If the deceased spouse had the right to reside for another reason, Subsections (1) and (2) apply, by analogy.

\section{Section 768 [Recodification]}

(1) If a marriage terminates by divorce and the spouses had the same or joint right to a building or an apartment in which their family household was located and failed to agree on who will continue to live in the building or apartment, a court shall, on the application of one of them according to the circumstances of the case, extinguish the current right of the divorced spouse who may be reasonably required to leave the building or apartment, and, where applicable, also decide on the method of compensation for the loss of the right; in doing so, the court shall take into account, in particular, which of the divorced spouses has been entrusted with the care of a minor child who has not yet acquired full legal capacity and for whom the spouses cared, as well as the opinion of the lessor, lender or another person in a similar position.

(2) A divorced spouse who has to leave a building or an apartment has the right to live there until the other spouse provides him with substitute housing, unless he was not granted such compensation in the proceedings under Subsection (1), in which case he is entitled to live in the building or apartment for up to one year. If, however, he was entrusted with the care of a minor child who has not yet acquired full legal capacity and for whom the spouses cared during the marriage, or a dependent child living with him, a court may, on the application of that spouse, create a right of residence for the benefit of that spouse; Section 767(2) applies by analogy.

\section{Section 769 [Recodification]}

If a marriage terminates by divorce and the spouses did not have the same or joint right to a building or an apartment in which their family household was located, and the spouses or divorced spouses failed to agree on further residence of a spouse who has only the right to reside in the building or apartment or another right that is weaker than the right of the other spouse, a court shall, on the application of the spouse having the right of ownership or another right in rem to the building or apartment or, where applicable, exclusive lease of the building or apartment or another right to the building or apartment arising from a duty, decide on the duty of the other spouse to move out; Section 767(2) applies by analogy.

\section{Section 770 [Recodification]}

If a marriage terminates by divorce and the spouses had the right to reside in a building or apartment, where one of those rights was derived from the other, the spouse having a right in rem to the building or apartment or another right to the building or apartment arising from an obligation where the right to reside of the other spouse was directly derived from such a right has the right to require the divorced spouse who only had a derived right to move out.

\section{TITLE II}

\section{FAMILY AND IN-LAW RELATIONSHIPS}

\section{Chapter 1}

\section{General provisions}

\section{Family relationship}

\section{Section 771 [Recodification]}

Family relationship is a relationship between persons based on consanguinity or adoption.

\section{Section 772}

(1) Persons are relatives in direct line if one is a descendant of the other.

(2) Persons are relatives in collateral line if they have a common ancestor, but one is not a descendant of the other.

Section 773

The degree of relationship between two persons is determined by the number of births which are between them if one is a descendant of the other in a direct line, and which are between both persons and their closest common ancestor in collateral line. 


\section{In-law relationship}

Upon the formation of marriage, an in-law relationship is created between one spouse and the relatives of the other spouse; the line and degree of the relationship of a person to one spouse determines the line and degree of his in-law relationship to the other spouse. If a marriage terminates by the death of a spouse, in-law relationship shall remain unaffected.

\section{Chapter 2}

\section{Relationships between parents and a child}

Division 1

\section{Determination of parenthood}

Section 775

\section{Maternity}

A mother is a woman who has given birth to a child.

\section{Paternity}

\section{Section 776 [Recodification]}

(1) If a child is born in a period between the date of entering into marriage and the three hundredth day after the marriage terminated or was declared invalid, or after the mother's spouse was declared absent, the mother's spouse is presumed to be the father.

(2) If a child is born to a remarried woman, the subsequent husband is presumed the father, even if the child was born before the three hundredth day after the previous marriage was terminated or declared invalid.

\section{Section 777 [Recodification]}

(1) If a child is born in a period between the initiation of proceedings for divorce and the three hundredth day after the divorce, and the spouse or the former spouse of the mother declares that he is not the father of the child, while another man claims to be the father of the child, the latter is presumed to be the father if the mother joins both men with a declaration.

(2) The statements of the child's mother's husband or her former husband, of the man who claims to be the father of the child and of the child's mother are made in court proceedings initiated on the application of any of them; the application may be filed no later than within one year after the child's birth.

(3) The paternity of the child under Subsections (1) and (2) may not be determined before the decision on the divorce of marriage becomes final and absolute.

(4) In case of proceedings for invalidity of marriage, Subsections (1) to (3) apply by analogy.

\section{Section 778 [Recodification]}

If a child conceived through artificial insemination is born to an unmarried woman, the man who gave consent to the artificial insemination is presumed to be the child's father.

\section{Section 779 [Recodification]}

(1) If paternity is not determined pursuant to Sections 776,777 or 778 , the man whose paternity has been determined by an affirmative statement of both the mother and the man is presumed to be the father. Paternity in respect of an unborn child may also be determined in this manner if the child has already been conceived.

(2) The statement is made in person before a court or a registry of births, deaths and marriages. A minor lacking full legal capacity shall always make the statement before a court.

\section{Section 780}

If the statement is made by a person lacking full legal capacity, it may only be made before a court. A court shall, according to the circumstances of the case, assess whether the person lacking full legal capacity is able to act on his own, or whether a guardian will act on his behalf.

\section{Section 781}

If a mother is unable to assess the meaning of her statement due to a mental disorder, or if obtaining her statement is associated with an obstacle difficult to overcome, paternity may not be determined through an affirmative statement. 
The paternity statement, as a special expression of will, is governed by the general provisions on juridical acts, unless otherwise provided. Invalidity, however, may only be invoked within the time limit for the denial of paternity.

\section{Section 783 [Recodification]}

(1) If paternity is not determined pursuant to Sections 776,777 or 778 or pursuant to Section 779 , the mother, child as well as the man who claims to be the father may apply to a court to determine paternity.

(2) The man who had sexual intercourse with the child's mother at a time from which at least hundred and sixty days and no more than three hundred days have elapsed until the child's birth is presumed to be the father, unless his paternity is excluded due to serious circumstances.

(3) If the putative father is not alive, the application is filed against a guardian appointed by a court for that purpose.

\section{Section 784}

(1) If, during the proceedings, the applicant dies, another person entitled to file such an application may continue in the proceedings.

(2) If, during the proceedings, the child dies, a descendant of that child may also file an application within six months after his death if he has a legal interest in the determination.

(3) If, during the proceedings, the putative father dies, the proceedings shall continue against a guardian appointed by a court for that purpose.

(4) If, during the proceedings, the man who claimed to be the father dies and the child or mother does not continue with the proceedings, a court shall stop the proceedings.

\section{Denial of paternity}

\section{Section 785 [Recodification]}

(1) A husband may deny his paternity in court within six months from becoming aware of the facts constituting reasonable doubt that he is the father of a child born to his wife, but no later than six years after the birth of the child. He denies paternity against the child and mother, if both are alive; if one of them is dead, against the other; if both of them are dead, the husband does not have this right.

(2) If, within the six-year time limit for denial, legal capacity of a husband was limited in a way making him unable to deny paternity, the paternity may be denied by his guardian appointed for this purpose by a court, within six months from the appointment by the court.

\section{Section 786}

(1) If a child is born between the one hundred and sixtieth day after the date of marriage and the three hundredth day after it is terminated or declared invalid, paternity may only be denied, except as provided under Section 777, if it is impossible that the mother's husband is the father of the child.

(2) If a child is born before the one hundred and sixtieth day after the date of marriage, it suffices that the mother's husband denies his paternity in order not to be presumed to be the father of the child. This does not apply if the mother's husband had sexual intercourse with the child's mother during a period between one hundred and sixtieth and three hundredth day before the child's birth, or if he knew, when entering into marriage, that she was pregnant.

\section{Section 787}

Paternity may not be denied with respect to a child born at a period between the one hundred and sixtieth day and three hundredth day after artificial insemination carried out with the consent of the mother's husband, or with the consent of another man if the mother is not married, regardless of the genetic substance used. This does not apply if the child's mother got pregnant in a different manner.

\section{Section 788}

If a subsequent husband has denied his paternity of a child of a remarried woman, the six-month time limit to deny the paternity of the previous husband starts to run on the date following the date on which the previous husband learned of the decision.

\section{Section 789}

A mother may, within six months of the child's birth, deny that the child's father is her husband. Provisions on denial of paternity by a husband apply by analogy.

\section{Section 790 [Recodification]}

(1) A man whose paternity has been determined by an affirmative statement of both parents may only deny the paternity of a child if it is impossible that he could have been the father of the child. He may do so within six months from the 
date on which the paternity was so determined; where the paternity is determined before the birth of the child, the time limit shall end no earlier than six months after his birth.

(2) The provisions of the second sentence of Section 785(1) and Section 785(2) apply by analogy.

\section{Section 791}

The child's mother may deny that the man whose paternity has been determined by an affirmative statement of both parents within the time limits specified in the second sentence of Section 790(1) is the child's father.

\section{Section 792 [Recodification]}

If an application for the denial of paternity is filed after the time limit for denial has elapsed, a court may decide that the elapsed time limit is waived if required by the child's interest and public order.

\section{Section 793 [Recodification]}

If required by the evident interest of the child and in order to fulfil the provisions guaranteeing fundamental human rights, a court may, even of its own motion, initiate proceedings on a denial of paternity if paternity has been determined by an affirmative statement of both parents, but the child's father determined in this manner cannot be his father. At the same time, the court shall also typically suspend the exercise of parental responsibility.

\section{Division 2}

\section{Adoption}

\section{Subdivision 1}

\section{Adoption, adoptive parent and child being adopted}

\section{Section 794 [Recodification]}

Adoption is to be understood as taking a person of another to be one's own.

\section{Section 795 [Recodification]}

The existence of such a relationship between an adoptive parent and an adopted child which exists between a parent and a child, or at least a basis for such a relationship, is a pre-requisite for adoption. Adoption of a minor must be in accordance with his interests.

\section{Section 796 [Recodification]}

(1) Adoption of a minor is decided by a court on the application of the person who wishes to adopt the child. Where an application to adopt a child from a foreign country is filed, the applicant shall attach a decision of a competent public body consenting to the adoption.

(2) Adoption of an adult is decided by a court on the joint application of the person wishing to adopt the adult and the adult to be adopted.

\section{Section 797 [Recodification]}

Based on a court decision on adoption, an adoptive parent or adoptive parents are registered in a registry of births, deaths and marriages as a parent or parents of the child.

\section{Section 798 [Recodification]}

No person may obtain unfair profit from the activities associated with the arrangement of adoption.

\section{Section 799 [Recodification]}

(1) Only an adult person having legal capacity may become an adoptive parent, provided that his personal characteristics and way of life, as well as the reasons and motives which lead him to become an adoptive parent, guarantee that he will be a good parent to the child being adopted.

(2) The health condition of an adoptive parent or both adoptive parents must not limit the care for the adopted child to any significant large extent.

\section{Section 800}

(1) Both or one of the spouses may become adoptive parents. In exceptional cases, another person may become an adoptive parent; in such a case a court shall also decide that the entry concerning the other parent is deleted from the registry of births, deaths and marriages.

(2) When a child is adopted by spouses, the spouses file the application for adoption jointly as joint adoptive parents. 
In the case of an adoption by a person who is a parent, a court shall assess whether the adoption is not in fundamental conflict with the interests of the adoptive parent's children; property interests are not decisive for the assessment.

Section 802

A minor child who has not yet acquired full legal capacity may be adopted.

Section 803

There must be a reasonable age difference between the adoptive parent and the child being adopted, typically not less than sixteen years; as an exception, the age difference between the adoptive parent and the child being adopted may be less than sixteen years only where a guardian representing the child in the proceedings consents to the adoption and the adoption is in accordance with the child's interests.

\section{Section 804 [Recodification]}

Adoption is excluded among persons related in direct line and between siblings. This does not apply in the case of surrogate motherhood.

\section{Subdivision 2}

\section{Consent to adoption}

\section{Section 805}

A decision on adoption may not be made without the consent of the child, the child's parents or persons who are authorised to give consent on behalf of the parents and, where applicable, the adoptive parent's spouse. This also applies where the consent was withdrawn.

\section{Consent of a child to adoption}

\section{Section 806 [Recodification]}

(1) If a child being adopted has reached at least the age of twelve, his personal consent is always required, unless it is beyond any doubt that the procedure requiring the personal consent of the child being adopted is fundamentally contrary to the interests of the child or that the child is not able to consider the consequences of his consent.

(2) Before a child being adopted makes a statement, a court shall properly advise him on the purpose, content and consequences of the consent to adoption.

\section{Section 807}

(1) If a child has not yet reached the age of at least twelve, the consent to adoption is given by his guardian in his name; a court shall typically appoint a body for social and legal protection of children as the guardian. Before the guardian gives his consent, he shall ascertain all the decisive facts that will lead him to the conclusion that the adoption will be in the interests of the child.

(2) Where possible, a court shall also hear the child being adopted and take his statement into account with regard to the degree of his mental development.

\section{Section 808}

A child being adopted may withdraw his consent to adoption up until the decision on adoption.

\section{Consent of parents}

Section 809

Adoption requires the consent of the parents of the child being adopted.

\section{Section 810}

(1) The consent of a parent is given through a personal statement addressed to a court. The statement must comply with the general requirements for juridical acts; however, if the consent is subject to a condition or if it is temporary, it is disregarded.

(2) Before a parent makes a statement, a court shall duly advise him on the nature and consequences of the statement of consent and the nature of adoption.

\section{Section 811}

(1) The consent of a parent to the adoption of his child is required even where the parent has not yet acquired full legal capacity. A parent who has not yet reached the age of sixteen may not give consent to adoption. 
(2) If the consent is given by a parent who has not yet acquired full legal capacity, his guardian may not act on his behalf; his capacity to give consent is assessed by a court according to general provisions.

\section{Section 812}

A parent whose legal capacity has been limited by a court decision may, in the matters of adoption, including the consent to adoption, make juridical acts only to the extent to which his legal capacity has not been limited.

\section{Section 813}

(1) The mother of a child being adopted may give consent to the adoption no earlier than six weeks after the child's birth. The father of a child being adopted may give consent to the adoption even before the expiry of the above period, but no earlier than after birth.

(2) If the consent of the father or mother was given before that, it is disregarded.

\section{Section 814}

It is irrelevant whether or not the consent to adoption was given for a specifically designated adoptive parent.

\section{Section 815}

If consent to adoption was given for a specifically designated adoptive parent and the application to adopt is withdrawn or dismissed, the consent shall cease to be effective.

\section{Section 816}

Consent to adoption shall always cease to be effective if the adoption does not take place within six years from the date on which the consent was given.

\section{Section 817}

(1) Consent to adoption may be withdrawn within three months from the date on which it was given.

(2) Consent to adoption may be withdrawn even after three months from the date on which it was given:

a) if the child being adopted has not yet been handed over to the care of the adoptive parent before the adoption,

b) if, according to the court decision made on the application of the parents, the child being adopted is to be handed over by the person to whose care he was entrusted because it is in the interest of the child to be with his parents.

(3) Withdrawal of consent is governed, by analogy, by the provisions on the manner in which consent to adoption is given, with respect to whom it is given and with what effects.

\section{Section 818}

(1) Consent to adoption of the parent of a child being adopted is not required if:

a) he has been relieved of his parental responsibility and the right to consent to adoption,

b)he is not able to express his will and recognise the consequences of his acts or to control them, or

c) his whereabouts are unknown and a court, in cooperation with other public bodies, is unable to determine his whereabouts even by exercising the necessary care.

(2) If these facts apply to both parents, consent of a tutor or a guardian appointed by a court for that purpose is required; this also applies where both parents have died or the parental relationship to the child being adopted has not been determined. Before granting or refusing the consent, it is necessary to ascertain all the decisive facts relating to the child being adopted and his family which could affect the decision on adoption; in particular, it must be ascertained whether the child being adopted has close relatives and whether they are interested in caring for the child; the person in whose care the child being adopted is currently placed shall also be heard.

\section{Section 819}

(1) Furthermore, consent of a parent who evidently lacks interest in the child is not required for adoption.

(2) A parent evidently lacks interest in his child if he fails to consistently display genuine interest in the child, thereby permanently culpably breaching his parental duties.

\section{Section 820}

(1) A parent's lack of interest in his child is presumed to be evident, if it lasts at least three months from the last display of genuine interest. However, if a parent's conduct cannot be considered to constitute material breach of his duties, he must be advised by a body for social and legal protection of children of the possible consequences of his conduct, and at least three months must pass from such advice. The body for social and legal protection of children must, no later than after such advice, provide the parent with counselling and assistance under the conditions provided by another legal regulation. 
(2) Advice under Subsection (1) is not required if a parent has left the place where he formerly stayed without disclosing his current whereabouts and if the parent's whereabouts are not determined within three months.

\section{Section 821}

(1) A court decides in special proceedings whether or not the consent of a parent is required for an adoption

(2) If a court decides that consent of neither of the parents is required for adoption, consent of the guardian appointed by a court for that purpose is required for the adoption. Before a guardian gives his consent, he shall obtain all the decisive facts relating to the child being adopted and his family, which could affect the decision on adoption; he shall in particular ascertain if the child being adopted has any close relatives who are interested in caring for him, and hear the person in whose care the child being adopted is placed.

\section{Section 822 [Recodification]}

(1) Even where consent of a parent is not required for adoption, adoption may not be granted if there is a close relative of the child who is willing and able to care for the child and applies to a court accordingly.

(2) A court shall entrust the child to the care of its close relative if it is in the interests of the child and if it is evident that this person is able to care for the child.

\section{Subdivision 3}

\section{Care before adoption}

\section{Section 823}

(1) With the consent of the prospective adoptive parent, a child being adopted may be handed over into the care of the prospective adoptive parent immediately after both parents have given their consent to the adoption. Subject to the consent of parents, a child may also be handed over to the care of a prospective adoptive parent earlier, as soon as allowed by the child's health condition. The parents of a child being adopted are required to inform the body for social and legal protection of children that they have handed over the child.

(2) The care of a child within three months from the date on which consent to adoption was given does not constitute care before adoption. During this period, the person in whose care the child was placed shall only have the right and duty to duly care for the child and protect him; the person may act in the matters of a child related to such care only if it is absolutely necessary.

\section{Section 824}

(1) A court shall decide on the handover of a child into care pursuant to Section 823.

(2) If a court presumes that there are circumstances under which the consent of a parent is not required for adoption, it may apply Section 823(1) by analogy.

\section{Section 825}

After three months from the date on which consent to adoption was given, the exercise of rights and duties stemming from parental responsibility is suspended; a court shall appoint the body for social and legal protection of children to be the tutor to the child being adopted, unless a tutor has already been appointed earlier. The provision of Section 929 apply by analogy.

\section{Section 826}

After three months from the date on which the consent to adoption was given, the child being adopted may be handed over to the care of the adoptive parent before adoption. A court shall decide on such a handover on the application of the adoptive parent.

\section{Section 827}

(1) A court shall decide on handing over the child to the care of the adoptive parent before adoption only after it has undertaken an inquiry to determine whether the child and the adoptive parent are mutually suitable, especially with regard to:

a) the personality and health condition of the adoptive parent and his social environment, in particular housing and household, as well as the adoptive parent's ability to care for the child and his motives for adoption,

b) the personality rights and health condition of the child, social environment the child comes from, as well as the rights regarding his personal status,

c) ethnic, religious and cultural environment of the child and the adoptive parent,

d) the period for which the child was in the care of the adoptive parent.

(2) If one of the spouses wishes to adopt a child, a court shall ascertain the reason why the other spouse has not joined the application. 
If a child being adopted has previously been handed over to the care of an adoptive parent, his further care is considered to be care before adoption. Care before adoption is not subject to a further decision of a public body.

\section{Section 829 [Recodification]}

(1) Before a decision on adoption is made, a child being adopted must be in the care of the adoptive parent at his expense. An adoptive parent has the rights and duties of a person to whose care a child has been entrusted under Sections 953 to 957.

(2) An adoptive parent's care of a child being adopted before adoption lasts for a period sufficient for a convincing conclusion that the adoptive parent and the child have developed a relationship fulfilling the purpose and aim of adoption; this care shall end no earlier than after six months.

(3) Another person's duty to maintain and support the child is suspended for the period during which a child is in the care of an adoptive parent.

\section{Section 830}

(1) If a man who claims to be the father of a child being adopted files an application for determination of paternity, a court may not decide on adoption until the application for the determination of paternity has been decided.

(2) If a child being adopted has been handed over to the care of a prospective adoptive parent under Section 823 and the three-month time limit in which consent to adoption may be withdrawn has expired before the application under Subsection (1) was submitted, Section 817 applies by analogy.

\section{Section 831}

Where a person who claims to be a close relative of a child being adopted files an application for having a child entrusted to the care pursuant to Section 953, a court may not decide on adoption until a decision on this application has been made.

\section{Subdivision 4}

\section{Consequences of adoption}

\section{Section 832}

(1) A child who has been jointly adopted by spouses or a spouse of his parent has the status of a common child of the spouses; otherwise, he has the status of an adoptive parent's child.

(2) Adoptive parents have parental responsibility.

\section{Section 833}

(1) Upon adoption, the family relationship between the adopted child and the original family as well as the rights and duties arising from that relationship are extinguished. Rights and duties of a guardian or a tutor who has been appointed to perform the rights and duties on behalf of the parents are also extinguished.

(2) If an adoptive parent is a spouse of one of the adopted child's parents, the adoption shall not affect the family relationship between the adopted child and that parent and his relatives, or the rights and duties arising from that relationship.

\section{Section 834}

If a child who is a parent has been adopted, the effects of adoption shall also apply to his child.

\section{Section 835}

(1) An adopted child has the surname of the adoptive parent; a common adopted child of spouses has the surname which was determined for their children when entering into marriage.

(2) If an adopted child who has the right to express his opinion about his surname disagrees with the change of his surname, a court shall decide that the adopted child will add the adoptive parent's surname to his own surname. If an adopted child has a second surname, the adoptive parent's surname may only be added to the first surname of the adopted child; if the adoptive parent has a second surname, only the first surname of the adoptive parent may be added to the surname of the adopted child.

Section 836

An adoptive parent is required to inform the adopted child of the adoption as soon as it seems appropriate, but no later than by the start of school attendance.

Section 837 [Recodification]

\section{Secrecy of adoption}


(1) An adoptive parent or adopted child may apply to the court for a decision that adoption and its circumstances be kept secret from the original family of the child. This applies, by analogy, to the secrecy of a blood parent and his consent to adoption.

(2) Even where adoption and its circumstances or a blood parent and his consent to adoption were kept secret, a court may decide on its disclosure if justified by a very serious situation threatening the life or health of the adopted child.

\section{Section 838}

Once an adopted child acquires legal capacity, he becomes entitled to become familiar with the contents of the file on his adoption proceedings.

\section{Section 839}

\section{Supervision of success in adoption}

(1) Regardless of whether or not supervision over success in adoption has been ordered, typically the body for social and legal protection of children shall provide the adoptive parents with counselling and services related to the care for the adopted child.

(2) If justified by the circumstances of the case, a court shall, even of its own motion, order supervision over the adoptive parent and adopted child for a necessary period, while also determining the length of that period; supervision is typically exercised through the body for social and legal protection of children.

\section{Cancellation of adoption}

Section 840

(1) If justified by important reasons, a court shall, on the application of an adoptive parent or adopted child, cancel the adoption; if the application is filed by only one of them, the other may join the application.

(2) Adoption may not be cancelled after three years from the decision on adoption. This does not apply if the adoption is contrary to a statute.

\section{Section 841}

(1) By cancelling adoption, the relationship created by adoption as well as the rights and duties arising from this relationship are extinguished and the previous family relationship is restored.

(2) Property rights and property duties of an adopted child created before the adoption was cancelled remain unaffected by cancelling the adoption.

\section{Section 842}

After adoption has been cancelled, the adopted child will have the surname which he had before the adoption, unless he declares that he will retain the existing surname.

\section{Section 843}

\section{Re-adoption of an adopted child}

An adopted child may be re-adopted, only if:

a) an earlier adoption has been cancelled,

b) he is to be adopted by a subsequent spouse of the adoptive parent after the previous spouse who was a joint adoptive parent died, or

c) the person who was the only adoptive parent or the persons who were joint adoptive parents died.

\section{Section 844}

If it is in the best interests of the child, a court may, on the application of an adoptive parent, decide that adoption may not be cancelled, even before the expiry of the three-year period from the decision on adoption.

\section{Section 845}

Adoption which may not be cancelled does not prevent the adopted child from being re-adopted.

\section{Subdivision 5}

\section{Adoption of an adult}

Section 846 [Recodification] 
An adult may be adopted unless it is contrary to good morals.

Section 847 [Recodification]

\section{Adoption analogous to adoption of a minor}

(1) An adult may be adopted if:

a) a blood sibling of the child being adopted has been adopted by the same adoptive parent,

b) at the time the application for adoption was filed, the child being adopted was a minor,

c) the adoptive parent cared for the child being adopted as his own already when he was a minor or

d) the adoptive parent wishes to adopt a child of his spouse.

(2) An adult may not be adopted if it is contrary to a legitimate interest of his blood parents.

(3) The provisions on the adoption of a minor, including the provisions on the consequences of adoption, apply by analogy except for Sections 838 and 839 .

\section{Adoption not analogous to the adoption of a minor}

\section{Section 848 [Recodification]}

(1) Unless to the detriment of the best interests of the descendants of the adoptive parent or the child being adopted, an adult may also be adopted in exceptional cases for reasons deserving special consideration, if it is mutually beneficial for the adoptive parent and the adopted child, or, in justified cases, for at least one of them. modifications.

(2) The provisions on the adoption of a minor, including the provisions on its consequences, apply with the necessary

\section{Section 849 [Recodification]}

(1) No family relationship is created between an adopted child and his descendants, and the members of the adoptive parent's family, and the adopted child and his descendants shall not acquire any property rights in relation to the members of the adoptive parent's family. By adoption, an adoptive parent does not acquire any property rights with respect to the adopted child and his descendants.

(2) By adoption, the adopted child and his descendants do not lose the rights in their own family.

\section{Common provisions for adoption of an adult}

\section{Section 850 [Recodification]}

(1) If a child being adopted lacks full legal capacity, his legal representative or a guardian appointed for that purpose by a court shall act on his behalf.

(2) During a marriage of a child being adopted, such a child may only be adopted with the consent of his spouse. If the spouse cannot give his consent because he lacks full legal capacity or if obtaining his consent is associated with an obstacle too difficult to overcome, a court shall separately assess whether the adoption is not contrary to the legitimate interests of that spouse or other family members.

\section{Section 851 [Recodification]}

(1) Adoption of an adult does not affect his surname.

(2) Subject to the consent of the adoptive parent, an adopted child may add the adoptive parent's surname to his own surname; during a marriage of the adoptive parent where the spouses have a common surname, the consent of the other spouse is required.

(3) During a marriage of the adopted child where the spouses have a common surname, the adopted child may add the adoptive parent's surname to his own surname only with the consent of his spouse.

\section{Section 852 [Recodification]}

Adoption gives rise to legal consequences for the adopted child and his descendants if they were born after the adoption. Adoption gives rise to legal consequences for the adopted child's descendants born before the adoption only where they gave their consent to adoption.

\section{Section 853 [Recodification]}

(1) Duty to maintain and support owed by an adopted child against his ancestors or descendants continues only if and to the extent that there are no other persons owing the duty, or such persons are unable to fulfil such duty. An adopted child has the right to maintenance and support from his ancestors and descendants only where and only to the extent that the adoptive parent is unable to fulfil his duty to maintain and support. 
(2) An adopted child inherits from his adoptive parent in the first statutory class of heirs, but is not involved in the adoptive parent's succession rights towards other persons. by analogy.

(3) If adoption also has legal consequences for the descendants of the adopted child, Subsections (1) and (2) apply Section 854 [Recodification] of an adult.

Adoption of a minor who has been granted legal capacity is governed, by analogy, by the provisions on the adoption

\section{Division 3}

\section{Parents and children}

\section{Subdivision 1}

\section{General provisions}

\section{Section 855}

(1) Parents and their child have rights and duties towards each other. They may not waive these mutual rights and duties; if they do so, it is disregarded.

(2) The rights and duties towards a child aim to provide moral and material welfare of the child.

\section{Section 856}

Rights and duties of parents associated with the personality rights of the child and rights and duties of a personal nature are created upon the child's birth and are extinguished when the child reaches the age of majority.

\section{Section 857 [Recodification]}

(1) A child is required to heed his parents.

(2) Until a child acquires legal capacity, his parents have the right to direct their child's behaviour using methods of upbringing, as appropriate to the developing abilities, including limitations in order to protect the morals, health and rights of the child as well as the rights of other persons and public order. The child is obliged to conform to those methods.

\section{Section 858}

Parental responsibility includes rights and duties of parents consisting in caring for the child, including, without limitation, care for his health, his physical, emotional, intellectual and moral development, the protection of the child, maintaining personal contact with the child, ensuring his upbringing and education, determining the place of his residence, representing him and administering his assets and liabilities; it is created upon the child's birth and extinguished upon the child acquiring full legal capacity. The duration and extent of parental responsibility may only be changed by a court.

\section{Section 859}

The duty to maintain and support and the right to maintenance and support are not part of parental responsibility; their duration does not depend on reaching the age of majority or legal capacity.

\section{Subdivision 2}

\section{Given name and surname of a child}

Section 860

(1) A child has the surname determined upon entry into marriage for the common children of the spouses.

(2) If the child lacks the surname under Subsection (1), his parents shall choose the surname of one of them for him; otherwise, his surname will be determined by a court. The same applies to the child's given name.

\section{Section 861}

If only one of the parents is known, the child has his surname. That parent shall also determine the child's given name; otherwise, it is determined by a court.

\section{Section 862}

(1) In the case of a child whose parents are not spouses, the parents shall choose the surname of one of them for the child; otherwise, his surname is determined by a court.

(2) If the mother of a child whose father is unknown enters into marriage, the child's mother and her husband may 
both declare before a registry of births, deaths and marriages that the surname designated for their other children will also be bestowed upon this child.

\section{Section 863}

(1) To change the surname of a child under Section 862 , the child must provide a statement under the same conditions as in other matters relating to the child; if the child is older than fifteen years of age, he must give his consent to have his surname changed.

(2) The provisions of Section 862 may not be used if the child has reached the age of majority.

\section{Section 864}

child.

If none of the parents is known, a court shall, even of its own motion, determine the given name and surname of the

\section{Subdivision 3}

\section{Parental responsibility}

\section{Section 865 [Recodification]} relieved of it.

(1) Both parents have parental responsibility equally. Every parent has parental responsibility, unless he has been

(2) If a court decides on limiting a parent's legal capacity, it shall also decide on his parental responsibility.

\section{Section 866 [Recodification]}

The interests of the child are decisive for the court's decision concerning the extent of parental responsibility or the manner or extent in which it is to be exercised by the parents.

\section{Section 867}

(1) Before making a decision that affects the interests of a child, a court shall provide the child with the necessary information in order for him to form his own opinion and communicate it.

(2) If a court finds that a child is unable to properly receive the information or form his own opinion or communicate it, the court shall inform and hear a person who is able to protect the interests of the child; the person's interests must not be in conflict with the interests of the child; a child over twelve years of age is presumed to be able to receive the information, make his own opinion and communicate it. The court pays due attention to the opinion of the child.

\section{Section 868}

(1) The exercise of parental responsibility of a minor parent who has not previously acquired full legal capacity by having been granted legal capacity or having entered into marriage is suspended until such time as the minor parent acquires full legal capacity; this does not apply to the exercise of right and duty to care for the child, unless a court, having regard to the personality of the parent, decides that the exercise of this right and duty is also suspended until such time as the parent acquires full legal capacity.

(2) The exercise of parental responsibility of a parent whose legal capacity has been limited in this area is suspended for the duration of such limitation, unless a court decides that the exercise of the parent's rights and duties relating to the care for the child and personal contact with the child is to be retained with regard to his personality.

\section{Section 869}

(1) If a parent is prevented from exercising his parental responsibility by a serious circumstance and there are reasons to believe that it is necessary in the best interests of the child, a court may decide that the exercise of parental responsibility of the parent be suspended.

(2) Suspension of the exercise of parental responsibility shall not affect the exercise of the duty to maintain and support the child.

\section{Section 870}

If a parent does not exercise his parental responsibility properly and if required by the interests of the child, a court shall limit his parental responsibility or its exercise, while determining the scope of this limitation.

\section{Section 871}

(1) If a parent abuses or seriously neglects his parental responsibility or its exercise, a court shall relieve him of his parental responsibility.

(2) If a parent has committed an intentional criminal offence against his child, or used his child who is not criminally liable for committing a criminal offence, or if the parent has committed a crime as an accomplice, instigator, aider and abettor or organiser of a criminal offence committed by his child, a court shall separately consider whether there are reasons for relieving 
the parent of his parental responsibility.

\section{Section 872}

Before a court decides on limiting parental responsibility, it shall always consider whether, given the best interests of the child, it is necessary to limit the parent's right to personal contact with the child. If a parent is relieved of his parental responsibility, he keeps the right to personal contact with the child only if the court decides to preserve such parent's right having regard to the interests of the child.

\section{Section 873}

If a court relieved a parent of his parental responsibility, it may also decide to relieve him of all or some of the rights and duties provided under Section 856 , in particular the right to consent to an adoption.

\section{Section 874}

Relieving a parent of his parental responsibility or the limitation thereof does not affect the parent's duty to maintain and support the child.

\section{Special provisions concerning the exercise of parental responsibility}

\section{Section 875}

(1) Parents exercise parental responsibility in the best interests of the child.

(2) Before making a decision that affects the interests of the child, parents shall inform the child of everything that is necessary for the child to form his own opinion on a given matter and communicate it to the parents; this does not apply if the child is unable to properly receive the message, or form his own opinion or communicate it to his parents. Parents shall pay due attention to the child's opinion and take the child's opinion into account when making a decision.

\section{Section 876}

(1) Parents exercise parental responsibility in mutual accord.

(2) If there is a danger in delay when deciding on the matters of a child, one of the parents may make the decision or give permission himself, but is obliged to immediately inform the other parent of the state of affairs.

(3) If one of the parents himself performs acts in a matter of the child with respect to a third person who acts in good faith, he is presumed to be acting with the consent of the other parent.

\section{Section 877}

(1) If parents fail to agree on a matter which is relevant for the child in particular with regard to his interests, the decision is made by a court on the application of one of the parents; this applies even where one parent excluded the other parent from making decisions on a relevant matter of the child.

(2) Especially medical and similar procedures other than those which are common, the determination of the place of residence and the choice of education or profession of a child are considered to constitute relevant matters.

\section{Section 878}

(1) If one of the parents is no longer alive or if he is unknown, if one of the parents lacks parental responsibility or if the exercise of his parental responsibility has been suspended, the parental responsibility is exercised by the other parent; this also applies where parental responsibility of one of the parents or the exercise thereof has been limited.

(2) If both parents lack full parental responsibility or if the exercise of parental responsibility of both parents has been suspended, or if the parental responsibility of parents has been affected in any of these manners, but each of the parents has been affected differently, a court shall appoint the child's tutor, who has the parents' rights and duties or is entitled to their exercise in place of the parents.

(3) If the parents' parental responsibility or its exercise has been limited, a court shall appoint a guardian for the child.

\section{Section 879}

(1) When making juridical acts towards a child who lacks the capacity to independently make juridical acts in a given matter, it shall suffice to make acts towards one of the parents as the child's representative.

(2) If it is of legal significance whether or not a child who lacks the capacity to independently make juridical acts in a given matter acts in good faith, the good faith of both parents needs to be considered; however, if a child is in the care of only one parent, good faith of only that parent is considered.

(3) If it is of legal significance whether or not a child who lacks the capacity to independently make juridical acts in a given matter knew or should have known of a matter or fact, both parents' knowledge of the matter or fact need to be considered; however, if a child is placed in the care of only one parent, only that parent's knowledge of the matter or fact is considered. 


\section{Child care and protection}

Section 880

(1) Parents exercise their parental responsibility towards a child in a manner and to the extent appropriate to the degree of the child's development.

(2) Where the parents decide about the education or employment of the child, they shall take into account his opinions, abilities and talents.

\section{Section 881}

Parents may entrust another person with the care for and protection of the child, his upbringing or some of its aspects, and his supervision; an agreement between the parents and such a person may but does not have to affect the duration or extent of parental responsibility.

\section{Section 882}

(1) If another person unlawfully detains a child, the parents have the right to request that their child be handed over by such a person; the same applies between the parents. A person who lawfully cares for the child has the same right. lawfully is.

(2) A person who unlawfully detains a child is obliged to duly hand the child over to the person in whose care the child

\section{Section 883}

Parents and child are obliged to help and support each other and respect each other's dignity.

\section{Section 884}

(1) Parents play a crucial role in child care. Parents are to be their children's all-round role models, especially with respect to the way of life and behaviour in the family.

(2) Means of upbringing may only be used in the form and to the extent which are appropriate to the circumstances, do not endanger the child's health or development and do not affect the dignity of the child.

\section{Section 885}

Where only one of parents cares for a child, the parent's spouse or partner is involved in the care for and upbringing of the child if he lives in the family household with the child. This also applies to a person who lives with the child's parent without having entered into marriage or registered partnership with him, provided that the person lives in the family household with the child.

\section{Section 886}

(1) If a child lives with his parents or with one of them in the family household and if he is properly cared for, the child shall also participate in the care of the household. This duty of the child is extinguished at the same time as the parent's provision of maintenance to the child.

(2) The child is involved in the care of the family household by contributing his own work, or money if he has his own income, or both. The abilities and potential of a child as well as justified needs of family members are decisive in determining the share of the child in the care of the family household.

\section{Right to personal contact between a parent and his child}

\section{Section 887}

The exercise of parent's right to personal contact with his child may not be entrusted to another person.

\section{Section 888}

A child who is in the care of only one of the parents has the right to have contact with the other parent to the extent in which it is in the interests of the child, and that parent has the right to have contact with the child, unless such contact is limited or prohibited by a court; a court may also specify conditions of the contact, especially where it is to take place, as well as to identify persons who may or may not participate in the contact. A parent who has the care of the child is obliged to prepare the child for the contact with the other parent, duly facilitate the child's contact with the other parent and cooperate with the other parent in the exercise of his rights to contact to the necessary extent.

\section{Section 889}

A parent who has the care of the child and the other parent must refrain from doing anything that would interfere with the child's relationship with both parents or that would make the child's upbringing more difficult. If a parent having the care of the child permanently or repeatedly prevents the other parent from having contact with the child for no reason, such behaviour constitutes grounds for a new court decision on which of the parents should have care of the child. 
Parents are required to inform each other of all important facts relating to the child and his interests.

\section{Section 891}

(1) A parent having care of a child and the other parent shall agree on the manner in which the parent not having care of the child will have contact with the child. If parents fail to agree or if required by the interest of the child's upbringing and the situation in the family, a court shall regulate the parent's contact with the child. In justified cases, a court may determine the place of a parent's contact with the child.

(2) If necessary in the best interests of a child, a court shall limit the right of a parent to have personal contact with the child, or even prohibit such contact.

\section{Representation of a child}

\section{Section 892 [Recodification]}

(1) Parents have the right and duty to represent the child in juridical acts for which the child lacks legal capacity.

(2) Parents represent the child jointly; however, any of them may perform acts; Section 876(3) applies by analogy.

(3) A parent may not represent a child in case of a possible conflict of interest between him and the child, or between the children of the same parents. In such a case, a court shall appoint a guardian for the child.

\section{Section 893}

If parents fail to agree which of them will represent the child in juridical acts, a court shall, on the application of a parent, decide which of the parents will make juridical acts on behalf of the child and how.

\section{Section 894}

(1) Parents, as legal representatives, may, in order to handle matters of a child other than matters of personal status, conclude a contract for representation with a person with expertise or another suitable person.

parents.

(2) If a child enters into a contract for representation, it shall not affect the legal representation of the child by his of the child.

(3) If the legal and contractual representatives fail to agree, a court shall decide in accordance with the best interests

\section{Section 895 [Recodification]}

If paternity has been denied, juridical acts made by the father as the legal representative remain unaffected.

\section{Care for the child's assets and liabilities}

\section{Section 896}

(1) Parents have the right and duty to care for the child's assets and liabilities, in particular to administer them with due managerial care. Funds which can be assumed not to be needed to cover the expenses related to the property of a child must be safely disposed of.

(2) In juridical acts that relate to an individual part of the child's assets and liabilities, parents act in the capacity of his representatives; Section 892(3) applies by analogy.

(3) If parents breach their duty to care for a child's assets and liabilities with due managerial care, they shall compensate the child for the resulting damage jointly and severally.

\section{Section 897}

If parents do not agree on substantial matters concerning the care of a child's assets and liabilities, a court shall decide on the application of a parent.

\section{Section 898}

(1) Parents need court approval for juridical acts concerning existing and future assets and liabilities of a child or the individual parts thereof, unless they are routine matters, or exceptional matters concerning a negligible property value.

(2) Court approval is especially required for juridical acts whereby the child:

a) acquires an immovable thing or part thereof and whereby he disposes of it,

b) encumbers property as a whole or its part which is not insignificant

c) acquires a gift, inheritance or legacy of property value which is not negligible, or refuses such a gift, inheritance or legacy, or provides such a gift or gift representing a part of his property which is not negligible, or 
d) concludes a contract which imposes an obligation to provide a long-term performance, a credit or similar contract, or a contract relating to housing, especially to lease.

(3) A juridical act of a parent made without the required court approval is disregarded.

$$
\text { Section } 899
$$

Everything which parents obtain by using the child's property is acquired by the child.

\section{Section 900}

(1) Parents shall use any income from the child's property which they will not use for the proper administration of his property (profit) primarily for the child's maintenance. If necessary, parents may then use the remaining profit from the child's property as his contribution to the actual maintenance of the parents and a minor sibling of the child if they and the child live in a family household, unless there are important reasons for which it is necessary to keep it for the child for the time after he acquires legal capacity.

(2) Subject to court approval, parents may only use a child's property to maintain themselves and the child's sibling if a significant disproportion between the situation of the child and that of the persons having the duty to maintain and support the child would occur without the obligor being at fault.

\section{Section 901}

(1) The right and duty of a parent to care for the child's assets and liabilities is extinguished upon the declaration of insolvency with respect to the parent's property. In the absence of the other parent who could care for the child's assets and liabilities, a court shall, even of its own motion, appoint a guardian for the administration of the child's assets and liabilities.

(2) Three years after the cancellation of bankruptcy, a court may, on the application of a parent or guardian responsible for the administration of the child's assets and liabilities, cancel the limitation of parental responsibility, unless the restoration of the right and duty of a parent to care for the child's assets and liabilities is contrary to the interests of the child.

Section 902

(1) Once a child acquires full legal capacity, his parents shall deliver to him the assets and liabilities which they administered, in particular they shall hand over to him the parts of his property or, where applicable, transfer to him the administration thereof, and provide the child with an account of the administration of assets and liabilities without undue delay, but no later than within six months from the date on which the child acquired full legal capacity. The account is not necessary if not required by the child.

(2) Where the parents incurred any costs in or in connection with the administration of the child's assets and liabilities, they may request reimbursement.

\section{Section 903}

(1) If the administration of assets and liabilities was very difficult, especially due to the vastness or diversity of the property set, and the parents administered the assets and liabilities with due care, they may, after delivering the administered assets and liabilities to the child, request a reasonable remuneration if possible given the yield from the assets and liabilities.

(2) If, during administration of assets and liabilities, it is evident from the circumstances that the administration is very difficult and the parents exercise it with due care, a court shall, on the application, grant to them an appropriate remuneration for the administration of assets and liabilities, payable annually or at other intervals.

\section{Section 904}

The handover and takeover of assets and liabilities shall not affect the liability of the parents for the administration of the child's assets and liabilities.

\section{Section 905}

(1) A court shall, even of its own motion, appoint a guardian for the administration of the child's assets and liabilities where the child's interests may be endangered, especially in the case of common property rights of the parents and the child, or of the child and his sibling. Parents are limited in exercising their rights and duties in relation to the child's assets and liabilities by the extent of the rights and duties of a guardian for administration of the child's assets and liabilities.

(2) The rights and duties of a guardian for administration of the child's assets and liabilities who has been appointed alongside the parents are governed, by analogy, by the provisions on tutors administering the assets and liabilities of a person under tutorship, or guardians administering the assets and liabilities of a ward.

\section{Exercise of parental responsibility after divorce}

\section{Section 906}

(1) If a decision on the divorce of a child's parents is to be made, a court shall first determine how each of the parents will care for the child in future, taking into account the interests of the child; with such regard, the court shall diverge from the affirmative statement of the parents only if required by the child's interests. The court shall take into account not only the child's 
relationship to each parent, but also his relationship to his siblings and, where applicable, also grandparents.

(2) A court may also decide to approve an agreement between the parents, unless it is evident that the agreed manner of exercising parental responsibility is not in the best interests of the child.

\section{Section 907}

(1) A court may entrust a child to the care of one of the parents or to shared or joint care; a court may also entrust a child to the care of a person other than a parent if it is necessary with regard to the interests of the child. If a child is to be entrusted to joint care, the consent of both parents is required.

(2) When deciding on entrusting the child to the care of another person, a court must decide in accordance with the interests of the child. In doing so, the court shall take into account the child's personality, especially his talents and abilities in relation to the potential to develop and to the life situation of the parents, as well as the emotional inclination and family background of the child, upbringing skills of each parent, existing and expected stability of the upbringing environment in which the child is to live in the future, emotional ties of the child to his siblings, grandparents, or other relatives and unrelated persons. A court shall always take into account which of the parents has until that point properly cared for the child and properly provided for his emotional, intellectual and moral upbringing, as well as which of the parents is better suited to provide the child with healthy and successful development.

(3) When deciding on entrusting the child to the care of another person, a court must also consider the right of the child to be cared for by both parents and to maintain regular personal contact with them, and the right of the other parent to whose care the child will not be entrusted to get regular information about the child; the court shall also take into account the ability of a parent to agree on the child's upbringing with the other parent.

\section{Section 908}

\section{Exercising rights and duties of parents who live apart}

If the parents of a minor child who lacks full legal capacity do not live together, and if they do not agree on the regulation of the care of the child, it is decided by a court, even of its own motion. In other respects, the provisions of Sections 906 and 907 apply by analogy.

\section{Section 909}

\section{Special provisions}

In case of a change in circumstances, a court shall change the decision regarding the exercise of rights and duties arising from parental responsibility, even of its own motion.

\section{Subdivision 4}

\section{Duty to maintain and support}

Section 910

(1) Ancestors and descendants have a mutual duty to maintain and support.

(2) The parents' duty to maintain and support a child is takes precedence over the grandparents' and other ancestors' duty to maintain and support a child.

(3) More distant relatives have a duty to maintain and support only if it cannot be exercised by closer relatives.

(4) Except for the relationship between the parents and their child, the descendants' duty to maintain and support takes precedence over the ancestors' duty to maintain and support.

\section{Section 911}

Maintenance and support may be granted if the obligee is not able to maintain himself.

\section{Section 912}

A minor child lacking full legal capacity has the right to maintenance and support even where he has his own property but the profit from the property together with the income from employment is not sufficient for his maintenance.

\section{Section 913}

(1) To determine the extent of maintenance and support, justified needs of the obligee and his property situation, as well as his abilities, potential and property situation of the obligor are decisive.

(2) In evaluating the abilities, potential and property situation of the obligor, it should also be considered whether the obligor has not given up, without a good cause, a more favourable employment or gainful activity, or property benefit, or whether he is not taking unreasonable property risks. Account should also be taken of the fact that the obligor personally cares for the obligee, and of the extent he does so; account shall also be taken of the care for the family household, where appropriate. 
Where there are several obligors in the same position to the obligee, the scope of the duty to maintain and support each of them is proportional to the relation between their property situation, abilities and potential and the property situation, abilities and potential of the others.

\section{Maintenance and support between parents and children, and ancestors and descendants}

\section{Section 915}

(1) In principle, the standard of living of a child is to be identical to the standard of living of his parents. This principle is superior to the principle of justified needs of the child.

(2) A child is required to ensure fair maintenance for his parents.

\section{Section 916}

If, in proceedings for the determination of a parent's duty to maintain and support his child or another ancestor's duty to maintain and support a minor child who has not yet acquired full legal capacity, a person obliged to provide maintenance and support fails to duly prove to the court his income by submitting all instruments and other materials allowing the assessment of property situation or to allow the court to ascertain other facts required for decision by making available data protected under another legal regulation, the average monthly income of such person is conclusively presumed to be twenty-five times the minimum living level for an individual under another legal regulation.

\section{Section 917}

If a court decides on a parent's duty to maintain and support a child or an ancestor's duty to maintain and support a minor child who has not yet acquired full legal capacity, and if permitted by the property situation of the person obliged to provide maintenance and support, justified needs of the child may be considered to also include the generation of savings, unless excluded by the circumstances of a special case; the maintenance and support provided passes into the ownership of the child. Administration of the amounts so provided is governed by the general rules on child's assets and liabilities.

\section{Section 918}

In proceedings on a parent's duty to maintain and support a child, a court may, in cases deserving special consideration, impose a duty upon the person obliged to provide maintenance and support to deposit an advance payment on maintenance and support due in the future; the maintenance and support provided passes into the ownership of the child gradually as of each date maintenance and support is due. The advance payment is considered to be the property of the obligor.

\section{Section 919}

If the parents of a minor child who has not yet acquired full legal capacity do not live together, if they fail to agree on fulfilling the duty to maintain and support the child, or if the parents of such a child live together, but one of them does not fulfil his duty to maintain and support the child, a court proceeds pursuant to Sections 915 to 918 . This also applies where a court decides on the care of a minor child who has not yet acquired full legal capacity if the parents fail to agree on fulfilling the duty to maintain and support the child.

\section{Section 920}

\section{Maintenance and support, and provision for the payment of certain costs for an unmarried mother}

(1) If the child's mother is not married to the child's father, the child's father shall provide her with maintenance for two years from the birth of the child and provide her with a reasonable contribution to cover the costs associated with pregnancy and childbirth. The man whose paternity is probable has the duty to reimburse the costs associated with pregnancy and childbirth even if the child is not born alive.

(2) A court may, on the application of a pregnant woman, order the man whose paternity is probable to provide an amount needed for maintenance and a contribution to cover the costs associated with pregnancy and childbirth in advance.

(3) A court may, on the application of a pregnant woman, also order the man whose paternity is probable to provide in advance an amount needed to provide for the maintenance of the child for a period for which the woman would be entitled to maternity leave as an employee under another legal regulation.

\section{Common provisions on maintenance and support}

\section{Section 921}

Maintenance and support is paid in regular instalments and is always due one month in advance, unless a court decides otherwise or the person obliged to provide maintenance and support has agreed otherwise with the obligee.

\section{Section 922}

(1) Maintenance and support may be granted only from the date the proceedings were initiated; in the case of child maintenance and support, it may also be granted for a maximum of three years prior to that date.

(2) Maintenance and support for an unmarried mother and covering the costs associated with pregnancy and 
childbirth may also be granted retrospectively, but for a maximum of two years prior to the date of childbirth.

\title{
Section 923
}

(1) If circumstances change, a court may change the agreement and the decision on maintenance and support for a minor child who has not yet acquired full legal capacity.

(2) In case maintenance and support for a past period for a minor child who has not yet acquired full legal capacity is cancelled or reduced, the maintenance and support which has been spent is not refundable. Moreover, the instalment of maintenance and support paid in favour of such a child a month in advance is not refunded if the child died before the end of the month.

\section{Division 4}

\section{Special measures in the upbringing of a child}

\section{Preventive, upbringing and punitive measures}

\section{Section 924}

If a child gets into a situation of insufficient due care, regardless of whether or not there is a person with the right to care for him, or if the child's life, normal development or other important interest is seriously threatened or if it has been disrupted, a court shall decide on a preliminary regulation of the child's situation for the necessary period; the court is not limited in making its decision by the fact that the child is not duly represented.

\section{Section 925}

(1) If required by the interest in the proper upbringing of a child, and unless done so by the body for social and legal protection of children, a court may:

a) appropriately caution the child, the parents, the person having the care of the child or the person who disrupts the due care of the child,

b) establish supervision over the child and carry it out in cooperation with the school, body for social and legal protection of children, and other institutions and individuals pursuing activities, in particular, in the place of residence or workplace of the child, or

c) impose restrictions upon the child or parents which prevent harmful effects on the child's upbringing, especially the prohibition of certain activities.

(2) A court shall monitor compliance with the methods of upbringing decided on, and evaluates their effectiveness, usually in cooperation with the body for social and legal protection of children and other persons, where applicable.

\section{Section 926}

If a court entrusts the care and protection of a child or the care of his assets and liabilities to a person other than his parent, and the parent and that person are unable to agree on the exercise of care, the decision is made by a court on the application of one of the persons involved.

\section{Division 5}

\section{Relationships between a child and other relatives and other persons}

\author{
Section 927
}

Persons having a close or distant family relationship to a child, as well as persons socially close to the child, have the right to contact with the child if the child has an emotional relationship to them which is not temporary if it is clear that the lack of contact with these persons would cause harm to the child. The child also has the right to contact with such persons if they consent to the contact.

\section{TITLE III}

\section{TUTORSHIP AND OTHER FORMS OF CHILD CARE}

\section{Chapter 1}

\section{Tutorship}

Section 928

(1) In the absence of a parent having and exercising his full parental responsibility with respect to a child, a court shall appoint a tutor to the child.

(2) In principle, a tutor has all the rights and duties towards the child as a parent except the duty to maintain and 
support. Having regard to a person acting in the capacity of a tutor to a child or the child's circumstances, as well as having regard to the reason why parents do not have all the rights and duties, the scope of rights and duties of a tutor may exceptionally be defined otherwise.

\section{Section 929}

In the case of the situation referred to in Section 928(1), tutorship is exercised by the body for social and legal protection of children as a public tutor, up until the court appoints a tutor to the child or until the tutor assumes his office.

\section{Section 930} appointed.

(1) A court shall appoint a tutor to a child immediately after it ascertains that it is a child who needs to have a tutor

(2) If a tutor dies, loses the ability or capacity to exercise tutorship or is relieved of or removed from office and another person is yet to be appointed as a tutor, Section 929 applies by analogy.

(3) A court shall, after the situation referred to in Section 928 or in Subsection (1) occurs, ascertain whether there is a suitable individual who might exercise tutorship. If the court fails to find such a person, it shall appoint the body for social and legal protection of children to act as the tutor.

\section{Section 931}

(1) Unless it is contrary to the interests of the child, a court shall appoint a person indicated by the parents to act as a tutor, unless that person refuses the tutorship. Otherwise, a court shall appoint one of the relatives or close persons of the child or his family to act as a tutor, unless a parent has expressly excluded such a person. In the absence of such a person, a court shall appoint another suitable individual to act as a tutor.

(2) A natural person appointed by a court to act as a tutor may refuse such appointment. The court shall then appoint another person.

\section{Section 932}

(1) Only a person with full legal capacity whose way of life ensures that he is able to properly discharge the office of a tutor may be appointed a tutor. Before appointing a person to act as a tutor, a court shall ascertain whether the appointment of such a person is not contrary to the interests of the child.

(2) A court may also appoint two persons to act as tutors; this typically applies to spouses.

Section 933

(1) A tutor is responsible for the proper discharge of his office and is subject to constant supervision of a court.

(2) A tutor assumes his office on the day of his appointment.

(3) Within ninety days after his appointment, a tutor shall submit to a court an inventory of the child's assets and liabilities; on the application of the tutor, the court may extend the time limit by a maximum of sixty days.

\section{Section 934}

(1) Any decision of a tutor in a matter other than an ordinary matter concerning the child must be approved by a court. A juridical act of a tutor which lacks the required court approval is disregarded.

(2) A tutor shall regularly report to the court on the child and his development and present the accounts of the administration of his assets and liabilities at least once a year, unless a shorter period of time is determined by a court. A court may release a tutor from his duty to present detailed accounts of the assets and liabilities under his administration if the yields from the property does not exceed the likely costs of maintaining the property and the upbringing and maintenance of the child.

\section{Section 935}

(1) Tutorship terminates if at least one of the parents of the person under tutorship acquires parental responsibility, or the ability to exercise it. Tutorship is also extinguished if the child acquires legal capacity, or if he is adopted.

(2) The office of a tutor is extinguished upon the death of a tutor, by a court decision relieving the tutor of or removing him from his office.

\section{Section 936}

A court shall relieve a tutor of office if the tutor so requests due to important reasons, or if the person discharging the office of a tutor loses the eligibility thereto.

\section{Section 937}

(1) A court shall remove from office a tutor who breaches his tutorship duties.

(2) A court shall consider the removal of a tutor if it finds reasons for which it is not appropriate for a tutor to continue 
to discharge his office.

\section{Section 938}

(1) After the office of a tutor expires, the person who discharged the office shall, without undue delay, but no later than within six months, hand over to the court everything he had in his possession in relation to the discharge of his office, and present the court with a final report on the discharge of the office of a tutor; it shall include a final account of the administration of the child's assets and liabilities.

(2) If a person who discharged the office of a tutor dies, his heir shall hand over to the court everything that the deceased had in his possession in relation to the discharge of his office of a tutor. In the absence of heirs, anyone who has access to the things the deceased had in his possession in relation to the discharge of his office of a tutor has this duty.

\section{Section 939}

If the person who personally cares for a child as if the child were permanently entrusted to his care is the tutor, he is entitled to material security as a foster parent.

\section{Section 940}

If a tutor cares for a child personally together with his spouse, the provisions on the relationship of a parent and his spouse to the child apply by analogy.

\section{Section 941}

(1) If a person who personally cares for a child acts as the tutor and the care for the child's property is very difficult, especially due to the vastness and diversity of the property set, the tutor may apply to the court to appoint a guardian to administer the child's property; the application shall include an inventory of the child's assets and liabilities as at the date on which the application is filed. guardian.

(2) If a court appoints a guardian under Subsection (1), it shall also define mutual rights and duties of the tutor and the

\section{Section 942}

If a guardian for the administration of assets and liabilities has not been appointed, the provisions relating to a guardian for the administration of assets and liabilities apply, by analogy, to the tutor who cares for the child's assets and liabilities, unless otherwise provided by the the provisions relating to a tutor.

\section{Chapter 2}

\section{Guardianship of a child}

\section{Division 1}

\section{Guardian}

\section{Section 943 [Recodification]}

A court shall appoint a guardian to a child, if there is a conflict of interests between the child and another person, if the legal representative fails to sufficiently defend the child's interests, if it is in the interests of the child for another reason, or where provided by a statute. An appointed guardian has the right to initiate proceedings whenever the interest of the child requires that a court or another public body decide on a matter of the child.

\section{Section 944}

The provisions on tutorship, tutors and persons under tutorship apply to guardianship, guardians and persons under guardianship with the necessary modifications.

\section{Section 945}

In its decision to appoint a guardian, a court shall specify the reason why the guardian is appointed, whether and how the term of his office is limited, what his rights and duties are in relation to other persons also, whether he needs court approval for any juridical acts, whether and how he reports to the court, and whether he is entitled to be reimbursed for all or some of the costs and to receive remuneration.

\section{Section 946}

Before a guardian makes a juridical act on behalf of the child for which he was appointed, he shall obtain the opinion of a parent or tutor, if possible, as well as the opinion of the child, and also the opinions of other persons, where appropriate.

\section{Section 947}

A guardian who has not been appointed to only make specific juridical acts is relieved of office by a court even where 
the need which led to his appointment no longer exists.

\title{
Division 2
}

\section{Guardian for the administration of the child's assets and liabilities}

\section{Section 948 [Recodification]}

In its decision to appoint a guardian for the administration of assets and liabilities, a court shall specify the scope of assets and liabilities to be administered by the guardian; it also typically determines the manner in which the guardian is to dispose of the individual parts of the assets and liabilities, or the manner of disposal which is prohibited.

\section{Section 949 [Recodification]}

A guardian for the administration of assets and liabilities discharges his office with due managerial care and must not take undue risks.

\section{Section 950}

(1) A guardian for the administration of assets and liabilities is responsible for the proper discharge of his office to a court and is subject to its constant supervision.

(2) The provisions on how parents administer the child's assets and liabilities apply, by analogy, to juridical acts of a guardian for the administration of assets and liabilities; if it considers it necessary, a court determine the juridical acts of a guardian for the administration of assets and liabilities which must be approved by the court

(3) A guardian for the administration of assets and liabilities shall present the court with regular reports on and accounts of the administration of the assets and liabilities, always for the period determined by court; this period may not be longer than one year.

\section{Section 951}

(1) A guardian for the administration of assets and liabilities has the right to deduct necessary costs related to administration of the child's assets and liabilities from the yield from the child's assets and liabilities. If the yield is insufficient, a court may decide that the costs will be paid from the property.

(2) A guardian for the administration of assets and liabilities has the right to reasonable remuneration from the yield from the child's assets and liabilities; Subsection (1) applies by analogy. The amount of the remuneration and the period for which it is to be granted to the guardian for the administration of assets and liabilities is determined by a court with regard to the nature of the yield from the child's assets and liabilities. Section 903(2) applies by analogy.

\section{Section 952}

If the guardianship for the administration of assets and liabilities is extinguished, the duties of the person who performed the office of a guardian are governed by analogy by the provision of Section 938(1). If a guardian dies, Section 938(2) applies by analogy.

\section{Chapter 3}

\section{Entrusting a child to the care of another person and foster care}

\section{Division 1}

\section{Entrusting a child to the care of another person}

\author{
Section 953
}

(1) If neither of the parents or a tutor can personally care for the child, a court may entrust the child to the care of another person (hereinafter a "caring person"). The decision to entrust a child to the care must be in accordance with the interests of the child.

(2) Entrusting a child to the care of the caring person does not substitute foster care, pre-foster care or care that must precede adoption. It takes precedence over institutional care for a child.

\section{Section 954 [Recodification]}

(1) The caring person must qualify as a person who can guarantee due care, have residence in the Czech Republic and consent to being entrusted with the care for the child.

(2) Where the care for a child has been assumed by a related or close person of the child, a court shall prefer such a person to another person, unless it is contrary to the best interests of the child.

\section{Section 955}

The rights and duties of a caring person are determined by a court; otherwise, the provisions on foster care apply with 
the necessary modifications.

\section{Section 956}

(1) A court shall order the parents to pay maintenance and support within the scope determined having regard to their potential, abilities and property situation, and impose upon them the duty to pay maintenance and support into the hands of the caring person.

(2) The caring person has the right to claim the maintenance and support ordered to be paid by the parents in favour of the child in his care, as well as the right to manage the child's maintenance and support in the child's interests, according to the child's needs and in accordance with his interests. A court may regulate the manner in which the child's maintenance and support is managed, especially to determine the part intended for consumption and the part to be used as the child's savings.

\section{Section 957}

If it is impossible to impose the duty to maintain and support the child upon parents or other relatives, the provisions of Sections 953 to 956 do not apply.

\section{Division 2}

\section{Foster care}

Section 958

(1) If none of the parents or a tutor can personally care for the child, a court may entrust the child to the care of a foster parent.

(2) Foster care takes precedence over institutional care for a child.

(3) A court may also place a child in foster care temporarily. Details are provided by another statute.

\section{Section 959} for the child.

(1) A court may decide on foster care for the duration of an impediment preventing the parents from personally caring

(2) A parent may request that the child be entrusted back to his personal care. A court shall grant the application if it is in the interests of the child.

\section{Section 960}

(1) Parents have rights and duties with respect to the child arising out of parental responsibility, except for the rights and duties imposed by a statute upon a foster parent, unless a court decides otherwise for reasons deserving special consideration.

(2) Parents have the right to personal and regular contact with the child as well as the right to information about the child, unless a court decides otherwise for reasons deserving special consideration.

\section{Section 96}

(1) Entrusting a child into foster care does not affect the continuation of the parents' duty to maintain and support the child. A court shall order the parents to pay maintenance and support in the scope determined with regard to their potential, abilities and property situation and the justified needs of the child.

(2) If another statute entitles the child to an allowance to cover his needs, the right of the child passes to the State. If the maintenance and support is higher than the allowance, the difference belongs to the child. A court shall decide on the method of payment and the management of the maintenance and support.

\section{Section 962 [Recodification]}

(1) A person who is to become a foster parent must qualify as a person who can guarantee due care, have residence in the Czech Republic and consent to being entrusted with foster care for the child.

(2) Where the care for a child has been assumed by a relative or close person of the child, a court shall prefer such a person to another person, unless it is contrary to the best interests of the child.

\section{Section 963}

A court may entrust the persons interested in foster care with pre-foster care for a child; its duration is determined having regard to the circumstances of the case. The court shall supervise over the course and success of pre-foster care.

Section 964

(1) A child may be entrusted to joint foster care of joint foster parents if they are married. 
(2) A court deciding on the divorce of joint foster parents shall not divorce this marriage until the rights and duties of the foster parents after the divorce are regulated. Joint foster care terminates upon the divorce of the spouses.

(3) If one of joint foster parents dies, the child remains in the foster care of the surviving spouse.

\section{Section 965}

(1) With the consent of the other spouse, a child may be entrusted to foster care of only one of the spouses.

(2) A child may be placed in foster care even without the consent of the other spouse if the other spouse lacks full legal capacity or if obtaining his consent is associated with an obstacle too difficult to overcome. family household.

(3) The spouse of a foster parent is also involved in the personal care for a child placed in foster care, if he lives in the

\section{Section 966}

(1) A foster parent is obliged and entitled to personally care for the child.

(2) A foster parent shall reasonably perform the rights and duties of parents in the upbringing of the child. He is obliged and entitled to decide only on common matters of the child, represent the child in these matters and administer his assets and liabilities. He has the duty to inform the child's parents about substantial matter relating to the child. If required by the circumstances, court shall determine additional rights and duties of a foster parent.

(3) Subsections (1) and (2) apply by analogy to a person interested in foster care who has been entrusted with prefoster care for a child.

\section{Section 967 [Recodification]}

A foster parent is obliged to maintain, develop and intensify togetherness between the child and his parents, other relatives and close persons of the child. He is obliged to allow both parents to have contact with their child in foster care, unless a court decides otherwise.

\section{Section 968}

A child entrusted to foster care shall help the foster parent in his household according to his potential and skills; if the child has his own income, he shall contribute to the payment of the common needs of the family.

\section{Section 969 [Recodification]}

If there is a material change in circumstances or a disagreement between parents and a foster parent in an essential matter concerning a child, the child, parent or foster parent may apply to a court for a change in the rights and duties, cancel foster care, or make another decision.

\section{Section 970}

Foster care is extinguished no later than upon the child acquiring full legal capacity, or otherwise upon the child reaching the age of majority.

\section{Chapter 4}

\section{Institutional care}

\section{Section 971 [Recodification]}

(1) If the upbringing of a child or the child's physical, intellectual or mental condition or his proper development are seriously threatened or disrupted to an extent contrary to the interests of the child, or if there are serious reasons for which the child's parents are unable to provide for his upbringing, a court may, as a necessary measure, also order institutional care. It will do so in particular where previously taken measures have not led to remedy. In doing so, a court shall always consider whether it would not be appropriate to prefer entrusting the child to the care of a natural person.

(2) Where parents are temporarily unable to provide for the upbringing of their children for serious reasons, a court shall place the child in a facility for children in need of immediate assistance for a period not exceeding six months.

(3) Inadequate housing or property situation of the child's parents or persons entrusted with the care for the child may not in themselves constitute grounds for a court decision ordering institutional care if the parents are otherwise capable of ensuring proper upbringing of the child and performing other duties arising from their parental responsibility.

(4) In its decision ordering institutional care, a court shall identify the facility in which the child is to be placed. In doing so, it shall take account of the interests of the child and the statement of the body for social and legal protection of children. A court shall ensure that the child is placed as close as possible to the place of residence of the parents or other close persons of the child. This applies even where the court decides to transfer the child to another facility for institutional or protective care. 
(1) Institutional care may be ordered for a maximum of three years. Institutional care may be extended within three years from the date it was ordered if the reasons for the institutionalisation still exist. The duration of institutional care may be extended repeatedly, each time for a maximum period of three years. Before the court decides on cancelling or extending institutional care, the child remains in institutional care even where the period previously determined by a court has expired.

(2) If the reasons for which institutional care was ordered cease to exist, or if it is possible to provide the child with care other than institutional care, a court shall immediately cancel institutional care and shall, according to the circumstances, also decide on the person to be henceforth entrusted with the care for the child.

(3) Institutional care terminates upon a court decision on adoption. If a decision has been made to entrust a child to the care of a prospective adoptive parent under Sections 823 or 829 , institutional care is suspended.

\section{Section 973}

If a court has made a decision under Section 971, the court is required to review, at least once every six months, whether there are still grounds for the measure and whether it is possible to provide the child with foster care. To that end, the court shall in particular:

a) request the report of the competent body for social and legal protection of children,

b) obtain the opinion of the child, if the child is able to make and express his opinion after being advised by the court, having regard to his age and intellectual maturity, and

c) invite the parents of the child to express their opinions.

Section 974

For important reasons, a court may extend institutional care by up to one year after reaching the age of majority.

Section 975

If a court decides to place a child in institutional or protective care, it shall also regulate the scope of the parents' duty to maintain and support.

\section{BOOK THREE}

\section{ABSOLUTE PROPERTY RIGHTS}

TITLE I

\section{GENERAL PROVISIONS}

Section 976

Absolute property rights are effective against everyone, unless otherwise provided by a statute.

Section 977

The rights in respect of property which are absolute are only provided by a statute.

\section{Section 978 [Recodification]}

Parties may derogate from the provisions of this Book by a stipulation having effects with respect to third persons only if permitted by a statute.

\section{TITLE II}

\section{RIGHTS IN REM \\ Chapter 1}

General provisions

\section{Section 979 [Recodification]}

The provisions of this Title apply to corporeal and incorporeal things; however, they only apply to rights to the extent permitted by their nature and unless otherwise indicated by a statute.

\section{Section 980 [Recodification]}

(1) If a right in rem is registered in a public register, ignorance of the registered information is no excuse. If provided by a legal regulation, the right to use or use and enjoy a thing, as well as a limitation of the scope or manner in which a thing is used or used and enjoyed by co-owners, shall also be registered in a public register in addition to a right in rem. 
(2) Where a right in rem is registered in a public register, it is presumed to have been registered in accordance with the actual legal state. If a right in rem has been deleted from a public register, it is presumed not to exist.

\section{Section 981 [Recodification]}

If a right in rem to a thing of another is registered in a public register, it shall take precedence over a right in rem which is not apparent from the public register.

\section{Section 982 [Recodification]}

(1) With regard to the order of rights in rem to a thing of another, the time of submission of the application to register is decisive. Rights registered on the basis of applications submitted at the same time have the same order.

(2) If an owner creates a right in rem to his own thing, he may, before that right, reserve and register in a public register preferential order for another right; if such a reservation is to be registered in a public register only after the right in rem has been created, the consent of the person whose right is to be affected is required. The registration of a right for which a more favourable order has been reserved does not require the consent of the person whose right has been limited by the reservation, unless the right subject to the reservation of a more favourable order is registered in the public register in a scope wider than that following from the reservation.

\section{Section 983 [Recodification]}

(1) If a priority right to create a right in rem in favour of another person is registered in a public register and no application to register the right subject to the priority right has been submitted within one year from the registration, the owner may successfully claim deletion of the priority right. If the person with a priority right proves that he filed an application contesting the transfer or other creation of a right in rem before the expiry of the time limit, the time limit commences from the end of the court proceedings; however, if the application is dismissed, the priority right is deleted on the application of the owner as of the date on which the decision becomes final and absolute.

(2) If a priority right is registered in a public register as conditional or with determination of time, the time limit under Subsection (1) commences on the date on which the priority right becomes enforceable.

\section{Section 984 [Recodification]}

(1) If the state registered in a public register is not in accordance with the actual legal state, the registered state is in favour of the person who has acquired the right in rem for consideration in good faith from the person authorised thereto according to the registered state. Good faith is assessed as at the time at which the juridical act was made; however, if a right in rem is created only upon the registration in a public register, it is assessed as at the time of submission of the application to register the right.

(2) The first sentence of Subsection (1) does not apply to a necessary passage easement, reserved rights of enjoyment and right in rem created on the basis of a statute without regard to the state of entries in a public register.

\section{Section 985 [Recodification]}

If the state registered in a public register is not in accordance with the actual legal state, the person whose right in rem has been affected may claim that the discrepancy be removed; if he proves to have asserted his right, this fact is registered in the public register on his application. A decision issued on the person's right in rem has effects against everyone whose right was registered in the public register after the person a requested the registration.

\section{Section 986 [Recodification]}

(1) A person who claims to have his right affected by a registration made in the public register without a legal cause in favour of another is entitled to claim the deletion of such a registration and request that this fact be noted in the public register. A body maintaining the public register shall delete a note on the disputability of a registration if, within two months after the application has been delivered, the applicant fails to prove to have asserted his right in court.

(2) If an applicant requested that the disputability of a registration be noted within one month from the date on which he learned of the registration, his right has effects against everyone who benefits from the disputed registration or who had another registration made on its basis; however, after the expiry of that time limit, the right shall only be effective against a person who had a registration made without acting in good faith.

(3) If an applicant was not duly notified of a registration of a right of another, the time limit under Subsection (2) is extended to three years; the time limit commences on the date on which the disputed registration was made.

\section{Chapter 2}

Possession

\section{Section 987 [Recodification]}

A person who exercises a right for himself is a possessor. 
(1) A right which may be transferred to another by making a juridical act and which permits permanent or repeated performance may be possessed.

(2) A personal right is not subject to possession or acquisitive prescription. However, a person who exercises his personal right fairly is entitled to exercise and defend his alleged right.

\section{Section 989 [Recodification]}

(1) A person who took a thing to keep it as its owner shall hold the right of ownership.

(2) Another right is held by a person who began to exercise the right as a person to whom such a right pertains under a statute and to whom other persons perform in accordance with such a right.

\section{Acquisition of possession}

Section 990 [Recodification]

(1) Possession may be directly acquired if a possessor assumes it by exercising his power. Possession is acquired directly in the scope in which a possessor has actually assumed it.

(2) Possession may be acquired derivatively if the current possessor transfers his possession to a new possessor, or if a new possessor acquires possession as the legal successor of the current possessor. Possession is acquired derivatively in the scope in which the current possessor held the possession and in which he transferred the possession to a new possessor.

\section{Section 991 [Recodification]}

\section{Lawful possession}

Lawful possession is one that is based on a valid legal reason. A person who assumes possession directly without disturbing the possession of another, or who assumes possession at the will of the previous possessor or on the basis of a statement of a public body is a lawful possessor.

\section{Possession in good faith}

\section{Section 992 [Recodification]}

(1) A person having a compelling reason to believe that the right he exercises pertains to him is a possessor in good faith. A person who knows or to whom it must be evident from the circumstances that the right he exercises does not pertain to him is a possessor in bad faith.

(2) If a representative acquires or exercises possession in bad faith, such possession is also in bad faith. This does not apply if the person represented, by a specific mandate given with respect to such possession, mandated the representative to assume or exercise the possession.

(3) A possessor in good faith shall enjoy the same rights as a lawful possessor.

\section{Section 993 [Recodification]}

\section{Genuine possession}

Unless it is proved that a person has acquired possession by wilful intrusion or acquired it in secret or by trickery, or that someone seeks to turn something he was only allowed to possess under a precarious loan into a permanent right, possession is genuine.

\section{Section 994 [Recodification]}

Possession is presumed to be lawful, in good faith and genuine.

\section{Section 995 [Recodification]}

If an application challenging possession or whether the possession is in good faith has been allowed, a possessor in good faith is considered a possessor in bad faith no later than from the service of the application on him. However, the possessor shall only be liable for an accidental event affecting the thing that would not have happened if the thing were in the possession of its owner, if the possessor intentionally delayed the proceedings.

\section{Possession of the right of ownership}

\section{Section 996 [Recodification]}

(1) A possessor in good faith may, within the limits of the legal order, possess and use, or even destroy or otherwise dispose of, a thing without being liable for doing so towards anyone.

(2) A possessor in good faith is entitled to all fruits of a thing, once they become separated. All the previously collected revenues which became due during the possession also pertain to him. 


\section{Section 997 [Recodification]}

(1) A possessor in good faith is reimbursed for the necessary costs required to continuously preserve the essence of a thing, as well as the reasonably incurred costs incurred costs which increase the usefulness or the value of the thing. The compensation is to be provided up to the current value, provided that the latter does not exceed the actual costs.

(2) Usual maintenance costs are not reimbursed.

\section{Section 998 [Recodification]}

The costs incurred by a possessor in good faith as a result of a hobby or for decoration are reimbursed only up to the amount whereby the usual value of the thing increased; however, a former possessor may, to his own benefit, remove everything that can be separated from the thing without deteriorating its essence.

\section{Section 999 [Recodification]}

himself.

Even a possessor in good faith may not claim that he be reimbursed the price which he paid to transfer the thing to

\section{Section 1000 [Recodification]}

A possessor in bad faith shall surrender all revenue acquired through the possession and provide compensation for the revenue which would have been acquired by the person whose rights were prejudiced, as well as for any damage that resulted from its possession.

\section{Section 1001 [Recodification]}

If a possessor in bad faith incurs necessary costs which were needed to preserve the essence of a thing, he is entitled to be reimbursed for these costs. With regard to other costs, the provisions on agents without mandate apply by analogy.

\section{Section 1002 [Recodification]}

\section{Possession of other rights}

Possessors of other rights are governed by Sections 996 to 1001 with the necessary modifications.

\section{Protection of possession}

Section 1003 [Recodification]

No one is entitled to wilfully disturb possession. A person whose possession has been disturbed may claim that the disturbing person refrain from doing so and restore everything to the previous state.

\section{Section 1004 [Recodification]}

(1) If a possessor's possession of an immovable thing is threatened by the building of a structure, or if, as a result, he may be justifiably concerned about the consequences set out in Section 1013, and if the builder fails to take legal precautions against him, the possessor being threatened may claim that the building of the structure be prohibited. A possessor may not claim the prohibition if, despite having the possibility to do so, the possessor failed to assert defences against the application for the permission to build such a structure in administrative proceedings to which he was a party.

(2) Until a decision on the matter is made, a court may prohibit the building of the structure. However, if there is a direct threat, or if the defendant provides reasonable security ensuring that he will restore the thing to the previous condition and provide compensation for damage, but the applicant fails to provide a security for the consequences of his prohibition, a court shall not prohibit the resumption of the building of the structure, unless the circumstances of the case justify the prohibition.

\section{Section 1005 [Recodification]}

Removal of structures is governed by Section 1004 by analogy.

\section{Retention of possession}

\section{Section 1006 [Recodification]}

A possessor may resist a wilful disturbance and, in the course of the act of disturbance, repossess the thing which was taken away from him, unless doing so exceeds the limits of self-defence.

\section{Section 1007 [Recodification]}

(1) If a possessor has been dispossessed, he may claim that the dispossessor refrain from further dispossession and restore the original state. An application to protect possession can be challenged by invoking acquisition of non-genuine possession by the applicant against the defendant or dispossession of the defendant by the applicant.

(2) Dispossession of rights occurs when the other party refuses to provide the performance which it has so far been 
providing, when someone prevents a right from being exercised or no longer complies with the duty to refrain from an act.

$$
\text { Section } 1008 \text { [Recodification] }
$$

\title{
Prescription time limits
}

(1) A court shall dismiss an application to protect or retain possession, if the application is filed after six weeks from the date on which the applicant became aware of his right and of the person who threatens or disturbs the possession, but no later than one year from the date on which the applicant could have asserted his right for the first time.

(2) A court shall disregard a defence of dispossession if the defendant asserts the defence after the time limits under Subsection (1) have expired.

\section{Section 1009}

\section{Extinction of possession}

(1) Possession is extinguished if waived by the possessor or if the possessor becomes permanently unable to exercise the content of the right which he has so far been exercising. Possession is also extinguished if a possessor is dispossessed and fails to retain it by self-help or an application.

(2) Possession is not extinguished if the possessor fails to exercise possession. Possession is not extinguished even upon the death or termination of the possessor.

Section 1010

Co-possession

Co-possession is governed by the provisions on possession and common rights with the necessary modifications.

\section{Chapter 3}

Ownership

Division 1

\section{Nature of the right of ownership and its scope}

\section{Subject and content of the right of ownership}

\author{
Section 1011 [Recodification]
}

Everything that belongs to someone, all his corporeal and incorporeal things constitute the person's ownership.

$$
\text { Section } 1012 \text { [Recodification] }
$$

An owner has the right to freely dispose of his property within the limits of the legal order and exclude other persons from such disposal. An owner may not, beyond what is reasonable given the circumstances, seriously disturb the rights of others or perform such acts whose main purpose is to cause nuisance or harm to others.

\section{Limitation of the right of ownership}

Section 1013 [Recodification]

(1) An owner shall refrain from anything that would cause waste, water, smoke, dust, gas, odour, light, shadow, noise, vibration and other similar effects (imission) to infiltrate the tract of land of another owner (neighbour) to the extent disproportionate to the local circumstances and substantially restrict normal use of the tract of land; this also applies to animals entering the tract of land of another. It is prohibited to directly conduct imission to the tract of land of another owner regardless of the extent of such effects and the level of nuisance caused to the neighbour, unless it is based on specific legal grounds.

(2) If imission is the result of the operation of an enterprise or a similar facility which has been officially approved, a neighbour only has the right to compensation for harm in money, even where the harm was caused by circumstances which had not been taken into account during the official proceedings. This does not apply if the operation exceeds the extent to which it has been officially approved.

\section{Section 1014 [Recodification]}

(1) If a movable thing of another appears on the tract of land, the owner of the tract of land shall, without undue delay, surrender the thing to its owner or to the person who had the possession of the thing; otherwise, the owner of the tract of land shall allow the owner of the thing to enter his tract of land, find the thing and take it away. Likewise, an owner may pursue a bred animal or a swarm of bees on the tract of land of another; however, if a swarm of bees enters an occupied hive of another, the owner of the hive acquires the right of ownership to the swarm without being obliged to provide any compensation. 
(2) If a thing, an animal, a swarm of bees or the exercise of a right under Subsection (1) causes damage on the tract of land, the owner of the tract of land is entitled to compensation for the damage.

\section{Section 1015 [Recodification]}

If a movable thing has caused damage to the tract of land of another, the owner of the tract of land may withhold the thing until he receives other security or compensation for the damage.

\section{Section 1016 [Recodification]}

(1) The fruits fallen from trees and shrubs onto the neighbouring tract of land belong to the owner of the neighbouring tract of land. This does not apply if the neighbouring tract of land is a public thing.

(2) If, within a reasonable period after being asked by a neighbour, an owner fails to remove the roots or branches of a tree extending over to the neighbour's tract of land, the neighbour may do so in a careful manner and at an appropriate time of year if such roots or branches cause damage or other difficulties to the neighbour outweighing the interest in leaving the tree intact. Everything which the neighbour acquires from the removed roots and branches shall also pertain to him.

(3) A neighbour may remove parts of other plants extending over to the neighbouring tract of land in a careful manner without further restrictions.

\section{Section 1017 [Recodification]}

(1) If an owner of a tract of land has a reasonable cause, he may require a neighbour to refrain from planting trees near the common border of the tracts of land, and to remove them where the neighbour has already planted the trees or let them grow. Unless otherwise provided by another legal regulation or indicated by local usages, the permitted distance from the common border of the tracts of land is 3 metres for trees typically growing up to a height exceeding 3 metres, and 1.5 metres for other trees.

(2) The provision of Subsection (1) does not apply where there is a wood or orchard on the neighbouring land, where the trees constitute a boundary marker or where they concern a tree specially protected under another legal regulation.

\section{Section 1018 [Recodification]}

A tract of land may not be altered in a way that the neighbouring land loses its proper support unless it is sufficiently reinforced in another manner.

\section{Section 1019 [Recodification]}

(1) An owner of a tract of land has the right to require a neighbour to alter a structure on the neighbouring tract of land so that the structure does not allow water to flow down, and snow and ice to fall on, the owner's tract of land. However, if there is water naturally flowing down on the tract of land from a higher tract of land, especially where the higher tract of land contains the source of water or where the water is a result of rain or thaw, the neighbour may not require the owner of the tract of land to alter his tract of land.

(2) If a lower tract of land requires inflow of water, a neighbour may require the owner of the higher tract of land not to prevent outflow of water to the extent to which he has no need of the water for himself.

\section{Section 1020 [Recodification]}

If an owner of a tract of land has a reasonable cause, he may require a neighbour to refrain from building a structure on the neighbouring tract of land adjacent to the common border of the tracts of land.

\section{Section 1021 [Recodification]}

An owner shall allow a neighbour to enter the former's tract of land at the time, to the extent and in the manner which is necessary for the maintenance or exploitation of the neighbouring tract of land, unless this purpose may be achieved otherwise; however, the neighbour shall compensate the owner of the tract of land for the resulting damage.

\section{Section 1022 [Recodification]}

(1) If a structure cannot be built or demolished, or if it cannot be repaired or renewed in a manner other than by using the neighbouring tract of land, the owner has the right to require the neighbour to tolerate what is necessary for this work in exchange for a reasonable compensation.

(2) Such a request may not be granted if the neighbour's interest in the peaceful use of the tract of land outweighs the interest in performing the work.

\section{Section 1023 [Recodification]}

(1) An owner of a tract of land must tolerate the use of the space above or under the tract of land, if it is justified by an important reason and if it is done in such a manner that gives the owner no rational reason to oppose it.

(2) Using space of another in such a manner does not entitle anyone to derive a right which any person might invoke after the reason which entitled the person to use the space ceases to exist; however, if the use resulted in the establishment of an officially approved facility, the owner may claim compensation for damage. 


\title{
Elements constituting a boundary
}

\author{
Section 1024 [Recodification]
}

(1) Fences, walls, baulks, ditches and other similar natural or artificial boundary markers between neighbouring tracts of land are presumed to be common.

(2) Each owner may use a common wall on his side up to the middle of its thickness and make niches in places where there are none on the other side. However, he may do nothing that would jeopardise the wall or interfere with the neighbour's use of his part.

\section{Section 1025 [Recodification]}

In the case of double boundary markers or where ownership is separated, each of the owners maintains his part at his own expense.

\section{Section 1026 [Recodification]}

An owner is not obliged to rebuild a dilapidated wall, fence or restore another boundary marker; however, he must keep it in a good condition if a neighbour might incur damage as a result of damage to the wall. However, if a boundary marker is disrupted in such a manner that the border between the tracts of land might become indistinguishable, each of the neighbours has the right to request that the boundary marker be repaired or restored.

\section{Section 1027 [Recodification]}

On the application of a neighbour and after obtaining the opinion of the construction authority, a court may oblige an owner to enclose his tract of land with a fence if it is necessary to ensure the undisturbed execution of the neighbour's right of ownership and if it does not prevent the efficient use of other tracts of land.

\section{Section 1028 [Recodification]}

If the borders between tract of land are indistinguishable or doubtful, each of the neighbours has the right to request that the borders be determined by a court according to the latest peaceful possession. If the borders may not be determined, a court shall determine them according to the principles of just discretion.

\section{Necessary passage}

\section{Section 1029 [Recodification]}

(1) An owner of an immovable thing which may not be duly managed or otherwise duly used because it is insufficiently connected to a public road may request that his neighbour allow him the necessary passage through his tract of land for compensation.

(2) A court may authorise a necessary passage to the extent corresponding to the need of the owner of an immovable thing to properly use it with the lowest possible costs, even as servitude. At the same time, care must be taken that by creating or using the necessary passage, the neighbour is bothered and his tract of land affected to the least extent possible. This must be especially considered where the applicant is to be authorised to create a new passage.

\section{Section 1030 [Recodification]}

(1) Reward and reparation of harm, unless already covered by the reward, is provided for the necessary passage. If shared use of a private road of another is authorised, the reward shall also include increased costs of its maintenance.

(2) An owner of an immovable thing in whose favour a necessary passage has been authorised shall provide a security appropriate to the potential damage caused to the tract of land concerned; this does not apply if it is evident that no apparent damage will be caused to the tract of land concerned.

(3) The performances under Subsections (1) and (2) pertain primarily to the owner of the tract of land affected by the authorisation of the necessary passage; however, where another person's right in rem in the tract of land concerned is to be affected by the authorisation, these performances shall also be provided to that person to the appropriate extent. Another person in whose favour another right in the immovable thing concerned has been created is entitled to compensation from the owner of the tract of land concerned for any harm incurred; this must be taken into account when determining the consideration under Subsection (1).

\section{Section 1031 [Recodification]}

If the creation of an artificial necessary passage on the tract of land concerned has been authorised, it is created and maintained by the person in whose favour it has been authorised.

\section{Section 1032 [Recodification]}

(1) A court shall not authorise a necessary passage:

a) if the damage to the neighbour's immovable thing would apparently exceed the advantage of the necessary passage, 
b) if the lack of access has been caused due to gross negligence or intentionally by the person applying for the necessary passage, or

c) if the necessary passage is only applied for in order to obtain a more convenient connection.

(2) A necessary passage may not be authorised through a space enclosed for the purpose of prohibiting access to trespassers or through a tract of land on which no such passage may be created on the ground of public interest.

\section{Section 1033 [Recodification]}

(1) If an immovable thing without access is surrounded by several neighbouring tracts of land, a necessary passage is permitted only through one of them. In doing so, consideration is given to which tract of land provides the most natural access, considering at the same time the circumstances provided under Section 1029(2).

(2) If an immovable thing loses its connection to a public road due to the tract of land having been divided, a necessary passage may only be requested from a person who was involved in the division. In this case, the necessary passage is authorised without a reward.

\section{Section 1034 [Recodification]}

When the cause for which a necessary passage was authorised ceases to exist without the obligee having any other reason for maintaining the necessary passage, a court shall cancel the necessary passage on the application of the owner of the tract of land concerned.

\section{Section 1035 [Recodification]}

(1) Upon the extinction of the right of necessary passage, the reward is not returned; however, a security paid is settled.

(2) If a reward for the necessary passage is due in payments or repeated instalments, the duty to pay the payments or instalments which are not due upon the extinction of the right of necessary passage is extinguished.

\section{Section 1036 [Recodification]}

In case there is a need to create an artificial necessary passage, the owner of the tract of land concerned may require the applicant to take over the ownership of the tract of land needed for the necessary passage. In such a case, the price is determined with regard to the price of the ceded tract of land as well as with regard to loss of the value of the remaining immovable property of the affected owner.

\section{Expropriation and limitation of the right of ownership}

\section{Section 1037 [Recodification]}

In an emergency situation or urgent public interest, an owner's thing may be used for the period and to the extent necessary if the purpose cannot be achieved otherwise.

\section{Section 1038}

In the public interest which cannot be satisfied otherwise, and solely by means of a statute, the right of ownership may be limited or a thing expropriated.

\section{Section 1039}

(1) For a limitation of the right of ownership or expropriation of a thing, the owner is entitled to full compensation corresponding to the extent to which his property has been affected by those measures. parties.

(2) Compensation is provided in money. However, it may also be provided in a different way, if so stipulated by the

\section{Protection of the right of ownership}

\section{Section 1040 [Recodification]}

(1) A person who wrongfully withholds a thing may be sued by its owner to surrender the thing.

(2) An action to surrender a thing may not be filed by a person who, in his own name, transferred the thing to the acquirer without being its owner and only subsequently acquired the right of ownership in the thing; upon acquiring the right of ownership by the transferor, the acquirer becomes the owner of the thing.

\section{Section 1041}

(1) A person who claims that his thing be surrendered to him must describe the thing by providing such features which distinguish it from other things of the same kind.

(2) Surrendering a movable thing which cannot be distinguished under Subsection (1), including, without limitation, 
money or bearer securities mixed with other things of the same kind, may only be claimed if the circumstances allow the determination of the right of ownership of the person exercising the right and lack of good faith of the person against whom the surrendering of the thing is claimed.

\section{Section 1042}

An owner may seek protection against anyone who unlawfully interferes with his right of ownership or disturbs it in a manner other than by withholding his thing.

\section{Protection of putative right of ownership}

\section{Section 1043}

(1) A person who has acquired the right of ownership in good faith and in a lawful and genuine way is considered to be the owner against any person who withholds his thing or otherwise disturbs his right of ownership if he has no legal reason to do so, or if he has a legal ground of the same strength or weaker.

(2) If the possession of the right of ownership has been acquired gratuitously by one person and for consideration by another person, gratuitous acquisition is considered to be the weaker legal cause.

\section{Section 1044}

A person who has possession of a thing without being subject to the presumption under Section 1043 may assert the right to protection pertaining to the owner in the person's own name.

\section{Division 2}

\section{Acquisition of the right of ownership}

\section{Subdivision 1}

\section{Appropriation and discovery}

\section{Appropriation}

\section{Section 1045 [Recodification]}

(1) A thing which belongs to no one may be appropriated by anyone, unless it is prohibited by a statute or another's right to appropriate the thing. A movable thing abandoned by its owner due to his unwillingness to possess it as his own belongs to no one.

(2) An abandoned immovable thing passes into the ownership of the state.

$$
\text { Section } 1046 \text { [Recodification] }
$$

A wild animal is masterless as long as they are free (at large).

(2) A captive animal becomes a masterless animal once it becomes free and its owner fails to promptly and consistently pursue or search for the animal in an attempt to recapture it. However, such an animal shall not become masterless if it is marked in such a way that its owner can be identified.

\section{Section 1047 [Recodification]}

(1) A tamed animal which is not pursued by its owner and which, although not prevented to do so by anyone, does not return to the owner by itself within a reasonable period, becomes a masterless animal, and it may be appropriated by the owner of the private tract of land if found on the private tract of land or by anyone if found on a public thing. It is conclusively presumed that a reasonable period for an animal to return to its owner is six weeks.

(2) Subsection (1) does not apply where an animal is marked in such a way that its owner can be identified.

\section{Section 1048 [Recodification]}

A domestic animal is considered abandoned if circumstances clearly show the owner's intention to get rid of or drive off the animal. This also applies to pet animals.

\section{Section 1049 [Recodification]}

Animals kept in a zoo and fish in a pond or a similar facility which is not a public thing are not masterless.

\section{Section 1050 [Recodification]}

(1) If an owner fails to exercise his right of ownership in a movable thing for three years, he is presumed to have abandoned it. A movable thing which was apparently of a very small value to the owner and was left in a place accessible to the public is considered abandoned without other considerations. 

abandoned it.

(2) If an owner fails to exercise his the right of ownership to an immovable thing for ten years, he is presumed to have

\title{
Discovery
}

\author{
Section 1051 [Recodification]
}

Everyone is presumed to wish to keep his ownership and a discovered thing is presumed not to be abandoned. A person who finds a thing may not automatically consider it abandoned and appropriate it.

\section{Section 1052 [Recodification]}

(1) A discoverer shall return a lost thing to the person who lost it or to the owner against a payment of the necessary costs and a discoverer's fee.

(2) If circumstances make it impossible to identify the person to whom a thing is to be returned and the thing is not considered abandoned, the discoverer shall, without undue delay, usually within three days, notify the discovery to the municipality in whose territory the thing has been found; however, if a thing has been found in a public building or means of public transport, the discoverer shall deliver the discovery to the operator of such a facility, which shall act in accordance with other legal regulations; in the absence of any such regulations, the operator shall proceed as if it were the discoverer.

\section{Section 1053 [Recodification]}

(1) A municipality shall publish a discovery in the usual manner. If a person who has lost a thing fails to claim it within a reasonable period and the thing is of substantial value, the municipality shall take appropriate steps to raise wider awareness of the discovery.

(2) If the municipality identifies the owner itself, especially according to an unmistakable mark on the thing, the municipality shall inform the owner of the discovery and request him to take over the thing.

\section{Section 1054 [Recodification]}

(1) A municipality shall decide how a discovered thing will be kept. If the discoverer or another person gives his consent and if appropriate, the municipality may decide that the thing will be deposited with that person. A municipality shall place things of significant value, in particular substantial amounts of money, in judicial custody or deposit them in another appropriate manner.

(2) A thing which may not be kept without apparent damage or may only be kept with unreasonable costs is sold by the municipality at public auction and the municipality shall use the proceeds in accordance with Subsection (1), after deducting its own costs incurred in the previous administration of the thing. A municipality shall dispose of an unsellable thing in any manner; this does not apply if there can be no doubt about the thing's uniqueness and value.

\section{Section 1055 [Recodification]}

A municipality shall surrender a thing or the proceeds gained from the sale of a thing including the fruits and revenues, having deducted the costs and the discoverer's fee, to the person who lost the thing, or to the owner if he claims the thing within one year after the publication of the discovery.

\section{Section 1056 [Recodification]}

(1) A discoverer is entitled to a discoverer's fee even where the owner apparently can be identified according to the marks on the things or from other circumstances.

(2) A discoverer's fee shall equal one tenth of the price of the discovery. However, if a lost thing is only valuable to the person who lost it or to its owner, the discoverer is entitled to a discoverer's fee according to the principles of fair discretion.

\section{Section 1057 [Recodification]}

(1) If no one claims a thing within one year from the announcement of its discovery, the discoverer, municipality, or another person to whom the thing has been entrusted may dispose of the thing as a possessor in good faith. However, where money has been discovered, these persons may only use it; this also applies to the proceeds gained from the sale of a thing.

(2) If a person who lost a thing or its owner claims the thing after the expiry of one year from the publication of the discovery and before the expiry of three years from the publication of the discovery, the thing or proceeds gained from the sale of the thing, after the costs and the discoverer's fee have been paid, are surrendered to the person concerned.

(3) If three years have elapsed since the publication of the discovery, the discoverer, municipality or another person to whom the thing has been entrusted shall acquire the right of ownership in the thing or the proceeds gained from the sale of the thing.

\section{Section 1058 [Recodification]}

(1) In case an animal which obviously had an owner is discovered, the discoverer shall, without undue delay, inform the municipality of the discovery, unless the circumstances make it possible to identify the person to whom the animal is to be 
returned. the owner.

(2) A person who cares for a discovered animal shall do so with due managerial care until the animal is taken over by

$$
\text { Section } 1059 \text { [Recodification] }
$$

(1) In case an animal obviously intended as a pet is found and no one claims the animal within two months from the publication of the discovery, the discoverer shall acquire the right of ownership in the animal.

(2) If a discoverer informs a municipality of his wish not to acquire an animal and the municipality irrevocably entrusts the animal to a person who operates an animal shelter, the latter may freely dispose of the animal if no one has claimed it within four months from the date on which the animal was entrusted to the person. If the discovery is published only after the animal was handed over, the time limit commences from the publication of the discovery.

\section{Section 1060 [Recodification]}

If a discoverer informs a municipality of his wish not to acquire a discovered thing, his right to use and acquire the thing or proceeds gained from the sale of the thing passes to the municipality in whose territory the thing was discovered. Upon acquiring the right of ownership, the municipality becomes obliged to pay the discoverer a discoverer's fee.

\section{Section 1061 [Recodification]}

A discoverer who fails to inform of a discovery, appropriates the discovered thing or otherwise breaches his duties is not entitled to reimbursement and a discoverer's fee, and he may also not use or acquire the right of ownership in the discovered thing under the provisions of this Act governing discovery. This does not affect his duty to compensate for damage.

\section{Section 1062 [Recodification]}

If a thing is discovered by several persons at the same time, they are entitled and obliged jointly and severally. A person who saw a thing and tried to acquire it is a co-discoverer, even where someone else seized the thing before him.

\section{Discovery of a hidden thing}

Section 1063 [Recodification]

The provisions on discovery of a lost thing shall also apply to discovery of a thing which is buried, walled-up or otherwise hidden. However, the discoverer is not entitled to any discoverer's fee if the owner knew of the place in which the thing was hidden.

\section{Section 1064 [Recodification]}

(1) If the owner of a hidden thing is not apparent, the discoverer shall inform the owner of the tract of land and the municipality in whose territory the thing was found of the discovery of the thing; Section 1062 applies by analogy.

(2) If a hidden thing does not pass into the ownership of the State, region or municipality under other legal regulations, the discoverer and the owner of the tract of land shall agree which of them will retain the thing and pay half of the price of the thing to the other. If they fail to agree, the thing belongs to the owner of the tract of land, who shall pay the discoverer half of its price.

Section 1065 [Recodification]

A person engaged to find a lost or hidden thing is not the discoverer and is only entitled to a fee for the search, if agreed.

\section{Subdivision 2}

\section{Natural accession}

\section{Accession of an immovable thing}

\section{Section 1066}

Fruits that the tract of land provides by itself without cultivation belong to the owner of the tract of land. The same applies by analogy to natural fruits of other immovable things.

\section{Section 1067}

A tree belongs to the person from whose tract of land the trunk grows. If the trunk grows on the border between tracts of land of different owners, the tree is common.

\section{Alluvium and tear-of}

$$
\text { Section } 1068 \text { [Recodification] }
$$

Alluvial soil gradually and imperceptibly formed on a bank belongs to the owner of the riparian land. This also applies 
to accessions created by wind or other natural forces.

Section 1069 [Recodification]

A large and recognisable part of land which a watercourse carries away to another bank becomes part of the riparian land if the original owner fails to assert his right to the land carried away within one year.

Section 1070 [Recodification]

(1) An island formed by a watercourse by separating a part of land belongs to the owner of the original land.

(2) In other cases, an island belongs to the owner of the watercourse bed.

Section 1071 [Recodification]

A watercourse bed created by tear-off or as a result of an island being formed passes into the ownership of the owner of the original bed.

Section 1072

\section{Accession of a movable thing}

Natural accession to a movable thing belongs to its owner.

\section{Section 1073 [Recodification]}

(1) Fruits produced by an animal belong to the owner of the animal.

(2) Remuneration for insemination may be requested only if agreed.

\section{Subdivision 3}

\section{Artificial accession}

\section{Processing}

\section{Section 1074}

(1) A new thing created by processing movable things of several owners in such a way that the processed things cannot be restored to the previous state at all or only at a significant cost or with a substantial loss is owned by the person whose material or work made the largest contribution to the resulting value.

(2) The owner of the new thing shall pay the person who has lost the right of ownership the value of the processed thing and remunerate the person having contributed with work for the work performed.

\section{Section 1075 [Recodification]}

(1) The owner of a thing which a processor processed into a new thing while not acting in good faith is at liberty to choose whether he will appropriate the new thing and compensate the other for what the latter has lost, or whether he will allow the latter to retain the thing in exchange for compensation.

(2) The right to choose a more convenient option is extinguished if not exercised within one month from the date on which the owner became aware that the things have been processed.

\section{Section 1076}

(1) If it is impossible to identify a single owner of a new thing, the thing becomes co-owned by the owners of the processed things. The shares are determined pro rata to the values of the processed things; where impossible, their shares are equal.

(2) Co-owners shall, jointly and severally, remunerate for work the person who has processed the thing.

\section{Section 1077}

If a thing of another is only used to repair some other thing, it shall devolve to the owner of the repaired thing, who is to compensate the owner of the processed thing for the value of the thing of another which was used.

\section{Mixing}

\section{Section 1078 [Recodification]}

(1) If movable things of several owners become mixed in such a way that the restoration of the previous state is impossible but the whole may be divided into parts without interfering with the essence, each person will be at liberty to choose whether to separate for himself a proportion of what has been created by mixing, or whether to require compensation for what 
he has lost. If the person who has mixed things did not act in good faith, the owner has the right to relinquish his share in the mixed thing to him in exchange for a full compensation.

(2) Section 1075(2) applies by analogy.

\section{Section 1079 [Recodification]}

When movable things of the same kind are mixed, including, without limitation, while they are held in deposit, the provision of Section 1078 does not apply; the ownership of a proportional part of the mixed things passes to the owners of the mixed things.

\section{Section 1080 [Recodification]}

A person involved in mixing of things of others who did not act in good faith shall also compensate the affected owners for lost profits; however, he shall only pay for actual damage to the extent to which the owners were not compensated for that damage under the foregoing provisions.

\section{Section 1081 [Recodification]}

The person who participated in joining things and has possession of the new thing even though he is to surrender it is not obliged to do so until the owner has paid compensation to him.

Section 1082 [Recodification]

\section{Common provisions}

A person who is obliged to provide compensation to another person in relation to processing or mixing of things is not obliged to perform more than what he would be obliged to perform in case of unjust enrichment.

\section{Structure}

\section{Section 1083}

(1) If a person uses a thing of another to build a structure on his tract of land, the structure becomes a component part of the tract of land. The owner of the tract of land shall compensate the owner of the thing used in the amount of its value.

(2) A person who did not act in good faith when using a thing of another to build a structure shall also compensate the owner of the thing used for lost profit; however, he shall only pay for the actual damage to the extent to which the owner was not compensated for the damage under Subsection (1).

\section{Section 1084 [Recodification]}

(1) A structure erected on the tract of land of another devolves to the owner of the tract of land.

(2) The owner of tract of land shall compensate a person who erected a structure on the tract of land of another in good faith for reasonably incurred costs. A person who did not act in good faith has the same rights and duties as an agent without mandate.

\section{Section 1085 [Recodification]}

A court may, on the application of the owner of the tract of land, order the person who erected a structure on the tract of land of another without having the right to do so to remove the structure at his own expense and restore the tract of land to its previous state. In doing so, the court shall take into account whether the structure was erected in good faith.

\section{Section 1086 [Recodification]}

(1) A person who erected a structure on the tract of land of another in good faith has the right to claim that the owner of the tract of land who knew about the erection of the structure and failed to prohibit it without undue delay transfer the tract of land to him for the usual price. Also, the owner of the tract of land has the right to require that the person who has erected the structure purchase the tract of land for the usual price.

(2) On the application of any of the parties, a court shall order the tract of land into the ownership of the person who has erected the structure and decide on his duty to pay compensation to the owner of the tract of land.

\section{Section 1087 [Recodification]}

\section{Property encroachment}

(1) If only a small part of a permanent structure erected on a person's own tract of land extends to the tract of land of another, the part of the tract of land covered by the encroaching property passes into the ownership of the person who has erected the structure; this does not apply if the person who has erected the structure did not act in good faith.

(2) A person who has erected a structure in good faith shall provide the owner of the tract of land whose part has been covered by the encroaching property with compensation in the amount of the usual price of the acquired tract of land. 


\section{Subdivision 4}

\section{Mixed accession}

Section 1088

(1) Where a tract of land is sown with seeds of another or planted with plants of another, the owner of the tract of land is entitled to everything thus added; however, the plants belong to him only after they take root.

(2) Compensation for the seeds and plants is governed by Sections 1083 and 1084 by analogy.

\section{Subdivision 5}

\section{Acquisitive prescription}

\section{Ordinary acquisitive prescription}

\section{Section 1089 [Recodification]}

(1) If a possessor in good faith has had the right of ownership for the specified period, he acquires it by prescription and acquires the thing into ownership.

(2) A possessor in good faith begins acquisitive prescription on the date on which he acquired the possession even where his predecessor was a possessor in bad faith.

\section{Section 1090 [Recodification]}

(1) Acquisitive prescription requires genuine possession and possession based on a legal cause which would suffice for the creation of the right of ownership if it were vested in the transferor or created by an authorised person.

(2) Where a decedent has acquired non-genuine possession of a thing, his heir may not acquire the right of ownership in the thing by prescription even if his possession were in good faith. This applies by analogy to the general legal successor of a legal person.

\section{Section 1091 [Recodification]}

(1) Uninterrupted possession lasting three years is required for the acquisition of the right of ownership in a movable thing by prescription.

(2) Uninterrupted possession lasting ten years is required for the acquisition of the right of ownership in an immovable thing by prescription.

\section{Section 1092 [Recodification]}

The acquisitive prescription period shall, for the benefit of the person acquiring his right by prescription, also include the period of lawful possession and possession in good faith by his predecessor.

\section{Section 1093 [Recodification]} period.

Possession is interrupted if not exercised by the possessor for more than one year during the acquisitive prescription

$$
\text { Section } 1094 \text { [Recodification] }
$$

Where a person is required to have a legal representative or a guardian, the acquisitive prescription period for the acquisition of the right of ownership by such a person commences on the date on which the legal representative or guardian of that person is appointed. A period which has already begun shall continue to run but shall end no earlier than one year after the obstacle is removed.

$$
\text { Section } 1095 \text { [Recodification] }
$$

\section{Extraordinary acquisitive prescription}

Upon the expiry of a period twice as long as would otherwise be necessary, a possessor shall acquire the right of ownership by prescription even if he fails to prove a legal cause on which his possession is based. This does not apply if he is proved to have unfair intention.

$$
\text { Section } 1096 \text { [Recodification] }
$$

\section{Inclusion of the acquisitive prescription period}

(1) If a person has acquired possession in good faith from a possessor in good faith whose possession is based on a legal cause which would suffice for the creation of the right of ownership (Section 1090(1)), the acquisitive prescription period of his predecessor is included in the overall acquisitive prescription period. 
(2) In case of extraordinary acquisitive prescription, the acquisitive prescription period of a predecessor in good faith shall automatically be included in the successor's acquisitive prescription period.

$$
\text { Section } 1097 \text { [Recodification] }
$$

\section{Prohibition of acquisitive prescription}

A legal representative may not acquire the right of ownership by prescription against the person represented; a person represented may not acquire the right of ownership by prescription against his legal representative. This applies by analogy to a guardian and a ward and to a tutor and a person under tutorship.

$$
\text { Section } 1098 \text { [Recodification] }
$$

\section{Suspension of acquisitive prescription period}

Between spouses, acquisitive prescription period neither commences nor runs while the marriage lasts. This applies by analogy to persons living in a common household, a legal representative and the person represented, guardian and ward, and tutor and person under tutorship.

\section{Subdivision 6}

\section{Transfer of the right of ownership}

\section{Section 1099 [Recodification]}

The right of ownership in a thing specified individually is transferred by the contract itself upon its effective date, unless otherwise stipulated or provided by a statute.

\section{Section 1100 [Recodification]}

(1) If a party transfers the right of ownership in a thing not registered in a public register to various persons by successively concluded contracts, the right of ownership is acquired by the first person to whom the transferor surrendered the thing. In the absence of any such person, the right of ownership is acquired by the person with whom the first contract to become effective was concluded.

(2) If a party successively transfers the right of ownership in a thing registered in a public register to several persons, the person who acts in good faith and whose right of ownership was the first to be registered in the public register becomes the owner, even if the person's right of ownership was created later.

\section{Transfer of the right of ownership in a movable thing}

\section{Section 1101}

The right of ownership to a movable thing determined by kind is acquired no earlier than at the time when the thing can be determined by sufficiently distinguishing it from other things of the same kind.

\section{Section 1102}

Where the right of ownership in a movable thing registered in a public register is transferred, the ownership of the thing is acquired upon registration in such a register, unless otherwise provided by another legal regulation.

\section{Section 1103}

(1) The right of ownership in bearer securities is transferred by a contract upon their handover.

(2) The right of ownership in securities to order is transferred by an endorsement and a contract upon their handover. The elements and acceptance of an endorsement, as well as the person entitled under the endorsement and the manner in which the person is to demonstrate the entitlement, are governed by the provisions of a legal regulation governing bills of exchange; however, the transferor of securities is only liable as a surety for the satisfaction of rights arising from the securities if specifically obliged to do so.

(3) The right of ownership in registered securities is transferred by the contract itself upon its effective date.

\section{Section 1104}

(1) The right of ownership in book-entry securities is acquired upon the registration of the book-entry security on the owner's account.

(2) If book-entry securities are also subject to registration in the customers' account, the right of ownership in the securities is acquired upon the registration in the customers' account.

(3) The acquisition of the right of ownership in immobilised securities under Section 2413(1) is governed by analogy by the provisions on the acquisition of the right of ownership in book-entry securities. 


\section{Transfer of the right of ownership in an immovable thing}

Where the right of ownership in an immovable thing registered in a public register is transferred, the ownership of the thing is acquired upon the registration in such a register.

\section{Common provisions on the transfer of the right of ownership}

\section{Section 1106}

The person who acquires the right of ownership also acquires the rights and duties associated with the thing.

$$
\text { Section } 1107 \text { [Recodification] }
$$

(1) A person who acquires the right of ownership also assumes any defects encumbering the thing which are registered in a public register; he assumes other defects only if he should and could have ascertained them from the circumstances, or if it has been stipulated or provided by a statute.

(2) Defects which do not pass to anyone are extinguished.

\section{Section 1108} than by transfer.

The provisions of Sections 1106 and 1107 also apply by analogy to the acquisition of the right of ownership otherwise

\section{Subdivision 7}

\section{Acquisition of the right of ownership from a non-entitled person}

\section{Section 1109 [Recodification]}

A person who has acquired a thing which is not registered in a public register and, considering all the circumstances, was in good faith that he was authorised by the other party to transfer the ownership on the basis of a proper title, is the owner of the thing, if it was acquired:

a) at a public auction,

b) from an entrepreneur in his business activities in the ordinary course of business,

c) for a reward from a person to whom the owner entrusted the thing,

d) from an unlawful heir, whose acquisition of inheritance has been confirmed,

e) when trading with an investment instrument, security or instrument made out to the bearer, or

f) when trading at the commodity exchange.

\section{Section 1110 [Recodification]}

If a person, acting in good faith, has acquired for consideration a used movable thing from an entrepreneur who trades in such things in his business activities in the ordinary course business, he shall surrender the thing to the owner who proves that he has lost the thing or that the thing was wilfully taken away from him and no more than three years have expired since the thing was lost or taken away.

\section{Section 1111 [Recodification]}

If a person acquires a movable thing under circumstances other than those provided under Sections 1109 or 1110 , he becomes the owner of the thing if he proves to have been in good faith that he was authorised by the transferor to transfer the right of ownership in the thing. This does not apply if the owner proves that he lost the thing due to his own fault or due to an act having the nature of an intentional criminal offence.

\section{Section 1112 [Recodification]}

A person who has acquired a movable thing knowing that the right of ownership was acquired from a non-entitled person may not invoke his right of ownership or the good faith of his predecessor to his advantage.

\section{Section 1113}

The provisions of Sections 1110 to 1112 do not apply to investment instruments, securities or deeds made out to the bearer, or to things acquired at a public auction, at an auction in the enforcement of a decision or during private enforcement by the sale of movable property, or to things acquired by trading on a commodity exchange.

\section{Subdivision 8}


The right of ownership is acquired by the decision of a court or another public body on the date which is indicated therein. In the absence of such a date in the decision, the right of ownership is acquired on the date on which the decision becomes final and absolute.

\section{Chapter 4}

\section{Co-ownership}

\section{Division 1}

\section{General provisions}

\section{Section 1115}

(1) Persons who have joint right of ownership in a thing are co-owners.

(2) The provisions on co-ownership apply to the community of other rights in rem with the necessary modifications.

\section{Section 1116}

With respect to the thing as a whole, co-owners are considered and dispose of the thing as a single person.

\section{Section 1117}

Each co-owner has the right to the entire thing. This right is limited by the same right of each of the other co-owners.

$$
\text { Section } 1118
$$

A co-owner is entitled to an account of how the undivided thing was disposed of and to the share of the fruits and revenues of the undivided thing.

\section{Section 1119}

An account may be requested after the expiry of a period typical with respect to the nature of the administration of the undivided thing, upon the extinction of co-ownership, and upon the extinction of participation therein, or for other important reasons.

\section{Section 1120}

(1) The fruits and revenues of an undivided thing are divided according to the proportion of shares.

(2) The manner to dispose of the fruits and revenues of an undivided thing which may not be divided according to shares is determined by an agreement between the co-owners. If the co-owners fail to reach an agreement, these fruits and revenues are sold in an appropriate manner, and the yield is divided according to their shares.

\section{Division 2}

\section{Co-ownership share}

Section 1121

Each of the co-owners is the full owner of his share.

Section 1122

(1) A share reflects the degree of participation of each of the co-owners in forming a common will and in the rights and duties arising from the co-ownership of the thing.

(2) The percentage of the share is based on a legal fact which forms the basis for the co-ownership or participation of a co-owner in the co-ownership. This does not prevent the co-owners from stipulating a different percentage of their shares; such a stipulation must meet the requirements provided for the transfer of a share.

(3) Shares are presumed to be equal.

\section{Section 1123}

A co-owner may dispose of his share according to his discretion. However, such a disposal may not prejudice the rights of the other co-owners regardless of what they are based on.

\section{Section 1124 [Recodification]}

(1) If co-ownership has been created by a disposition mortis causa or another legal fact in a way that made it 
impossible for the co-owners to affect their rights and duties from the beginning, and if one of the co-owners transfers his share, the other co-owners have a pre-emptive right to the share for a period of six months from the date on which the co-ownership was created, unless the co-owner transfers his share to another co-owner, his own spouse, sibling or relative in the direct line. Unless stipulated otherwise between the co-owners regarding the manner in which the pre-emptive right is exercised, the coowners have the right to redeem the share on a pro-rata basis according to the percentage of their shares.

(2) Co-owners have the pre-emptive right even where one of the co-owners transfers his share gratuitously; in that case, the co-owners have the right to redeem the share for the usual price. This also applies in other cases of a statutory preemptive right.

\section{Section 1125 [Recodification]}

(1) Where the co-ownership of an agricultural enterprise has been created by a disposition mortis causa or another legal fact in a way that made it impossible for the co-owners to affect their rights and duties from the beginning, and if one of the co-owners transfers his share, the other co-owners have a pre-emptive right to the share; the pre-emptive right shall also apply to an inheritance share. Unless stipulated otherwise between the co-owners or co-heirs regarding the manner in which the preemptive right is exercised, they have the right to redeem the share on a pro-rata basis according to the percentage of their shares.

(2) If a co-owner transfers his share to a person who would be his heir under the provisions on the statutory succession of heirs, or to another co-owner, Subsection (1) does not apply. This also applies if the co-owner has waived his preemptive right in writing.

\section{Division 3}

\section{Administration of an undivided thing}

\section{Section 1126}

(1) Each of the co-owners is entitled to participate in the administration of an undivided thing

(2) When deciding on an undivided thing, the vote of each co-owner is proportional to the percentage of his share.

Section 1127

Juridical acts concerning an undivided thing entitle and oblige all co-owners jointly and severally.

\section{Section 1128 [Recodification]}

(1) Co-owners make decisions concerning the usual administration of the undivided thing by majority vote.

(2) The decision has legal effects with respect to all co-owners only if all of them were informed of the need to make a decision, unless it was a matter which required immediate action. A co-owner left out from the decision on an urgent matter may apply to the court for a declaration that the decision on an urgent matter has no legal effects against him if he may not be reasonably required to bear such effects.

(3) If the application under Subsection (2) is not filed within thirty days from the date on which the decision was made, the right to file the application is extinguished; if a co-owner was not informed of the disposal, the time limit shall run from the date on which he became or could have become aware of the decision.

\section{Section 1129 [Recodification]}

(1) The decision on a relevant matter relating to the undivided thing, in particular a decision to significantly improve or deteriorate the thing, change its purpose or process it must be adopted by at least a two-thirds majority of the co-owners' votes. In case of a failure to achieve such a majority, the decision is made by a court on the application of a co-owner.

(2) A co-owner outvoted on the decision under Subsection (1) may apply to the court for a decision on the matter; within this, he may also move the court to temporarily prohibit acts based on the contested decision. Section $1128(3)$ applies by analogy.

\section{Section 1130 [Recodification]}

An outvoted co-owner who faces severe harm due to the decision, in particular a disproportionate restriction on the use of the undivided thing, or the creation of a duty evidently disproportionate to the value of his share, may apply to the court for cancellation of that decision. Section 1128(3) applies by analogy.

\section{Section 1131 [Recodification]}

If the majority of co-owners decide on a measure needed to maintain or improve an undivided thing and make a commitment towards an outvoted co-owner that they will not require him to pay a share of the costs, or that they will compensate him for any harm caused by the measure adopted and provide sufficient security, the outvoted co-owner shall not have the right under Section 1130.

\section{Section 1132 [Recodification]}

A decision forming the basis on which an undivided thing is to be encumbered or such an encumbrance cancelled 
and a decision forming the basis on which the rights of the co-owners are to be limited for more than ten years, shall require the consent of all co-owners.

\title{
Section 1133 [Recodification]
}

To create a pledge or other similar security to secure a pecuniary claim arising from the improvement or renewal of an undivided thing, the decision of at least a two-thirds majority of the co-owners shall suffice.

\section{Administrator of an undivided thing}

\section{Section 1134 [Recodification]}

The co-owners shall decide on the appointment and removal of an administrator as well as on matters concerning routine administration.

\section{Section 1135 [Recodification]}

An administrator has the legal status of a mandatary. He must provide an account of the administration to the coowners; he is entitled to reimbursement of reasonably incurred costs, which he may collect from the yields of the administered thing.

\section{Section 1136 [Recodification]}

A co-owner who has spent costs with regard to the undivided thing in the interests of the other co-owners without having notified them and without having obtained their consent may require:

a) in the case of a cost which was for the benefit of the co-owners, a part of compensation which is proportionate to the appreciation of the thing,

b) in the case of a cost which had to be incurred to save the thing, compensation for the necessary costs

\section{Section 1137 [Recodification]} one vote.

In case administration is entrusted to several persons, they shall make decisions by majority vote; each of them has

\section{Section 1138 [Recodification]}

If the co-owners of an immovable thing agree to administer the thing differently, the agreement shall require the form of a public instrument. The agreement is filed in the collection of instruments kept by the body maintaining the public register in which the immovable thing is registered.

\section{Section 1139 [Recodification]}

\section{Regulation of the relations between co-owners by court}

(1) If a co-owner applies to the court for a decision that a decision of the majority of the co-owners has no legal effects against him, to cancel such a decision or to replace it with the court's own decision, the court shall regulate the legal relations between the co-owners according to the principles of fair discretion. In particular, a court may decide whether a change is to be made without reservations, with reservations or against a security, or whether the change should be made at all.

(2) A court shall also decide in the manner provided under Subsection (1) if a co-owner seeks the court's decision because the required majority was not reached when deciding on an undivided thing.

\section{Division 4}

\section{Separation from co-ownership and cancellation of co-ownership}

\author{
Section 1140 [Recodification]
}

(1) No one may be forced to remain involved in co-ownership.

(2) Each of the co-owners may at any time request that he be separated from the co-ownership if it is possible to divide the co-owned thing, or that the co-ownership be cancelled. However, he may not make such a request at an inconvenient time or only to the detriment of one of the co-owners.

\section{Section 1141 [Recodification]}

(1) Co-ownership is cancelled by an agreement of all co-owners; the agreement must contain a stipulation on the method of settlement. The agreement must be in written form in the case of co-ownership of an immovable thing or an enterprise.

(2) Co-owners shall settle by dividing the undivided thing, by exercising the power of sale of the undivided thing or by selling it at a public auction with the subsequent division of the proceeds, or by transferring the right of ownership to one or several co-owners by buying out the others. 


\section{Section 1142 [Recodification]}

(1) Division is impossible in the case of an undivided thing which, as a whole, is to serve a specific purpose.

(2) Agricultural land may only be divided in a way that it results in the creation of tracts of land which may be efficiently cultivated both in terms of their amount, as well as the possibility of permanent access. This does not apply if the land is to be divided for the purpose of erecting a structure or such a purpose for which the land may be expropriated.

\section{Section 1143 [Recodification]}

If co-owners fail to agree to cancel the co-ownership, the decision to cancel the co-ownership is made by a court on the application of one of the co-owners. If a court decides to cancel the co-ownership, it shall also decide on the manner in which the co-owners will settle.

\section{Section 1144 [Recodification]}

(1) If possible, a court shall decide on the division of an undivided thing; however, it may not divide the thing if it results in a substantial decrease in its value.

(2) However, dividing a thing is not prevented by the inability to divide the thing into parts exactly corresponding to the co-owners' shares if the difference is compensated in money.

\section{Section 1145 [Recodification]}

In case co-ownership is cancelled by division of an undivided thing, a court may establish a servitude or another right in rem if necessary to allow the former co-owner to properly use the newly created thing.

\section{Section 1146 [Recodification]}

Common instruments may not be divided. If the co-owners fail to agree on the person who will hold the common instruments in deposit, they are to deposit the documents with the oldest co-owner unless it is otherwise excluded. Other coowners shall receive certified copies at the co-owners' common expense.

\section{Section 1147 [Recodification]}

If an undivided thing cannot be reasonably divided, a court shall order that it be given to one or more co-owners for a reasonable compensation. If none of the co-owners wants the thing, a court shall order its sale in a public auction; in justified cases, a court may decide that the thing will be auctioned only among the co-owners.

\section{Section 1148 [Recodification]}

(1) If a co-ownership is cancelled, co-owners shall mutually settle their claims and debts related to the co-ownership or the undivided thing.

(2) Each of the co-owners may request the payment of a claim which is due, as well as a claim which becomes due within one year after the agreement to cancel co-ownership becomes effective or after the proceedings for the cancellation of co-ownership have been initiated.

(3) If a thing is sold, all debts under the foregoing subsections are paid after deducting the costs of the sale before the proceeds are divided among the co-owners.

\section{Section 1149 [Recodification]}

(1) Former co-owners shall, at the request of any of them, deliver to each other a confirmation of the manner of mutual settlement, unless they concluded the agreement to cancel co-ownership in a movable thing in writing.

(2) In the case of settlement of co-ownership to an immovable thing which is registered in a public register, new rights of ownerships are created upon registration in the public register.

\section{Protection of third persons in the division of an undivided thing}

$$
\text { Section } 1150 \text { [Recodification] }
$$

thing.

The division of an undivided thing is without detriment to the person who possesses a right in rem to the undivided

\section{Section 1151 [Recodification]}

When dividing a dominant thing, the easement typically continues to encumber all its parts; however, it may not be extended or become more difficult. An easement which is only created in favour of some of the parts is extinguished with regard to other parts.

\section{Section 1152 [Recodification]} other parts.

If an encumbered thing is divided and if the easement only affects a certain part, the easement is extinguished on 


\section{Section 1153 [Recodification]}

(1) Where a right arising from a servitude or another encumbrance provides a right to the fruits or revenues:

a) each of the entitled persons if a dominant thing is divided, or

b) where a servient thing is to be divided, each of the persons charged with servitude may apply to a court to regulate the exercise of the right.

(2) A court shall regulate the exercise with regard to the nature and purpose of the encumbrance, as well as with regard to the economic particularities of individual parts, so that the result conforms to the principles of decency and the encumbrance does not increase.

\section{Deferral of cancellation of co-ownership}

\section{Section 1154 [Recodification]}

(1) A stipulation between the co-owners not to request the cancellation of co-ownership for a definite period not exceeding ten years may not exclude any other subsequent stipulation. If the deferral of the cancellation of co-ownership has been stipulated for a period of more than ten years, it is considered to have been stipulated for ten years. Deferral of cancellation of co-ownership may also be stipulated repeatedly.

(2) Where the stipulation to defer the cancellation of co-ownership is also to bind the co-owners' legal successors whose legal succession is created in a manner other than by inheritance or transformation of a legal person, such a stipulation must be expressly contained therein.

(3) The stipulation to defer the cancellation of co-ownership requires the form of a public instrument; where the stipulation concerns an immovable thing registered in a public register, the deferral of the cancellation of co-ownership is registered in the public register.

\section{Section 1155 [Recodification]}

(1) On the application of a co-owner, a court may defer the cancellation of co-ownership if it is to avoid property loss or a serious threat to a lawful interest of any of the co-owners, thus extending the duration of co-ownership by a maximum of two years.

(2) Cancellation of co-ownership may also be deferred by a disposition mortis causa.

\section{Section 1156 [Recodification]}

Deferral of cancellation of co-ownership may later be changed by an agreement among the co-owners, and in the absence thereof, by a court decision issued on the application of a co-owner who proves that he may not be reasonably required to remain involved in the co-ownership, or that there has been a significant change in circumstances due to which the deferral of co-ownership occurred.

$$
\text { Section } 1157 \text { [Recodification] }
$$

\section{Deferral of separation from co-ownership}

The separation from co-ownership is governed by Sections 1154 to 1156 by analogy.

\section{Division 5}

\section{Residential co-ownership}

\section{Subdivision 1}

\section{General provisions}

Section 1158 [Recodification]

(1) Residential co-ownership is a co-ownership of an immovable thing created by the ownership of units. Residential co-ownership may be created where a building with at least two apartments forms the component part of the immovable thing

(2) The provisions of this Division on apartments also apply to non-residential premises as well as to a set of apartments or non-residential premises.

\section{Section 1159 [Recodification]}

A unit includes an apartment as a spatially separated part of a building and a share in the common areas of an interconnected and inseparable immovable thing. A unit is an immovable thing.

\section{Common areas}




\section{Section 1160 [Recodification]}

(1) Common areas shall at least include those parts of an immovable thing which, by their nature, are intended to collectively serve the unit owners.

(2) Common areas always include the tract of land on which the building has been erected, or an easement creating the right of the unit owners to have the building on the tract of land, construction elements essential to maintaining the building, including its main structures, its shape and appearance, as well as to maintaining the apartment of another unit owner, and the facilities also serving another unit owner to use the apartment. This also applies in the event that a certain part is relinquished to a unit owner for exclusive use.

\section{Section 1161 [Recodification]}

If the shares in the common areas are not determined having regard to the nature, size and location of the apartment, or are determined as being the same, they are conclusively presumed to be determined as a ratio of the floor area to the total floor area of all apartments in the building.

\section{Section 1162 [Recodification]}

(1) If the shares in the common areas are determined in a manner other than as the ratio of the floor area of an apartment to the total floor area of all apartments in the building, or as being the same, a unit owner has the right to seek a change of this determination if the circumstances have changed so significantly that the determination of his share in the common areas is evidently unfair.

(2) If, on the proposal of a unit owner, the declaration (Section 1169) is not changed, it is changed by a court.

\section{Subdivision 2}

\section{Creation of a unit}

\section{Section 1163}

\section{Construction}

If parties have undertaken to do so in connection with the construction or change of a building, a unit is created by construction if the building is at least in such a state of completion that it is already enclosed by perimeter walls and a roof structure on the outside, and the apartment is enclosed by perimeter walls.

Section 1164

\section{Registration in a public register}

(1) A unit is created by registration in a public register if the owner or a person authorised to do so under another right in rem makes a statement dividing his right in the building and tract of land into the right of ownerships in units.

(2) A unit is also created by registration in a public register if so stipulated by the co-owners in case of its separation from, or cancellation and settlement of, the co-ownership, or if so stipulated by spouses in case of a change in the scope or settlement of community property. The provisions on declaration apply to this stipulation with the necessary modifications.

\section{Section 1165}

\section{Decision of a court}

A unit is created if so decided by a court in case of separation from co-ownership, cancellation and settlement of coownership, or reducing the scope or settlement of community property.

\section{Declaration}

\section{Section 1166} minimum:

(1) When dividing a right in an immovable thing into the right of ownerships to units, the following is provided as a

a) information on the tract of land, building, municipality and cadastral area,

b) information on the unit, including, without limitation:

1. Name and designation of individual apartments by at least a number and location specifying the purpose of use,

2. Specification and description of common areas with regard to their structural, technical or user nature and, where appropriate, specifying which of them are reserved for the exclusive use by the owner of a given unit,

3. percentage of the shares in the common areas,

c) the rights in rem and other rights and defects which pass to all unit owners or only to some of them upon the creation of the right of ownership. 
(2) If the division is to create at least five units, of which at least three are to be owned by three different owners, the declaration shall include the elements of the articles of association of unit owners (hereinafter an "association of unit owners"). If no association of unit owners is created in relation to the division, the declaration of an administrator shall determine the building administration rules, rules for the use of the common areas and the fees related to the costs associated with the administration of the building and tract of land.

(3) The declaration is accompanied by plans of all floors, or a figure thereof, determining the location of the apartments and common areas of the building, together with information of the floor areas of the apartments.

\section{Section 1167}

If the right of ownership in the units is registered in a public register, the declaration may not be declared invalid and it may not be determined that the right of ownership in a unit was not created where the right in rem in the unit has been acquired by another person.

$$
\text { Section } 1168 \text { [Recodification] }
$$

\section{Removing a defect in a declaration}

(1) If a declaration defines a unit vaguely or incorrectly and if the declarant fails to remove the defect without undue delay after being notified of the defect by a person with a legal interest therein, the defect may be removed by the owners of the affected units by means of a joint declaration. Failing that, the decision to remove the defect is made by a court on the application of the person with a legal interest therein.

(2) If a declaration determines a unit owner's share in the common areas vaguely or incorrectly, it is disregarded.

$$
\text { Section } 1169 \text { [Recodification] }
$$

\section{Changing the declaration}

(1) Unit owners may change the declaration. If a unit is encumbered, the declaration may be changed with the prior consent of the person entitled under a right in rem.

(2) The declaration may be changed subject to the agreement of the affected unit owners to change their rights and duties, which is to be concluded in writing. The agreement becomes effective if a written consent to it is given by unit owners with a majority of votes or, where applicable, with a qualified majority of votes determined in the declaration, even where they are not parties to the agreement.

\section{Subdivision 3}

\section{Construction of a building with units \\ Section 1170 [Recodification]}

\section{Contract for construction}

(1) By concluding a contract for construction, the parties undertake to jointly participate in constructing, completing or changing the building for the purpose of creating or changing units. The rights and duties of the parties are governed, with the necessary modifications, by the provisions of this Act on a partnership.

(2) In the contract, the parties shall at least stipulate the following:

a) the information determined as the elements of a declaration on the division of the right in the building and tract of land into the right of ownerships in units,

b) the method of payment of the construction costs or, where applicable, the valuation of the work performed by self-help,

c) the percentage of the co-ownership shares in the building and, if the building is to be a component part of the tract of land, the percentage of the co-ownership shares in the tract of land for a period until the first unit is constructed; the percentage of the co-ownership percentage is proportional to the unit owner's share in the common areas, and

d) if a building with at least five units is to be constructed, the elements of the articles of the association of unit owners, unless already created.

(3) The contract must be in writing.

\section{Section 1171}

If a contract for construction is concluded when the building is already at a certain stage of completion, but the construction of apartments has not yet begun, the parties shall stipulate the percentage of their shares in the immovable thing in proportion to the percentage of their co-ownership shares as future unit owners in the common areas.

\section{Section 1172}

(1) If a unit is to be constructed as an extension on, annex to, or a construction alteration of a building, and if units have not yet been defined in the building, the parties shall also contractually stipulate the definition of the units in the building, 
and the owner or a person entitled to do so under another rights in rem shall transfer the co-ownership share in the immovable thing to the person interested in acquiring a new unit in the percentage proportional to the percentage of his co-ownership share as a prospective unit owner in the common areas.

(2) If a new unit is to be constructed or if an existing unit is to be changed by an extension, annex, or a construction alteration in a building where units have already been defined, the parties shall also contractually stipulate the resizing of their co-ownership shares following the creation of a new unit or change of an existing unit and the transfer of such shares, in such a way that they are proportional to the newly defined percentage of co-ownership shares.

\section{Section 1173}

Unless the contract for construction contains an express stipulation on variations from the definition of units, construction is considered properly done if the variation is only slight and the affected co-owner should and could have reasonably expected it. If the parties fail to agree, a court shall decide the manner in which to settle the consequences of variation from the determination of units.

\section{Section 1174}

(1) If the result of a construction is a building, the parties continue to co-own the immovable thing under undivided coownership until the creation of the units. ownership.

(2) Upon the creation of a unit, the undivided co-ownership of an immovable thing changes into residential co-

\section{Subdivision 4}

\section{Rights and duties of a unit owner}

\section{Section 1175}

(1) A unit owner has the right to freely administer, exclusively use and make interior construction alterations to his apartment as well as use the common areas, but may not hinder the exercise of the same rights by another unit owner, or jeopardise, change or damage the common areas.

(2) A unit owner shall keep his apartment as required to maintain a defect-free condition and good appearance of the building; the same applies to the common areas reserved to be exclusively used by a unit owner.

\section{Section 1176}

Upon the creation of the right of ownership in a unit, the unit owner becomes obliged to follow the building administration rules and the rules for the use of the common areas if he was acquainted with these rules or should and could have known them, as well as to ensure compliance with these rules by persons who are provided access to the building or apartment by the unit owner.

\section{Section 1177 [Recodification]}

(1) A person who has acquired the right of ownership to a unit shall notify the unit owners of such an acquisition, including his addresses and the number of persons who will use the apartment as their household, through the person responsible for administering the building no later than one month from the date on which he learned or could have learned that he became an owner. This applies by analogy to the change of information contained in the notice.

(2) The unit owner shall, without undue delay, inform the person responsible for the administration of the building of a change in the number of persons who use the apartment as a household and live in it for a total period of at least three months in one calendar year. This applies even where the unit owner has relinquished the apartment another person for use; in such a case, he shall also provide the name and address of that person.

\section{Section 1178 [Recodification]}

If so requested by a unit owner, the person responsible for the administration of the building shall provide to him the name and address of any unit owner or lessee in the building.

\section{Section 1179 [Recodification]}

A unit owner has the right to become familiar with the economic management and the administration of the building and tract of land carried out by the person responsible for the administration of the building. A unit owner may inspect contracts concluded in matters of administration, as well as accounting books and documents kept with that person.

\section{Section 1180 [Recodification]}

(1) Unless determined otherwise, a unit owner shall contribute an amount corresponding to his share in the common areas to the administration of the building and the tract of land. If any of the common areas is reserved for the exclusive use by one of the unit owners, the amount of the fee is also determined with regard to the nature, size and location of that area and the extent to which the unit owner is obliged to administer that area at his own expense.

(2) The fees intended to be used to reward the person administering the building or the members of its bodies, and to pay bookkeeping and similar costs associated with the actual administrative activities, are apportioned among the units equally. 


\title{
Section 1181
}

(1) A unit owner shall pay advance payments for performances connected with or related to the use of the apartment (utilities) and has the right to be presented the accounts of the advance payments by the person responsible for the administration of the building, typically no later than within four months from the end of the billing period.

(2) If no due date for underpaid or overpaid advance payments is set, they are due on the same day of the month within three months after the expiry of the time limit under Subsection (1)

\section{Section 1182 [Recodification]}

If a unit owner makes construction alterations to his apartment, he shall allow his apartment to be accessed in order to check whether the construction alterations do not jeopardise, damage or change the common areas if previously requested to do so by the person responsible for the administration of the building.

\section{Section 1183}

(1) A unit owner shall refrain from everything that prevents the maintenance, repair, alteration, reconstruction and other changes to the building or tract of land, the decision on which was duly made; if carried out inside an apartment or in a common area intended to be exclusively used by a unit owner, the unit owner shall allow it to be accessed if previously requested to do so by the person responsible for the administration of the building. This also applies to the placement, maintenance and inspection of equipment for measuring the consumption of water, gas, heat and other utilities.

(2) If damage to a unit occurs as a result of the work under Subsection (1), the damage is compensated to the unit owner by the association of unit owners, or, in its absence, on a pro-rata basis by the co-owners of the building. However, if only one unit owner carried out this work in his own interest, he shall compensate the damage himself.

\section{Section 1184 [Recodification]}

On the application of the person responsible for the administration of the building or the affected unit owner, a court may order the sale of a unit of the owner who breaches a duty imposed on him by an enforceable court decision in a manner substantially limiting or precluding the rights of other unit owners.

\section{Section 1185 [Recodification]}

\section{Co-ownership of a unit}

(1) A unit owner may divide his right in a unit into shares, unless it has been excluded.

(2) The co-owners of a unit shall authorise a joint representative to exercise their rights against the person responsible for the administration of the building. This also applies to spouses whose unit is part of community property.

\section{Special provisions on transfer of a unit}

\author{
Section 1186 [Recodification]
}

(1) When transferring the right of ownership in a unit, the person responsible for the administration of the building does not become obliged to settle the building administration fees as of the effective date of the transfer.

(2) If an owner transfers the right of ownership in a unit, he shall present a confirmation issued by the person responsible for building administration to the acquirer, thereby documenting the debts associated with the administration of the building and tract of land which will pass to the acquirer of the unit, or the absence of such debts. The transferor is liable as a surety to the person responsible for the administration of the building for the debts that passed to the acquirer of a unit.

\section{Section 1187 [Recodification]}

(1) Where a unit was created by dividing the right in a building or tract of land into the right of ownerships in units, a lessee of an apartment has a pre-emptive right to the unit upon its first transfer. This also applies in the case of a lease of nonresidential premises, if leased in connection with an apartment in the same building. A pre-emptive right is extinguished if the lessee does not accept the offer within six months from its effective date.

(2) If the lessee is a legal person, the provision of Subsection (1) does not apply.

\section{Section 1188 [Recodification]}

(1) If a unit is created in a building owned or co-owned by a legal person, and if the lessee is a member or shareholder of the legal person who participated in the acquisition of the immovable thing by providing work or property interest, the right of ownership in the unit may only be transferred to that lessee. This also applies if a legal predecessor of the member or shareholder participated in the acquisition of the immovable thing.

(2) If another legal regulation requires that in order for a transfer to be valid the value of the property being transferred be determined based on the opinion of an expert appointed by a court, its provisions do not apply.

\section{Subdivision 5}




\section{Administration of a building and tract of land}

\section{Section 1189}

(1) The administration of a building and tract of land includes everything which does not pertain to the unit owner and which is necessary or effective in the interest of all for the proper care of the building and tract of land as a functional whole and the maintenance or improvement of common areas. Administration of the building also includes activities associated with the preparation and implementation of changes to the common areas of the building by way of extensions, annexes, construction alterations or changes in use, as well as the establishment, maintenance or improvement of facilities in the building or on the tract of land serving all co-owners of the building. co-owners.

(2) The administration is presumed to also apply to the common areas, which are used exclusively by only one of the

$$
\text { Section } 1190 \text { [Recodification] }
$$

The association of unit owners is the person responsible for administering the building and tract of land. In its absence, the administrator is the person responsible for the administration of the building.

\section{Administration in the absence of the association of unit owners}

\section{Section 1191 [Recodification]}

In the absence of an association of unit owners, the administration is governed by the rules specified in the declaration and the decision-making in matters of administration is governed, with the necessary modifications, by the provisions on assemblies; the administrator shall convene the unit owners of units to make decisions.

\section{Section 1192 [Recodification]}

(1) If a unit owner's share in the common areas exceeds one half, he becomes the administrator. In the absence of such a unit owner, the unit owners shall choose the administrator by majority vote. On the application of a unit owner, a court shall remove an administrator and appoint a new one, if justified by an important reason.

(2) An administrator may independently do what is necessary to maintain the property under administration; if determined otherwise, it is disregarded. This does not apply to decisions on matters which fall within the scope of competence of the assembly under this Act.

\section{Section 1193 [Recodification]}

When unit owners make decisions, the administrator's votes which exceed the sum of the votes of all other unit owners are disregarded if the building has fewer than five units.

\section{Association of unit owners}

\section{Section 1194}

(1) An association of unit owners is a legal person formed for the purpose of ensuring the administration of a building and tract of land; in fulfilling its purpose, it has the capacity to acquire rights and assume duties. An association of unit owners may not directly pursue business activities or be indirectly involved in the business or other activities of entrepreneurs or be their shareholder or member.

(2) Membership in an association of owners is indivisibly connected with the ownership of a unit. A member is liable as a surety for the debts of the association of unit owners in proportion to the percentage of his share in the common areas.

\section{Section 1195}

(1) An association of unit owners may acquire and dispose of property only for the purpose of administering the building and tract of land.

(2) Juridical acts whereby an association of unit owners secures the debt of another person are disregarded.

\section{Section 1196}

(1) An association of unit owners may, within the scope of its purpose, make juridical acts with regard to the unit owners and third persons.

(2) If unit owners acquire rights due to a defect of their units, the association of unit owners shall represent the unit owners in the enforcement of these rights.

\section{Section 1197}

If an association of unit owners unites with another association of unit owners to cooperate in the fulfilment of its purpose, or if it becomes a member of a legal person bringing together associations of unit owners or unit owners, or otherwise engaged in housing, it may not undertake to provide a property interest other than one-off membership contributions or recurring membership fees. If an association of unit owners undertakes to share the loss of another person, or pay or secure its debts, it is disregarded. 


\section{Section 1198 [Recodification]}

(1) If an association of unit owners has not been previously formed, it is formed by unit owners where there are at least five units of which at least three are owned by three different owners, no later than after the creation of the right of ownership in the first unit transferred.

(2) The right of ownership in other transferred units is not registered in a public register, unless the creation of the association of unit owners has been proved. This does not apply when the right of ownership in a unit is acquired by the first owner.

\section{Section 1199 [Recodification]}

In case of a building with less than five units, an association of unit owners may be formed subject to the consent of all unit owners.

$$
\text { Section } 1200 \text { [Recodification] }
$$

\section{Formation of an association of unit owners}

(1) An association of unit owners is formed by the approval of the articles of association. If an association of unit owners has not been formed by a declaration on the division of the right in the building and tract of land into the right of ownership in units, or by a stipulation in the contract for construction, the approval of the articles of association requires the consent of all unit owners.

(2) The articles of association shall contain at least:

a) the name containing the words "společenství vlastníkư" (association of unit owners) and the identification of the building for which the association of unit owners was established,

b) the registered office determined in the building for which the association of unit owners was created; if impossible, another suitable place is determined,

c) membership rights and duties of unit owners, as well as the manner in which they are enforced,

d) determination of the bodies, their competence, the number of members of elected bodies and their term of office, as well as the manner in which they are convened, their meetings are held and decisions made,

e) the determination of the first members of the governing body,

f) rules for the administration of the building and tract of land and the use of common areas,

g) rules for the creation of the association's budget, for administration fees and reimbursement of service costs, and the manner in which the amounts paid by individual unit owners is determined.

(3) Articles of association must be in the form of a public instrument. This does not apply if an association is formed by a declaration on the division of the right to the building and tract of land into the right of ownership in units by a stipulation in the contract for construction.

\section{Section 1201 [Recodification]}

If an association of unit owners has been formed by a declaration on the division of the right in the building and tract of land into the right of ownership in units, or by a stipulation in the contract for construction, amendments to the articles of association carried out before the association of unit owners was created are disregarded.

\section{Section 1202 [Recodification]}

(1) As long as a founder of the association of unit owners has a majority of votes, he is the administrator of the building and tract of land. For this purpose, the parties to the contract for construction are considered to be one person.

(2) Administration is governed by the rules specified in the declaration, and the provisions on assemblies apply by analogy to decision-making in matters of administration. The administrator shall convene the unit owners to make decisions; in making decisions, the administrator's votes which exceed the sum of the votes of all other unit owners are disregarded.

\section{Section 1203 [Recodification]}

If the administrator loses the majority of votes, he shall, no later than within sixty days, acting as the governing body of the association of unit owners, file an application for the registration of the association of unit owners in a public register, and shall convene an assembly no later than within ninety days. Failing that, it may be done by any unit owner.

\section{Section 1204 [Recodification]}

\section{Incorporation of an association of unit owners}

An association of unit owners is incorporated on the date of its registration in a public register. 


\section{Bodies of an association of unit owners}

(1) The assembly is the supreme body of an association of unit owners. The committee is the governing body, unless the articles of association provide that the chairman of the association of unit owners is the governing body. If the articles of association provide for other bodies, they may not be given the scope of competence reserved for the assembly or the governing body.

(2) A person eligible to be a member of an elected body or a representative of a legal person as a member of such a body must have full legal capacity and have no criminal record within the meaning of another legal regulation governing trade business.

\section{Assembly}

\section{Section 1206}

(1) An assembly consists of all unit owners. Each of them has a number of votes equal to the percentage of his share in the common areas; however, if the unit is owned by an association of owners, his vote is disregarded.

(2) An assembly achieves a quorum by the presence of unit owners having a majority of votes. Adopting a decision requires the affirmative vote of a majority of the votes of the attending owners, unless the articles of association or a statute require a higher number of votes.

\section{Section 1207}

(1) The governing body shall convene the assembly so that a session is held at least once a year. The governing body shall also convene the assembly on the initiative of least two owners who have more than a quarter of all votes; failing that, these owners shall themselves convene the assembly at the expense of the association of unit owners.

(2) If the invitation lacks attached documents relating to the agenda of the session, the convener shall provide each unit owner with the opportunity to become familiar with them in due time.

\section{Section 1208 [Recodification]}

The scope of competence of the assembly includes:

a) amending the articles of association,

b) changing the declaration on the division of the right in the building and tract of land into the right of ownership in units,

c) the election and removal of members of elected bodies, and deciding on the amount of their remuneration,

d) approving the financial statements, settlement of profit/loss and the report on the business management of the association of unit owners and the administration of the building, as well as the total amount of building administration fees for the next period and a decision on the account for or settlement of unspent fees,

e) approving the type of services and the amount of advance payments to pay these services, as well as the method of billing each unit for these services,

f) making decisions:

1. On the membership of the association of unit owners in a legal person engaged in housing,

2. on changing the purpose of use of the building or apartment,

3. on changing the floor area of an apartment,

4. on fully or partially merging or splitting units,

5. on changing a share in the common areas,

6. on changing the purpose of a common area exclusively used by one of the unit owners,

7. on repairing or making construction alterations to a common area of the building, if the costs exceed the amount provided by an implementing legal regulation; this does not apply if otherwise provided by the articles of association,

g) granting prior consent:

1. to acquire, alienate or encumber immovable things or to otherwise dispose of them,

2. to acquire, alienate or encumber movable things whose value exceeds the amount provided by an implementing legal regulation, or to otherwise dispose of them; this does not apply if otherwise provided by the articles of association,

3. to conclude a credit contract on behalf of the association of unit owners, including the approval of the amount and the terms of the loan,

4. to conclude an agreement creating a pledge on a unit, if the affected unit owner consented to the pledge agreement in writing,

h) to determine the person to provide for certain activities related to the administration of the building and tract of land,

and decide to change the person, as well as to approve a contract with such a person and approve changes in the contract relating to the stipulations on price and the scope of activities,

i) to decide on other matters provided by the articles of association, or on matters reserved by the assembly for decision. 
(1) If justified by an important reason, an outvoted unit owner, or the association of unit owners if it is the owner of a unit, may apply to a court for a decision on the matter; within that context, it may also move the court to temporarily prohibit acts based on the contested decision. If the application is not filed within three months from the date on which the unit owner learned or could have learned of the decision, his right is extinguished.

(2) If justified by an important reason, any unit owner may apply to the court for a decision on a matter which was properly submitted to the assembly for decision, but which was not decided due to a lack of quorum in the assembly.

\section{Decision-making outside meetings}

\section{Section 1210 [Recodification]}

(1) If an assembly which has been convened lacks a quorum, the person who is authorised to convene the assembly may propose in writing within one month from the date for which the meeting was convened that the unit owners decide on the same matters out of session.

(2) In other cases, out-of-session decisions may be made if permitted by the articles of association.

\section{Section 1211 [Recodification]}

The proposal must contain at least a draft resolution, the documents required for its assessment or the place where they are available, and an indication of the time limit in which a unit owner is to provide his statement. Unless a longer time limit is provided by the articles of association, the time limit is conclusively presumed to be fifteen days.

\section{Section 1212 [Recodification]}

In order for a vote to be valid, a unit owner must provide his statement indicating the date, month and year it was made, signed by his own hand on the instrument containing the full text of the draft decision.

\section{Section 1213 [Recodification]}

The governing body shall notify the unit owners of the outcome of the vote in writing, and if the resolution has been adopted, it shall provide them with the entire content of the resolution adopted. If it fails to do so without undue delay, the resolution may be provided at the expense of the association of unit owners by the person who proposed the resolution.

\section{Section 1214 [Recodification]}

Decisions are made by the majority vote of all unit owners, unless the articles of association require a higher number of votes. However, when changing the percentage of the shares of all the unit owners in the common areas or the ratio of the fees for the administration of the building and tract of land otherwise than as a result of a change in the shares in the common areas, the consent of all unit owners is required.

\section{Dissolution of an association of unit owners}

\section{Section 1215}

(1) An association of unit owners is dissolved on the date on which the right of ownership in all units in the building is extinguished.

(2) An association of unit owners may be dissolved by a decision of unit owners, if formed voluntarily, or if the number of units in the building dropped below five. In this case, the unit owners shall adopt rules for the administration of the building and tract of land and for the fees for such administration.

\section{Section 1216 [Recodification]}

No liquidation takes place upon the dissolution of an association of unit owners. On the date of its extinction, the rights and duties of an association of unit owners pass to the unit owners in the ratio determined by each unit owner's share in the common areas.

\section{Subdivision 6}

\section{Cancellation of residential co-ownership}

\section{Section 1217}

(1) Subject to an agreement among the unit owners on the transformation of residential ownership into an undivided co-ownership of an immovable thing, the residential ownership changes into undivided co-ownership upon the registration in a public register. The percentage of co-ownership share of each co-owner is presumed to be equal to the percentage of the share in the common areas which he had as a unit owner.

(2) If all units in a building are part of community property and if the spouses agree to transform the residential ownership into the ownership of an immovable thing included in community property, the residential ownership shall change to the ownership of an immovable thing included in community property upon its registration in a public register. 
(3) The agreement under Subsections (1) and (2) must be in writing.

\section{Section 1218}

(1) If a single owner has the right of ownership in all units in the building and declares that he will change the right of ownership in units to the right of ownership in an immovable thing, residential ownership is extinguished upon the registration in a public register.

(2) The declaration must be in writing.

\section{Section 1219}

If a unit is encumbered, the agreement or declaration on the extinction of residential ownership is valid only if the person entitled under a right in rem grants his consent in writing.

\section{Subdivision 7}

\section{Common provisions}

\section{Section 1220}

(1) If a declaration changes, the person responsible for building administration shall prepare its full text and file it, without undue delay, in the collection of instruments kept by the body maintaining the public register in which the immovable thing is registered; this does also apply if the elements of the declaration are contained in the contract for construction.

(2) If the person responsible for building administration is registered in a public register, it shall, without undue delay, also file the full text of the declaration in the collection of instruments kept by the body maintaining the public register.

\section{Section 1221 [Recodification]}

Unless something else follows from the provisions on associations of unit owners, the provisions on associations apply with the necessary modifications. However, the provisions on assemblies of delegates, partial members' meetings and alternate members' meetings do not apply.

\section{Section 1222}

An implementing legal regulation provides the manner by which to calculate the floor area of an apartment in a unit, what areas of an immovable thing are presumed to be common, and the details on the activities related to the administration of the building and tract of land.

\section{Division 6}

\section{Co-ownership of an accessory thing}

\section{General provisions}

\section{Section 1223 [Recodification]}

(1) A thing which belongs jointly to several owners of individual things intended for such use in a way that these things create a defined whole as to their location and purpose, and which serves a common purpose in a way that the use of the individual things is not reasonably possible without the thing, pertains to these owners as co-owners of an accessory thing. If coownership of an accessory thing concerns an immovable thing registered in a public register, the co-ownership of the accessory thing is also registered in that public register.

(2) Provisions on co-ownership of an accessory thing shall also apply, with the necessary modifications, to facilities jointly purchased or otherwise acquired by the owners under Subsection (1) in such a way that they serve all of them.

\section{Section 1224 [Recodification]} co-owners.

(1) A co-owned accessory thing may not be removed from serving the common purpose against the will of one of the

(2) A co-owned accessory thing may only be encumbered in a way that does not prevent its use for a common purpose.

\section{Section 1225 [Recodification]}

(1) None of the co-owners may be prevented from participating in the use of a co-owned accessory thing in a way that is in line with the common purpose and does not prevent it to be used by other co-owners.

(2) If one of the co-owners waives his right to participate in the use of a co-owned accessory thing, it shall not affect his legal successors. 
If a co-owned accessory thing serves the joint use of a tract of land, the co-owners' shares in an undivided thing is determined according to their share of the area of the tract of land. This does not prevent co-owners from stipulating a different amount of their share.

\section{Section 1227 [Recodification]}

(1) A share in a co-owned accessory thing may only be transferred when the right of ownership in the thing, the use of which the co-owned accessory thing serves, is simultaneously transferred. Where the right of ownership in such a thing is transferred, the transfer is conclusively presumed to also apply to the share in a co-owned accessory thing.

(2) This also applies to an encumbrance by a pre-emptive right, right to repurchase or similar, as well as to the creation of a pledge or similar security.

\section{Section 1228 [Recodification]}

(1) Separation from co-ownership of an accessory thing is possible on condition that the thing the use of which the coowned accessory thing hitherto served ceased to exist or changed its purpose, so that the co-owned accessory thing is no longer needed.

(2) For the same reason, any of the other co-owners may apply to the court to cancel a co-owner's participation in coownership of an accessory thing, and order that his share be transferred for consideration to the remaining co-owners in proportion to their shares.

\section{Section 1229 [Recodification]}

If a co-owned accessory thing loses its purpose, the co-ownership of an accessory thing is extinguished, and the coowners shall settle in accordance with the general provisions on the cancellation of co-ownership. As long as this purpose lasts, co-ownership of an accessory thing may not be cancelled.

\section{Administration of a co-owned accessory thing}

\section{Section 1230 [Recodification]}

Unless the co-owners agree otherwise, they shall elect one of the co-owners as the administrator to carry out routine administration of the co-owned accessory thing. If the co-owners fail to elect the administrator within three months, he is appointed by a court on the application of any of the co-owners.

\section{Section 1231 [Recodification]} has one vote.

(1) If no other agreement is reached, the co-owners shall elect the administrator by a majority vote; each co-owner

(2) A co-owner who did not vote for the administrator may apply to a court to remove the administrator, if justified by an important reason, and to appoint another co-owner as the administrator. If the application is not filed within thirty days from the receipt of the decision, the right to file the application is extinguished.

\section{Section 1232 [Recodification]}

If a co-owner assumes routine administration of a co-owned accessory thing of his own will and none of the other coowners challenges it for three months or files the application under Section 1230, he is considered to have been elected the administrator.

\section{Section 1233 [Recodification]}

(1) Unless stipulated otherwise, co-owners may remove an administrator by a majority vote; however, if an administrator has been appointed by a court, co-owners may remove him by at least two-thirds of their votes.

(2) Regardless of the manner in which an administrator has been selected, a court shall remove him, if justified by an important reason, on an application filed by co-owners having at least a third of the votes.

\section{Section 1234 [Recodification]}

Juridical acts of an administrator made in matters of ordinary administration oblige and entitle the co-owners and the administrators jointly and severally.

\section{Section 1235 [Recodification]}

(1) Co-owners shall contribute to the administration of a co-owned accessory thing in proportion to the percentage of their shares. To cover the costs associated with the administration of a co-owned accessory thing, the co-owners shall pay a reasonable advance payment into the hands of the administrator; unless agreed otherwise, the advance payment is due on 31 January.

(2) The co-owners shall decide the amount of the advance payment by a majority vote. If the co-owners fail to adopt such a decision by the end of the preceding year, the total amount of the advance payments for the following year is conclusively presumed to be determined by the amount paid in advance payments in the last year increased by a tenth. If the total amount of advance payments may not be so determined, it is determined by a court on the application of the administrator. 


\title{
Division 7
}

\section{Special provisions on community of assets and liabilities}

\author{
Section 1236 [Recodification]
}

If the right of ownership in a thing is acquired by several persons joined in a community by means of a contract, statute or another legal fact, whether it be spouses, persons joined in a family community, community of heirs or other similar communities, each of the persons is conclusively presumed to have the right to the entire thing.

\section{Section 1237 [Recodification]}

The rights and duties of the owners joined in a community are governed by the provisions under which the community was created. The provisions of Sections 1238 and 1239 apply, unless otherwise provided.

\section{Section 1238 [Recodification]}

(1) Unless stipulated otherwise, a unanimous decision of all the attendees is required to exercise the right of ownership in the undivided thing and dispose thereof.

(2) Unless stipulated otherwise, it is impossible to claim the division of an undivided thing while the community lasts, or to dispose of a share in an undivided thing.

\section{Section 1239 [Recodification]}

The right of ownership in an undivided thing is extinguished upon its alienation or the extinction of the community; settlement is governed by the provisions on co-ownership.

\section{Chapter 5}

\section{Rights in rem in things of others}

\section{Division 1}

\section{Right of superficies}

\section{Subdivision 1}

\section{General provisions}

\section{Section 1240 [Recodification]}

(1) A tract of land may be encumbered with another person's (a builder's) right in rem entitling the person to have a structure on the surface or below the surface of the tract of land. This applies regardless of whether or not the structure has already been erected.

(2) The right of superficies may be created in a way that it also applies to the tract of land which, although not required for the structure, serves to improve its use.

$$
\text { Section } 1241 \text { [Recodification] }
$$

The right of superficies may not be created with respect to a tract of land encumbered with a right which goes against the purpose of the structure. If a tract of land is encumbered with a pledge, it may only be encumbered with a right of superficies with the consent of the pledgee.

$$
\text { Section } 1242 \text { [Recodification] }
$$

The right of superficies is an immovable thing. A structure conforming to the right of superficies forms its component part, but is also subject to the provisions on immovable things.

\section{Subdivision 2}

\section{Creation and extinction of the right of superficies}

\section{Section 1243 [Recodification]}

(1) The right of superficies is acquired by contract, acquisitive prescription or, where provided by a statute, by a decision of a public body.

(2) A right of superficies created by contract is created by registration in a public register. A right of superficies created by a decision of a public body is also subject to registration in a public register. 
(1) The right of superficies may only be created as a temporary right; it may not be created for more than 99 years. The last day of the period for which the right of superficies is created must be evident from a public register.

(2) If a builder has acquired the right of superficies by acquisitive prescription, he shall acquire it for 40 years. If justified by a just cause, a court may, on the application of an affected party, reduce or extend the period for which the right of superficies is created.

\section{Section 1245 [Recodification]}

The duration of the right of superficies may be extended with the consent of the persons in whose favour encumbrances are registered on the tract of land in the order after the right of superficies.

$$
\text { Section } 1246 \text { [Recodification] }
$$
is disregarded.

The right of superficies may not be restricted by a resolutive condition; if a resolutive condition has been stipulated, it

$$
\text { Section } 1247 \text { [Recodification] }
$$

If the right of superficies has been created for consideration and the consideration has been stipulated to be paid in recurring fees as a superficies payment, the encumbrance by the right of superficies is that of a real burden. A stipulation under which the changes in the amount of the superficies payment are conditional on an uncertain future event is disregarded; this does not apply if the superficies payment is stipulated as conditional on the rate of appreciation and depreciation of money.

\section{Section 1248 [Recodification]}

If a builder renounces the right of superficies, the owner of the encumbered tract of land may, on the basis of instruments proving this fact, transfer the right of superficies to himself or to another person for a period which has not yet expired.

\section{Section 1249 [Recodification]}

If the right of superficies is extinguished before its period has expired, the legal consequences of the deletion of the right of superficies against a right in rem, which is held by a person for whom a right in rem encumbering the right of superficies was registered in a public register, shall occur only upon the extinction of such a right in rem. However, if the person consents to the deletion, the legal consequences of the deletion of the right of superficies against his right in rem shall occur as early as upon such deletion.

\section{Subdivision 3}

\section{Legal relations arising from the right of superficies}

\section{Section 1250 [Recodification]}

With regard to a structure conforming to the right of superficies, a builder has the same rights as the owner; in case the tract of land encumbered with the right of superficies is used otherwise, he has the same rights as a usufructuary, unless stipulated otherwise.

\section{Section 1251 [Recodification]}

(1) A contract may oblige a builder to complete the structure within a certain period.

(2) Unless stipulated otherwise, a builder has the duty to maintain the structure in good condition. A contract may oblige a builder to insure the structure.

(3) The right to approve a certain actual or juridical act made by a builder may be reserved for the owner of the tract of land; however, even if such a right is reserved for the owner of the tract of land, he may not withhold his consent to a juridical act which is not to his detriment.

\section{Section 1252 [Recodification]}

(1) The right of superficies may be transferred and encumbered.

(2) If the owner of the tract of land reserves the right to approve the encumbrance with the right of superficies, the reservation is registered in a public register. In this case, the encumbrance with the right of superficies may only be registered in a public register with the consent of the owner of the tract of land.

\section{Section 1253 [Recodification]}

The right of superficies passes to the heir and also to another general legal successor.

$$
\text { Section } 1254 \text { [Recodification] }
$$

A builder has the pre-emptive right to the tract of land and the owner of the tract of land has the pre-emptive right to the right of superficies. If the parties stipulate otherwise, it is registered in a public register. 


\section{Section 1255 [Recodification]}

In the absence of another stipulation, the owner of the construction tract of land shall provide the builder with compensation for the structure upon the extinction of the right of superficies by the expiry of the period for which it was created. The compensation amounts to half the value of the structure at the time of the extinction of the right of superficies, unless otherwise stipulated by the parties.

Section 1256 [Recodification]

Pledge and other rights attached to the right of superficies affect compensation.

\section{Division 2}

Easements

\section{Subdivision 1}

\section{General provisions on servitudes}

\section{Section 1257 [Recodification]}

(1) A thing may be encumbered with a servitude, which affects the owner of the thing as a right in rem in a way that he has to tolerate or abstain from doing something in favour of another.

(2) An owner may encumber his tract of land with a servitude in favour of another of his tracts of land.

\section{Section 1258}

A servitude includes everything which is required for its exercise. If the content or scope of a servitude is not determined, it is assessed in accordance with local usages; in their absence, it is presumed that there is rather less than more scope or content.

\section{Section 1259}

A person entitled under a servitude may seek protection of his rights; Sections 1040 to 1043 apply by analogy.

\section{Subdivision 2}

\section{Acquisition of servitude}

Section 1260 [Recodification]

(1) A servitude is acquired by contract, disposition mortis causa or acquisitive prescription for the period required to acquire by prescription the right of ownership in the thing which is to be encumbered with a servitude. A servitude is acquired on the basis of a statute or by a decision of a public body in cases provided by law.

(2) Where a servitude equivalent to a public thing is acquired by prescription, the municipality in whose territory the thing is located is the prescriptive acquirer.

\section{Section 1261}

A tract of land intended to function as a forest may be encumbered with a predial servitude, servitude of pasture or servitude of forest fruit picking only by contract, disposition mortis causa or decision of a public body. Such a servitude may be established only as redemptive, and the conditions for redemption must have already been determined before the servitude is established.

\section{Section 1262}

(1) Where a servitude on a thing registered in a public register is established by making a juridical act, it is created upon registration in such a register. Even where a servitude is created on a thing registered in a public register on the basis of another legal fact, it is registered in a public register.

(2) Where a servitude on a thing not registered in a public register is established, it is created on the effective date of the contract.

\section{Subdivision 3}

\section{Legal relations arising from a servitude}

\section{Section 1263}

An entitled person bears the cost of maintaining and repairing the thing which is intended for a servitude. However, if a thing is also used by a person charged with a servitude, he is obliged to proportionally contribute to the cost, or to refrain from use. 
(1) If the scope of a servitude is not determined, the need of the dominant land is decisive.

(2) A servitude does not change due to a change in the scope of the servient thing or dominant thing, or a change in the economic management of the dominant land.

\section{Section 1265}

(1) A predial servitude may not be combined with another dominant land.

(2) A personal servitude may not be transferred to another person.

(3) Rights in rem entitling a person to use the space below the surface may be created as alienable and heritable.

Section 1266

Multiple servitudes may be established on a thing, unless a later right is to the detriment of earlier rights.

\section{Subdivision 4}

\section{Certain predial servitudes}

\section{A servitude of public utilities}

\section{Section 1267 [Recodification]}

(1) A servitude of public utilities creates a right to set up on or lead through servient land water, sewage, energy, or other lines and operate and maintain them at one's own expense in a suitable and safe manner. An owner of the tract of land shall refrain from everything that may jeopardise the public utilities, and if consulted in advance with the owner, he shall allow an entitled person to enter the tract of land for the time and to the extent necessary for the inspection or maintenance of the public utilities.

(2) If expressly stipulated, a servitude includes the right to establish, have and maintain the necessary service facilities on the servient land, as well as the right to make alterations to the public utilities in order to modernise them or improve their performance.

(3) An entitled person shall make available to the owner of a tract of land the documents to the public utilities to the stipulated extent, and where no extent has been stipulated, to the extent necessary to protect his legitimate interests.

\section{Section 1268 [Recodification]}

If, due to sudden damage to the public utilities, a matter must be resolved without delay, its repair is provided for by an entitled person even without prior consultation; however, he shall immediately notify the affected persons of the repair works, and mark and secure the place. After completing the works, the entitled person shall, at his own expense, restore the servient land to its previous condition and provide compensation for the damage caused by executing the works.

Section 1269

\section{Support of a structure of another}

A person who is obliged to bear the weight of a structure of another shall also contribute to the maintenance of the walls or supports, but has no obligation with respect to the support of the dominant land.

\section{Section 1270}

\section{Servitude of eavesdrip}

(1) A person having a servitude of eavesdrip has the right to drain rainwater from his roof to an immovable thing of another, either freely or in a gutter; he may only elevate his roof if it poses no hindrance of the servitude.

(2) A person having a servitude of eavesdrip must maintain the drain gutter in a good condition where such a gutter is established. Also, when there is a lot of snow, he must promptly clear it.

\section{Section 1271}

\section{Right to channel rainwater from the roof of another}

(1) A person who has the right to channel rainwater from an adjacent roof to his tract of land shall pay all the costs of the necessary equipment.

(2) If a trench or a similar means is necessary to channel the rainwater, the costs of establishing and maintaining such a means are borne by the owner of the dominant land. 
(1) A person with the right to draw water from a tract of land of another shall also have access thereto.

(2) A person with the right to channel water from a tract of land of another to his own, or from his tract of land to the tract of land of another, may, at his own expense, erect and maintain the necessary facilities; their extent is determined by the needs of the dominant land.

\section{Section 1273}

\section{Servitude of flooding}

(1) A servitude of flooding entitles the owner of a water dam which enables controlled flooding to flood the servient land with water. The servitude also includes the right of the water dam's owner to have and maintain service facilities on the servient land, and if it is expressly stipulated, alter these facilities and the water dam in order to modernise them and improve their performance.

(2) The owner of the tract of land shall refrain from everything that may jeopardise the water dam and service facilities, and if consulted with the owner in advance, he shall allow an entitled person to access the tract of land for a time and to the extent necessary.

(3) The provisions of Section 1267(3) and Section 1268 apply by analogy.

\section{Servitudes of footpath, cattle path and passage}

\section{Section 1274}

(1) A servitude of footpath establishes the right to walk or exert human power to travel across the footpath, and the right entitling others to use the footpath to come to and leave the entitled person and exert human power to travel to that person.

(2) A servitude of footpath excludes the right to access the servient land by animals or drag loads across the servient land.

\section{Section 1275}

(1) A servitude of cattle path creates the right to drive animals across the servient land. The servitude of cattle path is also connected with the right to use any vehicles other than motor vehicles to travel across the tract of land.

(2) If the servient land is intended to function as a forest, it is forbidden to establish a servitude of cattle path. If a public body decides that servient land is intended to function as a forest after such a servitude has been established, the servitude is extinguished.

\section{Section 1276}

(1) A servitude of passage creates a right to use any vehicle to travel across the servient land.

(2) A servitude of passage does not include the right of cattle path.

(3) A person having the servitude of passage shall proportionately contribute to maintaining the passage, including bridges. The owner of the servient land shall contribute only if he uses those facilities.

\section{Section 1277}

The area used to exercise the servitude of footpath, passage or cattle path must be appropriate to the person's need and the place. If a footpath, passage or cattle path become impassable by accident, a person may claim that another area is reserved before they are restored to the previous condition.

\section{Right of pasture}

Section 1278

If the kind, amount of cattle or scope and time of pasture was not determined when creating the right of pasture, a peaceful ten-year possession is protected. If in doubt, the provisions of Sections 1279 to 1282 apply.

Section 1279

(1) The right of pasture covers every type of livestock except for pigs and poultry. Excessively dirty, sick or another person's animals are excluded from pasture.

(2) If the servient land contains forest cover, it is forbidden to establish a servitude of pasture.

\section{Section 1280}

(1) If the amount of cattle in pasture has changed in the past ten years, the average for the first three years of pasture is decisive. If even this amount is unclear, it is determined in accordance with the principles of decency and appropriately to the extent and quality of the pasture; however, an entitled person may not pasture more cattle on the servient land than can be fed over the winter with the forage supplied by the dominant land. 
(2) The amount under Subsection (1) shall exclude sucklings.

\section{Section 1281}

The pasture period is governed by local usages; however, due management of the tract of land may not be limited or hampered by pasture.

\section{Section 1282}

(1) A right of pasture does not include any other use. Typically, it does not even exclude the owner of the servient land from the right of common pasture.

(2) If there a threat of damage, cattle must be guarded.

\section{Subdivision 5}

\section{Right of use}

Section 1283

A servitude of the right of use provides the user with the right to use a thing of another for his own needs and those of his household. If these needs change after the servitude is established, it does not entitle the user to extend the servitude.

Section 1284

All the revenues that an owner of a thing may take without prejudice to a right of a user belong to such an owner. However, the owner bears all its defects and must maintain the thing in good condition. If the costs exceed the revenue that remains for the owner, the user must either bear these increased costs, or refrain from use.

\section{Usufruct}

\section{Section 1285 [Recodification]}

Usufruct grants the usufructuary the right to use a thing of another and take its fruits and revenues; the usufructuary also has the right to extraordinary yield from the thing. In the exercise of these rights, the usufructuary is obliged to preserve the substance of the thing.

\section{Section 1286 [Recodification]}

A usufructuary has no right to a hidden thing found in the tract of land.

\section{Section 1287}

A usufructuary accepts all the defects that were attached to the thing at the time the servitude was established. He also bears the costs, without which the fruits and revenues would not be achieved.

\section{Section 1288}

A usufructuary shall maintain the thing in the condition in which he took it over, and pay the usual maintenance costs related to the thing, including its renewal and usual insurance against damage. If, in spite of that, the proper use of the thing diminishes its value without the usufructuary being at fault, the usufructuary bears no liability for it.

\section{Section 1289}

(1) An owner may, after being notified by the usufructuary, execute at his own expense construction works necessary due to accident or age of the structure; in such a case, the usufructuary shall pay the owner an amount proportional to the improvement in use and enjoyment.

(2) If an owner is unable or does not wish to execute the construction work, the usufructuary is entitled to execute the work on his own and claim the same compensation as a possessor in good faith once the use and enjoyment are finished.

\section{Section 1290}

A usufructuary is obliged to tolerate the work, although unnecessary, if his right is not prejudiced or if all damage caused to him is compensated.

Section 1291

An owner shall pay the usufructuary the costs of improving the thing under the same conditions as if he was obliged to pay them to an agent without authorisation. If the usufructuary has incurred costs as a result of a hobby or for decoration, he has the same rights and duties as a possessor in good faith.

\section{Section 1292}

When received by a usufructuary, a thing is presumed to be of middle quality, in a state fit for proper use, and to 
include everything that is required for such use.

\section{Section 1293}

When use and enjoyment end, the fruits which have not yet been separated belong to the owner. However, the owner shall reimburse the usufructuary for all the costs incurred according to the provisions on a possessor in good faith. The usufructuary has the right to other revenues depending on the length of use enjoyment.

\section{Common provisions}

\section{Section 1294}

If the right of use or usufruct is created in consumable fungible things, a user or usufructuary may dispose of the things as he chooses. When his right ends, he shall return the same number of things of the same kind and quality.

\section{Section 1295}

(1) The user or usufructuary of a principal deposited with interest is entitled only to the interest. A user or usufructuary is also entitled to interest from the principal which replaces the former principal as a result of a change.

(2) A user or usufructuary and a creditor together decide whether or not to do something with the principal. If they fail to agree, the decision is made by a court.

(3) A debtor is released from a debt only by repaying the principal jointly to the creditor and the user or usufructuary of the principal. Each of the two, the creditor and the user or usufructuary, may only claim that the principal be placed in notarial or judicial custody for both of them.

\section{Section 1296}

An owner may not claim that the user or usufructuary provide security for the substance, unless it is in danger. If no security is provided, an owner may claim that the thing be surrendered for a fair lump-sum payment, where appropriate.

\section{Habitation}

\section{Section 1297 [Recodification]}

If habitation is established, it is presumed to have been established as a servitude of use.

Section 1298

An owner has the right to freely dispose of all parts of the building which are not covered by habitation, and he may not be hindered in the execution of necessary supervision.

\section{Subdivision 6}

\section{Extinction of servitude}

\section{Section 1299}

(1) A servitude is extinguished by a permanent change as a result of which the servient thing may no longer serve the dominant land or obligee.

(2) In case of a permanent change resulting in a gross disproportion between the encumbrance of the servient thing and a benefit for the dominant land or the entitled person, an owner of the servient thing may claim that the servitude be limited or cancelled for appropriate compensation.

\section{Section 1300}

(1) Subject to the parties' agreement to cancel a servitude registered in a public register, a servitude is extinguished upon the deletion from the public register.

(2) The period for which a servitude has been established in a person's favour may also be stipulated in such a way that the servitude is extinguished if another person reaches a certain age. In this case, an earlier death of that person is presumed as having no effect on the duration of the servitude.

\section{Section 1301}

A servitude is not extinguished by joining the ownership of a dominant and servient thing in a single person.

Section 1302

(1) A personal servitude is extinguished upon the death of the obligee; where a servitude is also extended to the heirs, statutory first class heirs are presumed to be such heirs. If a legal person has acquired a personal servitude, the servitude shall exist as long as that person exists.

(2) If a servitude serves the operation of an enterprise, it is not extinguished upon the transfer or passage of such an 
enterprise or such part thereof which will be operated as a separate enterprise.

\section{Subdivision 7}

\section{Real burdens}

Section 1303 [Recodification]

(1) If a thing is registered in a public register, it may be encumbered with a real burden so that the temporary owner of the thing is obliged as a debtor to the entitled person to provide something to or do something for such a person.

(2) The same real burden may encumber several things.

\section{Section 1304 [Recodification]}

A real burden unlimited in time may be established only as redemptive, and the conditions of the redemption must already be pre-determined upon the establishment of the real burden.

\section{Section 1305}

Where a real burden is established by a juridical act, it is created upon registration in a public register.

\section{Section 1306 [Recodification]}

If a real burden consists in a recurrent performance, a retained amount or its reimbursement may be requested from the person under whose the right of ownership the amount became due, as well as from the existing owner, but only if generated from the thing encumbered with the real burden.

\section{Section 1307}

(1) The owner of an encumbered thing shall refrain from doing anything which would cause deterioration of the thing to the detriment of the person entitled under a real burden.

(2) If a thing does not suffice for the real burden due to the owner being at fault or due to a defect revealed only later, the owner shall remedy such a state, to the same extent to which it was intended upon the establishment of the real burden, by depositing a security or otherwise, so that a person entitled under the real burden incurs no harm.

\section{Section 1308}

Extinction of real burdens is governed by analogy by the provisions on termination of servitudes.

\section{Division 3}

\section{Pledge}

\section{Subdivision 1}

\section{General provisions}

\section{Section 1309 [Recodification]}

(1) When a debt is secured by a pledge, the creditor becomes entitled to satisfy his claims from the proceeds gained from the sale of the pledged thing up to the stipulated amount if the debtor fails to discharge the debt properly and in due time, and if no amount has been stipulated, up to the amount of the claim with accessories as of the date on which the pledged thing was sold.

(2) An arrangement prohibiting the creation of a pledge has effects against a third person only if the prohibition is registered in the pledge registry under another legal regulation or in a public register, or if the third person was aware of such an arrangement.

\section{Section 1310 [Recodification]}

(1) Any marketable thing may be pledged.

(2) A pledge of a thing to which the pledgor will acquire the right of ownership in the future may also be created. If such a thing is registered in a public register or the pledge registry, the pledge of the thing is registered subject to the consent of the thing's owner.

\section{Section 1311 [Recodification]}

(1) A pledge may secure a certain amount of debt or a debt the amount of which can be determined at any time during the existence of the pledge. A pledge may secure a pecuniary or non-pecuniary debt, contingent debt, or even a debt which is yet to be incurred in the future.

(2) A pledge may also secure a certain type of debts incurred by the debtor against the pledgee at a certain time, and 
also various debts incurred against the pledgee for the same legal cause.

\section{Subdivision 2}

\section{Establishment of a pledge}

\section{Section 1312 [Recodification]}

(1) A pledge is established by a pledge agreement. In the agreement, the parties shall stipulate the thing subject to the pledge and the debt for which the pledge is established; where a debt which is not yet due or several debts are secured, it suffices to stipulate the maximum amount of principal to which the security is provided.

(2) A pledged thing may be determined individually, or in another way which would make it possible to determine such a thing at any time during the existence of the pledge.

\section{Section 1313}

A pledge secures a debt and its accessories; if separately stipulated, it may also secure a contractual penalty.

\section{Section 1314 [Recodification]}

(1) A pledge agreement must be made in writing if a pledged movable thing is not delivered to the pledgee or is given to a third person to be held in safekeeping for the pledgee.

(2) A pledge agreement must be in the form of a public instrument:

a) if an enterprise or another collective thing (universitas rerum) is pledged,

b) if an immovable thing which is not subject to registration in a public register is pledged, or

c) if a pledge of a movable thing is to be created by registration in the pledge registry.

\section{Section 1315 [Recodification]}

\section{Prohibited stipulations}

(1) Arrangements under which the debtor, or contracting pledgor, may not redeem the pledged thing are prohibited.

(2) Until a secured debt has become due, it is forbidden to stipulate that:

a) the pledgee will not claim satisfaction from the pledged thing,

b) a creditor may sell the pledged thing in any manner, or keep it for a price of his choice or predetermined price, or

c) a creditor may take the fruits or revenues of the pledged thing.

(3) If a consumer or a person who is a small or medium-sized entrepreneur is the contracting pledgor, or the pledgor, the stipulation with the content provided under Subsection (2)(b) is disregarded, whether they were stipulated before or after the secured debt became due.

\section{Section 1316 [Recodification]}

A pledge of a thing registered in a public register is created upon the registration in this register, unless otherwise provided by another legal regulation.

\section{Section 1317 [Recodification]}

(1) A pledge of a movable thing is created upon delivery of such a thing to the pledgee. If so requested by a contracting pledgor, the creditor shall provide him with a deed of pledge which shall describe the pledged thing so that it can be sufficiently distinguished from other things.

(2) Surrendering a movable thing may be substituted by a sign in such a way that the thing will be designated as pledged. If a pledge has been created by designation, it may be invoked against a third person where such a person did not act in good faith; otherwise, the thing is presumed not to have been designated.

\section{Section 1318 [Recodification]}

Where stipulated by the pledge agreement, a pledge of a movable thing is created when the contracting pledgor or pledgee delivers the thing to a third person to hold it in safekeeping for the pledgee and pledgor. Unless stipulated otherwise, the contracting pledgor shall pay the associated costs.

\section{Section 1319 [Recodification]}

(1) Where stipulated by the pledge agreement, the pledge of a movable thing will be created upon registration in the pledge register. 
(2) A pledge of an immovable thing which is not subject to registration in a public register, a pledge of an enterprise and a pledge of a collective thing (universitas rerum) are created upon registration in the pledge registry.

(3) A notary who drafted the pledge agreement shall enter the registration in the pledge registry without undue delay after the pledge agreement is concluded.

\title{
Pledging a share in a corporation
}

\author{
Section 1320 [Recodification]
}

(1) If a share in a corporation is freely transferable, it may also be pledged; if a share may only be transferred under certain conditions, the same conditions must be met when pledging the share. This does not apply if pledging the share is prohibited or limited under the memorandum of association.

(2) If a share concerns securities, only those securities will be eligible to be pledged.

Section 1321 [Recodification]

An agreement whereby a corporation receives a pledge of its own shares is disregarded.

\section{Section 1322 [Recodification]}

(1) A pledge of share is created upon registration in a public register in which the corporation is registered.

(2) The contracting pledgor or pledgee shall notify the corporation of the creation of the pledge without undue delay; however, such notification is not required, if a competent body of the corporation consented to the share being pledged.

\section{Section 1323 [Recodification]}

If a share is connected with voting rights, a pledgee may exercise such rights only if so stipulated.

\section{Section 1324 [Recodification]}

(1) If a claim becomes due, the pledgee becomes entitled to pecuniary and other in rem performances resulting from the interest in the corporation up to the amount of the secured debt. Such performances are set off against the debt, unless the parties stipulate otherwise.

(2) If a personal debtor or pledgor challenges the amount or existence of a debt in court proceedings, the performance under Subsection (1) is provided without undue delay after the decision on the amount or existence of the debt is made by the court; until then, the person who is to provide the performance is not in default.

\section{Section 1325 [Recodification]}

A pledgee shall notify all shareholders that the exercise of the pledge has begun. If these shareholders have a preemptive right to the share, such a pre-emptive right is extinguished unless the shareholders assert the right in the sale of the pledged thing.

\section{Section 1326 [Recodification]}

If so stipulated, a pledgee acquires the pledged share upon his failed attempt to sell the share in the exercise of the pledge. If it has not been stipulated that a pledgee acquires the pledged share at that moment, the pledgee may exercise shareholder rights associated with the share from that moment.

\section{Section 1327 [Recodification]}

(1) If a pledgee failed in his attempt to sell the share, he may claim that the pledgor transfer the pledged share to him under usual business terms for the payment of the debt. If a pledgee fails to assert his right within one month from the date on which his attempt to sell the share failed, his right is extinguished.

(2) If a pledgor fails to transfer the share to the pledgee within one month from the day on which he was requested to do so, the pledgee may claim that the content of the agreement be determined by a court.

\section{Pledge of securities or book-entry securities}

\section{Section 1328 [Recodification]}

(1) A pledge of securities is created when the securities are delivered to the pledgee. Where stipulated by the pledge agreement, a pledge of securities is created when the contracting pledgor or pledgee hand over the securities and a counterpart of the pledge agreement to a third person to hold it in safekeeping.

(2) The creation of a pledge of securities to order also requires a pledge endorsement containing a "to be pledged" clause (in Czech: "k zastavení") or a clause using other words with the same meaning, and the identification of the pledgee.

(3) If the parties stipulate that a pledge of bearer securities will be created by registration in the pledge registry, the pledged thing must be delivered for the duration of the pledge to the person who will register it in the pledge registry. 
(1) If securities are already held in deposit, a pledge will be created by delivering a pledgee's or contracting pledgor's notification to the depositary together with a counterpart of the pledge agreement. Once the notification is delivered, securities are conclusively presumed to be held in deposit jointly for the pledgee and pledgor. This does not affect the provision of Section 1328(2).

(2) A person who has placed securities in deposit as an entrepreneur shall mark it as pledged in his records so that it clearly shows the identity of the pledgee; the person shall keep the records separately, unless they concern a collective deposit.

\section{Section 1330}

If securities, when pledged, are already in the possession of a third person on the basis of a contract with the securities' owner, they may, during the existence of the pledge, be surrendered to the pledgor only with the consent of the pledgee.

\section{Section 1331}

(1) A pledge of book-entry securities is created upon registration in the owner's account in the relevant register. Registration is made by a person authorised to keep the register upon the mandate of the pledgor and to the debit of his account. Where the mandate is given by a pledgee, personal debtor or contracting pledgor, the pledge is registered if the mandator documents the establishment of the pledge.

(2) A pledge is deleted from the relevant register by a person entitled to keep such a register. Where the mandate is given by a pledgor, personal debtor or the contracting pledgor, the pledge is deleted if the mandator proves the occurrence of a fact which otherwise justifies the extinction of the pledge.

\section{Section 1332}

(1) For the duration of a pledge of securities, a pledgee may exercise the rights attached to the pledged securities to the extent stipulated by the parties.

(2) The yields and other payments gained from the securities are governed by the provisions on a performance from a pledged claim, unless the pledgee waives this right in favour of the pledgor.

\section{Pledging the account of an owner of book-entry securities}

Section 1333

A pledge of the account of book-entry securities is created upon its registration in this account in the relevant register. Registration and deletion of the pledge are governed by Section 1331 by analogy.

Section 1334

(1) A pledge of the account of an owner of book-entry securities applies to all securities registered in the account upon the creation of the pledge, as well as to securities transferred to the pledged account during the existence of the pledge. The provisions governing pledge of individual securities shall also apply by analogy to securities registered in a pledged account.

(2) If securities are transferred from a pledged account with prior consent of the pledgee, the pledge of such securities is also extinguished upon such transfer.

\section{Pledge of a claim}

\section{Section 1335 [Recodification]}

(1) A claim which may be assigned to another may be pledged. Where a pledgor's claim from a pledgee is pledged, the claim and debt are not extinguished upon a merger of the creditor and debtor by the formation of a new person.

(2) The pledge of a claim is created on the effective date of the pledge agreement, unless a later time is stipulated; however, the pledge becomes effective against the debtor under the pledged claim only when notified by the pledgor or proved by the pledgee to the debtor. This does not apply if the parties have stipulated the registration of a pledge in the pledge registry.

\section{Section 1336 [Recodification]}

(1) Before a secured debt becomes due, a debtor may only provide performance with respect to a pledged claim jointly to the pledgee and pledgor. Each of them has the right to request that the debtor deposit the performance with a third person for the benefit of both; if the pledgee and pledgor fail to agree on the depositary, he is appointed by a court on the application of any of the parties. If a secured debt has become due, the depositary shall surrender everything which is necessary to satisfy such a debt to the pledgee.

(2) If a secured debt has become due, the pledgee has the right to have the debtor under the pledged claim provide a performance only to him; if he chooses to assert the right, he shall inform the creditor under the pledged claim. If a pledged claim has not yet become due, the pledgee is entitled to have the claim assigned to him. 


\section{Section 1337 [Recodification]}

Where a payment is provided under a pledged claim, the pledgee shall surrender to the pledgor everything that exceeds the secured claim, including accessories and the reimbursement of costs to which the pledgee is entitled. Where another thing is performed, the pledge passes onto such a thing.

\section{Section 1338 [Recodification]}

(1) Where a juridical act of a creditor is necessary for a pledged claim to become due, including, without limitation, termination or withdrawal from an agreement, the consent of the pledgee is not required. A pledgee may demand that the creditor make a juridical act if the security is in jeopardy.

(2) If a juridical act of a debtor is required, such a juridical act has effects if also notified to the pledgee.

\section{Section 1339 [Recodification]}

If a pledge of a claim from account has been stipulated, the pledgee has the right to order the person who keeps the account to pay him the balance on the account up to the amount of the secured debt, provided that he informs him of the amount and the due date of the secured debt.

\section{Section 1340 [Recodification]}

The provisions of Sections 1336 and 1338 apply unless otherwise stipulated by the parties. If the parties stipulate that the creditor needs the consent of the pledgee to terminate the agreement or make another juridical act, the creditor may claim that such consent be granted if the security is in jeopardy.

\section{Section 1341 [Recodification]}

\section{Future pledge}

(1) If a thing of which a pledge is to be created for the pledgor in the future is to become pledged, the pledge will be created upon the acquisition of the right of ownership by the pledgor.

(2) Where registration in a public register or pledge registry is required for a pledge to be created, and if a future pledge has been registered therein, the pledge is created upon the acquisition of the right of ownership by the pledgor.

\section{Section 1342}

\section{pledge established by a decision of a public body}

Where a pledge is established by a decision of a public body, it is created on the date on which the decision becomes enforceable, unless a later time is determined by the decision. If registration in the pledge registry or a special public register is otherwise necessary for the creation of a pledge, the pledge is registered therein.

\section{Section 1343 [Recodification]}

\section{Pledge of a thing of another}

(1) A contracting pledgor may pledge a thing of another only with the consent of the owner.

(2) Where the contracting pledgor pledges a movable thing of another without the consent of the owner, the pledge is created if the thing is delivered to the pledgee and the pledgee receives the thing in good faith that the contracting pledgor is entitled to pledge the thing.

(3) If a person has a right in rem to the thing being pledged which is incompatible with the pledge, Subsections (1) and (2) apply by analogy.

\section{Section 1344 [Recodification]}

If the contracting pledgor pledges a movable thing of another in a pawnshop, and if it is not a thing which was entrusted to the contracting pledgor by the owner, the owner has the right to have the thing surrendered to him by the operator of the pawnshop if he proves to have lost possession of the thing due to loss or an act having the nature of an intentional criminal offence. The operator of a pawnshop has no right to require that the owner pay to him the amount paid to the contracting pledgor or the accrued interest before surrendering the thing to the owner.

\section{Section 1345}

\section{Multiple pledge}

The same debt may be secured by pledging several things. If the same debt is secured by several separate pledged things, the pledgee may satisfy his claim from any or all of the pledged things.

\section{Subdivision 3}

\section{Scope of a pledge}




\section{Section 1346 [Recodification]}

(1) A pledge applies to a pledged thing, its accessions as well as accessories, unless otherwise stipulated by the pledge agreement. A pledge applies only to those fruits and revenues that are not separated.

(2) If a claim is pledged, the pledgee is also entitled to all the rights securing the claim.

$$
\text { Section } 1347 \text { [Recodification] }
$$

When pledging a collective thing (universitas rerum), the pledge applies to the individual things of the contracting pledgor which belong to and serve the pledged thing, wherever they are. A pledge applies to every individual thing that is added to the collective thing (universitas rerum), and it is extinguished with respect to each such individual thing upon its separation therefrom.

\section{Section 1348 [Recodification]}

If, during the existence of a pledge of a collective thing (universitas rerum), a separate pledge to an individual thing belonging to the pledged thing is agreed, the pledge will not be created. If a pledge of an individual thing was established before it was added to the collective thing (universitas rerum), or before the collective thing (universitas rerum) was pledged, the provisions governing order of pledges apply.

\section{Section 1349 [Recodification]}

The duration and scope of a pledge of securities is affected neither if the issuer of the pledged securities exchanges such securities pledged by the pledgor for other securities, nor if the securities are transformed to book-entry securities or bookentry securities transformed to securities. If exchange or transformation results in the creation of securities to order, the issuer shall affix pledge endorsement to such securities before they are surrendered to the person entitled to have the securities in his possession.

\section{Section 1350 [Recodification]}

(1) If a pledged thing is transformed into a new thing, the pledge shall also encumber such a new thing.

(2) If a pledged thing joins with another thing, the pledgee has the right to the restoration to the previous state at the expense of the pledgor. If this is not possible, the pledge shall encumber the entire thing, but only up to the value of the pledged thing at the time the things were joined. Where a pledged thing has been valuated, the price of the pledged thing is presumed to be determined by the amount of its valuation.

\section{Section 1351 [Recodification]}

Where a pledged thing is divided, the pledge shall encumber all things created by the division.

\section{Section 1352 [Recodification]}

For the purposes of a pledge, if two pledged things are joined, the joining is considered not to have occurred; this does not apply if the joined pledged things secure the discharge of the same debt.

\section{Subdivision 4}

\section{Rights and duties arising from a pledge}

\section{Section 1353}

A pledgor shall refrain from everything which causes the pledge to deteriorate to the detriment of the pledgee. If a pledgor performs an act which will cause a sufficient security of a pledgee to become insufficient, or if an insufficient security becomes reduced, the pledgor shall replenish it as appropriate.

\section{Section 1354}

(1) If a pledged thing is insured and an insured event occurs, the insurer shall provide a performance under the insurance contract to the pledgee, if he proves to the insurer in due time that the things is encumbered with his pledge, or the contracting pledgor or pledgor informs the insurer of such an encumbrance in due time.

(2) A pledgee has the right to retain the performance under an insurance contract and satisfy his claim therefrom if his claim is not discharged properly and in due time, unless stipulated otherwise. A pledgee shall surrender to the pledgor everything which exceeds the claim, including accessories and the costs to the reimbursement of which the pledgee is entitled.

\section{Section 1355}

If a pledged thing is relinquished to another for use without the consent of the pledgee, it has no legal effect against the pledgee. This does not apply if the parties stipulate that such consent is not required.

Section 1356

(1) A pledgee to whom a pledged thing has been delivered is entitled to have the thing in his possession for the entire duration of the pledge. He is obliged to take care of the thing with due managerial care and has the right to be reimbursed for 
the associated costs by the contracting pledgor as a possessor in good faith.

(2) A pledgee may use a pledged thing only with the consent of the pledgor and in a manner which is not to his detriment; if a pledgee is in good faith that the contracting pledgor is the pledgor, the consent of the contracting pledgor shall suffice. Unless stipulated otherwise, the benefit from a pledged thing is set off against the payment of costs under Subsection (1).

\section{Section 1357}

If a pledged thing has been delivered to a third person to hold it in safekeeping, such a person may not use the pledged thing, allow such use by another, or deliver it to another person; by doing so, such a person is also liable for an accidental event affecting the pledged thing which would not have happened if the pledged thing were in the possession of the person.

\section{Section 1358}

If an essential fact about a pledge registered in the pledge registry or in a public register changes, and if no other legal regulation obliges another person to make the change in the registration, the person concerned by the change shall apply for the change of registration to be made without undue delay; if no such person can be identified, the pledgee shall apply for the change of registration to be made. If several persons have such a duty, it shall suffice if it is fulfilled by at least one of them.

\section{Subdivision 5}

\section{Exercise of a pledge}

\section{Section 1359 [Recodification]}

(1) Once a secured debt becomes due, a pledgee may satisfy his claim in a manner agreed in writing with the contracting pledgor, or pledgor; otherwise, he may satisfy his claim from the proceeds gained from the sale of the pledged thing at a public auction, or such a sale under another statute. If securities admitted to trading on a European regulated market are pledged, they are sold in or outside of this market at the price amounting at least to that determined by the European regulated market.

(2) A pledgee is entitled to receive from the contracting pledgor reimbursement of the necessary costs incurred in the exercise of the pledge.

\section{Section 1360}

If it has been stipulated that the pledgee may sell the pledged thing otherwise than at a public auction, it is also binding upon the legal successor to the pledgor. When transferring the pledged thing, the pledgor shall notify the acquirer of the creditor's right to sell the pledged thing in such a way.

\section{Section 1361}

If specific acts need to be made against the debtor in order for a claim to become due and the personal debtor and pledgor are different persons, such acts must also be directed against the pledgor so that the pledgee can satisfy his claim from the pledged thing.

\section{Section 1362 [Recodification]}

(1) A pledgee shall notify the pledgor of the commencement of the exercise of a pledge in writing; in the notification, the pledgee shall provide information on the manner in which he will satisfy his claims from the pledge.

(2) If a pledge is registered in a public register or the pledge registry, the pledgee shall also provide for the registration of the commencement of the exercise of the pledge in this register.

\section{Section 1363}

If a pledgor has been notified of the commencement of the exercise of a pledge, he may not alienate the pledged thing without the consent of the pledgee. Violation of the ban does not affect the rights of an acquirer to whom the pledgor has transferred the right of ownership in a thing in the ordinary course of business, unless the acquirer knew or should have known from the circumstances that the exercise of the pledge has commenced.

\section{Section 1364}

(1) A pledgee may sell the pledged thing only after thirty days after notifying the pledgor of the commencement of the exercise of the pledge.

(2) If the commencement of the exercise of a pledge was registered in a public register or the pledge registry only after the pledgee notified the pledgor of the commencement of the exercise of a pledge, the thirty-day time limit shall commence on the date on which the pledge was registered in a public register or the pledge registry.

(3) If a shorter time limit was stipulated before the notification, it is disregarded. 
(1) If the parties agree that the pledgee may sell the pledged thing otherwise than at a public auction, he shall proceed with doing so with professional care in his own interest as well as in the interest of the pledgor in such a way that he will sell the pledge at the price for which a comparable thing can be usually sold under comparable circumstances at a given place and time. If a pledgee breaches this duty, it shall not affect the rights of third persons acquired in good faith.

(2) If the parties agree on the manner in which the pledgee will sell the pledged thing, the creditor may, at any time during the exercise of the pledge, change the manner in a way that the pledged thing will be sold at a public auction or sold under another statute. A creditor shall, in due time, notify a pledgor in writing of a change in the manner in which a pledge is exercised.

\title{
Section 1366
}

If so requested by a person interested in the acquisition of a pledged thing or by an auctioneer, the pledgee shall demonstrate to such a person that he notified the pledgor of the commencement of the execution of the pledge.

\section{Section 1367}

(1) A pledgor shall suffer the exercise of a pledge, surrender to the pledgee the pledged thing, including the instruments necessary for its takeover, sale and use, and provide him with other necessary cooperation. If a third person has a pledged thing or instruments in his possession, he has the same duty.

(2) A person who has a pledged thing in his possession shall refrain from doing anything which would reduce the value of the pledged thing; usual wear and tear is disregarded.

\section{Section 1368 [Recodification]}

(1) Proceeds gained from the sale of a pledged thing are used to pay the claim, including accessories and reimbursement of costs to which the pledgee is entitled. If a non-pecuniary debt has been secured, the creditor is presumed to be entitled to a payment not exceeding the amount of the usual price of the claim at the time the pledge was created; this applies even where the secured debt's accessories are of non-pecuniary nature.

(2) Upon the payment of the claim from the proceeds gained from the sale of a pledged thing, a pledgor shall acquire the same rights as if he discharged the debt himself.

$$
\text { Section } 1369 \text { [Recodification] }
$$

A pledgee shall, without undue delay after the sale of the pledged thing, provide the pledgor with a written report which shall contain information on the sale of the pledged thing, the associated costs and other costs to the reimbursement of which the pledgee is entitled, as well as the proceeds gained from the sale and the use thereof.

\section{Section 1370}

If the proceeds gained from the sale of a pledged thing do not cover the amount of the claim, a personal debtor shall pay the difference. A pledgor is entitled to the proceeds exceeding the claim.

\section{Subdivision 6}

\section{Exercise of a pledge with several pledgees}

\author{
Section 1371 [Recodification]
}

(1) If a pledged thing is encumbered with multiple pledges, their order is determined according to the time the pledge was created. Where the creation of a pledge is to be registered in a public register, the time the application for registration was filed is decisive for the order.

(2) If a thing to which a contracting pledgor is to acquire the right of ownership in the future is pledged, the order of pledges is determined according to the time at which the pledge agreement was concluded; if a future pledge is subject to registration in the pledge registry or in a public register, the order in which the applications for registration were filed is decisive.

(3) If multiple pledges encumber a movable thing, the right of the pledgee registered in the pledge registry or in a public register is satisfied according to the order in which it was registered in preference to a right created in another way. A right created by delivering a pledged thing to the pledgee or a third person is satisfied in priority to a right created by designating a thing with a sign.

\section{Section 1372 [Recodification]}

(1) If multiple pledges are created on a pledged thing, pledgees may stipulate their order in writing. Such an arrangement becomes effective against third persons upon registration in the pledge registry or in a public register, if registration in such a register is required for the creation of the pledge. The registration is applied for by all pledgees who have stipulated the order of pledges.

(2) Where the stipulation is to prejudice the rights of a pledgee who did not agree with the stipulation, it has no legal effect against him. 
(1) A pledgee shall also notify the commencement of the exercise of a pledge to those pledgees who are, given their order, entitled to be satisfied before him. Section 1362 applies by analogy.

(2) A pledgee may sell the pledged thing no earlier than after thirty days after notifying all pledgees under Subsection (1). This does not apply if, within that time limit, such a pledgee is notified by a pledgee who, given his order, has the right to be satisfied before him, that he commences to exercise his pledge; if the latter pledgee fails to commence to exercise his pledge without undue delay, his notification is disregarded.

\section{Section 1374}

(1) If a pledgee exercises a pledge which is first in the order for the satisfaction of pledges (hereinafter a "priority pledgee"), the pledged thing passes to the acquirer without being encumbered with other pledges.

(2) If the proceeds gained from the sale of a pledged thing exceed the claim, including accessories and the costs to the reimbursement of which the priority pledgee is entitled, he shall place the surplus in judicial custody for the benefit of the creditors under other claims who are entitled under the pledge, and for the benefit of a pledgor, unless otherwise agreed between them and the priority pledgee.

(3) The surplus is used to satisfy the creditors of other claims who are entitled under a pledge in the order for the satisfaction of pledges. Any remaining amounts are surrendered to the pledgor.

\section{Section 1375}

(1) If a pledge is exercised by a pledgee other than a priority pledgee, the pledged thing encumbered with the rights of the pledgees who, given their order, are entitled to be satisfied before the acquirer passes to the acquirer. Such a pledgee shall, in due time, advise the acquirer of the pledged thing of the fact that the pledged thing passes with an encumbrance.

(2) A pledgee who exercises his pledge and an acquirer of a pledged thing shall provide for the registration of the change in the identity of the pledgor in the pledge registry or in a public register, if such registration is required for the creation of a pledge; otherwise, they shall compensate for the damage caused thereby.

(3) The rights of pledgees who, given their order, are entitled to be satisfied after a creditor who exercises a pledge under Subsection (1) are governed by Section 1374 by analogy.

\section{Subdivision 7}

\section{Extinction of a pledge}

Section 1376

If a secured debt is extinguished, so is the pledge.

\section{Section 1377 [Recodification]}

(1) A pledge is extinguished but the claim will continue to exist if:

a) the pledged thing ceases to exist,

b) a pledgee waives his pledge,

c) the pledgee returns the pledged thing to the contracting pledgor or pledgor,

d) the contracting pledgor, or pledgor deposits the price of the pledged thing for the benefit of the pledgee, or

e) the period for which a pledge has been established expires.

(2) The effects under Subsection (1) will occur even where another person has acquired the right of ownership in the pledged thing in good faith that the thing was not pledged. This does not apply if the pledge is registered in the pledge registry or in a public register.

(3) If a thing and pledge are not registered in a public register, the effects under Subsection (1) shall occur even where the pledged thing or part thereof has been transferred:

a) and the pledge agreement stipulates that the pledged thing or part thereof can be transferred without being encumbered with a pledge, or

b) in the ordinary course of business in the business activities of the transferor.

\section{Section 1378}

If a pledge remains registered in the pledge registry or a public register even after its extinction, it constitutes a defect encumbering the pledged thing.

\section{Section 1379}

(1) If a pledge registered in the pledge registry is extinguished, the pledgee shall, without undue delay, apply for its 
deletion, and the pledge will be deleted. This also applies where the pledge has been registered in a public register, unless the parties have stipulated that the pledgee shall not apply for the deletion of the pledge, or the owner has applied for the registration of a released pledge.

(2) A pledgor may apply for the deletion of a pledge; where a pledge has not been extinguished due to the expiry of the period, it is deleted from the pledge registry or from a public register if the pledgor proves the extinction of the pledge by an instrument confirmed by the pledgee, a decision of a court, or another public instrument. If the pledgee fails to confirm the extinction of the pledge at the pledgor's request, he shall provide compensation for any resulting damage.

\title{
Subdivision 8
}

\section{Rights of an owner in the release of a pledged thing}

\author{
Section 1380 [Recodification]
}

If a pledged thing is released upon the extinction of a pledge before the registration of the pledge in a public register is deleted, the pledge is considered released, and the owner of the thing may attach the released pledge as a security to a new debt not exceeding the original debt.

\section{Section 1381 [Recodification]}

If so requested by the owner, a record is made in a public register that the pledge has been released and the security of the original debt has terminated, if the owner proves the extinction of the pledge by an instrument confirmed by the pledgee or a decision of a court or another public instrument. If an owner secures no other debt with a released pledge within ten years from the registration of the release of the pledge, his right to do so is extinguished.

\section{Section 1382 [Recodification]}

If the release of a pledge has been registered in a public register, it may only be deleted jointly with the pledge within the first ten years.

\section{Section 1383 [Recodification]}

If an owner secures no other debt with a released pledge, the released pledge is disregarded when dividing the proceeds after the pledged thing has been sold.

\section{Section 1384 [Recodification]}

If, when establishing a pledge, or later, an owner undertakes not to use a pledge registered in a more favourable order to secure a new debt, and if this fact is registered in a public register, the released pledge may not be used to secure a new debt for the duration of the pledge of the creditor in whose favour the owner undertook not to use the pledge.

\section{Subdivision 9}

\section{Replacement of a pledge}

\section{Section 1385 [Recodification]}

If a pledge has been registered in a public register, the owner of the thing may request that another pledge be registered in the same order of the pledge encumbering the thing to secure a debt not exceeding the original debt, on condition that the old pledge is deleted within one year after the registration of the new pledge.

\section{Section 1386 [Recodification]}

The deletion of the old pledge may be applied for by the owner of the thing or the creditor in whose favour the new pledge is to be established. If he fails to successfully do so within a year, the new pledge is extinguished upon the expiry of this period. A competent public body shall delete the new pledge, even of its own motion, together with all registrations relating to it.

\section{Section 1387 [Recodification]}

If an old pledge is encumbered with another right or restriction registered in a public register, the new pledge may be registered in this register on condition that the defect will be deleted or, with the consent of the parties, transferred to the new pledge.

\section{Section 1388 [Recodification]}

If, upon the establishment of a pledge, or later, an owner agrees not to allow a new pledge to be registered in place of the old one, and if this is registered in a public register, the old pledge may not be transformed into a new one.

\section{Section 1389 [Recodification]}

If a new pledge is to be registered in place of several pledges registered in a successive order, the provisions of this subdivision apply with necessary modifications.

\section{Subdivision 10}




\section{Section 1390}

Sub-pledge is created by pledging a claim secured by another pledge.

Section 1391 pledgor:

(1) The consent of the pledgor is not required to pledge the claim. A sub-pledge becomes effective against the

a) if he has been served a notice of its creation, or

b) upon the registration in the pledge registry or a special public register, if a thing whose pledge is created upon the registration in such registers is pledged; a sub-pledge is created upon such registration.

(2) The notification under Subsection (1) may be made by a contracting sub-pledgor or a sub-pledgee; however, he must prove the creation of the sub-pledge to the sub-pledgor.

\section{Section 1392} 1353.

By handing over the thing to the sub-pledgee, a contracting sub-pledgor is not relieved of the duties under Section

\section{Section 1393}

A sub-pledgee may claim satisfaction from the sub-pledge instead of the contracting sub-pledgor once the debt secured by the sub-pledge becomes due.

\section{Section 1394}

Sub-pledges are governed by the provisions on pledges with the necessary modifications.

\section{Division 4}

\section{Retention right}

\section{Section 1395}

(1) A person obliged to surrender a movable thing of another which he has in his possession may choose to retain it to secure a debt due by the person to whom he would otherwise be required to surrender such a thing.

(2) A debt which is not yet due may also be secured by retention right:

a) if the debtor failed to secure the debt otherwise, although he was obliged to do so under a contract or a statute,

b) if the debtor declares that he will not discharge the debt, or

c) if it becomes otherwise evident that the debtor will fail to discharge the debt as a result of a circumstance which occurred in relation to the debtor, and of which the creditor was not and could not have been aware at the time the debt was incurred.

\section{Section 1396}

(1) A thing of another may not be retained by a person who keeps it unlawfully, in particular where he seized it by force or trickery.

(2) A thing of another may not even be retained by a person who was ordered to dispose of it in a manner incompatible with the exercise of the retention right; this does not apply if he had the thing in his possession at the time the insolvency proceedings dealing with the insolvency or imminent danger of insolvency of a debtor were initiated.

\section{Section 1397 [Recodification]}

(1) A person who has retained a thing of another shall inform the debtor of the retention and the reasons for it. If a creditor has a thing in his possession on the basis of a contract concluded in writing, the notification must also be in writing.

(2) A creditor is obliged to administer the retained thing with due managerial care and is entitled to be reimbursed for the costs by the debtor as a lawful possessor. A creditor may use a retained thing only with the consent of the debtor and in a manner which is harmless for the debtor. Unless stipulated otherwise, the benefit from a thing is set off against the reimbursement of costs under Subsection (1).

\section{Section 1398}

A creditor who has secured his claim with a retention right is entitled to be preferentially satisfied from the proceeds gained from the sale of the retained thing before other creditors, even before a pledgee. The sale of a retained thing by a creditor is governed by Section 1359 by analogy. 
A retention right is extinguished:

a) upon the extinction of the secured debt or retained thing,

b) if the creditor waives his retention right unilaterally or by an agreement with the owner of the retained thing,

c) if the thing gets permanently out of the creditor's control, or

d) if the creditor is provided with sufficient security.

\title{
Chapter 6
}

\section{Administration of property of others}

\section{Division 1}

\section{General provisions on administration of property of others}

\section{Subdivision 1}

\section{General provisions}

Section 1400 [Recodification]

(1) Any person who is entrusted with the administration of property which does not belong to him for the benefit of another (hereinafter a "beneficiary"), is an administrator of the property of another.

(2) An administrator is presumed to make juridical acts as the owner's legal representative.

\section{Section 1401 [Recodification]}

(1) An administrator shall perform his duties in person. He may delegate his powers to another person or have another person represent him only in individual juridical acts; in doing so, he is obliged to carefully choose such a person and give him sufficient instructions.

(2) Where an administrator has another person represent him unlawfully or unlawfully authorises another person to exercise his powers, he and such person are jointly and severally liable to the beneficiary for everything the person has done.

\section{Section 1402 [Recodification]}

(1) An administrator is presumed to be entitled to the usual remuneration according to the nature of his services.

(2) A person who administers another's property without a legal cause is not entitled to remuneration.

\section{Section 1403 [Recodification]}

An administrator shall distribute profit and costs among the beneficiaries in accordance with the articles of association or another contract, or otherwise as fairly as possible with regard to the nature and subject of the administration and the circumstances of its creation with respect to general practice. Unless a different proportion for the distribution of profits and costs among beneficiaries can be defined, the shares are conclusively presumed to be equal.

\section{Section 1404 [Recodification]}

If a specific act is conditional on the beneficiary's consent, it may be substituted by the decision of a court where the beneficiary is unknown or the beneficiary's opinion cannot be obtained in due time. This also applies if the beneficiary refuses to give his consent without having a just cause.

\section{Subdivision 2}

\section{Simple administration of property of others}

\author{
Section 1405 [Recodification]
}

it.

A person who performs simple administration of property of others shall do everything which is necessary to preserve

$$
\text { Section } 1406 \text { [Recodification] }
$$

In simple administration, an administrator asserts all the rights relating to the administered property and manages it with due care. An administrator may not change the purpose of the administered property without the consent of the beneficiary.

\section{Section 1407 [Recodification]}

If an administrator administers funds, he must spend them prudently. If any part of the administered property has 
been previously spent in a certain way, an administrator may later change the chosen method.

Section 1408 [Recodification]

(1) An administrator may alienate a part of the administered property if it is in the interests of preserving the value, essence and purpose of the administered property, or if it is necessary to pay the debts associated with such property; if that is not the case, he may do so only for consideration. For the same purpose, the administrator may pledge the administered property or otherwise use it as security. To make these juridical acts, an administrator must be granted consent by the beneficiary.

(2) An administrator does not need the consent to alienate the property where it is under threat of rapid decay or it is likely to quickly lose value.

\title{
Subdivision 3
}

\section{Full administration of property of others \\ Section 1409 [Recodification]}

A person who is entrusted with full administration of the property of others shall ensure its increase and use in the interests of the beneficiary.

\author{
Section 1410 [Recodification]
}

An administrator may use the administered property to do whatever is necessary and useful.

\section{Division 2}

\section{Rules of administration}

\section{Subdivision 1}

\section{Duties of an administrator to the beneficiary}

Section 1411 [Recodification]

An administrator of the property of another shall exercise his powers and perform his duties with due managerial care.

\section{Section 1412 [Recodification]}

(1) Where there are more beneficiaries, either simultaneously or subsequently, an administrator must act against all impartially, taking into account their respective rights.

(2) If an administrator is himself a beneficiary, he must take the same account of his own interests as of those of other beneficiaries, and exercise his competence for a common interest.

\section{Section 1413}

Where there is no interest or right following from a juridical act establishing the administration, an administrator must, without undue delay, inform the beneficiary and the person who supervises the administration of property or the interest of the beneficiary of:

a) any interest he may have in the course of business or activities seeking property benefit which could conflict with the interests of the beneficiary, and

b) any right he may have which he could assert with regard to the beneficiary or in respect of the administered property.

\section{Section 1414 [Recodification]}

An administrator shall keep reliable records of the administered property and may not combine his own property with the administered property.

Section 1415

(1) An administrator may become a party to a contract relating to the administered property, contractually acquire a right to such property or acquire a right with respect to the beneficiary only with the beneficiary's consent.

(2) An administrator may use the administered property or information obtained in the administration for his own benefit only with the consent of the beneficiary, unless the possibility of such use is determined by the articles of association or another contract, or where provided by a statute.

\section{Section 1416}

An administrator may gratuitously transfer the administered property only if it is directly allowed by the nature of the administration, or in the case of property of negligible value which the administrator disposes of in the interests of the 
beneficiary or in conformity with the purpose of the administration.

\title{
Section 1417 [Recodification]
}

An administrator shall not provide compensation for any damage to the property caused by force majeure, age or other natural development, and normal wear and tear in normal use.

\section{Section 1418 [Recodification]}

In determining the amount of compensation for damage, a court may reduce the extent of compensation for damage to be paid by an administrator only with respect to the circumstances under which the administration was assumed, or where the administrator performs administration gratuitously, or where the administrator is a minor or his legal capacity has been limited.

\section{Subdivision 2}

\section{Duties of an administrator and beneficiary to third persons}

\author{
Section 1419
}

(1) An administrator does not become personally liable from an obligation stipulated with another person on the account of the beneficiary. This applies even where it is obvious that the administrator acts on the account of a trust.

(2) If, in the exercise of his competence, an administrator acts on the account of the beneficiary in his own name, he is obliged jointly with the beneficiary; however, the beneficiary may be required to provide a performance only from the administered property. This applies even where an administrator acted on the account of a trust, although it was not obvious.

\section{Section 1420}

If an administrator exceeds his competence, his acts are binding upon him personally. However, if a third person relied in good faith on the proper exercise of the administrator's competence, or if the beneficiary has confirmed, even if only tacitly, the juridical acts of the administrator, the administrator and beneficiary are liable jointly and severally; however, the beneficiary may only be required to provide a performance from the administered property.

Section 1421

An administrator exceeds his powers if he exercises them on his own, although obliged to exercise it together with another person; this does not apply if in doing so, the administrator has obtained for the administered property a benefit exceeding what is to be expended from the property.

\section{Section 1422 [Recodification]}

If a person having legal capacity pretends before a third person that his property is administered by another person, the parties, acting in good faith, who conclude contracts with such other person shall incur the same duties under such contracts as if the property of the pretending person were under administration.

\section{Subdivision 3}

\section{Inventory, security and insurance}

\section{Section 1423}

(1) An administrator shall make an inventory, provide security for the proper administration or insure the administered property, where provided by articles of association, another contract or a statute.

(2) On the application of a beneficiary or another person with a legal interest therein, a court may impose the duty under Subsection (1) on the administrator, taking into consideration the value of the administered property, the position of the parties and other circumstances of the case. An application may not be granted if it is contrary to the contract establishing the administration concluded between the administrator and beneficiary.

\section{Section 1424}

(1) If an administrator is obliged to make an inventory, he shall provide in it a true and accurate list of assets and liabilities included in the administration, including a list of relevant documents.

(2) Personal things included in the inventory may only be described in general, unless they include things having value which is not negligible.

\section{Section 1425}

made.

The property described in the inventory is presumed to be in good condition as of the date on which the inventory is

Section 1426

An administrator shall deliver the inventory to the person who appointed him as the administrator, to the beneficiary 
and to the person stipulated or provided by a statute. A beneficiary or another person with a legal interest therein has the right to invoke inaccuracy of any item of the inventory, or request that a new inventory be made.

\section{Section 1427} beneficiary.

(1) An administrator is authorised to insure the administered property against usual risks at the expense of the

(2) An administrator has the right to get property liability insurance under the administration at the expense of the beneficiary if he exercises the administration gratuitously.

\section{Subdivision 4}

\section{Joint administration}

$$
\text { Section } 1428 \text { [Recodification] }
$$

Several administrators charged with joint management shall decide and act by majority vote, unless otherwise provided under a contract or statute. Each of the joint administrators is presumed to have one vote.

\section{Section 1429 [Recodification]}

(1) Where joint administrators may not act under Section 1411 due to a hindrance caused by a legal event, continuous inaction or opposition of one of the administrators, or other similar reasons, other administrators may decide and act independently in matters needed to maintain the status quo. In other matters, they may only so act with the approval of a court.

(2) If a state under Subsection (1) lasts, a court may, on the application of the person with a legal interest therein, decide that the administrators may decide and act in a different manner than as provided under Section 1428, that one of the administrators will have the casting vote, or that the administration will be exercised in another manner appropriate to the circumstances of the case.

\section{Section 1430 [Recodification]}

Administrators are liable under the administration jointly and severally, unless otherwise provided by a statute.

\section{Section 1431 [Recodification]}

(1) If one of the joint administrators fails to inform the other administrators without delay that he disagrees with a decision, and if he fails to inform the beneficiary thereof without undue delay, he is presumed to have approved that decision.

(2) If joint administrators adopt a decision in the absence of any of them, the absent administrator is presumed to have approved that decision if he failed to inform the other administrators and the beneficiary of his disagreement with the decision without undue delay after becoming aware thereof.

\section{Subdivision 5}

\section{Prudent investments}

\section{Section 1432 [Recodification]}

An administrator decides on investments taking into account their yield and expected profit; if possible, he shall spread investment risk in order to achieve such a ratio between fixed income and variable yields which reasonably corresponds to economic conditions.

\section{Section 1433 [Recodification]}

An administrator may not acquire more than $5 \%$ of shares of the same issuer for the beneficiary. Also, an administrator may not acquire for the beneficiary a share, bond or other debt securities of a person who breached the duty to pay yield from the securities; the administrator is also prohibited to provide a credit to such a person.

\section{Section 1434}

An administrator may deposit the administered funds in an account at a bank, foreign bank or savings and loan cooperative with the possibility to withdraw the funds on demand or within thirty days.

\section{Section 1435 [Recodification]}

An administrator may keep an investment made before he assumed the administration, even if it was imprudent.

\section{Subdivision 6}

\section{Presenting accounts}

\section{Section 1436}

(1) An administrator shall submit to the beneficiary an account of the administration at least once a year. Where there 
are several administrators, they shall present joint accounts, unless otherwise provided under a contract or statute with regard to the division of their competence.

(2) The accounts must be prepared in such detail so as to allow the verification of their accuracy.

Section 1437

An administrator shall allow the beneficiary to examine at any time the accounting books and documents relating to the administration, and provide him on his request with the necessary information on the manner in which the administration is exercised.

\section{Division 3}

\section{End of administration}

Section 1438

The office of an administrator ends by resignation, removal, limitation of legal capacity of a person hitherto having full legal capacity, or by proving the administrator's insolvency.

\section{Section 1439}

An administration terminates by the expiry of the period for which it was established, by the administration having reached its purpose or by extinction of the beneficiary's rights to the administered property.

\section{Section 1440}

(1) If an administrator states his resignation, his duties will end upon delivering his statement of resignation to the person authorised to select a new administrator, unless the statement contains a later date of the resignation. An administrator shall also deliver the statement of resignation to the other administrators, the beneficiary, and the person who exercises supervision over the administration.

(2) An administrator may not resign from the administration at inconvenient time, or otherwise thereby breach his duty to exercise due administration; otherwise, he shall provide compensation for damage under Book Four of this Act.

\section{Section 1441}

The person who installed the administrator may remove him through a declaration made in writing.

\section{Section 1442}

A juridical act made by a person who acted as an administrator in good faith that the administration has not yet ended is binding on the beneficiary. A beneficiary is also bound by juridical acts of a person who is no longer an administrator, if the other party acted in good faith that the administration still lasted.

\section{Section 1443}

When an administration ends, the administrator shall, with effects obliging the beneficiary, do everything that is needed for such an end or to avoid losses.

\section{Section 1444 [Recodification]}

(1) If an administrator dies or the administration terminates, the person who is obliged to provide for the administrator's matters shall, without undue delay after becoming aware of the administrator's death or termination, notify the extinction of the administration to the person who authorised him to be the administrator, as well as to the beneficiary and another person stipulated or provided by a statute. This applies even where the administration terminated because the administrator's legal capacity was limited.

(2) A person obliged to notify under Subsection (1) shall do everything that the administrator is otherwise entitled or obliged to do upon the extinction of administration.

\section{Section 1445}

At the end of the administration, the administrator shall present the beneficiary with accounts. He shall also submit the accounts to the administrator who will take his place. The provisions of Sections 1426 and 1427 apply by analogy.

\section{Section 1446}

(1) At the end of the administration, an administrator shall hand over the administered property to the beneficiary or incoming administrator at the place where the property is located, unless agreed otherwise.

(2) The duty to hand over the administered property includes surrendering everything that the administrator acquired for the beneficiary during the administration, including the compensation required to be provided by the administrator under the preceding provisions. 
In order to secure its claims from the administration, the administrator has a retention right to the property which he is required to surrender. However, if an administrator is to surrender funds, he shall set off any claims he may have against the mutual claim of the beneficiary.

\section{Division 4}

trust

\section{Subdivision 1}

\section{Definition of a trust and its creation}

Section 1448 [Recodification]

(1) A trust is created by setting aside part of the property owned by the founder in such a way that the owner entrusts the administrator with the property for a particular purpose through a contract or disposition mortis causa, and the trustee undertakes to keep and administer the property.

(2) The creation of a trust establishes separate and independent ownership of the part of property and the trustee is obliged to assume the property and its administration.

(3) The rights arising from the right of ownership in the property in a trust are exercised by the trustee in his own name and on the account of the trust; however, the property in a trust is not owned by the administrator or the founder, or the person entitled to receive a performance from the trust.

\section{Section 1449 [Recodification]}

(1) A trust may have a publicly beneficial or private purpose.

(2) A trust established for a private purpose serves the benefit of a certain person or in his memory. Such a fund can be established and for the purpose of investing to make a profit to be distributed among the founders, employees, shareholders or other persons.

(3) The primary purpose of a publicly beneficial trust may not be profit-making or the operation of an enterprise.

\section{Section 1450}

(1) A trust must have its own designation.

(2) The designation of a trust must express its purpose and contain the words "svěřenský fond" (trust).

Section 1451

A trust is created when a trustee accepts the authorisation to administer it; where there are several trustees, acceptance of the authorisation by at least one of them shall suffice. However, if a trust has been established by a disposition mortis causa, it is created upon the death of the decedent.

\section{Section 1452}

(1) Every trust must have by-laws. The by-laws of a trust are issued by its founder. Where a trust is established by a disposition mortis causa, Section 311 applies with the necessary modifications.

(2) By-laws shall contain at least:

a) the designation of the trust,

b) identification of the property that constitutes the trust upon its creation,

c) definition of the purpose of the trust,

d) the conditions to provide a performance from the trust,

e) information on the duration of the trust; in its absence, the fund is conclusively presumed to be established for an indefinite period, and

f) the identity of the ultimate beneficiary or the manner of his determination if a performance is to be provided from the trust to a particular person as to the ultimate beneficiary.

(3) By-laws require the form of a public instrument.

\section{Subdivision 2}

\section{Administration of a trust}




\section{Section 1453 [Recodification]}

(1) Any person with full legal capacity may be a trustee.

(2) A legal person may be a trustee, where provided by a statute.

\section{Section 1454 [Recodification]}

Under the conditions provided under Section 1453, the founder of a trust or the person who is to receive a performance from the trust may also be a trustee. In this case, however, a trust must have another third-party trustee; the trustees must make juridical acts jointly.

\section{Section 1455 [Recodification]}

(1) A trustee is appointed and removed by the founder. A founder may determine another method of appointment or removal of the trustee in the by-laws.

(2) On the application of a person with a legal interest therein, a trustee is appointed by a court if the person authorised to do so fails to appoint him within a reasonable period, or if he cannot be installed under Subsection (1).

\section{Section 1456 [Recodification]}

A trustee is entitled to exercise full administration of the property in a trust. A trustee is registered in a public or other register as the owner of the property in a trust with the note "svěřenský správce" (trustee)

\section{Subdivision 3}

\section{Ultimate beneficiary}

\section{Section 1457 [Recodification]}

(1) A founder has the right to appoint the ultimate beneficiary and determine the performance to be provided to him from the trust, unless the by-laws of the trust determine otherwise.

(2) If the founder fails to exercise his rights under Subsection (1), the trustee shall appoint the ultimate beneficiary and determine the performance to be provided to him from the trust. In the case of a trust established for private purposes, a trustee may exercise that right if the by-laws determine the group of persons from which the ultimate beneficiary may be appointed.

(3) An ultimate beneficiary may be granted the right to the fruits and revenues from the trust, or the right to property from the trust, or, where appropriate, the share therein.

\section{Section 1458 [Recodification]}

(1) A person who is authorised to appoint the ultimate beneficiary or determine the performance to be provided to him from the trust shall proceed in accordance with the by-laws and at his own discretion. He may change or cancel his decision under the conditions determined by the by-laws.

(2) No person is authorised to appoint the ultimate beneficiary or determine the performance to be provided to him from the trust for his own profit.

$$
\text { Section } 1459 \text { [Recodification] }
$$

An ultimate beneficiary's right to the performance from the trust is created under the conditions determined by the bylaws.

$$
\text { Section } 1460 \text { [Recodification] }
$$

(1) If a trust has been established for private purposes, an ultimate beneficiary's right to such a performance is created no later than after one hundred years from the establishment of the trust, even where the by-laws determine a later time. However, even after one hundred years, an ultimate beneficiary may acquire the right to such a performance if he is entitled under the by-laws to get a share of the property no later than upon the extinction of the last right to the fruits or revenues, as well as if he was a contemporary of the founder or a child of the founder or of his contemporary, provided that, according to the by-laws, he is to succeed no later than upon the death or termination of the ultimate beneficiary who, given his order, precedes him, in order to be the following ultimate beneficiary to acquire the fruits or revenues; throughout his life, other persons may acquire fruits or revenues along with him.

(2) If a trust has been established for private purposes, an ultimate beneficiary's right to fruits or revenues is extinguished no later than after one hundred years from the creation of the trust; however, in the case of individuals, such a right may last until his death.

\section{Section 1461 [Recodification]}

(1) During the existence of a trust, an ultimate beneficiary has the right to request that in conformity with the by-laws he be provided with a relevant performance. 
(2) An ultimate beneficiary of a trust established for private purposes may waive his rights under Subsection (1) by means of a declaration made in the form of a public instrument.

\section{Section 1462 [Recodification]}

In the case of a right to fruits or revenues and in the absence of any other ultimate beneficiary to whom such a right could pass, it passes to the ultimate beneficiaries who are entitled to the right to property from the trust.

\section{Subdivision 4}

\section{Supervision over the administration of a trust}

\section{Section 1463 [Recodification]}

(1) Supervision over the administration of a trust is exercised by the founder and a person designated as the ultimate beneficiary, or by other persons if so determined by the by-laws.

(2) In the cases provided by a statute, the administration over a trust is supervised by another person or a group of persons, or a public body.

\section{Section 1464 [Recodification]}

If a trust has been established for the benefit of the ultimate beneficiary who does not yet exist or cannot be determined on the date on which the fund is created, the founder shall appoint a person authorised to supervise the administration of the trust in the interests of the ultimate beneficiary. If this is not possible, or if the founder is inactive, a court shall appoint such a person on the application of the administrator or a person with an interested therein.

\section{Section 1465 [Recodification]}

(1) The trustee shall, without undue delay, deliver to the person with a statutory right to supervise the administration of the trust a notification in which he shall state at least the designation, purpose and duration of the trust and his name and address. The notification is not necessary if the person authorised to supervise is already aware of these facts.

(2) On the request of the person with the right to supervise the administration of the trust, the trustee shall allow the documents of the trust to be checked and submit to him the requested accounts, reports or other information.

\section{Section 1466 [Recodification]}

(1) The founder, an ultimate beneficiary or any other person with a legal interest therein may apply to the court to order or prohibit the trustee to perform a certain act, or to remove the trustee and appoint a new one. These persons may also invoke invalidity of a juridical act whereby an administrator damages the trust or a right of the ultimate beneficiary; however, if a third person has acquired a right in good faith, it must not result in its detriment.

(2) On the application of the person under Subsection (1), a court shall authorise such a person to initiate or pursue proceedings in the interest of a trust instead and in the name of a trustee, if the trustee is inactive without sufficient cause.

\section{Section 1467 [Recodification]}

If a trustee, founder or ultimate beneficiary participates in acts aimed to intentionally harm the rights of the founder's creditor or harm the trust, they are liable jointly and severally.

\section{Subdivision 5}

\section{Changes of a trust}

Section 1468 [Recodification]

A person who increases the property of a trust by a contract or disposition mortis causa is not its founder. Property so acquired is subject to administration under the by-laws and statutes.

\section{Section 1469}

(1) On the application of a person with a legal interest therein, a court may decide that a trust be cancelled if it is impossible or difficult to achieve its purpose, primarily due to circumstances which are unknown or unpredictable to the founder. Where a trust has been established for a publicly beneficial purpose, a court may decide to replace its original purpose with a similar one.

(2) If, in accordance with the original intention of the founder, it is possible to achieve or better benefit the purpose of the trust by changing the fund's by-laws, a court shall amend the by-laws.

\section{Section 1470}

Before making a decision under Section 1469, the court shall seek the opinion of the founder or his legal successor, the trustee, ultimate beneficiary and the person entitled to supervise the trust, unless they are applicants.

\section{Subdivision 6}




\section{Extinction of a trust}

Section 1471

The administration of a trust shall end upon the expiry of the period for which a trust has been established, by achieving the purpose for which a trust has been established, or by a decision of a court. If a trust has been established for private purposes, its administration shall also end in case all ultimate beneficiaries waive their right to receive a performance from the trust.

Section 1472

Upon the extinction of the administration of a trust, a trustee shall surrender the property to the person entitled thereto. An ultimate beneficiary and, in his absence, the founder of the trust are presumed to be entitled to the property; in the absence of both, the property passes into the ownership of the State.

\section{Section 1473 [Recodification]}

(1) If the administration of a trust established for a publicly beneficial purpose is extinguished because it is impossible to fulfil that purpose, a court shall, on the application of the trustee, decide that the property will be transferred to another trust or into the ownership of a legal person aiming to achieve a purpose which is as close as possible to the original purpose of the trust. Before making the decision, the court shall obtain the opinion of the person entitled to supervise the administration of the trust.

(2) The decision under Subsection (1) may not be made if the by-laws of the trust provide for the manner in which property should be disposed of upon the extinction of the trust.

\section{Section 1474}

If, upon the extinction of the administration, the trustee disposes of the property in accordance with the by-laws, or if he surrenders the property under Section 1472 or transfers it under Section 1473, the trust is is extinguished.

\section{TITLE III}

\section{LAW OF SUCCESSION}

\section{Chapter 1}

\section{Right to decedent's estate}

\section{Section 1475 [Recodification]}

(1) Succession right is a right to a decedent's estate or a proportional share thereof.

(2) A decedent's estate consists of the entire assets and liabilities of a decedent except for the rights and duties exclusively bound to him personally, unless they have been acknowledged or enforced as a debt before a public body.

(3) A person holding a succession right is an heir, and the decedent's estate in relation to an heir is his inheritance.

\section{Section 1476 [Recodification]}

Inheriting takes place on the basis of an inheritance contract, testament or by means of a statute. These reasons may also operate together.

\section{Section 1477 [Recodification]}

(1) A legacy establishes a claim for a legatee to be given a particular thing or one or several things of a certain kind, or a claim to a particular right.

(2) A legatee is not an heir.

\section{Section 1478 [Recodification]}

A legal person who is yet to be incorporated may be designated to be an heir or legatee. Such a legal person has the capacity to be an heir or legatee if it is incorporated within one year after the death of the decedent.

\section{Moment of creation of succession right}

\section{Section 1479}

Succession right is created upon the decedent's death. A person who dies before or at the same time as the decedent shall not inherit.

\section{Section 1480}

A succession right which is yet to be created may only be renounced; it may not be otherwise transferred or disposed 


\title{
Incapacity to inherit
}

\author{
Section 1481 [Recodification]
}

A person is excluded from his succession right if he commits an act having the nature of an intentional criminal offence against the decedent, his ancestor, descendant or spouse, or a despicable act against the decedent's last will, especially by forcing or deceitfully seducing the decedent to express his last will, frustrating his expression of last will, or concealing, falsifying, forging or intentionally destroying his testament, unless he was expressly forgiven for such an act by the decedent.

\section{Section 1482 [Recodification]}

(1) If, on the date of the decedent's death, divorce proceedings initiated on the application of the decedent are in progress, where the application was filed because his spouse committed an act constituting domestic violence against the decedent, the decedent's spouse is excluded from succession rights as a statutory heir.

(2) If a parent has been relieved of his parental responsibility because he abused or was at fault for seriously neglecting such responsibility or its exercise, the parent is excluded from the succession right entitling him to inherit from his child by statutory succession of heirs.

\section{Section 1483 [Recodification]}

A descendant of the person excluded from his succession right shall, in the case of statutory succession of heirs, take such a person's place, even where the excluded person survives the decedent. This does not apply to the case provided under Section 1482(1).

\section{Section 1484 [Recodification]}

\section{Renunciation of succession right}

(1) A succession right may be renounced in advance by a contract with the decedent; unless stipulated otherwise, the renunciation also has effects against the descendants. By renouncing his succession right, a person also renounces his right to the forced share; however, a person who only renounces his right to the forced share does not renounce his right arising from succession of heirs.

(2) If a person has renounced his succession right in favour of another person, the renunciation is presumed to be valid only if such a person becomes an heir.

(3) The agreement must be in the form of a public instrument; however, the rights and duties under such an agreement may be extinguished if the parties do so in writing.

\section{Refusal of inheritance}

\section{Section 1485 [Recodification]}

(1) An heir has the right to refuse inheritance after the decedent's death; however, the same applies to a contractual heir only if it is not excluded by the inheritance contract. If a forced heir refuses inheritance, he may do so with the reservation of the forced share.

(2) An agent may declare on behalf of an heir that he refuses, does not refuse or accepts the inheritance only if expressly authorised to do so by the power of attorney.

\section{Section 1486}

If an heir refuses inheritance, he is considered never to have acquired it.

\section{Section 1487 [Recodification]}

(1) An express declaration made before a court is required for the refusal of inheritance. Inheritance may be refused within one month from the date on which a court notified an heir of his right to refuse inheritance and the consequences of refusal; if the heir's only residence is abroad, the time limit for the refusal of inheritance is three months. Based on serious grounds, a court shall appropriately prolong the time limit for an heir to refuse inheritance.

(2) Upon the expiry of the time limit for refusal of inheritance, the right to refuse inheritance is extinguished.

\section{Section 1488 [Recodification]}

If an heir dies before the time limit for refusal of inheritance has expired, his right to refuse inheritance passes to his heir and is not extinguished before the expiry of that heir's time limit for refusal of inheritance also from the previous heir.

\section{Section 1489}

(1) Refusal of inheritance by an heir with a condition, reservation or only in part shall render such a refusal of inheritance invalid. 
(2) Refusal of inheritance is disregarded if the heir's actions alone make it obvious that he wishes to accept the inheritance. An expression of will whereby the heir withdraws his previous declaration stating that he refuses, does not refuse or accepts the inheritance is also disregarded.

\section{Section 1490 [Recodification]}

\section{Waiver of inheritance}

(1) An heir who has not refused inheritance may waive it before a court in succession proceedings in favour of another heir; where such refusal is made by a forced heir, he also waives his right to the forced share, with effect also for his descendants. With the consent of the other heir, the provisions of Sections 1714 to 1720 apply by analogy; however, in the absence of such consent, a waiver of inheritance is disregarded.

(2) If an heir who waived inheritance was charged with a mandate, order of legacy or another measure which, according to the decedent's will, the heir may and is to fulfil only in person, he is not relieved of the duty to fulfil such a measure.

\section{Chapter 2}

\section{Disposition mortis causa}

\section{Division 1}

\section{General provisions}

Section 1491

A disposition mortis causa is a testament, inheritance contract or testamentary clause on legacy.

$$
\text { Section } 1492 \text { [Recodification] }
$$

A disposition mortis causa may not reduce the forced share of a forced heir who has not renounced his right to the forced share and has not even been disinherited. If this is in contradiction to the disposition mortis causa, a forced heir is entitled to the forced share.

\section{Section 1493 [Recodification]}

(1) If a decedent made a disposition mortis causa at the period when he was in the care of a facility which provides health care or social services, or when he otherwise received its services, and if he designated a person who administers, is employed or otherwise engaged in such a facility to be an heir, such designation of these persons as heirs or legatees is invalid unless it is made by means of a testament in the form of a public instrument.

(2) If, after the care at such a facility ended or the period in which he otherwise received their services expired, the decedent could have made a disposition mortis causa in the form of a public instrument without difficulty, Subsection (1) does not apply in the case of invalidity of testament or testamentary clause on legacy.

\section{Division 2}

Testament

\section{Subdivision 1}

\section{General provisions}

Section 1494 [Recodification]

(1) A testament is a revocable expression of will whereby a decedent personally leaves to one or several persons at least a share in his decedent's estate and also legacy, where appropriate, to be received upon his death. If the day, month and year the testament was made is not clear and if the decedent made several contradictory testaments, or if its legal effects otherwise depend on the determination of the time it was made, the testament is invalid.

(2) A testament is to be interpreted so that it accommodates the will of the decedent to the maximum possible extent. The words used in a testament are to be interpreted according to their usual meaning, unless it is proved that the decedent developed a habit of attributing a special meaning of his own to certain expressions.

\section{Section 1495 [Recodification]}

If, in his testament, a decedent refers to the content of another instrument, such other instrument has the same legal effects if it meets the requirements for a testament. If it does not meet such requirements, its contents may only be used to explain the decedent's will.

\section{Section 1496}

The right to designate an heir is a personal right of a decedent. A decedent may not entrust designation of heirs to another or make a disposition mortis causa jointly with another person. 
A decedent must express his will with such accuracy that a mere consent to a proposal made to him does not suffice.

\author{
Section 1498 [Recodification]
}

Testamentary clause on legacy

By a testamentary clause on legacy, a decedent may order a legacy, make a legatee or heir subject to a condition, determine time or impose a mandate on a legatee or heir. Provisions on testaments shall also apply by analogy to testamentary clauses on legacy.

\title{
Devolution of decedent's estate to heirs
}

\section{Section 1499}

The entire decedent's estate shall devolve to an heir if he is designated as a sole heir. Where only a share of the decedent's estate is left by the decedent to the designated heir, the remaining share of the decedent's estate shall devolve to statutory heirs.

\section{Section 1500 [Recodification]}

(1) Where several heirs have been designated and no shares have been determined, the heirs are entitled to an equal share of the decedent's estate.

(2) Where several heirs have been designated in such a way that a share has been determined for each of them but a part of the decedent's estate still remains, the statutory heirs are entitled to the remaining share of the decedent's estate. Statutory heirs shall not have such a right where a decedent has apparently left the entire decedent's estate to the designated heirs, despite having overlooked something in the listing of shares or things.

\section{Section 1501}

(1) If a decedent designates certain shares to some designated heirs but not to others, the designated heirs without a share are equally entitled to the remaining share of the decedent's estate.

(2) If nothing is left, a proportionate deduction from all the designated shares is made for the designated heir without a share in an amount which equals to the share of the heir for whom the smallest share has been designated. If the shares of the other heirs are equal, a deduction therefrom is made in such an amount that the designated heir without a share receives an equal share as the others.

\section{Section 1502 [Recodification]}

In all cases where the decedent has apparently made a miscalculation, the estate is designated so that his will is fulfilled in the best way possible.

\section{Section 1503 [Recodification]}

(1) If, in statutory succession of heirs, some of the designated heirs are considered to be one person in relation to others, they are also considered to be one person when dividing the estate under the testament; this does not apply in case there is an evident decedent's will to the contrary.

(2) If a decedent designates a group of persons to be an heir without providing further details, the persons who belonged to such a group at the time of the decedent's death are presumed to be the heirs.

(3) If a decedent designates the poor or a similarly designated group of persons as heirs without providing further details, the municipality in whose territory the decedent's last residence was located is presumed to be the heir and use the inheritance in favour of the designated group.

\section{Vacant share}

\section{Section 1504}

The share of an heir who does not inherit and has no substitute heir becomes vacant and shall proportionately accede to the shares of the other designated heirs only if all heirs have been designated to receive an equal share of the inheritance, or a share defined by a general expression signifying equal division.

\section{Section 1505}

(1) A person to whom a particular share of inheritance has been left does not have the right to the accession.

(2) If some heirs have been designated with a share while with others without it, the vacant share shall accede in favour of the designated heirs without a share. 
The restrictions associated with the vacant share of inheritance pass to the person in whose favour it accedes, unless the decedent expressed the will to only have such restrictions apply to the designated heir personally, or if it follows from the nature of the case.

\section{Substitution of heirship}

\section{Section 1507 [Recodification]}

In case the inheritance is not acquired by a person designated as an heir by the decedent, the decedent may designate the person's substitute heir; he may also successively designate substitute heirs to such a substitute heir. If a decedent so designates several substitute heirs, the person on the list of substitute heirs who is closest to the person who did not acquire inheritance is entitled to inherit.

\section{Section 1508 [Recodification]}

If a decedent designates substitute heirs for the case where the designated person does not wish to or cannot inherit, the substitution is presumed to have been established for both of these cases.

\section{Section 1509 [Recodification]}

Restrictions imposed on an heir shall also affect his substitute heirs unless the decedent expressed his will to only have these restrictions apply to the heir personally, or if it follows from the nature of the case.

\section{Section 1510 [Recodification]}

If the co-heirs themselves are designated as substitute heirs, the decedent is presumed to have wished to divide the inheritance among the substitute heirs in the same proportion as among the heirs. However, if a person other than a co-heir is designated as a substitute heir, the vacant share shall devolve equally to all, unless the decedent wishes otherwise.

\section{Section 1511 [Recodification]}

(1) Once a designated heir acquires the inheritance, substitution of heirship is extinguished.

(2) Unless a decedent wishes otherwise, substitution of heirship created by the decedent for his child at a time when the child had no descendants is extinguished if the child is survived by descendants having the capacity to inherit. This also applies if the decedent establishes substitution of heirship for another of his descendants at the time when such a descendant has no descendants of his own.

\section{Succession by fideicommissum}

Section 1512 [Recodification]

(1) A decedent may order that upon death or in certain other cases, the inheritance pass to a fideicommissary as the subsequent heir. Designation of a fideicommissary is also considered to be designation of a substitute heir.

(2) If a decedent's order is vague to such an extent that it is impossible to ascertain whether he designated a substitute heir or a fideicommissary, his order is considered to have designated a substitute heir.

\section{Section 1513 [Recodification]}

If a decedent designates an heir for one of his heirs, prohibits one of his heirs to make dispositions mortis causa of the estate, designates a person who does not yet exist upon the decedent's death to be an heir, or designates an heir subject to a condition or for a definite time, it is considered to constitute the establishment of succession by fideicommissum.

\section{Section 1514 [Recodification]}

If all fideicommissaries are contemporaries of the decedent, the list with the successive order of fideicommissaries is not limited.

\section{Section 1515 [Recodification]}

(1) If several fideicommissaries are designated, some of whom do not yet exist as persons upon the decedent's death, succession by fideicommissum is extinguished once assets and liabilities are acquired by the first of the fideicommissaries who are not the decedent's contemporaries.

(2) Succession by fideicommissum is extinguished no later than one hundred years after the death of the decedent, even where he determined a longer time. However, if a fideicommissary is to acquire inheritance no later than upon the death of an heir alive at the time of the decedent's death, succession by fideicommissum is extinguished only once the first of the fideicommissaries acquires the inheritance from such an heir.

\section{Section 1516 [Recodification]}

Succession by fideicommissum is also extinguished where there are no more fideicommissaries or if the event for which it was established does not occur. 


\section{Section 1517 [Recodification]}

If a decedent has designated a fideicommissary for the decedent's minor child who lacks the capacity to make dispositions mortis causa, and if the child later acquires the capacity to perform such acts, succession by fideicommissum is extinguished within the scope of the forced share.

\section{Section 1518 [Recodification]}

Succession by fideicommissum established by the decedent for his child at a time when the child had no descendants is extinguished if the child is survived by a descendant having the capacity to inherit, unless the decedent evidently has other intention. This also applies if the decedent establishes succession by fideicommissum for another of his descendants at a time when such a descendant has no descendants of his own.

\section{Section 1519 [Recodification]}

If a decedent has designated a fideicommissary for a person who lacks the capacity to make dispositions mortis causa due to limitation of legal capacity, succession by fideicommissum is extinguished forever if such a person acquires the capacity to make dispositions mortis causa, unless the decedent wished otherwise.

\section{Section 1520 [Recodification]}

(1) If so requested by a fideicommissary, an heir shall, without undue delay and in the fideicommissary's presence, prepare a written inventory of everything that the heir has acquired by succession, including the day of preparation, and surrender it to the fideicommissary. On request of a fideicommissary, the heir's signature on the inventory must be authenticated.

(2) A fideicommissary has the right to request that the inventory be prepared in the form of a public instrument.

(3) The costs of preparation of the inventory are paid from the inheritance.

\section{Section 1521 [Recodification]}

If a decedent has ordered succession by fideicommissum to an heir excluding his right to freely dispose of the inheritance, the heir's the right of ownership in what he acquired by succession, as well as what he acquired as compensation for the destruction, damage or removal of things from the inheritance are limited to the rights and duties of a usufructuary. This does not apply if a thing under the inheritance is alienated or encumbered in order to pay the decedent's debts.

\section{Section 1522 [Recodification]}

(1) If a decedent has ordered succession by fideicommissum to an heir excluding his right to freely dispose of the inheritance, an heir may alienate or encumber a thing acquired by succession only with the consent of the fideicommissary; the consent must be in the form of a public instrument.

(2) If due managerial care requires that a thing be encumbered or alienated, a court may, on the application of an heir, replace the consent of a fideicommissary. If a court decides that a thing be encumbered or alienated for consideration, the court shall determine how to dispose of the proceeds; in doing so, it shall take into account the legitimate interests of a fideicommissary.

\section{Section 1523 [Recodification]}

If inheritance includes a thing bearing fruits or revenues, a fideicommissary may request that a court determine the manner and scope in which an heir is to manage or use and enjoy the thing.

\section{Section 1524 [Recodification]}

(1) If a thing and its owner are subject to registration in a public register, succession by fideicommissum is also subject to registration in that public register. If a thing and succession by fideicommissum have been registered in a public register and if an heir disposes of a thing which he acquired from the inheritance in a way that frustrates or limits the rights of a fideicommissary without his consent, it has no legal effects with respect to the fideicommissary.

(2) If a thing or succession by fideicommissum are not registered in a public register and if an heir disposes of a thing which he acquired from the inheritance in a way that frustrates or limits the rights of a fideicommissary without the fideicommissary's consent, the fideicommissary has the right to claim, under the provisions on relative ineffectiveness, that a court declare that the juridical acts made by the heir are not legally effective towards him.

\section{Incapacity to make dispositions mortis causa}

\section{Section 1525 [Recodification]}

to 1528 .

A person lacking legal capacity is incapable of making dispositions mortis causa except as provided in Sections 1526

\section{Section 1526 [Recodification]}

A person who has reached the age of fifteen and has not yet acquired full legal capacity may make dispositions mortis 
causa in the form of a public instrument without the consent of a legal representative.

Section 1527 [Recodification]

A person whose legal capacity has been limited so that he is incapable of making disposition mortis causa may still make valid disposition mortis causa in any form if he recovers to the extent that he is able to express his will.

Section 1528 [Recodification]

(1) A person whose legal capacity has been limited may, within the relevant limitations, only make dispositions mortis causa in the form of a public instrument.

(2) A person whose legal capacity has been limited due to a pathological addiction to alcohol consumption, use of psychotropic substances, or similar products or toxins, or due to a pathological addiction to gambling which constitutes a serious mental disorder may, within the relevant limitations, make dispositions mortis causa in any form prescribed, but of no more than half of the decedent's estate. The remaining share of the decedent's estate shall devolve to the statutory heirs; however, where only the State is to inherit as a statutory heir, a decedent may make disposition mortis causa of the entire decedent's estate.

\section{Effects of error}

Section 1529 [Recodification]

A substantial error of a decedent invalidates the provision of the testament in question.

$$
\text { Section } 1530 \text { [Recodification] }
$$

(1) An error is substantial if it concerns a person to whom a thing is left by a decedent, or a share or thing left to a person by a decedent, or the essential properties of a thing. Properties are essential if it is evident that the decedent would have determined otherwise in his testament had he not made an error about such properties.

(2) A provision of a testament is valid if it becomes evident that a person or thing was only incorrectly described.

$$
\text { Section } 1531 \text { [Recodification] }
$$

If a decedent's will is only based on a wrong motive, it shall invalidate the provision of the testament in question.

\section{Subdivision 2}

\section{Form of testament}

Section 1532

\section{Written form of testament}

A testament must be in written form, unless it was made with concessions.

\section{Testament made by means of a private instrument}

\section{Section 1533}

A person who wishes to make dispositions mortis causa in writing without witnesses shall write and sign the entire testament with his own hand.

\section{Section 1534}

If a decedent has not written the testament by his own hand, he must sign it by his own hand and at the same time expressly declare before two witnesses that the instrument contains his last will.

\section{Section 1535}

(1) If a decedent is blind, he shall express his last will before three witnesses present at the same time in an instrument that must be read aloud by a witness who has not written the testament. A decedent shall confirm before the witnesses that the instrument contains his last will.

(2) If the decedent is a person with a sensory disability and he cannot read or write, he shall express his last will before three witnesses present at the same time in an instrument whose contents must be interpreted in a special method of communication of the decedent's choosing by a witness who did not write the testament; all witnesses must have command of the method of communication used to interpret the contents of the instrument. The decedent shall use the chosen method of communication to confirm before the witnesses that the instrument contains his last will.

\section{Section 1536}

(1) A testament made by a person with sensory disabilities who cannot read or write shall state the fact that the decedent cannot read or write, the person who wrote the testament, the person who read or interpreted it, and the method which the decedent used to confirm that the instrument contains his last will. If the contents were interpreted using a special method of communication, it is indicated in the instrument including the method of communication chosen by the decedent. 
(2) The instrument shall also be signed by the decedent; if he cannot write, Section 563 applies by analogy.

\section{Testament made by means of a public instrument}

Section 1537

A decedent may express his last will in a public instrument. If a testament in this form is made by a blind person or a person with sensory disabilities who cannot read or write, Section 1535 applies by analogy.

\section{Section 1538}

A person drawing up a public instrument about a testament shall make sure that the last will is expressed with prudence, seriously and without coercion.

\section{Witnesses to a testament}

\section{Section 1539}

(1) Witnesses are present during the making of a testament in such a manner that they are able to confirm that the decedent and the person making the testament are one and the same person. A witness shall sign the instrument containing the testament; to his signature, he shall typically attach a clause referring to his capacity as a witness and information allowing his identification.

(2) A person lacking legal capacity or command of the language or method of communication used to make the expression of will may not be a witness.

$$
\text { Section } 1540 \text { [Recodification] }
$$

(1) An heir or legatee may not testify about a thing which is left to him by a decedent. Likewise, a close person or an employee of the heir or legatee may not be a witness.

(2) In order for the provisions of a testament made in favour of a person under Subsection (1) to be valid, they must be written by the decedent's own hand or confirmed by three witnesses.

\section{Section 1541}

Section 1540 applies by analogy to a person designated by the decedent to be the executor of testament or the person acting as the writer, reader, interpreter or official in the making of a testament.

\section{Concessions in the making of a testament}

\section{Section 1542 [Recodification]}

(1) A person who is under imminent threat to life due to a contingency has the right to make a testament orally before three witnesses present at the same time. A person in a place where usual social intercourse is paralysed as a result of a contingency and who cannot be reasonably required to make a disposition mortis causa in another form has the same right.

(2) If witnesses do not make a record of the decedent's last will, the succession of heirs will be based on a judicial protocol of the examination of witnesses.

\section{Section 1543 [Recodification]}

Where there is a reasonable concern that a decedent would die before he can make a testament in the form of a public instrument, his last will may be recorded, in the presence of two witnesses, by a mayor of the municipality in whose territory the decedent is located. A person entitled to exercise the powers of a mayor under another legal regulation may, under the same conditions, also record a decedent's last will.

\section{Section 1544 [Recodification]}

(1) If a decedent has a serious reason, his last will may be recorded in the presence of two witnesses aboard a naval vessel sailing under the national flag of the Czech Republic or an aircraft registered in the Czech Republic by the commander of the naval vessels or aircraft, or by his representative, unless he is prevented from doing so due to considerations of safety of the voyage or flight. The validity of a testament may not be denied by claiming that the decedent had no serious reason to make the testament.

(2) If a testament has been made under Subsection (1) on board of:

a) a naval vessel, the commander shall record the testament in the logbook and hand it over without undue delay to an embassy of the Czech Republic closest to the port to which the naval vessel arrives, or to the public body which maintains the naval register in which the naval vessel is registered, or

b) an aircraft, the commander shall record the testament in the logbook and hand it over without undue delay to the embassy of the Czech Republic closest to the place abroad where the plane landed, or to the public body which maintains the aircraft register in which the aircraft is registered. 


\title{
Section 1545 [Recodification]
}

(1) When participating in an armed conflict or military operations, the last will of a soldier or another member of the armed forces may be recorded in the presence of two witnesses by a commander of a military unit of the Czech Republic or another soldier at the rank of officer or higher. If a testament is made in this manner, its validity is not to be denied.

(2) A commander shall, without undue delay, deliver the testament made under Subsection (1) to a commander of superior command, who shall, without undue delay, hand it over to the Ministry of Defence of the Czech Republic.

\section{Section 1546 [Recodification]}

If a testament was made under Section 1543, the municipality shall, without undue delay, ensure that the testament is deposited with a notary. If a testament was made under Sections 1544 or 1545 , the same is provided for by the authority to which the testament was handed over.

\section{Section 1547 [Recodification]}

(1) If a decedent has made a disposition mortis causa under Sections 1543,1544 or 1545, the person making the record must also sign it together with both witnesses and read it to the decedent in the presence of both witnesses, and the decedent must confirm that the record constitutes the expression of his last will. A testament so made is to be considered a public instrument.

(2) Where a testament is made under Sections 1543,1544 or 1545 and the prescribed formalities are not adhered to, in particular where the instrument lacks the signatures of the witnesses present, although they are required, but it is nevertheless certain that the instrument reliably records the decedent's last will, it does not cause the testament to be invalid; however, such an instrument is not to be considered a public instrument.

\section{Section 1548 [Recodification]}

(1) Where a testament with relief is made, persons who have reached the age of fifteen and persons whose legal capacity has been limited may also be witnesses if they have the capacity to credibly describe facts relevant to the validity of the testament.

(2) Where a testament with concessions is made, its validity shall remain unaffected if it is not signed by the decedent or a witness because he could not write or due to another serious obstacle provided that it is explicitly stated in the instrument.

\section{Section 1549 [Recodification]}

If a decedent is alive, a testament made under Section 1542 shall lose its validity after two weeks, and a testament made under Section 1543, 1544 or 1545 shall lose its validity after three months from the date on which it was made. However, these periods neither commence nor run until the decedent can make a testament in the form of a public instrument.

Section 1550

\section{Confidentiality}

A person who acted as a writer, witness, reader, interpreter, depositary or an official in the making of a testament or making another juridical act which is subject to the same requirements as a testament under this Act shall keep confidential the content of the decedent's will, unless it is obvious that the decedent wished otherwise; if such a person breaches this duty, he shall compensate the decedent for the harm caused thereby.

\section{Subdivision 3}

\section{Clauses of lesser importance in a testament}

\author{
Section 1551 [Recodification]
}

(1) In his testament, a decedent may provide a condition, determination of time or a mandate.

(2) Where a clause of lesser importance only aims to apparently harass an heir or legatee as a result of the decedent's manifest arbitrariness, it is disregarded. A clause of lesser importance which is clearly contrary to public order or is incomprehensible is also disregarded.

\section{Section 1552 [Recodification]}

A clause of lesser importance whereby a decedent obliges an heir or legatee to enter or not to enter into marriage, to remain in marriage or to cancel a marriage is disregarded. However, a decedent may create a right for someone for the period before he enters into marriage.

\section{Executor of testament}

\section{Section 1553 [Recodification]}

(1) In his testament, a decedent may designate an executor of testament and, where applicable, determine his duties and whether or not he will be remunerated and how. 
(2) If a court, during succession proceedings, ascertains that an executor of testament has been designated, it shall inform him thereof. An executor of testament may resign his office at any time; the resignation is effective when it reaches a court.

\section{Section 1554 [Recodification]}

(1) An executor of testament shall ensure the proper fulfilment of the last will of the decedent while exercising due managerial care. He has all the rights necessary for the fulfilment of his tasks, including the right to defend the validity of the testament and invoke incapacity of an heir or legatee in court, and generally ensure the fulfilment of the decedent's instructions.

(2) If a decedent designated no administrator of the decedent's estate, the executor of testament is also entitled to administer the decedent's estate until a court decides on another measure. If an executor of testament has been designated by a public instrument, the provisions on administrators of the decedent's estate apply to him by analogy; otherwise they apply with the necessary modifications.

\section{Section 1555 [Recodification]}

When invalidity of the selection of an executor of testament for office is invoked, he may assert his rights and fulfil his duties until the decision invalidating the expression of the decedent's will becomes final and absolute, unless the court adopts another measure.

\section{Administrator of the decedent's estate}

\section{Section 1556 [Recodification]}

(1) A decedent may select an administrator of the decedent's estate or any part thereof (hereinafter an "administrator of the decedent's estate") and, where appropriate, determine his duties, and whether or not, and how, he will be remunerated. The selection of an administrator of the decedent's estate must be in the form of a public instrument.

(2) An expression of will whereby an administrator of the decedent's estate was selected may be cancelled in the same way as a testament.

\section{Section 1557 [Recodification]}

If an administrator of the decedent's estate is aware that he has been selected, he shall assume administration once he learns of the decedent's death. If the fact that an administrator of the decedent's estate has been selected is only ascertained by a court, it shall inform him thereof.

\section{Section 1558 [Recodification]}

If an executor of testament has been selected, an administrator of the decedent's estate shall follow his instructions; their mutual rights and duties are assessed under the provisions on mandates.

\section{Section 1559 [Recodification]} a court.

An administrator of the decedent's estate may resign his office at any time; the resignation is effective when it reaches

$$
\text { Section } 1560 \text { [Recodification] }
$$

If an executor of testament or administrator of the decedent's estate seriously breaches his duties, is unable to fulfil his duties properly or where there is another serious reason, a court shall remove him, even of its own motion.

\section{Conditions}

\section{Section 1561 [Recodification]}

Where a condition consists in an act which an heir or legatee may repeat, he must perform such an act again after the death of the decedent although he already did so while the decedent was alive, unless another wish of the decedent is evident.

\section{Section 1562 [Recodification]}

To acquire what has been left by a decedent with a suspensive condition, the person to whom something has been left in this manner must survive the decedent and have the capacity to inherit.

\section{Section 1563 [Recodification]}

(1) If a person is granted a right with an impossible resolutive condition, it is disregarded.

(2) A provision of a testament which grants a person a right with an impossible suspensive condition is invalid.

\section{Determination of time}


If a decedent limits a person's right by determination of time and it is not certain whether or not the moment will occur, the right left to the person by the decedent is conclusively presumed to be conditional.

\section{Section 1565 [Recodification]}

If time is determined so that the decisive moment must occur, the right left to a person by a decedent shall also pass, the same way as other unconditional rights, to the heirs of the person to whom inheritance has been left in this manner.

\section{Section 1566 [Recodification]}

If it is certain that the period determined in a testament can never occur, such a determination of time is treated as an impossible condition. However, if it is beyond doubt that a decedent merely made an error when determining the time, the decisive moment is determined according to what his will would likely have been.

\section{Special provisions}

Section 1567 [Recodification]

(1) As long as a right of the subsequent heir remains postponed until the condition is met or the determined time occurs, the right of a preceding heir to whom the inheritance devolved is limited to that of a usufructuary; the provisions of Sections 1520 to 1524 apply by analogy.

(2) An heir whose right has been postponed due to an imposition of a condition or determination of time by the decedent shall acquire what has been left to him with the duty to proportionately contribute to the preceding heir's payments to satisfy the decedent's debts, or to a forced heir's forced share.

\section{Section 1568 [Recodification]}

Where a preceding and subsequent legatee has been designated, Section 1567 applies by analogy.

\section{Mandate}

\section{Section 1569 [Recodification]}

(1) If a decedent leaves something to someone with a mandate, the mandate is treated as a resolutive condition, so that the right left by the decedent is frustrated if the mandate is not executed, unless the decedent expressed another wish.

(2) The prohibition to alienate or encumber is binding on a person charged with a mandate only if it is imposed for a specific reasonable period and justified by a serious interest worthy of legal protection; otherwise, a court may, on the application of the person charged with the mandate, decide that the prohibition is disregarded. If a prohibition has been registered in a public register, the person charged with a mandate may apply to a court to cancel the prohibition; the court shall not grant such an application unless it is proved that the interest in cancelling the prohibition apparently exceeds the interest in maintaining it.

\section{Section 1570 [Recodification]}

If a mandate cannot be fulfilled exactly as ordered, it must be fulfilled at least as closely as possible to its contents. Where even that is impossible, a person charged with the mandate shall acquire what has been left to him, unless the decedent expressed another wish. However, a person who has rendered himself unable to fulfil the mandate knowing that it would result in its frustration shall lose what has been left to him.

\section{Section 1571 [Recodification]}

In addition to the person who benefits from a mandate, an executor of testament or another person designated in the testament is also entitled to enforce the fulfilment of a mandate.

\section{Section 1572 [Recodification]}

(1) If a mandate aims to benefit multiple persons without further specification, the person charged with a mandate shall fulfil the mandate towards a legal person entitled to protect the interests of such persons. Where there are several such legal persons and the decedent's will is not obvious, the choice lies with the person charged with the mandate; if he fails to choose without undue delay, the entitled person is designated by a court on the application of a person with a legal interest therein.

(2) Where a mandate aims to achieve public benefit, the fulfilment of the mandate may also be enforced by the competent public body.

\section{Section 1573 [Recodification]}

If a decedent makes a statement about the purpose for leaving something to someone, but imposes no duty to use the things left to the person by the decedent for that purpose, his expression of will is considered to be a wish without a legally binding effect. 
A provision whereby a decedent charges an heir or legatee with a mandate not to challenge the testament under a sanction of losing some benefits has no legal effect where only the authenticity of the testament or the interpretation of its meaning is challenged.

\section{Subdivision 4}

\section{Cancellation of testament}

Section 1575

(1) A decedent has the right to cancel his testament or the individual provisions thereof at any time.

(2) A testament is cancelled upon revocation or the making of a subsequent testament.

Section 1576

\section{Making a new testament}

When a subsequent testament is made, an earlier testament is cancelled to the extent to which it cannot be performed having regard to a subsequent testament.

\section{Revocation of a testament}

Section 1577 testament.

An expression of will made in the form prescribed for the making of a testament is required to expressly revoke a

Section 1578

(1) The destruction of the instrument on which the testament was written is required to tacitly revoke a testament. If a decedent destroys only one of several copies of a testament, it cannot lead to the assumption that it has been revoked.

(2) If a decedent has damaged the instrument in any other way, or has not renewed his testament knowing that the instrument was destroyed or lost, the testament will be cancelled provided that the decedent's intention to cancel the testament undoubtedly follows from the circumstances.

\section{Section 1579}

(1) If a testament has been made in the form of a public instrument, the decedent has the right to request at any time that it be surrendered to him; a testament may only be surrendered to the decedent in person. If a testament is surrendered to the decedent, it is considered revoked; the person who surrendered the testament to the decedent shall advise the latter accordingly, and make a note about the revocation of the testament and the advice on the instrument surrendered, as well as in his file.

(2) If a testament has been placed in official deposit, the decedent has the right to request that it be surrendered to him; surrender of a testament has no legal consequences anticipated under the second sentence of Subsection (1).

\section{Section 1580 [Recodification]}

If a decedent cancels a subsequent testament but keeps a previous one, the previous testament is presumed to have remained valid and considered never to have been cancelled.

Section 1581

\section{Ineffective cancellation clause}

If a decedent declares that all his subsequent dispositions mortis causa, or those which are not made in a particular form, are to be invalid, it is disregarded.

\section{Division 3}

\section{Inheritance contract}

\section{Section 1582 [Recodification]}

(1) By an inheritance contract, a decedent designates the other contracting party or a third person to be an heir or legatee, and the other party accepts it.

(2) An inheritance contract must be in the form of a public instrument.

$$
\text { Section } 1583 \text { [Recodification] }
$$

The provisions of this Division on contractual heirs also apply by analogy to contractual legatees. 


\section{Section 1584 [Recodification]}

(1) An adult decedent having full legal capacity may conclude an inheritance contract; if a decedent's legal capacity has been limited, he may conclude an inheritance contract and change an obligation arising therefrom with the consent of his guardian. personal act.

(2) The parties may conclude an inheritance contract and change an obligation arising therefrom only through a

\section{Section 1585 [Recodification]}

(1) Disposition of the entire decedent's estate is not allowed under an inheritance contract. A quarter of the decedent's estate must remain vacant so that the decedent may make disposition thereof according to his specifically expressed will. Where a decedent also wishes to leave this quarter to a contractual heir, he may do so in his testament.

(2) A person whose legal capacity has been limited due to a pathological addiction to alcohol consumption, use of psychotropic substances, or similar products or toxins, or due to a pathological addiction to gambling which constitutes a serious mental disorder, may make in an inheritance contract a disposition of the property of which he has capacity to make a disposition by means of a testament. This property is the basis to calculate one quarter reserved for disposition mortis causa according to his specifically expressed will.

\section{Section 1586 [Recodification]}

If an inheritance contract has been concluded where the other heirs have renounced their succession right, such a renunciation ceases to be effective if the heir designated in the inheritance contract does not inherit.

$$
\text { Section } 1587 \text { [Recodification] }
$$

The conditions in an inheritance contract are governed by Sections 548 and 549.

$$
\text { Section } 1588 \text { [Recodification] }
$$

(1) An inheritance contract does not prevent the decedent from disposing of his property at will while he is alive. Unless stipulated otherwise, the party designated as an heir may not transfer his right to another person.

(2) However, if a decedent makes a disposition mortis causa or enters into a donation contract so that it is inconsistent with an inheritance contract, a contractual heir may invoke the ineffectiveness of these juridical acts.

\section{Section 1589 [Recodification]}

(1) If the parties agree that the decedent will transfer property to a contractual heir while he is still alive, the property may be listed in the form of a public instrument. In such a case, if the decedent does not transfer all of his property or if he acquires other property after the transfer, the inheritance contract applies only to the property so listed, unless stipulated otherwise.

(2) Where property was delivered while the decedent was still alive, the rights and duties arising from the inheritance contract pass to an heir of the contractual heir, unless stipulated otherwise.

\section{Section 1590 [Recodification]}

A decedent may also exinguish his duties under an inheritance contract by a testamentary disposition. The consent of the contractual heir made in the form of a public instrument is required for the cancellation to become effective.

\section{Section 1591 [Recodification]}

An inheritance contract invalid due to lack of form, the failure to meet the conditions under Sections 1584 and 1585 or inconsistency with the provisions on contracts under Book Four of this Act may still have the effects of a testament if it otherwise fulfils all the requirements for a testament.

\section{Special provisions on an inheritance contract concluded between spouses}

\section{Section 1592 [Recodification]}

(1) Spouses may conclude an inheritance contract whereby one party designates the other to be an heir or legatee and the other party accepts it, or where spouses mutually designate each other as heirs or legatees.

(2) Such an agreement may also be concluded by fiancés for when they enter into marriage; however, the agreement becomes effective only upon the formation of marriage.

\section{Section 1593 [Recodification]}

(1) Divorce does not extinguish the rights and duties arising from an inheritance contract, unless the inheritance contract stipulates otherwise. After a divorce, each party may claim that the inheritance contract be cancelled by a court. A court shall dismiss such application if it is aimed against the person who was not at fault for the breakdown of the marriage and disagreed with the divorce. 
(2) If a marriage is declared invalid, the rights and duties arising from an inheritance contract are extinguished unless such marriage terminated earlier by the death of a spouse.

\section{Chapter 3}

Legacy

\section{Division 1}

\section{General provisions}

\section{Allocation of legacy}

Section 1594 [Recodification]

(1) A decedent may allocate a legacy by ordering a person in a disposition mortis causa to surrender the bequeathed thing to a legatee. Only a person having the capacity to inherit may be a legatee. If a decedent designates an heir and determines that the heir is not to inherit a particular thing, it is considered an allocation of legacy to statutory heirs.

(2) Donation dependent on the condition that the beneficiary survives the donor is considered a legacy unless the donor has waived his right to revoke the gift.

\section{Section 1595 [Recodification]}

Legacies may be allocated by a person having the capacity to make testamentary dispositions. A decedent lacking the capacity to make dispositions mortis causa may, from his property, only bequeath items of small value to another person.

\section{Section 1596 [Recodification]}

A decedent may also bequeath a preferential legacy to an heir or co-heirs; they will be considered legatees with respect to such legacy.

\section{Charging with legacy}

Section 1597 [Recodification]

Legacies are charged to all the heirs in proportion to their shares, even where the thing bequeathed belonged to one of the co-heirs. This does not apply if the decedent specifically orders an individual co-heir or legatee to carry out the legacy.

\section{Section 1598 [Recodification]}

At least a quarter of the value of the inheritance must be left free from charge with legacies for each heir. If a decedent charges an heir in excess, the heir is entitled to a proportionate reduction in the legacy.

Section 1599 [Recodification]

\section{Sub-legacy}

(1) Where a decedent orders a legatee to carry out an additional legacy, the fact that its value exceeds the value of the legacy does not relieve the legatee of the duty to carry out the additional legacy.

(2) If a legatee does not acquire a legacy, the additional legacy is carried out by a person to whom the legacy devolves. He is released from that duty if he relinquishes the legacy devolved on him to the person to whom the additional legacy was bequeathed.

\section{Section 1600 [Recodification]}

A decedent who allocates a legacy to support a particular group of persons, especially his relatives or the poor, or a publicly beneficial, charitable or similar purpose, may leave it up to an heir or another person to determine which of those persons or purposes are to receive a share of the legacy, and how. In the absence of any statement of the decedent, the choice is up to the heir. If the heir cannot make the choice, the legatees are chosen by a court.

\section{Section 1601 [Recodification]}

\section{Substitution with respect to legacy}

A decedent may order substitution or succession by fideicommissum with respect to a legacy. Such cases are governed by the provisions of Sections 1507 to 1524 with the necessary modifications.

\section{Revocation of legacy}


A legacy is presumed to have been revoked where the decedent:

a) destroyed or alienated a bequeathed thing and has not reacquired it,

b) altered a bequeathed thing in such a way that it becomes another thing, or

c) enforced and collected a bequeathed claim.

\section{Section 1603 [Recodification]}

A legacy is not presumed to have been revoked if the bequeathed thing was acquired by another person, or altered or destroyed without the will of the decedent. This also applies where a debtor has settled a bequeathed claim to the decedent on his own initiative.

\section{Division 2}

\section{Special rules on the different types of legacies}

\section{Subdivision 1}

\section{Legacy of a particular kind of things}

Section 1604

(1) Where a thing of a particular kind is bequeathed and there are several such things in the decedent's estate, the person charged with the legacy shall decide which of the things will be surrendered to the legatee. However, he must choose a thing which the legatee will be able to use.

(2) If it is left up to the legatee to choose from several things himself, he may even choose the best thing.

\section{Section 1605}

(1) Where a thing of a particular kind which is not part of the decedent's estate is bequeathed, such a legacy is invalid. If a decedent has bequeathed several things of a particular kind, and the decedent's estate does not contain the determined number of those things, the legatee shall settle for those that are contained in the decedent's estate.

(2) However, if a decedent does not expressly bequeath a thing of a particular kind from his property and if such a thing is not part of the decedent's estate, the person charged with the legacy shall obtain it for the legatee in the quality appropriate to the legatee's personal circumstances and needs.

\section{Section 1606}

(1) A decedent may also authorise another person to choose which of several things a legatee is to acquire. If that person fails to make the choice, the legacy is determined by a court having regard to the legatee's personal circumstances and needs.

(2) A court shall also determine a legacy where a legatee fails to make the choice committed to him within the time limit set for the application of a person charged with a legacy.

\section{Section 1607}

A legacy of money obliges a person charged with the legacy to pay the sum of money, whether or not the decedent's estate contains cash.

\section{Subdivision 2}

\section{Legacy of a determined thing}

\section{Section 1608}

Where a legacy of a determined thing repeats in one or several provisions, the legatee is not entitled to both the bequeathed thing and its price. Other legacies, even if they contain a thing of the same kind or the same amount of money, belong to the legatee as many times as they are repeated.

\section{Section 1609}

The legacy of a thing which belonged to the legatee at the time the testament was made is disregarded. If he acquired such a thing later, he is paid the usual price of the thing; however, if he acquired the thing gratuitously from the decedent himself, the legacy is conclusively presumed to have been revoked.

\section{Section 1610}

(1) The legacy of a thing of another belonging neither to the decedent, nor the heir or legatee who is to give it to someone else, is disregarded. If these persons have a share in or right to the bequeathed thing, the legacy only concerns such a share or right. 
(2) If a decedent has ordered that a thing of another is to be bought and provided to a legatee, but its owner does not wish to sell it for the usual price, the legatee are paid such price.

Section 1611

pledge or other encumbrance of a bequeathed thing affects the recipient as a legacy defect.

\section{Subdivision 3}

\section{Legacy of a claim}

Section 1612

Where a decedent's claim is bequeathed, the person charged with a legacy shall assign such a claim with accessories and, where applicable, with security to the legatee, surrender the necessary documents regarding the claim to him and provide him with all information necessary to assert the claim against the debtor.

\section{Section 1613}

Although a legacy of all claims includes all claims existing after the legacy has been allocated, it does not include claims arising from transferable securities and savings books, or claims encumbering immovable things and claims arising from a right in rem.

\section{Section 1614}

A legacy of a decedent's claim from a legatee obliges the person charged with the legacy to surrender an acquittance to the legatee or return the debt instrument.

\section{Section 1615}

A waiver of a debt does not apply to debts incurred after the legacy has been allocated. A waiver of the security of a debt does not imply a waiver of the debt itself. A mere extension of the time limit for payment does not imply a waiver of interest.

\section{Section 1616}

(1) The legal effect of a legacy of a debt to be paid by a decedent to a legatee is one which obliges the person charged with the legacy to acknowledge the debt, which is precisely expressed by the decedent or proved by the legatee, and to pay it no later than within the time limit to carry out the other legacies, regardless of the conditions and time limits stipulated between the person charged with legacy and the decedent.

(2) If a decedent orders that a legatee's claim be secured, the latter must be provided with sufficient security.

\section{Section 1617}

If an amount which a decedent has bequeathed to a person is the same as what he owes the person himself, he is presumed not to have wished to discharge his debt by the legacy. A legatee shall receive the debt and the legacy.

\section{Subdivision 4}

\section{Other legacies}

Section 1618

\section{Legacy to children and relatives}

Where a decedent has allocated a legacy to the children of another, children are to be understood only as sons and daughters. However, where the decedent's own children are concerned, children are also to be understood as the descendants taking their place.

Section 1619

Section 1503 shall also apply, by analogy, to legacies other than those under Sections 1594 to 1618 .

\section{Division 3}

\section{Acquisition of legacy}

Section 1620

(1) A legatee acquires the right to a legacy for himself and his successors upon the death of the decedent.

(2) Where a right to a legacy is yet to be created, such a right is governed by Section 1480 by analogy. 
(1) A legatee acquires a bequeathed thing in the same manner as when acquiring the right of ownership.

(2) If the right to a legacy becomes due, a legatee may claim that the bequeathed thing be surrendered to him. Where a bequeathed thing is subject to registration in a public register, the surrender of the thing is replaced by a declaration of the executor of testament, or otherwise by a declaration of the person charged with the legacy, with an authenticated signature; unless the due date of a legacy has been postponed, the legatee is registered in the public register directly after the decedent.

\section{Section 1622}

thereof.

Before the death of a decedent, a legatee may not transfer the right to a legacy or make a disposition mortis causa

\section{Section 1623}

If a legatee declares, in the manner provided for the refusal of inheritance, that he does not wish to acquire the legacy, he is considered never to have acquired the legacy.

\section{Section 1624}

(1) A legacy of individual things from the decedent's estate and a legacy of rights relating to such things may be requested immediately. This also applies to a legacy of smaller rewards for employees and publicly beneficial, charitable and similar legacies. Other legacies are due one year after the death of the decedent.

(2) Subsection (1) applies, unless another wish of the decedent is evident.

\section{Section 1625}

In the case of a legacy of an individual thing, a legatee is entitled to the fruits and revenues as well as to everything that is added to the thing, including the associated rights, from the day on which the legacy becomes due. From the same day, the legatee is affected by the defects of the bequeathed thing, as well as its deterioration or decay resulting from the facts for which no one is responsible.

\section{Section 1626}

(1) In the case of a legacy of benefits due annually, monthly or otherwise, a legatee becomes entitled to the amount for the entire period if he is still alive at the beginning of the period; however, the payment shall only become due on the determined due date.

(2) A legacy of maintenance and support is governed by Section 922 by analogy.

$$
\text { Section } 1627
$$

\section{Right of a legatee to security}

(1) In the case of a legacy of a recurrent performance or a legacy whose performance may not yet be claimed with respect to a statutory time limit, or a time limit or condition determined by the decedent, the legatee has the right to be provided with sufficient security with respect to the person charged with the legacy. This does not apply if it is evident that security is not needed. creditor.

(2) In other cases, a legatee has the same rights with respect to the person charged with the legacy as any other

\section{Vacant legacy}

\section{Section 1628}

(1) If a legatee is unable or refuses to accept a legacy, the legacy shall devolve to a substitute legatee. Where there is no substitute legatee and the entire legacy has been bequeathed to several persons either without determining the shares, or through a general expression signifying equal division, the vacant share is proportionately added to the shares of other holders.

(2) If a particular share has been bequeathed to a legatee, the legatee is not entitled to an accession under Subsection (1), unless there is an evident will of the decedent to bequeath the entire legacy to the listed legatees, and that he determined the shares only to mutually restrict the legatees.

(3) In other cases, the duty to carry out the legacy is extinguished.

\section{Section 1629}

A person who benefits from a legacy becoming vacant or from the extinction of the duty to carry out the legacy is also affected by the encumbrances associated with the legacy. This does not apply in the case of personal acts of the person originally charged with the legacy.

\section{Rights of an heir having reserved estate inventory}


(1) If the net decedent's estate is charged with a legacy so that it becomes almost used up and an heir fails to assert his right under Section 1598, the heir shall only be entitled to the reimbursement of costs incurred in carrying out legacies and to a reasonable remuneration for his efforts. If the decedent's estate is insufficient for the payment of such costs and remuneration, they are paid by the legatees in proportion to the value of their legacies; the heir has a retention right to secure his right to the bequeathed things; the heir is not required to deal with the legacies without sufficient security.

(2) However, if a legatee has already received the legacy, a deduction is made according to the value of the legacy at the time it was received and according to the revenues which he has already gained therefrom. A legatee may be relieved of the contribution duty by surrendering to the heir the legacy including the revenues, or the price thereof. In other respects, the legatee is considered to be a possessor in good faith.

\section{Section 1631}

(1) If the net decedent's estate is insufficient for the payment of all debts and other mandatory expenses, the legacies are proportionately reduced.

(2) If the net decedent's estate is insufficient to deal with all legacies, the legacies of provision for life, upbringing and maintenance are satisfied as a matter of priority; other legacies are proportionately reduced.

\section{Section 1632}

\section{Fulfilment of last will by an administrator of the decedent's estate}

If an executor of testament has not been appointed and the heir does not wish to expend the time and effort to fulfil the last will, a court shall, on the application of an heir, appoint an administrator of the decedent's estate for that purpose, or order an already selected administrator of the decedent's estate to fulfil the last will.

\section{Chapter 4}

\section{Statutory succession of heirs}

\section{Section 1633}

(1) Where there is no succession of heirs under an inheritance contract or testament, statutory succession of heirs to the decedent's estate or part thereof arises. If there is no statutory heir or if he does not acquire the inheritance, legatees become heirs in proportion to the value of their legacies.

(2) A person who acquired an inheritance because an heir or a substitute heir designated in the inheritance contract or testament did not wish to or could not inherit shall fulfil the other orders of the decedent.

\section{Section 1634 [Recodification]}

\section{Escheat}

(1) Where no heir inherits even under statutory succession of heirs, the inheritance shall devolve to the State, and the State is considered to be the statutory heir; however, the State does not have the right to refuse inheritance or the right to legacy under the third sentence of Section 1594(1). inventory.

(2) With respect to other persons, the State has the same status as an heir who has made a reservation as to estate

\section{Section 1635}

\section{First class of heirs}

(1) The decedent's children and spouse inherit in the first class of heirs, each of them equally.

(2) If any of the children does not inherit, his share is acquired equally by his children; the same applies to more distant descendants of the same ancestor.

Section 1636

\section{Second class of heirs}

(1) If the decedent's descendants do not inherit, the second-class heirs include the spouse, the decedent's parents and those who lived with the decedent in the common household for at least one year before his death and, as a result, cared for the common household or were dependent in maintenance on the decedent.

(2) Second class heirs inherit equally; however, the spouse shall always inherit at least half of the decedent's estate. 
(1) If neither the spouse nor any of the parents inherit, decedent's siblings and those who lived with the decedent in the common household for at least one year before his death and, as a result, cared for the common household or were dependent in maintenance on the decedent, inherit in the third class of heirs equally.

(2) If one of the decedent's siblings does not inherit, his share of inheritance is acquired by his children equally.

\title{
Section 1638 [Recodification]
}

\section{Fourth class of heirs}

If no heir inherits in the third class, the decedent's grandparents inherit in the fourth class equally.

\author{
Section 1639 [Recodification]
}

\section{Fifth class of heirs}

(1) If none of the fourth-class heirs inherits, only the grandparents of the decedent's parents inherit in the fifth class. The grandparents of the decedent's father is entitled to half of the inheritance, the grandparents of the decedent's mother to the other half. Both couples of grandparents shall equally divide between them the half to which they are entitled.

(2) If one of the grandparents from a couple does not inherit, the vacant eighth shall devolve to the other grandparent. If a couple does not inherit, the quarter shall devolve to the other couple from the same side. If none of the couples from the same side inherits, the inheritance shall devolve to the couples from the other side in the same proportion as they divide the half of the inheritance to which they are entitled to directly.

\section{Section 1640 [Recodification]}

\section{Sixth class of heirs}

(1) If none of the fifth-class heirs inherits, the sixth class of heirs shall include the children of the decedent's siblings' children and the children of the decedent's grandparents, each of them equally.

(2) If any of the children of the decedent's grandparents does not inherit, his children shall inherit.

Section 1641

\section{Multiple family relationship}

If a person is related to the decedent from more than one side, he has succession right from each side which he would hold as a relative from that side.

\section{Chapter 5}

\section{Forced share}

\section{Inclusion in forced share and inheritance share}

\section{Division 1}

\section{Forced heir}

Section 1642 [Recodification]

A forced heir is entitled to a forced share of the decedent's estate.

$$
\text { Section } 1643 \text { [Recodification] }
$$

(1) Forced heirs include the decedent's children and, if they do not inherit, their descendants.

(2) If a forced heir is a minor, he must inherit at least three-quarters of his statutory inheritance share. If a forced heir is an adult, he must inherit at least a quarter of his statutory inheritance share.

Section 1644

(1) A forced share may be handed down as an inheritance share or legacy, but must be left to a forced heir completely free of burden.

(2) Mandates of a decedent which restrict the mandatory part are disregarded. If a decedent leaves more than a forced share to a forced heir, such an order, if given in a disposition mortis causa, applies only to the part which exceeds the value of the forced share. This does not apply if a forced heir dies before the decedent, or he does not inherit for any other reason.

(3) A decedent may also oblige a forced heir to make a choice between what is given to him with restrictions, and the forced share. 
A person who has renounced inheritance or the forced share, lacks the capacity to inherit or has been disinherited by the decedent is not entitled to the forced share, but when calculating the forced shares, he is considered to never have been excluded from a succession right.

\section{Division 2}

\section{Disinheritance}

\section{Section 1646 [Recodification]}

(1) For statutory reasons, a forced heir may be excluded from his right to inherit the forced share or his right may be prejudiced by disinheritance. A decedent may disinherit a forced heir who:

a) failed to provide him with the necessary assistance at a time of need,

b) fails to show such genuine interest in the decedent as he should,

c) has been convicted of a criminal offence committed under circumstances which indicate his perverse nature, or

d) permanently leads a dissolute life.

(2) A decedent may also disinherit a forced heir who lacks the capacity to inherit, and therefore excluded from a succession right.

(3) If a disinherited descendant survives the decedent, the descendants of the disinherited descendant shall not inherit either, unless the decedent wishes otherwise. If a disinherited descendant dies before the decedent's death, his descendants shall inherit except those who are specifically excluded from the succession right.

\section{Section 1647 [Recodification]}

A decedent may also disinherit a forced heir whose indebtedness or prodigal acts raise concern that the forced share will not be maintained for the descendants. However, he may do so only by leaving his forced share to the children of the forced heir, or, in their absence, to their descendants.

\section{Section 1648 [Recodification]}

If a decedent fails to specify the reason for disinheritance, the forced heir has the right to the forced share, unless a statutory reason for disinheritance is proved against him.

\section{Section 1649 [Recodification]} a testament.

(1) Declaration of disinheritance may be made, or changed or cancelled, in the same manner as making or cancelling

(2) In the same way, a decedent may declare that one of the heirs who is not a forced heir and who is entitled to statutory succession of heirs will not acquire the decedent's estate.

\section{Division 3}

\section{Protection of a forced heir}

\section{Section 1650}

A forced heir disinherited in an invalid manner is entitled to a forced share; if the net value of his forced share was reduced, he has the right to have the share completed.

\section{Section 1651}

(1) A forced heir of whom the decedent knew that he was alive and yet excluded him in the testament shall also have the right to the forced share.

(2) If a person excluded otherwise than accidentally has committed something that fulfils a statutory reason for disinheritance, such exclusion is considered to be disinheritance made tacitly and lawfully.

\section{Section 1652}

If a forced heir proves that his exclusion is only attributable to the fact that the decedent did not know about him when making the disposition mortis causa, such an heir has the right to the mandatory part to which he is entitled under a statute.

\section{Section 1653}

If a forced heir has been excluded or his share reduced, the heirs and legatees shall proportionately contribute to compensate for his right. 


\title{
Division 4
}

\section{Calculation of the forced share}

\author{
Section 1654 [Recodification]
}

(1) A forced heir is not entitled to a share of the decedent's estate, but only to a sum of money equal to the value of his forced share. If justified by particularly serious reasons on the part of the heirs and if it may be reasonably required from the forced heir, a court may authorise the instalments of the mandatory part or a postponement of its due date; however, the claim bears interest from the date on which it was originally due.

(2) Subsection (1) does not prevent the forced heir from agreeing otherwise with the testamentary heirs or heirs under inheritance contract; however, if it prejudices the rights of other creditors, such a contract is ineffective against them. If, during the succession proceedings, it is stipulated that a forced heir shall, instead of payment, be surrendered from the decedent's estate a thing registered in a public register, the forced heir is registered in that public register directly after the decedent.

\section{Section 1655}

(1) To establish a forced share, the property in the decedent's estate is estimated and its inventory made; the debts of the decedent and defects encumbering the property already at the time of the decedent's death is deducted from the value of the property. When calculating the forced share, what is credited against a forced share under Sections 1660 and 1661 is added to the decedent's estate.

(2) A forced heir has the right to be present during the estimation, ask questions and make comments.

\section{Section 1656}

A forced share is determined without regard to legacies and other defects arising from the disposition mortis causa. Until the forced share has been determined, a forced heir shall proportionately participate in the profit and loss of the decedent's estate. A person who is entitled to a forced share is also entitled to a proportionate account of the share in the profit or loss of the decedent's estate from the death of the decedent until the determination of the forced share.

\section{Section 1657}

If a forced heir and other heirs agree on a lump-sum payment, and if such an agreement is approved by a court, the provisions of Sections 1655 and 1656 do not apply.

\section{Division 5}

\section{Inclusion in forced share and inheritance share}

\section{Section 1658}

Inclusion in a forced share or inheritance share does not create a duty to surrender something except as provided under Section 2072.

\section{Section 1659}

In the case of inclusion, the value of what was provided and is subject to inclusion is calculated according to the time of delivery. In exceptional cases, a court may decide otherwise.

\section{Inclusion in forced share}

\section{Section 1660}

(1) Everything that a forced heir has actually acquired from the decedent's estate through a legacy or another act of the decedent is included in the forced share.

(2) Inclusion in a forced share also includes everything that a forced heir has gratuitously acquired from the decedent in the last three years before his death, unless the decedent orders a longer period; in addition, what a decedent's ancestor gratuitously received from the decedent is also included in favour of the descendant. However, usual donations are disregarded in the case of inclusion.

\section{Section 1661}

(1) Inclusion in a forced share of a descendant includes what the decedent gave him when he was alive to assist with the costs associated with the establishment of his own household, or marital or similar life, or with starting employment or business; inclusion in the forced share also includes what the decedent used to pay the debts of an adult descendant. If it had occurred earlier than in the last three years before the decedent's death, inclusion is made unless the decedent has expresses his will to the contrary.

(2) Inclusion in a forced share of the descendant who takes the place of his ancestor also includes what the decedent gave the descendant's parents whose place he takes. 
Inheritance shares are calculated in the same manner as a forced share.

Section 1663

In succession of heirs under a disposition mortis causa, or in statutory succession of heirs, inclusion in an inheritance share is only made if it was ordered by the decedent by an expression of will made in the form prescribed for the making of a testament.

\section{Section 1664}

A court may also make inclusion in an inheritance share without an order by the decedent, provided that the forced heir would otherwise be unreasonably disadvantaged; however, usual donations are disregarded.

\section{Chapter 6}

\section{Right of certain persons to provision for life}

\section{Section 1665 [Recodification]}

A person who would otherwise be a forced heir, but is not entitled to a forced share, has a right to essential maintenance, provided he is lacking it, and is unable to provide for himself; in this manner, however, he may not get more from the decedent's estate than what his forced share would be. However, a person whose descendant inherits in his place or where a descendant is designated to be entitled to a forced share in his place does not have the right to essential maintenance.

\section{Section 1666 [Recodification]}

(1) A surviving spouse has the right to fair maintenance from the decedent's estate for six weeks after the death of his spouse. If a widow is pregnant, she has the right to fair maintenance until the end of the sixth week after birth; the mother of the decedent's child who was not married to the decedent has the same right.

(2) If a surviving spouse has been denied statutory inheritance or his statutory inheritance has been reduced, the surviving spouse is entitled to the necessary provision for life until he remarries, provided that he otherwise lacks such a provision for life and he is unable to provide for himself; in this manner, however, he may not get more from the decedent's estate than what half of his statutory inheritance share would have been. However, a spouse who, without serious reasons, did not share the family household with the decedent, a spouse lacking the capacity to be an heir or a spouse who renounced or refused inheritance is not entitled to the necessary provision for life.

(3) If the right to fair maintenance under Subsection (1) prejudices the right to essential maintenance under Section 1665 , all these rights are prejudiced so that all obligees receive an equal share. Necessary provision for life under Subsection (2) may not be provided if it prejudices the right to essential maintenance under Section 1665.

\section{Section 1667 [Recodification]}

The surviving spouse shall acquire the right of ownership in movable things which form the basic equipment of a family household even where he is not an heir. This does not apply if the surviving spouse, without serious reasons, did not share the family household with the decedent.

\section{Section 1668 [Recodification]}

(1) If a surviving parent has been denied the statutory inheritance or his statutory inheritance share has been reduced, the surviving parent is entitled to the necessary provision for life, provided that he otherwise lacks such a provision for life and he is unable to provide for himself; in this manner, however, he may not get more from the decedent's estate than what a third of his statutory inheritance share would have been. A parent lacking the capacity to be an heir, a parent who has renounced or refused his inheritance or a parent who has committed an act constituting grounds for disinheritance does not have the right to the necessary provision for life.

(2) Necessary provision for life may not be provided to a parent if it prejudices the right to essential maintenance under Section 1665.

\section{Section 1669 [Recodification]}

Persons who enjoyed gratuitous provision for life in the household of the decedent until his death are entitled to the same provision for life for another three weeks after the decedent's death.

\section{Chapter 7}

\section{Devolution of the decedent's estate to an heir}

\section{Division 1}


Acquisition of inheritance is confirmed by a court. A court confirms acquisition of inheritance by a person whose succession right has been proved.

\section{Section 1671}

(1) If an heir fails to assert his succession right before a court within a time limit determined by the court, the heir's succession right is not extinguished; however, it is disregarded during succession proceedings. This also applies to the succession right of an unknown heir or to an heir of unknown whereabouts who has been notified of his right through a judicial notice and failed to contact the court within a specified time limit.

(2) If an unknown heir or heir of unknown whereabouts has a guardian, the guardian may not make a declaration stating that the heir refuses, does not refuse or accepts the inheritance.

\section{Section 1672}

Where the right to inheritance is asserted by multiple persons and if they are contradictory, a court shall advise the heir whose legal cause is weaker to assert his right by filing an application. If the heir does not file the application within the time limit specified by the court, his right is not extinguished but it is disregarded in decedent's estate proceedings.

\section{Section 1673}

(1) All testamentary or statutory heirs are advised to file an application against an heir who relies on an inheritance contract undisputed as to its authenticity. All statutory heirs are advised to file an application against an heir who relies on a testament undisputed as to its authenticity.

(2) If a decedent has specified the reason for disinheritance, the descendant who claims to have been disinherited unlawfully is advised to file an application. If the reason for disinheritance is not specified, the person who is to inherit in his place is advised to file an application.

\section{Reservation as to estate inventory}

\section{Section 1674 [Recodification]}

(1) A decedent may not take away the heir's right to make a reservation as to estate inventory of the decedent's estate. If the parties to an inheritance contract waive this right, it is disregarded.

(2) The right to a reservation as to estate inventory may be asserted by means of a declaration made orally before a court, or a declaration sent to a court in writing. If an heir makes a reservation as to estate inventory with reservations or conditions, it is disregarded. This also applies to an heir's declaration stating that he does not make a reservation as to estate inventory.

\section{Section 1675 [Recodification]}

An heir has the right to reserve estate inventory if he does so within one month from the day on which a court informed him of this right. Where justified by important reasons, the court shall extend the time limit.

\section{Section 1676 [Recodification]}

(1) An heir having legal capacity who is known and present, is not a spouse, descendant or ancestor of the decedent and who failed to provide a statement within the time limit under Section 1675 is conclusively presumed not to make a reservation as to estate inventory. After summoning and advising the other heirs, a court shall obtain their express statements, unless the effects under Section 1681 have occurred with respect to the decedent's spouse, descendant or ancestor lacking legal capacity.

(2) A person who failed to make a reservation as to estate inventory or declared that he does not assert the right to do so may not subsequently make a reservation as to estate inventory.

\section{Division 2}

\section{Administration of the decedent's estate and the decedent's estate inventory}

\section{Administration of the decedent's estate}

\section{Section 1677}

(1) If a decedent has designated an administrator of the decedent's estate or executor of testament, the administrator of the decedent's estate shall administer the decedent's estate until the acquisition of the inheritance is confirmed; after that the decedent's estate is administered by the executor of testament. If a decedent has designated neither of them, the decedent's estate is administered by an heir; where there are multiple heirs and they do not stipulate otherwise, the decedent's estate is administered by all the heirs.

(2) If justified by a serious reason, a court shall order another measure. 
(1) A person who administers the decedent's estate shall perform simple administration thereof.

(2) A person who administers the decedent's estate shall provide payments from the decedent's estate to persons entitled to receive them as provision for life, and deliver to the legatees a report of the legacies allocated to them. He shall surrender legacies which have become due if authorised by a court.

\section{Section 1679}

(1) If required by the interest in preserving the value or essence of the property under administration, things from the decedent's estate may be alienated or used as security during the administration, otherwise only if it is for consideration. This also applies where the purpose of the property under administration is to be changed.

(2) An administrator of estate or executor of testament may perform an act exceeding the scope of simple administration only with the consent of the heirs. If the heirs fail to agree or if a person under special protection is an heir, the approval of a court is required.

\section{Section 1680}

(1) A court may, even before the end of succession proceedings, allow an heir whose succession right has been clearly established to dispose freely of certain objects which are part of the decedent's estate if the fulfilment of the decedent's last will is ensured or if the other co-heirs, forced heirs and legatees consent to it.

(2) Where the right to inheritance is asserted by multiple persons in contradiction, the measure under Subsection (1) may not be taken. If, however, an heir has been previously provided with an advantage, it may not be taken away from him.

\section{Section 1681 [Recodification]}

(1) If an heir assumes full administration of the decedent's estate without being entitled to do so, the effects of a reservation as to estate inventory, where made by the heir, are cancelled with effect from the beginning. This applies even where it is proved that an heir has intentionally concealed the decedent's property by mixing parts of the decedent's estate with parts of his property making it impossible to distinguish what belongs to whom, unless this was already the case before the decedent's death. The same effect with respect to the reservation as to estate inventory also occurs with respect to the heir who administered the decedent's estate in this manner being directly or indirectly represented by someone else. If the decedent's estate is administered in this manner by a close person of the heir, the person is presumed to also act as his representative.

(2) The effects under Subsection (1) shall not occur if, before confirming the acquisition of inheritance, the heirs only divide among them documents, portraits or records and other things of family or commemorative nature.

\section{Closure of the decedent's estate}

\section{Section 1682 [Recodification]}

(1) A court shall promptly take a measure to secure the decedent's estate (a closure), if:

a) any of the heirs lacks legal capacity,

b) the whereabouts of any of the heirs are unknown,

c) there is concern that the decedent's estate is over-indebted,

d) a creditor has proposed separation of the decedent's estate, or

e) there is another important reason for particular caution.

(2) If any of the heirs only lacks legal capacity, is not present or is unknown, closure of the part of the decedent's estate which is sufficient to satisfy his succession right shall suffice. This applies even where there is a person who has the right to a forced share.

\section{Section 1683}

A closure is not necessary if the decedent's estate includes an immovable thing which provides sufficient security.

\section{Decedent's estate inventory}

Section 1684 [Recodification]

(1) A decedent's estate inventory aims to ascertain the decedent' assets and liabilities and determine the net value of the property at the time of the decedent's death.

(2) Unless it poses a serious risk to the timely drafting of the inventory, it may be prepared in the presence of, and questions may be asked and comments made by:

a) an executor of testament,

b) an administrator of the estate, 
c) anyone who claims and proves his succession right or the right to a forced share, or who is known to be likely to hold such a right,

d) a creditor who has requested separation of decedent's estate,

e) any other person who proves a legal interest therein, if approved by a court; however, this applies to a legatee only if there is a risk that he will be obliged to proportionately contribute to the forced share.

\section{Section 1685 [Recodification]}

(1) A court shall order that an estate inventory be made if an heir asserts his right to make a reservation as to estate inventory, or if it is necessary for the calculation of the forced share.

(2) A court shall also order that a decedent's estate inventory be made if:

a) the heirs include a person who lacks full legal capacity, or is unknown or not present, or a publicly beneficial legal person or a legal person established in the public interest (hereinafter a "person under special protection")

b) there is uncertainty about whether a person is an heir, or who the heir is

c) it is required by a creditor under Section 1709 , or

d) the creditor of the decedent proves that there is another serious reason to draft the inventory.

\section{Section 1686}

(1) The costs of making an inventory are paid from the decedent's estate and be proportionately deducted from the inheritance shares of those heirs who benefit from the inventory. If it is not reasonably possible to pay the cost of making a decedent's estate inventory, a court shall order such heirs to proportionately contribute to the payment of these costs.

(2) If a court has ordered that an inventory be made for the calculation of a forced share, the costs are paid from the decedent's estate and be proportionately borne by the heirs and a person entitled to a forced share. If it is not reasonably possible to pay the cost of making a decedent's estate inventory, a court shall order such persons to proportionately contribute to the payment of these costs.

(3) Where a person requires that an inventory be made without having a serious reason to do so, a court shall order the person to bear the cost of making the inventory.

\section{Section 1687}

(1) If justified by the circumstances of the case, a court may decide to replace a decedent's estate inventory by an inventory of the decedent's property made by the administrator of the decedent's estate and confirmed by all heirs. Where an administrator of the decedent's estate has not yet been appointed, a court may appoint him for that purpose.

(2) Unless challenged by the heirs, a court may, in simple cases, decide to replace a decedent's estate inventory by a joint statement of the heirs on the decedent's property.

\section{Section 1688 [Recodification]} insignificant:

(1) If it is proved that a statement or list under Section 1687 does not correspond to reality to an extent which is not

a) where the heirs made a reservation as to estate inventory, its effects are cancelled with effect from the beginning, where applicable,

b) the person under Section 1685(2) has the right to request that a court order the preparation of a new decedent's estate inventory if he proves that he has a legal interest therein.

(2) The effect under Subsection (1)(a) shall not operate against a person under special protection, unless it is proved that such a person intentionally concealed the decedent's property. This effect shall not even operate against an heir who proves that he was not at fault for the incompleteness of the statement or list.

(3) If an administrator has caused the list under Section 1687 to be incomplete, he shall compensate the resulting damage.

\section{Section 1689}

If a creditor is known, a court shall inform him that a decedent's estate inventory has been drafted and allow him to comment thereon.

\section{Division 3}

\section{Confirmation of inheritance}


(1) A person who has not refused the inheritance and, according to the succession proceedings, has the best succession right shall, receive a confirmation of the acquisition of inheritance issued by a court after the due fulfilment of the decedent's will has been ensured.

(2) If an executor of testament has been selected, he shall provide a court with a confirmation that the decedent's instructions have been fulfilled; if he has not been selected, such a confirmation is provided by the heirs. If the heirs fail to agree, or if they challenge what was confirmed by the executor of testament, a court shall decide on the manner in which it will obtain the proof.

\section{Section 1691}

(1) Where legacies have been ordered, a court shall confirm inheritance only after it has been proved to the court that:

a) legatees have been notified of their legacies,

b) due legacies to persons lacking full legal capacity, publicly beneficial legal persons or legal persons established in the public interest, or legacies made for charitable and publicly beneficial purposes, have been carried out, and that carrying out non-due legacies has been ensured,

c) carrying out legacies to unknown persons or persons that are not present has been ensured.

(2) A court may waive a security where such a security is evidently unnecessary.

Section 1692

(1) A court shall provide a sole heir with a confirmation that he has acquired the inheritance. The court shall indicate the identity of the heir, the decedent whose decedent's estate he acquires, for what reason and whether or not this occurs with a reservation as to estate inventory.

(2) In case of several heirs, a court shall also confirm their inheritance shares in the amount after inclusion in inheritance share and inclusion of any legacies, where applicable. When dividing the decedent's estate, a court shall also confirm the legacy which each of the heirs has acquired and the reason for the division of inheritance.

(3) Where a succession of heirs has been ordered by establishing succession by fideicommissum, determination of time or otherwise, a court shall confirm that it has been ordered, who follows as the next heir and on what condition. If a decedent has determined that a preceding heir may freely dispose of the inheritance, it shall also be confirmed by a court.

\section{Section 1693 [Recodification]}

(1) Heirs may agree on the amount of their inheritance shares in succession proceedings before a court. The court shall approve the agreement, unless it is contrary to the interests of a person under special protection.

(2) In the case of inheritance based on a disposition mortis causa, heirs may agree on an amount of inheritance shares other than that designated for them by the decedent if expressly allowed by the decedent.

(3) In the case of inheritance based on statutory succession of heirs, an heir has the right to require settlement from the other heirs if he cared of the decedent for a longer period or significantly contributed to maintaining or increasing the decedent's property by work, financial support or similar means without having been remunerated. Settlement is provided in an amount appropriate to the duration and scope of his performance and the value of the decedent's estate; his inheritance share shall increase by this amount. This also applies where the heir who is not a surviving spouse performed the duty to maintain and support or a similar duty with respect to the decedent.

\section{Division 4}

\section{Division of decedent's estate}

Section 1694 [Recodification]

(1) If a decedent has made a disposition mortis causa, the decedent's estate is divided according to his will. Heirs may agree before a court that they will divide the entire decedent's estate or a part thereof otherwise, if expressly allowed by the decedent.

(2) Where the decedent has allocated individual things from his assets and liabilities to the heirs without explicitly ordering that the decedent's estate must be divided as he instructed, or that a designated heir may only accept what has been allocated to him, or, where applicable, that a certain thing is to remain co-owned by the heirs, his expression of will is considered to be a wish without legally binding effect.

\section{Section 1695}

(1) Where a decedent has made no disposition mortis causa, the heirs may agree before a court on the division of the decedent's estate in any manner.

(2) Where a decedent has made no disposition of a part of the decedent's estate or has not instructed how the decedent's estate or part thereof is to be divided, or where the division of the decedent's estate according to the decedent's will is impossible, Subsection (1) applies by analogy. 


\section{Section 1696}

(1) A court shall approve an agreement of the heirs on division, unless it is contrary to the will of the decedent or, within its scope, to the interests of a person under special protection. If a court does not approve the agreement, it shall provide the heirs with a confirmation of the acquisition of inheritance according to their inheritance shares.

(2) For an agreement on division of decedent's estate to be valid, the entire known decedent's estate must be divided as a result of its conclusion. An agreement may also establish an easement or a pledge or another right in rem, even where the decedent has made no disposition thereof.

\section{Section 1697}

(1) A court shall divide the decedent's estate in accordance with the instructions of the decedent. If the decedent has made a third person responsible for specifying how the decedent's estate is to be divided, a court shall determine a reasonable time limit of at least two months for that person; however, the court shall disregard such specification which is clearly unjust or made after the time limit has expired.

(2) Unless prevented by the decedent's instruction, a court shall divide the decedent's estate by approving the agreement of the heirs; in the absence of such an agreement, the court shall divide the decedent's estate if requested by all the heirs and if they have no dispute concerning what things form part of the decedent's estate. In doing so, the court has regard to the interests of a person under special protection.

(3) In other cases, a court shall not divide the decedent's estate and provide the heirs with a confirmation of the acquisition of the inheritance according to their inheritance shares.

\section{Section 1698}

When dividing the decedent's estate, the right to compensation from the arrangements between the co-heirs may be settled and inclusion in an inheritance share and inclusion of legacies may be made.

\section{Section 1699}

(1) Under certain circumstances, a claim or debt may be allocated to a single heir. If a debt is allocated to a single heir, it does not affect the rights of the creditor.

(2) An heir whose share has been reduced by the allocation of a defective thing is entitled to be compensated by the co-heirs for the reduction caused by the defect.

\section{Section 1700}

(1) If the decedent's estate is divided by a court on the application of the heirs, the court shall establish a register based on the decedent's estate inventory or an inventory confirmed by all the heirs. If a thing from the decedent's estate has been lawfully sold by the will of an heir, the purchase price obtained is included in the decedent's estate; if the thing was otherwise alienated by the will of an heir, the typical price on the day on which the succession right was created is included in the decedent's estate. Each object is allocated to the share of each of the heirs expressed in money according to the price specified in the register.

(2) If a court does not allocate an object to all the heirs in proportion to their shares, it shall estimate its price where the price is not evident.

\section{Division 5}

\section{Debts affecting an heir}

\section{Section 1701}

(1) A decedent's debts pass to the heirs, unless otherwise provided by a statute.

(2) An heir is obliged to pay the costs of a decedent's burial and the arrangement of the decedent's grave site, unless these costs were paid from the decedent's estate under Section 114(2).

\section{Section 1702}

An heir may not be released from the duty imposed on him by a disposition mortis causa by rejecting the inheritance and asserting his right as a statutory heir. He may become an heir under the disposition mortis causa or reject the inheritance.

\section{Section 1703}

\section{Rights of creditors prior to the confirmation of inheritance}

Until a court confirms the acquisition of the inheritance by an heir, creditors may only claim a performance against the person who administers the decedent's estate and only claim satisfaction from the property belonging to the decedent's estate. 


\title{
Section 1704 [Recodification]
}

If an heir has not made a reservation as to estate inventory, he shall pay the decedent's debts in full. If several heirs have not made a reservation as to estate inventory, they shall pay the decedent's debts jointly and severally.

\section{Section 1705 [Recodification]}

With respect to an heir who has not made a reservation as to estate inventory, drafting an estate inventory has no legal effects for the scope of his duty to pay debts.

\section{Legal effects of a reservation as to estate inventory}

\author{
Section 1706 [Recodification]
}

If an heir has made a reservation as to estate inventory, he shall pay the decedent's debts up to the price of the acquired inheritance. This also applies where a court has ordered the preparation of a decedent's estate inventory in the interests of a person under special protection.

\section{Section 1707 [Recodification]}

Each of the heirs who has made a reservation as to estate inventory shall pay the decedent's debts jointly and severally with the other heirs; however, a creditor may require that each heir who has made a reservation as to estate inventory only provide a performance not exceeding his inheritance share.

\section{Section 1708 [Recodification]}

Sanctions among co-heirs are governed by the general provisions on joint debts.

\section{Separation of the decedent's estate}

\section{Section 1709 [Recodification]}

(1) A creditor who proves his concern of an heir's over-indebtedness may, before a court confirms the acquisition of inheritance, apply to the court to keep the decedent's estate separated from the decedent's assets and liabilities and have it managed as separate assets and liabilities. The court shall dismiss the application if there is evidently no reason for the concern. inheritance.

(2) An application to separate the decedent's estate does not prevent a court from confirming the acquisition of

\section{Section 1710 [Recodification]}

A creditor who requested separation is satisfied from the separated decedent's estate. However, such a creditor shall lose the right to satisfaction from the other property of the decedent, even where the heir has not made a reservation as to estate inventory.

\section{Ascertaining the debts of the decedent}

\section{Section 1711 [Recodification]}

An heir who has reserved inventory or administers the decedent's estate may also apply to a court, before the court makes a decision on confirming the inheritance, to request the creditors to report and document their claims within an appropriate time limit in order to ascertain the decedent's debts. Until the proceedings so initiated are closed, the heir or the person administering the decedent's estate is not obliged to satisfy the creditors.

\section{Section 1712}

(1) If the decedent's estate has been used up by satisfying registered claims, a creditor who fails to register within the time limit is not entitled to have his claims satisfied by the heir.

(2) Subsection (1) does not apply:

a) if the creditor proves that the heir knew of the claim, or

b) if a creditor's claim is secured by a pledge or another right in rem belonging to the decedent's estate.

\section{Section 1713}

Where an invitation to creditors has not been applied for, or where the heir satisfies one of the registered creditors without regard to the rights of the others and it results in a creditor's claim from the decedent's estate not being fully satisfied, the heir is obliged to the creditor beyond the scope of Section 1692 up to the amount which would satisfy the creditor's claim in case of liquidation of the decedent's estate under another legal regulation.

\section{Chapter 8}




\section{Alienation of inheritance}

Section 1714 [Recodification]

(1) An inheritance may be alienated after the decedent's death; if the contract is concluded before that, it is disregarded. By alienating inheritance, the acquirer enters into the rights and duties belonging to the decedent's estate.

(2) Inheritance is alienated by an aleatory contract unless the contract alienating the inheritance was based on the list of rights and duties. If such a list was used as a basis, the extent to which Sections 1716 and 1717 shall also apply shall depend on the contents of the contract and on the stipulation between the parties.

(3) The contract must be in the form of a public instrument.

\section{Section 1715 [Recodification]} inheritance.

The parties shall, without undue delay, notify the court conducting the succession proceedings of the alienation of the

\section{Section 1716 [Recodification]}

(1) The acquirer is not entitled to a thing belonging to the transferor for a legal cause other than being an heir, or to documents, portraits and records of family nature.

(2) On the other hand, the acquirer is entitled to everything that is added to the inheritance as a result of a decrease in the number of legatees or co-heirs or in any other manner, provided that the transferor would have been entitled thereto.

\section{Section 1717 [Recodification]}

An acquirer is entitled to everything that the transferor has already acquired under his succession right. However, the acquirer shall reimburse the transferor for his own property which he expends on accepting the inheritance or on the decedent's estate and, unless the parties stipulate otherwise, also for the costs of the decedent's funeral and cemetery arrangements.

\section{Section 1718 [Recodification]}

Where a transferor administered the decedent's estate before it was surrendered to the acquirer, he is obliged with respect to the acquirer as a mandatary.

\section{Section 1719 [Recodification]}

The transferor of the inheritance is liable to the transferee for the authenticity of his succession right as it was stated. If the acquirer incurs damage, the transferor shall compensate such damage according to Book Four of this Act.

Section 1720 [Recodification]

The acquirer and the transferor are liable to the creditors for the decedent's debts jointly and severally

\section{BOOK FOUR}

\section{RELATIVE PROPERTY RIGHTS}

\section{TITLE I}

\section{GENERAL PROVISIONS ON OBLIGATIONS}

\section{Chapter 1}

\section{Creation of obligations and their content}

\section{Section 1721}

Under an obligation, a creditor has the right to a particular performance as a claim from the debtor, and the debtor has the duty to satisfy that right by discharging the debt.

\section{Section 1722}

The performance which constitutes the subject of the obligation must be of property nature and be consistent with the interest of the creditor, even if this interest does not only relate to property.

\section{Section 1723} the legal order.

(1) An obligation arises from a contract, an unlawful act or another legal fact capable of creating the obligation under

(2) The provisions on obligations arising from contracts shall also apply with the necessary modifications to 
obligations arising from other legal facts.

\section{Chapter 2}

\section{Contract}

\section{Division 1}

\section{General provisions}

Section 1724 the contract.

(1) By a contract, parties express their will to create between them a mutual obligation and adhere to the contents of

(2) The provisions on contracts also apply with the necessary modifications to an expression of will whereby one person reaches out to other persons, unless it is excluded by the nature of the expression of will or a statute.

\section{Section 1725}

A contract is concluded once the parties have stipulated its contents. The parties are free to conclude a contract and determine its contents within the limits of the legal order.

\section{Section 1726 [Recodification]}

If parties consider a contract to have been concluded, even though, in fact, they failed to stipulate an element required to be stipulated in a contract, the expression of their will is considered to constitute a concluded contract where it can be reasonably expected that, in particular with regard to their subsequent conduct, the parties would have concluded the contract even without stipulating that element. However, if one of the parties, at the conclusion of the contract, showed that achieving consensus on a particular element is a prerequisite for concluding the contract, the contract is presumed not to have been concluded; in that case, the stipulation on other elements does not oblige the parties even where they were written down in a record.

\section{Section 1727}

Each of several contracts concluded at the same meeting or included in the same instrument is considered separately. If the nature of several contracts or their purpose known to the parties at the conclusion of the contracts indicates that they are mutually dependent, the creation of each individual contract is required for the creation of the other contracts. The extinction of an obligation arising from any of the contracts without satisfying the creditor cancels other dependent contracts with analogous legal effects.

\section{Section 1728 [Recodification]}

(1) Any person may conduct negotiations of a contract freely and is not liable for the failure to conclude it, unless he commences or continues the negotiations of a contract without the intention to conclude it.

(2) When negotiating a contract, the contracting parties shall notify each other of all the factual and legal circumstances of which they know or must know, so that each of the parties can verify the possibility to conclude a valid contract and the interest of each party in concluding the contract is evident to the other party.

\section{Section 1729 [Recodification]}

(1) If contract negotiations between parties reach a point where the conclusion of the contract seems highly probable, the party which terminates the negotiations without a just cause despite reasonable expectations of the other party to conclude the contract acts unfairly.

(2) A party who acts unfairly shall compensate the other party for the damage, but only to an extent not exceeding the loss from failing to conclude a contract in similar cases.

\section{Section 1730 [Recodification]}

(1) If parties, when negotiating a contract, provide each other with information and communications, each party has the right to keep records thereof, even if the contract is not concluded.

(2) If, during negotiations of a contract, a party obtains confidential information or communication about the other party, it shall take care that such information or communication is not unlawfully misused or disclosed. If a party breaches this duty resulting in its enrichment, it shall surrender to the other party what constitutes such enrichment.

\section{Division 2}

\section{Conclusion of a contract}

\section{Proposal to conclude a contract}




\section{Section 1731 [Recodification]}

The proposal to conclude a contract (hereinafter an "offer") must clearly indicate that the person making the offer intends to conclude a particular contract with a person with respect to whom the offer is made.

\section{Section 1732 [Recodification]}

(1) A juridical act leading to the conclusion of a contract constitutes an offer if it contains the essential elements of a contract so that the contract can be concluded by a simple and unconditional acceptance of the juridical act, and if it indicates the will of the offeror to be bound by the contract if the offer is accepted.

(2) The proposal to supply goods or provide a service for a specified price made in the context of business activities through advertising, in a catalogue, or by displaying goods is presumed to constitute an offer subject to availability of stock or loss of the entrepreneur's ability to provide a performance.

\section{Section 1733 [Recodification]}

An expression of will which is inconsistent with Section 1732 does not constitute an offer and may not therefore be accepted. An expression of will containing a promise to perform for a specific performance or result constitutes a public promise; otherwise, it merely constitutes an invitation to submit an offer. The same applies to an expression addressing an unspecified group of persons, or an expression which is of advertising nature, unless something else evidently follows therefrom.

\section{Section 1734 [Recodification]}

An offer made orally must be accepted without delay, unless otherwise indicated by its contents or the circumstances under which it was made. This also applies to an offer made in writing to a person in his presence.

\section{Section 1735 [Recodification]}

An offer made in writing to a person not in his presence must be accepted within the time limit specified therein. If no time limit is specified, the offer may be accepted within a period appropriate to the nature of the proposed contract and the speed of the means used by the offeror to dispatch the offer.

\section{Section 1736 [Recodification]}

An offer is irrevocable if expressly expressed therein or if agreed between the parties. An offer is also irrevocable if it follows from negotiations between the parties regarding the conclusion of a contract, their previous business dealings, or usages.

\section{Section 1737 [Recodification]}

\section{Cancellation of an offer}

Even if an offer is irrevocable, it may be cancelled if the expression of cancellation reaches the other party prior to or at least simultaneously with the delivery of the offer.

\section{Section 1738 [Recodification]}

\section{Revocation of an offer}

(1) Even if an offer is revocable, it may not be revoked within the time limit for its acceptance, unless it is reserved in the offer. A revocable offer may be revoked only if the revocation reaches the other party before that party has dispatched the acceptance of the offer.

(2) An offer may not be revoked if it expresses irrevocability.

\section{Section 1739 [Recodification]}

(1) If an offer is rejected, it expires when the rejection becomes effective.

(2) If one of the parties dies or loses its legal capacity to conclude contracts, the offer expires if it is obvious from the offer itself or from the nature and purpose of the proposed contract.

\section{Acceptance of an offer}

\section{Section 1740 [Recodification]}

(1) An offeree accepts an offer if he indicates consent to it in relation to the offeror. Silence or inaction do not themselves constitute acceptance.

(2) An expression of will which contains addenda, reservations, limitations or other changes constitutes a rejection of an offer and is considered to be a new offer. However, a response that defines the contents of a proposed contract in other words constitutes the acceptance of an offer.

(3) A response with an addendum or a variation which does not substantially alter the terms of an offer constitutes an acceptance of the offer unless the offeror rejects such an acceptance without undue delay. An offeror may exclude acceptance 
of an offer with an addendum or a variation in advance in the offer itself or in any other way which raises no doubts.

$$
\text { Section } 1741 \text { [Recodification] }
$$

In the case of an offer made to several persons, a contract is concluded if the offer is accepted by all these persons, provided that its contents indicate the offeror's intention that all persons to whom the offer is made become parties to the contract, or if such an intention can be reasonably assumed from the circumstances under which the offer was made. The same applies by analogy in the case of an evident offeror's intention that a particular number of those persons become a party to the contract.

$$
\text { Section } 1742 \text { [Recodification] }
$$

Acceptance of an offer may be cancelled if the cancellation reaches the offeror no later than upon the acceptance.

$$
\text { Section } 1743 \text { [Recodification] }
$$

(1) Late acceptance of an offer has the effect of timely acceptance if the offeror, without undue delay, at least verbally informs the offeree that he considers the acceptance to have been made in due time, or if he starts to act in accordance with the offer.

(2) If a document expressing the acceptance of an offer indicates that it was dispatched under such circumstances that it would have reached the offeror in due time had it been carried in a normal way, a late acceptance is effective as a timely acceptance unless the offeror at least verbally informs the offeree that he considers the offer expired.

\section{Section 1744 [Recodification]}

Having regard to the contents of an offer or the practice established between the parties, or if it is usual, an offeree may accept an offer by acting in accordance therewith, in particular if he provides or accepts a performance. The acceptance of an offer becomes effective upon such an act if the act was made in time.

\section{Section 1745 [Recodification]}

A contract is concluded when the acceptance of an offer becomes effective.

\section{Division 3}

\section{Contents of a contract}

Section 1746

(1) The statutory provisions governing various types of contracts apply to contracts whose contents include the essential elements of a contract provided under the basic provision for each of those contracts.

(2) Parties may also conclude a contract which is not specifically regulated as a type of contract.

Section 1747

If a contract is gratuitous, a debtor is presumed to have intended to bind himself less rather than more.

\section{Section 1748}

A stipulation that the parties are to stipulate a certain part of the contents of a contract subsequently is presumed to constitute a condition suspending the effectiveness of the concluded contract.

\section{Section 1749}

(1) If the parties stipulate that a certain element of a contract is determined by a third person or a court, such a determination constitutes a condition suspending the effectiveness of the contract. If the third person fails or refuses to determine the element of the contract within a reasonable time limit, any of the parties may apply to a court to do so.

(2) In determining the element, account is taken of the evident purpose of the contract, the circumstances under which the contract was concluded, as well as of the need to provide for a fair arrangement of the rights and duties of the parties.

\section{Section 1750}

If the obligee fails to propose that a contract be supplemented within the stipulated time limit, or otherwise within one year from the conclusion of the contract, the contract is presumed to be cancelled from the beginning.

\section{Section 1751 [Recodification]}

(1) A part of the contents of a contract may be determined by reference to standard commercial terms which are attached to the offer by the offeror or of which the parties are aware. Any stipulations in the contract which derogate from the standard commercial terms shall prevail over the text of the standard commercial terms.

(2) If, in an offer and the acceptance thereof, parties make a reference to the standard commercial terms which are contradictory, the contract is still concluded with the contents determined to the extent to which the standard commercial terms 
are not contradictory; this also applies where such a conclusion is excluded by the standard commercial terms. If it is excluded without undue delay by any of the parties no later than after exchanging the expressions of will, the contract is not concluded.

(3) In the case of a contract concluded between entrepreneurs, a part of the contents of the contract may be determined simply by a reference to standard commercial terms prepared by professional or interest organisations.

\section{Section 1752 [Recodification]}

(1) If, in the ordinary course of business, a party concludes contracts with a number of persons and such contracts oblige the parties to provide a long-term recurrent performance of the same kind with reference to standard commercial terms, and the nature of the obligation already indicates in the course of the contract negotiations that subsequent changes thereto will be reasonably necessary, the parties may stipulate that a party may amend the standard commercial terms to an appropriate extent. The stipulation is valid if at least the manner in which the change is to be notified to the other party is stipulated in advance, and if the party becomes entitled to refuse the changes and, as a result, terminate the obligation with a notice period sufficient to procure similar performances from another supplier; however, a stipulation which links the termination to a special duty encumbering the terminating party is disregarded.

(2) If the parties do not stipulate the extent of changes to the standard commercial terms, changes caused by such a change in the circumstances which the party referring to the standard commercial terms must have expected at the conclusion of the contract, or changes induced by a change in the party's personal or property situation are disregarded.

\section{Section 1753 [Recodification]}

A provision of the standard commercial terms which the other party could not have reasonably expected is ineffective, unless expressly accepted by that party; any stipulation to the contrary is disregarded. Whether or not a provision is of such a nature is assessed with regard to its content as well as to the manner in which it is expressed.

\section{Section 1754}

(1) If the parties use a contractual clause provided in the rules of interpretation which the parties use, the parties are presumed to have used the clause with the intention to produce legal effects provided by the rules of interpretation to which they referred in the contract, or by those rules of interpretation which are generally used with regard to the nature of the contract.

(2) If one of the parties is not an entrepreneur, the meaning of the clause may be invoked with respect to that party only if it is proved that that party was aware of its meaning.

\section{Section 1755 [Recodification]}

If a party waives its right to generally assert defences to the validity of a contract, it is disregarded.

\section{Division 4}

\section{Form of a contract}

Section 1756

If a contract is not concluded in words, the will to stipulate its elements must be obvious from the circumstances; in doing so, account is taken of the conduct of the parties as well as issued price lists, public offers and other documents.

\section{Section 1757 [Recodification]}

(1) After the conclusion of a contract between the parties in a form other than in writing, the parties are free to decide whether they will mutually confirm the contract in writing

(2) If, in the course of business of the parties, one of them provides the other with a confirmation that it accurately reflects the contents of the contract, the contract is conclusively presumed to have been concluded with the contents specified in the confirmation, even where it shows variations from the actually stipulated contents. This only applies if the variations indicated in the confirmation do not substantially vary from the actually stipulated contents of the contract and are of such a nature that a reasonable entrepreneur would still have approved them, and if the other party does not reject these variations.

(3) Subsection (2) also applies where the contract was concluded in the course of business of one of the parties and its contents are confirmed by the other party.

\section{Section 1758}

If the parties agree to use a particular form to conclude a contract, they are presumed not to intend to be bound by such a contract unless the form is complied with. This also applies where one of the parties expresses its will to conclude the contract in written form.

\section{Division 5}

\section{Effects of a contract}

\section{General provisions}


A contract is binding on the parties. It may only be changed or cancelled with the consent of all the parties, or on other statutory grounds. A contract has effects with respect to other persons only where provided by a statute.

\section{Section 1760}

The fact that a party was not entitled to dispose of the subject of performance under the contract at the time the contract was concluded does not in itself invalidate the contract.

\section{Section 1761 [Recodification]}

A prohibition to encumber or alienate a thing has effect only between the parties, unless it has been established as a right in rem. Such a prohibition is valid if it has been established for the duration of a trust, succession by fideicommissum, representation or for another specific and reasonable period in such an interest of a party which deserves legal protection.

\section{Section 1762}

(1) Where a statute provides that the effectiveness of a contract is conditional on a decision of a particular body, a contract is effective upon that decision.

(2) Unless an application for the decision has been filed within one year from the conclusion of a contract, the contract is presumed cancelled from the beginning. This also applies where the application was dismissed.

\section{Section 1763}

Where a party grants various persons the right to use or use and enjoy the same thing in the same period under consecutively concluded contracts, such a right is acquired by the first person that has been granted the right to use or use and enjoy the thing by the transferor. In the absence of any such person, the right is acquired by the person with whom the first contract to become effective was concluded.

\section{Change in circumstances}

Section 1764 [Recodification]

If, after concluding a contract, circumstances change to the extent that the performance arising from the contract becomes more onerous for one of the parties, it does not affect the party's duty to discharge the debt. This does not apply in cases provided under Sections 1765 and 1766.

\section{Section 1765 [Recodification]}

(1) If there is such a substantial change in circumstances that it creates a gross disproportion in the rights and duties of the parties by disadvantaging one of them either by disproportionately increasing the cost of the performance or disproportionately reducing the value of the subject of performance, the affected party has the right to claim the renegotiation of the contract with the other party if it is proved that it could neither have expected nor affected the change, and that the change occurred only after the conclusion of the contract or the party became aware thereof only after the conclusion of the contract. Asserting this right does not entitle the affected party to suspend the performance. circumstances.

(2) The affected party shall not acquire the right under Subsection (1) if it assumed the risk of a change in

\section{Section 1766 [Recodification]}

(1) Upon failure to reach agreement within a reasonable time limit, a court may, on the application of any of them, decide to change the contractual obligation by restoring the balance of rights and duties of the parties, or to extinguish it as of the date and under the conditions specified in the decision. The court is not bound by the applications of the parties.

(2) A court shall dismiss an application to change an obligation if the affected party fails to assert the right to renew contract negotiations within a reasonable time after it must have ascertained the change in circumstances; this time limit is presumed to be two months.

\section{Contract in favour of a third person}

\section{Section 1767}

(1) If a debtor is to perform in favour of a third person under a contract, the creditor may require that the debtor discharge his debt to that person.

(2) It is to be considered whether or not, and when, the third person also acquired a direct right to require that the debt be discharged, relying on the content, nature and purpose of the contract. A third person is presumed to have acquired such a right if the performance is to primarily benefit such a third person.

(3) A debtor also has contractual defence against a third person.

\section{Section 1768}

If a third person rejects a right acquired under a contract, it is considered to never have acquired the right to any 
performance. A creditor may require that a performance be provided to him unless it contradicts the contents and purpose of the contract.

\title{
Section 1769
}

\section{Contract for the performance of a third person}

If a person undertakes to ensure that a third person discharge a debt in favour of another party, he is obliged to induce the third person to provide the stipulated performance. However, if a person undertakes that a third person fully discharges the stipulated debt, he shall compensate the creditor for the damage resulting from the failure to discharge the debt.

\section{Division 6}

\section{Special manners of concluding a contract}

\section{Section 1770 [Recodification]}

The provisions on offers and acceptance of offers apply with the necessary modifications to cases where the parties stipulate a different process of concluding a contract.

\author{
Section 1771
}

\section{Auction}

(1) At an auction, a contract is concluded by the fall of the hammer.

(2) An offer already made expires if a higher offer is made, or if the auction ends $i$ the fall of the hammer.

\section{Public competition for the best bid}

\author{
Section 1772 [Recodification]
}

A person bringing to public notice a competition for the best bid launches an invitation to bid.

\section{Section 1773 [Recodification]}

An inviting party shall, at least in a general way, define in writing the subject of performance and principles of other contents of the intended contract which the person insists on and shall determine the manner in which the bids are to be submitted, the deadline by which they must be submitted, as well as the deadline for the announcement of the selected bid. The inviting party shall appropriately publish the conditions of the competition.

\section{Section 1774 [Recodification]}

The inviting party may not change the conditions of the competition once they have been published or cancel the competition, unless it has reserved such a right in the conditions. A change or cancellation is published in the same manner as the conditions of the competition.

\section{Section 1775 [Recodification]}

(1) The inviting party shall include the bid in the competition if its content is consistent with the published conditions of the competition. A bid may derogate from the conditions of the competition only to the extent permitted by these conditions.

(2) A bid submitted after the time limit specified in the conditions of the competition may not be included in the competition

(3) The bidder has the right to the reimbursement of the costs associated with participation in the competition, if the right is granted by the conditions of the competition.

\section{Section 1776 [Recodification]}

(1) Unless the conditions of the competition specify otherwise, a bid may not be revoked after the expiry of the time limit specified in the conditions of the competition for the submission of bids.

(2) Conditions of the competition may determine that a bid may be changed or supplemented; however, changing or supplementing a bid after the expiry of the time limit specified in the conditions of the competition for the submission of bids is disregarded. Errors made in the preparation of a bid may be corrected at any time, unless excluded by the conditions of the competition.

\section{Section 1777 [Recodification]}

(1) The inviting party shall select the most advantageous bid and notify its acceptance in a manner and within the time limit specified in the conditions of the competition.

(2) Unless the manner for the selection of a bid is specified in the conditions of the competition, the inviting party is entitled to select the bid that suits it best. 


\section{Section 1778 [Recodification]}

(1) The inviting party shall accept a bid selected pursuant to Section 1777. If it notifies the bidder of the acceptance after the time limit specified in the conditions of the competition, the contract is not concluded if the selected bidder informs the inviting party without undue delay that it refuses the acceptance of the bid as having been made late.

(2) The inviting party may reject all the submitted bids if it has been reserved in the conditions of the competition.

\section{Section 1779 [Recodification]}

The inviting party shall, without undue delay after the competition ends, inform the unsuccessful bidders of the fact that their bids were rejected.

\section{Public offer}

\section{Section 1780 [Recodification]}

(1) A public offer is an expression of the offeror's will whereby he approaches unspecified persons with a proposal to conclude a contract.

(2) If an invitation to conclude a contract does not indicate the intent to conclude a specific contract or lacks the elements under Section 1732(1), it is considered an invitation to bid.

\section{Section 1781 [Recodification]}

A public offer may be revoked if the offeror published the revocation in the same manner in which the public offer was published and before the public offer was accepted.

\section{Section 1782 [Recodification]}

(1) On the basis of a public offer, a contract is signed with the first person who, in due time and in accordance with the public offer, informs the offeror that he accepts the public offer. If several persons accept a public offer at the same time, the contract is concluded with the person selected by the offeror.

(2) Unless specified in the public offer, the time limit for acceptance is conclusively presumed to be the time limit which is appropriate to the nature of the public offer.

\section{Section 1783 [Recodification]}

(1) The offeror shall notify the offeree of the conclusion of the contract without undue delay after accepting the public offer. It shall notify the others that they have not succeeded.

(2) If an offeror provides the offeree with a confirmation of the contract later than specified under Subsection (1), the contract is not concluded if the offeree refuses to conclude the contract without undue delay after the offeror's confirmation of the conclusion of the contract has reached him.

\section{Section 1784 [Recodification]}

(1) If expressly determined by a public offer, a contract is concluded with a certain number of persons or, where applicable, with all persons who accepted the public offer within the time limit under Section 1782.

(2) If the offeror fails to fulfil the notification duty, he is bound by all the acceptances of the public offer provided by the offerees who were not notified by the offeror.

\section{Division 7}

\section{Preliminary contract}

\section{Section 1785 [Recodification]}

\section{Basic provisions}

By a preliminary contract, at least one party undertakes to conclude a future contract upon request and within the stipulated time limit, otherwise within one year; the contents of such a contract are to be at least stipulated in a general way.

\section{Section 1786 [Recodification]}

The obligor becomes obliged to conclude the contract without undue delay after being requested to do so by the obligee in accordance with the preliminary contract.

\section{Section 1787 [Recodification]}

(1) If the obligor fails to fulfil the duty to conclude the contract, the obligee may request that the contents of the future contract be determined by a court or the person designated in the contract. If such a person fails to determine the content of the future contract within a reasonable time limit or refuses to provide such determination, the obligee may apply to a court to do so. 
(2) The contents of a future contract are determined according to the evident purpose of the future contract. In doing so, the court motions of both parties are relied on, taking into consideration the circumstances under which the preliminary contract was concluded, as well as the necessity to ensure a fair arrangement of the rights and duties of the parties.

\section{Section 1788 [Recodification]}

(1) If the obligee fails to request the obligor to conclude the contract in due time, the duty to conclude the future contract is extinguished.

(2) Where the circumstances relied on by the parties in the course of creating the obligation arising from the preliminary contract have changed to the extent that the obligor may not be reasonably required to conclude the contract, the duty to conclude the future contract is extinguished. If the obligor fails to notify the obligee of a change in circumstances without undue delay, it shall compensate the obligee for the resulting damage.

\section{Chapter 3}

\section{Content of obligations}

\section{General provisions}

\section{Section 1789}

An obligation obliges a debtor to give something, do something, refrain from doing something or tolerate something, and the creditor is entitled to require that from him.

\section{Section 1790}

An obligation may not be changed without a stipulation between the creditor and the debtor, unless otherwise provided by a statute.

\section{Section 1791}

(1) An absence of the expression of the cause for which the debtor owes performance does not prevent the creation and duration of the obligation; however, the creditor must demonstrate the cause for the obligation.

(2) In the case of an obligation arising from securities, the creditor does not demonstrate the cause for the obligation, unless specifically provided by a statute.

$$
\text { Section } 1792
$$

\section{Consideration for a performance}

(1) If a contract specifies a duty of the parties to provide and receive a performance for consideration and there is no stipulation on its amount or the manner in which the amount is to be determined, the consideration is conclusively presumed to have been stipulated in the amount which was usual at the time and place at which the contract was concluded. If the amount of the consideration cannot be so determined, it is determined by a court having regard to the contents of the contract, the nature of the performance and usages.

(2) If the consideration has been stipulated contrary to the legal regulations on prices, the consideration which is permissible under the regulations is conclusively presumed to be the one stipulated.

\section{Lesion}

\section{Section 1793 [Recodification]}

(1) If the parties undertake to provide each other with a mutual performance and the performance provided by one of the parties is grossly disproportionate to the performance provided by the other party, the injured party may request that the contract be cancelled and the original state restored unless the other party reimburse the lesion, having regard to the usual price at the time and place at which the contract was concluded. This does not apply if the disproportion between the mutual performances is based on a fact which the other party neither knew nor was required to know.

(2) Subsection (1) does not apply to cases of acquisition at a commodity exchange, in the course of trading with an investment instrument under another statute, at an auction or in a manner equal to a public auction, to cases of betting or gaming, or settlement or novation, if they were made fairly.

\section{Section 1794 [Recodification]}

(1) The right under Section 1793 is not created if the reason for the disproportion between mutual performances is based on a special relationship between the parties, especially if the injured party intended to perform partly for consideration and partly gratuitously, or where the amount of the lesion can no longer be determined.

(2) The right under Section 1793 is also not created if the injured party has expressly waived that right and declared that it acceped the performance at an exceptional price based on its sentimental value, or consented to a disproportionate price although it was or must have been aware of the actual price of the performance. 
Section 1795 [Recodification]

The right under Section 1793 is extinguished if not asserted within one year from concluding the contract.

Section 1796 [Recodification]

Usury

If a person exploits distress, inexperience, mental weakness, agitation or carelessness of the other party when concluding a contract and causes the other party to promise or provide to him or another person performance whose property value is in gross disproportion to the mutual performance, such a contract is invalid.

\section{Section 1797 [Recodification]}

An entrepreneur who concluded a contract in the course of his business is not entitled to require that the contract be cancelled under Section 1793(1), and may not invoke the invalidity of the contract under Section 1796.

\section{Contracts of adhesion}

\section{Section 1798 [Recodification]}

(1) The provisions on contracts of adhesion apply to any contract whose essential terms were determined by one of the parties or according to the party's instructions, without the weaker party having any real opportunity to affect the contents of these essential terms.

(2) If a contractual form used in business dealings or another similar means is used to conclude a contract with the weaker party, the contract is presumed to have been concluded as a contract of adhesion.

\section{Section 1799 [Recodification]}

A clause in a contract of adhesion which refers to the terms stipulated outside the actual text of the contract is valid if the weaker party has been acquainted with the clause and its meaning or if it is proved that the meaning of the clause must have been known to him.

\section{Section 1800 [Recodification]}

(1) If a contract of adhesion contains a clause which can only be read with particular difficulties or a clause which is incomprehensible to a person with average intelligence, such a clause is valid if it causes no harm to the weaker party or if the other party proves that the meaning of the clause was sufficiently explained to the weaker party.

(2) If a contract of adhesion contains a clause which is particularly disadvantageous to the weaker party without any reasonable ground, in particular if a contract significantly and for no special reason derogates from the usual terms stipulated in similar cases, the clause is invalid. If required by the fair arrangement of rights and duties of the parties, a court shall decide in accordance with Section 577 by analogy.

\section{Section 1801 [Recodification]}

If the parties derogate from Section 1799 or 1800 or exclude any of these provisions, it is disregarded. This does not apply to contracts between entrepreneurs, unless one of the parties proves that a clause stipulated outside the text of the contract and proposed by the other party is grossly inconsistent with business usages and the principle of fair business dealings.

\section{Interest}

\section{Section 1802 [Recodification]}

If interest is to be paid and its rate has not been stipulated, the debtor shall pay interest at a rate specified by a legal regulation. If interest is not specified in this manner, the debtor shall pay the usual interest charged for credits provided by banks at the place of residence or registered office of the debtor at the time of the conclusion of the contract.

\section{Section 1803 [Recodification]}

The stipulated rate of interest is presumed to relate to a period of one year.

$$
\text { Section } 1804 \text { [Recodification] }
$$

Interest is payable in the same currency as the principal debt (principal).

$$
\text { Section } 1805 \text { [Recodification] }
$$

(1) If the period for which interest is due has not been stipulated, the interest is due with the principal, and if the principal is due later than after one year, interest is due annually in arrears. 
(2) A creditor who is unreasonably late with the assertion of his right to have a debt repaid so that the accrued interest equals to the amount of the principal shall lose the right to require further interest. However, he is entitled to further interest from the date on which he asserted his right in court.

$$
\text { Section } 1806 \text { [Recodification] }
$$

Compound interest may be claimed if so stipulated. Where the claim arose from an unlawful act, compound interest may be claimed from the date on which the claim was asserted in court.

$$
\text { Section } 1807 \text { [Recodification] }
$$

\section{Advance payment}

What one party gave to the other before concluding a contract is presumed to be an advance payment.

\section{Earnest}

\section{Section 1808 [Recodification]}

(1) Where an earnest has been stipulated, it must be delivered no later than at the conclusion of a contract. An earnest confirms the conclusion of a contract and the party which provided it provides a security ensuring that it will discharge the debt.

(2) If the person who provided the earnest fails to discharge the debt, the other party may retain the earnest. If this party provided an earnest, it is entitled to request that it either be given twice as much, or that the debtor discharge the debt, or that it be provided with compensation for damage if discharging the debt is no longer possible.

\section{Section 1809 [Recodification]}

If a party has provided an earnest and, at the same time, the right to withdraw from the contract has been stipulated without separately stipulating any withdrawal fee, the earnest is considered to be the withdrawal fee. If the party which provided the earnest withdraws from the contract, it loses its right to have it returned; if the party which received the earnest withdraws from the contract, it shall give the other party twice as much.

\section{Chapter 4}

\section{Provisions on obligations arising from contracts concluded with consumers}

\section{Division 1}

\section{General provisions}

\section{Section 1810 [Recodification]}

The provisions of this Division apply to contracts concluded between an entrepreneur and a consumer (hereinafter "consumer contracts") and to obligations arising therefrom.

\section{Section 1811 [Recodification]}

(1) All of an entrepreneur's communications with a consumer must be made clearly and understandably in the language in which the contract is concluded.

(2) If the dealings of the parties aim at concluding a contract and these facts are not evident from the context, the entrepreneur shall, sufficiently in advance before the conclusion of the contract or before the consumer makes a binding offer, provide the consumer with:

a) the entrepreneur's identity or, where applicable, his phone number, email address or other contact information,

b) the designation of the goods or service, and a description of their main properties,

c) the price of the goods or service, or, where applicable, the method of its calculation including all taxes and fees,

d) the method of payment and the method of supply or performance,

e) the costs of supply, and if these costs cannot be calculated in advance, an indication that they may be subsequently charged,

f) information on the rights arising from a defective performance, as well as the rights arising from a guarantee and other conditions for those rights to be asserted,

g) information indicating the period of the obligation and the conditions for the extinction of the obligation where a contract is concluded for an indefinite period,

h) information on the functionality of digital content, including technical protection measures, and 
i) information on the hardware and software interoperability with digital content of which the entrepreneur is aware or where he can be reasonably expected to have been aware of it.

(3) Subsection (2) does not apply to contracts:

a) concluded for the purpose of dealing with the matters of everyday life if the mutual performance is to be provided immediately after the conclusion of the contract, and

b) for the supply of digital content, if supplied on a tangible medium.

\section{Section 1812 [Recodification]}

used.

(1) If the contents of a contract allow different interpretations, the interpretation most favourable to the consumer is

(2) Stipulations derogating from the statutory provisions on consumer protection are disregarded. This also applies where a consumer waives a special right conferred upon him by a statute.

\section{Section 1813 [Recodification]}

Stipulations which establish, contrary to the requirement of proportionality, a significant imbalance in the rights or duties of the parties to the detriment of the consumer are presumed to be prohibited. This does not apply to stipulations on a subject of performance or price if they are provided to the consumer clearly and understandably.

\section{Section 1814 [Recodification]}

The prohibition in particular applies to stipulations which:

a) exclude or limit the rights of the consumer arising from a defective performance or to compensation for harm,

b) oblige the consumer to perform while the entrepreneur becomes obliged to perform only when a condition depending on his will is met,

c) allow the entrepreneur not to surrender to the consumer what the consumer surrendered to the entrepreneur, even where the consumer fails to conclude or withdraws from the contract,

d) entitle the entrepreneur, but not the consumer, to withdraw from the contract for no reason,

e) entitle the entrepreneur to terminate an obligation for no reason deserving special consideration without an appropriate notice period,

f) irrevocably oblige the consumer to perform under conditions with which he had no opportunity of becoming familiar before the conclusion of the contract,

g) allow the entrepreneur to change the rights or duties of the parties at his discretion,

h) postpone the determination of the price up until the time of the performance,

i) allow the entrepreneur to raise the price without giving the consumer the right to withdraw from the contract in case of a significant increase in the price,

j) exclude or hinder the consumer's right to file an application or use other procedural remedy, or oblige the consumer to assert his right exclusively before an arbitration court or an arbitrator who is not bound by the legal regulations on the protection of consumers,

k) pass on the consumer the burden of proof that the entrepreneur has fulfilled his duty imposed on him by the provisions of the contract for the provision of financial services, or

I) exclude the consumer's right to determine which obligation is to be paid from the performance provided as a matter of priority.

$$
\text { Section } 1815 \text { [Recodification] }
$$

Disproportionate stipulations are disregarded unless invoked by the consumer.

\section{Section 1816 [Recodification]}

(1) If at least a part of the price is covered by a credit or loan for consumption provided by the entrepreneur, and if the consumer exercises his right to withdraw from the contract, the effects of the withdrawal shall also apply to the credit contract or contract of loan for consumption; it shall also apply where the credit or loan for consumption has been provided by a third person under a contract concluded with the entrepreneur. In such a case, the provider of a credit or loan for consumption or, where applicable, another person, is prohibited from asserting any sanctions against the consumer.

(2) Subsection (1) applies in the case of distance consumer contracts, timeshare consumer contracts and other holiday-service consumer contracts. In other cases, the provision of Subsection (1) applies unless the parties exclude or derogate from these provisions in the credit contract or contract of loan for consumption. 
An entrepreneur may not require the consumer to provide a payment other than what the consumer is required to pay under the main contractual obligation, unless the consumer has given his express consent to such an additional payment.

\title{
Section 1818 [Recodification]
}

If a consumer has the right to withdraw from the contract under the provisions of this Chapter, he is not required to give any reasons; no sanction may be attached to the right of withdrawal. If the consumer exercises his right to withdraw from the contract pursuant to the provisions of this Chapter, the time limit for withdrawal is considered to have been observed if the consumer dispatches the entrepreneur a notice of withdrawal within such a time limit.

\section{Section 1819 [Recodification]}

The textual form is observed if information is provided in such a way that it can be kept and displayed repeatedly.

\section{Division 2}

\section{Concluding distance contracts and obligations arising from contracts negotiated away from business premises}

\section{Subdivision 1}

\section{General provisions}

\author{
Section 1820 [Recodification]
}

\section{Communications made before the conclusion of a contract}

(1) If the dealings of the parties aim at concluding a contract and if, during such dealings, the entrepreneur exclusively uses at least one communication means which allows a contract to be concluded without the simultaneous physical presence of the parties (hereinafter a "means of distance communication"), or if such dealings aim at concluding a contract negotiated away from business premises, the entrepreneur shall, well in advance before the conclusion of the contract or before the consumer makes a binding offer, also communicate to the consumer the following:

a) the costs of the means of distance communication if they differ from the basic rate,

b) information on the duty to pay an advance or similar payment, if required,

c) in the case of a contract stipulating a recurrent performance, the shortest period for which the contract will bind the parties,

d) in the case of a contract concluded for an indefinite period or one which stipulates a recurrent performance, information on the price or the manner of its determination for one billing period, which shall always be one month if the price remains constant,

e) in the case of contracts concluded for an indefinite period or those which stipulate a recurrent performance, information on all taxes, fees and the costs of supplying the goods or service determined in the manner under paragraph (b),

f) if the right of withdrawal may be exercised, the conditions, time limit and procedures necessary to assert such a right, as well as the withdrawal form, whose elements are provided by an implementing legal regulation,

g) information specifying that in case of a withdrawal, the consumer will bear the cost of returning the goods, and in the case of a distance contract, the cost of returning the goods if, given their nature, the goods cannot be returned by ordinary mail,

h) information on a duty to pay a proportional part of the price in case of a withdrawal from a contract concerning services whose provision has already begun,

i) in the case of a contract under Section 1837(I), information specifying that the consumer may not withdraw from the contract, and, where applicable, the conditions under which his right of withdrawal from contract is extinguished, and

j) an indication of the existence, manner and conditions of out-of-court settlement of consumer complaints, including information on whether a controlling body or state supervision body may be approached with such a complaint.

(2) An entrepreneur may also provide the information under Subsection $1(\mathrm{f}),(\mathrm{g})$ and $(\mathrm{h})$ to a consumer using sample advice of the possibility to withdraw from the contract, whose elements are provided by an implementing legal regulation.

(3) If an entrepreneur has provided a consumer with completed sample advice on the possibility to withdraw from the contract, he is presumed to have provided the consumer with the information referred to under Subsection $1(\mathrm{f}),(\mathrm{g})$ and $(\mathrm{h})$.

\section{Section 1821 [Recodification]}

If an entrepreneur has not provided the consumer with the information on other taxes and fees borne by the consumer under Section 1811(2)(c) or the costs under Section 1811(2)(e) or Section 1820(1)(g), the consumer is not obliged to pay these taxes, fees or costs to the entrepreneur. 


\section{Section 1822 [Recodification]}

\section{Contents of a contract}

(1) A contract must also contain information communicated to the consumer before it was concluded. This information may be changed if expressly stipulated by the parties. A concluded contract must be consistent with the information communicated to the consumer before its conclusion. This information may be changed if expressly stipulated by the parties; otherwise, the contents of the contract which is more favourable to the consumer applies. consumer.

(2) An entrepreneur shall, immediately after concluding a contract, surrender at least one of its copies to the

$$
\text { Section } 1823 \text { [Recodification] }
$$

\section{Obligations arising from contracts for the provision of services}

If a contract concerns the provision of services, the entrepreneur starts performing his duty within the time limit for withdrawal from the contract only at the express request of the consumer made in textual form.

\section{Special provisions on obligations arising from distance contracts}

\section{Section 1824 [Recodification]}

(1) If a contract is negotiated through a means of distance communication, the entrepreneur shall provide the consumer with the information referred to under Section 1811(2) and Section 1820(1).

(2) If the means of distance communication does not allow the consumer to be provided with all the information, he shall receive at least the information under Section 1811(2), (a), (b), (c) and (g) and the information under Section 1820(1)(b),(c) and $(h)$. The entrepreneur shall provide the consumer with the other information in textual form no later than by the time of the performance.

\section{Section 1825 [Recodification]}

If a contract is negotiated over the phone, the entrepreneur shall, at the beginning of the call, provide the consumer with basic information about himself and with the purpose of the call.

\section{Section 1826 [Recodification]}

(1) When using electronic means, the entrepreneur shall also provide information:

a) specifying whether the concluded contract will be kept by him and whether he will make it accessible to the consumer,

b) on the languages in which the contract can be concluded,

c) on the individual technical steps leading to the conclusion of the contract,

d) on the possibility of finding and correcting errors incurred during data entry before placing an order and

e) on codes of conduct that are binding on the entrepreneur or which he voluntarily complies with, and on their accessibility by electronic means.

(2) The provision of Subsection (1) does not apply where a contract is concluded only through email or similar means allowing separate connection and data storage.

(3) Before placing an order, a consumer using electronic means must be allowed to check and change all the input information which he entered in the order.

\section{Section 1827 [Recodification]}

(1) Where a consumer places an order through a means of distance communication, the entrepreneur is obliged to use a means of distance communication to immediately acknowledge its receipt; this does not apply when a contract is concluded exclusively by exchange of electronic mail or equivalent individual communication.

(2) If a contract is concluded through electronic means, the entrepreneur shall, in addition to the text of the contract, provide the consumer with the text of the standard commercial terms.

\section{Section 1828 [Recodification]}

\section{Special provisions on obligations arising from contracts negotiated away from business premises}

(1) If a contract is negotiated away from an entrepreneur's usual business premises, the entrepreneur shall provide the consumer with the information under Section 1811(2) and Section 1820(1) in writing; he shall provide the consumer with such information in another textual form only with the consent of the consumer.

(2) A contract negotiated away from business premises also includes a contract concluded: 
a) within the entrepreneur's usual business premises if it was concluded immediately after the entrepreneur approached the consumer outside of these premises, and

b) during a package tour organised by an entrepreneur for the purpose of promoting and selling goods or providing services.

\section{Withdrawal from contract}

\section{Section 1829}

(1) A consumer has the right to withdraw from a contract within fourteen days. The time limit under the first sentence starts on the date of conclusion of the contract, and in the case of:

a) a contract of sale, from the date of the takeover of goods,

b) a contract concerning several kinds of goods or the supply of several parts, from the date on which the last supply of goods is taken over, or

c) a contract concerning a regular recurrent supply of goods, from the date on which the first supply of the goods is taken over.

(2) If a consumer has not been advised of his right to withdraw from a contract in accordance with Section 1820(1)(f), the consumer may withdraw from the contract within one year and fourteen days from the beginning of the time limit for withdrawal under Subsection (1). However, if the consumer has been advised of his right of withdrawal within this time limit, the fourteen-day time limit for withdrawal commences on the date on which the consumer received the advice.

\section{Section 1830}

If an entrepreneur allows a consumer to withdraw by completing and dispatching a standard withdrawal form on a website, he shall provide the consumer with a confirmation of its receipt in textual form without undue delay.

\section{Section 1831}

(1) If a consumer withdraws from a contract, he shall, without undue delay and no later than fourteen days after the withdrawal, dispatch or hand over to the entrepreneur the goods received from him. If a service has already been provided to the consumer, he incurs no duty towards the entrepreneur thereunder, with the exception of Section 1834.

(2) An entrepreneur may only require a consumer to pay the costs provided by this Act.

\section{Section 1832}

(1) If a consumer withdraws from a contract, the entrepreneur shall, without undue delay and no later than fourteen days after the withdrawal, return to the consumer in the same way all funds, including the costs of supply, which the entrepreneur received from the consumer under the contract. The entrepreneur may return to the consumer the received funds in another way only with the consent of the consumer and only if the consumer incurs no additional costs thereby.

(2) If a consumer has chosen a supply method other than the cheapest supply method offered by the entrepreneur, the entrepreneur shall return to the consumer costs of supply in the amount corresponding to the cheapest supply method offered.

(3) An entrepreneur shall pay to the consumer the costs of returning the goods if he did not inform the consumer about the duty to bear these costs in accordance with the provision of Section 1820(1)(g).

(4) If a consumer withdraws from a contract of sale, the entrepreneur is obliged to return the funds received from him only after the consumer has handed over the goods to the entrepreneur or proved to him that the goods were dispatched to him.

\section{Section 1833}

A consumer is liable to an entrepreneur only for the reduction in the value of goods caused by the handling of the goods in a manner other than that which is necessary with regard to its nature and properties. This does not apply if the entrepreneur did not provide the consumer with the information under Section 1820(1)(f).

\section{Section 1834}

If a consumer withdraws from a contract for the provision of services and the entrepreneur, at an express request of the consumer, began to perform before the end of the time limit for withdrawal from contract, the consumer shall pay to the entrepreneur a part of the agreed price proportional to the performance provided until the time of withdrawal from contract. If the agreed price is excessive, the consumer shall pay to the entrepreneur a part of the price proportional to the market value of the performance provided.

\section{Section 1835}

An entrepreneur shall, at his own cost, take over the goods from the consumer at the latter's household if the consumer withdraws from a contract negotiated away from business premises, the goods were supplied to the consumer's household at the time of conclusion of the contract and the nature of the goods does not allow them to be dispatched by usual mail. 
If a consumer withdraws from a contract, he bears no costs in the case of a contract:

a) concerning the provision of services where the entrepreneur has provided the consumer with no information under Section $1820(1)(d)$ and (f), or where the entrepreneur began to perform before the end of the time limit for withdrawal without the consumer having expressly requested him to do so, or

b) for the supply of digital content if it was not supplied on a tangible medium and the entrepreneur supplied it before the end of the time limit for withdrawal without the consumer having expressly asked him to do so or having expressly acknowledged that his right of withdrawal from contract will be extinguished, or where the entrepreneur failed to hand over a copy of the contract to the consumer.

\section{Section 1837}

A consumer may not withdraw from a contract:

a) for the provision of services if they were performed with his prior express consent before the end of the time limit for withdrawal and the entrepreneur informed the consumer before concluding the contract that he shall thereby lose the right of withdrawal,

b) for the supply of goods or a service whose price depends on fluctuations of the financial market which are beyond the control of the entrepreneur and which may occur during the time limit for withdrawal,

c) for the supply of alcoholic beverages which can only be supplied after thirty days and whose price depends on fluctuations of the financial market which are beyond the control of the entrepreneur,

d) for the supply of goods which were customised or personalised,

e) for the supply of goods subject to rapid decay, as well as goods which were irreversibly mixed with other goods after supply,

f) for repair or maintenance work carried out at the place designated by the consumer at his request; however, this does not apply in the case of subsequent unsolicited repairs or supply of unsolicited spare parts,

g) for the supply of sealed goods which were unsealed after supply by the consumer and which are not suitable for return due to hygiene reasons,

h) for the supply of audio or video recordings or computer software whose original seal was unsealed after supply,

i) for the supply of newspapers, periodicals or magazines,

j) for accommodation, transport, catering or leisure activities where the entrepreneur provides the performances at a specific date,

k) concluded at a public auction in accordance with the statute governing public auctions, or

I) for the supply of digital content which is not supplied on a tangible medium if it was supplied with the prior express consent of the consumer before the time limit for withdrawal and the entrepreneur informed the consumer before concluding the contract that he shall thereby lose his right of withdrawal.

\section{Section 1838}

\section{Unsolicited performance}

If an entrepreneur has supplied a thing to the consumer without the consumer's order and if the consumer assumed the possession thereof, he is considered to be a possessor in good faith. The consumer is not obliged to give anything back to the entrepreneur at his own expense, or even inform him thereof.

\section{Common provisions}

\section{Section 1839 [Recodification]}

In case of doubt, an entrepreneur must prove that he provided a consumer with the information which he is required to provide under this Subdivision.

$$
\text { Section } 1840 \text { [Recodification] }
$$

The provisions of this Subdivision do not apply to contracts:

a) concerning the provision of social services, social housing, childcare and support for persons who are permanently or temporarily in an emergency situation,

b) concerning the provision of health care,

c) concerning betting, gaming or lottery,

d) concerning the creation, transfer or extinction of a right to an immovable thing and the lease of an apartment, 
e) concerning the construction of a new building and substantial reconstruction of a building,

f) for a package tour,

g) for the supply of foodstuffs, beverages or other goods intended for everyday consumption supplied to the consumer's household or another place designated by the consumer,

h) for carriage of a person,

i) concluded by means of automatic vending machines or automated commercial premises, or

j) concluded with the provider of a publicly available electronic communications service for the use of, and by, a payphone or concluded for a single connection of the consumer by phone, fax or internet.

\section{Subdivision 2}

\section{Financial services}

Section 1841

For the purpose of regulating consumer contracts, a financial service contract in this Act shall mean any consumer contract concerning banking, credit, payment or insurance service, any contract concerning supplementary pension insurance, currency exchange, the issuing of electronic money and any contract concerning the provision of investment services or trading in the investment instruments market.

\section{Section 1842}

(1) The provisions of this Subdivision apply to a contract for financial services and the rights and duties arising therefrom if the contract was concluded solely through a means of distance communication.

(2) However, if other successive contracts of the same or similar nature are concluded on the basis of the contract under Subsection (1), the provisions of this Subdivision only apply to the first contract; however, this does not apply if more than one year has elapsed since the conclusion of the last contract. If, on the basis of the contract under Subsection (1), there is another expression of will of the same or similar nature, the procedure applies by analogy.

\section{Section 1843}

\section{Communications made before the conclusion of a contract}

(1) Sufficiently in advance before the conclusion of a contract or before the consumer makes a binding offer, the entrepreneur shall provide the consumer in textual form with at least the following:

a) the information specified in Section 1811(2)(a), (b), (d) and Section 1820(1)(a) and (c),

b) the primary objects of business,

c) the name and address of the body responsible for controlling or state supervision over the entrepreneur's activities in the case of a business subject to a licence,

d) the total price of the service provided, including all fees and taxes paid through the entrepreneur and other associated costs; where the total price cannot be determined in advance, all information about the method of calculation of the final price allowing the consumer to verify the price,

e) the details of other taxes or costs which are not paid through the entrepreneur or which he does not charge,

f) the potential risks beyond the control of the entrepreneur associated with the provision of the financial service, including, where applicable, a warning that past performance is no guarantee of future results,

g) advice of the possibility or impossibility to withdraw from the contract under Section 1846, including the advice of the time limits for asserting the right of withdrawal, the conditions under which it can be asserted, the amount whose payment may be required from the consumer under Section 1849, as well as the advice of the consequences of the failure to assert the right of withdrawal,

h) practical instructions for asserting the right of withdrawal, including the address to which notification of withdrawal is to be sent,

i) advice of the right of each party to end a contractual obligation early or unilaterally on the basis of contractual terms, including advice of sanctions, where applicable,

j) the Member State(s) of the European Union whose legal regulations are taken by the entrepreneur as a basis for the establishment of relations with the consumer prior to the conclusion of the contract,

k) information on the contractual clause on the governing law and jurisdiction in the event of a dispute under the contract,

l) information on the language or languages in which the entrepreneur and the consumer will communicate for the duration of 
the obligation and in which he will provide the consumer with the contractual terms and other information,

m) information on the existence, manner and conditions of out-of-court settlement of consumer complaints, including information on whether a controlling body or state supervision body may be approached with such a complaint,

n) information on the existence of a guarantee fund, and

o) the period for which the information provided, including the information about price, remains valid.

(2) Where an entrepreneur acts through a representative or a consumer deals with an agent, the information under Subsection (1) is supplemented with the information under Section 1811(2)(a) concerning the representative or agent, as well as the legal cause which forms the basis for the agent to make juridical acts.

(3) The information provided to the consumer must allow for its business purpose to be identified.

\section{Section 1844}

(1) A concluded contract must be consistent with the information communicated to the consumer before its conclusion. Where, nonetheless, the contents of the contract are to be different from this information, they must be communicated to the consumer before the contract is concluded, and the amendments must be expressly identified in the contract; otherwise, the information more favourable to the consumer is conclusively presumed to form the contents of the contract.

(2) The information communicated to the consumer before the contract was concluded must be in accordance with the information that needs to be communicated to the consumer under the legal order governing the conclusion of the contract.

\section{Section 1845}

(1) If a contract has been concluded at the consumer's request using such means of distance communication which do not allow the provision of contractual terms and other information in accordance with Section 1843, the entrepreneur shall fulfil this duty immediately after the conclusion of the contract.

(2) If so requested by the consumer at any time during an obligation arising from a contract, the consumer has the right to be given the contractual terms in printed form, as well as the right to change the means of distance communication, unless it is contrary to the nature of the services provided or the contract concluded.

\section{Withdrawal from contract}

\section{Section 1846}

(1) A consumer may exercise the right of withdrawal within fourteen days from the conclusion of the contract; however, if the information under Sections 1843 to 1845 was communicated to him only after the contract was concluded, he may exercise the right of withdrawal within fourteen days from the date on which it was communicated. A consumer may withdraw from a life insurance contract or a supplementary pension insurance contract within thirty days from the date on which he was informed by the entrepreneur that a distance contract had been concluded.

(2) If an entrepreneur provides a consumer with deceptive information, the consumer has the right to withdraw from the contract within three months from the date on which he became aware or should and could have become aware thereof.

Section 1847

The provision of Section 1846 does not apply:

a) if the price of the financial services depends on price fluctuations in the financial markets which are beyond the entrepreneur's control, such as services relating to foreign exchange value and investment instruments, or

b) in the case of a contract for travel insurance, baggage insurance or a similar short-term insurance with a period of insurance shorter than one month.

\section{Section 1848}

If another distance contract concerning the services provided by the entrepreneur is related to a contract for financial services, the obligation arising from the related contract is also extinguished from the beginning upon the withdrawal from the contract for financial services. This also applies where the performance is provided by a third person under a contract concluded with the entrepreneur.

\section{Section 1849}

If a consumer withdraws from a contract, the entrepreneur may require immediate payment of the price only for the service actually provided until that time; the price may not be disproportionate to the scope of the service provided. However, the entrepreneur shall not become entitled to the payment of the price if he began to perform before the end of the time limit for withdrawal under Section 1846 without the consumer's consent or if the entrepreneur fails to prove that he advised the consumer on the entrepreneur's right to request the price or a proportionate part thereof upon the consumer's withdrawal under Section $1843(1)(g)$. 
If a consumer withdraws from a contract, the entrepreneur shall return to him all funds received from him under the contract without delay, but no later than within thirty days from the date of withdrawal. Also the consumer shall, within thirty days from the date on which he dispatched the notice of withdrawal, return to the entrepreneur all the funds or other property received from him under the contract.

\section{Section 1851}

\section{Unsolicited performance}

If an entrepreneur provides a consumer with a financial service without an express order, the consumer shall incur no duty to pay him for such a performance or any other duty.

\section{Division 3}

\section{Timeshare and other holiday services}

Section 1852

(1) The provisions of this Division apply to consumer contracts whereby a consumer, for consideration, acquires:

a) the right to use overnight accommodation for more than one period of occupation, or the right to benefits in respect of accommodation, including, where applicable, transport or other services, where such a contract has a duration of more than one year,

b) participation in an exchange system associated with the right to a performance under paragraph (a) in exchange for the granting to another person the possibility to exercise similar contractual rights arising from a contract under paragraph (a), or

c) the right to the entrepreneur's assistance in the acquisition or transfer of a right under paragraph (a) for consideration.

(2) The provisions of this Division apply by analogy to preliminary contracts under Subsection (1).

\section{Section 1853}

If the duration of the obligation is decisive for the application of the provisions of this Division, account is taken of any stipulations that allow the renewal of the contract or extension of the obligation even without the explicit expression of will of a contractual party.

Section 1854

\section{Communications made before the conclusion of a contract}

(1) Where a promotional or sales event is concerned, an entrepreneur shall clearly indicate the business purpose and nature of the event in the invitation. Throughout its duration, a consumer must have access to the information under Subsection (2).

(2) Before a consumer concludes a contract or undertakes to do so, the entrepreneur shall, gratuitously, in text, on a form and sufficiently in advance, provide the consumer with information which, together with the elements of the form, is provided by the implementing legal regulation, so that the consumer has easy access thereto. An entrepreneur shall also expressly notify the consumer of his right of withdrawal, the length of the time limit for withdrawal and the prohibition of advance payments and other performances or ensuring thereof during the time limit for withdrawal.

(3) An entrepreneur shall communicate the information to the consumer in an official language of a Member State of the European Union in which the consumer resides, or of which the consumer is a national, according to the consumer's choice.

\section{Section 1855}

\section{Form of a contract}

A contract must be in writing; however, an entrepreneur does not have the right to invoke invalidity of a contract with respect to the consumer due to lack of form.

\section{Contents of a contract}

\section{Section 1856}

(1) A contract must state the names of the parties and their place of residence or registered office, information communicated to the consumer before concluding the contract, as well as the date and place of conclusion of the contract.

(2) A withdrawal form is part of a contract; the information in the form is completed by the entrepreneur. Elements of the form and a list of information are provided in an implementing legal regulation.

\section{Section 1857}

(1) A contract must also contain information communicated to the consumer before it was concluded. This information may be changed if expressly stipulated by the parties or if an unpredictable and insurmountable cause independent of the 
entrepreneur's will has produced its inconsistency with the information contained in the contract.

(2) If, before concluding a contract, an entrepreneur fails to notify a consumer of these changes in textual form in a manner which allows easy access, and if he fails to expressly indicate them in the contract, the information more favourable to the consumer is conclusively presumed to form the contents of the contract.

\section{Section 1858}

A stipulation on the right of withdrawal, on the time limit for withdrawal and on the prohibition of advance payments and other performances or ensuring thereof during this time limit shall each be signed separately by the consumer.

\section{Section 1859}

An entrepreneur shall, immediately after concluding a contract, surrender at least one of its copies to the consumer.

Section 1860

\section{Language of a contract}

An entrepreneur shall conclude a contract with a consumer in an official language of the Member State of the European Union in which the consumer resides, or of which the consumer is a national, according to the consumer's choice. If the language under the preceding sentence is different from that of the Member State of the European Union on whose territory an immovable thing or part thereof which forms the subject of a contract whereby a consumer acquires the right to use accommodation under Section 1852(1)(a) is located, the entrepreneur shall also provide the consumer with the official translation of the text of the contract into that language.

\section{Withdrawal from contract}

\section{Section 1861}

(1) A consumer may withdraw from a contract in writing within fourteen days from the conclusion of the contract.

(2) If a consumer has been offered to conclude a contract creating, for consideration, his right to use overnight accommodation for more than one period of occupation, with a duration of more than one year, and, at the same time, conclude a contract establishing his participation in an exchange system under Section 1852(1)(b), a single time limit for withdrawal from both contracts runs. The contract which creates a consumer's right to use the accommodation is decisive for the running of this time limit.

\section{Section 1862}

(1) If, after concluding a contract, a consumer was not provided with a copy of the contract, the end of the time limit for withdrawal shall depend on the date on which the consumer received the copy of the contract.

(2) If a consumer was not provided with a completed withdrawal form, he may withdraw from the contract within one year and fourteen days. However, if the consumer was provided with the form within one year from the date on which the contract was concluded or, where applicable, from the date on which the consumer received a copy of the contract if it occurred later, the time limit for withdrawal shall end on the fourteenth day from the receipt of the form.

(3) If a contract does not specify the information which must be communicated to a consumer before concluding a contract, the consumer may withdraw from the contract within three months and fourteen days. However, if the information was communicated to the consumer within three months from the date on which the contract was concluded or, where applicable, from the date on which the consumer received a copy of the contract if it occurred later, the time limit for withdrawal shall end on the fourteenth day from the communication of the information.

\section{Section 1863}

If a consumer withdraws from a contract, he is not obliged to return anything at his own expense to the entrepreneur. If he has already been provided with a service, he has no duty to the entrepreneur thereunder.

\section{Section 1864}

(1) If a consumer has concluded a contract under Section 1852(1)(a) or (b), no one may request that he provide an advance payment or another performance, or security for such a payment or performance, under the contract for the duration of the time limit for withdrawal from such a contract. If, during this time, the consumer acknowledges a debt under this contract, such an acknowledgement is invalid.

(2) If a consumer concludes a contract under Section 1852(1)(c), no one may request that he provide an advance payment or another performance, or security for such a payment or performance, under the contract until a right is acquired or transferred for consideration, or until the entrepreneur's duty arising from this contract is extinguished for any other legal cause. If, during this time, the consumer acknowledges a debt under this contract, such an acknowledgement is invalid.

\section{Section 1865}

If a consumer withdraws from a contract under Section 1852(1)(a), the effects of withdrawal from this contract shall also apply to a contract establishing the consumer's participation in an exchange system under Section 1852(1)(b), as well as to every other ancillary contract or stipulation based on which the consumer acquired a right to a service associated with the 
principal contract, whether or not the service is to be provided by the other party of the principal contract or by another person on the basis of a stipulation with that party. Tying the effects of the withdrawal to a consumer's duty to pay any costs or provide any other performance is prohibited.

\section{Special provisions}

\section{Section 1866}

(1) If a consumer has concluded a contract with a duration of more than one year whereby he acquired, for consideration, the right to benefits in respect of accommodation, including, where applicable, transport or other services, a stipulation obliging the consumer to make payments under such a contract, including a member's fee, otherwise than in equal payments divided into annual instalments of the same amount, are disregarded. This does not apply if the parties stipulate a change in the amount of annual instalments after the first year based on price developments.

(2) An entrepreneur shall request a consumer to provide payment in textual form, each time no later than fourteen days in advance; otherwise, the debt becomes due within fourteen days after the entrepreneur requested the consumer to make payment.

\section{Section 1867}

If a consumer has concluded a contract with a duration of more than one year whereby he acquired, for consideration, the right to benefits in respect of accommodation, including, where applicable, transport or other services, and if he has paid the second instalment, he is entitled, at any time thereafter and without stating a reason, to withdraw from the contract in writing within fourteen days from the date on which he was requested by the entrepreneur to make any further payment or instalment.

\section{Chapter 5}

\section{Joint debts and claims}

\section{Section 1868}

\section{General provision}

(1) Where several debtors owe the same performance or a debtor owes the same performance to several creditors, both the joint debt and the joint claim are administered according to the principles of co-ownership.

(2) If one of the parties is comprised of multiple persons, the other party has the right to require that a joint representative be determined for the purpose of delivery of correspondence. If the party fails to do so, the representative is determined by a court on application.

\section{Indivisible performance}

Section 1869

A creditor may require that any of several debtors provide an indivisible performance, unless the nature of the obligation indicates that the debt may only be discharged by the joint activity of the debtors.

Section 1870

If a debtor is obliged to provide an indivisible performance to several creditors, he is not obliged to provide the performance to a creditor unless that creditor gives him a reasonable security, or if it is agreed by all the creditors. Whether or not a co-creditor who received the whole performance has any obligation to the other co-creditors depends on the mutual arrangements among the co-creditors; otherwise, he is presumed to have no duty.

\section{Section 1871}

\section{Divisible performance}

(1) Each of several co-debtors obliged to provide a divisible performance owes his part only, and each of several creditors entitled to a divisible performance is entitled to his part only, unless otherwise specified by a contract, statute or a court decision.

(2) If it has been stipulated that any of the creditors may demand the entire performance, the debtor shall discharge the entire debt in favour of the first creditor to make such a demand. If a debtor has discharged the entire debt to a single cocreditor, the others may no longer require that he provide anything else.

\section{Debtors obliged jointly and severally}

\section{Section 1872}

(1) If several debtors are obliged to perform jointly and severally, they are obliged to perform one for all and all for one. A creditor may demand the entire performance or any part thereof from all, only some, or any of the co-debtors.

(2) A special stipulation between a creditor and a co-debtor is not effective against the other co-debtors. 
Section 1873

If a creditor is in default with respect to one of the co-debtors, he is also in default with respect to the other co-debtors.

Section 1874

If several entrepreneurs are jointly obliged to perform, they are presumed to be obliged jointly and severally.

Section 1875

The mutual proportion of shares of all co-debtors in a debt is presumed to be equal.

Section 1876

(1) If a creditor claims more than corresponds to his share from any of the co-debtors, such a co-debtor shall inform the others accordingly and give them the opportunity to assert defences against the claim. He has the right to require that they discharge the debt in proportion to their shares or that they otherwise relieve him of the debt to this extent.

(2) If a co-debtor has performed more than his corresponding share, he is entitled to be reimbursed by the other codebtors. If a co-debtor cannot discharge his debt, it is allocated to all the others on a pro rata basis.

\section{Creditors entitled jointly and severally}

Section 1877

If a debtor is obliged to provide a performance to several creditors who are entitled to have such performance provided by him jointly and severally, any of them may demand the entire performance. A debtor shall discharge the entire debt in favour of the first person to have so requested.

Section 1878

(1) If one of the co-creditors is in default, so are the other co-creditors.

(2) If a claim and a debt merge in one of the co-creditors personally, the claims of the other co-creditors against the debtor are also extinguished.

\section{Chapter 6}

\section{Changes in obligations}

\section{Division 1}

\section{Change in the identity of a creditor or debtor}

\section{Subdivision 1}

\section{Change in the identity of a creditor}

\section{Assignment of a claim}

Section 1879 [Recodification]

By a contract, a creditor may, as an assignor, assign the entire claim or part thereof to another person (an assignee) even without the consent of the debtor.

\section{Section 1880}

(1) By assigning a claim, an assignee shall also acquire the accessories and rights associated with the claim, including the security for the claim.

(2) An assignor shall surrender to the assignee the necessary documents regarding the claim and inform him of everything that is required to assert the claim.

$$
\text { Section } 1881 \text { [Recodification] }
$$
creditor.

(1) It is possible to assign a claim which may be alienated, unless excluded by a stipulation between the debtor and

(2) It is not possible to assign a claim which is extinguished upon death or the contents of which would change upon a change of the creditor to the detriment of the debtor.

\section{Section 1882}

(1) Until an assignor informs the debtor or the assignee proves the assignment of the claim to the debtor, the debtor may be released from his duty by discharging his debt in favour of the assignor or making another settlement with him. 
(2) If an assignor has assigned the same claim to several persons, the assignment of which the debtor became aware first is effective against the debtor.

\title{
Section 1883
}

An assignment of a claim has no effects against a person who secured a debt with a pledge, suretyship or otherwise until the assignment of the claim is notified to such a person by the assignor or proved to him by the assignee.

\section{Section 1884}

(1) Even after the assignment, the debtor shall retain defences against the claim which he had at the time of the assignment. Mutual claims which a debtor had against the assignor may also be invoked by the debtor against the assignee, even where they were not yet due at the time of the assignment; however, he must notify the assignee of his claims without undue delay after becoming aware of the assignment. his creditor.

(2) However, if a debtor acknowledged that a claim against a fair assignee is genuine, he is obliged to satisfy him as

$$
\text { Section } 1885 \text { [Recodification] }
$$

(1) If a claim has been assigned for consideration, the assignor guarantees, with respect to the assignee, the existence of the claim at the time of the assignment and is liable as a surety for its recoverability up to the amount of the consideration received plus interest. This does not apply if the assignee knew that it was a future, uncertain or irrecoverable claim.

(2) The assignor bears no liability for the recoverability of the assigned claim if it became irrecoverable only after the assignment either by accident or inadvertence of the assignee. Inadvertence may be attributed to the assignee especially if he fails to enforce the claim without undue delay after it became due or if he suspends the maturity thereof.

(3) Otherwise, the rights and duties of an assignor and assignee are governed by the provisions of Sections 1914 to 1925 with the necessary modifications; however, an assignee must assert a defect of a claim with respect to the assignor without undue delay after the former could and should have discovered it.

\section{Section 1886}

(1) At an assignee's request, an assignor may enforce an assigned claim in his own name on the account of the assignee; if the assignment of a claim has already been notified or proved to the debtor, the assignor may enforce the claim if he proves the consent of the assignee and the assignee does not enforce the claim himself.

(2) If an assignor enforces a claim, the debtor may invoke against the claim his mutual claims which he has against the assignor, excluding his claims against the assignee.

\section{Section 1887 [Recodification]}

\section{Assignment of a set of claims}

It is also possible to assign a set of claims, whether present or future, if such a set of claims is sufficiently determined, in particular with respect to claims of a certain kind created at a particular time, or various claims arising from the same legal cause.

\section{Subdivision 2}

\section{Change in the identity of a debtor}

\section{Assumption of a debt}

\author{
Section 1888 [Recodification]
}

(1) If a person and a debtor stipulate that the person will assume the debtor's debt, the person shall enter in the debtor's place as a new debtor, subject to the consent granted by the creditor to the original debtor or the person assuming the debt.

(2) If, in the transfer of the right of ownership in a thing registered in a public register, a registered pledge or another security encumbering the thing also passes to the acquirer, the debt secured by the security is also presumed to have passed with it. After the transfer of the right of ownership, the transferor may request the creditor in writing to accept the acquirer as the new debtor in his place. If the creditor does not refuse to give his consent, the consent is conclusively presumed to have been given if the creditor was expressly notified of this consequence in the request.

\section{Section 1889 [Recodification]}

If a creditor does not approve the assumption of the debt or refuses to give his consent thereto, the creditor shall acquire no direct right with respect to the person assuming the debt; however, the person assuming the debt is obliged with respect to the debtor to ensure that the debtor is not required to provide a performance to the creditor. A person that undertakes, with respect to a debtor, to procure a performance for his creditor, also has such a duty towards the debtor. 
(1) By assuming a debt, the contents of an obligation remain unchanged. The person assuming a debt is entitled to all the defences that could have been asserted by the original debtor. Assumption of a debt does not affect the ancillary rights associated with the claim.

(2) However, a security for a debt provided by a third person continues to exist only if the third person consents to the change in the identity of the debtor.

\title{
Section 1891
}

A stipulation whereby the former debtor, whose debt is terminated, is replaced by a new debtor having a debt from a separate legal relationship or having a duty to perform a different subject does not have the effects of assumption of debt and is assessed as a novation.

\author{
Section 1892 [Recodification]
}

\section{Accession to a debt}

(1) A person who, without the debtor's consent, stipulates with the creditor the discharge of the debt on behalf of the debtor becomes a new debtor in parallel to the original debtor, both of them being liable jointly and severally.

(2) Where the debt of the original debtor has been secured by a third person, no claim may be asserted against the third person for the failure of the new debtor to perform the debt without the third person's consent.

\section{Section 1893 [Recodification]}

\section{Takeover of property}

(1) If a person takes over from a transferor all property or a proportionately determined part thereof, he shall, jointly and severally with the transferor, become a debtor in respect of the debts which are associated with the property taken over and of which the acquirer was or must have been aware at the conclusion of contract. However, the acquirer is not obliged to perform beyond the value of the property thus acquired.

(2) In case such property is taken over by a close person of the transferor, such a close person shall, jointly and severally with the transferor, become a debtor in respect of the debts associated with the property taken over; the liability is not limited to the value of the property thus acquired. This does not apply if the close person proves that he neither knew nor was required to know of a particular debt.

(3) A stipulation to the contrary between the transferor and acquirer has no effect against the creditor.

$$
\text { Section } 1894 \text { [Recodification] }
$$

Section 1893 does not apply to transformation of a legal person or alienation of an enterprise or a branch thereof.

\section{Subdivision 3}

\section{Assignment of a contract}

\section{Section 1895 [Recodification]}

(1) Unless excluded by the nature of a contract, either party may, as an assignor, transfer his rights and duties under a contract or part thereof to a third person if the assigned party consents to it and if the contract has not yet been fully executed.

(2) Where a continued or periodic performance is envisaged under a contract, the contract may be assigned with effects in respect of the part of the contract which has not yet been executed.

\section{Section 1896 [Recodification]}

In the case of a partial assignment of a contract or assignment of a contract to several assignees, the rights of the assigned party arising from clauses of lesser importance in the contract may not be prejudiced; clauses of lesser importance include, without limitation, stipulations on condition, advance payment, earnest, contractual penalty, withdrawal from contract and withdrawal fee or the arbitration clause.

\section{Section 1897 [Recodification]}

(1) Assignment of a contract becomes effective against the assigned party upon its consent. If such consent was granted in advance, the assignment of the contract against the assigned party becomes effective when the assignment of the contract is notified to that party by the assignor or proved to it by the assignee.

(2) If a contract concluded in writing contains a stipulation that it has been concluded to the order of one of the parties or another stipulation having the same meaning, that party shall assign the contract by endorsing the instrument. The elements of an endorsement, as well as the persons entitled thereunder and the manner in which they demonstrate their right, are governed by legal regulations on promissory notes. They are also relied on when considering the person who may be required to provide the instrument to a person who has lost it. 


\section{Section 1898 [Recodification]}

When the assignment of a contract becomes effective against the assigned party, the assignor becomes liberated from his duties to the extent of the assignment.

\section{Section 1899 [Recodification]}

(1) The assigned party may prevent the consequences under Section 1898 by declaring, with respect to the assignor, that it refuses such liberation. In that case, the assigned party may require the assignor to perform in case the assignee fails to fulfil the duties assumed.

(2) The declaration may be made within fifteen days from the date on which the assigned party became or must have become aware that the assignee failed to perform. Although a declaration made late does not eliminate its effects under Subsection (1), the assigned party shall compensate any damage caused by the default.

\section{Section 1900 [Recodification]}

The assigned party shall also retain all the contractual defences against the assignee. The assigned party shall retain other defences which it had against the assignor if such retention is reserved in the contract or in the consent to the assignment of the contract.

\section{Division 2}

\section{Changes in the contents of obligations}

Section 1901

The parties are free to stipulate a change in their rights and duties.

Section 1902

\section{Novation}

An agreement to change the contents of an obligation extinguishes the existing obligation and replaces it with a new one. However, if an existing obligation may co-exist in parallel with the new obligation, it is presumed not to have been extinguished.

\section{Settlement}

\section{Section 1903}

(1) An existing obligation may also be replaced with a new one in such a way that the parties, by a stipulation, change their rights and duties which have so far been contentious or doubtful between them. In the case of a settlement of a right in rem registered in a public register, the settlement becomes effective upon the registration in that register. the parties.

(2) A settlement may not be challenged only because it created a disproportion between the mutual performances of

\section{Section 1904 [Recodification]}

The validity of a settlement shall remain unaffected by an error in what was contentious or doubtful between the parties, unless a party employed trickery to cause the error. A settlement agreed in good faith shall remain valid even after subsequently disclosed facts show that one of the parties lacked a claim.

\section{Section 1905}

A settlement which is to govern all the rights between the parties may not be applied to rights which were excluded or to any rights which the parties cannot have evidently envisaged.

\section{Common provisions}

Section 1906

A stipulation on novation or settlement must be in writing if the original obligation was created in writing or where it is made with respect to a right which has already become time-barred.

\section{Section 1907}

Security for the rights which are subject to novation or settlement also apply to the rights arising therefrom. However, if security has been provided by a third person which did not accede to the novation or settlement, such a third person is not obliged beyond the original obligation and retains all the defences which the person could have asserted against the claim had the novation or settlement not taken place. 


\section{Chapter 7}

\section{Extinction of obligations}

\section{Division 1}

Discharge

\section{General provisions}

Section 1908 [Recodification]

(1) Discharge of the debt extinguishes the obligation.

(2) A debtor must discharge the debt at his own expense and risk, properly and in due time.

\section{Section 1909 [Recodification]}

If a debtor used, in accordance with a contract, a promissory note as a means of payment, the issuance of the promissory note has no effect on the duration of a pecuniary debt, but the creditor may require that the debtor perform the debt only if he could not achieve discharge of the debt from the promissory note; however, if the creditor achieved the discharge of the debt, the debt is considered discharged already upon the issuance of the promissory note. This also applies where a letter of credit has been opened, a check issued or in other similar cases.

\section{Section 1910 [Recodification]}

A creditor may not be forced to accept against his will something other than what pertains to his claim, and a debtor may not be forced to provide against his will something other than what he owes. The same applies to the place, time and manner of discharge.

\section{Section 1911 [Recodification]}

Where the parties are to mutually perform at the same time, a discharge may only be required by the party which has already discharged the debt, or is willing and able to discharge the debt simultaneously with the other party.

\section{Section 1912 [Recodification]}

(1) A person who is to perform in advance in case of a mutual performance may withhold such a performance until the mutual performance is provided or ensured to him, but only if the performance of the other party is jeopardised by circumstances which occurred in respect of the other party of which he was not and should not have been aware at the conclusion of the contract.

(2) In the case under Subsection (1), an appropriate additional time limit for the discharge of the debt or ensuring the performance may also be provided, and it is possible to withdraw from the contract upon the expiry of the additional time limit within which the debt is not discharged or performance ensured.

\section{Section 1913 [Recodification]}

A party may not withhold a performance or withdraw from the contract because the other party's debt arising from another legal cause was not discharged properly and in due time.

\section{Proper performance}

\section{Section 1914 [Recodification]}

(1) A person who performs for consideration to another is obliged to perform without defects, in conformity with the reserved or usual properties so that the subject of the performance can be used in accordance with the contract, and also in accordance with the purpose of the contract, if known to the parties.

(2) If a debt is discharged defectively, the recipient has rights arising from a defective performance.

\section{Section 1915 [Recodification]}

A debtor is obliged to provide performance of a medium quality, unless the parties have stipulated different quality.

\section{Section 1916 [Recodification]}

(1) Cases in which a debtor provides a defective performance include, but are not limited, to those where he:

a) provides the subject of performance lacking the determined or stipulated properties,

b) fails to notify the defects of the subject of performance, although the subject usually lacks such defects,

c) falsely assures the creditor that the subject of performance has no defect, or that the thing is fit for a particular use, or 
d) unlawfully alienates a thing of another as his own.

(2) An expression of will whereby a transferor limits in advance the scope of his statutory liability for a defective performance is disregarded. If an acquirer waives his right from a defective performance in advance, a written form for such an expression of will is required.

\section{Section 1917 [Recodification]}

If a defect is obvious and already evident at the conclusion of the contract, or if a defect can be ascertained from a public register, the acquirer is liable for the defect. This does not apply if the transferor employed trickery to conceal the defect or expressly assured him that the thing is free from that defect or from any defects.

\section{Section 1918 [Recodification]}

If a thing is relinquished "as is" (caveat emptor), its defects are borne by the acquirer. This does not apply if the thing lacks a property declared by the transferor or contractually reserved by the acquirer.

\section{Section 1919 [Recodification]}

(1) If a transferor assumes quality guarantee, he guarantees that the subject of performance will be, for a definite period after the discharge, fit for use for the stipulated purpose and that it will retain the stipulated properties; where no properties have been stipulated, the guarantee applies to the usual purpose and properties.

(2) If a guarantee is not stipulated in a contract, the transferor may assume it by a declaration in the guarantee statement or by indicating the guarantee period or its "use by" or "best before" dates on the packaging. If a contract stipulates a guarantee period different from that indicated on the packaging, the stipulated guarantee period applies. If a guarantee statement specifies a guarantee period longer than the period which is stipulated or indicated on the packaging, the longer guarantee period applies.

\section{Section 1920 [Recodification]}

(1) The subject of performance has a legal defect if a third person asserts its right thereto, unless the acquirer knew or must have known of such a restriction. In such a case, the acquirer shall, without undue delay, inform the transferor accordingly.

(2) A person who has transferred to himself a right to a thing of which he knows that it does not belong to the transferor or that the transferor is not entitled to create such a right, he shall acquire no right from such a defect.

\section{Section 1921 [Recodification]}

(1) An acquirer may assert his right from a defective performance in court if he claimed the defect towards the transferor without undue delay after he had the opportunity to inspect the thing and discover the defect, either by identifying the defect or notifying the manner in which it manifests itself. A defect may be claimed within six months from the takeover of the subject of performance.

(2) An acquirer must claim a defect covered under a guarantee towards the transferor without undue delay after he had the opportunity to inspect the subject of performance and discover the defect, but no later than within the time limit for making a claim defined by the guarantee period. This does not affect Subsection (1).

(3) Where the acquirer fails to claim a defect in time and the transferor invokes a delay in making the claim, a court shall not grant the acquirer the right. This does not apply if the defect occurred as a result of a fact of which the transferor knew or must have known upon handover.

\section{Section 1922 [Recodification]}

(1) Once an acquirer discovers a defect, he shall, without undue delay, notify and hand over the subject of performance to the transferor or deposit it according to the transferor's instructions, or otherwise handle it appropriately so that the defect can be reviewed. In the case of an item subject to rapid decay, an acquirer may sell the item without delay after notifying the transferor.

(2) If an acquirer lawfully claims a defect towards the transferor, the time limit for asserting the right from a defective performance or the guarantee period is suspended for the time during which the acquirer cannot use the defective thing.

\section{Section 1923 [Recodification]}

If a defect can be removed, an acquirer may demand either a repair or supplementing what is missing, or a reasonable price reduction. If a defect cannot be removed and prevents the proper use of the subject, the acquirer may either withdraw from the contract or demand a reasonable price reduction.

\section{Section 1924 [Recodification]}

A person having the right under Section 1923 is also entitled to reimbursement of the costs reasonably incurred in asserting this right. However, if he fails to assert the right to compensation within one month after the time limit for claiming the defect has expired, a court shall not grant that right if the transferor invokes late assertion of the right to compensation. 
A right from a defective performance does not exclude the right to compensation for damage; however, what can be achieved by asserting the right from a defective performance may not be claimed for any other legal cause.

\section{Manner of performance}

Section 1926 [Recodification]

(1) If a debt can be discharged in several manners, the choice of the manner of performance is presumed to lie with the debtor. If the right to choose lies with the creditor, he must choose the manner of performance within the stipulated period, or otherwise without undue delay so that the debtor can discharge the debt in accordance with the creditor's choice.

(2) If a party fails to make the choice in time, the right to choose the manner of performance is permanently acquired by the other party.

(3) A person who chose the manner of performance may not change it without the consent of the other party.

$$
\text { Section } 1927 \text { [Recodification] }
$$

(1) If a debtor is to provide one of several performances left to his choice, he is not entitled to provide part of one and part of another performance, and may not even be forced to do so.

(2) If one of several performances left to his choice become impossible, the obligation is restricted to the remaining performances. However, if the person who did not have the right to choose caused the impossibility, the other party may withdraw from the contract.

\section{Section 1928 [Recodification]}

The person who had the right to choose may withdraw from the contract if the choice was frustrated by force majeure or by the other party.

\section{Section 1929 [Recodification]}

If a debtor is to perform a thing determined by kind, he is obliged to provide the creditor with a thing which is suitable for the purpose for which things of the same kind are usually used under similar contracts.

$$
\text { Section } 1930 \text { [Recodification] }
$$

(1) A debt is to be performed in its entirety.

(2) If a debtor offers a partial performance, the creditor must accept it unless it is contrary to the nature of the obligation or the purpose of the contract, provided that the purpose must have been at least obvious to the debtor. The creditor shall thus incur no other duties. The debtor shall reimburse the creditor for any increased costs which he incurred due to a partial performance.

\section{Section 1931 [Recodification]}

If a performance in instalments has been stipulated and the debtor has failed to perform any of the instalments, the creditor has the right to have the entire claim discharged where the parties have so stipulated. A creditor may assert this right no later than when the next instalment becomes due.

\section{Section 1932 [Recodification]}

(1) Where a debtor is to perform in respect of the principal, interest and costs associated with asserting a claim, the performance is first imputed to costs that have already been determined, then default interest, then the interest and finally the principal, unless the debtor expresses different will when performing. the interest.

(2) If a debtor determines that he will first perform in respect of the principal, interest accrues on both the costs and

$$
\text { Section } 1933 \text { [Recodification] }
$$

(1) If a debtor is obliged to provide a performance of the same kind under several obligations and, in doing so, fails to determine the debt in respect of which his performance is provided, the performance is first imputed to the obligation the discharge of which has already been reminded to the debtor by the creditor, and otherwise against the least secured obligation. In case several obligations have the same level of security, the performance is first imputed to the obligation which is due first.

(2) Payments are imputed against any compensation for damage only after having discharged the obligation the breach of which resulted in the duty to provide such compensation for damage, unless otherwise determined by the debtor.

\section{Section 1934 [Recodification]}

If a debtor lacking full legal capacity has discharged his debt due, he is released from the obligation. However, if he performed against a debt which was not certain or due, it may be requested that the performance be returned to him; this does not apply if the debt has become due in the meantime. 


\section{Section 1935 [Recodification]}

If a debtor performs through another person, the debtor is liable in the same way as if he performed himself.

\section{Section 1936 [Recodification]}

(1) A creditor must accept a performance offered to him by a third person with the consent of the debtor. This does not apply if the performance is tied to the personal characteristics of the debtor.

(2) A person who performs a debt of another without being liable as a surety or providing any other security for such a debt may, before or upon the discharge of the debt, require that the creditor assign his claim to him.

\section{Section 1937 [Recodification]}

(1) The debtor's consent is not required if a third person performs his debt to the creditor because the third person is liable for the obligation as a surety or otherwise secures the debt.

(2) Upon the discharge of the debt, the third person enters into the creditor's rights and has the right to be reimbursed by the debtor for what the third person performed on behalf of the debtor. The creditor's claim passes to the third person including accessories, security and other rights associated with the claim. (2) The creditor shall surrender to the person who has performed for the debtor the necessary documents concerning the claim and inform him of everything that is required to assert the claim.

\section{Section 1938 [Recodification]}

(1) Where a third person performs only a part of a debt instead of a debtor, the third person may only request the reimbursement of the part which the person performed instead of the debtor. The original creditor has the right to request the reimbursement of the remainder of his claim, enjoying priority to the new creditor, unless he has guaranteed in respect of the new creditor that the new creditor would be reimbursed for what the new creditor paid for the debtor.

(2) Where several persons perform for a debtor, each of them is entitled to be reimbursed in proportion to the share in which he performed for the debtor.

\section{Voucher}

\section{Section 1939}

(1) A voucher entitles a voucher payee to collect, in his own name, a performance from a voucher payer, and the voucher obliges the voucher payer to perform to the voucher payee on the account of the voucher issuer. A voucher payee shall acquire a direct right against the voucher payer only if the voucher payer accepts the voucher.

(2) A voucher may also be issued as a voucher to order or a bearer voucher.

\section{Section 1940}

In the absence of another legal cause between the voucher issuer and the voucher payer, the rights and duties of each of them are governed by the provisions on contracts of mandate; however, a voucher is not extinguished upon the death of the voucher issuer or the voucher payer.

\section{Section 1941}

A voucher payee shall, without undue delay, notify the voucher issuer of the former's unwillingness to use the voucher or of the refusal of the voucher payer to accept or perform according to the voucher.

\section{Section 1942}

Until a voucher payer has accepted a voucher with respect to the voucher payee, the voucher issuer may revoke it. Whether or not the revocation of the voucher is also effective with respect to the voucher payee shall depend on the legal relationship between the voucher issuer and the voucher payee.

\section{Section 1943}

A voucher payer who has accepted a voucher may only assert those defences against the voucher payee which concern the validity of acceptance, invalidity of the voucher or its defects, or defences which are based on an express provision of the voucher or those which the voucher payer is entitled to assert against the voucher payee personally.

\section{Section 1944}

(1) If a voucher payer already owes the voucher issuer the performance which he is to provide to him, he is obliged to grant the voucher and his debt is extinguished only upon its discharge in favour of the voucher payee. If a voucher is to be used to discharge a voucher issuer's debt owed to a consenting voucher payee, the voucher payee is obliged to request the voucher payer to perform.

(2) The voucher payer is obliged to perform only against the issuance of an acquitted voucher. 
If, in the relationship between a voucher issuer and voucher payee, a limitation period with regard to an obligation whose performance constitutes the subject of the voucher commenced before the moment when notice of the acceptance of the voucher reached the voucher payee, the limitation period in the relationship between the voucher payer and voucher payee commences at that moment.

\section{Section 1946}

\section{Voucher to order}

(1) If a voucher is issued to order, it may be transferred by endorsement.

(2) Upon endorsement, all the rights arising from a voucher pass to the person entitled under the endorsement.

(3) The elements of an endorsement, as well as the persons entitled thereunder and the manner in which they demonstrate their right, are governed by legal regulations on promissory notes. They are also relied on when considering the person who may be required to provide the voucher to a person who has lost it.

\section{Section 1947}

\section{Bearer voucher}

If a voucher has been issued as a bearer voucher, the voucher payer shall pay the debt to anyone who submits the voucher to him.

\section{Section 1948}

The provisions on vouchers to order and bearer vouchers apply by analogy to the cases of a transfer of a claim confirmed by an instrument issued by a debtor as an instrument to order or a bearer instrument.

\section{Acquittance}

\section{Section 1949 [Recodification]}

(1) If a creditor receives a performance, he shall provide the debtor, at his request, with a confirmation that the debt has been discharged (an acquittance). The acquittance shall indicate the name of the debtor and creditor, the subject of performance and the place and time of discharge of the debt. If an acquittance has been issued in respect of a principal, the accessories of the claim are presumed to also have been paid.

(2) A debtor may withhold a performance if the creditor fails to simultaneously provide him with an acquittance.

\section{Section 1950 [Recodification]}

In the case of a recurrent performance for the same legal cause, the person who submits an acquittance concerning a performance with a later due date is presumed to also have discharged what was due before it.

\section{Section 1951}

A debtor also discharges a debt by discharging it with respect to a person who presents him with the creditor's confirmation entitling the person to accept the performance, or by presenting the debtor with an acquittance issued by the creditor, unless the debtor knew that the person who presented the confirmation was not entitled to accept the performance.

\section{Section 1952 [Recodification]}

\section{Debt instrument}

(1) A creditor who has a debtor's acknowledgment of debt or any other debt instrument must return it to the debtor upon the discharge of the debt or mark on the debt instrument that it has been discharged partially. If it is impossible, a debtor may require that the creditor issue to him a confirmation that the debt instrument has ceased to be valid to the extent to which the debt has been discharged. This does not affect the provisions on acquittance.

(2) If a debtor receives a debt instrument without an acquittance, the debt is presumed to have been discharged.

\section{Section 1953}

\section{Substitute discharge}

(1) If a debt cannot be discharged because the creditor is unknown or not present, or unreasonably refused to accept performance, because a debtor, without being at fault, lacks certainty about the identity of the creditor, or because of other important reasons on the part of the creditor, the debtor is entitled to place the subject of performance in judicial custody. Reasonably incurred costs associated with a substitute discharge are borne by the creditor.

(2) A court shall notify the placement of the subject of performance into judicial custody to the person in whose favour it took place, and if necessary, the court shall provide for his representation. 


\section{Place of performance}

\section{Section 1954}

A proper discharge requires that the debt be discharged at a determined place. If the place of performance cannot be ascertained from the contract, the nature of the obligation or the purpose of performance, the performance shall take place at a place provided by a statute.

\section{Section 1955 [Recodification]}

(1) A debtor performs a non-pecuniary debt at the place of his residence or registered office. A debtor shall perform a pecuniary debt at the place of residence or registered office of the creditor.

(2) If an obligation was created in the operation of an enterprise, a debt is performed at the place of the enterprise. This applies by analogy where an obligation was created in the operation of an establishment.

\section{Section 1956 [Recodification]}

If a performance is to be provided at the creditor's place and if the creditor, after concluding the contract, changes the place of residence or registered office, or location of the enterprise or establishment, the creditor bears the increased costs and increased risk incurred by the debtor.

\section{Section 1957}

(1) Where a debtor performs a pecuniary debt through a payment service provider, the debt is discharged when the amount of money is credited to the account of the creditor's payment service provider.

(2) Where a debtor performs a pecuniary debt through a postal order, the debt is discharged when:

a) the relevant amount is credited to the account kept by the creditor's financial institution if the debt is paid to an account, or

b) the amount of money is paid to the creditor in cash.

\section{Time of performance}

\section{Section 1958}

(1) If the time of performance has been exactly stipulated or otherwise determined, the debtor is obliged to perform even without being requested to do so by the creditor.

(2) If the parties do not stipulate the time when the debtor is to discharge a debt, the creditor may demand performance immediately and the debtor is then obliged to discharge the debt without undue delay.

\section{Section 1959 [Recodification]}

Unless established prior practice of the parties or usages indicate otherwise, the parties are presumed to have stipulated the time of performance by using the following expressions:

a) "the beginning of a period of time", which means within the first ten days of the period of time,

b) "middle of a month", which means within the period of time from the 10th to the 20th day of the given month,

c) "middle of a quarter", which means in the second month of the quarter,

d) "the end of a period of time", which means within the last ten days of the period of time,

e) "immediately", which means a period of up to five days, or a period of up to two days in the case of supply of foodstuffs or raw materials, or a period of up to ten days in the case of supply of engineering products.

\section{Section 1960}

If a contract entitles a debtor to determine the time of performance and he fails to do so within a reasonable period, the time of performance is to be determined by a court on the application of the creditor according to the circumstances of the case.

\section{Section 1961}

If the parties do not stipulate whether the time of performance is determined in favour of both or only one of them, it is conclusively presumed to have been stipulated in favour of both parties. This does not apply if excluded by the nature of the performance.

\section{Section 1962 [Recodification]}

(1) If the time of performance is in favour of both parties, the creditor may not require that the performance be provided early, and the debtor may not perform the debt early. 
(2) If the time of performance is in favour of the debtor, the creditor may not require that performance be provided early, but the debtor may discharge the debt early.

(3) If the time of performance is determined in favour of the creditor, he may require that performance be provided early, but the debtor may not discharge the debt early.

Section 1963 [Recodification]

(1) If a mutual obligation between entrepreneurs consists in a duty to supply goods or provide a service for consideration, the price is due, without the need for a request for payment, within thirty days from the date on which the debtor received an invoice or other request of a similar nature, or from the date of receipt of the goods or service, whichever occurs later. However, in case a takeover of goods or service or, where appropriate, verification of whether or not the debt was properly discharged has been stipulated, the price is due within thirty days from the date of takeover or, where appropriate, verification. This also applies to an obligation between an entrepreneur and a public corporation or, where appropriate, legal persons formed by such a corporation, even where they are not entrepreneurs.

(2) The parties may stipulate a due date exceeding sixty days only where it is not grossly unfair to the creditor. However, if an obligation between entrepreneurs consists in a duty to supply goods or a service to a public corporation, the parties may stipulate a later due date only if it is justified by the nature of the obligation; the due date may not exceed sixty days.

\section{Section 1964 [Recodification]}

(1) A party to a contract has the right to invoke ineffectiveness of a stipulation on the time of performance which derogates from the provisions of Section 1963 or a provision which derogates from the statutory default interest rate if such stipulations are grossly unfair to the creditor.

(2) A legal person formed to protect the interests of small and medium-sized entrepreneurs is also entitled to invoke ineffectiveness under the conditions provided under Subsection (1) if these stipulations are contained in the standard commercial terms.

(3) If a court declares a stipulation to be ineffective, statutory provisions are used in its place unless a court decides otherwise in the interest of a fair solution.

\section{Section 1965 [Recodification]}

If entrepreneurs stipulate a takeover of goods or a service or, where appropriate, verification whether the debt has been properly discharged, the period of such takeover or, where appropriate, verification shall not exceed thirty days. The time of takeover or verification may exceed thirty days only where it is not grossly unfair to the creditor.

\section{Section 1966 [Recodification]}

The provision of Section 1963 does not affect the right of the parties to stipulate a performance in instalments

$$
\text { Section } 1967 \text { [Recodification] }
$$

Where a debtor performs a pecuniary debt earlier than agreed, he is not entitled, without the consent of the creditor, to deduct from the outstanding amount the interest which would have accrued during the period from the early performance until the agreed time.

\section{Debtor's default}

\section{Section 1968}

A debtor who fails to perform his debt properly and in due time is in default. A debtor is not liable for the default if he cannot perform due to the creditor's default.

\section{Section 1969}

A creditor may enforce the discharge of the debt from the debtor in default or may withdraw from the contract under the conditions stipulated in the contract or provided by a statute.

\section{Section 1970 [Recodification]}

A creditor who has properly fulfilled his contractual and statutory duties may require that a debtor who is in default of payments of a pecuniary debt pay default interest, unless the debtor is not liable for the default. The rate of default interest is determined by a government decree; if the parties do not stipulate the amount of default interest, the rate thus determined is considered to be the one stipulated.

\section{Section 197}

A creditor is entitled to compensation for damage incurred as a result of the failure to discharge a pecuniary debt only if it is not covered by default interest. 
(1) A creditor has the right to invoke ineffectiveness of a provision on default interest which, without a just cause, derogates from a statute in a way that, having regard to all the circumstances and conditions of the case, deteriorates his position. If a court declares the stipulation to be ineffective, statutory provisions are used in its place unless otherwise decided by a court in the interest of a fair solution.

(2) A legal person formed to protect the interests of small and medium-sized entrepreneurs is also entitled to invoke ineffectiveness of standard commercial terms to the extent contrary to Subsection (1).

\section{Section 1973}

In the case where the creditor and the debtor agree that an debt already due will be paid in instalments and the creditor wishes that the debtor also pay the default interest in the same way, it must be expressly agreed.

\section{Section 1974}

A debtor bears the risk of damage to the thing incurred for whatever reason for the duration of his default, unless he proves that the damage would have also been incurred had he properly fulfilled his duty, or that the damage was caused by the creditor or owner of the thing. This also applies if the debtor disposes of the thing in contradiction to his other duties under the obligation.

\section{Creditor's default}

Section 1975

A creditor is in default if he fails to accept a properly offered performance or fails to provide the debtor with the assistance necessary to discharge the debt.

\section{Section 1976}

If the subject of performance is a thing, a creditor bears the risk of damage to the thing incurred for whatever reason for the duration of his default. This does not apply if the damage is caused by the debtor.

\section{Common provisions}

\section{Section 1977 [Recodification]}

If, by its default, a party fundamentally breaches its contractual duty, the other party may withdraw from the contract if it notifies the party in default accordingly without undue delay after learning of the default.

\section{Section 1978 [Recodification]}

(1) If a default of one of the parties constitutes a non-fundamental breach of its contractual duty, the other party may withdraw from the contract after the defaulting party fails to fulfil its duty even within a reasonable additional time limit expressly or implicitly provided by the other party.

(2) If a creditor notifies the debtor that he grants him an additional time limit to perform and that there will be no extension thereof, he is conclusively presumed to have withdrawn from the contract upon the expiry of the additional time limit within which the debtor fails to perform.

\section{Section 1979 [Recodification]}

If a creditor has provided a debtor with an unreasonably short additional time limit to perform and withdraws from the contract after the time limit expires, the withdrawal becomes effective only after the expiry of the reasonable additional period which should have been granted to the debtor within which the debtor fails to perform. This also applies if the creditor withdraws from the contract without providing the debtor with any additional time limit to perform.

\section{Section 1980 [Recodification]}

\section{Fixed obligation}

(1) If an exact time of performance has been stipulated in a contract, and the contract or the nature of the obligation indicate that the creditor can have no interest in a delayed performance, the obligation is extinguished upon the beginning of the debtor's default, unless the creditor informs the debtor without undue delay that he insists on the execution of the contract.

(2) The extinction of an obligation produces the same effects as a withdrawal from the contract by a creditor.

\section{Division 2}

\section{Other manners of extinction of obligations}

Section 1981

\section{Agreement}

The parties are free to stipulate the extinction of an obligation without creating a new one. 


\section{Section 1982 [Recodification]}

(1) If parties owe to each other performance of the same kind, each of them may declare with respect to the other party that it sets off its claim against the claim of the other party. A claim may be set off once a party becomes entitled to demand satisfaction of its own claim and perform its own debt.

(2) By a set-off, both claims become extinguished to the extent to which they cover each other; if they do not cover each other entirely, a claim is set off in a manner similar to discharge. These effects occur at the time when both claims become eligible for set-off.

\section{Section 1983 [Recodification]}

A declaration on conditional set-off or a set-off with determination of time is disregarded.

\section{Section 1984 [Recodification]}

(1) If a debtor owes jointly and severally with others, he may set off a claim of his co-debtor against the creditor only to the extent of the co-debtor's share in the joint debt.

(2) A debtor who is obliged with respect to creditors who are entitled jointly and severally may set off against any of the co-creditors what the co-creditor owes to him only to the extent of the co-creditor's share in the joint claim.

\section{Section 1985}

A person who maintains an account for the other party may set off the funds deposited in such an account against a mutual claim arising from the account contract.

\section{Section 1986}

If a claim has been consecutively transferred to several persons, a debtor may only set off a claim which he had against the first creditor at the time of the transfer, and a claim which he has against the last creditor.

\section{Section 1987 [Recodification]}

(1) Claims eligible for set-off are those which can be asserted in court.

(2) An uncertain or indeterminate claim is not eligible for set-off.

\section{Section 1988 [Recodification]}

(1) A set-off against a claim for maintenance and support for a minor lacking full legal capacity is prohibited.

(2) A set-off against a claim for compensation for bodily harm, unless it is a mutual claim for compensation of the same kind, and against claims for wages, salary, remuneration from a contract to perform dependent work creating a similar obligation between an employee and an employer and against reimbursement for wages or salary in the amount exceeding their half, is prohibited.

\section{Section 1989 [Recodification]} for set-off.

(1) If a claim becomes time-barred, it does not prevent set-off if it became time-barred after the claim became eligible

(2) If, on the debtor's request, the creditor gratuitously postpones the time of performance, he may nevertheless set off his claim after the expiry of the original time when the debtor was to perform.

\section{Section 1990}

If each claim is to be satisfied at a different place, it shall not prevent it from being set off, but the party against whom the set-off was made is entitled to compensation for the damage the party incurred as a result of the inability to receive or provide performance at the stipulated location.

\section{Section 1991}

The prohibition to set off a claim by a declaration of one of the parties does not prevent the parties from stipulating a set-off; however, the stipulation on a set-off against a claim for maintenance and support for a minor lacking full legal capacity is disregarded. 
If the parties stipulate that one of them may extinguish the obligation by paying a withdrawal fee, the obligation is extinguished upon the payment of the withdrawal fee, analogously to a withdrawal from contract. However, the party which has, if only in part, accepted performance from or provided performance to the other party shall not have the right to extinguish the obligation by paying the withdrawal fee.

\section{Merger of a right and duty}

\section{Section 1993} a statute.

(1) If a right and duty merge in one person in any way, the right and duty is extinguished unless otherwise provided by extinguished.

(2) If a right of a creditor merges with a duty of a person who secures the obligation; the principal debt is not

$$
\text { Section } 1994 \text { [Recodification] }
$$

Upon the merger of a right of a creditor and a duty of one of the debtors who are obliged jointly and severally, the debt is extinguished to the extent of the share of the co-debtor. Upon the merger of a duty of a debtor and a right of one of the creditors who are entitled jointly and severally, the claim is extinguished to the extent of the share of the co-creditor.

\section{Waiver of a debt}

\section{Section 1995 [Recodification]}

(1) If a creditor waives a debt owed to him by a debtor, the debtor is presumed to consent to the waiver of the debt unless he, without undue delay, expresses his disagreement expressly or by performing the debt.

(2) A debt is waived even where a creditor issues an acquittance or returns a debt instrument to a debtor even if he has not discharged the debt; if the creditor issues an acquittance or returns a debt instrument covering the entire debt to one of the debtors, he is presumed to have waived the debt with respect to all the co-debtors.

\section{Section 1996 [Recodification]}

(1) If a creditor waives a debt owed to him by one of the debtors who are obliged jointly and severally, the waiver of debt has effects against other debtors to the extent of the share of the co-debtor who has been released from the obligation.

(2) If one of the creditors who are entitled jointly and severally waives a debt owed to him by a debtor, the debtor is relieved of the debt to the extent of the share of the co-creditor.

\section{Section 1997 [Recodification]}

If a creditor waives a duty owed to him by a person who secures a debt, the waiver has no effect against the principal debt. However, if a creditor releases one of the co-sureties from an obligation, the other co-sureties retain the defences which could have been asserted by the co-surety whose duty was waived.

\section{Termination of an obligation}

\section{Section 1998}

(1) A party may terminate an obligation if so stipulated by the parties or provided by a statute.

(2) If a party terminates an obligation, the obligation is extinguished upon the expiry of the notice period. However, if an obligation may be terminated without a notice period, the obligation is extinguished on the effective date of the notice of termination.

\section{Section 1999}

(1) If a contract concluded for an indefinite period obliges at least one party to perform a continuous or recurrent activity, or obliges at least one party to tolerate such an activity, the obligation may be extinguished by the end of a calendar quarter by at least three months' notice of termination.

(2) If a party has agreed to refrain from a certain activity and the nature of the obligation clearly shows that the duty is not limited in time, the provision of Subsection (1) does not apply.

\section{Section 2000 [Recodification]}

(1) If a contract has been concluded for a definite period without a serious reason in a way that it obliges an individual for his entire life, or obliges anyone for more than ten years, extinction of the obligation may be claimed after ten years from its creation. A court shall also extinguish an obligation if the circumstances on which the parties apparently relied when the obligation was created have changed to such an extent that the obligor cannot be reasonably required to be further bound by the contract.

(2) If a party waives its right to claim extinction of an obligation in advance, it is disregarded. This does not apply if a 
legal person is the obligor.

\section{Withdrawal from contract}

Section 2001 [Recodification]

A party may withdraw from a contract if so stipulated by the parties or provided by a statute.

\section{Section 2002 [Recodification]}

(1) If a party fundamentally breaches a contract, the other party may withdraw from the contract without undue delay. A fundamental breach means such a breach of which the breaching party, at the conclusion of the contract, knew or should have known that the other party would not have concluded the contract had it foreseen such a breach; in other cases, a breach is presumed not to be of a fundamental nature.

(2) A party may withdraw from a contract without undue delay after the conduct of the other party undoubtedly indicates that the party is about to commit a fundamental breach of contract and fails to provide a reasonable security after being requested to do so by the obligee.

\section{Section 2003 [Recodification]}

(1) Once the party entitled to withdraw from a contract notifies the other party of its intention to withdraw from or to insist on the contract, it may no longer change its choice on its own.

(2) If a party became entitled to withdraw from a contract due to a fundamental breach of a contractual duty but did not exercise the right, it is not prevented from withdrawing from the contract at a later point with reference to similar conduct of the other party.

\section{Section 2004 [Recodification]}

(1) Upon withdrawal from the contract, the obligation is extinguished from the beginning.

(2) If a debtor provides a partial performance, the creditor may withdraw from the contract only in respect of the nondischarged part of the performance. However, if a partial performance is irrelevant for the creditor, the creditor may withdraw from the contract in respect of the whole performance.

(3) If a contract obliges a debtor to provide continuous or recurrent activities or provide a progressive partial performance, the creditor may withdraw from the contract only with effect from that moment onward. This does not apply if partial performances which have already been accepted are no longer in itself relevant for the creditor.

\section{Section 2005 [Recodification]}

(1) Upon withdrawal from a contract, the rights and duties of the parties are extinguished to the extent of the withdrawal. This does not affect the rights of third persons acquired in good faith.

(2) Withdrawal from a contract does not affect the right to be paid a contractual penalty or default interest if already due, the right to be compensated for damage resulting from a breach of a contractual duty, or a stipulation which, given its nature, is to oblige the parties even after the withdrawal, including, but not limited to, a stipulation on the resolution of disputes. If a debt has been secured, the security shall also remain unaffected by the withdrawal from the contract.

\section{Subsequent impossibility of performance}

\section{Section 2006}

(1) If, after the creation of an obligation, a debt becomes impossible to be discharged, the obligation is extinguished due to impossibility of performance. A performance is not impossible if the debt can be discharged under more difficult conditions, at higher costs, with the help of another person or only after a determined period.

(2) The impossibility of a performance is proved by the debtor.

\section{Section 2007}

Where only part of a performance is impossible to be provided, the obligation is extinguished in full if the nature of the obligation or the purpose of the contract of which the parties were aware at the conclusion of the contract indicate that the performance of the rest is irrelevant for the creditor. Otherwise, the obligation is extinguished only to the extent of the affected part.

\section{Section 2008}

If a debtor fails to notify the creditor that the discharge of a debt has become impossible without undue delay after he became or must have become aware thereof, he shall compensate the creditor for the damage incurred as a result of the creditor not having been made aware of the impossibility of performance in due time. 
(1) A debtor's duty is not extinguished upon his death, unless it consisted in a performance which was to be provided by the debtor personally.

(2) A creditor's right is extinguished upon his death if the performance was to be provided only to him personally.

\section{Chapter 8}

\section{Securing and corroboration of debts}

\section{Division 1}

\section{General provisions}

Section 2010 [Recodification]

(1) A debt can be secured if a third person binds himself towards the creditor or for the benefit of the creditor for a debtor's performance, or if someone provides a creditor or for the benefit of a creditor a proprietary security for the discharge of a debt by the debtor. A debt can be corroborated by stipulating a contractual penalty or by acknowledging the debt.

(2) If a security is administered by another person for the benefit of the creditor, that person may assert the same rights and fulfil the same duties with respect to the debtor or the provider of security as the creditor.

\section{Section 2011 [Recodification]}

The creditor shall inform the person who provided the security of the amount of the secured debt, at his request, at any time and without undue delay.

\section{Security}

\section{Section 2012 [Recodification]}

(1) A person who is required to provide security shall fulfil his duty by creating a pledge.

(2) A person who is unable to provide security by creating a pledge shall provide it through an eligible surety. A person who may be sued in the Czech Republic and who has sufficient property is presumed to be an eligible surety.

\section{Section 2013 [Recodification]}

No one is obliged to accept a thing as security for an amount exceeding two thirds of its usual price.

\section{Section 2014 [Recodification]}

(1) A plot of construction tract of land or immovable thing which serves business purposes is presumed to constitute sufficient security up to half of its usual price. The right of superfices is presumed to constitute sufficient security up to half of its usual price if the consideration stipulated as the superficies payment is to be paid off no later than five years before the extinction of the right of superficies.

price.

(2) Securities providing a safe yield are presumed to constitute sufficient security up to three quarters of their usual insured.

(3) Deposits in banks or savings and loan co-operatives constitute eligible security up to the amount to which they are

\section{Section 2015 [Recodification]}

(1) A security secures the interest on pecuniary debt up to the statutory interest rate; this does not apply if the person providing the security was made aware of the interest stipulated between the creditor and the debtor before the security was provided. accrued.

(2) If a security is provided for a debt which already bears interest, the security also covers the interest not yet

\section{Section 2016 [Recodification]}

If a security provided to several creditors is based on different rights to the same thing, satisfaction is consecutively provided, to the extent of such rights and in the order based on the creation of the security, to the creditors secured by a right in rem registered in a public register or pledge registry in the first group, and to creditors secured by a right in rem not registered in a public register or pledge registry in the second group. Then, in the third group, satisfaction is provided to creditors secured by a right arising from an obligation.

Section 2017

(1) If a security loses its value so that securing becomes insufficient, the creditor is entitled to require that the debtor 
appropriately supplement the security without undue delay; if the debtor fails to do so, the unsecured part of the claim becomes due.

(2) The provision of Subsection (1) does apply where the security has been lawfully used.

\section{Division 2}

\section{Security of a debt}

\section{Suretyship}

\section{Section 2018 [Recodification]}

(1) A person who declares in relation to a creditor that he will satisfy him if the creditor's debtor fails to discharge his debt becomes the creditor's surety. A creditor who does not accept a surety may require nothing from him.

(2) A suretyship declaration must be in writing.

\section{Section 2019 [Recodification]}

(1) Suretyship is contingent on the debtor's debt being valid; suretyship may also be provided for future or conditional debts, as well as for a set of certain kind of debts incurred by the debtor at a particular time or a set of various debts arising from the same legal cause.

(2) The validity of suretyship is not prevented by the fact that a debtor's obligation is invalid due to the debtor's lack of capacity to assume duties, provided that the surety had or must have had such knowledge upon the assumption of the obligation arising from suretyship.

\section{Section 2020}

If suretyship secures only part of a debt, the scope of the suretyship is not reduced by partial performance as long as the debt is not discharged to the extent to which it is secured by the suretyship.

\section{Section 2021 [Recodification]}

(1) A creditor has the right to require the surety to discharge the debt if the debtor fails to discharge it within a reasonable time limit despite having been requested to do so by the creditor in writing. A request is not necessary where the creditor is unable to make it or where it is beyond doubt that the debtor will not discharge the debt.

(2) If suretyship has been stipulated for a definite period, the creditor also retains the right if the creditor requested the surety to perform within that period.

\section{Section 2022}

A surety may withhold a performance if the creditor is at fault for preventing the debtor from satisfying the claim.

\section{Section 2023}

(1) A surety may assert against the creditor all the defences which the debtor has against the creditor.

(2) If a surety asserts the defences communicated to him by the debtor, the debtor shall reimburse the surety for the costs incurred if the defences were unsuccessful.

\section{Section 2024}

If a surety satisfies the creditor without the knowledge of the debtor, the debtor may assert against the surety all the defences that he would have been entitled to assert against the creditor had the creditor enforced the discharge of the debt by the debtor. However, a debtor may not assert against the surety a defence of which the debtor failed to notify the surety without undue delay after the surety informed him that the creditor had asserted his right arising from suretyship.

\section{Section 2025}

(1) The right of the creditor against the surety does not become time-barred before his right against the debtor becomes time-barred.

(2) An acknowledgement of debt by a debtor is effective against a surety with the surety's consent.

Section 2026

(1) Suretyship is extinguished upon the extinction of the debt it secures.

(2) However, suretyship is not extinguished if the debt has been extinguished because the debtor could not discharge it and the surety can discharge it, or because the legal person constituting the debtor terminates. 
If the same debt is secured by several sureties, each of them is liable as a surety for the entire debt in respect of the creditor. A surety has the same rights with respect to the other sureties as a co-debtor.

\section{Section 2028}

A statutory suretyship for a non-pecuniary debt secures a pecuniary claim to which a creditor is entitled in case of a breach of the secured debt.

\section{Financial guaranty}

Section 2029 [Recodification]

(1) A financial guaranty is created by a declaration of an issuer in a guaranty instrument that he will satisfy the creditor according to the guaranty instrument up to a certain pecuniary amount if a debtor fails to discharge a certain debt to the creditor or if other conditions specified in the guaranty instrument are met. If the issuer is a bank, a foreign bank or a savings and loan co-operative, it is a bank guaranty.

(2) A guaranty instrument must be in writing.

Section 2030 [Recodification]

When securing a non-pecuniary claim, a pecuniary claim to which a creditor is entitled in the case of a breach of a secured duty to perform is presumed to be secured up to the amount determined by a guaranty instrument.

\section{Section 2031 [Recodification]}

(1) If a financial guaranty is confirmed by another issuer, a creditor may assert the right arising from the financial guaranty against any of these issuers.

(2) An issuer which confirmed a financial guaranty and performed in its capacity as a confirming person is entitled to reimbursement from the issuer which requested that it confirm the financial guaranty.

\section{Section 2032 [Recodification]}

If an issuer has provided a financial guaranty at the request of another issuer, the issuer which has provided the guaranty is entitled to reimbursement by the requesting issuer if the former performed the guaranty provided and met the conditions specified in the request.

\section{Section 2033 [Recodification]}

If an issuer notifies another person that another issuer provided a financial guaranty, the notifying issuer incurs no duty therefrom; however, if he causes damage by improper notification, he compensate the damage.

\section{Section 2034 [Recodification]}

(1) An issuer is liable as a surety for the discharge of a secured debt up to the amount and under the conditions specified in the guaranty instrument. An issuer may only assert against a creditor the defences which are allowed by the guaranty instrument.

(2) If a financial guaranty secures the discharge of a debt, a partial performance of the debt has no effect on the scope of the financial guaranty if the amount of the non-performed debt is at least equal to the amount specified on the guaranty instrument.

\section{Section 2035 [Recodification]}

(1) If the conditions specified in the guaranty instrument are met, the issuer shall fulfil the duty arising from the financial guaranty if so requested by the creditor in writing. If a guaranty instrument makes the issuer's performance conditional on the submission of a particular document, such a document must be submitted upon request or without undue delay thereafter, but always during the term of the financial guaranty.

(2) Unless the guaranty instrument indicates otherwise, an issuer may not assert against the creditor the defences which a debtor would be entitled to assert against the creditor. A previous request by the creditor that the debtor discharge the debt is required if specified in the guaranty instrument.

\section{Section 2036 [Recodification]}

A creditor may assign the right to performance arising from a guaranty. If allowed by the guaranty instrument, a creditor may also assign the right to claim a financial guaranty; the right to the performance under the guaranty shall also pass upon such an assignment.

\section{Section 2037 [Recodification]}

If, under a guaranty instrument, an issuer is obliged to perform in favour of an obligee to another issuer, he is obliged to perform to the account of the obligee maintained by that issuer. 
A financial guaranty may be limited to a definite period. If a creditor fails to assert his right with respect to an issuer within the time specified in the guaranty instrument, the financial guaranty is extinguished.

Section 2039 [Recodification]

(1) A debtor shall reimburse the issuer for what he performed under the guaranty instrument issued in accordance with the concluded contract. If a third person and an issuer conclude a contract for the provision of a financial guaranty, the third person shall reimburse the issuer for the performance provided by the third person under the guaranty instrument issued in accordance with the contract.

(2) A debtor may not assert against the issuer the defences which he could assert against the creditor unless the creditor and the debtor have stipulated that the issuer will reserve the assertion of such defences against the creditor in the guaranty instrument.

\section{Transfer of a right as security}

\section{Section 2040 [Recodification]}

(1) By a contract for a transfer of right as security, a debtor or a third person secures a debt by temporarily transferring his right to a creditor. discharged.

(2) A transfer of right as security is presumed to be a transfer with a resolutive condition that the debt will be

$$
\text { Section } 2041 \text { [Recodification] }
$$

If a transfer of right as security concerns a thing registered in a public register, the security is created upon the registration in this register; the temporary nature of a transfer of right as security is also registered in a public register.

\section{Section 2042 [Recodification]}

If the right of ownership is transferred as security and the thing was handed over to the creditor, the creditor is entitled to keep it by him for the duration of the transfer of right as security and shall perform simple administration of the thing. If the thing is in the control of the person who created the security for the creditor by transferring the right as security, the person shall carry out the simple administration of the thing.

\section{Section 2043 [Recodification]}

If the cause for the existence of a transfer of right as security is extinguished, the creditor shall allow the person who provided the security to exercise the right in its original scope. At the same time, the creditor shall surrender to the person everything which he acquired from the transferred right or which was added to it in return for reimbursement of costs reasonably incurred in connection with the exercise of the transfer of right as security.

\section{Section 2044 [Recodification]}

(1) If a secured debt has not been discharged, the transfer of right as security becomes unconditional and the debtor shall hand over to the creditor everything which is necessary for the full exercise of the transferred right.

(2) If the usual price of a security evidently exceeds the amount of secured debt, the creditor shall pay the person who provided the security an amount equal to the difference; in doing so, the creditor shall include the costs reasonably incurred in connection with the exercise of the transfer of right as security. If the contract for the transfer of right as security does not specify the amount of debt and a reliable valuation of the right transferred as security, the creditor is required to prove that the usual value of the security evidently does not exceed the amount of the secured debt.

\section{Agreement on deductions from wages or other income}

\section{Section 2045 [Recodification]}

(1) A debt may also be secured by an agreement between the creditor and the debtor on deductions from wages or salary, from remuneration under a contract to perform dependent work creating a similar obligation between an employee and an employer, or from reimbursement of wages or salary, in each case not exceeding half the amount of each of the above. Except for the deductions under the first sentence to satisfy the rights of an employer, the prior consent of the employer is required to conclude the agreement.

(2) A creditor acquires the right to the payment of the deductions from the payer of wages or salary once the agreement has been submitted to the payer.

$$
\text { Section } 2046 \text { [Recodification] }
$$

The costs associated with the payment of deductions are borne by the payer of wages or salary; however, if the payer of wages or salary is to perform simultaneously under several agreements for deductions from wages or salary, the costs of paying the deductions under the second and subsequent agreements are borne by the debtor. 
The provisions of Sections 2045 and 2046 also apply to other income, which is treated as wages or salary in enforcement procedure.

\section{Division 3}

\section{Corroboration of a debt}

\section{Contractual penalty}

Section 2048 [Recodification]

If, for the event of a breach of a contractual duty, the parties stipulate a contractual penalty in a particular amount or a manner to determine the amount, a creditor may claim the contractual penalty without regard to whether or not he actually incurred damage by a breach of the corroborated duty confirmed. The contractual penalty may be stipulated in a form other than pecuniary performance.

Section 2049 [Recodification]

Payment of a contractual penalty does not relieve the debtor of the duty to discharge the debt corroborated by the contractual penalty.

Section 2050 [Recodification]

If a contractual penalty has been stipulated, the creditor is not entitled to compensation for damage resulting from the breach of the duty which is subject to the contractual penalty.

\section{Section 2051 [Recodification]}

A court may reduce an excessively high amount of contractual penalty on the application of the debtor, having regard to the value and relevance of the secured duty; the amount may be reduced up to the amount of damage incurred before the decision as a result of the breach of the duty which is subject to the contractual penalty. If the aggrieved party later becomes entitled to compensation for damage, it is entitled to compensation for damage up to the amount of the contractual penalty.

\section{Section 2052}

The provisions on a contractual penalty also apply to a penalty provided by a legal regulation for a breach of contractual duty (penalty provided by a legal regulation).

\section{Acknowledgement of a debt}

Section 2053 [Recodification]

If a person acknowledges his debt in terms of its cause and amount by a declaration made in writing, the debt is presumed to exist to the extent and at the time it was acknowledged.

\section{Section 2054 [Recodification]}

(1) The payment of interest is considered to be an acknowledgement of the debt with respect to the amount on which the interest is paid.

(2) Where a debtor performs his debt partially, the partial performance has the effect of an acknowledgement of the rest of the debt if it can be concluded from the circumstances that the debtor thereby also acknowledged the rest of the debt.

(3) The provisions of Subections (1) and (2) do not apply if the creditor's claim has been extinguished.

\section{TITLE II}

\section{OBLIGATIONS ARISING FROM JURIDICAL ACTS}

\section{Chapter 1}

Transfer of a thing into the ownership of another

\section{Division 1}

Donation

\section{Subdivision 1}

\section{General provisions}




\section{Basic provisions}

(1) By a donation contract, a donor gratuitously transfers the right of ownership in a thing or undertakes to transfer the thing into the ownership of the donee, and the donee accepts the gift or offer.

(2) A performance provided as a mere social favour does not constitute donation if it is evident from the conduct of the parties that they do not intend to become contractually bound.

\section{Section 2056 [Recodification]}

A promisor of a gift is not obliged to donate, but the promisee is entitled to be compensated by the promisor for the costs reasonably incurred in anticipation of the gift.

Section 2057

(1) Donation of a thing registered in a public register requires a contract in writing.

(2) A contract in writing is also required where the thing is not delivered simultaneously with the expression of will to donate and accept the gift. A donor is obliged to deliver the gift, but not to pay default interest.

\section{Section 2058 [Recodification]}

(1) A donor may even donate all of his existing property if he so decides. A contract whereby a person donates his future property is only valid insofar as it does not exceed half of the property.

(2) Donation of a thing which is not in the donor's ownership is only valid if the donor contractually undertakes to acquire the thing.

\section{Section 2059 [Recodification]}

If a donor undertakes to deliver a gift after concluding the contract, he may withdraw from the contract and withhold the delivery of the gift if the circumstances following the conclusion of the contract change to such an extent that the performance provided under the contract would seriously jeopardise the donor's maintenance or the fulfilment of the donor's duty to maintain and support. If a donor has already surrendered a part of the gift, he may withdraw from the contract only in respect of what he is yet to discharge.

\section{Section 2060}

If a thing was given to a person as a sign of recognition, with regard to his merits or as a special reward, it shall constitute donation unless the donee had previously been entitled thereto.

\section{Section 2061}

If it has been stipulated that the donor will also mutually receive donation, only the difference between the value of one party's performance and the value of the other party's performance constitutes donation.

\section{Section 2062 [Recodification]}

\section{Donation of support}

If a donor undertakes to periodically support a donee, the right as well as the duty to support passes to the donor's heir and the donee's heir only if it has been expressly stipulated.

\section{Section 2063 [Recodification]}

\section{Donation mortis causa}

Donation dependent on the condition that the donee survives the donor is generally considered as a legacy. It is governed by the provisions on donation if the donee accepts the gift and the donor expressly waives his right to revoke the gift and provides the donee with an instrument containing a confirmation thereof. This does not affect Section 2057.

\section{Section 2064 [Recodification]}

(1) In the case of donation with a mandate, the donor may require that the mandate be fulfilled only if he has already performed himself.

(2) If the fulfilment of a mandate is in the public interest, the fulfilment of the mandate after the donor's death may also be required by the competent public body or a legal person authorised to protect such interest.

\section{Section 2065 [Recodification]}

If a person knowingly donates a thing of another and conceals it from the donee, the person shall compensate the resulting damage. A donor shall also compensate the donee for damage if the damage was incurred as a consequence of a defect of the donated thing and the donor knew of such defect and failed to notify the donee thereof. In these cases, the donee may also withdraw from the contract and return the gift. 


\title{
Subdivision 2
}

\section{Special provisions on the validity of donation}

\author{
Section 2066 [Recodification]
}

A person whose legal capacity has been limited is eligible to donate and accept gifts of small value or gifts which are usual given the circumstances.

\section{Section 2067 [Recodification]}

(1) Donation to a person who operates a facility which provides health care or social services, or to a person who manages or is employed in such a facility, is invalid if it occurred at the time when the donor was in the care of such a facility or otherwise received its services.

(2) Subsection (1) does not apply if the donee is a close person of the donor.

\section{Subdivision 3}

\section{Revocation of a gift}

\section{Revocation of a gift due to destitution}

\author{
Section 2068 [Recodification]
}

(1) If, after making donation, a donor falls into such destitution that he even lacks the means for his own essential maintenance or the essential maintenance of the person in respect of whom he has the statutory duty to maintain and support, he may revoke the gift and require that the donee return to him the gift or pay to him its usual price, but only to an extent not exceeding the scope in which the donor lacks the means for such maintenance. The donee may be released from that duty by providing what is needed for such maintenance.

(2) A donee shall not have the duty under Subsection (1) if he himself is in a similar state of destitution as the donor.

\section{Section 2069 [Recodification]}

If several persons have been provided with a gift, the person who was provided with the gift earlier is required to perform only to the extent to which the contribution of a person provided with the gift later is insufficient to provide the maintenance.

\section{Section 2070 [Recodification]}

The right to revoke a gift does not pass to the donor's heirs. However, if the donor fails to assert his right, the person in respect of whom the donor has a statutory duty to maintain and support shall, under the same conditions, be entitled to demand that the donee supplement what the donor is unable to provide.

\section{Section 2071 [Recodification]}

A donor who inflicted the state of destitution upon himself intentionally or through gross negligence shall not have the right to revoke a gift.

\section{Revocation of gift due to ingratitude}

\section{Section 2072 [Recodification]}

(1) If a donee hurt the donor intentionally or through gross negligence in a way that was in clear conflict with good morals, the donor may withdraw from the donation contract due to his ingratitude unless he has forgiven the donee. If a gift has already been delivered, the donor is entitled to require to have the entire gift surrendered to him, and if that is impossible, the payment of the usual price.

(2) If justified by the circumstances, an apparent conflict with good morals against the close person of the donee is also considered to constitute ingratitude.

Section 2073

Ingratitude causes a donee to personally become a possessor in bad faith.

\section{Section 2074}

If the donor was prevented from revoking the gift by the donee or by force majeure, the right to revoke a gift passes to the donor's heir.

\section{Section 2075}

(1) A donor may revoke a gift due to ingratitude within one year after the date on which the donee hurt the donor; if the donor becomes aware of it later, he may do so within one year after the date on which he became aware of a reason for the 
revocation of the gift. A donor's heir may revoke a gift no later than within one year after the death of the donor.

(2) If a gift is revoked later and the donee invokes late revocation, a court shall not take the revocation into account.

\section{Common provisions}

Section 2076 [Recodification]

If, in the case of donation inter vivos, a donor waives in advance his right to revoke a gift due to destitution or ingratitude, it is disregarded.

\section{Section 2077}

If a duty obliging the donee under a donation contract is associated with a gift, it is extinguished for the future upon the revocation of the gift.

\section{Section 2078}

If the donee no longer has a gift or its full value, a revocation of the gift obliges him to surrender what is still left of his enrichment. This does not apply if he got rid of the gift to frustrate the surrender or if the gift was revoked by the very donor due to ingratitude.

Division 2

\section{Purchase}

\section{Subdivision 1}

\section{General provisions}

Section 2079

\section{Basic provisions}

(1) By a contract of sale, the seller undertakes to deliver a thing which constitutes the subject of the purchase to the buyer and allow him to acquire the right of ownership therein, and the buyer undertakes to take over the thing and pay the seller the purchase price. same time.

(2) Unless the contract or usages indicate something else, the seller and buyer are obliged to fulfil their duties at the

\section{Section 2080}

A purchase price is stipulated with sufficient certainty where at least the method of its determination is stipulated.

\section{Section 2081}

The costs associated with the delivery of a thing at the place of performance are borne by the seller. Costs associated with the takeover of a thing are borne by the buyer

\section{Section 2082}

(1) The risk of damage to a thing passes to the buyer simultaneously with the acquisition of the right of ownership. If the buyer acquires the right of ownership before the delivery of the thing, the seller has the rights and duties of a depositary until the delivery of the thing.

(2) At the conclusion of a contract with a suspensive condition, the risk of damage to the thing passes to the buyer no earlier than on the date on which the condition is met.

\section{Section 2083}

A person who buys future revenues "as is" (caveat emptor) or with a hope of uncertain future revenues is entitled to all lawfully acquired revenues. However, he bears the loss if his expectations were frustrated.

\section{Section 2084}

When negotiating a contract of sale, a seller shall notify the buyer of the defects in a thing of which he knows.

\section{Subdivision 2}

\section{Purchase of a movable thing}

\section{Basic provisions}


(1) Any purchase the subject of which is not an immovable thing is assessed as a purchase of a movable thing; the same applies to a purchase of a component part of an immovable thing if the buyer is to contractually acquire the component part as a movable thing after its separation. Any contract for the supply of consumer goods which need to be assembled or created is always considered to constitute a contract of sale.

(2) Where the parties intend to conclude a contract of sale without determining the purchase price, the purchase price at which the same or a comparable thing is usually sold at the time of the conclusion of the contract and under similar contractual terms is conclusively presumed to be the stipulated purchase price.

\section{Section 2086 [Recodification]}

(1) A contract for the supply of a thing which is yet to be produced is assessed as a contract of sale, unless the person to whom the thing is to be supplied undertakes to hand over to the other party a substantial part of what is needed to produce the thing.

(2) A contract under which the dominant part of the supplier's performance consists in the performance of an activity is not considered to constitute a contract of sale.

\section{Duties of the seller}

\section{Section 2087}

The seller shall deliver the thing as well as the related documents to the buyer and allow the buyer to acquire the right of ownership in the thing in accordance with the contract.

\section{Section 2088}

The seller fulfills his duty to deliver the thing to the buyer by allowing him to dispose of the thing at the place of performance and notify him thereof in due time.

\section{Section 2089}

(1) If a buyer is to subsequently determine the properties of the thing purchased and fails to do so in time, the seller shall determine them himself and notify the buyer of the properties he has determined. In doing so, he has regard to the needs of the buyer of which he knows.

(2) The buyer has the right to notify the seller if the properties determined for the thing purchased differ from those determined by the seller; if he fails to do so without undue delay after the seller's notification, he is bound by what was determined by the seller.

\section{Section 2090 [Recodification]}

(1) If the seller is to dispatch the thing, he delivers the thing to the buyer by handing it over to the first carrier for carriage to the buyer and allow the buyer to assert the rights arising from the contract of carriage against the carrier.

(2) If the buyer is a consumer, Subsection (1) applies only if the carrier was determined by the buyer, without being offered by the seller to the buyer. Otherwise, the thing is deemed delivered to the buyer upon the handover by the carrier.

\section{Section 2091}

(1) With regard to dispatching, the delivery of a thing to a buyer takes effect upon the handover to the carrier provided that the seller visibly and sufficiently marks the thing as a consignment for the buyer.

(2) If a seller fails to mark a thing, delivery shall take effect if the seller notifies the buyer without undue delay that the thing has been dispatched to him and if he sufficiently determines the thing in the notification. Without the notification, the thing is delivered to the buyer once it is handed over to him by the carrier.

\section{Section 2092}

The period within which the seller is to perform shall commence on the effective date of the contract. However, if the buyer is to fulfil a certain duty before the delivery of the thing, the period within which the seller is to perform commences on the date of the fulfilment of this duty.

\section{Section 2093}

If the seller supplies a quantity of things which exceeds that which has been stipulated, the contract of sale is also concluded in respect of the excess quantity, unless the buyer refused it without undue delay.

\section{Section 2094}

(1) A seller shall hand over the documents necessary for the takeover and use of the thing to the buyer. If the thing is to be handed over upon payment of the purchase price, the seller shall hand over the documents at the place of payment.

(2) The seller shall hand over the documents which relate to carriage and are required to take over and dispose of the thing to the buyer without undue delay after they are issued. The seller shall hand over other documents specified in the 
contract to the buyer upon the delivery of the thing.

\section{Thing purchased}

Section 2095

The seller shall deliver the thing purchased to the buyer in the stipulated quantity, quality and design. Where quality and design have not been stipulated, the seller shall perform in the quality and design appropriate for the purpose evident from the contract, or otherwise for the usual purpose.

\section{Section 2096}

Where the quality or design has been determined according to an agreed sample or model, the quality or design of the thing must correspond to the sample or model. If the quality or design determined in the contract differs from the sample or model, the contract is decisive. If a contract and sample determine the quality or design of a thing differently, but not in contradiction, the thing must correspond to both the contract, and the sample or model.

\section{Section 2097}

Unless it has been stipulated how a thing is to be packaged, the seller shall package the thing according to usages; in their absence, he shall do so in a manner necessary to preserve and protect the thing. The seller shall furnish the thing with packaging for carriage in the same manner.

\section{Section 2098}

If the contract or the nature of the thing purchased indicates that the quantity is only approximate, the exact quantity is determined by the seller. It is presumed that a deviation may not exceed five per cent of the quantity specified in the contract.

\section{Rights arising from defective performance}

\section{Section 2099}

(1) A thing is defective if it does not have the properties specified in Sections 2095 and 2096. The provision of another thing is also considered to constitute a defect. Defects in the documents required for the use of the thing are also considered to constitute a defect.

(2) If the seller's declaration or document of handover indicates that the seller has supplied a smaller quantity of things, the provisions on defects do not apply to the missing things.

\section{Section 2100}

(1) The right of the buyer arising from a defective performance is established by a defect which a thing has upon the passage of the risk of damage to the buyer, even if it reveals later. The right of the buyer is also established by a defect which occurs later and which is caused by the seller's breach of duty.

(2) This does not affect the seller's duties arising from a quality guarantee.

\section{Section 2101}

(1) In the case of an early performance, the seller may remove the defects within the time specified for the delivery of the thing. By exercising his right, he may not cause unreasonable inconvenience or expenses to the buyer. This does not affect the buyer's right to compensation for damage.

(2) Subsection (1) applies by analogy to defects in documents.

\section{Section 2102}

(1) The rights of a buyer arising from a defective performance remain unaffected if the defect was caused by the use of a thing which the buyer handed over to the seller. This does not apply if the seller proves that he informed the buyer of the defective nature of the thing handed over and the buyer insisted on its use, or if he proves that he could not have discovered the defective nature of the thing handed over even by exercising adequate care.

(2) If the defect of a thing was caused because the seller relied on the designs, samples or documents provided to him by the buyer, Subection (1) applies by analogy.

\section{Section 2103}

A buyer has no rights arising from a defective performance in case of a defect which he must have discovered at the conclusion of the contract by paying usual attention. This does not apply if the seller expressly assured him that the thing is free from defects or employed trickery to conceal the defect.

\section{Section 2104}

A buyer shall inspect the thing as soon as possible after the passage of the risk of damage to the thing and verify its properties and quantity. 

its destination.

(1) If a seller dispatches a thing, the buyer may postpone the inspection until after the thing has been transported to

(2) If, during carriage, a thing is routed to another destination, or if the buyer forwards the thing without having the opportunity to inspect it, and the seller, at the time of the conclusion of the contract, knew or should have known of the possibility of such a change of destination or such forwarding, the buyer may postpone the inspection until after the thing has been transported to the new destination.

\section{Section 2106}

(1) If a defective performance constitutes a fundamental breach of contract, the buyer has the right to:

a) have the defect removed by having a new defect-free thing or a missing thing supplied,

b) the removal of the defect by having the thing repaired,

c) a reasonable reduction of the purchase price, or

d) withdraw from the contract.

(2) The buyer shall notify the seller of the right he has chosen upon the notification of the defect or without undue delay thereafter. The buyer may not change the choice made without the consent of the seller; this does not apply if the buyer requested the repair of a defect which proves to be irreparable. If the seller fails to remove the defects within a reasonable time limit or if he notifies the buyer that he will not remove the defects, the buyer may, instead of having the defects removed, request a reasonable reduction of the purchase price or withdraw from the contract.

(3) If the buyer fails to make his choice of right in time, he has the rights under Section 2107.

\section{Section 2107}

(1) If a defective performance constitutes a non-fundamental breach of contract, the buyer has the right to have the defects removed, or to a reasonable reduction of the purchase price.

(2) Until the buyer asserts his right to a reduction of the purchase price or withdraws from the contract, the seller may supply what is missing or remove a legal defect. The seller may remove other defects by repairing the thing or supplying a new thing, the choice being the seller's; the choice must not cause the buyer to incur unreasonable costs.

(3) If the seller fails to remove a defect of a thing in time or refuses to remove the defect, the buyer may request a reduction of the purchase price or withdraw from the contract. The buyer may not change his choice without the consent of the seller.

\section{Section 2108}

Until a defect is removed, the buyer is not obliged to pay the part of the purchase price which is estimated as reasonably corresponding to his right to the price reduction.

Section 2109

When the new thing is supplied, the buyer shall return the originally supplied thing to the seller at the seller's expense.

Section 2110

A buyer may not withdraw from a contract or demand the supply of a new thing if he cannot return the thing in the same condition in which he received it. This does not apply if:

a) there has been a change in its condition as a result of inspection to discover a defect of the thing,

b) the buyer used the thing before the discovery of a defect,

c) the buyer did not cause the impossibility to return the thing in the same condition by an act or omission, or

d) the buyer sold the thing before the discovery of the defect, consumed it or altered the thing during its normal use; if it occurred only partially, the buyer shall return to the seller everything he still can and shall compensate the seller in the amount of the benefit he enjoyed as a result of the use of the thing.

\section{Section 2111}

If a buyer fails to notify the defect of a thing in time, he shall lose the right to withdraw from the contract.

\section{Section 2112}

(1) If a buyer fails to notify the defect without undue delay after he could have discovered it during a timely inspection and by exercising adequate care, a court shall not grant him the right arising from a defective performance. In case of a latent defect, the same applies if the defect was not notified without undue delay after the buyer could have discovered it by exercising 
due care, but no later than two years after the delivery of the thing.

(2) A court shall take into account the effects under Subsection (1) only in case the seller invokes late notification of a defect. However, the seller is not entitled to assert the defence if the defect is due to a fact of which the seller was or must have been aware at the time the thing was delivered.

\section{Quality guarantee}

\section{Section 2113 [Recodification]}

By a quality guarantee, a seller undertakes that a thing will be fit for use for the usual purpose for a certain period or that it will retain the usual properties. Specification of a guarantee period or the "use by" date of a thing on the packaging or in advertising has the same effect. A guarantee may also be provided for an individual component part of a thing.

\section{Section 2114}

Where a contract and declaration of guarantee determine different guarantee periods, the longest period applies. However, if the parties stipulate a guarantee period other than that which is indicated on the packaging as the thing's "use by" date, the stipulation between the parties prevails.

\section{Section 2115}

The guarantee period commences upon the delivery of the thing to the buyer; if the thing was dispatched according to the contract, it commences when the thing reaches its destination. If the purchased thing is to be commissioned by a person other than the seller, the guarantee period shall commence on the date on which the thing was commissioned if the buyer ordered the commissioning no later than within three weeks from the takeover of the thing and provided assistance in the performance of the service properly and in due time.

\section{Section 2116}

A buyer does not have the right arising from guarantee if the defect was caused by an external event after the risk of damage to the thing passed to him. This does not apply if the defect was caused by the seller.

Section 2117

The notification of a defect covered by a guarantee and asserting the right arising from a defective performance are governed by Sections 2172 and 2173 by analogy.

\section{Duties of the buyer}

Section 2118

A buyer shall pay the purchase price and take over the thing.

Section 2119

(1) A buyer need not pay the purchase price until he has had the opportunity to inspect the thing. This does not apply if the parties stipulate that a thing is to be handed over in such a manner which excludes the possibility to inspect it.

(2) In determining the price based on weight, the net weight of the thing purchased is presumed to be decisive.

\section{Section 2120}

(1) If a buyer is in delay with the takeover of a thing or in default of the payment of the purchase price, the seller shall keep the thing for the buyer in a manner appropriate to the circumstances, if he can dispose of it. circumstances.

(2) If the buyer took over a thing which he intends to refuse, he shall keep it in a manner appropriate to the

(3) A person who keeps a thing for the other party may retain it until the other party reimburses the costs reasonably incurred by the person in the keeping of the thing.

\section{Risk of damage to a thing}

\section{Section 2121}

(1) The risk of damage to a thing passes to the buyer upon takeover. dispose of it.

(2) The same consequences shall occur if a buyer fails to take over a thing although he is allowed by the seller to

\section{Section 2122}

If a buyer is to take over a thing from a third person, the risk of damage passes to him when he can dispose of the thing, but no earlier than at the time stipulated as the time of performance. 
(1) If a seller hands over a thing to a carrier for carriage to the buyer at the place stipulated by the contract of sale, the risk of damage passes to the buyer upon the handover to the carrier at that place, and if no such place has been agreed, upon the handover to the first carrier for carriage to the destination.

(2) If a thing is already being carried at the conclusion of the contract, the risk of damage to the thing passes to the buyer upon handover to the first carrier. However, the seller is liable for any damage incurred before concluding the contract of which the seller knew or should have known, given the circumstances.

\section{Section 2124}

The risk of damage to a thing determined by kind shall not pass to the buyer who did not take over the thing before the thing is sufficiently separated and distinguished from other things of the same kind for the purpose of the contract.

\section{Section 2125}

(1) Damage to a thing incurred after the risk of damage passed to the buyer does not affect his duty to pay the purchase price, unless the seller caused the damage by being in breach of his duties.

(2) Subsection (1) does not apply if the buyer has asserted the right to request the supply of a replacement thing or has withdrawn from the contract.

\section{Sale by self-help}

Section 2126

(1) If a party is in delay with taking over a thing, the other party becomes entitled to appropriately sell the thing on the account of the delaying party after previously notifying the delaying party and after the delaying party has been provided with an additional reasonable time limit for takeover.

(2) This also applies if a party is in default with a payment which is required for the handover of a thing.

\section{Section 2127}

In case a thing is subject to rapid decay and there is no time for notification, it is not necessary.

\section{Subdivision 3}

\section{Purchase of an immovable thing}

Section 2128 [Recodification]

(1) In the case of a sale and purchase of an immovable thing, the contract of sale must have the form under Section 560. However, a different form suffices for stipulations on the reservation of the right of ownership, the right of repurchase, the prohibition to alienate or encumber, the reservation of a pre-emptive right, the reservation of a better buyer as well as for stipulations on trial purchases, unless such a stipulation is to create a right in rem.

(2) Where a stipulation on the reservation of the right of ownership, the right of repurchase, the prohibition to alienate or encumber, the reservation of a pre-emptive right or reservation of a better buyer, or a stipulation on trial purchases creates a right in rem registered in a public register, such a right is created only upon the registration in the public register.

\section{Section 2129 [Recodification]}

(1) A buyer is entitled to a reasonable reduction of the purchase price if a tract of land does not have the area stipulated in the contract of sale. However, if a tract of land does not have the area registered in a public register, the buyer is entitled to a reasonable reduction of the purchase price only if so stipulated.

(2) If a buyer fails to notify the seller of a latent defect associated with a structure firmly attached to the tract of land within five years from the date of acquisition, a court shall not grant the buyer the right arising from a defective performance if the seller invokes late notification of the defect. However, the seller is not entitled to assert the defence if the defect is due to a fact of which the seller was or must have been aware at the time the thing was delivered.

\section{Section 2130 [Recodification]}

If the parties stipulate when a buyer is to take over an immovable thing, the buyer is entitled to the fruits and revenues of the immovable thing from the stipulated time of takeover. The risk of damage to the thing shall also pass to the buyer at this time.

\section{Section 2131 [Recodification]}

In other respects, contracts for the purchase of an immovable thing are governed by the provisions on the purchase of a movable thing with the necessary modifications.

\section{Subdivision 4}




\title{
Ancillary stipulations when concluding a contract of sale
}

\section{Reservation of the right of ownership}

\author{
Section 2132 [Recodification]
}

If a seller reserves the right of ownership in a thing, the buyer is presumed to become the owner only upon the full payment of the purchase price. However, the risk of damage to the thing passes to the buyer as early as upon its takeover.

\section{Section 2133 [Recodification]}

If the acquisition of the right of ownership by the buyer is subject to the payment of the purchase price in instalments, the buyer's default of instalments not exceeding one tenth of the purchase price does not in itself entitle the seller to withdraw from the contract and demand the return of the thing if the buyer pays the instalment no later than when the next instalment becomes due and together with the instalment which is due.

\section{Section 2134 [Recodification]}

Reservation of the right of ownership is effective with respect to the buyer's creditors only if the stipulation was made in the form of a public instrument, or if it was made in writing and the signatures of the parties were authenticated, but in this case it is effective only from the date of the authentication of signatures. However, if the reservation of the right of ownership has been stipulated in respect of a thing registered in a public register, it has effect against third persons only if it has been registered in that register.

\section{Reservation of repurchase}

\section{Section 2135 [Recodification]}

(1) A stipulation on a reservation of repurchase obliges the buyer to transfer, upon request, a thing back to the seller for consideration. The buyer shall return the thing to the seller in an undeteriorated condition, and the seller shall reimburse the purchase price paid by the buyer; this shall also settle the revenues of money and fruits of a thing which may have been acquired. stipulated.

(2) The reservation of repurchase is binding on heirs; the right of repurchase may be alienated only if expressly

\section{Section 2136 [Recodification]}

If a buyer incurred costs to improve the thing or extraordinary costs for its preservation, he is entitled to the same compensation as a possessor in good faith; however, if the return of the thing is frustrated or its value decreased for reasons for which the buyer bears liability, the buyer shall compensate the seller for the damage.

\section{Section 2137 [Recodification]}

Where no time limit in which the seller has the right to demand the return of a thing has been stipulated, a three-year time limit in respect of a movable thing and a ten-year time limit in respect of an immovable thing is conclusively presumed to have been stipulated.

\section{Section 2138 [Recodification]}

If the reservation of repurchase has been stipulated in respect of a thing registered in a public register as a right in rem, the thing may only be encumbered with the consent of the person in whose favour the right of repurchase is registered in the public register.

\section{Section 2139 [Recodification]}

\section{Reservation of resale}

The provisions on repurchase apply by analogy to the stipulation whereby the buyer reserves the right to sell the thing back to the seller.

\section{Section 2140 [Recodification]}

\section{Pre-emptive right}

(1) If a person stipulates a pre-emptive right to a thing, the debtor that intends to sell it to a third person (a willing buyer) incurs the duty to offer the purchase of the thing to the person having the pre-emptive right.

(2) The pre-emptive right may be extended to other manners of alienation by a special stipulation. The pre-emptive right may also be stipulated in cases unrelated to the contract of sale.

\section{Section 2141 [Recodification]}

Where several persons jointly hold the pre-emptive right, they may only assert it in its entirety. However, if the preemptive right of any of them is extinguished, or if one person fails to assert it, the remaining persons having the pre-emptive right may assert the right in its entirety. 


\section{Section 2142 [Recodification]}

Reservation of pre-emptive right is binding on heirs; a pre-emptive right can be alienated if expressly stipulated.

\section{Section 2143 [Recodification]}

The duty of a seller to offer a thing for sale to the person having the pre-emptive right becomes due upon the conclusion of the contract with a willing buyer.

\section{Section 2144 [Recodification]}

(1) If a pre-emptive right is created as a right in rem, a person having the pre-emptive right is entitled to claim, with respect to the successor of the other party who acquired the thing by purchase or in a manner which is equal to a purchase by a stipulation on pre-emptive right, that the successor transfer the thing to him for appropriate consideration.

(2) If a successor acquires the right of ownership in a thing in another manner, the duty to offer the sale of the thing to the person having the pre-emptive right passes to him under the conditions which were binding on his predecessor. preserved.

(3) If a person having the pre-emptive right does not buy the thing offered to him, his pre-emptive right shall remain

$$
\text { Section } 2145 \text { [Recodification] }
$$

If a willing buyer knew or must have known of the pre-emptive right, the contract is conclusively presumed to have been concluded with a resolutive condition of asserting the pre-emptive right.

\section{Section 2146 [Recodification]}

If a seller and willing buyer stipulate that the seller withdraws from a contract concluded between them if a person having the pre-emptive right asserts his right, or that an obligation will change or be extinguished if a person having the preemptive right fails to assert his right, such stipulations are ineffective against the person having the pre-emptive right. A stipulation to the contrary is disregarded.

\section{Section 2147 [Recodification]}

(1) A seller shall make an offer to the person having the pre-emptive right by notifying all the conditions. When making an offer, a notification of the contents of the contract concluded with the willing buyer is required. An offer to purchase an immovable thing must be in writing.

(2) If a person having the pre-emptive right accepts an offer, the purchase between the seller and the person having the pre-emptive right is concluded under the same conditions as those agreed between the seller and the willing buyer.

\section{Section 2148 [Recodification]}

(1) A person having the pre-emptive right shall pay the purchase price within the stipulated time limit, or otherwise within eight days after the offer in the case of a movable thing, and within three months after the offer in the case of an immovable thing. Failure to do so extinguishes the right.

(2) If a seller has postponed the willing buyer's deadline to pay the purchase price or if he allowed him to pay in instalments, a person having the pre-emptive right may claim the same benefit if he secures the postponed payment with a sufficient security.

\section{Section 2149 [Recodification]}

(1) A person having the pre-emptive right shall pay the purchase price in the amount offered by the willing buyer and meet the conditions offered by the willing buyer in addition to the purchase price. If the willing buyer agreed to provide an ancillary performance which cannot be provided by a person having the pre-emptive right, the person having the pre-emptive right shall pay its value to the seller. Where even paying the estimated price cannot compensate the ancillary performance, the pre-emptive right is extinguished; this does not apply where it can be reasonably expected that the contract with the willing buyer would have also been concluded without the obligation to provide the ancillary performance.

(2) If a willing buyer has agreed to buy a thing together with others for an aggregate price, a person having the preemptive right shall pay a proportion of the aggregate price. A seller may require that a person having the pre-emptive right buy the thing together with everything which cannot be separated therefrom without damage.

\section{Trial purchase}

\section{Section 2150 [Recodification]}

(1) A person who makes a trial purchase of a thing buys the thing on condition that he will approve the thing in the trial period.

(2) If the parties do not stipulate a trial period, it is three days from the conclusion of the contract for movable things and one year from the conclusion of the contract for immovable things. However, if it follows from the negotiations on the conclusion of the contract that the thing is to be inspected or tried out after delivery, the trial period shall commence on the date 
of delivery.

\section{Section 2151}

(1) If a buyer fails to take over a thing, the condition is of a suspensive nature. The condition is considered frustrated if the buyer fails to inform the seller during the trial period that he approves the thing.

(2) If a buyer takes over a thing, the condition is of a resolutive nature. The buyer is conclusively presumed to have approved the thing if he did not refuse it in the trial period.

(3) A buyer is not entitled to refuse a thing if he cannot return it in the same condition in which he took it over. The changes produced by trying out the thing are disregarded.

\section{Reservation of a better buyer}

\section{Section 2152 [Recodification]}

(1) By concluding a contract of sale with a reservation of a better buyer, a seller acquires the right to give priority to a better buyer if the better buyer claims his interest within a particular time limit. This time limit is three days from the conclusion of the contract for movable things and one year from the conclusion of the contract for immovable things.

(2) The seller decides whether or not the new buyer is better; in particular, he may give priority to the new buyer even where the first buyer offers a higher price.

\section{Section 2153}

As in the case of a trial purchase, assessment is to be made of the cases in which the reservation of a better buyer has the nature of a suspensive condition and in which it has the nature of a resolutive condition.

\section{Price clause}

\section{Section 2154}

Where a price clause has been stipulated, the purchase price of a thing is subsequently adjusted having regard to the costs of production. Where the decisive costs are not determined, the purchase price shall change in proportion to the price changes of key raw materials needed to produce the thing.

\section{Section 2155}

(1) If the parties do not determine the time which is decisive for the assessment of price changes, account is taken of the prices at the time of the conclusion of the contract and at the time when the seller was to supply the thing. If a thing is to be supplied within a certain time limit, the time of the actual timely performance is decisive, otherwise it is the end of this time limit.

(2) If a seller supplies a thing late and if the prices of the decisive components of production costs are lower than those under Subsection (1), the lower prices are taken into account.

\section{Section 2156}

The rights and duties of the parties arising from a price clause are extinguished if the obligee fails to assert his rights with respect to the other party without undue delay after the thing has been supplied.

\section{Section 2157}

\section{Other ancillary stipulations}

If the parties stipulate other reservations or conditions which allow for a change or extinction of rights and duties under the contract, a reservation or condition is extinguished no later than within one year after the effective date of the contract of sale if it is not asserted within this time limit by the person entitled under the reservation or condition.

\section{Subdivision 5}

\section{Special provisions on the sale of consumer goods}

\section{Section 2158}

(1) If a seller is an entrepreneur, the sale within his business activities, in addition to the general provisions on a contract of sale, is also governed by the provisions of this Subdivision, unless the buyer is also an entrepreneur and at the conclusion of the contract it is evident from the circumstances that the purchase is also related to the buyer's business activities.

(2) Performances which are not usually provided in the sale of a thing must be stipulated separately.

\section{Section 2159}

(1) If a seller supplies a thing to the place specified by the buyer, the buyer shall take over the thing upon supply; in other cases, the buyer shall take over the thing upon the sale. 
(2) If a buyer fails to take over a thing within the period specified in Subsection (1), the seller is entitled to a consideration for storage. If the parties do not stipulate the amount of the consideration, the usual amount is conclusively presumed to be the one stipulated.

\section{Section 2160}

(1) A buyer acquires the right of ownership in a thing upon its takeover.

(2) In the case of a self-service sale, a buyer acquires the right of ownership in a thing upon the payment of the purchase price. Until such time, the buyer may put the thing back to its original place. If damage is caused to a thing before the payment of the purchase price, it is compensated in accordance with the general provisions.

\section{Section 2161 [Recodification]}

\section{Quality upon takeover}

(1) A seller is liable to a buyer for a defect-free condition of a thing upon takeover. A seller is in particular liable to ensure that at the time the buyer takes over the thing:

a) the thing has the properties stipulated by the parties, and in the absence of such a stipulation such properties which the seller or producer described, or which the buyer expected given the nature of the goods concerned and the advertising presented by the seller or producer,

b) the thing is suitable to be used for the purpose stated by the seller or to which the thing of such kind is usually used,

c) the thing's quality or design corresponds to the agreed sample or model if such quality or design was determined on the basis of an agreed sample or model,

d) the thing has the quantity, measurement or weight and

e) the thing meets the requirements laid down by legal regulations. upon takeover.

(2) In case there is a defect within six months from takeover, the thing is presumed to have already been defective

\section{Section 2162}

If allowed by the nature of the purchase, a buyer has the right to have a thing checked before him or to have its functions demonstrated.

\section{Section 2163}

In the case of a consumable thing, indication is made of its "best before" date or, in the case of a thing subject to rapid decay, of the period for which the thing may be used, where applicable.

\section{Section 2164}

If a thing has a defect which does not prevent it from being used as intended, it may only be sold at a lower price than the usual price of a defect-free thing. The seller shall notify the buyer that a thing has a defect and what defect it is, unless it is obvious from the very nature of the sale.

\section{Rights arising from a defective performance}

\section{Section 2165 [Recodification]}

(1) The buyer is entitled to assert his right arising from a defect which occurs in consumer goods within twenty four months from the takeover.

(2) If the period for which a thing may be used is specified on the sold thing, its packaging, the instruction manual attached to the thing or in advertising in accordance with other legal regulations, the provisions on quality guarantee apply.

\section{Section 2166}

(1) If so requested by a buyer, a seller shall confirm to him in writing the extent and the duration of his duties in the case of a defective performance. A seller has duties arising from a defective performance at least to the extent to which the producer's duties arising from a defective performance exist. In the confirmation, he shall state his name, registered office and identifying information and, where appropriate, other information required for his identification.

(2) If necessary, the seller shall, in an understandable manner, explain in the confirmation the content, extent, conditions and duration of his liability as well as the manner in which the rights arising from the liability can be asserted. In the confirmation, the seller shall also state that other rights of the buyer related to the purchase of the thing are not affected. Failure to fulfil these duties does not prejudice the validity of the confirmation.

(3) Unless prevented by the nature of the thing, the confirmation under Subsection (1) may be replaced by a document of purchase containing the above information. 
The provision of Section 2165 does not apply:

a) to a defect of a thing sold for a lower price for which the lower price was stipulated,

b) to the wear and tear of a thing caused by its normal use,

c) to a defect of a used thing corresponding to the extent of use of the thing or its wear and tear upon takeover by the buyer, or

d) if it follows from the nature of the thing.

Section 2168 [Recodification]

If the seller and buyer stipulate a reduction of the period for asserting the rights arising from a defective performance, such a stipulation is disregarded. This does not apply if the parties have reduced this period to half of the statutory period in the case of purchasing used consumer goods; where they have stipulated a greater reduction, half of the statutory period is conclusively presumed to be the stipulated period.

\title{
Section 2169 [Recodification]
}

(1) If a thing lacks the properties specified in Section 2161, the buyer may also require the supply of a new thing without defects, unless it is disproportionate to the nature of the defect, but where the defect only concerns a component part of the thing, the buyer may only request a replacement of that component part; if it is impossible, he may withdraw from the contract. If, however, it is disproportionate to the nature of the defect, in particular where the defect can be removed without undue delay, the buyer has the right to have the defect removed gratuitously.

(2) Even where a defect is removable, the buyer is entitled to have a new thing supplied or a component part replaced if he cannot use the thing properly due to the repeated occurrence of the defect after a repair or due to a larger number of defects. In this case, the buyer shall also have the right to withdraw from the contract.

(3) If a buyer fails to withdraw from the contract or assert his right to have a new defect-free thing supplied, its component part replaced or the thing repaired, he may require a reasonable price reduction. A buyer also has the right to a reasonable price reduction where the seller cannot supply to him a new defect-free thing, replace a component part of the thing or repair it, as well as where the seller fails to provide for a remedy within a reasonable time or where such a remedy would cause substantial difficulties to the consumer.

\section{Section 2170}

A buyer shall not have the right arising from a defective performance if, before the takeover of the thing, he was aware that the thing had a defect, or if it was caused by the buyer himself.

\section{Section 2171}

If a thing has a defect which creates an obligation for the seller, and it is a thing sold for a lower price or a used thing, the buyer has the right to a reasonable price reduction instead of the right to have the thing replaced.

\section{Section 2172}

The rights arising from defects are asserted against the seller from which the thing was purchased. However, if the confirmation under Section 2166 designates another person to carry out repairs who is located at the place of the seller or another place closer to the buyer, the buyer shall assert his right of repair against the person designated to carry out repairs. The person so designated to carry out repairs shall do so within a time limit agreed between the seller and the buyer upon the purchase of the thing.

\section{Section 2173}

If a buyer asserts his right arising from a defective performance, the other party shall provide him with a written confirmation of the time when he asserted this right, as well as of the completion of the repair and its duration.

\section{Section 2174}

If, before a buyer can assert his right arising from a defect of a thing, the parties stipulate that the buyer's rights become limited or extinguished, it is disregarded.

\section{Subdivision 6}

\section{Special provisions on the purchase of an enterprise}

\author{
Section 2175 [Recodification]
}

(1) By purchasing an enterprise, the buyer shall acquire everything that pertains to the enterprise as a whole. Even where the parties exclude an individual item from the purchase whereby the whole does not lose its nature of an enterprise, it is considered as a purchase of an enterprise.

(2) A purchase of an enterprise is considered to constitute a transfer of the employer's activities. 
The purchase price is presumed to have been stipulated on the basis of information on the assets and liabilities being transferred in the accounting records concerning the enterprise being sold and in the contract on the date of its conclusion; if the contract is to take effect later, the purchase price shall change depending on the increase or decrease of the assets and liabilities which may occur in the meantime.

\section{Section 2177 [Recodification]}

(1) By purchasing an enterprise, the buyer becomes a creditor in respect of claims and a debtor in respect of debts which pertain to the enterprise; however, the buyer shall only assume those debts of the existence of which he was aware, or which he must have at least reasonably expected. If the creditor has not given his consent to the assumption of debt by the buyer, the seller is liable as a surety for the discharge of the debt. Acquisition of claims by the buyer is otherwise governed by the provisions on assignment of claims.

(2) The seller shall, without undue delay, notify his creditors and debtors whose claims and debts were acquired by the buyer upon the purchase of the enterprise that he sold the enterprise and to whom.

\section{Section 2178}

It is prohibited to transfer to the buyer, by a sale of an enterprise, a right arising from industrial or other intellectual property where such a transfer is excluded by a contract which granted the right to the seller, or if it is excluded by the nature of the right.

\section{Section 2179}

(1) In the record of the handover, the parties shall make a list of everything which the enterprise includes and which is being handed over to the buyer, as well as everything which jointly forms the enterprise according to the contract or accounting records, but is missing. The seller shall, no later than in the record, notify the buyer of defects of the subject of sale of which he is, should have and could have been aware.

(2) If a thing pertaining to the enterprise is not included in the record, it is acquired by the buyer along with the enterprise. Where a debt is not included in the record, the buyer shall acquire it if he must have at least reasonably expected its existence.

\section{Section 2180 [Recodification]}

(1) If a buyer is registered in a public register, he acquires the right of ownership in the enterprise as a whole upon the publication of the information that the buyer has filed a document on the acquisition of the enterprise in the collection of instruments in accordance with another legal regulation.

(2) If the buyer is not registered in a public register, he acquires the right of ownership in the enterprise as a whole on the effective date of the contract.

(3) The provisions of Subsections (1) and (2) do not affect the duties to register rights in rem under other legal regulations and to the restrictions following from license or similar agreements.

\section{Section 2181 [Recodification]}

If the recoverability of a claim is deteriorated by the sale of an enterprise, the seller's creditor who did not consent to the sale may claim that a court declare the sale of the enterprise ineffective with respect to this creditor. This right is extinguished if not asserted by the creditor within one month from the date on which he became aware of the sale, but no later than three years after the effective date of the contract.

\section{Section 2182}

(1) If one of the parties withdraws from the contract, the claims and debts which pertain to the enterprise pass to the seller; however, the seller shall acquire only those debts of the existence of which he was aware or which he must have at least reasonably expected. If the creditor has not given his consent to the assumption of a debt by the seller, the buyer is liable as a surety for the discharge of the debt. Acquisition of claims by the seller is otherwise governed by the provisions on assignment of claims.

(2) A buyer shall, without undue delay, notify his creditors and debtors whose claims and debts were acquired by the seller that the obligation was extinguished upon the withdrawal from the contract.

\section{Section 2183}

The provisions of this Subdivision also apply by analogy to other transfers of the right of ownership in an enterprise and the sale or other transfer of part of an enterprise forming a separate organisational component.

\section{Division 3}

\section{Exchange}




\title{
Section 2184 [Recodification]
}

\section{Basic provisions}

(1) By a contract of exchange, each of the parties undertakes to transfer to the other party the right of ownership in a thing in exchange for the obligation of the other party to transfer the right of ownership in another thing. the contract.

(2) The parties shall deliver the things to each other in the condition in which they were at the time of the conclusion of

\section{Section 2185 [Recodification]}

(1) Where an accidental decay of a thing occurs before the passage of risk of damage to the thing, the contract is considered never to have been concluded. If a thing, before being delivered, accidentally deteriorates to the extent that the value of the thing falls to less than half, the other party has the right to withdraw from the contract.

(2) Other accidental deterioration of a thing or any encumbrance thereof is to the detriment of the transferor; slight decreases in value are disregarded.

(3) In case of an "as is" exchange of things, an accidental decay or accidental deterioration of individual things is to the detriment of the transferee, unless the whole is otherwise devalued to less than half of its price.

\section{Section 2186 [Recodification]}

When a thing is dispatched, the risk of damage to the thing passes to the transferee upon takeover. However, if he determined or approved the manner in which the thing is to be dispatched, the risk of damage to the thing passes to the transferee as early as upon dispatch.

\section{Section 2187 [Recodification]}

The fruits and revenues of an exchanged thing belong to the transferor until the time when he is to deliver the thing under the contract; from that time, the fruits and revenues belong to the transferee, even where the thing has not yet been delivered to him.

\section{Section 2188 [Recodification]}

In other respects, a contract of exchange is governed with the necessary modifications by the provisions on a contract of sale; within the exchange, each of the parties is considered to constitute the seller in respect of the thing it gives, and the buyer in respect of the thing it receives.

\section{Chapter 2}

\section{Relinquishing a thing to be used by another}

\section{Division 1}

\section{Precarious loan}

\author{
Section 2189 [Recodification]
}

\section{Basic provisions}

A precarious loan is created if a lender relinquishes a thing to another for gratuitous use without stipulating the period or purpose of such use.

\section{Section 2190 [Recodification]}

(1) The person who has relinquished the thing to the precarious borrower may request that it be returned at his will.

(2) The precarious borrower may not return the thing at a time when it would cause the lender difficulties, unless the lender consents to it.

\section{Section 2191 [Recodification]}

(1) The precarious borrower shall compensate the lender for damage to the thing, unless he proves that he used the thing in a manner appropriate to its nature.

(2) If the precarious borrower allows the thing to be used by someone else without the consent of the lender, he shall compensate the lender for the resulting damage, unless the damage would have occurred in any case.

\section{Section 2192 [Recodification]}

If a lost thing for which the precarious borrower has already provided compensation is found, he does not become 
entitled to keep the thing against the will of the lender, but shall return the thing to the lender in return for the compensation.

\section{Division 2}

\section{Loan for use}

\section{Section 2193}

\section{Basic provisions}

By a contract of loan for use, a lender relinquishes a non-consumable thing to a borrower and undertakes to allow him its gratuitous temporary use.

\section{Section 2194}

The borrower acquires the right to use the thing in the stipulated manner or, where no manner of use has been stipulated, in a manner appropriate to the nature of the thing. The borrower is not entitled to relinquish the thing to another person without the consent of the lender.

\section{Section 2195}

(1) The lender shall relinquish the thing to the borrower in a condition which is fit for use. If damage is caused as a consequence of a defect of the thing which the lender failed to reveal, the lender shall compensate the borrower for the damage incurred.

(2) The lender shall advise the borrower on how to use the thing, unless the rules are generally known or it follows from the circumstances that this is not necessary. If the lender fails to do so, he shall compensate the borrower for the resulting damage.

\section{Section 2196}

Where only the purpose for which the thing is to be used has been stipulated, the borrower shall make such arrangements so as to begin using the thing without undue delay and return it after fulfilling the purpose without undue delay.

\section{Section 2197}

The borrower has the right to return the thing early; however, should it cause the lender difficulties, the borrower may not return the thing without the lender's consent.

\section{Section 2198} contract.

(1) The lender may not demand early return of the thing; this does not apply if the borrower uses the thing in breach of

(2) If the lender inevitably needs the thing to be returned earlier due to reasons which he could not have predicted at the conclusion of the contract, he may claim its early return only if so stipulated.

\section{Section 2199}

(1) The usual costs associated with the use of the thing are borne by the borrower at his own expense.

(2) In case extraordinary costs are needed, the borrower may hand over the thing to the lender so that the lender can incur the costs himself. If the lender cannot or does not intend to do so and the borrower himself incurs the extraordinary costs to the necessary extent, the borrower is entitled to reimbursement as an agent without mandate.

\section{Section 2200}

The rights of the lender and borrower must be asserted within three months after the return of the thing; otherwise, they will not be granted by a court if the other party invokes late assertion of the right.

\section{Division 3}

\section{Lease}

\section{Subdivision 1}

\section{General provisions}

Section 2201 [Recodification]

\section{Basic provisions}

By a lease contract, a lessor undertakes to relinquish a thing to a lessee for temporary use and a lessee undertakes to pay rent to the lessor for such use. 


\section{Section 2202 [Recodification]}

\section{Subject of lease}

(1) Both immovable and non-consumable movable things may be leased. A part of an immovable thing may also be leased; the following provisions on a thing shall also apply to lease of its part.

(2) A thing which is yet to be created in the future may also be leased if it can be specified at the conclusion of the lease contract with sufficient accuracy.

\section{Section 2203 [Recodification]}

If a leased thing is registered in a public register, the right of lease is also registered upon application of the owner of the thing or the lessee with the owner's consent.

\section{Section 2204 [Recodification]}

(1) If the parties do not stipulate the period of lease or the date when the lease ends, the lease is conclusively presumed to be a lease for an indefinite period.

(2) If the parties stipulate a lease for a definite period exceeding fifty years, the lease is presumed to have been stipulated for an indefinite period; during the first fifty years, the lease may only be terminated on the stipulated grounds for termination and within the stipulated notice period.

\section{Lessor}

\section{Section 2205}

A lease contract obliges the lessor to:

a) relinquish the thing to the lessee so that the lessee can use it for the stipulated or usual purpose,

b) maintain the thing in such a condition so as to be fit for the use for which it was leased,

c) ensure that the lessee may peacefully use the thing for the period of lease.

Section 2206

(1) The lessor shall deliver the thing to the lessee within the stipulated period, or otherwise on the date following the date on which the lessee so requests.

(2) The lessor shall deliver the thing to the lessee together with everything that is necessary for the proper use of the thing.

\section{Section 2207}

(1) The lessee shall carry out routine maintenance of the thing for the period of lease, unless the lessor has undertaken to do so. The lessor shall carry out other maintenance and the necessary repairs of the thing, unless the lessee has undertaken to carry out maintenance of certain manner or kind and the repair of certain defects.

(2) The lessor is not liable for a defect of which the parties knew at the time of the conclusion of the lease contract and which does not prevent the use of the thing.

\section{Section 2208}

(1) If a lessee notifies the lessor properly and in due time of a defect of a thing which the lessor is to remove and the lessor fails to do so without undue delay, wherefore the lessee can use the thing only with difficulty, the lessee is entitled to a reasonable price reduction of the rent, or repair the thing himself and claim reimbursement of the reasonably incurred costs. However, if the defect makes the use substantially more difficult or completely prevents its use, a lessee is entitled to have the rent waived or may terminate the lease without a notice period.

(2) A lessee has the right to set off his claims from the lessor under Subsection (1) up to the amount of a month rent or, where the period of lease is shorter, only up to the amount of the rent.

(3) If a lessee fails to assert his right under Subsection (1) within six months from the date on which he discovered or could have discovered the defect, a court shall not grant him such a right if the lessor invokes late assertion of the right.

\section{Section 2209}

During the lease, a lessor is not entitled to change the thing at his will.

Section 2210

(1) Where, during the lease, a need arises to make a necessary repair of the thing which cannot be postponed until 
after the end of the lease, the lessee must tolerate it even if the repair causes him difficulties or restricts his use of the thing.

(2) Where the duration of the repair is unreasonably long in respect of the period of lease or if the repair makes the use of the thing unusually difficult, the lessee is entitled to a reduction of the rent according to the duration and extent of the repair.

(3) Where the repair is of such a nature that the use of the thing is completely prevented for the duration of the repair, the lessee is entitled to be provided with a different thing by the lessor for temporary use or terminate the lease without a notice period.

\section{Section 2211}

Where a third person jeopardises the lessee's right of lease or causes harm to the lessee by infringing his right of lease, the lessee may seek protection himself.

\section{Section 2212 [Recodification]}

(1) If a third person asserts the right of ownership or another right in a thing or claims that a thing be surrendered or vacated, the lessee shall notify the lessor thereof; the lessor shall provide the lessee with protection at the lessee's request. period.

(2) If the lessor fails to provide the lessee with sufficient protection, the latter may terminate the lease without a notice

(3) If the lessee is disturbed in the use of a thing or otherwise affected by the conduct of a third person, he is entitled to a reasonable reduction of the rent, provided that he notified the lessor of such conduct of the third person in time.

\section{Lessee}

Section 2213

Even without a special stipulation, a lessee is obliged to use the thing with due managerial care for the stipulated purpose or, where no purpose has been stipulated, for the usual purpose, and to pay the rent.

Section 2214

A lessee shall notify the lessor that a thing has a defect which is to be removed by the lessor immediately after the lessee discovered or could have discovered the defect in careful use of the thing.

\section{Sublease}

\section{Section 2215 [Recodification]}

(1) A lessee may create the right of use in a thing for a third person with the consent of the lessor; where the lease contract was concluded in writing, the lessor's consent must also be given in writing.

(2) If the lessee creates the right of use in a thing for a third person without the lessor's consent, it is considered a material breach of the lessee's duties causing a serious harm to the lessor.

(3) The right of use may be created for a third person only for the period of lease of the thing; a stipulation to the contrary is disregarded.

Section 2216

If a lessee allows a third person to use the thing, the lessee is liable to the lessor for the acts of that person as if the lessee used the thing himself.

\section{Rent}

\section{Section 2217}

(1) Rent is to be paid in the stipulated amount or, where no rent has been stipulated, in the amount usual at the time of conclusion of the lease contract, having regard to the rent for the lease of similar things under similar conditions.

(2) Where parties stipulate that the rent is to be provided by other means than in money, the property value of the performance expressed in pecuniary terms is decisive.

Section 2218

Rent is paid monthly in arrears.

\section{Other rights and duties of the parties}


(1) If notified by a lessor within a reasonable time in advance, the lessee shall allow the lessor to inspect the thing to the necessary extent and provide him with access to or into the thing for the purpose of carrying out a necessary repair or maintenance thereof. Prior notification is not required if it is necessary to prevent damage or in case of danger in delay.

(2) If the lessor's activities under Subsection (1) cause difficulties to the lessee which are not merely insignificant, the lessee is entitled to a reduction of the rent.

\section{Section 2220}

(1) The lessee may only change the thing with the prior consent of the lessor; if the lease contract has been concluded in writing, the lessor's consent must also be given in writing. The lessee shall change the thing at his own expense; if the change increases the value of the thing, the lessor shall make a settlement with the lessee at the end of the lease according to the extent of the increase.

(2) If the lessee changes the thing without the lessor's consent, the lessee shall restore its original state upon the lessor's request, but no later than upon the end of the lease of the thing. If, at the request of the lessor, the lessee fails to restore the thing to its original state, the lessor may terminate the lease without a notice period.

\section{Change of ownership}

Section 2221 [Recodification]

(1) If the owner of a thing changes, the rights and duties arising from the lease pass to the new owner.

(2) If the lessor has transferred the right of ownership in a thing, the new owner is not bound by any stipulations on the lessor's duties which are not provided by a statute. This does not apply if the new owner was aware of such stipulations.

\section{Section 2222 [Recodification]}

(1) A party is not entitled to terminate the lease only on the grounds that the owner of the thing has changed. In the case of a stipulation to the contrary, a lessor is entitled to terminate the lease within three months after he became or must have become aware of the identity of the lessee, and the lessee is entitled to terminate the lease within three months after he became aware of the change of ownership.

(2) If the new owner had no reasonable cause to doubt that he was buying a thing free of any lease, he is entitled to terminate the lease within three months after he became or must have become aware that the thing is leased and who the lessee is. This does not affect the lessee's rights with respect to the person with whom he concluded the lease contract.

(3) In the case of an immovable thing, the notice period is three months. In the case of a movable thing, the notice period is one month.

$$
\text { Section } 2223 \text { [Recodification] }
$$

A party who terminates a lease shall provide the other party with a reasonable withdrawal fee.

$$
\text { Section } 2224 \text { [Recodification] }
$$

If the lease concerns an apartment in which the lessee lives, the lessor is not entitled to terminate the lease due to the change of ownership. A stipulation to the contrary is disregarded.

\section{End of lease}

Section 2225

(1) Upon the end of a lease, the lessee shall deliver the thing to the lessor at the place of takeover and in the same condition as it was upon takeover, taking into account normal wear and tear caused by proper use, unless the thing ceased to exist or lost its value; delivery is also to be understood as a handover of a vacated immovable thing. Where, in the delivery of the thing to the lessee, a record was made containing the description of the thing, it is also taken into account in the delivery.

(2) Upon the delivery of the thing, the lessee shall separate and take everything he put in or on the thing at his own expense, provided that it is possible and does not deteriorate the essence of the thing or unreasonably hinder the use of the thing.

\section{Section 2226}

(1) If a thing ceases to exist during the period of lease, the lease shall end.

(2) If a thing partially ceases to exist during the period of lease, the lessee shall either have the right to a reasonable reduction of the rent, or may terminate the lease without a notice period.

\section{Section 2227}

If a thing becomes unusable for the stipulated purpose or, where no such purpose has been stipulated, for the usual purpose for reasons not attributable to the lessee, the lessee has the right to terminate the lease without a notice period. 
(1) Where the lessee uses a thing in a way that it is becoming worn beyond reasonable extent given the circumstances or there is a risk of destruction of the thing, the lessor shall request that the lessee use the thing properly and give him a reasonable time limit for a remedy and notify him of the possible consequences of failure to comply with the request. The request must be in writing and must be delivered to the lessee.

(2) If the lessee fails to comply with the request under Subsection (1), the lessor has the right to terminate the lease without a notice period.

(3) Where, however, grave danger in delay is imminent in the case under Subsection (1), the lessor has the right to terminate the lease without a notice period without having requested the lessee to provide for a remedy. becomes due.

(4) The lessor may also proceed under Sections (1) and (2) if the lessee fails to pay the rent before the next rent

\section{Section 2229 [Recodification]}

Each party may terminate a lease stipulated for a definite period only if the contract also stipulates the grounds for termination and notice period.

\section{Section 2230 [Recodification]}

(1) Where a lessee continues to use a thing after the expiry of the period of lease and the lessor fails to request, within one month, that the lessee deliver the thing to the lessor, the lease is conclusively presumed to have been renewed under the originally stipulated conditions. If the original period of lease exceeded one year, the contract is conclusively presumed to have been renewed for one year; if the original period of lease was shorter than one year, the contract is conclusively presumed to have been renewed for that period.

(2) Even where the lessee continues to use the thing, the provision of Subsection (1) does not apply if any of the parties, within a reasonable time in advance, has expressed the intention to end the lease or has already terminated it.

\section{Section 2231}

(1) A lease stipulated for an indefinite period ends if terminated by notice by any of the parties. The notice period is one month for movable things, and three months for immovable things.

(2) The parties are not obliged to justify the notice of termination; this does not apply if a party has the right to terminate the lease without a notice period.

\section{Section 2232 [Recodification]}

If a party commits a particularly serious breach of its duties, thereby causing significant harm to the other party, the party affected has the right to terminate the lease without a notice period.

\section{Section 2233}

(1) Within three months before the end of the lease, provided that the parties are aware of the end date of the lease, the lessee of a thing which is to be leased again shall provide a prospective lessee with access to the thing to the necessary extent for inspection in the presence of the lessee and lessor; the lessor shall notify the lessee of his visit within a reasonable time in advance.

(2) The provision of Section 2219(2) also applies to this Section.

$$
\text { Section } 2234 \text { [Recodification] }
$$
the thing.

In order to satisfy a claim from the lessee, a lessor has the right to retain movable things which a lessee has on or in

\section{Subdivision 2}

\section{Specific provisions on the lease of an apartment and the lease of a building}

\section{Basic provisions}

\section{Section 2235 [Recodification]}

(1) If a lease contract obliges the lessor to relinquish to the lessee an apartment or building which constitutes the subject of the lease in order to provide for the housing needs of the lessee and, where appropriate, his household members, any provisions prejudicing the lessee's rights under this Subdivision are disregarded.

(2) The provisions of this Subdivision do not apply where the lessor leases an apartment or building to the lessee for recreation or another apparently short-term purpose. 
(1) An apartment is to be understood as a room or a set of rooms which form part of a building, constitute residential premises and are intended and used for residential purposes. If the lessor and lessee stipulate that premises other than residential premises are to be leased for housing purposes, the parties have the same obligations as if residential premises were leased.

(2) The fact that the leased premises are not intended for residential purposes may not be to the detriment of the lessee.

(3) Where a building is leased for the use by the lessee for housing purposes, the provisions on lease of an apartment apply with the necessary modifications.

\section{Section 2237 [Recodification]}

A contract must be in writing; however, the lessor does not have the right to invoke invalidity of a contract against the lessee on the grounds of a lack of form.

\section{Section 2238 [Recodification]}

Where a lessee has used an apartment for a period of three years in good faith that he holds a lawful lease, a lease contract is considered to be properly concluded.

\section{Section 2239 [Recodification]}

\section{Prohibited stipulations}

A stipulation imposing on the lessee a duty to pay the lessor a penalty or a duty which, given the circumstances, is evidently excessive is disregarded.

\section{Section 2240}

\section{Special provisions on the lease of a cooperative apartment}

A contract for the lease of a cooperative apartment may be concluded under the conditions provided by another statute or by articles of association of the housing cooperative. The same applies to the rights and duties of the lessor and lessee.

\section{Section 2241}

In the case of an apartment which is owned by a legal person and used for housing purposes by a member or shareholder of the legal person on the basis of the membership, the rights and duties of the parties are governed, in particular, by the articles of association or memorandum of association.

\section{Delivery of an apartment}

Section 2242

(1) Where no time has been stipulated for the lessor to make an apartment available to the lessee in a condition fit for moving in and occupancy, the lessor shall make the apartment available to the lessee on the first day of the month following the effective date of the contract. An apartment is deemed to have been made available if the lessee receives the keys and nothing prevents the lessee from entering the apartment.

(2) The lessor and the lessee may agree that the lease will concern an apartment which is not fit for occupancy. Such a stipulation is only valid if specific rights and duties arising from the specific nature of the apartment have been simultaneously stipulated, including the amount and manner of payment of the costs of the necessary alterations.

\section{Section 2243}

An apartment is fit for moving in and occupancy if it corresponds to the stipulations in the contract and, in the absence of any stipulation, an apartment is fit for moving in and occupancy if it is clean and in a condition which is usually considered good, and the provision of the necessary performances associated with or related to the use of the apartment is ensured.

\section{Section 2244}

(1) If an apartment is not fit for moving in and occupancy at the stipulated time or if it is in a condition that does not correspond to the information provided by the lessor, the lessee has the right to refuse to move in. If he moves in, he has the right to require that the lessor execute the contract; if the lessee fails to do so without undue delay, his right is extinguished.

(2) If the lessee was already aware of the condition of the apartment at the conclusion of the contract, the provision of Subsection (1) does not apply. This also applies where the lessee was not aware of the condition of the apartment at the conclusion of the contract due to his failure to inspect the apartment despite having been properly invited to do so by the lessor in due time.

\section{Section 2245}

If the lessee exercises his right not to move in an apartment, he is not obliged to pay rent for the duration of the defect. If he moves in, he has the right to a reasonable reduction of the rent until the lessor removes the defect; this also applies 
in the case of a substantial defect in the provision of a performance associated with or related to the use of the apartment.

\section{Rent and other payments}

\section{Section 2246 [Recodification]}

(1) The parties shall stipulate a fixed amount of rent. Rent is presumed to be agreed for one month.

(2) If the parties do not stipulate the amount of rent, the lessor becomes entitled to rent corresponding to a rent usually paid, at the given place, for a new lease of a similar apartment under similar contractual terms on the date of the contract.

\section{Section 2247}

(1) The parties shall stipulate what performances associated with the use of the apartment or related services are to be provided by the lessor; in the absence of such a stipulation, the provision of Subsection (2) apply.

(2) The lessor shall provide the necessary services for the duration of the lease. Necessary services are presumed to include water supply, waste water disposal including cesspool emptying, heat supply, municipal waste disposal, lighting and cleaning of the common areas of the building, provision of radio and television broadcasting, operation and cleaning of chimneys, and operation of the lift, where applicable.

(3) The manner of allocating costs and payments for services is provided by another legal regulation.

(4) The parties shall stipulate the manner of allocating costs and payments of any other services, unless provided by another legal regulation or decided by a price regulation body. The manner of allocating costs must be determined before a service is provided.

\section{Section 2248 [Recodification]}

The parties may stipulate an annual rent increase.

\section{Section 2249 [Recodification]}

(1) If the parties do not stipulate or expressly exclude a rent increase, the lessor may propose to the lessee in writing a rent increase up to the amount of comparable rent usual at the given place, provided that the proposed increase, along with an increase already made in the previous three years, does not exceed twenty per cent. A proposal which was made before the expiry of a twelve-month period within which rent was not increased or which does not indicate the amount of rent and document that the conditions under this provision have been met is disregarded.

(2) An implementing legal regulation shall provide for the details and the procedure for identifying comparable rent usual at the given place.

(3) If a lessee accepts the proposal to increase the rent, he shall pay the increased rent as proposed from the third calendar month after the proposal has reached the lessee. If a lessee fails to notify the lessor in writing within two months after the proposal reaches the lessee that he accepts the increase in the rent, the lessor has the right to submit, within further three months, an application to the court to determine the amount of the rent; a court shall not grant an application filed after the expiry of the time limit if the lessee invokes late filing of the application. On the application of the lessor, a court shall determine the rent in an amount not exceeding the amount usual at the given place and time, with effect from the date of the application.

(4) If a lessee proposes a rent reduction, the provisions of Subsections (1) to (3) apply by analogy.

\section{Section 2250 [Recodification]}

(1) If a lessor carries out construction alterations which permanently improve the utility value of the leased apartment or the general living conditions in the building or result in permanent energy or water savings, the lessor may agree on an increase in the rent with the lessees up to a maximum of ten per cent of the reasonably incurred costs per year. If the lessees of at least two thirds of the apartments in the building consent to the proposal for such a rent increase, the increased rent shall also apply to the other lessees.

(2) If there is no agreement under Subsection (1), the lessor may, for the above reasons, propose a rent increase by three and a half per cent of the incurred costs per year; costs are presumed to have been incurred reasonably. A proposal which does not specify the amount of rent or does not document that conditions under this provision have been met is disregarded.

\section{Section 2251}

(1) A lessee shall pay the rent in advance for each month or for another stipulated payment period no later than on the fifth day of the relevant payment period unless a later day has been stipulated. Together with the rent, the lessee shall pay the advance payments or the cost of services ensured by the lessor; Section 2253 applies to such advance payments and costs by analogy.

(2) A lessor may not require that the lessee provide another performance than that under Subsection (1), whether in the form of a contribution or otherwise, or pay the rent by a check with a later date or in another similar manner. 
(1) If so requested by a lessee, the lessor shall allow the lessee, usually no later than within four months after the end of the billing period period, to inspect the accounts of the cost of the services provided for the previous calendar year, as well as to make extracts from and transcripts or copies of these accounts; the same applies to documents concerning the costs charged.

(2) Any underpayments or overpayments of advance payments for the services provided are due on the same date; unless another period has been stipulated, they are due within three months after the expiry of the time limit under Subsection (1).

\section{Section 2253}

(1) Where the parties fail to agree on the rent owed, the lease may not be terminated for non-payment of rent if the lessee places the rent owed, or its disputed part, into notarial deposit and informs the lessor thereof.

(2) If the lessee claims performance under the contract and the lessor refuses to provide it on the grounds of nonpayment of rent, the lessee shall place the rent owed, or its disputed part, into notarial deposit and inform the lessor thereof.

\section{Section 2254 [Recodification]}

Security

(1) If the parties stipulate that the lessee will give the lessor a pecuniary security guaranteeing his payment of the rent, and that he will fulfil other duties arising from the lease, the security may not be more than six times the monthly rent.

(2) When a lease ends, the lessor shall return the security to the lessee; in doing so, he sets off the amount of the lessee's debt arising from the lease, where applicable. The lessee is entitled to interest on the security at least at the statutory rate which accrued from the date of its provision.

\section{Rights and duties of the parties}

Section 2255 [Recodification]

(1) A lessee shall use the apartment properly and in accordance with the lease contract.

(2) A lessee may work or do business in the apartment, provided that this does not cause increased burden on the apartment or building.

\section{Section 2256}

(1) For the period of lease, the lessor shall maintain due order in the building which is usual under local circumstances.

(2) For the period of lease, the lessee shall comply with usual rules of conduct applicable in the building and observe reasonable instructions of the lessor for maintaining due order which are usual under local circumstances.

\section{Section 2257}

(1) For the period of lease, a lessor shall maintain the apartment and building in a condition fit for use. apartment.

(2) The lessee shall only carry out and pay for routine maintenance and minor repairs related to the use of the

\section{Section 2258}

A lessee has the right to keep an animal in the apartment unless, given the circumstances in the building, it constitutes excessive inconvenience for the lessor or other residents of the building. If the keeping of an animal results in increased costs of maintenance of the common areas of the building, the lessee shall compensate the lessor for these costs.

\section{Alterations and other changes made to an apartment or building}

\section{Section 2259}

The lessee is only obliged to tolerate an alteration of the apartment or building or its reconstruction or another change if it does not reduce the value of living and if it can be done without major inconvenience to the lessee or where it is carried out on the mandate of a public body or if there is a direct risk of a particularly serious harm. In other cases, a change may only be carried out with the consent of the lessee.

\section{Section 2260}

(1) If the lessee's consent is not required to carry out an alteration, reconstruction or another change of an apartment or building requiring vacation of the apartment, the lessor is entitled to commence the work only after he undertakes to provide the lessee with adequate reimbursement of costs efficiently incurred by the lessee in connection with vacating the apartment and pays the lessee a reasonable advance payment to cover these costs. 
(2) If it is not excluded by the circumstances of the case, the lessor shall notify the lessee no less than three months before the commencement of the work at least of the nature of the work, its anticipated commencement date, an estimate of its duration and the necessary period for which the apartment must be vacated, and advise the lessee of the consequences of the refusal to vacate; the lessor shall also undertake to provide reimbursement under Subsection (1) and specify the advance payment for the reimbursement that he offers.

(3) If, within ten days after the notification, a lessee fails to state with respect to the lessor that he will vacate the apartment for the required period, he is presumed to have refused to vacate the apartment.

\section{Section 2261}

If it is necessary to vacate an apartment for a maximum of one week, it is sufficient to notify the lessee no less than ten days before the commencement of the work. The time limit for the lessee's statement is reduced to five days.

\section{Section 2262}

(1) If a lessee refuses to vacate an apartment, the lessor may apply to a court to order the vacation; however, if the lessor fails to file the application within ten days after the lessee's refusal, his right to claim that the apartment be vacated is extinguished.

(2) If a lessor proves the purposefulness of an alteration, reconstruction or another change made to an apartment or building and the necessity to vacate the apartment, a court shall grant such an application; it may also impose appropriate restrictions on the parties that may be reasonably required from them. No work may be carried out before the decision on vacating the apartment, unless the court so permits.

\section{Section 2263}

(1) A lessee may carry out an alteration, reconstruction or other changes of an apartment or a building with the consent of the lessor. If the lessor refuses, without a serious and fair reason, to give his consent to a change which is necessary due to the disability of the lessee or a member of his household or another person living in the apartment, the lessor's consent is replaced by a court on an application of the lessee.

(2) When a lease ends, the lessee shall remove the changes which he made to the apartment or building, unless the lessor does not require restoration to the previous state.

\section{Section 2264}

(1) If a lessee discovers damage or a defect in the apartment which must be removed without delay, he shall immediately notify the lessor thereof; he shall notify the lessor of another defect or damage preventing normal living without undue delay.

(2) Having regard to his circumstances, a lessee shall do what he can be expected to do to prevent further damage from damage or a defect that must be removed without delay. The lessee is entitled to reimbursement of the costs reasonably incurred in the prevention of further damage, unless the damage or a defect was caused by circumstances for which the lessee bears liability.

\section{Section 2265} by the lessee.

(1) A lessor shall remove damage or a defect within a reasonable time after he was notified of the damage or defect

(2) If a lessor fails to remove the damage or defect properly and without undue delay, the lessee may remove the damage or defect and claim reimbursement of reasonably incurred costs, or a reduction of the rent, unless the damage or defect is not substantial.

(3) If a lessee fails to notify the lessor of damage or a defect without undue delay after he should and could have discovered it by exercising due care, the lessee is not entitled to any reimbursement of costs; if the lessee removes the damage or defect himself, he is also not entitled to a reduction of the rent.

\section{Section 2266}

If a lessor fails to remove damage or a defect even within an additional time limit and the damage or defect was caused by circumstances for which the lessee bears no liability, the lessee is entitled to terminate the lease without a notice period if the lessor's default of the removal of the damage or defect, or the damage or defect itself, constitutes a material breach of lessor's duties.

\section{Section 2267}

If a lessee fails to remove the damage or defect caused by circumstances for which he bears liability, the damage or defect is removed by the lessor at the expense of the lessee.

\section{Section 2268}

(1) The provisions on damage to or a defect of an apartment apply by analogy if the use of an apartment is prevented by a right of a third person. 
(2) The provisions on damage to or a defect of an apartment also apply by analogy where the use of an apartment is prevented by the provisions of a statute or a decision of a public body issued on the basis of a statute.

\section{Section 2269}

(1) If the lessee knows in advance about his absence in the apartment which is to be longer than two months, and also that he will not have easy access to the apartment during that time, he shall notify the lessor in due time. At the same time, he shall designate a person who, during his absence, shall provide access to the apartment in case it is absolutely necessary; if the lessee has no such person available, the lessor is such a person.

(2) If the lessee fails to fulfil his duty under Subsection (1), such conduct is considered to constitute a material breach of the lessee's duties; this does not apply if no serious harm is incurred as a result.

\section{Joint lease}

Section 2270

(1) Where several persons conclude a lease contract with the lessor, they become joint lessees of the apartment; a person who, with the consent of the parties, accedes to the contract, also becomes a joint lessee.

(2) Provisions on a lessee apply by analogy to joint lessees, unless otherwise provided below.

$$
\text { Section } 2271 \text { [Recodification] }
$$

Joint lessees have equal rights and duties. The provisions on a partnership apply with the necessary modifications.

\section{Members of the lessee's household}

\section{Section 2272 [Recodification]}

(1) A lessee has the right to receive anyone into his household. If a lessee receives a new member into his household, he shall notify the lessor of the increase in the number of persons living in the apartment without undue delay; if the lessee fails to do so within two months after the change, he is presumed to have seriously breached his duty.

(2) A lessor is entitled to reserve, in the contract, the right to approve a new member to be received into the lessee's household. This does not apply to close persons or to other cases deserving special consideration. The lessor's approval of a person other than a close person to be received as a member of the lessee's household must be in writing.

(3) The lessor has the right to require that the number of persons living in the lessee's household be appropriate to the size of the apartment and does not prevent cohabitation of all these persons in the apartment in the usual conditions in terms of comfort and satisfactory hygiene.

\section{Section 2273} undue delay.

If the number of members of the lessee's household decreases, the lessee shall notify the lessor accordingly without

\section{Sublease}

\section{Section 2274 [Recodification]}

If a lessee permanently resides in an apartment, he may sublease part of it to a third person even without the consent of the lessor. Section 2272 applies with the necessary modifications.

\section{Section 2275 [Recodification]}

(1) If a lessee does not permanently reside in an apartment, he may sublease the apartment or part of it to a third person only with the consent of the lessor.

(2) A request for consent to sublease and the consent to sublease must be in writing. If the lessor fails to respond to the request within one month, the consent is considered granted; this does not apply if a prohibition of sublease has been stipulated.

\section{Section 2276}

Where a lessee subleases an apartment or part of it to a third person in contravention of Sections 2274 and 2275, he materially breaches his duty.

\section{Section 2277}

A sublease ends together with the lease. If a lease is to end, a lessee shall inform the sublessee accordingly, providing him with the decisive facts; these include, without limitation, the day the lease ends and, where applicable, the length of the notice period and its commencement. 
A sublease shall end no later than the lease.

\section{Consequences of the death of a lessee}

\section{Section 2279 [Recodification]}

(1) If a lessee dies and there is no joint lease of the apartment, the lease passes to a member of the lessee's household who lived in the apartment on the day of the lessee's death and has no apartment of his own. If such a person is someone other than the lessee's spouse, partner, parent, sibling, son-in-law, daughter-in-law, child or grandchild, the lease passes to such a person only if the lessor consents to the passage of the lease to that person.

(2) A lease of an apartment after its passage under Subsection (1) shall end no later than two years from the date of the passage of the lease. This does not apply if the person to whom the lease passed reached the age of seventy years on the date of passage of the lease. Likewise, this does not apply if the person to whom the lease passed has not reached the age of eighteen years on the date of passage of the lease; in such a case, the lease shall end no later than on the date on which the person reaches the age of twenty years, unless the lessee and the lessor agree otherwise.

(3) Where several members of the lessee's household meet the conditions for the passage of the lease, the rights and duties arising from the lease pass to all of them jointly and severally.

(4) Any person meeting the conditions for passage of the lease may, within one month after the death of the lessee, notify the lessor in writing that he does not intend to continue the lease; his lease is extinguished on the date on which the notification reaches the lessor.

(5) In the case of the death of a lessee of a cooperative apartment which is not subject to a joint lease of spouses, the lessee's membership in the cooperative and the lease of the apartment passes upon the lessee's death to the heir to whom the membership share devolved.

\section{Section 2280 [Recodification]}

If a lessee's descendant is a member of the lessee's household, he has a preferential right to have the rights and duties arising from the lease pass to him. In case there are several such persons, the rights and duties arising from the lease pass to all of them jointly and severally; however, each of them may make a personal declaration that he does not intend to continue the lease.

\section{Section 2281 [Recodification]}

(1) Where the rights and duties arising from the lease pass to a member of the lessee's household, the lessor has the right to require that he provide a security if the deceased lessee did not do so. This also applies where the lessor becomes obliged to settle the security with the lessee's heir.

(2) If the rights and duties arising from the lease pass to a member of the lessee's household and the lessee has paid the rent in advance, the member of the lessee's household shall surrender to the heir everything which he saved or acquired by such payment.

\section{Section 2282 [Recodification]}

If the rights and duties arising from the lease do not pass to a member of the lessee's household, they pass to the lessee's heir. Persons who lived with the lessee in a common household until his death are obliged, jointly and severally with the lessee's heir, for the debts which arose from the lease before the lessee's death.

\section{Section 2283 [Recodification]}

(1) A lessor may terminate the lease without stating a reason by giving two months' notice within three months after he learns that the lessee has died, that the rights and duties arising from the lease have not passed to a member of the lessee's household and who is the lessee's heir or who administers his decedent's estate.

(2) A lessee's heir may terminate the lease by two months' notice within three months after he learns of the lessee's death, of his succession right and of the fact that the rights and duties arising from the lease have not passed to a member of the lessee's household, but no later than six months after the lessee's death. A person who administers the decedent's estate shall also have the right to terminate the lease.

\section{Section 2284 [Recodification]}

Where the heir of the lessee is still unknown even after six months after the lessee's death, the lessor may have the apartment vacated, whereby the lease is extinguished. The lessor shall deposit things from the apartment in a public warehouse or with another depositary at the heir's expense; if the lessee's heir fails to take over the things without undue delay, the lessor may, on the heir's account, sell them in an appropriate manner.

\section{End of lease}

\section{Section 2285 [Recodification]}

If a lessee continues to use the apartment for at least three months after the date on which the lease of the apartment was to end and the lessor fails to request the lessee to leave the apartment, the lease is conclusively presumed to have been 
stipulated again for the same period as before but for no more than two years; this does not apply if otherwise stipulated by the parties. The request must be in writing.

\section{Section 2286}

(1) A notice of termination of lease must be in writing and must reach the other party. The notice period commences on the first day of the calendar month following the month in which the notice of termination reached the other party.

(2) If the lease is terminated by the lessor, he shall advise the lessee about his right to assert defences against the termination and apply to a court to review the lawfulness of the termination; otherwise, the termination is invalid.

\section{Section 2287 [Recodification]}

A lessee may terminate a lease for a definite period in case the circumstances which the parties apparently relied on when the obligation arising from the lease contract was created have changed to the extent that the lessee cannot be reasonably required to continue the lease.

\section{Section 2288 [Recodification]}

(1) A lessor may terminate a lease for a definite or indefinite period by three months' notice if:

a) the lessee materially breaches his duty arising from the lease,

b) the lessee is convicted of an intentional criminal offence against the lessor or a member of his household or a person who lives in the building in which the lessor's apartment is located, or against the property of another which is located in the building,

c) the apartment is to be vacated because it is necessary in the public interest to dispose of the apartment or the building in which the apartment is located in such a way that any use of the apartment will be impossible, or

d) there is another similarly serious reason for the termination of the lease.

(2) A lessor may also terminate a lease for an indefinite period by three months' notice if:

a) the apartment is to be used by the lessor or his spouse who intends to leave the family household and a petition for divorce has been filed or marriage was divorced,

b) the lessor needs the apartment for his relative or his spouse's relative in a direct line or collateral line in the second degree.

(3) If a lessor terminates the lease for reasons under Subsections (1) and (2), he shall indicate the reason in the notice of termination.

\section{Section 2289}

If a lessor has given the lessee a notice for any of the reasons under Subsection 2288(2), he is obliged to lease the apartment to the lessee again or compensate him for the damage if he fails to use the apartment within one month after the lessee has vacated it for the purpose stated as the reason for termination. This time limit is suspended for the time necessary to alter the apartment, provided that the alteration commences no later than two weeks after vacating and there is due progress.

Section 2290

A lessee has the right to apply to a court to review the lawfulness of the termination within two months from the date on which the notice of termination reached him.

\section{Section 2291 [Recodification]}

(1) If a lessee commits a particularly serious breach of his duty, the lessor has the right to terminate the lease without a notice period and demand that the lessee deliver the apartment to him without undue delay, but no later than one month after the end of the lease.

(2) A particularly serious breach of a lessee's duty occurs, without limitation, if the lessee fails to pay the rent and the costs of services for at least three months; seriously or irreversibly damages the apartment or building; otherwise causes serious damage or inconvenience to the lessor or persons living in the building; or unlawfully uses the apartment in a manner or for a purpose other than that which has been stipulated.

(3) If, in the notice of termination, the lessor fails to indicate what he regards as particularly serious breach of the lessee's duty or fails to request the lessee, before the delivery of the notice of termination, to remove the lessee's defective conduct or unlawful condition within a reasonable time, the notice of termination is disregarded.

\section{Section 2292}

A lessee shall deliver the apartment to the lessor on the day the lease ends. The apartment has been delivered when the lessor receives the keys and nothing other prevents him from accessing and using the apartment. If the lessee leaves the apartment in such a manner that the lease can unquestionably be considered to be ended, the apartment is presumed to have been delivered immediately. 
(1) The lessee shall deliver the apartment in the same condition as upon takeover, without regard to the usual wear and tear caused by normal use and any defects which the lessor is obliged to remove.

(2) Where the parties have stipulated that the lessee will restore the apartment to its original condition when the lease ends, the lessee shall remove any changes to the apartment which he made with the consent of the lessor.

(3) A lessee shall remove all changes to the apartment which he made without the consent of the lessor, unless the lessor informs the lessee that he does not request the removal of the changes; nevertheless, the lessee may not require compensation, even where the changes increased the value of the apartment. A lessor may claim compensation in the amount of any reduction in the value of the apartment caused by changes made by the lessee without the consent of the lessor.

\section{Section 2294}

Equipment and objects attached to the walls, floor and ceiling of an apartment which cannot be removed without undue reduction in the value of the apartment or building, or damage thereof, pass into the ownership of the owner of the immovable thing upon their attachment or insertion. A lessee is entitled to require that the lessor settle with him without undue delay; this does not apply to what the lessee carried out without the consent of the lessor. The settlement is due no later than on the date the lease ends.

\section{Section 2295}

If the lessee fails to deliver the apartment to the lessor on the day on which the lease ends, the lessor has the right to compensation in the amount of the stipulated rent until the date when the lessee actually delivers the apartment to the lessor.

\section{Section 2296}

(1) If a thing which may be presumed to belong to the lessee or a member of his household is located in the apartment, the lessor shall take care of the thing for the benefit and on the account of the lessee. If the lessee fails to take over the thing without undue delay, the lessor shall, after prior notice to the lessee and on his account, become entitled to sell the thing in an appropriate manner after he has provided the lessee with a reasonable additional time limit for takeover.

(2) The provision of Subsection (1) does not apply in the case of a thing which was apparently abandoned by the lessee or a member of his household.

\section{Lease of a company apartment}

Section 2297 [Recodification]

If lease of an apartment has been stipulated in connection with the performance of employment, office or other work and the contract expressly states that the subject of lease is a company apartment, the rights of the lessee of the company apartment may be limited. This also applies where the lease of a building has been stipulated in this context.

\section{Section 2298}

(1) Lease of a company apartment shall end on the last day of the calendar month following the month in which the lessee ceased to perform the work under Section 2297 without a serious reason.

(2) If a lessee ceases to perform the work for reasons of his age or health condition, for reasons on the part of the lessor or for another serious reason, the lessee's lease of the company apartment shall end two years after the date on which he ceased to perform the work.

\section{Section 2299}

Lease of a company apartment ends upon the death of the lessee. A person who lived in the apartment together with the lessee has the right to reside in the apartment; however, if the lessor requests that the person vacate the apartment, the person shall do so within three months from the date on which the request was received.

\section{Lease of a special purpose apartment}

\section{Section 2300}

(1) If the subject of the lease is an apartment intended for accommodation of persons with disabilities or an apartment in a building with facilities intended for such persons or an apartment in a nursing home, such lease shall constitute a lease of a special purpose apartment.

(2) A lessor may only conclude a contract for the lease of a special purpose apartment on the basis of a written recommendation of the person who created the apartment at his expense, or such a person's legal successor.

\section{Section 2301}

(1) The provision of Section 2279 does not apply to special purpose apartments. If a lessee dies, the lease of a special purpose apartment ends and the lessor shall request the persons who live in the apartment with the lessee to vacate the apartment within three months from the date on which they received the request; in the absence of such persons in the apartment, the lessor shall submit such a request to the lessee's heirs. 
(2) A lessor may terminate the lease of a special purpose apartment only with the prior consent of the person who created the apartment at his expense, or such person's legal successor.

\title{
Subdivision 3
}

\section{Special provisions on the lease of business premises}

\section{Basic provisions}

\author{
Section 2302 [Recodification]
}

(1) The provisions of this Subdivision apply to the lease of premises or a room for the purpose of conducting business in such premises or room, if the premises or room are subsequently used at least predominantly for business activities, regardless of whether or not the purpose of the lease is stated in the lease contract (hereinafter "business premises"). Lease of business premises is governed by general provisions on leases, unless otherwise provided below.

(2) In the case of a lease of premises or a room for purposes other than residential purposes or conducting business activities within the meaning of Subsection (1), the general provisions on leases apply.

Section 2303

If the lease of business premises is connected with the provision of services, the provisions relating to the provision of services connected with the lease of an apartment apply by analogy.

\section{Section 2304}

(1) A lessee may not perform other activities or change the manner or conditions of performance of the activities as follows from the purpose of the lease or another stipulation between the parties, or as could be reasonably expected at the conclusion of the contract, if such a change would deteriorate the conditions in the immovable thing or be harmful to the lessor or other users of the immovable thing beyond a reasonable degree.

(2) The provision of Subsection (1) does not apply where a change in the circumstances on the part of the lessee results in an insignificant change in his activities in some respect.

Section 2305

The lessee may, with the lessor's consent and to an appropriate extent, install signboards, posters and similar signs on the immovable thing where the business premises are located; the lessor may refuse to grant consent for a serious reason. Where the lessee applies for consent in writing and the lessor fails to respond within one month, the lessor's consent is considered granted.

\section{Section 2306}

When the lease ends, the lessee shall remove the signs which he installed on the immovable thing and restore the affected part of the immovable thing to its original condition.

Section 2307

\section{Transfer of lease of business premises}

(1) A lessee may, with the prior consent of the lessor, transfer the lease in connection with a transfer of the business activities for which the premises are used; the consent of the lessor, as well as the lease transfer contract, must be in writing.

(2) Section 2306 applies by analogy.

\section{End of lease}

\section{Section 2308}

A lessee may terminate a lease for a definite period even before the expiry of the stipulated period if:

a) he loses the eligibility to pursue the activities for which the business premises are intended,

b) the leased premises are, for objective reasons, no longer fit for pursuing the activities they were intended for, and the lessor fails to provide the lessee with adequate replacement premises, or

c) the lessor materially breaches his duties towards the lessee.

\section{Section 2309}

A lessor may terminate a lease for a definite period even before the expiry of the stipulated period if:

a) the immovable thing in which the premises used for business activities are located is to be removed or reconstructed so that further use of the premises will be prevented and the lessor was not required to foresee nor could not have foreseen it at the conclusion of the contract, or 
b) the lessee materially breaches his duties towards the lessor, including, without limitation, by acting contrary to the provisions of Section 2305 or being more than one month in default of the payment of rent or services associated with the use of the business premises, despite having been requested to remedy the situation by the lessor.

\section{Section 2310}

(1) A notice of termination must indicate the grounds for termination; a notice of termination indicating no grounds for termination is invalid.

(2) The notice period is three months

\section{Section 2311}

The provisions on the end of lease of an apartment for a definite period apply by analogy.

Section 2312

In case of a lease for an indefinite period, a party may terminate such lease by six months' notice; however, if a party has a serious reason for termination, the notice period is three months; where the duration of a lease is more than five years and, given the circumstances, a party could not have expected that the other party would terminate the lease, the notice period is always six months.

\section{Section 2313}

If a lessee vacates the premises used for business activities as required in the notice of termination, the notice of termination is considered to be valid and accepted by the lessee without objections.

\section{Section 2314 [Recodification]}

(1) The terminated party may assert defences against the notice of termination within one month from the date of delivery thereof; the defences must be in writing. is extinguished.

(2) If the terminated party fails to assert the defences in time, the right to apply for a review of lawfulness of the notice

(3) If the terminated party asserts the defences in time, but the terminating party fails to withdraw the notice of termination within one month from the date on which the defences were delivered to it, the terminated party has the right to apply to a court to review the lawfulness of the notice within two months from the date on which the time limit for withdrawal of the notice expired without the terminating party having withdrawn the notice of termination.

\section{Section 2315 [Recodification]}

\section{Compensation for acquisition of customer base}

If a lease ends by notice of termination given by the lessor, the lessee is entitled to compensation for the benefit which the lessor or a new lessee gained by acquiring the customer base established by the terminated lessee. The lessee has no such right if his lease was terminated due to a material breach of his duties.

\section{Subdivision 4}

\section{Special provisions on a commercial lease of movable things}

Section 2316

\section{Basic provisions}

(1) By a lease contract, the lessor who is an entrepreneur and whose business activities consist in leasing things undertakes to relinquish a movable thing to a lessee for his use for a definite period and the lessee undertakes to pay rent to the lessor for the use.

below.

(2) Commercial lease of movable things is governed by the general provisions on lease, unless otherwise provided

\section{Section 2317}

Upon the handover to the lessee, the lessor shall make sure that the thing is in good condition, show the lessee that it is functional, where customary, and familiarise the lessee with the rules for handling the thing or provide him with relevant instructions in writing.

Section 2318

(1) If a thing has a defect due to which it cannot be properly used or it can only be used with considerable difficulties, the lessee is entitled to be provided with a different thing serving the same purpose by the lessor.

(2) For the period during which a lessee could not properly use a thing or could only use it with considerable difficulties, the lessee is entitled to have the rent waived or receive a reduction of or a decrease in the rent; the lessee must 
assert his right against the lessor by the end of the stipulated lease period; otherwise, the right is extinguished.

Section 2319

(1) The lessee shall notify the lessor of any damage, loss or destruction of the thing without undue delay.

(2) The lessee shall pay the rent, until he notifies the lessor of damage to the thing preventing him from proper use of the thing or its loss or destruction; the lessee shall also pay the rent for a period when he is in delay with returning the thing.

(3) The lessee is not liable for the wear and tear of the thing caused by proper use.

\section{Section 2320}

(1) A lessee has the right to terminate the lease at any time. The notice period is ten days.

(2) The provision on the renewal of a lease contract after the expiry of the period of lease if the lessor fails to request the return of the thing does not apply.

\section{Subdivision 5}

\section{Special provisions on the lease of a means of transport}

Section 2321

\section{Basic provisions}

By a lease contract, the lessor undertakes to relinquish a means of transport to the lessee for his use for a definite period and the lessee undertakes to pay rent to the lessor for the use.

\section{Section 2322 [Recodification]}

(1) The lessor shall deliver the means of transport to the lessee along with the necessary documents within the stipulated period, or otherwise without undue delay after the conclusion of the contract.

(2) The means of transport must be fit for operation and the stipulated manner of use, or otherwise for the usual use of the means of transport.

(3) If the means of transport is unfit for operation under Subsection (2), the lessee has the right to refuse to take over the means of transport, and if he ascertains such unfitness only subsequently, he has the right to return the means of transport and request that the defect be removed, another means of transport delivered or the contract cancelled.

\section{Section 2323}

The lessee shall insure the means of transport only if so stipulated.

\section{Section 2324}

The lessee shall pay the rent after he ceases to use the means of transport; however, if the lease has been stipulated for a period longer than three months, the lessee shall pay the rent at the end of each calendar month.

\section{Section 2325}

(1) The lessee shall maintain the means of transport in the same condition as upon takeover, taking into account normal wear and tear.

(2) The lessor shall reimburse the lessee for the costs incurred by the lessee for maintenance; if the lessee fails to assert the right against the lessor within three months after incurring the costs, the right is extinguished.

\section{Subdivision 6}

\section{Accommodation}

\section{Section 2326}

\section{Basic provisions}

By an accommodation (a short-term lease) contract, the accommodation provider undertakes to provide short-term accommodation to a guest for a stipulated period or a period following from the purpose of the accommodation in a dedicated facility, and the guest undertakes to pay the accommodation provider for the accommodation and services associated with accommodation within the time limit prescribed by the accommodation rules or, where applicable, within a usual time limit.

\section{Section 2327 [Recodification]}

(1) A guest has the right to use the premises reserved for his accommodation, as well as the common areas of the accommodation facility (accommodation premises), and use the services associated with the accommodation. 
(2) If a guest so requires, the accommodation provider shall place the guest's money, jewellery and other valuables in deposit, unless they constitute dangerous things or their value or extent is disproportionate with regard to the accommodation facility. The accommodation provider may require that the things to be placed in deposit be handed over to him in a closed or sealed box.

\section{Section 2328}

The accommodation provider shall deliver the accommodation premises to the guest in a condition fit for proper use and ensure the peaceful exercise of the guest's rights related to accommodation.

\section{Section 2329}

A guest uses the accommodation premises and receive services associated with the accommodation in a proper manner; he may not make any substantial changes to the accommodation premises without the consent of the accommodation provider.

Section 2330

(1) A guest may terminate the contract before the expiry of the stipulated period.

(2) If the accommodation provider proves that he could not have prevented the damage which he incurred due to the premature cancellation of accommodation by the guest, he may request that the guest compensate him for such damage.

Section 2331

An accommodation provider may terminate the contract without a notice period before the expiry of the stipulated period if a guest, despite having been warned, materially breaches his duties under the contract, or good morals.

\section{Division 4}

\section{Usufructuary lease}

\section{Subdivision 1}

\section{General provisions}

\section{Section 2332 [Recodification]}

\section{Basic provisions}

(1) By a usufructuary lease contract, the usufructuary lessor undertakes to relinquish a thing to a usufructuary lessee for temporary use and enjoyment, and the usufructuary lessee undertakes to pay the rent to the usufructuary lessor, or provide him with a proportion of the yield from the thing.

(2) In case of a single contract whereby a party relinquishes to the other party several things, some of which are intended for use and others for use and enjoyment, the contract is assessed according to the nature of the principal thing.

\section{Section 2333 [Recodification]}

If a thing subject to a usufructuary lease is registered in a public register, the right of the usufructuary lease is also registered therein on application of the owner of the thing or the usufructuary lessee with the owner's consent. This also applies in the case of a registration in a public register of an individual thing belonging to a collective thing (universitas rerum) which is subject to usufructuary lease.

\section{Section 2334 [Recodification]}

If a usufructuary lessee leases a thing subject to usufructuary lease to another for usufructuary lease, relinquishes such a thing to another for use or changes its economic purpose or the way it is used or used and enjoyed without the previous consent of the usufructuary lessor, the usufructuary lessor may terminate the usufructuary lease without a notice period.

\section{Section 2335}

(1) If a usufructuary lessor carries out measures on the thing subject to the usufructuary lease to which he is entitled or obliged under the contract or for any other legal cause, he shall reimburse the usufructuary lessee to a reasonable extent for the costs and loss of yield incurred by the usufructuary lessee as a result of such measures; if so requested by the usufructuary lessee, the usufructuary lessor shall provide him with adequate advance payment. The usufructuary lessee's right to a reduction of the usufructuary rent or a waiver thereof shall remain unaffected.

(2) If a usufructuary lessor improves a thing subject to usufructuary lease to the extent that the usufructuary lessee can, by exercising due managerial care, achieve higher yield, the usufructuary lessor may claim a reasonable increase in the usufructuary rent. 
A usufructuary lessee shall take care of the thing subject to a usufructuary lease with due managerial care.

Section 2337

(1) If a usufructuary lessor fails to remove, without undue delay, a defect of the thing which he is obliged to remove and, as a result, the yield from the thing subject to the usufructuary lease decreases to under half of the current yield, the usufructuary lessee is entitled to a reduction of the usufructuary rent; if the usufructuary lessee removes the defect himself, he is entitled to reimbursement of the costs incurred.

(2) In the case of a defect that significantly hinders or even prevents the use and enjoyment of a thing subject to a usufructuary lease so that it provides no more than a negligible yield, the usufructuary lessee is entitled to have the usufructuary rent waived or to terminate the usufructuary lease without a notice period.

\section{Section 2338}

Where a usufructuary lease has been stipulated for at least three years, any of the parties may, no less than six months before the expiry of the stipulated period, request the other party to state whether or not that party intends to continue the usufructuary lease, and if the other party grants its consent within three months after the request is delivered, the usufructuary lease is extended by the period for which it was originally stipulated; otherwise, the usufructuary lease ends after the expiry of the originally stipulated period.

\section{Section 2339}

(1) A usufructuary lease stipulated for an indefinite period may be terminated by six months' notice so as to finish at the end of the usufructuary lease year. If the contract was concluded in writing, the notice of termination must also be in writing.

(2) In the case of an agricultural usufructuary lease, the usufructuary lease year is presumed to be a period of time from 1 October to 30 September of the following year; in other cases of usufructuary lease, it corresponds to a calendar year.

\section{Section 2340}

If a usufructuary lessee fails to return the thing subject to the usufructuary lease to the usufructuary lessor at the end of the usufructuary lease, the usufructuary lessor is entitled to a usufructuary rent as if the usufructuary lease continued; the fruits and revenues acquired by the usufructuary lessee at that time are counted as revenues for the entire year.

\section{Section 2341}

Unless otherwise provided by the provisions of this Division, usufructuary lease is governed by the provisions on leases with the necessary modifications.

\section{Inventory}

\section{Section 2342 [Recodification]}

(1) If a thing is leased together with inventory, the usufructuary lessee shall retain the individual items listed in the inventory. Where livestock is part of the inventory, the usufructuary lessee shall renew the amount of livestock with due managerial care.

(2) If any item listed in the inventory is destroyed or worn to the extent that it can no longer be used, the usufructuary lessor shall renew it unless the damage is attributable to the usufructuary lessee; this also applies in the case of a defective thing subject to a usufructuary lease.

\section{Section 2343 [Recodification]}

(1) If a thing is leased together with inventory at a stipulated price and the usufructuary lessee undertakes to return the items of the inventory to the usufructuary lessor at the end of the usufructuary lease at the same price, the usufructuary lessee may dispose of the items of the inventory freely with due managerial care, but bears the risk of damage, albeit accidental. The usufructuary lessee maintains the items of the inventory and replaces them with due managerial care; if a thing is registered as part of the inventory, the usufructuary lessor acquires the right of ownership therein.

(2) If a usufructuary lease ends, the usufructuary lessee shall return the items of the inventory to the usufructuary lessor. A usufructuary lessor may refuse to take over an item listed in the inventory procured by the usufructuary lessee if its price is disproportionate with regard to the thing subject to the usufructuary lease and the due management thereof, or if it is redundant for the thing subject to the usufructuary lease; upon refusal, the right of ownership in the refused piece is acquired by the usufructuary lessee.

(3) Any price difference between the items of the inventory taken over and returned is compensated in money.

\section{Section 2344}

The things which are part of the inventory are encumbered with a pledge as a security for the usufructuary lessee's claims against the usufructuary lessor. However, if the usufructuary lessor provides the usufructuary lessee with other security, the pledge does not apply to the extent of the security.

\section{Subdivision 2}




\title{
Agricultural usufructuary lease
}

\author{
Section 2345 [Recodification]
}

\section{Basic provisions}

(1) Where a tract of agricultural or forest land is subject to a usufructuary lease, an agricultural usufructuary lease has been stipulated.

(2) Where a usufructuary lease is stipulated for more than two years and the contract is not concluded in written form, the usufructuary lease is presumed to have been stipulated for an indefinite period.

Section 2346

Usufructuary rent is payable annually in arrears and is due on 1 October.

\section{Section 2347}

A usufructuary lease stipulated for an indefinite period may be terminated by twelve months' notice.

\section{Section 2348}

(1) If, for health reasons, a usufructuary lessee becomes incapable of managing the tract of land, he has the right to terminate the lease by three months' notice even where the usufructuary lease was stipulated for a definite period.

(2) If a usufructuary lessee dies, his heir has the right to terminate the lease by three months' notice, even where the usufructuary lease was stipulated for a definite period; the notice of termination must be given within six months from the date on which the usufructuary lessee died.

\section{Subdivision 3}

\section{Usufructuary lease of an enterprise}

\author{
Section 2349 [Recodification]
}

(1) If the subject of a usufructuary lease is an enterprise, the usufructuary lessee shall use and enjoy it in the manner and to the extent necessary for the proper operation of the enterprise. A usufructuary lessee may change the objects of activities pursued in the enterprise only if it has been expressly stipulated.

(2) A usufructuary lease of an enterprise is considered to constitute a transfer of the employer's activities.

\section{Section 2350}

(1) If a usufructuary lessee is registered in a public register, he acquires the right to the enterprise upon publication of the information that he has filed a document on the usufructuary lease of the enterprise in the collection of instruments in accordance with another legal regulation.

(2) If a usufructuary lessee is not registered in a public register, he acquires the right to the enterprise upon the effective date of the contract. regulations.

(3) The provisions of Subsections (1) and (2) do not affect the duties to register the rights to things under other legal

\section{Section 2351}

Transfer of industrial or other intellectual property rights to the usufructuary lessee is prohibited where excluded by the contract whereby the industrial or other intellectual property right was granted to the usufructuary lessor, or by the nature of such a right.

\section{Section 2352 [Recodification]}

(1) By leasing an enterprise, a usufructuary lessee becomes a creditor in respect of the claims and debtor in respect of the debts associated with the operation of the enterprise; however, in terms of debts, the usufructuary lessee shall only assume those debts which were known to him or which he must have at least reasonably expected. Where a creditor has not given his consent to the assumption of a debt by the usufructuary lessee, the usufructuary lessor is liable as a surety for the discharge of the debt. Acquisition of claims by the usufructuary lessee is otherwise governed by the provisions on assignment of claims.

(2) A usufructuary lessor shall, without undue delay, notify his creditors and debtors whose claims and debts were acquired by the usufructuary lessee through the usufructuary lease of the enterprise that he has leased the enterprise.

\section{Section 2353}

(1) If the parties make a record of the handover of the enterprise, they shall list everything which belongs to the enterprise and which is handed over to the usufructuary lessee, as well all missing items that are to form part of the enterprise 
according to the contract or accounting records. The usufructuary lessor shall, no later than in the record, notify the usufructuary lessee of the defects of the subject of the usufructuary lease of which he knows, or was required to know and could have known.

(2) If a thing belonging to the enterprise is not included in the record, the usufructuary lessee acquires the right of usufruct in the thing together with the right of usufruct in the enterprise. Where a debt is not included in the record, the usufructuary lessee acquires it if he must have at least reasonably expected its existence.

\section{Section 2354 [Recodification]}

Where a usufructuary lease deteriorates the recoverability of a claim, the usufructuary lessor's creditor who disagreed with the usufructuary lease has the right to apply to a court to declare the usufructuary lease ineffective against the creditor. This right to invoke invalidity is extinguished if it is not asserted by the creditor within one month from the date on which he became aware of the usufructuary lease, but no later than three months after the effective date of the contract.

\section{Section 2355}

(1) Claims and debts belonging to an enterprise pass to the usufructuary lessor on the date of the extinction of the usufructuary lease; however, with regard to debts, the usufructuary lessor acquires only those of the existence of which he knew or which he must have at least reasonably expected. Where a creditor has not given his consent to the assumption of a debt by the usufructuary lessor, the usufructuary lessee is liable as a surety for the discharge of the debt. Acquisition of claims by the usufructuary lessor are otherwise governed by the provisions on the assignment of claims.

(2) A usufructuary lessee shall, without undue delay, notify his creditors and debtors whose claims and debts were acquired by the usufructuary lessee through the usufructuary lease of the enterprise that the usufructuary lease has been extinguished.

\section{Section 2356}

Creation or extinction of a usufructuary lease becomes effective with respect to a third person on the date of publication of the usufructuary lease, unless the parties prove that the third person was aware of those facts before that date.

\section{Section 2357}

The provisions of this Subdivision apply by analogy to the usufructuary lease of a part of an enterprise constituting a separate organisational component.

\section{Division 5}

\section{Licence}

\section{Subdivision 1}

\section{General provisions}

Section 2358 [Recodification]

\section{Basic provisions}

(1) By a licence agreement, a licensor grants to a licensee an authorisation to exercise intellectual property rights (a licence) within the stipulated limited or unlimited extent, and a licensee undertakes to pay remuneration to the licensor, unless otherwise stipulated.

(2) The agreement must be in writing in the following cases:

a) where an exclusive licence is granted, or

b) where the licence is to be registered in the relevant public register.

(3) A licence to a subject of industrial property registered in a public register becomes effective against third persons upon registration in the register.

\section{Section 2359}

(1) A licensee is not required to use the licence, unless the maintaining of the right depends on the exercise thereof

(2) A licensor shall maintain the right for the period of licence where required by its nature.

Section 2360 [Recodification]

\section{Exclusive or non-exclusive licences}

(1) Where an exclusive licence has been stipulated, the licensor may not grant the same licence to a third person for the period of the exclusive licence. Unless expressly stipulated otherwise, a licensor shall also refrain from exercising himself the right to which he has granted an exclusive licence. 
(2) Where, during the term of the licensee's exclusive licence, a licensor grants the licence to a third person without the licensee's written consent, the licence will not be created. However, where a non-exclusive licence was granted before the granting of an exclusive licence, the non-exclusive licence remains valid.

\section{Section 2361}

Where a non-exclusive licence has been stipulated, the licensor is entitled to exercise the right to which he granted the non-exclusive licence, as well as to grant a licence to a third person.

\section{Section 2362}

Unless an exclusive licence has been expressly stipulated, the licence is conclusively presumed to be non-exclusive.

\section{Section 2363 [Recodification]}

\section{Sublicence}

A licensee may only grant an authorisation forming part of the licence to a third person, in whole or in part, if this was stipulated by the licence agreement.

\section{Section 2364}

(1) A licensee may only assign the licence to a third person, in whole or in part, with the consent of the licensor. The consent must be in writing.

(2) Where the licensee has assigned the licence, he shall notify the licensor without undue delay of the assignment and the identity of the assignee.

\section{Section 2365}

Where an enterprise or its separate part was transferred, the licensor's consent to transfer the licence is only required where specifically stipulated.

\section{Section 2366}

\section{Remuneration}

(1) If the amount of the remuneration or the manner of its determination has not been stipulated, the agreement is nevertheless valid if:

a) the negotiations of the parties to conclude the agreement show their will to conclude an onerous agreement even without determining the amount of the remuneration; in such a case, the licensee shall pay to the licensor remuneration in an amount which is usual at the time of the conclusion of the agreement under similar contractual terms and for such a right, or

b) the parties have stipulated in the agreement that the licence is provided gratuitously.

(2) Where the amount of the remuneration has been stipulated based on the yields from the use of the licence, the licensee shall allow the licensor to inspect the accounting records or other documents to determine the actual amount of the remuneration. Where the licensee thus provides the licensor with information designated as confidential by the licensee, the licensor may not disclose such information to a third person or use it for his needs contrary to the purpose for which it was provided.

(3) The licensee shall submit to the licensor periodic accounts of the fee under Subsection (2) at the stipulated intervals; unless stipulated otherwise, the licensee shall submit the accounts at least once a year.

\section{Section 2367}

The licensor shall provide the licensee with all documents and information necessary for the exercise of the licence without undue delay after the conclusion of the agreement.

\section{Section 2368}

(1) The licensee shall conceal from third persons documents and communications which he received from the licensor, unless the agreement or the nature of the underlying documents and communications indicate that the licensor has no interest in concealing them. A third person is not understood as an employee or a person participating in the business of the entrepreneur, provided that he was obliged by the entrepreneur to maintain confidentiality.

(2) After the termination of the licence, the licensee shall return the underlying documents; he shall keep communications confidential until they become generally known.

Section 2369

Where the licensor's licence is endangered or infringed, the licensee shall inform the licensor accordingly without 
undue delay after ascertaining this fact. The licensor shall provide the licensee with cooperation to ensure the legal protection of his licence.

Section 2370

\section{Termination of an obligation}

If an agreement is concluded for an indefinite period, a notice of termination becomes effective one year after the end of the calendar month in which the notice of termination reached the other party.

\section{Subdivision 2}

\section{Special provisions for licences to items protected by the Copyright Act}

\section{Section 2371}

\section{Basic provisions}

By a license agreement, an author grants to a licensee an authorisation to exercise the right to use a copyrighted work in its original, adapted or otherwise altered form, in a certain manner or all manners of use, to a limited or unlimited extent.

\section{Section 2372}

(1) An author may only grant authorisation to exercise the right to use a copyrighted work in a manner which is known at the time of the conclusion of the agreement; a stipulation to the contrary is disregarded.

(2) A licensee is obliged to use the licence to use a copyrighted work, unless stipulated otherwise.

Section 2373

(1) If the expression of will is aimed at an indefinite number of persons, it shall also constitute a proposal to conclude an agreement. The content of the agreement or a part thereof can also be determined by reference to the licence conditions of which the parties are aware or which are publicly available.

(2) Having regard to the content of the proposal, the practice established between the parties or usages, a person who intends to accept a proposal may accept the proposal to conclude the agreement by performing a certain act without notifying the offeror, including, without limitation, by rendering or accepting performance. In such a case, the acceptance of the proposal becomes effective when the act is performed.

(3) If a proposal intended for an indefinite group of persons which may be accepted without notifying the offeror in accordance with Subsection (2) specifies a time limit for acceptance, the proposal may not be revoked during this time limit.

\section{Section 2374 [Recodification]}

(1) Where the stipulated remuneration for the granting of a licence is not based on the yields from the use of the licence and it is so low that it is clearly disproportionate to the profits from the use of the licence and the relevance of the subject of the licence for gaining such profit, the author has the right to an adequate additional remuneration; he may not waive this right.

(2) The amount of the additional remuneration is determined by a court, having particular regard to the amount of the original remuneration, the profit gained from the use of the licence, the relevance of the work for such profit, and the usual amount of a remuneration in comparable cases if based on yields; an out-of-court agreement of the parties on the amount of the additional remuneration is not thereby excluded.

\section{Section 2375}

\section{Limitations on a licensee}

(1) A licensee may only alter or otherwise change the identification of the author if it has been stipulated.

(2) A licensee may alter or otherwise change the work or its name only if it has been stipulated, unless it can be reasonably expected that the author would have consented to the alteration or another change given the circumstances; however, even in such a case, the licensee may not alter or otherwise change the work or its name if the author has reserved permission and the licensee is aware of the reservation. collected works.

(3) Subsection (2) applies by analogy to the merging of a work with another work or the inclusion of a work into

\section{Section 2376}

(1) A licence may be limited to specific manners of use of the work; the manners of use of the work may be limited in scope, in particular in terms of quantity, territory or time.

(2) A licence is presumed to have been granted for such manners of use and in such a scope as is necessary to achieve the purpose of the agreement. 
(3) Unless the purpose of the agreement indicates otherwise, it is presumed that:

a) the territorial scope of a licence is limited to the territory of the Czech Republic,

b) the temporal scope of a licence is limited to the period usual for the given type of work and manner of use, but for no more than one year from the granting of the licence or, where the work is to be delivered only after the licence has been granted, from such a delivery, and

c) the quantitative scope of a licence is limited to the amount which is customary for the given type of work and manner of use.

(4) A licence to reproduce a work includes the right to acquire reproductions, irrespective of whether direct or indirect, permanent or temporary, in whole or in part, acquired by any means and in any form.

(5) A licence to reproduce a work also includes a licence to distribute reproductions made in this manner.

\section{Section 2377}

\section{Reproduction for the author}

Where it can be rightfully required from the licensee holding a licence to reproduce a copyrighted work and it is customary, the licensee shall provide the author, at the licensee's expense, with at least one reproduction of the author's copyrighted work from the reproductions he made under the relevant licence.

\section{Withdrawal from licence agreement due to inactivity of the licensee}

\section{Section 2378}

(1) Where a licensee does not use an exclusive licence at all or where he uses it insufficiently, thereby significantly adversely affecting the legitimate interests of the author, the author may withdraw from the agreement. This does not apply in case the failure to use or insufficient use of the licence is caused by circumstances dominantly attributable to the author.

(2) An author may withdraw from a licence agreement on the grounds set out in Subsection (1) only after he has sent the licensee a request to sufficiently use the licence within a reasonable time limit after delivering the request and the licensee fails to do so despite the request. In the request, the author must notify the licensee that the author may withdraw from the agreement upon expiry of the reasonable time limit within which the licensee fails to sufficiently use the licence. No request is required if the use of the licence by the licensee is impossible or if the licensee states that he will not use the licence.

Section 2379

(1) The right of withdrawal from the agreement due the licensee's failure to act may not be asserted by the author before the expiry of two years from the granting of the licence or, where applicable, from the delivery of the copyrighted work if it was delivered to the licensee only after the licence was granted; the time limit is three months for contributions to daily periodicals and one year for contributions to other periodicals.

(2) A request to the licensee to sufficiently use the licence within a reasonable period, where required, may not be made before the expiry of the time limits under Subsection (1).

\section{Section 2380}

The author shall compensate the licensee for any damage which the licensee incurred as a consequence of the withdrawal from the agreement, if justified by reasons deserving special consideration. In this context, the reasons for which the licensee failed to sufficiently use the licence is taken into account.

\section{Section 2381}

(1) If a licence has not been used at all, the author shall return to the licensee the remuneration which he received from the licensee under the agreement from which the author withdrew; if a licence has only been used insufficiently, the author shall return the remuneration reduced by the part corresponding to the actual use, based on the proportion between the actual scope of use of the licence and the stipulated or statutory scope of use of the licence.

(2) If a licensee is obliged to use the licence and breaches this duty, the author's right to remuneration remains unaffected by the withdrawal from the agreement for the licensee's failure to act. Where remuneration based on yields from the copyrighted work has been stipulated, the author is presumed to have become entitled to remuneration in an amount equivalent to that to which the author would have become entitled had the licensee sufficiently used the licence before the withdrawal from the agreement.

\section{Section 2382}

\section{Withdrawal from the agreement due to a change of the author's conviction}

(1) An author may withdraw from the agreement if an unpublished copyrighted work no longer corresponds to his opinions and publication of the copyrighted work would significantly adversely affect his legitimate personal interests.

(2) An author shall compensate the licensee for the damage incurred by the licensee as a result of the withdrawal from the agreement under Subsection (1). The withdrawal becomes effective upon the compensation for damage or provision of 
sufficient security.

(3) If, after the withdrawal from the agreement under Subsection (1), the author again expresses his interest in the use of the copyrighted work, he shall preferentially offer the licence to the licensee under the conditions comparable to those stipulated originally.

(4) Section 2381(2) applies by analogy.

\section{Section 2383}

\section{Extinction of a licence}

Upon the death of a natural person or the termination of a legal person that is a licensee, the rights and duties under the licence agreement pass to the person's legal successor. A licence agreement may exclude such a passage of rights and duties to the legal successor.

\section{Subdivision 3}

\section{Special provisions for publishing licence agreements}

Section 2384

\section{Basic provisions}

(1) By a publishing licence agreement, an author provides a licensee with a licence to reproduce and distribute literary, dramatic musical, musical or pictorial, graphic, sculptural, architectural and applied art copyrighted work or a copyrighted work of photography or expressed in a manner similar to photography, except for the use of a copyrighted work presented by performing artists.

(2) The licence is considered to be exclusive, unless a non-exclusive licence has been expressly stipulated in the agreement; this does not apply in the case of the reproduction and distribution of the copyrighted work in a periodical.

\section{Section 2385}

(1) Prior to publishing a copyrighted work, the licensee shall provide the author with a reasonable time limit to make small creative changes to his work; such changes may not cause the licensee to incur disproportionate cost and may not change the nature of the work (author's correction).

(2) If a licensee does not allow the author to make author's corrections, the author may withdraw from the agreement if, as a result, the copyrighted work would be used in a way decreasing its value.

\section{Section 2386}

If the quantitative scope of a licence is limited to a certain number of reproductions and the reproductions are sold out before the expiry of the period for which the licence was granted, the licence is extinguished unless the parties agree to increase the quantitative scope within six months from the date on which the author requested the licensee to make such an amendment to the licence agreement.

\section{Subdivision 4}

\section{Special provisions for rights related to copyright and rights of an author of a database}

\section{Section 2387}

Artistic performances are governed by Sections 2371 to 2383 by analogy; however, a performing artist does not have the right under Section 2377.

\section{Section 2388}

Audio recordings, audio-visual recordings and radio and television broadcasting are governed by Sections 2371 to 2376 and Section 2383 by analogy; however, a producer of an audio or audio-visual recording or a radio or television broadcaster does not have the right provided under Section 2374.

\section{Section 2389}

Databases which are subject to a special right of an author of a database are governed by Sections 2371 to 2376 and Section 2383 with the necessary modifications; an author of a database does not have the right under Section 2374.

\section{Division 6}

\section{Loan for consumption}

Section 2390 [Recodification]

\section{Basic provisions}


If a loan provider relinquishes a fungible thing to a loan beneficiary to use it in any manner and return a thing of the same kind after a certain period of time, this constitutes a contract of loan for consumption.

\section{Section 2391 [Recodification]}

(1) Where a pecuniary loan for consumption is to be returned in a currency other than that in which it was provided, the loan beneficiary shall repay the loan for consumption so that the value of what he returns equals to what was provided. $A$ loan for consumption is to be repaid in the currency of the place of performance.

(2) In the case of a non-pecuniary loan for consumption, a thing of the same kind as the loaned thing is to be returned, irrespective of whether its price increased or decreased in the meantime.

\section{Section 2392 [Recodification]}

(1) In the case of a pecuniary loan for consumption, interest may be stipulated. The same applies to a loan for consumption provided in securities.

(2) In the case of a non-pecuniary loan for consumption, provision of an appropriately larger quantity or things of higher quality, but of the same kind, may be stipulated instead of interest.

\section{Section 2393 [Recodification]}

(1) Where the contract does not stipulate the time limit for returning the subject of loan for consumption, the due date shall depend on the termination of the contract. The notice period is six weeks, unless other provisions on termination have been stipulated.

(2) A loan beneficiary may repay the loan for consumption even without termination by notice, provided that no interest has been stipulated.

\section{Section 2394 [Recodification]}

Where returning the subject of a loan for consumption in instalments has been stipulated, the loan provider may withdraw from the contract and demand the discharge of the debt including interest if the loan beneficiary is in default of more than two instalments, or with one instalment for more than three months.

\section{Division 7}

\section{Credit}

\section{Section 2395 [Recodification]}

\section{Basic provisions}

By a credit contract, a credit provider undertakes to provide a credit recipient with funds up to a specific amount at the credit recipient's request and for the credit recipient's benefit, and a credit recipient undertakes to return the funds provided and pay interest.

\section{Section 2396}

A credit recipient shall repay the funds to the credit provider in the currency in which they were provided. Interest is paid in the same currency.

\section{Section 2397}

A credit recipient may assert the right to be provided with the money within the time limit set out in the contract. In the absence of such a stipulation, he may assert the right within the duration of the contractual obligation.

\section{Section 2398}

(1) A credit provider shall provide the credit recipient with funds at the credit recipient's request within the period specified in the request; if the credit recipient determines no period of performance in the request, the credit provider shall provide the performance without undue delay.

(2) If a credit is contractually designated solely for a particular purpose, the credit provider may limit the provision of the money only to the fulfilment of the credit recipient's duties arising in connection with this purpose.

Section 2399

(1) The credit recipient shall repay the provided funds to the credit provider within the agreed time or otherwise within one month from the date on which he was requested to repay the funds.

(2) A credit recipient may repay the funds to the credit provider before the agreed time. He shall only pay interest for the period from the time the funds were provided to the time they were repaid. 
If the contract stipulates that funds are to be used only for a specific purpose and the credit recipient uses them for a different purpose, the credit provider may withdraw from the contract and demand that the credit recipient repay what he received plus interest without undue delay. This also applies if the use of the money for the agreed purpose is impossible.

\section{Chapter 3}

\section{Employment}

\section{Section 2401 [Recodification]}

(1) Employment and the rights and duties of an employee and an employer arising from employment are governed by another statute. The same applies, to the extent provided by another statute, to contracts to perform dependent work creating a similar obligation between an employee and an employer. employers.

(2) The provisions of the this Act on consumer protection do not apply to rights and duties of employees and

\section{Chapter 4}

\section{Obligations arising from safekeeping contracts}

\section{Division 1}

\section{Deposit}

\section{Subdivision 1}

\section{General provisions}

Section 2402

\section{Basic provisions}

By a contract of deposit, a depositary undertakes to take over a thing to hold it in safekeeping for the depositor. A contract may stipulate that a depositary may deposit the thing with another depositary.

\section{Section 2403}

(1) A depositary shall take hold the deposited thing in safekeeping as stipulated, or otherwise as carefully as is appropriate with regard to the nature of the thing and the depositary's circumstances so that no damage is incurred to the thing, and, after the expiry of the deposit period, return the thing to the depositor along with what was added thereto.

(2) If the depositor so requests, the depositary shall return the thing to him even before the expiry of the stipulated deposit period. However, the depositary is not entitled to return the thing earlier, unless he is unable to hold it in safekeeping safely or without causing damage to himself due to an unforeseeable event.

\section{Section 2404}

If it is not evident from the circumstances how long a thing is to be deposited, the depositor may, at any time, request that the thing be returned, and the depositary may, at any time, return the thing.

\section{Section 2405}

If a depositary uses a deposited thing for himself, allows another to use it or deposits it with another without the depositor's permission or without urgent need, he shall compensate the depositor for any damage, even accidental. This does not apply if the depositary proves that the damage to the thing would have occurred in any case.

\section{Section 2406 [Recodification]}

(1) The depositor shall reimburse the depositary for the necessary costs which the latter incurred in the safekeeping of the thing; the depositary is entitled to be reimbursed for other costs as an agent without mandate, unless stipulated otherwise.

(2) The depositary is entitled to consideration for the deposit only if so stipulated, or if it follows from the usages, previous dealings of the parties or the objects of activities of the depositary.

\section{Section 2407 [Recodification]}

If the depositor fails to assert his right to compensation for damage or the depositary fails to assert his right to be paid consideration or to be reimbursed for the costs within three months after the thing was returned, a court shall not grant the right if the other party invokes late assertion of the right. 
The provisions on deposits also apply with the necessary modifications to cases where someone is to hold a thing in safekeeping for another under a contract or other statutory provisions.

\section{Subdivision 2}

\section{Deposit of securities}

Section 2409 [Recodification]

(1) A depositary holds securities in deposit separately from its own securities or securities of other depositors; this does not apply in the case of collective deposits or where agreed otherwise with the depositor.

(2) A depositary shall keep records of the deposited securities, which shall also include the identification of the depositor and the location of the securities.

\section{Section 2410 [Recodification]}

\section{Collective deposit}

In the case of a collective deposit, securities are deposited together with the securities of other depositors separately from the securities of the depositary. Securities held in collective deposit belong jointly to all depositors, but each depositor may assert his rights against the depositary individually, including, but not limited to, the right to be returned the same securities that were deposited with the depositary.

\section{Section 2411 [Recodification]}

(1) The share of each depositor is determined as the ratio of the sum of the nominal values of the securities deposited to the sum of the nominal values of all securities in the same collective deposit; where the securities have no nominal value, the depositor's share is determined according to the number of securities.

(2) The transfer of shares is governed by the provisions on co-ownership by analogy; other provisions on coownership do not apply to the securities in collective deposit.

\section{Section 2412 [Recodification]}

(1) A depositary may deposit the securities deposited with him with another depositary (secondary deposit); his rights and duties shall remain unaffected.

(2) In the case of a collective deposit of immobilised securities, its terms are governed by the rules for keeping separate records of investment instruments under the statute regulating business activities on the capital market; the establishment of a secondary deposit does not require the handover of the securities to the secondary depositary.

\section{Immobilisation of securities}

\section{Section 2413 [Recodification]}

(1) Where securities are placed in collective deposit by their issuer, the securities are issued on the date on which the issuer hands over the instrument to the depositary for the benefit of its owner as the initial acquirer (immobilised securities). If registered securities or securities to order are placed in deposit, the name of the owner of the securities is not provided on the securities when they are deposited.

(2) The owner of the deposited securities shall only have the right to claim that the securities be surrendered to him under the conditions set out in the terms of issue of the securities. Before releasing securities from a deposit, the depositary shall provide registered securities or securities to order with the name of their owner.

(3) Only a person authorised to keep separate records of investment instruments in accordance with the statute regulating business activities on the capital market may be a depositary of immobilised securities; only a person authorised to keep records based on separate records of investment instruments in accordance with the statute regulating business activities on the capital market may be a secondary depositary.

Section 2414 [Recodification]

Securities held in deposit in cases where individual securities may not be reclaimed are governed, with the necessary modifications, by the provisions of another statute on book-entry securities.

\section{Division 2}

\section{Storage}

\section{Section 2415}

\section{Basic provisions}

(1) By a storage contract, a storage provider undertakes to take over a thing so that he can store it and hold it in 
safekeeping, and a person having the right of storage undertakes to pay him a storage fee.

(2) If the safekeeping of things constitutes the objects of business of the storage provider, the parties are presumed to have concluded a storage contract.

Section 2416

If a person having the right of storage hands over a thing to a storage provider, the storage provider shall take over the thing and provide the person having the right of storage with a confirmation of the takeover in writing.

\section{Section 2417 [Recodification]}

(1) A confirmation of the takeover of a thing may be substituted with a warehouse receipt. A warehouse receipt is a security which confers the right to reclaim the stored thing; it may be issued as a registered security, security to order or a bearer security.

(2) A warehouse receipt contains at least:

a) the name of the storage provider and his place of residence or registered office,

b) the name of the person having the right of storage and his place of residence or registered office,

c) designation, quantity, weight or volume of the things stored,

d) the form of the warehouse receipt; if it was issued as a registered certificate or certificate to order, it shall also contain the designation of the person in the name or to the order of whom it was issued,

e) an indication of the place where the thing is stored, and

f) the place and date the warehouse receipt was issued and the storage provider's signature.

(3) If a warehouse receipt does not contain the name of the person to the order of whom it was issued, it is considered to have been issued to the order of the person having the right of storage.

\section{Section 2418}

If a third person is entitled to reclaim the stored thing on the basis of a warehouse receipt, he shall, upon request, provide the storage provider with a confirmation of the takeover of the thing on the warehouse receipt. The person is not obliged to pay a storage fee, but if the fee is not paid, the storage provider is not obliged to surrender the goods if he asserts his retention right to the goods stored in the warehouse.

\section{Section 2419}

If a thing is not handed over to the storage provider within the stipulated period or otherwise within six months after the conclusion of the contract, the obligation is extinguished.

\section{Section 2420}

A storage provider shall store a thing separately from other stored things with an indication that it belongs to the person having the right of storage. The person having the right of storage has the right to check the condition of the stored thing and take samples therefrom.

\section{Section 2421 [Recodification]}

A storage provider shall insure the thing if so stipulated or if it is in accordance with usages.

\section{Section 2422}

(1) If storage takes longer than six months, the storage fee is payable semi-annually in arrears.

(2) The storage fee for an unfinished half-year as well as for a shorter storage period is payable upon the collection of the stored thing.

(3) Even after the extinction of a contractual obligation, a storage provider has the right to a storage fee for the period during which a thing was stored with him because the person having the right of storage did not collect it in time.

\section{Section 2423}

Storage fee covers all costs associated with storage except for the costs of insurance. The storage provider is entitled to reimbursement of the costs of insurance if he was obliged to have the thing insured.

\section{Section 2424}

(1) If storage has been stipulated for an indefinite period, a storage provider (the person having the right of storage trans.) may at any time reclaim the thing; he shall pay a storage fee for the actual storage period. Storage is extinguished upon the collection of the thing. 
(2) A storage provider may terminate a storage stipulated for an indefinite period; the notice period is one month and commences on the first day of the month following the delivery of the notice of termination.

\title{
Section 2425
}

Even where storage has been stipulated for a definite period, the person having the right to storage may collect the thing before the expiry of the stipulated period, but must first pay the storage fee for the entire stipulated period. Before the expiry of the stipulated period, a person having the right of storage may request that the thing be taken over for storage again until the end of this period, provided that he reimburses the storage provider for the associated costs.

\section{Section 2426}

(1) A storage provider shall compensate a person having the right of storage for any damage incurred from the time the thing was taken over to the time it was surrendered, unless he proves that he could not have prevented it.

(2) A storage provider does not compensate for the damage caused by the person having the right of storage or the owner of the thing, or by a defect or inherent nature of the thing. A storage provider shall compensate the damage caused by a defect of packaging if he could have discovered the defect by exercising professional care and if he noted the defect in the confirmation under Section 2416.

(3) Where damage was incurred for causes under Subsection (2), a storage provider shall exercise professional care to reduce the damage as much as possible.

\section{Section 2427}

A storage provider may terminate storage without a notice period:

a) if a person having the right of storage has concealed the dangerous nature of a thing and if, as a result, the storage provider is at risk of incurring considerable damage,

b) if a person having the right of storage owes storage fees for at least three months, or

c) in case of a risk of substantial damage to a stored thing which the storage provider may not prevent.

$$
\text { Section } 2428
$$

\section{Sale by self-help}

If a person having the right of storage fails to collect a thing once the period for which the storage provider is obliged to store the thing ends, the latter may provide the former with a reasonable time limit for its collection. If, in doing so, the storage provider informs the person having the right of storage that he will otherwise sell the thing, the former may, after the expiry of the time limit, sell the thing on the account of the latter in an appropriate manner; he shall surrender the proceeds to the person having the right of storage without undue delay, but may deduct the storage fees and reasonably incurred costs associated with the sale.

\section{Section 2429 [Recodification]}

As long as a storage provider has a stored thing with him, he has the retention right to the thing in order to secure the debts following from the contract.

\section{Chapter 5}

\section{Obligations arising from mandate-type contracts}

\author{
Division 1
}

Mandate

\section{Section 2430 [Recodification]}

\section{Basic provisions}

By a mandate contract, a mandatary undertakes to arrange a matter for the mandator.

\section{Section 2431 [Recodification]}

If a person arranges certain matters as an entrepreneur, the person, if asked to arrange such a matter, is obliged to expressly demonstrate to the other party without undue delay whether or not he will assume the arrangement of the matter; otherwise, he shall compensate for the resulting damage.

Section 2432

(1) A mandatary fulfils a mandate fairly and diligently according to his abilities; in doing so, he shall use every means 
required by the nature of the matter being arranged, as well as that which conforms to the will of the mandator. A mandatary may derogate from the mandator's instructions if it is necessary in the latter's interest and if the mandatary cannot obtain the mandator's consent in time.

(2) A mandatary shall relinquish all revenue of the arranged matter to the mandator.

\section{Section 2433}

If a mandator gives the mandatary an instruction which is obviously incorrect, the latter shall notify the former accordingly and comply with such an instruction only if the mandator insists on it.

\section{Section 2434}

A mandatary shall perform the mandate in person. By engaging another person to perform the mandate, he has the same liability as if he performed the mandate himself; however, if the mandator allowed the mandatary to appoint a substitute or if a substitute was necessary, the mandatary shall compensate the damage caused by a wrong choice of substitute.

\section{Section 2435}

Upon the mandator's request, the mandatary shall submit reports on the progress with the fulfilment of the mandate to the mandator and transfer to him the revenue acquired from the mandate being performed; after having performed the mandate, the mandatary shall present the mandator with an account.

\section{Section 2436}

Upon the mandatary's request, the mandator shall provide the mandatary with an advance payment to cover cash expenses and reimburse him for the costs reasonably incurred in the performance of the mandate, even where the result has not been achieved.

\section{Section 2437}

(1) A mandator shall compensate the mandatary for the damage which the latter incurred in connection with the fulfilment of the mandate.

(2) Where a mandatary has agreed to perform a mandate gratuitously, the mandator shall compensate him for the damage accidentally incurred by the mandatary when fulfilling the mandate. However, a mandatary is not entitled to a compensation exceeding a usual remuneration which has been stipulated.

\section{Section 2438}

(1) A mandator shall provide the mandatary with remuneration if it has been stipulated or if it is usual, in particular with regard to the mandator's business activities.

(2) A mandator shall provide the remuneration even where the mandatary failed to achieve a result, unless the failure was caused by the mandatary having breached his duties. This applies even where the fulfilment of the mandate was frustrated by an accident attributable to the mandatary.

\section{Section 2439 [Recodification]}

If a mandatary is required to make a juridical act for the mandator in order to arrange a matter, the mandator shall authorise the mandatary through a power of attorney in due time. If the power of attorney is not contained in the contract, it is not replaced with a stipulated assumption of the mandator's duty to act in the name of the mandatary; this also applies where a third person in respect of whom the mandatary makes juridical acts knows about this duty.

\section{Section 2440}

(1) A mandatary may terminate a mandate no earlier than before the end of the month following the month in which a notice of termination was delivered.

(2) If a mandatary terminates a mandate before arranging the matter for which he was specifically authorised or the arrangement of which he began under a general authorisation, he shall compensate the resulting damage according to general provisions.

\section{Section 2441}

An obligation arising from a mandate is extinguished upon the death of the mandator as well as upon the death of the mandatary. This also applies in the case of termination of a legal person without a legal successor.

\section{Section 2442}

If a mandate is extinguished by revocation, termination or death, the mandatary shall arrange everything which cannot be delayed until the mandator or his successor expresses another intention.

Section 2443

The mandator may withdraw a mandate at will; however, he shall compensate the mandatary for the costs which he 
has incurred until that time and for any damage incurred, where applicable, as well as pay him a part of the remuneration appropriate to the effort made by the mandatary.

\section{Section 2444}

The provisions on mandates also apply, with the necessary modifications, to cases where a person has a duty arising from a contract or other statutory provisions to arrange a matter on the account of another.

\section{Division 2}

\section{Brokerage}

\section{Section 2445}

\section{Basic provisions}

(1) By a brokerage contract, a broker undertakes to arrange the conclusion of a contract between the client and a third person, and a client undertakes to pay the broker a commission.

(2) If, at the conclusion of a contract whereby one party undertakes to arrange for the other party the opportunity to conclude a contract with a third person, it is evident from the circumstances that remuneration will be required for the arrangement of such a contract, it is presumed that a brokerage contract has been concluded.

\section{Section 2446}

(1) A broker shall, without undue delay, inform the client of everything that is relevant for him to make the decision on the conclusion of the contract being arranged.

(2) The client shall inform the broker of everything which is of decisive importance for him to conclude such a contract.

\section{Section 2447}

(1) A commission is due on the date of the conclusion of the brokerage contract; if the contract was concluded with a suspensive condition, the commission is due only once the condition has been met.

(2) If it has been stipulated that a broker will arrange for the client the opportunity to conclude a contract with a third person with certain content, the commission is due once the opportunity has been arranged.

\section{Section 2448}

If it has been stipulated that a broker will become entitled to a commission only after a third person has fulfilled a duty arising from the arranged contract, the client shall pay the commission even if the fulfilment of the duty has been delayed or frustrated for reasons for which the client bears liability. If the amount of the commission is to be determined according to the extent of the performance of a third person, the basis also includes the performance unrealised for reasons for which the client bears liability.

\section{Section 2449}

Where no commission has been stipulated, a broker has the right to be reimbursed for the costs associated with brokerage. If a commission has been stipulated, it is presumed to also include these costs

\section{Section 2450 [Recodification]}

A broker is not entitled to a commission and reimbursement of costs if he he was active in favour of the other party of the contract being arranged, thus breaching the contract.

\section{Section 2451}

A broker shall keep for the client the documents acquired in connection with the brokerage activities for the period for which they may be of relevance to protect the interests of the client.

\section{Section 2452}

A broker may not propose that the client conclude a contract with a person about whom he has or, given the circumstances, should have reasonable doubt as to whether such person will fulfil the duties under the arranged contract properly and in due time. If so requested by the client, the broker shall provide him with the information necessary to assess the credibility of the person with whom the broker proposes to conclude the contract.

\section{Section 2453}

If the contract being arranged is not concluded within the stipulated period, the obligation is extinguished. Where no period has been stipulated, either party may extinguish the obligation by notifying the other party. 
A broker's right to a commission is unaffected if the contract to which the broker's activities were related was concluded or executed only after the extinction of the obligation arising from the brokerage contract.

\section{Division 3}

\section{Undisclosed mandate}

\section{Section 2455}

\section{Basic provisions}

By a contract of undiclosed mandate, a mandatary undertakes to arrange, in his own name, a particular matter for an undisclosed mandator on the undisclosed mandator's account, and an undisclosed mandator undertakes to remunerate him.

\section{Section 2456}

Juridical acts made by the mandatary with respect to a third person do not oblige or entitle the undisclosed mandator, but the mandatary himself.

\section{Section 2457}

The mandatary may derogate from the undisclosed mandator's instructions if it is in the interests of the undisclosed mandator and if the mandatary cannot obtain the undisclosed mandator's consent in time; otherwise, the undisclosed mandator is not obliged to recognise the act as performed on his account if he refuses the effects of the act for himself without undue delay after becoming aware of the content of the act.

Section 2458 [Recodification]

If the mandatary arranges the undisclosed mandator's matter under more favourable conditions than those determined by the undisclosed mandator, only the undisclosed mandator is entitled to the benefits.

\section{Section 2459 [Recodification]}

(1) If the mandatary sells a thing for a lower price than that determined by the undisclosed mandator, he shall compensate the undisclosed mandator for the price difference. This does not apply if he proves that the thing could not have been sold at the determined price and that by selling the thing he prevented a risk of damage to the undisclosed mandator.

(2) If the mandatary purchased the thing for a price higher than that determined by the undisclosed mandator, the undisclosed mandator may refuse the purchase as if the thing was never purchased on his account, unless the mandatary, together with the submission of the report on purchase, undertook to pay him the price difference. If the undisclosed mandator does not refuse a purchase without undue delay after receiving the report on purchase, he is conclusively presumed to have approved it.

\section{Section 2460}

(1) The mandatary protects the undisclosed mandator's interests of which he knows, and informs him of every circumstance which can result in a change of the undisclosed mandator's mandate".

(2) The mandatary informs the undisclosed mandator of the fulfilment of his mandate. After arranging the matter, he provides the undisclosed mandator with an account, assigns to him the rights acquired in connection with the arrangement of the matter and surrenders to him everything which he acquired in doing so.

\section{Section 2461}

If, in his report on the performance of the mandate, the mandatary fails to specify the person with whom he concluded a contract on the account of the undisclosed mandator, the undisclosed mandator may assert his rights against the very mandatary as a party obliged under such a contract.

\section{Section 2462}

If the mandatary cannot fulfil a contractual duty himself, he shall use another person to execute the contract.

Section 2463

If the mandatary violates a mandate given by the undisclosed mandator in respect of a person with whom a contract was to be concluded, he is liable as a surety for the fulfilment of the duty by the person with whom he concluded the contract.

\section{Section 2464}

(1) A thing entrusted to the mandatary for sale remains in the ownership of the undisclosed mandator until the right of ownership is acquired by a third person.

(2) A claim under a contract concluded by the mandatary for the undisclosed mandator, is considered, in the relationship between the undisclosed mandator and the mandatary or his creditor, to be the undisclosed mandator's claim. 


\section{Section 2465 [Recodification]}

(1) For the period when the mandatary keeps the things taken over from or for the undisclosed mandator, the mandatary has the same duties as a storage provider. If there is a risk of damage to a thing or if the undisclosed mandator fails to dispose of the thing despite being obliged to do so, the mandatary may sell the thing in accordance with Section 2428.

(2) The mandatary has the retention right to the thing to secure the contractual debts as long as the thing is kept by him or as long as he may otherwise dispose of it.

\section{Section 2466}

If a third person fails to fulfil a duty arising from a contract concluded between such a third person and the mandatary, the mandatary shall enforce the fulfilment of that duty on the account of the undisclosed mandator. The mandatary may assign the corresponding right to the undisclosed mandator with his consent.

\section{Section 2467}

The undisclosed mandator may require that a third person provide to him the performance which was arranged for him by the mandatary if the mandatary, for reasons attributable to him, is unable to arrange the provision of the performance by the third person to the undisclosed mandator.

\section{Section 2468}

Where no amount of remuneration has been stipulated, the mandatary is entitled to remuneration appropriate to the activity performed and the result achieved.

\section{Section 2469}

(1) If the costs that the mandatary reasonably incurred while arranging the undisclosed mandator's matters are not included in the remuneration, they are to be paid by the undisclosed mandator to the mandatary together with the remuneration; the undisclosed mandator shall also release the mandatary from the duties which he assumed in the performance of the contract.

(2) The costs referred to in Subsection (1) are presumed to be included in the remuneration.

\section{Section 2470}

The undisclosed mandator has the right to revoke the mandate only before an obligation is created between the mandatary and a third person.

\section{Division 4}

\section{Forwarding}

Section 2471

\section{Basic provisions}

(1) By a forwarding contract, a forwarder undertakes to arrange for a mandator, in the forwarder's name and on the mandator's account, the carriage of a consignment from a particular place to another particular place and, where applicable, also arrange or perform acts associated with carriage, and a mandator undertakes to remunerate the forwarder.

(2) If it has been stipulated that a forwarder will arrange for a mandator the receipt of funds from a consignee or perform another act of collection before handing the consignment or a document allowing the disposal of the consignment over to the consignee, the provisions on documentary collection apply with the necessary modifications.

\section{Section 2472}

If no contract is concluded in writing, a forwarder has the right to request that the mandator deliver to him the mandate to arrange the carriage (a forwarding mandate).

\section{Section 2473}

A forwarder may use another forwarder to arrange the carriage (an intermediate forwarder).

\section{Section 2474}

Unless it is contrary to the contract or prohibited by the mandator no later than upon the beginning of the carriage, the carriage which a forwarder is to arrange may be carried out by the forwarder himself.

\section{Section 2475}

The manner and terms of carriage are to be stipulated by a forwarder with necessary care so as to best suit the mandator's interests of which the forwarder is aware. The forwarder is obliged to insure the consignment only if so stipulated. 
If a mandator fails to provide a forwarder with the correct information about the contents of the consignment and all the facts necessary to conclude a forwarding contract, he shall compensate the damage incurred by the forwarder as a result of a breach of this duty.

\section{Section 2477}

(1) A forwarder shall notify the mandator of the damage which may be or has already been incurred to the consignment as soon as he becomes aware of such damage; otherwise the forwarder shall compensate the mandator for the damage caused by the forwarder's failure to notify the mandator.

(2) If there is an immediate risk of substantial damage to the consignment and no time to obtain the mandator's instructions, or if the mandator delays the provision thereof, the forwarder has the right to sell the consignment according to Sections 2126 and 2127.

\section{Section 2478}

In case damage is incurred to a consignment taken over in the arrangement of carriage, the forwarder shall compensate such damage unless he proves that he was unable to prevent it.

\section{Section 2479 [Recodification]}

If a consignee knew or must have known of a claim following from the forwarding contract which the forwarder had against the mandator, he becomes a surety for the claim upon accepting the consignment.

\section{Section 2480}

Where no amount of remuneration has been stipulated, a forwarder is entitled to a reasonable remuneration usual at the time of the conclusion of the contract and under similar contractual terms. In addition, a forwarder is entitled to the reimbursement of costs reasonably incurred in the performance of the contract.

\section{Section 2481}

(1) As long as a forwarder has the consignment with him or has the instruments allowing the disposal of the consignment, he has the pledge of the consignment to secure the mandator's contractual debts. This also applies if the consignment or instruments are kept by a person in the name of the forwarder.

(2) An intermediate forwarder shall, at the request of preceding forwarders, assert all the rights to which they are entitled under their pledge, and is also entitled and obliged to satisfy their rights. If he satisfies these rights, they pass to him along with the pledge which secures them.

Section 2482

In other respects, forwarding is governed by the provisions on an undisclosed mandate.

\section{Division 5}

\section{Commercial agency}

\section{Basic provisions}

\section{Section 2483}

(1) By a commercial agency contract, a commercial agent, as an independent entrepreneur, undertakes to pursue long-term activities for the principal aimed at facilitating the conclusion of a certain type of business transactions by the principal or negotiating business transactions in the name of the principal and on his account, and a principal undertakes to pay the commercial agent a commission.

(2) A commercial agency contract must be in writing.

\section{Section 2484 [Recodification]}

A person who can, from the position of his membership in the body of the principal or another person with whom a business transaction is to be concluded, oblige the principal or this person, an official receiver of a legal person or an insolvency administrator, may not become a commercial agent of a legal person. Stipulations to the contrary are disregarded.

\section{Section 2485 [Recodification]}

\section{Relevant geographical area}

In the absence of a stipulation as to where a commercial agent is to pursue his activities, the Czech Republic is conclusively presumed to be the stipulated geographical area; if the commercial agent is a foreign person, the country of the commercial agent's registered office at the time of the conclusion of the contract is the stipulated geographical area. 
A commercial agent is not entitled to conclude business transactions in the principal's name, accept anything for him or otherwise make juridical acts in the principal's name. In the case of a stipulation to the contrary, the related rights and duties of the parties are governed by the provisions on mandates.

Section 2487

\section{Exclusive commercial agency}

(1) Where an exclusive commercial agency has been stipulated, the principal is not entitled to use another commercial agent in the relevant geographical area or for the designated group of persons; a commercial agent is, within the same scope, not entitled to exercise commercial agency for other persons or conclude business transactions on his own account or the account of another person.

(2) A principal has the right to conclude business transactions covered by an exclusive commercial agency even without the participation of a commercial agent. In this case, however, the commercial agent is entitled to a commission, as if these business transactions were concluded with his participation.

\section{Section 2488}

\section{Non-exclusive commercial agency}

If a contract does not indicate that a commercial agency is exclusive, the principal may also entrust another person with the same commercial agency as was stipulated with the commercial agent, and the commercial agent may also perform the activity to which he undertook with respect to the principal for other persons or, where applicable, conclude business transactions subject to the commercial agency on the agent's own account or the account of another person.

\section{Duties of a commercial agent}

\section{Section 2489}

(1) A commercial agent shall carry out his activities with professional care. A commercial agent shall mind the principal's interests, act in accordance with the authorisation and reasonable instructions of the principal and provide the principal with the necessary information which he learned in connection with the performance of his duties and which is connected with such performance.

(2) A commercial agent shall provide the principal with information on market developments and all other circumstances relevant to the legitimate interests of the principal, including, without limitation, to his decisions connected with the conclusion of business transactions.

\section{Section 2490}

Where the right of a commercial agent to conclude business transactions in the name of the principal has been stipulated, such business transactions may only be concluded under the standard commercial terms determined by the principal, unless the principal gives his consent to a different procedure.

\section{Section 2491}

(1) Where it would be contrary to the interests of the principal, a commercial agent may not provide a third person with information which he obtained from the principal or use such information for himself or other persons, unless approved by the principal. The same applies to information which a commercial agent did not learn directly from the principal, but in the performance of his duties under the contract, and the use of which could cause harm to the principal.

(2) The duty of a commercial agent under Subsection (1) is not extinguished upon the extinction of the commercial agency.

\section{Section 2492}

A commercial agent is liable as a surety for the fulfilment by a third person of duties following from a business transaction the conclusion of which the commercial agent proposed to the principal or which he concluded in the name of the principal himself, only if he undertook to do so in writing and if a special consideration was stipulated for the assumption of the suretyship.

Section 2493

If, in his activities, a commercial agent acquires documents which may be relevant to the protection of the legitimate interests of the principal, he shall keep them for the necessary time.

\section{Section 2494}

If a commercial agent cannot pursue his activities, he shall inform the principal without undue delay.

\section{Duties of a principal}


A principal shall arrange and provide a commercial agent with the information necessary to perform the commercial agent's duties.

\section{Section 2496}

(1) A principal shall provide a commercial agent with the necessary documentation relating to the subject of the business transactions.

(2) A principal shall hand over to a commercial agent all documents and things necessary for the performance of his duties. The documents and things handed over shall remain in the ownership of the principal; the commercial agent shall return them to the principal after the end of commercial agency, unless, given their nature, they were consumed during the commercial agency.

\section{Section 2497}

A principal shall, without undue delay, inform a commercial agent whether he accepted or rejected or, where appropriate, failed to perform a business transaction arranged by the commercial agent.

\section{Section 2498}

Where a principal anticipates a significant reduction in the scope of activities with regard to what a commercial agent could reasonably expect, he shall notify the commercial agent within a reasonable period.

\section{Commission}

\section{Section 2499}

(1) Where the amount of commission has not been stipulated, a commercial agent is entitled to a commission in the amount corresponding to the usages at the place of his activity with respect to the kind of goods or services which constitute the subject of business transactions; in the absence of such usages, the commercial agent is entitled to a commission in a reasonable amount which takes into account the substantial circumstances of the acts performed.

(2) If the basis for the calculation of commission is based on the scope of duties fulfilled by a third person, the basis shall also include performance unrealised for reasons on the part of the principal.

(3) Each part of consideration the amount of which varies according to the number and value of business transactions concluded is considered to be a component of the commission.

Section 2500

A commercial agent's commission is presumed to also include costs associated with the commercial agency. If it has been stipulated that a principal will pay these costs to a commercial agent in addition to commission, the commercial agent becomes entitled to be reimbursed for the costs if he also becomes entitled to a commission.

\section{Section 2501}

(1) A commercial agent is entitled to a commission for acts performed under the commercial agency if a business transaction has been concluded as a result of his activities or if it has been concluded with a third person acquired by the commercial agent for the purpose of executing such a business transaction before the effective date of the contract.

(2) In the case of an exclusive commercial agency, a commercial agent also has the right to a commission for business transactions executed with a third person coming from a geographical area, or from a group of persons, which are not covered by the exclusive commercial agency.

(3) If a commercial agency is extinguished, a commercial agent is entitled to a commission if the business transaction was executed mainly as a result of his activities within a reasonable period after the extinction of the commercial agency, or if a third person made an order with the commercial agent or principal before the extinction of the commercial agency under the conditions provided under Subsections (1) or (2).

\section{Section 2502}

A commercial agent does not become entitled to a commission under Section 2501(1) and (2) if a previous commercial agent is entitled to the commission under Section 2501(3), unless it is fair, given the circumstances, to split the commission between two commercial agents.

\section{Section 2503}

If it has been stipulated that a commercial agent will only arrange for the principal an opportunity to conclude a business transaction with certain content, the former shall already be entitled to a commission upon arranging this opportunity.

\section{Section 2504}

(1) If it has not been stipulated that a commercial agent will only arrange for the principal an opportunity to conclude a business transaction with a certain content, the former becomes entitled to a commission when the principal has fulfilled the duty or was obliged to discharge the obligation arising from a contract concluded with a third person, or where a third person 
has discharged the obligation arising from such a contract.

(2) The right to commission is created no later than when a third person has discharged his part of the obligation, or was obliged to do so if the principal has discharged his part. However, if a third person is to fulfil his duties only after more than six months after the conclusion of the business transaction, the commercial agent is entitled to remuneration upon the conclusion of the business transaction.

\section{Section 2505}

Commission is due no later than by the last day of the month following the end of the quarter in which the right to the commission was created.

\section{Section 2506}

(1) The principal shall hand over to the commercial agent a statement of the commission due no later than by the last day of the month following the end of the quarter in which the commission became due. In the statement, the principal shall provide the main information relevant to the calculation of the commission.

(2) A commercial agent is entitled to have all information made available to him by the principal, at least the information from accounting or similar records which the principal has and which are necessary to verify the amount of commission.

\section{Section 2507}

If it is clear that the business transaction between the principal and a third person will not be executed, there will be no right to commission; this does not apply if the business transaction is not performed for reasons attributable to the principal.

\section{Section 2508}

A commercial agent is not entitled to remuneration and the stipulated reimbursement of costs if, in concluding a business transaction, he acted for both parties as a commercial agent or broker.

\section{Section 2509}

\section{Term of commercial agency}

(1) If the period of commercial agency has not been stipulated, and if it does not even follow from the purpose of the contract, the commercial agency is conclusively presumed to have been stipulated for an indefinite period.

(2) If a commercial agency has been stipulated for a definite period and if the parties adhere to the contract even after the expiry of the stipulated period, commercial agency is considered to have been stipulated for an indefinite period.

\section{Termination of commercial agency}

\section{Section 2510}

(1) Where a commercial agency has been stipulated for an indefinite period, it may be terminated by notice. The notice period is one month for the first year, two months for the second year and three months for the third and subsequent years of commercial agency; a stipulation on a shorter notice period is disregarded. If the parties stipulate a longer notice period, the period binding upon the principal may not be shorter than the period which the commercial agent must observe.

(2) The notice period ends on the last day of the calendar month.

Section 2511

Section 2510 applies to a commercial agency which, under Section 2509, is considered to have been stipulated for an indefinite period; the notice period is calculated taking into account the duration of the commercial agency prior to its transformation to a commercial agency for an indefinite period.

\section{Section 2512}

(1) Where an exclusive commercial agency has been stipulated, each party has the right to terminate the commercial agency if the volume of business transactions in the previous twelve months did not reach the volume specified in the contract; in the absence of a stipulation on volume, the volume appropriate to the business transaction potential is decisive.

(2) The provisions of Sections 2510 and 2511 apply by analogy.

\section{Section 2513}

(1) Where an exclusive commercial agency has been stipulated and the principal uses another commercial agent, the commercial agent affected may terminate the commercial agency without a notice period.

(2) Where an exclusive commercial agency has been stipulated and the commercial agent pursues for other persons the same activity to the pursuit of which he is obliged with respect to the principal, the principal may terminate the commercial agency without a notice period. 


\section{Special remuneration}

Section 2514 [Recodification]

(1) If a commercial agency is extinguished, a commercial agent is entitled to special remuneration if:

a) he acquired new customers or significantly developed the business with the existing customers for the principal, and the principal still enjoys substantial benefits from this business and

b) the payment of special remuneration is fair with regard to all the circumstances of the case, provided that all circumstances are taken into account, including, but not limited to, the commission which the commercial agent has lost and which is based on the business transactions with such customers; these circumstances shall also include any stipulation, or lack thereof, of a noncompete clause.

(2) If the conditions under Subsection (1) are met, the right to special remuneration shall remain unaffected even where the commercial agency is extinguished by the death of the commercial agent.

\section{Section 2515}

The amount of special remuneration may not exceed the annual remuneration calculated from an annual average of the remuneration gained by the commercial agent over the previous five years. Where the commercial agency lasted less than five years, the amount of the special remuneration is calculated from the average of the remuneration for its entire duration; where it lasted less than a year, it may not exceed the sum of all commissions paid throughout its entire duration.

\section{Section 2516} agency.

The right to special remuneration is extinguished if not asserted within one year from the end of the commercial

\section{Section 2517}

The right to special remuneration is not created if:

a) a principal ends the commercial agency due to such a breach of duties by a commercial agent which entitles him to withdraw from the contract,

b) a commercial agent ends the commercial agency, unless it was ended for reasons on the part of the principal, or for reasons of age, disability or illness of the commercial agent, and if the commercial agent cannot be reasonably expected to continue his activities, or

c) a commercial agent, based on an agreement with the principal, transfers the rights and duties arising from the commercial agency to a third person.

Section 2518

\section{Non-compete clause}

(1) The parties may stipulate that after the extinction of the commercial agency, the commercial agent may not, in a designated geographical area or with respect to a designated group of persons in this geographical area, pursue, on his own account or the account of another, activities of a competitive nature in relation to the principal's business, including, but not limited to, the activities which he performed for the principal under the commercial agency. A contradicting non-compete clause or one which is stipulated for more than two years from the extinction of the representation is invalid.

(2) If a non-compete clause limits a commercial agent more than required by the necessary level of protection of the principal, a court may restrict the non-compete clause.

\section{Section 2519 [Recodification]}

\section{Prohibited stipulations}

(1) Stipulations which derogate from Sections 2489, 2495, 2496(1), 2497 or 2498 are prohibited.

(2) Stipulations which derogate from Sections 2504(2), 2505, 2506, 2507, 2514, 2515, 2516 or 2517 to the detriment of the commercial agent are disregarded.

\section{Section 2520}

(1) The provisions on commercial agency do not apply if it has been stipulated that a representative receives no remuneration for his activities.

(2) The provisions on commercial agency do not apply to the obligations of persons operating in a regulated market, multilateral trading facility or commodity exchange under another statute and to the obligations of stock exchange brokers under another law.

\section{Chapter 6}




\section{Package tour}

\section{Basic provisions}

Section 2521

By a package tour contract, an organiser undertakes to arrange for a customer a pre-arranged package of tourist services (package tour) and a customer undertakes to pay the total price.

\section{Section 2522 [Recodification]}

(1) A package tour is conclusively presumed to be a set of tourist services if it is organised for more than twenty-four hours or if it includes an overnight stay and contains at least two of the following performances:

a) accommodation

b) transport,

c) other tourist services not ancillary to transport or accommodation and accounting for a significant proportion of the package of the services offered.

(2) If an organiser charges for each performance within the same package tour separately, he is not released from his duties under this Chapter.

\section{Section 2523 [Recodification]}

(1) A person who offers a package tour to the public or a group of people on a commercial basis, even through a third person, is considered to be an organiser.

(2) A person who brokers or arranges individual tourist services is considered to be an organiser if, under special circumstances, he makes third persons think that he provides the tourist services as a package tour on his own responsibility.

\section{Section 2524}

An organiser shall, before concluding the contract, appropriately inform a customer of the passport and visa requirements and the time limits for their arrangement, and also inform him of the health formalities required for the journey and the stay.

\section{Package tour certificate}

\section{Section 2525 [Recodification]}

(1) The organiser shall, at the conclusion of the contract or immediately thereafter, provide the customer with a proof of the contract (package tour certificate). Package tour certificates must be in writing.

(2) If the contract is prepared in writing, a copy of the contract replaces a package tour certificate if such a copy contains all the elements required for a package tour certificate.

(3) If the contract and the package tour certificate contain different information about the package tour, a customer may invoke what is more convenient for him.

\section{Section 2526}

Along with the package tour certificate, the organiser shall provide the customer with a proof of its own insurance under another legal regulation issued by the insurer.

\section{Section 2527}

(1) In a package tour certificate, the organiser shall provide the following:

a) designation of the parties,

b) definition of the package tour by at least indicating the time it begins and ends and all the tourist services included in the package tour price, as well as the places where they are to be provided and their duration,

c) information on the price of the package tour, including the schedule of payments and the amount of the advance payment, as well as the fees not included in the total price,

d) an indication of the manner in which a customer is to assert his right arising from a breach of the organiser's duties, including information on the time limit within which he may do so, and

e) the amount of withdrawal fee payable by the customer to the organiser in cases provided under Section 2536 . 
(2) An organiser shall also include in the package tour the following elements:

a) where the package tour includes other services whose price is not included in the price of the package tour, the information on the number and amount of payments for these services,

b) where the package tour includes accommodation, its location, its tourist category, degree of comfort, its main features and its compliance with the legal regulations of the country concerned,

c) where the package tour includes transport, the type, characteristics and category of the transport to be used, as well as information on the route, and

d) where the package tour includes a meal plan, its type and extent.

(3) Where a brochure which the organiser handed over to the customer contains all the required information defining a package tour under Subsection (1)(b), the organiser may refer in the package tour certificate only to the number or other designation of the package tour in the brochure.

\section{Section 2528}

(1) Where a package tour taking place is conditional on reaching a certain number of customers, the organiser shall state it in the package tour certificate and expressly provide the time limit within which he must notify the customer of a cancellation of the package tour due to a failure to reach the specified number of customers.

(2) If there are grounds to determine the conditions which a package tour participant must comply with, the organiser shall state the conditions in the package tour certificate, including, if necessary, the time limit within which the customer may announce that another person will participate in the package tour in his stead.

\section{Section 2529}

(1) An organiser shall, at least seven days before the package tour begins, deliver to the customer other detailed information important to the customer concerning all the facts which he knows, unless they are already included in the contract, package tour certificate or in the brochure which the organiser handed over to the customer.

(2) In doing so, an organiser shall provide a customer with information including, without limitation:

a) specification of information under Section 2527(2),

b) information on the participation of a minor unaccompanied by a custodian, information on the manner to contact the minor or the organiser's representative in the place of stay of the minor,

c) information on the person who can be contacted in difficulty during the package tour with a request for assistance, including, without limitation, the name, address and telephone number of the local representative of the organiser and the address and telephone number of the embassy.

(3) If required by the circumstances, an organiser shall, within the same time limit, hand over to the customer the airline ticket, accommodation or meal voucher, document necessary for the provision of optional trips or another document necessary for the package tour to take place.

(4) If the contract is concluded within less than seven days before the beginning of the package tour, an organiser shall fulfil the duties under Subsections (1) and (3) at the conclusion of the contract.

\section{Section 2530}

\section{Change in the price of a package tour}

(1) An organiser may increase the price of a package tour for reasons provided under Subsection (2) if it is stipulated in the contract together with a precisely defined manner of calculating the price increase.

(2) An organiser may increase the price of a package tour if, no later than on the twenty-first day before the stipulated commencement of the package tour, there is an increase in:

a) the price of transport including fuel prices,

b) the payments related to transport, such as airport, port or other fees included in the price of the package tour, or

c) the exchange rate of the Czech crown used for the determination of the price of the package tour by more than $10 \%$.

(3) If an organiser dispatches a notice of price increase to a customer later than the twenty-one days before the commencement of the package tour, the price increase has no legal effects.

\section{Section 2531}

\section{Changes to a contract}

(1) If, due to external circumstances, an organiser is forced to change the conditions of a package tour, he shall propose a change to the contract to the customer. Where a change to the contract results in a change in the price of the 
package tour, the organiser shall provide the new price in the proposal.

(2) If a customer does not consent to the change to the contract, he has the right to withdraw; the organiser may determine an appropriate time limit for withdrawal which may not be less than five days and must end before the commencement of the package tour. If the customer fails to withdraw within the determined time limit, he is conclusively presumed to have consented to the change to the contract.

\section{Section 2532}

\section{Contract assignment} tour.

(1) A customer may assign the contract to a third person who meets the conditions for participation in the package

(2) A change in the identity of a customer is effective with respect to the organiser if the assignor delivers in due time to the organiser a notification along with a statement of the assignee that he consents to the contract concluded and that he will meet the conditions for the participation in the package tour. An announcement is delivered in due time if it is delivered at least seven days before the commencement of the package tour; a shorter time limit may be stipulated if the contract is concluded within less than seven days before the commencement of the package tour.

(3) The assignor and assignee are jointly and severally liable for the payment of the package tour price and the costs incurred by the organiser associated with the change in the identity of the customer.

\section{Withdrawal from contract}

\section{Section 2533}

A customer may always withdraw from the contract before the commencement of the package tour; an organiser may do so only if the package tour is cancelled or if the customer has breached his duty.

\section{Section 2534}

(1) If a customer withdraws from the contract under Section 2531(2), or if the organiser cancels the package tour for a reason other than a breach of duty by the customer, the organiser shall offer the customer a replacement package tour generally at least equivalent to what was originally stipulated, as long as it is within the organiser's powers to offer it.

(2) If the parties agree on a replacement package tour, the organiser is not entitled to increase the price, even if the replacement package tour is of higher quality. If the replacement package tour is of lower quality, the organiser shall pay the customer the price difference without undue delay.

\section{Section 2535}

(1) If an organiser cancels a package tour less than twenty days before its commencement, he shall pay the customer a penalty of $10 \%$ of the package tour price. This does not affect the customer's right to compensation for damage.

(2) An organiser is released from his duties under Subsection (1) if he demonstrates that the package tour was cancelled in accordance with Section 2528(1), or due to force majeure.

\section{Section 2536}

(1) If a customer withdraws from the contract for a reason other than a breach of the duty of the organiser, he shall pay the organiser a withdrawal fee under Section 2527(1)(e). The customer shall pay the same withdrawal fee if the organiser withdraws from the contract for a breach of duty by the customer.

(2) If a customer withdraws from the contract because the organiser breached its duty, the customer is not obliged to pay a withdrawal fee. This also applies where the customer was not provided with a replacement package tour.

\section{Defects of package tour}

\section{Section 2537}

(1) If a package tour lacks the characteristics of which the organiser assured the customer or which the customer reasonably expected with regard to the offer and usages, the organiser shall provide a remedy unless it entails disproportionate cost.

(2) If an organiser fails to provide a remedy within a reasonable time limit determined by the customer, the customer may remedy the situation himself and he is reimbursed by the organiser for reasonably incurred costs. Determining a time limit to provide a remedy is not necessary if the organiser refuses to provide a remedy or if immediate remedy is required given the special interests of the customer.

\section{Section 2538}

If substantial defects of a package tour occur after the departure and if the organiser does not take measures to ensure that the package tour can continue, or if a customer refuses the measure for a good reason, the organiser shall, at its expense, provide for the customer's carriage to the point of departure or another stipulated place. 
(1) If the continuation of a package tour cannot be ensured otherwise than through tourist services of lower quality than those specified in the contract, the organiser shall pay the price difference to the customer.

(2) If an organiser ensures the continuation of a package tour at a higher cost, such costs are borne by the organiser.

$$
\text { Section } 2540 \text { [Recodification] }
$$

Where a package tour has a defect and a customer has claimed it without undue delay, the customer is entitled to a price reduction in the amount appropriate to the extent and duration of the defect. If a customer is at fault for not claiming the defect without undue delay, a court shall not grant him the right to a price reduction if the organiser invokes that the customer did not assert his right within one month from the end of the package tour either against the organiser or against the person who brokered the conclusion of the contract.

\section{Section 2541 [Recodification]}

\section{Assistance in difficulties}

If, after the commencement of a package tour, a customer gets into difficulties, the organiser shall provide him with assistance without delay.

\section{Compensation for damage}

\section{Section 2542}

An organiser is liable to the customer for fulfilling the duties under the package tour contract regardless of whether or not the package tour involves individual tourist services provided by other persons.

\section{Section 2543 [Recodification]}

(1) In case the organiser breaches any of the duties for which it bears liability, it shall, in addition to the damage to property, compensate the customer for the harm associated with a disruption of holiday, including, without limitation, where the package tour was frustrated or substantially reduced.

(2) If a customer withdraws from the contract or asserts his right arising from a defective package tour, it does not affect his right to compensation under Subsection (1).

\section{Section 2544}

Where an international treaty binding upon the Czech Republic allows the limitation of the amount of compensation for damage incurred as a result of breach of duty arising from a package tour contract, the organiser is to compensate the damage only to the extent of this limitation if so stipulated in the contract. This does not apply if the damage was caused intentionally or by gross negligence.

\section{Student homestay}

Section 2545 [Recodification]

Where a package tour concerns the stay of a student with a host family in another country stipulated for at least three months which includes regular school attendance, the organiser, with the cooperation of the student, shall provide the student with suitable accommodation in a host family, as well as supervision and care for him according to the circumstances usual in country of the homestay. At the same time, the organiser shall create conditions for the student to be able to regularly attend school.

\section{Section 2546}

(1) The organiser is not entitled to a withdrawal fee if the customer withdraws from the contract before the commencement of the student homestay because the organiser failed to provide the customer at least two weeks in advance with the following:

a) the name and address of the host who will provide the student with accommodation upon arrival, and

b) the name and address of the authorised person (coordinator) in the country of homestay which can be contacted with a request for assistance, and information regarding the manner in which such a person may be contacted.

(2) An organiser is not entitled to a withdrawal fee if the customer withdraws from the contract because the organiser failed to properly prepare the student for the homestay.

\section{Section 2547}

(1) A customer is entitled to withdraw from the contract during the student homestay; the organiser is entitled to the stipulated remuneration minus the costs not incurred. The organiser shall take measures necessary to transport the student back; the customer shall pay the organiser the increased costs associated therewith.

(2) An organiser is not entitled to the performance under Subsection (1) if a customer withdraws from the contract due 
to a breach of the organiser's duties.

\section{Common provisions}

Section 2548

A package tour under this Chapter shall not mean a package of tourist services provided to an entrepreneur for his pursuit of further business activities, or a package of tourist services offered and provided for purposes other than business.

\section{Section 2549 [Recodification]} invalid.

The provisions in the contract that derogate from the provisions of this Chapter to the detriment of the customer are

\section{Chapter 7}

\section{Obligations arising from contracts of carriage}

\section{Division 1}

\section{Carriage of persons and things}

\section{Subdivision 1}

\section{Carriage of a person}

Section 2550

\section{Basic provisions}

By a contract for the carriage of a person, a carrier undertakes to carry a passenger to his destination, and a passenger undertakes to pay the fare.

\section{Section 2551} carriage.

During carriage, a carrier shall ensure the safety and comfort of the passenger. Details are governed by the rules of

\section{Section 2552}

(1) If a passenger has luggage, it is carried by the carrier either together with the passenger and under his supervision, or separately.

(2) Where luggage is carried separately, the carrier shall ensure that it is carried to its destination no later than at the same time as the passenger.

\section{Section 2553 [Recodification]}

(1) In the case of regular carriage of persons, rules of carriage provide the rights of passengers with respect to carriers where carriage was not performed in due time.

(2) In the case of irregular carriage of persons, the carrier shall compensate the damage incurred by the passenger by not effecting carriage in due time; the conditions and scope for the compensation is provided by rules of carriage.

(3) A passenger must assert the rights under Subsections (1) and (2) against the carrier without undue delay. If no such right has been asserted within six months, a court shall not grant it if the carrier invokes late assertion of the right.

\section{Section 2554}

(1) If, during carriage, a passenger incurs bodily harm or damage to luggage carried along with him, or if there is damage to a thing which the passenger had with him, the carrier shall provide compensation under the provisions on damage caused by the operation of means of transport.

(2) A carrier shall provide compensation for damage caused to luggage carried separately from the passenger according to the provisions on compensation for damage during the carriage of a thing.

\section{Subdivision 2}

\section{Carriage of a thing}

Section 2555

\section{Basic provisions}

(1) By a contract for the carriage of a thing, a carrier undertakes to carry a consignor's thing as a consignment from 
the point of dispatch to the destination, and a consignor undertakes to pay freight to the carrier.

(2) If a consignor fails to request that the carrier take over the consignment within the stipulated period, and where no such period is stipulated within six months after the conclusion of the contract, the rights and duties arising from the contract are extinguished.

\section{Section 2556}

A consignor shall provide the carrier, at the carrier's request, with a confirmation of the order of the carriage. The carrier shall provide the consignor, at the consignor's request, with a confirmation of the takeover of the consignment. The confirmation must be in writing.

\section{Section 2557}

(1) The consignor shall provide the carrier with correct information about the contents and nature of the consignment.

(2) Where a special instrument is required for the carriage to be provided, it is handed over by the consignor to the carrier no later than upon the handover of the consignment for carriage.

\section{Section 2558}

A carrier shall carry the consignment to its destination with professional care and within the stipulated period, or without undue delay where no period has been stipulated. The period is presumed to commence on the day following the takeover of the consignment by the carrier.

\section{Section 2559}

\section{Interruption of carriage}

If a carrier has not yet handed the consignment over to the consignee, the consignor may mandate that the carriage be interrupted and the consignment be disposed of according to his mandate; however, the consignor is to reimburse the carrier for the costs reasonably incurred in connection therewith.

\section{Section 2560}

(1) If the carrier knows the consignee, it shall deliver the consignment to him. However, if, according to the contract, the consignee is to collect the consignment at the place of its destination, the carrier shall only notify the consignee of the end of carriage and surrender the consignment to the consignee at the consignee's request.

(2) If a contract obliges a carrier to collect a certain amount or perform another act of collection before handing over the consignment, the provisions on documentary collection apply with the necessary modifications.

\section{Section 2561}

The consignee indicated in the contract acquires the rights arising from the contract if he requests that the consignment be surrendered to him after it reaches the destination, or after the expiry of the period within which it was to reach the destination. At that moment, the consignee shall also acquire the right to compensation for damage to the consignment.

Section 2562

Upon the receipt of the consignment, the consignee becomes the consignor's surety for the carrier's contractual claims relating to the carriage of the consignment which has been taken over. The consignee is released from the suretyship if he proves that he did not know and was not required to know of these claims.

\section{Section 2563}

A carrier shall not surrender the consignment to the consignee if it is contrary to the mandate of the consignor under Section 2559. In that case, the consignor continues to have the right to dispose of the consignment. If the consignor identifies to the carrier another person as the consignee, that person shall acquire the rights arising from the contract in the same manner as the original consignee.

\section{Freight}

\section{Section 2564}

(1) Freight becomes due without undue delay after the consignment has been delivered to its destination.

(2) If the amount of freight has not been stipulated, the carrier is entitled to freight which is usual at the time of the conclusion of the contract, having regard to the content of the obligation.

\section{Section 2565}

If the carrier is unable to complete the carriage for reasons for which he bears no liability, the carrier is entitled to a part of the freight, taking into account the carriage which he has already competed. 


\section{Compensation for damage}

\section{Section 2566}

(1) A carrier shall compensate the damage caused to a consignment between its receipt by the carrier and its surrender to the consignee. This does not apply if the carrier proves that the damage could not have been prevented even by exercising professional care.

by:

(2) A carrier is released from the duty to provide compensation for damage by proving that the damage was caused

a) the consignor, consignee or owner of the consignment or

b) a defect or inherent nature of the consignment, including usual loss.

(3) Where damage is caused by the consignment's defective packaging, the carrier is released from the duty to provide compensation for damage by proving that it notified the consignor of the defect upon the takeover of the consignment for carriage; where a consignment note or bill of lading was issued, it must contain an indication of the defective packaging. If the carrier fails to notify of the defective packaging, it is released from the duty to provide compensation for damage by proving that the defect could not have been discovered upon the takeover of the consignment.

(4) Stipulations limiting the carrier's liability under Subsections (1) to (3) are disregarded.

Section 2567

(1) In case of loss or destruction of a consignment, the carrier shall provide compensation in the amount of the price of the consignment at the time when it was taken over.

(2) In case of damage to or loss of value of a consignment, the carrier shall compensate the difference between the consignment's price at the time of its takeover by the carrier, and the price a consignment that was damaged or lost its value would have had at that time.

\section{Section 2568}

(1) If damage is incurred to a consignment, the carrier shall notify the consignor of the damage. However, once the consignee becomes entitled to have the consignment surrendered to him, the carrier shall notify the consignee.

(2) If a carrier fails to notify of the damage without undue delay, it shall compensate the consignor or consignee for the resulting damage.

\section{Section 2569 [Recodification]}

If the right to compensation for damage is not asserted against the carrier within six months from the date of takeover of the consignment or, if the consignment was not taken over, within six months from the date on which it should have been delivered, a court shall not grant such right if the carrier invokes late assertion of the right.

\section{Section 2570}

\section{Sale by self-help}

A carrier may sell the consignment on the account of the consignor if there is an imminent threat of substantial damage to the consignment, there is no time to obtain instructions from the consignor, or the consignor delays the giving of such instructions.

\section{Section 2571 [Recodification]}

(1) A carrier has a pledge of the consignment as long as it can dispose of it to secure the contractual debts.

(2) If several pledges encumber a consignment, the carrier's pledge has priority over the pledges established earlier, and a carrier's pledge has priority over a forwarder's pledge.

\section{Subdivision 3}

\section{Bill of lading}

\section{Section 2572}

(1) A confirmation of the takeover of the consignment can be substituted with a bill of lading. A bill of lading is a security which confers the right to require the carrier to surrender the consignment in accordance with the contents of the bill of lading; it can be issued as a registered bill of lading, bill of lading to order or a bearer bill of lading.

(2) The bill of lading shall contain at least:

a) the name of the carrier, his place of residence or registered office,

b) the name of the consignor, his place of residence or registered office, 
c) designation, quantity, weight or volume of the things carried,

d) the form of the bill of lading; if it was issued as a registered bill of lading or bill of lading to order, it shall also contain the designation of the person in the name or to the order of whom it was issued,

e) the place of destination and

f) the place and date the bill of lading was issued and the carrier's signature.

(3) If a bill of lading does not contain the name of the person to the order of whom it was issued, it is considered to have been issued to the order of the consignor.

Section 2573

In case a bill of lading is issued in counterparts, the carrier shall indicate their number on each counterpart.

Section 2574

In case a bill of lading becomes destroyed or lost, a carrier shall issue to the consignor a new bill of lading indicating that it is a replacement. The consignor shall compensate the carrier for the damage which he may incur as a result of a misuse of the original bill of lading.

\section{Section 2575}

After issuing a bill of lading, only the person entitled under the bill of lading has the right to interrupt the carriage. Where several counterparts of the bill of lading have been issued, the submission of all counterparts is required.

Section 2576 lading.

After a bill of lading is issued, the consignment may be surrendered to the person entitled thereto under the bill of

\section{Section 2577}

(1) With respect to the holder of the bill of lading, a carrier may only assert the defences arising from the content of the bill of lading or from his rights against the holder.

(2) With respect to the holder of the bill of lading, a carrier may invoke the stipulations contained in the contract which the carrier concluded with the consignor if these stipulations are contained in the bill of lading or expressly referred to therein.

\section{Subdivision 4}

\section{Common provisions on the carriage of persons and things}

\section{Section 2578}

A detailed regulation on the carriage of persons and things is provided by another legal regulation, including, but not limited to, regulations providing for rules of carriage, unless provided by a directly applicable regulation of the European Communities.

\section{Section 2579}

Where several carriers join to effect carriage, rules of carriage may also determine which of the carriers is liable for the carriage and under what conditions.

\section{Section 2580 [Recodification]}

(1) If rules of carriage limit the carrier's duty to compensate for bodily harm, it is disregarded.

(2) The duty of carriers operating public transport to compensate for damage or other harm may be limited by rules of carriage only in particularly justified cases where the need for such limitation for national carriage necessarily follows from the principles applicable to international carriage.

(3) Any limitation of a carrier's duty to provide compensation for harm in rules of carriage does not apply to cases of harm caused intentionally or by gross negligence.

Section 2581

(1) If a person entitled to collect luggage or a consignment has not collected it for more than six months, the carrier may sell the thing on account of that person. If it is a thing of a greater value and if the carrier knows the address of that person, he shall notify such a person in advance of the intended sale and provide him with additional reasonable time limit to collect it.

(2) In justified cases, rules of carriage may provide for shorter time limits for the collection of some luggage and consignments, especially in the case of things of a dangerous nature or perishable things. 


\title{
Division 2
}

\section{Operation of a means of transport}

\section{Section 2582}

By a contract for the operation of a means of transport, an operator undertakes to carry cargo designated by the client and make at least one predetermined journey for that purpose or make a number of journeys within the agreed time as determined by the client, and a client undertakes to remunerate the operator.

\section{Section 2583}

(1) An operator shall ensure the fitness of the means of transport for the journey agreed and its usability for the carriage agreed, and provide the means of transport with competent crew and fuel and other necessary things.

(2) If a means of transport is not fit for use under Subsection (1), the operator shall compensate the client for the resulting damage, unless the operator proves that he could not have predicted the unfitness even by exercising necessary care.

Section 2584

A client may assign the right to demand the agreed operation of a means of transport to another person.

\section{Section 2585 [Recodification]}

If an operator receives cargo for carriage, the determination of the rights and duties of the parties are governed by the provision on contracts of carriage with the necessary modifications if allowed by the nature of the contract for the operation of a means of transport.

\section{Chapter 8}

\section{A work}

\section{Division 1}

\section{General provisions}

\author{
Section 2586 [Recodification]
}

\section{Basic provisions}

(1) By a contract for work, a contractor undertakes to perform a work, at his own expense and risk, for a client, and a client undertakes to take over the work and pay the price.

(2) The price of the work has been stipulated with sufficient accuracy if at least the manner in which it is to be determined has been agreed, or if it has at least been determined as an estimate. If the parties intend to conclude a contract without determining the price of the work, the price paid for an identical or comparable work at the time of the conclusion of the contract and under similar contractual terms is conclusively presumed to be the stipulated price.

\section{Section 2587}

A work is to be understood as the making of a particular thing which is not subject to a contract of sale, as well as maintenance, repair or alteration of a thing, or an activity with any other result. A work is to be understood as any construction, maintenance, repair or alteration of a structure or part thereof.

\section{Section 2588 [Recodification]}

(1) If the performance of a work depends on special personal skills of the contractor, the obligation is extinguished upon the loss of his capability or his death. This does not apply if the work can be successfully performed by the person who assumed the activities of the contractor as his legal successor.

(2) The death of a client does not in itself extinguish the obligation, unless the discharge of the obligation becomes impossible or futile as a result. This also applies in case the obligation is extinguished by the client's death.

\section{Manner of performance of a work}

\section{Section 2589}

A contractor shall either perform the work in person, or have it performed under his personal direction. This does not apply if the performance of the work is not conditional on the personal characteristics of the contractor or if it is not necessary given the nature of the work.

Section 2590

(1) A contractor shall perform the work with necessary care within the stipulated period and procure all that is needed 
for its performance.

(2) Where no period of performance has been stipulated, the contractor shall perform the work within a period appropriate to its nature. The time of performance is presumed to have been stipulated in favour of the contractor.

\section{Section 2591 [Recodification]}

Where a client's cooperation is required for the performance of the work, the contractor shall specify a reasonable time limit for him to provide such cooperation. If the time limit expires and the client failed to provide any cooperation, the contractor is entitled to choose to either provide for a replacement performance on the account of the client, or withdraw from the contract if he warned the client thereof.

\section{Section 2592}

A contractor shall act independently in performing the work. A contractor is bound by the mandate of the client concerning the manner of performance of the work only if it follows from usages or if so stipulated.

\section{Section 2593}

A client has the right to inspect the performance of the work. If he ascertains that the contractor is in breach of his duty, he may require the contractor to provide for a remedy and perform the work properly. If the contractor fails to do so within a reasonable time and where his acts would undoubtedly result in a fundamental breach of contract, the client may withdraw from the contract.

\section{Section 2594}

(1) The contractor shall notify the client without undue delay of the unsuitability of a thing handed over or a mandate given to him by the client. This does not apply if he could not have ascertained the unsuitability even by exercising necessary care.

(2) If an unsuitable thing or mandate hinders the proper performance of the work, the contractor shall suspend the work to the extent necessary until the thing is replaced or the mandate changed; if the client insists on performing the work using the thing handed over or the mandate given, the contractor is entitled to require the client to do so in writing.

(3) The time limit for the completion of the work is extended by the period of suspension. The contractor is entitled to be reimbursed for the costs associated with the suspension of the work or the use of unsuitable things up to such time as their unsuitability could have been ascertained.

(4) If a contractor proceeds in accordance with Subsections (1) and (2), the client shall not have the rights arising from a defective work caused by an unsuitable thing or mandate.

\section{Section 2595 [Recodification]}

If the client insists that the work be performed according to an apparently unsuitable mandate or using an apparently unsuitable thing even after having been notified by the contractor, the contractor may withdraw from the contract.

\section{Things to be used to perform a work}

Section 2596

If a contractor procures a thing which was processed during the performance of the work and such a thing becomes a component part of the work, the contractor is in the position of a seller in respect of that thing. The purchase price of the thing is presumed to be included in the price of the work.

\section{Section 2597}

(1) Where a client is to procure a thing for the performance of the work, he shall hand it over to the contractor within the agreed period; otherwise, he shall do so without undue delay after the conclusion of the contract. The price of the work is presumed not to be reduced by the price of the thing.

(2) If a client fails to procure a thing in time and fails to do so even within an additional reasonable period after having been requested to do so by the contractor, the contractor may procure the thing on the account of the client. The client shall pay the contractor the price of the thing and costs reasonably incurred in the procurement thereof without undue delay after having been requested to do so by the contractor.

\section{Section 2598}

(1) A client bears the risk of damage to a thing which he procured for the performance of the work for the duration of his right of ownership in the thing.

(2) With respect to a thing taken over from a client, a contractor has the liability of a storage provider. Upon the completion of the work, the contractor shall present the client with accounts and return to him the unprocessed part of his things.

\section{Right of ownership in the subject of a work}


(1) If the subject of a work is a thing determined individually, the right of ownership in such a thing is acquired by the client. This does not apply where the contractor processed a client's thing at a place other than the client's place, his tract of land or tract of land procured by the client, or where the value of the work is equal to or greater than the value of the client's processed thing; in that case, the right of ownership in the subject of a work is acquired by the contractor.

(2) If the subject of a work is a thing determined by kind, the right of ownership in such a thing is acquired by the contractor. This does not apply if the contractor made the thing at the client's place, on his tract of land or on tract of land procured by the client; in that case, the right of ownership is acquired by the client.

\section{Section 2600 [Recodification]}

If a contractor has acquired the right of ownership in a thing by processing, and the work is frustrated for reasons for which the contractor bears no liability, the client is not entitled to compensation for the thing which he handed over to the contractor for processing. Rights arising from unjust enrichment shall remain unaffected.

\section{Section 2601 [Recodification]}

If a contractor has acquired the right of ownership in a thing by processing and the work is frustrated for reasons for which the contractor bears liability, he shall provide the client with a pecuniary compensation for the client's processed thing or return to him a thing of the same kind.

\section{Section 2602 [Recodification]}

(1) If a client has acquired the right of ownership in a thing by processing and the work is frustrated for reasons for which the contractor bears liability, the client may either request to have the thing created by processing surrendered to him, or refuse the thing and require compensation for his things used for processing.

(2) If a contractor surrenders to the client a thing created by processing, this does not affect the contractor's right arising from unjust enrichment. If a client refuses a thing created by processing, he is entitled to be compensated by the contractor for the client's processed thing in money or to have a thing of the same kind returned.

\section{Section 2603 [Recodification]}

If the right of ownership in a thing has been acquired by the client and the work is frustrated for reasons for which the contractor bears no liability, the client may only request to have the thing created by processing surrendered to him; however, he shall compensate the contractor for the price of the contractor's thing used for processing.

\section{Performance of a work}

\section{Section 2604}

A work is presumed to have been performed once it has been completed and handed over.

\section{Section 2605 [Recodification]}

(1) A work is completed once its fitness to serve its purpose has been demonstrated. The client shall take over the completed work with or without reservations.

(2) If a client takes over a work without reservations, a court shall not grant him the right arising from evident defects of the work if the contractor invokes late assertion of the right.

\section{Section 2606}

Where a work is performed gradually and its individual stages can be distinguished, it may also be handed over and taken over in parts.

\section{Section 2607}

(1) Where the completion of a work is to be demonstrated by performing stipulated tests, the work is considered to be completed upon the successful performance of these tests. The contractor shall, in due time, invite the client to participate in such tests; the client's absence in the tests where it is not excluded by the nature of the thing shall not prevent the tests from being performed.

(2) The test result is recorded in a report; in the absence of the client, the report shall, instead of the client, be confirmed by a credible, competent and impartial person who participated in the tests. If it is not in conflict with the nature of the obligation, the contractor is obliged to hand over the report to the client at the client's request.

Section 2608

(1) Where the subject of a work is a thing, the handover of the thing is governed by the provisions on a contract of sale by analogy.

(2) Upon a takeover, the client shall acquire the right of ownership in the thing and the risk of damage to the thing passes to the client, unless this has already taken place earlier. 


\section{Section 2609 [Recodification]}

\section{Sale by self-help}

(1) If the subject of a work is a thing and if the client fails to take over the thing without undue delay after the work was to be completed or, if it was completed later, without undue delay after having been notified of the completion of the work, the contractor may sell the thing on the account of the client in an appropriate manner. Unless prevented by the nature of the thing, the contractor shall notify the client of the intended sale and provide him with an additional time limit of no less than one month to take over the thing.

(2) If a client that is unknown or not easy to reach has not claimed the work for more than six months or, where applicable, if a client that is prevented from doing so by the nature of the thing has not claimed the work within a period appropriate to its nature, the contractor may sell the thing on the client's account even without notification.

\section{Price for a work}

\section{Section 2610}

(1) The right to be paid the price of a work is created upon the performance of the work.

(2) Where a work is to be taken over in parts, the right to be paid the price of each part is created when the part has been performed.

\section{Section 2611}

Where a work is performed in parts or with considerable costs and the parties did not stipulate the payment of any advance payments, the contractor may require that he be paid a reasonable part of the remuneration during the performance of the work, having regard to the costs incurred.

\section{Section 2612 [Recodification]}

(1) If, after the conclusion of the contract, the contractor ascertains that the price determined as an estimate will be considerably exceeded, he shall notify the client without undue delay with a justified determination of a new price; if he fails to do so without undue delay after he ascertained, or should and could have ascertained, the need to increase the price, he is not entitled to the payment of the price difference.

(2) A client may withdraw from the contract; he shall pay the contractor a proportion of the originally determined price if he benefited from the partial performance provided by the contractor. If a client fails to withdraw from the contract without undue delay after the delivery of the notice of an increased price, he is conclusively presumed to consent to the price increase.

\section{Section 2613}

If a client frustrates the performance of the work for reasons for which the client bears liability, the contractor is entitled to the price for the work decreased by the costs saved by the non-performance of the work.

\section{Section 2614}

If, after the conclusion of the contract, the parties agree on limiting the scope of the work and do not stipulate any consequences for the amount of the price, the client shall pay the price adjusted having regard to the difference between the scope of the necessary activities and the efficiently incurred cost associated with the changed performance of the work.

\section{Defects of a work}

Section 2615

(1) A work has a defect if it is not in compliance with the contract.

(2) The client's rights arising from a defective performance are governed by analogy by the provisions on a contract of sale. However, the client is not entitled to request a replacement work to be performed if the subject of the work, given its nature, cannot be returned or handed over to the contractor.

\section{Section 2616}

If, under the legal order of the Czech Republic or under the legal order of the state where the subject of a work is to be used, third-party industrial property or other intellectual property rights are jeopardised or infringed upon due to the use of the work, the contractor is obliged to the client for such a jeopardy or infringement if the contractor knew or must have known of these rights of a third person being jeopardised or infringed upon at the time of the conclusion of the contract. Legal defects of a work are governed by analogy by the provisions on legal defects of things purchased.

\section{Section 2617}

If, upon handover, a work has a defect, the contractor shall incur duties under a defective performance; however, where the risk of damage passes to the client later, the time of the passage is decisive. After this time, the client has the rights arising from a defective performance if the defect was caused by the contractor by a breach of his duty. 
A court shall not grant a client the right arising from a defective performance if the client failed to notify the defects of the work without undue delay after he has discovered them or should have discovered them by paying due attention, but no later than two years after the handover of the work, and the contractor invokes late assertion of the right.

Section 2619 analogy.

(1) Where a contractor has provided quality guarantee for the work, the provisions on a contract of sale apply by

(2) The guarantee period for the work commences upon the handover of the work.

\section{Division 2}

\section{Determining the price according to the budget}

\section{Section 2620}

(1) Where the price has been stipulated as a fixed amount or by reference to a budget which forms part of the contract or was communicated to the client by the contractor no later than upon the conclusion of the contract, neither the client nor the contractor may request a change in the price because effort or costs other than those which were expected were required for the work.

(2) However, in case of a completely extraordinary and unforeseeable circumstance which significantly hinders the completion of the work, a court may, at its discretion, decide on a fair increase in the price of the work, or to cancel the contract and determine mutual settlement between the parties. This does not apply if one of the parties assumed the risk of a change in circumstances, or if it is a circumstance of which one of the parties previously declared that it would not occur.

\section{Section 2621}

(1) If a work has been contracted according to a budget, the contractor may not require an increase in the price of the work even where the scope or high cost of work result in budget overrun.

(2) If a budget has been guaranteed as final, the contractor may not require an increase in the price of the work in case additional work is needed to complete the work.

\section{Section 2622}

(1) However, if the price has been determined on the basis of a budget with a reservation that its finality is not guaranteed or with a reservation that the budget is non-binding, the contractor may require the price to increase if, in the case of the budget with no guarantee of finality, activities not included in the budget are required for the performance of the work, provided that they were not foreseeable upon the conclusion of the contract; in the case of the non-binding budget, the contractor may require the price to increase by an amount by which the costs reasonably incurred by the contractor inevitably exceed the costs included in the budget. If the client does not consent to the price increase, it is determined by a court on the application of the contractor.

(2) The contractor's entitlement to determine the price increase under Subsection (1) is extinguished if he fails to notify without undue delay the need to exceed the budgeted amount and the amount of the required price increase after its inevitability became evident during the performance of the work.

(3) The client may, without undue delay, withdraw from the contract if the contractor requests that the budgeted amount increase by more than $10 \%$. In that case, the client is obliged to pay the contractor a part of the price corresponding to the scope of the partial performance of the work according to the budget.

\section{Division 3}

\section{Structure as a subject of a work}

\section{Section 2623 [Recodification]}

Unless otherwise provided below, a contract for the alteration of an immovable thing and a contract for the erection, repair or alteration of a structure is governed by the provisions of Division 1 of this Chapter.

\section{Section 2624 [Recodification]}

\section{Risk of damage}

Where a structure is being erected to the order of a client, the contractor bears the risk of damage or destruction of the structure until its handover, unless the damage would have occurred in any case.

\section{Section 2625 [Recodification]}

\section{Right to be presented with accounts}

If the price of a work is determined with reference to the actual scope of work and its value or to the value of the things used and the amount of additional costs, the contractor shall, at the client's request, present the client with the accounts 
for work performed so far as well as costs incurred up to that point.

Section 2626 [Recodification]

\section{Inspecting the performance of a work}

(1) If a contract stipulates that the client is to inspect the subject of the work at a certain stage of its performance, the contractor shall invite the client to carry out such an inspection. If he fails to invite him in time or does so at an evidently inconvenient time, he shall allow the client to carry out an additional inspection and bear the associated costs.

(2) If the client fails to appear for the inspection to which he was duly invited or which was to be held in accordance with a stipulated schedule, the contractor may continue the performance of the work. The client has the right to carry out an additional inspection, but shall reimburse the contractor for the associated costs, if he was prevented from participating in the inspection by force majeure and requested an additional inspection without undue delay; otherwise, all that is incurred as a result of the additional inspection is borne by the client.

\section{Section 2627 [Recodification]}

\section{Latent obstacles}

(1) If, in the performance of a work, the contractor discovers latent obstacles relating to the place where the work is to be performed and preventing the contractor from performing the work in the manner agreed, he shall notify the client accordingly without undue delay and suggest a change of the work. Until an agreement on the changes to the work has been reached, the contractor may suspend its performance.

(2) If the parties fail to agree to amend the contract within a reasonable time limit, any of them may withdraw from the contract. The contractor is entitled to be paid the price of the part of the work performed until such time as the obstacle could have been discovered by exercising necessary care.

\section{Section 2628 [Recodification]}

\section{Takeover of a structure}

A client does not have the right to refuse to take over a structure due to isolated small defects which, by themselves or in conjunction with others, neither functionally or aesthetically prevent the use of the structure, nor substantially limit its use.

\section{Defects of a structure}

\section{Section 2629 [Recodification]}

(1) A court shall not grant the right arising from a latent defect of which the client failed to notify without undue delay after he could have discovered it by exercising sufficient care, but no later than five years after taking over the structure, if the other party invokes late assertion of the right. The same applies to a latent defect in project documents and other similar performances.

(2) An implementing legal regulation may, in justified cases, provide that the period under Subsection (1) be reduced for certain parts of a structure to a minimum of two years. If the parties stipulate such a reduction and the client is the weaker party, it is disregarded.

\section{Section 2630 [Recodification]}

(1) If a defective performance has been provided, the following persons shall, in respect of what they themselves supplied, be liable jointly and severally with the contractor:

a) a contractor's subcontractor, unless he proves that the defect was entirely caused by the decision of the contractor or the structure's supervisor,

b) the person who supplied construction documents, unless he proves that the defect was not caused by an error in the construction documents, and

c) the structure's supervisor, unless he proves that the defect was not caused by a failure in supervision.

(2) A contractor is released from his duty arising from a defect of the structure if he proves that the defect was entirely caused by an error in the construction documents supplied by a person chosen by the client, or entirely by a failure in supervision exercised by a person chosen by the client.

\section{Division 4}

\section{A work consisting in an incorporeal result}

Section 2631

If a work consists in a result of activity other than the making, maintenance, repair or alteration of a thing, the contractor shall perform the activity as stipulated and with professional care so as to achieve the result specified in the contract. 
If the subject of a work is not a corporeal thing, the contractor shall deliver the result of his activity to the client. A work containing incorporeal results is considered to have been handed over if it is completed and the contractor allows the client to use it.

\section{Section 2633}

The contractor may provide a result of an activity which is subject to an industrial property or other intellectual property right also to persons other than the client, if so stipulated. Unless the provision of such a result is expressly prohibited in the contract, the contractor is entitled to do so, provided that it is not contrary to the client's interests, given the nature of the work.

\section{Section 2634}

If the subject of a work consists in a result of an activity which is protected by an industrial or other intellectual property right, the contractor is presumed to have provided it to the client for the purpose following from the contract.

\section{Section 2635} (a competition work)

The provisions of this Division apply by analogy to results of activities made under the provisions on a public promise

\section{Chapter 9}

\section{Health care}

\section{Section 2636 [Recodification]}

\section{Basic provisions}

(1) By a contract for health care, the provider undertakes, with respect to the mandator and within the provider's occupation or objects of activities, to care for the health of the patient, whether the patient is the mandator or a third person.

(2) The provider shall receive remuneration from the mandator, if so stipulated; this does not apply if another legal regulation provides that the health care is exclusively paid from other sources.

\section{Section 2637 [Recodification]}

Health care includes intervention, examination and advice, and all other services which directly relate to the patient and whose purpose is to improve or maintain the patient's health condition. However, health care is not an activity merely consisting in the sale or other transfer of medicinal products.

Advice

\section{Section 2638 [Recodification]}

(1) The provider shall clearly explain to the patient the intended examination and the proposed health care; after the relevant examination, the provider shall also explain to the patient his health condition and health care during subsequent procedures. If so requested by the patient, the provider shall provide him with the explanation in writing.

(2) If the patient lacks full legal capacity but is nevertheless capable of judgement, he is advised in a manner appropriate to his ability to understand the explanation; the explanation is also given to his legal representative.

\section{Section 2639 [Recodification]}

(1) Explanation is properly given if it can be reasonably expected that the patient has understood his health condition, the manner, purpose and necessity of health care including the expected consequences and possible risks to his health, as well as whether or not any other method of health care is possible.

(2) If a provider must be aware that he made a patient believe that the patient will achieve a certain result through health care, although he knows or must know that such a result may not be achieved, he is also obliged to explain this fact to the patient.

\section{Section 2640 [Recodification]}

(1) If this would obviously and seriously jeopardise the health condition of the patient, the patient may be given the explanation in full subsequently, when there is no need to worry about the danger. The provider is presumed not to have that right unless the obviousness and seriousness of the danger is confirmed by another person providing health care in the relevant field.

(2) If the patient is denied the explanation and if it is required by the patient's interests, the explanation is given to another person authorised by the patient, unless otherwise provided by another legal regulation. 
If the patient has clearly indicated that he does not wish to be given an explanation, it is not given unless the potential danger to the patient or another person clearly exceeds the patient's interest.

\section{Rights and duties of the parties}

\section{Section 2642 [Recodification]}

(1) Each health care intervention requires the consent of the patient, unless a statute provides that such consent is not required. If the patient refuses to grant the consent, he shall, at the provider's request, provide the provider with a written confirmation of this fact.

(2) If the provider or patient requires the other party to provide him with a written confirmation of what the consent was granted for, the other party shall do so.

\section{Section 2643 [Recodification]}

(1) The provider shall proceed under the contract with due professional care as well as in accordance with the rules applicable to his field.

(2) The patient shall provide the provider, to the best of his knowledge, with all the necessary information, and provide him with the cooperation necessary, required under reasonable expectations, for the provider to fulfil the duties under the contract.

\section{Section 2644 [Recodification]}

The provider shall allow no other person to observe the provision of health care to the patient, unless the patient has given his consent therewith. This does not apply if the presence of another person is required in order to prove the extent to which the requirements of professional care have been met.

\section{Section 2645 [Recodification]} disregarded.

The provider is liable for fulfilling his duties with due professional care; stipulations which exclude or limit that are

\section{Section 2646 [Recodification]}

(1) Where health care is provided in a health care facility, social service facility or a similar facility not operated by a party to the contract, the patient or mandator must be informed in due time of the identity of the provider and of the fact that the operator of the facility is not a party to the contract.

(2) If the provider cannot be identified, the operator of the facility where health care was provided shall even be considered to be the provider; this applies even where the operator fails to inform the patient or mandator of the identity of the provider without undue delay. Stipulations to the contrary are disregarded.

\section{Health care records}

\section{Section 2647 [Recodification]}

(1) A provider shall maintain health care records which must clearly show information on the patient's health condition and on the provider's activities, including documents certifying the accuracy of that information, to the extent necessary to provide due health care. The provider shall keep the records as long as required by the need of professional care.

(2) The provider shall, at his discretion, also attach to the records documents and, where applicable, statements given to the provider by the patient or mandator.

(3) In the records, the provider shall always indicate who inspected them.

\section{Section 2648 [Recodification]}

(1) If so requested by the patient, the provider shall, without undue delay, allow him to inspect the records maintained about him, and allow him to make extracts, duplicates or copies, or provide him with such extracts, duplicates or copies against the payment of a reasonable reimbursement.

(2) If the records also contain information about a third person, they may not be made available without the third person's consent.

\section{Section 2649 [Recodification]}

(1) Unless otherwise provided by a statute, the records may not be made available to any other person without the express consent of the patient, not even if such a person is the mandator or the patient's representative. provider.

(2) If the patient has granted his consent or refused to do so, it is indicated in the patient's records maintained by the 
(1) The provider may disclose information about the patient without the patient's consent in an anonymous form for purposes of scientific or statistical studies concerning the health condition of the population and its groups, if it can be reasonably assumed that such consent cannot be obtained at all or in due time and:

a) if the study is conducted with such a degree of security that there is no risk of a disproportionate interference with the patient's privacy or

b) if the provider discloses the information so as to exclude the subsequent identification of the person concerned.

(2) The provider shall not have the right under Subsection (1) if the study is not conducted in the public interest, if it can also be conducted without information about a particular patient or if the patient expressly disagrees with the disclosure of the information about him.

\section{Section 2651 [Recodification]}

If a patient is different from the mandatary, he may refuse health care; his refusal extinguishes the obligation.

\section{Chapter 10}

Inspection

Section 2652

\section{Basic provisions}

(1) By a contract of inspection, an inspector undertakes to impartially ascertain the state of a certain thing or verify the result of a certain activity and issue an inspection report, and a client undertakes to remunerate him.

(2) A stipulation whereby a duty which could affect the impartiality of the inspection or the accuracy of the inspection report is imposed on an inspector is disregarded.

\section{Section 2653}

An inspector shall carry out the inspection with professional care in accordance with the determined manner, time, place and extent of inspection, also taking into account the state of the subject of inspection at the time it is carried out. The inspector shall note his observations in the inspection report.

\section{Section 2654}

An inspector shall carry out the inspection to the extent and in the manner usual with respect to similar inspections. It is presumed that the inspection is to be carried out without undue delay at the place of the subject of inspection. The client shall notify the inspector in due time where the inspection is to take place.

\section{Section 2655}

A client shall assist the inspector to the extent necessary to carry out the inspection; in particular, he shall allow him access to the subject of inspection.

\section{Section 2656}

(1) An inspector becomes entitled to remuneration upon completing the inspection and issuing the inspection report.

(2) Together with the right to remuneration, the inspector also becomes entitled to the reimbursement of costs reasonably incurred during the inspection, unless the nature of these costs indicates that they are already included in the remuneration.

Section 2657

Where no remuneration has been stipulated, the client shall remunerate the inspector in the amount which is usual with respect to the subject, extent, manner and place of the inspection at the time of the conclusion of the contract.

\section{Section 2658}

The inspection shall not affect the legal relations between the client and other persons, in particular those for whom the subject of inspection is intended or from whom it originates.

Section 2659

If an inspector fails to carry out an inspection properly, he is not entitled to remuneration and reimbursement of costs.

\section{Section 2660}

(1) An inspector shall provide compensation for the damage caused by a breach of the duty to carry out the inspection properly to the extent to which the client cannot effectively obtain compensation by asserting the right arising from a defective 
performance against the person who provided the subject of inspection as performance. The inspector does not have the duty to provide compensation for the damage if the client failed to enforce his right against a third person in time, or if he cannot enforce the right due to the stipulations made with the third person.

(2) The restriction under Subsection (1) does not apply if the inspector assured the client that he will find all defects regardless of the scope and manner of inspection, or if he assures the client that the inspection report is complete and accurate.

\section{Section 2661}

If an inspector compensates a client for damage, the client's right with respect to a third person passes to the inspector as if it were assigned to him.

\section{Chapter 11}

\section{Obligations arising from an account contract, lump-sum deposit contract, letter of credit contract and collection contract}

Division 1

Account

\section{Subdivision 1}

\section{General provisions}

\section{Section 2662 [Recodification]}

\section{Basic provisions}

By an account contract, the person that maintains the account undertakes to set up an account for its owner from a certain time and in a certain currency, allow cash to be deposited into or withdrawn from the account or make transfers of funds between accounts.

\section{Section 2663}

If an account is set up for more than one person, each of them has the status of the account holder. These persons shall use the account jointly. Their shares in the funds in the account are presumed to be equal.

\section{Section 2664}

An account holder and, under the conditions stipulated in the contract, his authorised agents may dispose of the funds in the account in the stipulated manner. Unless the authorisation indicates the contrary, it is not extinguished upon the principal's death.

\section{Section 2665}

If the parties stipulate that the person which maintains the account will allow cash to be withdrawn or make a transfer of funds from the account where there are insufficient funds, the provisions on credit apply with the necessary modifications.

\section{Section 2666}

In the case of death of the account holder, the person which maintains the account shall, on the date following the date on which the person was presented with a proof of the account holder's death, stop those cash payments and transfers of funds from the account which the account holder identified as those which are not to continue after his death.

\section{Section 2667}

Interest on funds in the account is due at the end of a given calendar month. The person which maintains the account shall credit the interest to the remaining balance in the bank account without undue delay after it has become due.

\section{Section 2668}

If an obligation is extinguished, the person which maintains the account shall, without undue delay, settle the claims and debts related to the account, in particular by transferring funds from the account by way of a means of payment and cheques before the date on which the obligation was extinguished, by cancelling the account and by paying the remaining balance to the account holder.

\section{Subdivision 2}

\section{Payment account}

\section{Section 2669 [Recodification]}

Payment accounts are governed by another statute. Another statute also governs the transfer of funds in an account other than a payment account if it concerns a payment transaction under another statute. 


\section{Subdivision 3}

\section{Account other than a payment account}

\section{Section 2670}

The provisions of this Subdivision apply to accounts other than payment accounts. The provisions of this Subdivision also apply to the deposits and withdrawals of cash or transfers of funds carried out in a payment account, except in the case of payment transactions under another statute.

\section{Section 2671}

Where interest has been agreed, the account holder is entitled to the interest accrued from the date on which the funds are credited to the account up to the date preceding the date on which the funds are debited from the account.

\section{Section 2672}

The person which maintains the account shall credit the funds received or transferred to the account no later than on the working day following the date on which the person acquired the right to dispose of them.

\section{Section 2673 [Recodification]}

(1) A person which maintains the account shall notify the account holder of a deposit or withdrawal of cash, or a transfer of funds which occurred during the preceding calendar month without undue delay after the end of a calendar month.

(2) A person which maintains the account shall inform the account holder of the balance of funds in the account without undue delay after the end of a calendar year.

Section 2674

The account holder may also terminate the obligation arising from the account contract without a notice period, even where the contract has been concluded for a definite period.

\section{Section 2675}

(1) A person that maintains the account may terminate the obligation arising from the account contract with effect from the end of the month following the month in which the notice of termination reached the account holder.

(2) If the account holder fundamentally breaches a stipulated duty, the person which maintains the account may terminate the obligation arising from the account contract without a notice period.

\section{Subdivision 4}

\section{Savings book}

\section{Section 2676 [Recodification]}

(1) By a savings book, the issuer of the savings book confirms cash deposits into and cash withdrawals from an account. The account for which a savings book was issued does not serve to transfer funds. A savings book may be issued only in the name of its owner. A savings book must clearly indicate the amount of funds in the account, and its changes.

(2) The amount of funds in the account is presumed to correspond to the records in the savings book.

\section{Section 2677 [Recodification]}

The savings book holder may dispose of the funds in the account. The funds in the account may only be disposed of upon presenting the savings book.

\section{Section 2678 [Recodification]}

In the case of loss or destruction of a savings book, the savings book issuer shall issue a new savings book at the request of the savings book holder. The new savings book shall replace the original one which shall lose its validity on the date on which the new savings book is issued.

\section{Section 2679 [Recodification]}

If a savings book holder has not disposed of the funds in the account for twenty years or if he has not presented the savings book to supplement the record, the obligation shall terminate upon the expiry of that period; the savings book holder has the right to be paid the balance of funds in the account, including interest as at the date on which the obligation is extinguished.

\section{Division 2}


(1) By a lump-sum deposit contract, a depositor undertakes to provide the beneficiary with a fixed lump-sum deposit at a certain amount, and a beneficiary undertakes to accept the deposit, return it after the obligation is extinguished and pay interest to the depositor.

(2) If the disposal of a deposit was conditional on the provision of a password and the depositor does not know the password, the depositor may dispose of the deposit if he can prove that the deposit belongs to him.

Section 2681

\section{Certificate of deposit}

By a certificate of deposit, a beneficiary confirms a fixed-term lump-sum deposit in the amount specified on the certificate of deposit.

\section{Division 3}

\section{Letter of credit}

\section{Section 2682 [Recodification]}

\section{Basic provisions}

By a letter of credit contract, the issuer of the letter of credit undertakes to issue to the mandator, at his request, on his account, and in favour of a third person (beneficiary) a letter of credit, and a mandator undertakes to remunerate the issuer of the letter of credit.

\section{Section 2683 [Recodification]}

(1) The issuer of the letter of credit shall notify the beneficiary in writing without undue delay after the conclusion of the contract that a letter of credit has been opened in his favour, and inform him of its contents.

(2) A letter of credit at least specifies that the issuer of the letter of credit undertakes to pay a certain amount, accept a promissory note or undertakes to provide another performance, and also contains the terms of the letter of credit specifying the date by which the beneficiary is to meet them in order to be able to request a performance from the issuer of the letter of credit.

\section{Section 2684 [Recodification]}

The obligation of the issuer of the letter of credit against the beneficiary is created when the letter of credit is issued. Such an obligation is independent of the obligation between the issuer of the letter of credit and the mandator, as well as that between the mandator and the beneficiary.

\section{Section 2685 [Recodification]}

The issuer of the letter of credit may use the letter of credit to authorise another issuer to provide the performance for him. Where an authorised issuer has provided a performance, he has the right to be reimbursed by the issuer of the letter of credit; if the letter of credit has been confirmed, he also has the same right with respect to the confirming issuer.

\section{Section 2686 [Recodification]}

Unless otherwise expressly provided by a letter of credit, it may be changed or cancelled by the issuer of the letter of credit only with the consent of the beneficiary and the mandator.

\section{Confirmed letter of credit}

\section{Section 2687 [Recodification]}

(1) If, at the request of its issuer, a letter of credit is confirmed by another issuer, the beneficiary also becomes entitled to be provided with a performance by the confirming issuer from the time when the confirming issuer notified the beneficiary of the confirmation of the letter of credit.

(2) To change or cancel a confirmed letter of credit, the consent of the confirming issuer is also required.

\section{Section 2688 [Recodification]}

If the confirming issuer provided a performance to the beneficiary under the terms of the letter of credit, he is entitled to be reimbursed by the issuer of the letter of credit.

\section{Section 2689 [Recodification]}

The issuer of the letter of credit that only notifies the beneficiary that another issuer has opened a letter of credit in the beneficiary's favour incurs no obligation arising from the letter of credit; however, he shall compensate for the resulting damage if the notification was incorrect. 


\section{Documentary letter of credit}

Section 2690 [Recodification]

(1) In the case of a documentary letter of credit, the issuer of the letter of credit provides a performance to the beneficiary he it is presented with documents determined by the letter of credit in accordance with the terms of the letter of credit. This also applies if the documents are presented to the issuer authorised by a letter of credit.

(2) If a documentary letter of credit has been confirmed, the confirming issuer shall provide a performance to the beneficiary if the confirming issuer or the issuer authorised through the letter of credit is presented with documents under Subsection (1).

\section{Section 2691 [Recodification]}

The issuer of the letter of credit shall exercise professional care and review whether the contents of the documents presented and their correlation clearly correspond to the terms determined by the letter of credit.

\section{Section 2692 [Recodification]}

In the case of loss or destruction of, or damage to, the documents at the time when the issuer of the letter of credit has these documents in his possession, the issuer of the letter of credit shall compensate the mandator for the resulting damage. This does not apply if the issuer of the letter of credit could not have prevented the damage even by exercising professional care.

\section{Section 2693 [Recodification]}

\section{Other letters of credit}

The provisions on a documentary letter of credit also apply, with the necessary modifications, to a letter of credit under which a performance may be claimed subject to conditions other than the presentation of documents.

\section{Division 4}

\section{Collection}

\section{Section 2694 [Recodification]}

\section{Basic provisions}

(1) By a contract for collection, a collection provider undertakes to arrange for a mandator the receipt of a pecuniary amount or another act of collection from a third person, and the mandator undertakes to remunerate the collection provider.

(2) If the amount of remuneration has not been stipulated, the mandator shall remunerate the collection provider in the amount usual at the time of the conclusion of the contract.

\section{Section 2695 [Recodification]}

The collection provider shall request a third person to perform the act of collection. If the person refuses to comply with the request, the collection provider shall inform the mandator accordingly without undue delay.

\section{Section 2696 [Recodification]}

When arranging the collection, the collection provider proceeds with professional care, following the mandator's instructions. If, nonetheless, the collection fails to materialise, this constitutes no reason to sanction the collection provider.

\section{Section 2697 [Recodification]} collection

(1) The collection provider shall, without undue delay, surrender to the mandator everything which he received in the

(2) If the collection provider received securities or a document, he shall compensate the mandator for the damage caused by their loss, destruction or damage at the time the collection provider had possession of such securities or a document. This does not apply if the collection provider could not have prevented the damage even by exercising professional care.

\section{Section 2698 [Recodification]}

Where the collection provider, following the mandator's instructions, uses another collection provider to arrange collection, he shall do so on the account and at the risk of the mandator.

\section{Documentary collection}

\section{Section 2699 [Recodification]}

In the case of a documentary collection, the collection provider undertakes with respect to the mandator to surrender to a third person documents against the payment of a particular pecuniary amount, or to perform another act of collection before 
surrendering the documents, and the mandator undertakes to remunerate the collection provider.

\title{
Section 2700 [Recodification]
}

In case the documents are lost, destroyed or damaged at the time when the collection provider had possession of the documents, the collection provider shall compensate the mandator for the resulting damage. This does not apply if the collection provider could not have prevented the damage even by exercising professional care.

\section{Chapter 12}

\section{Obligations arising from contracts for the provision for life}

\section{Division 1}

\section{Pension}

\section{Section 2701 [Recodification]}

\section{Basic provisions}

(1) By a contract for pension, a payer undertakes to pay regular pecuniary benefits (pension) to a beneficiary.

(2) If a payer undertakes to pay a pension for a person's lifetime or for a period longer than five years, the contract must be in writing.

\section{Section 2702}

Where no duration of the obligation has been stipulated, the duty to pay a pension is conclusively presumed to last for the beneficiary's lifetime.

\section{Section 2703 [Recodification]}

Where no due date of a pension has been stipulated, the benefits are due monthly in advance. If the person for whose lifetime a pension has been stipulated dies, the payer shall pay the benefit which became due while that person was still alive. However, if it has been stipulated that the pension is due in arrears, the payer shall pay the benefit for the period during which that person was still alive.

\section{Section 2704}

The right to a pension may not be assigned to another; a stipulation to the contrary is disregarded. However, a claim for a benefit which has become due may be assigned.

\section{Section 2705 [Recodification]}

If a payer has established a pension gratuitously, he may also reserve that the beneficiary's creditors may not subject the beneficiary's benefits to private enforcement proceedings or insolvency proceedings. Such a reservation is effective against third persons as well as public bodies, but only up to the amount which the beneficiary indispensably needs for his provision for life given his circumstances.

\section{Section 2706 [Recodification]}

(1) If a pension has been provided for consideration, non-payment of benefits shall not entitle a party to withdraw from the contract and reclaim the consideration. This does not apply if the payment of pension has been secured and the security is extinguished or deteriorates, and the payer fails to replenish it to its original amount within a reasonable time limit.

(2) If it is justified by the circumstances, a court shall, on the application of the beneficiary, order that a part of the payer's property be sold and the proceeds used to pay the pension for a reasonable period in the future.

\section{Division 2}

\section{Reserved rights of enjoyment}

\author{
Section 2707 [Recodification]
}

\section{Basic provisions}

(1) By a contract for reserved rights of enjoyment, the owner of an immovable thing reserves, for himself or for a third person in connection with its transfer, the benefits, acts or rights which are to serve the provision for life or for a definite period, and the acquirer of the immovable thing undertakes to provide such a provision for life. Unless otherwise provided or stipulated, the content of the rights of a person enjoying reserved rights is determined by local usage.

(2) According to the content of the juridical act which created the reserved rights of enjoyment, the contract for reserved rights of enjoyment is also governed by the provisions on the rights which constitute the reserved rights of enjoyment, 
including, but not limited to, the provisions on servitude of apartment or the provisions on pensions.

Section 2708 [Recodification]

(1) If reserved rights of enjoyment have been created as a real burden, the acquirer of the immovable thing shall do everything which he is required to do to have the reserved rights of enjoyment registered in a public register. Unless the person enjoying reserved rights has waived the registration, the acquirer's right of ownership may only be registered in the public register jointly with the registration of the reserved right.

(2) The owner of an immovable thing may also register for himself future reserved rights of enjoyment in a public register before transferring the immovable thing.

\section{Section 2709 [Recodification]}

Even where not stipulated upon the creation of the reserved rights of enjoyment, the person obliged to provide the reserved rights of enjoyment shall provide auxiliary assistance to the person enjoying the reserved rights who has an acute need of such assistance due to sickness, accident or similar emergency. The obligor is released from the duty if he provides for the placement of the person enjoying the reserved rights in a health care or similar facility. Unless the person obliged under the reserved rights of enjoyment is obliged to pay the costs of the stay at the facility for a special legal cause, the person enjoying the reserved rights shall pay for the costs himself.

\section{Section 2710 [Recodification]}

(1) If the circumstances change to the extent that the person obliged to provide the reserved rights of enjoyment cannot be reasonably required to continue providing a non-pecuniary performance, and if the parties fail to agree, a court may, on the application of the person obliged to provide the reserved rights of enjoyment, decide that the non-pecuniary performance be replaced in whole or in part by a pecuniary pension; a court may, even of its own motion, also order the person obliged to provide reserved rights of enjoyment to deposit a principal for the provision for life in the specified amount in favour of the person enjoying the reserved rights with an operator of a suitable care-giving facility.

(2) If reserved rights of enjoyment have been transformed into a pecuniary pension, a court may change the agreement of the parties or its decision subject to a substantial change in circumstances.

(3) By the decisions under Subsection (1) or (2), it is not possible to adopt such a measure which would jeopardise the provision for life of the person enjoying reserved rights.

\section{Section 2711 [Recodification]}

In the case of the decay of a structure in which a dwelling was reserved for the person enjoying reserved rights, the person obliged under the reserved rights shall, at his own expense, procure suitable replacement housing for the person enjoying the reserved rights.

\section{Section 2712 [Recodification]}

Reserved rights of enjoyment reserved for spouses is not prejudiced by the death of one of them.

\section{Section 2713 [Recodification]}

Reserved rights may not be assigned; assignment may only be made of the right to benefits due, excluding those whose scope is determined by the personal needs of the person enjoying reserved rights.

\section{Section 2714 [Recodification]} rights.

The entitlement to reserved rights of enjoyment shall not devolve to the heirs of the person enjoying the reserved

\section{Section 2715 [Recodification]}

Where a contract on the transfer of an immovable thing has been concluded in connection with the creation of the reserved rights of enjoyment, withdrawal from such a contract due to the failure to fulfil a duty by the person obliged to provide the reserved rights of enjoyment is impossible.

\section{Chapter 13}

\section{Partnership}

\section{Division 1}

\section{General provisions}

Section 2716 [Recodification]

\section{Basic provisions}


(1) If several persons contractually undertake to be associated as partners for a common purpose of an activity or thing, they create a partnership.

(2) Where a pooling of property has been stipulated, the inventory of the partners' contributions signed by them are required for the contract to be valid. Property is presumed to be pooled only to the extent specified in the inventory.

\section{Section 2717}

(1) Where a thing is contributed to a partnership by a partner, the provisions on purchases apply with the necessary modifications; however, if the partner only contributes the right to use a thing, the provisions on leases apply with the necessary modifications, and where he contributes the right to use and enjoy a thing, the provisions on usufructuary leases apply with the necessary modifications.

(2) If a partner undertakes to pursue an activity for the partnership, the provisions on works or the provisions on mandates apply with the necessary modifications.

\section{Section 2718}

(1) If a partner contributes all of his assets and liabilities to the partnership, the assets and liabilities are presumed to be current as at the effective date of the contract.

(2) A stipulation that the contribution of a partner also includes his future property does not apply to property acquired by inheritance, unless this has been expressly stipulated.

\section{Section 2719}

(1) Funds and consumable things as well as things defined by kind which have been contributed to a partnership become co-owned by the partners who contributed them; other things become co-owned only if they have been valued in pecuniary terms. Co-ownership shares of partners are determined by the relative values of property contributed to the partnership by each partner.

(2) The partners acquire the right of gratuitous use and enjoyment in respect of other contributed things.

\section{Section 2720 [Recodification]}

A partner who has undertaken to only contribute an activity to the common purpose has the right to a share in the profits and the right to use the things contributed to the partnership, but not the right to use and enjoy these things, nor does he become a co-owner pursuant to Section 2719(1).

\section{Division 2}

\section{Mutual rights and duties of partners}

Section 2721

The mutual rights and duties of partners are governed by analogy by the provisions on co-ownership.

\section{Section 2722}

(1) A person who has undertaken to only contribute an activity to the partnership is not required to make any other contribution. A person who has undertaken to only contribute property is not required to work towards achieving the common purpose in any other way.

(2) A partner may not be forced to contribute more than he has undertaken to. However, if the conditions change so that the common purpose cannot be achieved without increasing the contribution, the person who is not willing to increase his contribution may leave or be expelled from the partnership.

\section{Section 2723}

Where only the total contribution to the partnership is determined, each of the partners shall contribute equally.

\section{Section 2724}

Each of the partners shall generally make an equal effort to achieve the common purpose. Where a partner has arranged a common matter in good faith, he is entitled to remuneration as a mandatary.

\section{Section 2725 [Recodification]}

A partner shall pursue activities for the partnership in person, and is not entitled to create a membership in the partnership for, or assign his own membership to, another person.

\section{Section 2726}

A partner may not perform acts harmful to the partnership. 
(1) Without the consent of the other partners, a partner shall, on his own account or the account of another, do nothing of a competitive nature in respect of the common purpose. If he does so, the other partners may claim that the partner refrain from doing so.

(2) If a partner performed an act on his own account, the other partners may claim that such an act be declared to have been performed on the account of all partners. If a partner performed an act on the account of another, the other partners may claim that the right to remuneration be assigned to them to the common account, or that they be given remuneration, where already provided. These rights are extinguished if not asserted within three months from the date on which the entrepreneur learned of the acts, but no later than one year from the date on which the acts occurred.

(3) Instead of the rights under Subsection (2), the other partners may claim compensation for damage.

\section{Section 2728 [Recodification]}

(1) If the contract stipulates no ratio in which the partners participate in the property acquired during the existence of a partnership, and in the partnership's profit and loss, their shares are equal. If the contract determines the ratio of a partner's participation only in the property, the same ratio applies to profit or loss; if the contract determines the ratio of a partner's participation only in profit or loss, the same ratio applies to the property.

(2) A stipulation excluding a partner's right to a share in the profits has no legal effects. A stipulation excluding a partner's duty to participate in the loss shall only have legal effect among the partners.

\section{Section 2729 [Recodification]}

(1) Decisions on the matters of a partnership are adopted by majority vote, each partner having one vote. A stipulation or decision of the partners preventing a partner from participating in the decision-making has no legal effects.

(2) A decision amending the contract of partnership must be adopted unanimously.

\section{Division 3}

\section{Administration of a partnership}

Section 2730

(1) Partners may divide the scope of authority in the administration of common matters as they deem appropriate. In the absence of such a division, each partner shall act as a mandatary of the other partners in respect of these matters.

(2) Partners may, of their own will, substantially change the state or purpose of the common property only if they take into account the convenience of such a change.

\section{Section 2731} third person.

(1) Partners may entrust the administration of undivided things to someone from among their number, or even to a

(2) If an administrator has been appointed in the contract of partnership, he may be removed only for a serious reason; otherwise, his appointment may be cancelled as in the case of mandates.

\section{Section 2732}

A partner who is not entitled to administer may not dispose of the common property. If the partner does so with respect to a third person who is in good faith, the invalidity of the juridical act may not be invoked with respect to the third person.

\section{Section 2733}

Where multiple administrators have been appointed without further specification of their scope of competence, each of them shall act independently in the matters of the partnership.

\section{Section 2734}

An administrator shall keep proper accounts and an overview of the property situation of the partnership; he shall present the partners with regular accounts of the partnership's property, including accounts of income and expenditures, as well as the profit or loss, at least once per calendar year no later than two months after its end.

\section{Section 2735}

Even if a partner is not involved in administration, he may inspect the financial situation of the partnership, review accounting records and other documents, as well as be informed about common matters; however, while asserting that right, he may neither interfere with the operation of the partnership more than is necessary, nor prevent other partners from asserting the same right. If partners stipulate something else, it is disregarded.

\section{Division 4}




\section{Rights and duties of partners towards third persons}

\section{Section 2736}

Partners are liable to third persons jointly and severally for the debts arising from common activities.

\section{Section 2737}

(1) If a partner performs an act towards a third person in respect of a common matter, he is considered to be a mandatary of all the partners. If partners stipulate something else, it may not be invoked against a third person who acted in good faith.

(2) If a partner made an act towards a third person in respect of a common matter in his own name, the other partners may assert the rights arising therefrom; however, the third person is only obliged to the partner who made the juridical act towards the third person. This does not apply if the third person was aware that the partner was acting on the account of the partnership.

\section{Section 2738 [Recodification]}

(1) If a person pretends to be a partner although he is not, the real partners and the person are liable jointly and severally for the person's acts performed with respect to a third person, if

a) one of the partners prompted the error of the third person, or

b) the partners could have anticipated such an error by exercising the necessary care, but none of them took steps to prevent the third person from being misled.

(2) Subsection (1) does not apply if the third person did not act in good faith.

\section{Division 5}

\section{Extinction of membership}

Section 2739

A partner may leave the partnership even where its duration has been stipulated for a definite period; however, he may not do so at an inappropriate time or to the detriment of the other partners. However, he may leave at any time for serious reasons, even where a notice period has been agreed.

\section{Section 2740 [Recodification]} expelled if:

(1) If a partner fundamentally breaches a contractual duty, he may be expelled from the partnership. He may also be

a) insolvency proceedings were initiated against his property on his application,

b) the partner has joined an application for the initiation of insolvency proceedings concerning his insolvency or impending insolvency, or

c) the partner's insolvency was declared in insolvency proceedings.

(2) A limitation of a partner's legal capacity constitutes a cause for his expulsion only if this condition is to the detriment of the partnership.

\section{Section 2741}

(1) A partner whose membership has been extinguished has the right to be presented with the accounts and given everything to which he was entitled as at the date of extinction of his membership. His share in the property acquired during the existence of the partnership is to be paid to him in money.

(2) Upon the extinction of his membership, a partner shall present the other partners with accounts of all his obligations to the partnership, and settle them.

Section 2742

A partner's heir does not become a partner, but has the rights provided under Section 2741.

\section{Section 2743}

(1) If it has been stipulated that the contract of partnership also applies to the heirs, the heir becomes a partner instead of the decedent. Such a stipulation may not be binding on the heirs' heirs.

(2) If an heir is unable to carry out for the partnership the activities which the decedent undertook to carry out, his share may be appropriately reduced.

\section{Division 6}




\section{Extinction of a partnership}

Section 2744

A partnership is extinguished if so agreed by the partners, if the conditions stipulated in the contract of partnership have been met, if the period for which the partnership was stipulated has expired, if the purpose for which the partnership was established has been achieved, or if the purpose has become unachievable.

\section{Section 2745}

If a partner dies and there is no stipulation that the contract of partnership also applies to his heirs and the partnership has two partners, the partnership is extinguished. If a partnership has more than one partner, the other partners are presumed to intend to continue being partners in the partnership.

\section{Section 2746}

(1) If a partnership is extinguished, the administrator shall present accounts in accordance with Section 2734 within two months of its extinction.

(2) Each partner is to be given what he owns, and common property is to be divided under the provisions on the settlement of co-ownership.

\section{Chapter 14}

\section{Silent partnership}

\section{Section 2747 [Recodification]}

\section{Basic provisions}

(1) By a silent partnership contract, a silent partner undertakes to make a contribution whereby he will share in the profits and losses of an entrepreneur's business activities throughout the duration of the silent partnership, and the entrepreneur undertakes to pay the silent partner a share of the profits.

(2) A silent partnership contract may also stipulate that a silent partner will participate in the operation of only some of the entrepreneur's enterprises.

\section{Section 2748 [Recodification]}

(1) A silent partner shall hand over to the entrepreneur the subject of contribution without undue delay after the creation of the silent partnership, or allow him to dispose of it.

(2) Where the subject of contribution is an immovable thing, the entrepreneur acquires the right of use and usufruct in the thing for the duration of the silent partnership. If the subject of contribution is something else, the entrepreneur is presumed to have acquired the right of ownership in the subject upon the creation of the silent partnership.

\section{Section 2749 [Recodification]}

(1) A silent partner has the right to inspect business documents and accounting records of the entrepreneur. A stipulation which restricts or excludes that right is disregarded if the silent partner proves to have a good reason to believe that the business documents and accounting records are not maintained properly or fairly.

(2) An entrepreneur shall issue a copy of the financial statements to a silent partner without undue delay after they have been compiled and approved where approval is required; a stipulation to the contrary is disregarded.

\section{Section 2750}

(1) Regardless of the silent partnership, all legal facts arising from business activities only oblige the entrepreneur.

(2) If the name of a silent partner is contained in the name or corporate name of the entrepreneur, the silent partner is liable as a surety for the entrepreneur's debts.

(3) If a silent partner declares, with respect to the person with whom the entrepreneur is negotiating the conclusion of a contract, that he and the entrepreneur pursue business activities jointly, the silent partner is liable as a surety for the entrepreneur's debts following from the concluded contract.

\section{Share of a silent partner in profits or losses}

\section{Section 2751}

(1) A silent partner shall share in the entrepreneur's profits or losses in the stipulated scope, or otherwise in the scope determined with regard to the amount of his contribution and the regular dealings of the parties, or to usages, where applicable. A stipulation which excludes the silent partner from sharing in the profits or losses is disregarded. 
(2) The amount of a silent partner's share is determined on the basis of net profit. If an entrepreneur is to create a fund which he is not allowed to dispose of freely, the statutory allocation to such a fund is deducted from the net profit.

\section{Section 2752}

An entrepreneur shall pay a share of the profits within thirty days after the compilation of the financial statements and their approval where such an approval is required. A silent partner's contribution shall not increase by his uncollected share of the profits.

\section{Section 2753}

(1) A silent partner shares in the losses in the same manner as in the profits; a stipulation to the contrary is disregarded. A silent partner's contribution is reduced by his share of the loss; a silent partner is not obliged to replenish his contribution in the amount of his share of the loss. loss.

(2) If a silent partner has already been paid his share of the profits, he is not obliged to return it in case of a future

\section{Extinction of a silent partnership}

\section{Section 2754}

(1) Unless a silent partnership has been stipulated for a definite period, it may be terminated no later than six months before the end of an accounting period.

(2) A silent partnership is also cancelled:

a) if the silent partner's share of the loss reaches the amount of his contribution, unless he pays his share of the loss or replenishes his contribution,

b) if the business activities related to the silent partnership end, or

c) if the insolvency of the entrepreneur or silent partner has been declared, by cancelling the bankruptcy proceedings after fulfilling the resolution on the distribution of property, by cancelling the bankruptcy proceedings because the property is absolutely inadequate, or by dismissing the insolvency petition due to a lack of property.

\section{Section 2755}

An entrepreneur shall, without undue delay after the extinction of a silent partnership, surrender to the silent partner his contribution adjusted for the share of the profit or loss generated by the entrepreneur's business activities as at the date of extinction of the silent partnership.

\section{Chapter 15}

\section{Obligations arising from aleatory contracts}

\section{Division 1}

\section{General provisions}

Section 2756

If the parties have stipulated that the benefit or detriment of at least one of the parties depends on an uncertain event, they have concluded an aleatory contract.

\section{Section 2757 [Recodification]}

The obligations arising from aleatory contracts are not governed by the provisions on the change in circumstances (Sections 1764 to 1766) and lesion (Sections 1793 to 1795).

\section{Division 2}

Insurance

\section{Subdivision 1}

\section{Basic provisions}

\section{Section 2758}

(1) By an insurance contract, an insurer undertakes to provide the policyholder or a third person with insurance indemnity in the case of a random event covered by insurance (an insured event), and the policyholder undertakes to pay a premium to the insurer.

(2) Unless insurance has been stipulated for a period of insurance of less than one year, the insurance contract must 
be in writing. If a policyholder has accepted the offer by a timely payment of the premium, the written form of the contract is considered to have been kept.

\section{Section 2759}

(1) If no date by which an offer is to be accepted is specified in the offer, it must be accepted within one month from the date on which the offer was delivered to the other party; however, if the conclusion of the contract is subject to a medical examination, an offer must be accepted within two months. A policyholder may also accept an insurer's offer by a timely payment of the premium in the amount specified in the offer.

(2) If the response to an offer is considered to be a new offer, it is conclusively presumed to have been refused if the other party does not accept it within one month from the date of delivery.

(3) If a party proposes a change to the contract, Subsections (1) and (2) apply by analogy.

Section 2760

An insurer shall, before concluding a contract, provide the prospective policyholder with information whose scope and manner of handover is provided by another statute governing the insurance industry. This also applies to the facts which change during the period of insurance.

\section{Insurable interest}

\section{Section 2761 [Recodification]}

An insurable interest is a legitimate need for protection against the consequences of an insured event.

\section{Section 2762 [Recodification]}

(1) A policyholder has an insurable interest in his own life and health. A policyholder is presumed to have an insurable interest in the life and health of another person if he proves to have an interest conditional on a relationship to that person, whether it is based on a family relationship or it is conditional on a benefit or advantage arising if the person continues to be alive.

(2) A policyholder has an insurable interest in his own property. A policyholder is presumed to also have an insurable interest in the property of another person if he proves that he would face a direct property loss without the existence and preservation of the property. been proved.

(3) If the insured person has given his consent to insurance, the policyholder's insurable interest is presumed to have

\section{Section 2763 [Recodification]}

In the case of property insurance, a future insurable interest may also be insured. If a contract has been concluded having regard to future business activities or another future interest which will not arise, the policyholder is not obliged to pay the premiums; however, the insurer has the right to an appropriate remuneration, if so stipulated.

\section{Section 2764 [Recodification]}

(1) If the prospective policyholder had no insurable interest and the insurer was or must have been aware of that at the conclusion of the contract, the contract is invalid.

(2) If a policyholder has knowingly insured a non-existent insurable interest, of which the insurer was not and could not have been aware, the contract is invalid; however, the insurer is entitled to remuneration equal to the premiums up until the time when the insurer becomes aware of the invalidity.

\section{Section 2765 [Recodification]}

If an insurable interest is extinguished during the period of insurance, so will the insurance; however, the insurer has the right to premiums up to the time when he becomes aware of the extinction of the insurance interest.

\section{Section 2766}

\section{Insured person}

The person whose life, health, property, liability or another insurable interest value is covered by the insurance is the insured person.

$$
\text { Section } 2767 \text { [Recodification] }
$$

\section{Insurance of the insurance peril of another}

(1) If a policyholder concludes, for his own benefit, a contract relating to an insurance peril as a possible cause of an insured event of a third person, the policyholder may assert the right to an insurance indemnity if he proves that he made the third person familiar with the content of the contract and that the third person, being aware that he will not acquire the right to an 
insurance indemnity, has agreed that the policyholder will receive the insurance indemnity. Where a policyholder's descendant who lacks full legal capacity is to be the insured person, no special consent is required if the policyholder himself is the legal representative of the insured person and the insurance does not concern property.

(2) Where the consent of the insured person or his legal representative is required and the policyholder fails to demonstrate the consent within the stipulated period, or otherwise within three months from the date of the conclusion of the contract, the insurance is extinguished upon the expiry of that period. If an insured event occurs during that period and no consent has been given, the right to the insurance indemnity is acquired by the insured person; if the insured event is the death of the insured person, the right is acquired by the persons under Section 2831.

(3) If a policyholder assigns the contract without the consent of the insured person or his legal representative, where applicable, the assignment is disregarded. This does not apply if the assignee is a person for whom the consent to the insurance of an insurance peril is not required.

(4) The insured person shall enter into the insurance on the day of the policyholder's death, or the policyholder's termination without a legal successor; however, if the insured person notifies the insurer in writing within thirty days from the date of the policyholder's death or termination that he has no interest in the continuation of the insurance, the insurance is extinguished on the date of the policyholder's death or termination. Default becomes effective against the insured person only after fifteen days from the date on which the insured person became aware of his entry into the insurance; if a shorter period has been stipulated, it is disregarded.

\section{Section 2768}

(1) If a contract has been concluded in favour of a third person, the person may also grant his consent to the contract subsequently when asserting his right to an insurance indemnity. A third person has the right to an insurance indemnity if the insured person or his legal representative has authorised the third person to receive the insurance indemnity after becoming familiar with the contents of the contract.

(2) If an insurance peril of another has been insured in favour of a third person, Section 2767 applies by analogy.

\section{Section 2769}

\section{Equal treatment}

If an insurer determines the amount of premium or the calculation of insurance indemnity taking into consideration nationality, racial or ethnic origin, or any other consideration contrary to the principle of equal treatment under another statute, the increase in the premium or a decrease in the insurance indemnity on the basis of these considerations is disregarded. This also applies where the amount of premiums is determined or insurance indemnity calculated taking pregnancy or maternity into consideration.

\section{Section 2770}

\section{Beneficiary}

A beneficiary is understood as a person who becomes entitled to an insurance indemnity as a result of an insured event.

\section{Section 2771 [Recodification]}

A stipulation to reduce or extend the limitation period is disregarded.

\section{Section 2772}

(1) Where no time of the creation of insurance has been stipulated, the insurance is created on the first day following the date of the conclusion of the contract.

(2) If it has been stipulated that the insurance also relates to the period before the date of conclusion of the contract, the insurer is not obliged to provide insurance indemnity if the policyholder was aware, or should and could have been aware, at the time the offer was made that the insurance event had already occurred, and the insurer has no right to premiums if the insurer was aware, or should and could have been aware, at the time the offer was made that the insured event cannot occur.

\section{Section 2773}

(1) A juridical act relating to insurance must be in writing, unless the parties stipulate that such a form is not required.

(2) Notifications must be in writing only if so stipulated. However, if a policyholder requests the insurer in writing to provide him with information relevant to rendering the performance under the contract, the insurer shall provide him with such information in writing without undue delay.

\section{Section 2774}

\section{Insurance conditions}

(1) Insurance conditions generally define the details of the creation, period and extinction of insurance, define the insured event, exclusions from insurance and the manner of determining the scope of insurance indemnity and its due date. 
(2) Where reference is made in the contract to insurance conditions, the insurer shall familiarise the policyholder with these conditions before concluding the contract; this does not apply when concluding a distance contract. Section 1845 applies by analogy.

\section{Insurance policy}

\section{Section 2775} contract.

(1) An insurer shall provide the policyholder with the insurance policy as a confirmation of the conclusion of the

(2) In the case of loss, damage or destruction of the insurance policy, the insurer shall, at the request and expense of the policyholder, provide the policyholder with a duplicate; this applies by analogy to the provision of a copy of the contract.

\section{Section 2776}

If the contract establishes a duty to present the insurance policy in order to assert the right to an insurance indemnity, the insurer may require that the original insurance policy be redeemed before issuing the duplicate.

\section{Section 2777}

(1) If the contract was not concluded in writing, the insurer shall specify in the insurance policy at least the following:

a) the contract number,

b) the identification of the policyholder,

c) the identification of the beneficiary or how he will be determined,

d) the insured event and the insurance peril,

e) the amount of premium, its due date and whether it is a current or lump-sum premium,

f) the period of insurance,

g) stipulations derogating from the insurance conditions, where applicable, and

h) the method of determining the amount of the share of the insurer's yields where it has been stipulated, in the case of personal insurance, that the beneficiary will share in such yields.

(2) If the contract has been concluded in writing, it must contain the information provided under Subsection (1), and the insurer shall specify in the policy at least the following:

a) the contract number,

b) the identification of the policyholder,

c) the identification of the beneficiary or how he will be determined,

d) the insured event and the insurance peril, and

e) the period of insurance.

(3) In determining the persons under Subsections (1) or (2), their name or names, address of residence and identifying information are specified. The same applies to the determination of the insured person.

\section{Section 2778}

A stipulation whereby the parties derogate from Section 2775 or 2777 is disregarded. This also applies if the policyholder waives his right to be provided with the insurance policy.

\section{Compulsory insurance}

Section 2779

(1) If another statute obliges a particular person to conclude an insurance contract, the contract may derogate from the provisions of this Division only if permitted by a statute and if the scope of insurance provided by another statute is not thereby reduced.

(2) Where provided by another statute, the insurer incurs the duty to conclude an insurance contract so that he incurs the duty to provide insurance indemnity even where the damage has been caused by a deliberate act of the policyholder, the insured person or any other person. 
In the case of compulsory insurance, the insurer may refuse to provide insurance indemnity only where the provision of false information, incompletely answered questions made in writing or knowingly false or grossly distorted information was the exclusive doing of the injured party, or another person with the injured party's knowledge.

\section{Section 2781}

The insurer has the right to withdraw from the contract or terminate the compulsory insurance only if so permitted under another statute. This does not preclude other stipulations whereby the insurer acquires another right to penalise the policyholder or the insured person in the event of a breach of their duties.

\section{Insurance premium}

\section{Section 2782}

(1) The insurer is entitled to premiums for the duration of the insurance period.

(2) If the insurance is extinguished as a result of an insured event, the insurer is entitled to premiums for the period of up to the end of the insurance period in which the insured event occurred, in which case the insurer is entitled to the entire lump-sum premium.

\section{Section 2783}

(1) Where no time of the creation of the insurer's right to premiums has been stipulated, the insurer shall acquire the right on the date of the conclusion of the contract.

(2) A lump-sum premium is due on the day of the commencement of the insurance. If current premiums have been stipulated, they are due on the first day of the insurance period; where the period of insurance has not been stipulated as a time period usual for the payment of current premiums, an insurance period of one year is considered to have been stipulated. premiums.

(3) If so requested by the policyholder, the insurer shall inform him of the principles for determining the amount of the

\section{Section 2784}

The insurer is also obliged to accept due premiums and other due claims arising from the insurance from the policyholder's pledgee, from the beneficiary or the insured person.

\section{Section 2785}

(1) If the contract stipulates no conditions which are to be met in order to entitle the insurer to adjust the new amount of the current premiums for the following insurance period, the amount of premiums may not be changed without an agreement with the policyholder.

(2) If the insurer reserves the right to change the amount of insurance premiums for a reason other than a change of the conditions decisive for determining the amount of premiums, or if, in the case of personal insurance, the insurer reserves the right to change the amount of insurance premiums subject to age or health condition, it is disregarded.

\section{Section 2786}

(1) If the insurer changes the amount of the insurance premiums, the insurer shall notify the policyholder of the amount at least two months before the due date of the insurance premium for the insurance period in which the amount of premium is to be changed.

(2) If the policyholder disagrees with the change, he may express his disagreement within one month from the date on which he became aware of it; in that case the insurance is extinguished upon the expiry of the insurance period for which insurance premium has already been paid. However, if the insurer failed to warn the policyholder of that consequence in the notification under Subsection (1), the insurance shall continue and the amount of insurance premium shall not change in the case of the policyholder's disagreement.

\section{Section 2787}

The insurer has the right to deduct receivable premiums or other insurance claims which are due from the insurance indemnity. This does not apply in the case of a duty to provide insurance indemnity arising from compulsory insurance; stipulations to the contrary are disregarded.

\section{Section 2788 [Recodification]}

\section{Duty to provide true information}

(1) If the insurer asks a prospective policyholder in writing during the negotiations to conclude a contract, or a policyholder in the negotiations to amend the contract, about the facts which are relevant to the insurer's decision on how the insurer will evaluate the insurance risk, whether or not the insurer will insure the insurance risk and under what conditions, the prospective policyholder or the policyholder shall respond to these questions truthfully and completely. The duty is considered to have been duly fulfilled if nothing substantial has been concealed in the response. 
(2) The provisions of Subsection (1) governing the policyholder's duties also apply by analogy to the insured person.

\section{Section 2789 [Recodification]}

(1) If, when concluding the contract, the insurer must be aware of the discrepancies between the insurance offered and the prospective policyholder's requirements, the insurer shall inform him thereof. In doing so, account is taken of the circumstances under which, and the manner in which, the contract is being concluded, as well as whether an agent independent of the insurer assists the other party in the conclusion of the contract.

(2) If the prospective policyholder, during the negotiations to conclude the contract, or the policyholder, during the negotiations to amend the contract, asks the insurer in writing about the facts relating to insurance, the insurer shall respond to these questions truthfully and completely.

\section{Change in insurance risk}

\section{Section 2790 [Recodification]}

(1) In case the circumstances that were stipulated in the contract or about which the insurer asked (Section 2788) change so significantly that they increase the likelihood of the occurrence of an insured event arising from an expressly stipulated insured peril, the insurance risk will increase.

(2) Without the insurer's consent, a policyholder may not do, or allow a third person to do, anything that would increase the insurance peril; if the policyholder finds out only subsequently that he allowed an insurance peril to increase without the insurer's consent, he shall inform the insurer accordingly without undue delay. If an insurance peril increases independently of a policyholder's will, he shall notify the insurer without undue delay after becoming aware of it. insured person.

(3) If an insurance risk of another has been insured, the duties provided under Subsection (2) are incurred by the

\section{Section 2791}

(1) If the insurer proves that he would have concluded the contract under other conditions had an increased insurance risk existed at the conclusion of the contract, he has the right to propose a new amount of insurance premiums. If the insurer fails to do so within one month from the date on which he was notified of the change, his right is extinguished.

(2) If the proposal is not accepted or the newly determined insurance premium paid within the stipulated period, or otherwise within one month from the date on which the proposal was delivered, the insurer has the right to terminate the insurance by giving eight days' notice; however, the insurer does not have the right if he failed to inform of the possibility of termination in the proposal. If the insurer does not terminate the insurance within two months from the date on which he received a statement of disagreement with the proposal, or on which the period under Subsection (1) expired without the insurer having presented any proof, his right to terminate the insurance is extinguished.

\section{Section 2792}

If the insurer proves that, given the conditions valid at the time of the conclusion of the contract, he would not have concluded the contract had the increased insurance risk existed at the conclusion of the contract, he has the right to terminate the insurance by giving eight days' notice. If the insurer does not terminate the insurance within one month from the date on which he was notified of the change, his right to terminate the insurance is extinguished.

\section{Section 2793}

(1) If the policyholder or the insured person is in breach of his duty to inform of the increase in the insurance risk, the insurer has the right to terminate the insurance without a notice period. If the insurer terminates the insurance, he is entitled to the insurance premiums until the end of the insurance period in which the insurance was extinguished; in that case, the insurer is entitled to the entire lump-sum premium. If the insurer does not terminate the insurance within two months from the date on which he became aware of the increase in the insurance risk, his right to terminate the insurance is extinguished.

(2) If the policyholder or the insured person is in breach of his duty to inform of the increase in the insurance risk and an insured event has occurred after this change, the insurer has the right to reduce the insurance indemnity in proportion to the ratio of insurance premiums which the insurer received to the insurance premiums which the insurer should have received if he had become aware of the increase in the insurance risk in time.

\section{Section 2794}

If the insurance risk decreases substantially during the period of insurance, the insurer shall incur a duty to reduce the insurance premiums in proportion to the decrease in the insurance risk with effect from the date on which the insurer became aware of the decrease.

\section{Section 2795}

(1) The provisions on the increase in the insurance risk do not apply if the increase in the risk was due to the prevention or mitigation of greater damage, or as a result of an insured event, or as a result of conduct induced by the principles of humanity.

(2) The provisions on the change in the insurance risk does not apply to personal sickness insurance. The provisions on the change in the insurance risk do not apply to personal insurance against other cases if the insurance risk changes during 
the period of insurance; if that change has not been reflected in the calculation of insurance premiums, the duty to inform the insurer shall arise if the policyholder or the insured person was notified of such a duty.

\section{Investigating an insured event}

\section{Section 2796}

(1) In the case of an event which the person who considers himself to be the beneficiary associates with a claim for insurance indemnity, the person shall notify the insurer accordingly without undue delay and truthfully explain to the insurer the occurrence and extent of such an event, the rights of third persons, and any multiple insurance; at the same time, the person shall present the insurer with the necessary documents and proceed as stipulated in the contract. If he is not simultaneously the policyholder or the insured person, these duties are also incurred by the policyholder and the insured person.

(2) The same notification may be made by any person who has a legal interest in the insurance indemnity.

\section{Section 2797}

(1) The insurer shall, without undue delay after the notification under Section 2796, commence an investigation to determine the existence and extent of his duty to provide indemnity. The investigation is completed by notifying the person who asserted his right to insurance indemnity of its results; at the person's request, the insurer shall provide the person in writing with the justification of the amount of the insurance indemnity, or the reason for its dismissal, where applicable.

(2) If the notification contains deliberately false or grossly distorted material facts related to the extent of the notified event, or if it deliberately conceals information related to that event, the insurer is entitled to a reimbursement of the costs reasonably incurred in the investigation of the facts in respect of which the information was provided to or concealed from the insurer. The insurer is presumed to have incurred the costs in the documented amount reasonably.

(3) If the policyholder, the insured person or any other person who asserts the right to an insurance indemnity induces the costs of investigation or their increase by breaching a duty, the insurer is entitled to be paid adequate compensation by such a person.

\section{Section 2798}

(1) Where no due date of the insurance indemnity has been stipulated, it is due within fifteen days from the date of completion of the investigation.

(2) If an investigation necessary to identify the insured event, the extent of insurance indemnity or the person entitled to receive the insurance indemnity cannot be completed within three months from the date of notification, the insurer shall inform the notifier of the reasons why the investigation cannot be completed; if so requested by the notifier, the insurer shall provide him with the reasons in writing. The insurer shall provide the person who asserts the right to an insurance indemnity, on the person's request, with a reasonable advance payment for the insurance indemnity; this does not apply where there is a reasonable cause to refuse the provision of such an advance payment.

(3) If the insurer violated the duty under Subsection (2) for reasons on his part, he is in default; a stipulation to the contrary is disregarded.

\section{Section 2799}

If an insured event has been intentionally caused either by the person exercising the right to an insurance indemnity, or a third person on the person's initiative, the right to the insurance indemnity shall arise only if this has been expressly stipulated, or where provided by this Act or another statute.

Section 2800

\section{Consequences of a breach of duties}

(1) If, during the negotiations to conclude or amend the contract, lower insurance premiums have been stipulated as a result of a breach of the policyholder's or the insured person's duties, the insurer has the right to reduce the insurance indemnity by the ratio of the premiums which the insurer received, to the premiums which the insurer should have received.

(2) If the breach of duties of the policyholder, insured person or any other person entitled to an insurance indemnity had a substantial impact on the occurrence of the insured event, its progress, the increased scope of its consequences or the identification or determination of the amount of the insurance indemnity, the insurer has the right to reduce the insurance indemnity in proportion to the impact of such breach on the scope of the insurer's duty to provide indemnity.

\section{Section 2801}

\section{Suspension of insurance}

(1) If insurance premium has not been paid, the insurance is suspended; the period of suspension begins two months after the insurance premium becomes due and end upon its payment.

(2) If insurance becomes suspended during the period of insurance, there is no duty to pay the insurance premiums during the period of suspension and there is no entitlement to indemnity arising from the events which occurred during the period of suspension and would otherwise have constituted insured events. The period of suspension is included in the period of insurance only if expressly stipulated. 
(3) If there are statutory reasons for a compulsory insurance to be ongoing, the compulsory insurance may not be suspended. Life insurance may be suspended only if this has been stipulated.

\section{Extinction of insurance}

\section{Section 2802}

In order for an agreement to extinguish insurance to be valid, the parties are required to stipulate the manner of settlement in the agreement. Where the date of extinction of insurance has not been stipulated, it is conclusively presumed that the insurance was extinguished on the date when the agreement came into effect.

\section{Section 2803}

(1) Insurance is extinguished upon the expiry of the period of insurance.

(2) Where insurance has been stipulated for a definite period, it may be stipulated that the insurance will not be extinguished upon the expiry of that period of insurance if, at least six weeks before the expiry of the period of insurance, the insurer or the policyholder does not inform the other party of his wish not to continue the insurance. If the insurance is not extinguished and if no conditions and period of extension have been stipulated, the insurance is extended under the same conditions for the same period for which it was stipulated.

\section{Section 2804}

If the insurer reminds the policyholder to pay insurance premium and advises him in the reminder that the insurance will be extinguished unless the insurance premium is paid within an additional time limit of at least one month from the date of delivery of the reminder, the insurance is extinguished upon the expiry of the time limit within which the insurance premium has not been paid.

\section{Section 2805}

The insurer or the policyholder may terminate the insurance:

a) by giving eight days' notice within two months from the date of conclusion of the contract, or

b) by giving one month's notice within three months from the date of notification of the insured event; however, if the insurer terminates life insurance, it is disregarded.

Section 2806

The policyholder may terminate the insurance by giving eight days' notice:

a) within two months from the date on which he became aware that the insurer determined the amount of insurance premiums or insurance indemnity on the basis of a consideration prohibited under Section 2769 ,

b) within one month from the date on which a notice of transfer of insurance portfolio or its part, or on the transformation of the insurer was delivered to him, or

c) within one month from the date of publication of the notification that the insurer's licence to pursue insurance business has been revoked.

\section{Section 2807}

Where insurance has been stipulated with current premiums, the insurance is extinguished on the basis of a notice of termination given by the insurer or the policyholder at the end of the insurance period; however, if the notice of termination is delivered to the other party less than six weeks before the expiry of the insurance period, the insurance is extinguished at the end of the following insurance period. If the insurer terminates a life insurance, the termination is disregarded.

Section 2808

(1) If the policyholder or the insured person intentionally or negligently breaches the duty under Section 2788 , the insurer has the right to withdraw from the contract if the insurer proves that he would have not concluded the contract had the questions been answered truthfully and completely. The policyholder has the right to withdraw from the contract if the insurer has breached the duty under Section 2789. The right of withdrawal from contract is extinguished if not exercised by the party within two months from the date on which the party became or must have become aware of the breach of duty under Section 2788.

(2) If the policyholder withdraws from the contract, the insurer shall, within one month from the date on which the withdrawal becomes effective, reimburse to him the premiums paid less any indemnity paid, if applicable; if the insurer withdraws from the contract, he shall also have the right to set off the costs associated with the creation and administration of insurance. If the insurer withdraws from the contract and if the policyholder, the insured person or any other person has already received insurance indemnity, he shall pay the insurer within the same time limit a reimbursement of the amount of insurance indemnity paid which exceeds the premiums paid.

(3) Where a distance contract has been concluded, the policyholder has the right to withdraw from the contract without giving any reason within fourteen days from its conclusion or from the date on which he was provided with the insurance 
conditions, if they were provided at his request after the conclusion of the contract. In the case of insurance falling under the life insurance category under another statute, the policyholder is entitled to withdraw from the contract within thirty days from the date on which he was notified of having concluded a distance contract, or from the date on which he was provided with the insurance conditions, if they were provided at his request after the conclusion of the contract; this also applies if the contract has been concluded otherwise than as a distance contract.

(4) Subsection (3) does not apply to contracts falling under insurance of aid to persons in need while travelling or while away from their place of residence, including the insurance of financial losses directly related to travel, if these contracts were concluded for a period of less than one month.

(5) If the policyholder withdraws from the contract under Subsection (3), the insurer shall return to him the premiums paid without undue delay, but no later than thirty days after the date on which the withdrawal becomes effective; in doing so, the insurer has the right to deduct the amount of insurance indemnity already paid. However, if the insurance indemnity has been paid in excess of the amount of the premiums paid, the policyholder, or the insured person or the ultimate beneficiary shall return to the insurer the amount of the insurance indemnity paid which exceeds the insurance premiums paid.

\section{Section 2809}

The insurer may refuse to pay insurance indemnity where the insured event was caused by a fact:

a) of which the insurer became aware only after the insured event occurred,

b) which, in negotiating the insurance or its change, the insurer could not have ascertained due to a culpable breach of the duty provided under Section 2788, and

c) the knowledge of which at the conclusion of the contract would have led the insurer not to conclude the contract or to conclude it under other terms.

\section{Section 2810}

Insurance is extinguished upon the extinction of the insurable interest, the extinction of the insurance peril, on the date of death of the insured person, on the date of termination of the insured legal person without a legal successor or on the date of rejection to provide insurance indemnity.

\section{Subdivision 2}

\section{Insurance against loss and damage}

Section 2811

\section{Scope}

In the case of insurance against loss and damage, the insurer shall provide insurance indemnity which shall, to the stipulated extent, compensate for the loss of property incurred as a result of an insured event.

Section 2812

\section{Change in the ownership of the insured property}

Unless it has been expressly stipulated that the insurance is not extinguished by the change of ownership or coownership of the insured property, the insurance is extinguished on the date on which the change was notified to the insurer.

\section{Insurance indemnity threshold}

\section{Section 2813}

Where an insurance indemnity threshold has been stipulated, it is presumed to cover one loss event.

Section 2814

(1) If it has been agreed that there will be a maximum threshold for insurance indemnity, the maximum threshold is determined by the sum insured or insurance indemnity limit.

(2) If, in the case of property insurance, the property's insurance value can be determined at the conclusion of the contract, the maximum limit of insurance indemnity is determined on the proposal of the policyholder as the sum insured in the amount equal to the insurance value of the insured property at the time of conclusion of the contract. The insurer has the right to review the value of the insured property at the conclusion of the contract.

(3) If, in the case of property insurance, the insurance value of the property cannot be determined at the conclusion of the contract, a maximum threshold of insurance indemnity is determined on the proposal of the policyholder as the insurance indemnity limit. The limit is also stipulated where the insurance covers only part of the value of the property insured under Subsection (2) (fractional insurance). If it is consistent with the insurable interest, the maximum threshold of insurance indemnity may also be determined in this manner in the case of insurance under Subsection (2). 
If the contract expressly stipulates that the loss of property the amount of which does not exceed a stipulated limit, or a part of that loss, will be to the detriment of the person who becomes entitled to insurance indemnity, the insurer is not obliged to provide insurance indemnity to the extent of the deductible so stipulated.

Section 2816

\section{Insurance with multiple insurers}

Insurance with multiple insurers arises when the same insurable interest is insured against the same insurance peril and for the same period with several insurers. Insurance with several insurers may arise as:

a) co-insurance, if a contract has been concluded between the policyholder and multiple insurers represented by the leading insurer, and if the policyholder has undertaken to pay the premiums to only one of them,

b) concurrent insurance, if the total of the sums insured does not exceed the insurance value of the insured property, or if the total of the insurance indemnity limits does not exceed the actual amount of the damage incurred, or

c) multiple insurance, if the total of the sums insured exceeds the insurance value of the insured property, or if the total of the insurance indemnity limits exceeds the actual amount of damage incurred.

\section{Section 2817 [Recodification]}

\section{Co-insurance}

(1) Where co-insurance has been stipulated, the leading insurer specified in the contract shall determine the insurance conditions and the amount of premiums, administer the co-insurance, receive claim notifications and carry out investigations necessary to determine the extent of the insurers' duty to provide insurance indemnity; to that extent, the leading insurer acts in the name of other insurers. If no manner of premium income has been stipulated, the leading insurer shall also receive premiums.

(2) Within co-insurance, a contract may also be concluded between the policyholder and several insurers who stipulated, in the name and on the account of all the insurers, a common approach when insuring certain insurance perils, and who determined the leading insurer or, where applicable, entrusted a joint body created for this purpose or an insurance agent qualified for a higher level of professional competence under another statute with performing the leading insurer's duties.

(3) The right to the insurance indemnity is asserted against the leading insurer. Insurers shall mutually settle according to their shares; where no shares have been stipulated, they are conclusively presumed to be equal.

(4) In the case of the liquidation of an insurer, its insurance duties following from a co-insurance are fulfilled in the same way as duties arising from other types of insurance stipulated by that insurer.

(5) Stipulations which derogate from Subsections (1) to (4) are disregarded, even where one of the insurers participates in co-insurance through a commercial network formed at the place of the insurer's registered office or through its branch located in the territory of a Member State of the European Union or a Member State of the European Economic Area other than the state of registered office of the insurer, or if the insurance risk is located in any of these states or in the Czech Republic. This does not apply in the case of the insurance of large risks under another statute regulating the insurance industry.

Section 2818

\section{Multiple insurance}

(1) If multiple insurance arises, the policyholder shall notify each insurer accordingly without undue delay and specify in the notification the other insurers and the sums insured or insurance indemnity limits stipulated under the other contracts.

(2) The first insurer to receive a claim notification shall provide indemnity up to the sum insured or insurance the indemnity limit stipulated in the contract which is binding on the insurer, and shall, without undue delay, notify this to the other insurers of which he became aware. This does not affect the right of the beneficiary to claim from the other insurers an insurance indemnity of up to the amount of compensation for the loss of property if the sum insured or the insurance indemnity limit stipulated in the contract with the first insurer is insufficient to compensate for the entire loss of property arising from the insured event.

(3) Insurers shall settle in the same proportion as the ratio of the sums insured or insurance indemnity limits stipulated in the contracts which are binding on them, having regard to the insurance indemnity provided according to Subsection (2), the second sentence.

\section{Section 2819}

\section{Salvage costs}

(1) Where a policyholder has reasonably incurred costs in averting an imminent insured event to mitigate the consequences of an already existing insured event, or because he was performing the duty to clear damaged insured property or its remnants for health, environmental or safety reasons, he has the right to be reimbursed by the insurer for such costs, as well as to be compensated for damage which he incurred in connection with this activity. 
(2) No account is taken of a stipulation whereby the insurer has, in respect of the reimbursements and compensations under Subsection (1), reserved the right to:

a) reduce the sum insured or the insurance indemnity limits by these reimbursements or compensations,

b) limit them to less than $30 \%$ of the sum insured or the insurance indemnity limit in the case of salvation of life or health, or

c) limit them if the policyholder incurred salvage costs with the consent of the insurer, although he was otherwise not required to do so.

(3) If salvage costs were incurred by the insured person or another person beyond the scope of duties provided by another statute, he has the same right to be reimbursed by the insurer as a policyholder.

\section{Section 2820}

\section{Passage of a right to the insurer}

(1) If, in connection with an imminent or existing insured event, a person who is entitled to the insurance indemnity, an insured person or a person who incurred salvage costs became entitled to be compensated by another person for damage or another similar right, the claim, including accessories, security and other associated rights, passes to the insurer upon the payment of the insurance indemnity, up to the amount of indemnity which the insurer lawfully paid to the beneficiary. This does not apply if such a person became so entitled with respect to a person who lives in the same household or is dependent on the former in maintenance, unless the latter caused the insured event intentionally.

(2) A person whose rights passed to the insurer shall provide the insurer with the necessary documents and inform him of everything that is needed to assert the claim. If the person frustrates the transfer of the right to the insurer, the insurer has the right to reduce the insurance indemnity by the amount he could have otherwise obtained. If the insurer has already provided the insurance indemnity, he is entitled to compensation of up to that amount.

\section{Subdivision 3}

\section{Fixed-amount insurance}

\section{Section 2821}

Fixed-amount insurance undertakes the insurer to provide, in case of an insured event, a lump-sum or repeated insurance indemnity in the stipulated amount. The amount determined on the proposal of the policyholder which the insurer is to pay in the event of an insured event, or the amount and frequency of payment of a pension, shall form the basis for determining the amount of premium and calculating the insurance indemnity.

\section{Section 2822}

The right to an insurance indemnity from fixed-amount insurance shall not affect the right to compensation for damage or another right against the person obliged to compensate for the damage.

\section{Section 2823}

The time when fixed-amount insurance establishes the right to a reduced period of insurance, to the surrender value and the renewal of insurance after reducing the sum insured, after reducing the annual pension or after reducing the period of insurance, is stipulated in the contract, unless this right is established directly by this Act.

\section{Subdivision 4}

\section{General provisions on personal insurance}

Section 2824

(1) In personal insurance, a person may be insured against the risk of death, of reaching a certain age or date contractually agreed as the end of insurance, against sickness, accident or another fact related to health or change of personal status of the person insured.

(2) Personal insurance entitles the person designated in the contract to the payment of the stipulated amount or pension, or to an insurance indemnity in the stipulated amount in the case of the insured event under Subsection (1).

\section{Section 2825}

Where disability insurance has been stipulated, and if the contract does not stipulate a clear indication of the nature and extent of the disability covered by the insurance, insurance against the inability to perform the insured person's usual occupation is considered to have been stipulated.

\section{Section 2826}

(1) If a policyholder concludes a contract in favour of an ultimate beneficiary, the consent of the insured person is also required to conclude the contract. Where a policyholder's descendant who lacks full legal capacity is to be the insured person, no special consent is required if the policyholder himself is the legal representative of the insured person. 
(2) Where the consent of the insured person or his legal representative is required and the policyholder fails to demonstrate the consent within the stipulated period, or otherwise within three months from the date of the conclusion of the contract, the insurance is extinguished upon the expiry of that period. If an insured event occurs during that period and no consent has been given, the right to the insurance indemnity is acquired by the insured person; if the insured event is the death of the insured person, the right is acquired by the persons under Section 2831.

(3) The consent under Subsection (1) is also required to change the ultimate beneficiary, change the shares in the insurance indemnity where multiple ultimate beneficiaries have been designated, and to pay the surrender value; if consent is not granted, they are disregarded.

\section{Section 2827}

\section{Group insurance}

(1) If insurance covers the members of a particular group or their families and their dependants, where applicable, the contract does not have to contain the names of the insured persons if the insured persons can be identified without any doubts no later than at the time of the insured event.

(2) The consent of the insured persons under Section 2826 is not required. This applies by analogy if the policyholder has assigned the contract.

(3) A breach of the duty to truthfully and completely respond to the questions of the insurer shall, in the case of a group insurance, only affect the insurance of those persons involved in the breach of this duty.

\section{Section 2828}

(1) Where there are reasons related to determining the level of insurance risk, the amount of premiums or the investigation of an insured event, the insurer may require information on the health condition, and the determination of the health condition or cause of death of an insured person if the insurer was given consent to do so by the insured person. An investigation is conducted on the basis of reports and medical records requested from treating physicians by the person operating the health care facility authorised by the insurer and, if necessary, by an examination conducted by the health care facility.

(2) If it has been stipulated that the policyholder is released from the duty to pay the premiums, the insurer may request information about his health condition and, subject to the consent of the policyholder, review his health condition in the manner provided under Subsection (1).

\section{Section 2829}

Where the death of the insured person is the insured event, the policyholder may determine the ultimate beneficiary by his name or by his relationship to the insured person. Until the occurrence of the insured event, the policyholder may change the ultimate beneficiary; the change becomes effective on the date on which the notification is delivered to the insurer.

\section{Section 2830}

(1) If the policyholder has designated his spouse to be the ultimate beneficiary, and if it has been stipulated that the designation is irrevocable, its effects are extinguished upon divorce or invalidation of the marriage.

(2) If the policyholder has designated his ancestor or descendant as the ultimate beneficiary and it has been stipulated that the designation is irrevocable, its effects are extinguished when the ultimate beneficiary or policyholder becomes adopted. This also applies where the insured person's adopted child or adopted parent has been irrevocably determined as the ultimate beneficiary, and the adoption was cancelled.

Section 2831

(1) If the ultimate beneficiary was not designated at the time of the insured event, or if he did not acquire the right to the insurance indemnity, the right is acquired by the insured person's spouse, and in his absence by the insured person's children.

(2) In the absence of the person under Subsection (1), the rights to the insurance indemnity are acquired by the insured person's parents, and in their absence by the insured person's heirs. Provisions on the protection of the lawful heir shall remain unaffected.

(3) If several persons acquire the right to an insurance indemnity, their shares are presumed to be equal.

\section{Section 2832 [Recodification]}

(1) The ultimate beneficiary shall acquire the right to an insurance indemnity upon the occurrence of the insured event. Before the ultimate beneficiary acquires that right, the policyholder may freely dispose of the rights arising from the insurance, especially to pledge or assign them, as well as to change the designation of the ultimate beneficiary. However, in the case of a pension insurance, the consent of the insurer is required to change the ultimate beneficiary, otherwise the change is not binding on the insurer.

(2) If the insured person is a person other than the policyholder, the consent of the insured person is required for the juridical acts under Subsection (1), otherwise they are disregarded. 


\section{Subdivision 5}

\section{Life insurance}

Section 2833

Life insurance of death risk, reaching a certain age or a date contractually determined as the end of insurance, or in case of another fact relating to the change in the personal status of a person may only be stipulated as fixed-amount insurance.

\section{Section 2834}

(1) If the insurer has erroneously determined premiums, the period of insurance, the premium payment period or the sum insured because the policyholder had provided an incorrect date of birth or sex of the insured person, the insurer has the right to reduce the insurance indemnity in the proportion of the amount of insurance premiums that have been paid to the amount of insurance premiums that would have been paid had the policyholder provided the correct date of birth or sex of the insured person.

(2) If, as a result of providing incorrect information under Subsection (1), higher premiums were paid, the insurer shall adjust their amount starting from the insurance period following the insurance period in which the insurer received the correct information. Insurance premiums paid for the subsequent insurance periods are reduced by the overpaid premiums; in the case of a lump-sum premium, the insurer shall refund the overpayment to the policyholder without undue delay.

\section{Section 2835}

Where an incorrect date of birth of the insured person has been provided, the insurer has the right to withdraw from the contract if he proves that, given the insurance conditions in force at the time the contract was concluded, he would not have concluded the contract. If the insurer fails to assert the right to withdraw from the contract during the life of the insured person and within three years after the date of conclusion of the contract, but no later than two months after he became aware of the incorrect information, his right is extinguished.

\section{Section 2836}

If the insured person and the ultimate beneficiary die at the same time or under circumstances that prevent the determination of which of them died first, the insured person is considered, for insurance purposes, to have been determined to have survived the ultimate beneficiary. However, if the insured person dies and the persons under Sections 2829 and 2830 have not acquired the right to the insurance indemnity, the ultimate beneficiary is considered, for these purposes, to have been determined to have survived the insured person.

Section 2837

\section{Exclusions from insurance}

An insurer is not obliged to provide the insurance indemnity in the case of the suicide of the insured person if the insurance lasted continuously for less than two years before the suicide.

\section{Reduction of the sum insured, reduction of annual pension and reduction of period of insurance}

\section{Section 2838}

(1) If the current premium was paid for insurance for the period stipulated in the contract and if, after this period, further current premium was not paid within the agreed time limit, such insurance shall change into insurance with a reduced sum insured (reduction of the sum insured) or into reduced annual pension, without the duty to pay current premiums.

(2) If the reduced sum insured or reduced annual pension is less than the limit stipulated in the contract, the period of insurance is reduced.

\section{Section 2839}

A reduction of the sum insured, a reduction of an annual pension or a reduction of the period of insurance will occur on the first day after the expiry of the time limit, upon the expiry of which insurance would have otherwise been extinguished due to non-payment of insurance premiums.

\section{Section 2840}

The policyholder may require that the reduced sum insured or the amount of annual pension increase back to the original amount only if it has been expressly stipulated. The same applies to an extension of the reduced period of insurance to its original length.

Section 2841

Where insurance of death risk has been stipulated for an exact time and for current insurance premiums, nonpayment of premiums shall not create the right to a reduction of the sum insured, a reduction of annual pension or a reduction of the period of insurance, and the insurance is extinguished due to non-payment of premiums.

\section{Surrender value}


(1) If, in the case of life insurance stipulated with current premiums, premiums for at least two years have been paid, or in the case of insurance for a lump-sum premium stipulated for a period of more than one year, or in the case of insurance with a reduced sum insured, the policyholder has the right to have the surrender value paid to him by the insurer on the policyholder's request, unless excluded by the contract. The surrender value is due within three months after the date on which the request for its payment was delivered to the insurer; the insurance is extinguished upon the payment of the surrender value.

(2) If, at any time during the insurance period, the policyholder requests the insurer to inform him of the amount of the surrender value, the insurer shall inform the policyholder of the value, including the calculation of the surrender value, within one month from the date on which the request was received.

\section{Section 2843}

In the case of fixed-term insurance of death risk, the right to be paid the surrender value shall arise only if it has been expressly stipulated. The same applies to insurance from which a pension is paid if the pension has already been paid.

\section{Subdivision 6}

\section{Accident insurance}

Section 2844

Under an accident insurance, the insurer shall provide an insurance indemnity in the contractually stipulated amount in the case of an accident of the insured person.

\section{Section 2845}

The insurer has the right to refuse to provide insurance indemnity in the case of an accident of the insured person in connection with a criminal offence for which the insured person was found guilty of intentional criminal offence, or by which he deliberately harmed his health.

\section{Section 2846}

(1) The insurer has the right to reduce the insurance indemnity down to one half if the injury was caused as a result of the victim having consumed alcohol or an addictive substance or a product containing such a substance, if justified by the circumstances under which the injury occurred. However, if such an accident resulted in the death of the victim, the insurer has the right to reduce the indemnity only if the accident occurred in connection with a victim's act whereby he caused severe bodily harm or death to another.

(2) The insurer shall not have the right under Subsection (1) if alcohol or addictive substance was contained in a medicinal product which the insured person took in a manner prescribed by his physician, and if the insured person had not been warned by the physician or producer of the medicinal product that it was prohibited to carry out the activity which resulted in the injury under the influence of the medicinal product.

\section{Subdivision 7}

\section{Sickness insurance}

\section{Section 2847}

In the case of sickness insurance, the insurer shall, within the stipulated scope, pay to the beneficiary for the insured person the cost of or a stipulated amount for health care resulting from sickness or injury and the interventions associated with the health condition of the insured person, including, without limitation, illness, injury, pregnancy and preventive or follow-up care or other facts related to the insured person's health condition.

\section{Section 2848}

Where waiting period has been stipulated, its duration, beginning from the date of commencement of the insurance, may be no more than three months, or no more than eight months in the case of childbirth, psychotherapy, dental and orthopaedic prostheses, or no more than three years in the case of nursing care.

\section{Subdivision 8}

\section{Property insurance}

\section{Section 2849}

Where, in the case of property insurance, no insurance value has been stipulated, the insurance value is equal to the usual value of the property at the time at which its value is determined.

\section{Section 2850}

(1) Where a collective thing is insured, the insurance covers all the things which belong to the collective thing upon the occurrence of the insured event. The provisions on the sum insured or insurance indemnity limit, insurance value, under- 
insurance and over-insurance apply to the entire collective thing. Where insurance covers several collective things, the sum insured or insurance indemnity limit is determined separately for each set.

(2) Where a set of things has been insured, Subsection (1) applies by analogy.

Section 2851

(1) If an insured event has damaged or destroyed property, the person entitled to the insurance indemnity shall refrain from repairing the damaged property or removing the remnants of the destroyed property until consent is given by the insurer. Where a period by which the insurer is to provide a statement has been stipulated, such duty is extinguished no later than upon the expiry of that period; in the absence of such a stipulation, the duty is extinguished if the insurer fails to provide a statement within a period appropriate to the circumstances of the case.

(2) Subsection (1) does not apply if it is necessary to begin to repair the property or remove its remnants earlier due to safety, protection of health or the environment, or for any other serious reason.

\section{Section 2852}

(1) If, after the event on the basis of which a policyholder or another beneficiary claims insurance indemnity, he learns that the lost or stolen property concerned by the event has been found, he shall notify the insurer without undue delay. However, property is not considered to have been found if:

a) possession of the property was lost and it either cannot be re-acquired, or it can be re-acquired only with unreasonable inconvenience or costs, or

b) the thing was damaged to the extent that it ceased to exist as such, or if it can be repaired only with disproportionate costs.

(2) If, after the insured event, the insurer provided the insurance indemnity, the ownership of the insured property shall not pass to the insurer, but the insurer has the right to be given what he provided as the insurance indemnity. However, the beneficiary may deduct the costs reasonably incurred in the removal of defects incurred the time when the beneficiary was deprived of the opportunity to dispose of the property.

Section 2853

\section{Over-insurance}

(1) If the sum insured exceeds the value of the insured property, the insurer as well as the policyholder is entitled to propose to the other party that the sum insured be reduced, while also proportionately reducing the insurance premiums for the insurance period following this change. If a party does not accept the proposal within one month of its receipt, the insurance is extinguished.

(2) If the sum insured exceeds the insurance value of the insured property and if lump-sum insurance premium has been stipulated, the insurer has the right to claim a reduction in the sum insured under the condition that the insurance premium will also be proportionately reduced, and the policyholder has the right to claim a reduction in the premium under the condition that the sum insured will also be proportionately reduced.

Section 2854

\section{Under-insurance}

If, at the time of the insured event, the sum insured is less than the insurance value of the insured property, the insurer shall reduce the insurance indemnity in the same proportion as the ratio of the sum insured to the actual amount of the insurance value of the insured property; this does not apply if the parties stipulate that the insurance indemnity will not be reduced.

\section{Section 2855 [Recodification]}

\section{Special provisions}

Where insurance of human tissues or organs intended for transplant under another statute, or human blood or its components collected for the production of blood derivatives and for use in humans under another statute has been stipulated, the provisions of Sections 2849 to 2854 apply by analogy. This also applies if, after a person's death, his body or its separated part is insured.

\section{Subdivision 9}

\section{Legal expenses insurance}

\section{Section 2856}

(1) By a contract of legal expenses insurance, the insurer undertakes to pay, in the stipulated scope, the insured person's costs associated with the assertion of his rights, and provide associated services.

(2) If a legal expenses insurance has been stipulated under a contract covering multiple insurance perils 
(comprehensive insurance policy), the stipulation is valid if it is specified in a special part of the policy stipulating the content and scope of the legal expenses insurance, as well as the amount of insurance premium for the legal expenses insurance.

(3) Legal expenses insurance may only be stipulated as insurance against loss and damage.

Section 2857

Stipulations restricting the insured person's freedom of choice of his representative are disregarded.

Section 2858

The insurer shall ensure that:

a) none of its employees authorised by it to settle the rights arising from legal expenses insurance or legal counselling in this class of insurance carries out, at the same time, a similar activity in another class of insurance pursued by the insurer which concluded the contract of legal expenses insurance; this also applies where such a similar activity is pursued in another class of insurance by another insurer pursuing non-life insurance which is a controlled or controlling person in relation to the insurer which concluded the contract of legal expenses insurance,

b) the settling of the rights arising from insurance is carried out by a person who is independent of the insurer and who is stipulated in the contract, or

c) at the time when the right to insurance indemnity arises, the beneficiary has the opportunity to choose a representative to protect his interests.

Section 2859

(1) If the policyholder so requests, the insurer is obliged to conclude with the policyholder a contract for an arbitrator to settle disputes arising from the legal expenses insurance. The policyholder must be informed of his right to demand the conclusion of an arbitration agreement in the insurance contract.

(2) If, in resolving a disputed matter between the insurer and the policyholder, there is a conflict of interest or disagreement in settling such a matter, the insurer is obliged to inform the policyholder of his right under Subsection (1) and of the possibility to resolve the dispute by arbitration.

\section{Section 2860}

The provisions of Sections 2857 to 2859 do not apply to:

a) legal expenses insurance relating to the operation of maritime vessels or insurance perils arising in connection with such an operation,

b) representation of the insured person, if such an activity is simultaneously pursued under third-party liability insurance in the insurer's own interest, and

c) legal expenses insurance provided by the insurer as a supplement to insurance for the assistance to persons who get into difficulties while travelling or while away from their place of residence.

\section{Subdivision 10}

\section{Third-party liability insurance}

\section{Section 2861}

(1) Under third-party liability insurance, an insured person has the right, in the event of an insured event, to have the insurer compensate the injured person for damage or other harm, where applicable, to the extent and in the amount prescribed by a statute or contract, if the insured person incurred the duty to provide compensation.

(2) The injured party becomes entitled to indemnity from the insurer only if it has been stipulated, or where provided by another statute.

(3) The insurance may only be stipulated as insurance against loss and damage.

\section{Section 2862}

(1) The insured person shall inform the insurer without undue delay of the loss event and the fact that the victim has asserted his right to compensation against him, and provide a statement regarding his duty to compensate for the damage or harm, where applicable, and regarding the compensation claimed and the amount thereof.

(2) The insured person shall also notify the insurer without undue delay of any proceedings before a public body or arbitration proceedings initiated against him in connection with the loss event; the insured person shall also inform the insurer of the identity of his legal representative and of the course and outcomes of the proceedings. In the proceedings on compensation for damage, the insured person proceeds in accordance with the insurer's instructions; the insurer shall pay the costs of the proceedings to the insured person. 
The insurer has the right to deal with the loss event for the insured person once the insured person has been notified thereof. The insurer has the right to request that the injured party provide the information under Section $2777(3)$.

\section{Section 2864 [Recodification]}

The insurer has the right to ascertain, in the investigation of the loss event, the information concerning the health condition or cause of death of the injured party if it has been granted consent to do so by the injured party or another beneficiary; Section 2828 applies by analogy.

\section{Section 2865}

(1) Where no insurance indemnity limit has been stipulated, the insurer shall compensate in full the injured party for the damage or other harm. If the insured person compensated the damage or harm covered by insurance, he is entitled to be compensated by the insurer up to the amount of the indemnity which the insurer would have otherwise be obliged to provide to the injured party.

(2) If the insurer and the injured party agree that in the case of rights entitling to a recurrent indemnity, in particular the right to compensation for loss of earnings or the costs of survivors' maintenance, the insurer will provide the injured party with a lump-sum compensation in the amount determined using actuarial methods, the lump-sum payment shall settle all the current as well as future rights. Such a stipulation requires the consent of the insured person. If he cannot grant it, the consent is not required.

\section{Section 2866 [Recodification]}

(1) If the insured person caused a loss event under the influence of alcohol, or an addictive substance or a product containing such a substance, the insurer is entitled to be compensated by the insured person for the indemnity provided on his behalf.

(2) The insurer shall not have the right under Subsection (1) if alcohol or an addictive substance was contained in a medicinal product which the insured person took in a manner prescribed by his physician, and if the injured person had not been warned by the physician or producer of the medicinal product that it was prohibited to carry out the activity which resulted in the loss event under the influence of the medicinal product.

\section{Section 2867}

If the insurance is connected with the right of ownership and it has not been expressly stipulated that the insurance is not extinguished upon the change of ownership or co-ownership, the insurance is extinguished on the date on which the change was notified to the insurer.

\section{Subdivision 11}

\section{Credit insurance or guaranty insurance}

\section{Section 2868 [Recodification]}

(1) Credit insurance is stipulated to protect against consequences to property which the insured person may incur as a result of his debtor's failure to repay the funds he provided.

(2) Guaranty insurance is stipulated for the performance from an obligation arising from suretyship of the insured person, forfeiture of bail or security, or a performance provided under bail or security or for another similar stipulated reason.

(3) Credit insurance or guaranty insurance may only be stipulated as insurance against loss and damage.

\section{Section 2869 [Recodification]}

If the person who acquired the right to an insurance indemnity fails to inform the insurer of the loss event within the time limit stipulated in the contract, a court shall not grant such a right if the insurer invokes late notification of the loss event.

\section{Section 2870 [Recodification]}

Credit insurance with state support is governed by this Act and the statute governing the insurance and financing of exports with state support.

\section{Subdivision 12}

\section{Insurance of financial losses}

\section{Section 2871 [Recodification]}

(1) Insurance of financial losses concerns costs incurred as a result of a loss event, or loss of profit, or other financial losses stipulated in the contract.

(2) Insurance of financial losses may be stipulated as insurance against loss and damage or fixed-amount insurance. 


\section{Insurance against large insurance risk}

(1) If an insurer insures against a large insurance risk in non-life insurance under another statute regulating the insurance industry, it is possible to derogate from any provision of this Book in favour of any party, if required by the purpose and nature of the insurance.

(2) Insurance of a large insurance risk may only be stipulated as insurance against loss and damage.

\section{Division 3}

\section{Bets, games and lot-drawing}

\section{Subdivision 1}

\section{Bets}

Section 2873

\section{Basic provisions}

(1) By making a bet, at least one party undertakes to provide the other with a prize if the former's assertion about a fact unknown to the parties proves to be incorrect, or if the latter's assertion about the same fact proves to be correct. the bet is invalid.

(2) If the party whose assertion proves to be correct was certain of the outcome and concealed it from the other party,

\section{Section 2874 [Recodification]}

If a prize has not been provided, it may not be enforced by the winning party.

\section{Section 2875}

The return of a prize which has been provided may not be enforced by the losing party. This does not apply if the losing party was a person with evidently insufficient mental or intellectual capacity.

\section{Section 2876}

If the prize provided was manifestly excessive given the circumstances of the case and the position and potential of the parties, a court may adequately reduce it on the application of the losing party.

\section{Section 2877}

A claim arising from a loan for consumption or credit consciously granted with a bet may not be enforced either. This does not apply if a loan for consumption or credit was provided by a person with insufficient mental or intellectual capacity.

\section{Section 2878}

An unenforceable claim arising from a bet or from a loan for consumption or credit granted consciously with a bet may not be lawfully secured. If a debt equivalent to such a claim has been acknowledged, it is disregarded.

\section{Section 2879}

The provisions on bets do not apply where, in connection with the business activities of the parties, the parties have concluded a contract for the supply of a movable thing under which the thing is not to be supplied but only the difference between the agreed price and the market price at the time of supply is to be paid. This also applies if the supply of the thing is not directly excluded under the contract, but the circumstances of which the parties must be aware clearly indicate that the parties only aim to gain such a difference.

\section{Section 2880}

The provisions on bets do not apply if the contract was concluded on a commodity exchange, regulated market, multilateral trading facility, or if it is a contract between entrepreneurs concerning an investment instrument under the statute regulating business activities on the capital market.

\section{Subdivision 2}

\section{Game}

\section{Section 2881}

Games are governed by the provisions on bets by analogy; however, in the case of games only requiring skill or physical exercise from both parties, only Section 2875 under the provisions on bets applies. 


\title{
Subdivision 3
}

\section{Lot-drawing}

Section 2882

Lot-drawing is governed by the provisions on bets with the necessary modifications. However, these provisions do not apply if lot-drawing is to decide a dispute, divide an undivided thing or decide a vote.

\section{Subdivision 4}

\section{Common provisions}

Section 2883

The provisions on the unenforceability of claims arising from bets, games or lot-drawing, and the provisions on the power of a court to reduce the prize do not apply to claims arising from bets, games or lot-drawing operated by the state or subject to official licence.

\section{Chapter 16}

\section{Obligations arising from a juridical act of a single person}

\section{Division 1}

\section{Public promise}

\section{Subdivision 1}

\section{Promise of a reward}

\author{
Section 2884 [Recodification]
}

The promise of a reward for a performance made to an unspecified person obliges the promisor if the promise is publicly announced.

\section{Section 2885 [Recodification]}

(1) If the promisor has not waived his right to withdraw a public promise, he may withdraw it before the performance has been carried out in the same form in which the public promise was given, and if it is not possible, in a form with an equal effect.

(2) A withdrawal is not effective against a person who carried out the performance with regard to the public promise if, at that time, the person neither knew nor was required to know of the withdrawal.

\section{Section 2886 [Recodification]}

(1) If several persons meet the conditions of a public promise, the reward belongs to the first person who carried out the performance, unless the public promise indicates that the promisor wished otherwise.

(2) If several persons meet the conditions of a public promise at the same time, the promisor shall divide the reward among them equally, unless the public promise indicates that the promisor wished otherwise.

(3) Subsection (2) shall not prevent the rewarded persons from agreeing a different division of the reward, and in the absence of such an agreement, it shall not exclude the right of each of the rewarded persons to claim from the others a part of the reward proportional to his contribution to the result achieved.

\section{Subdivision 2}

\section{Announcement of a prize}

Section 2887

(1) If a reward is promised in the form an announcement of a prize for the best possible performance, a public promise is valid if it also specifies the period during which a person may try to win the prize.

reward.

(2) Unless otherwise provided below, the announcement of a prize is governed by the provisions on the promise of a

\section{Section 2888}

(1) An announcement of a prize may be revoked only for serious reasons.

(2) If a promisor revokes the announcement of a prize, he shall reasonably reimburse the person who had carried out 
at least a partial performance before the condition of a public promise was revoked. The promisor shall inform of this right in the revocation, unless he already did so when announcing the prize.

\section{Section 2889}

If a promisor, when announcing the prize, did not specify who is to assess the fulfilment of the conditions of a public promise and according to what criteria, as well as who is to appraise such fulfilment and within what time limit, the promisor shall assess and appraise the fulfilment of the conditions himself.

\section{Division 2}

\section{Promise of indemnity}

\section{Section 2890 [Recodification]}

By a promise of indemnity, the indemnifying promisor undertakes to compensate the promisee for the damage which the latter may incur by performing a particular act which the indemnifying promisor requested the promisee to perform, and which the promisee was not obliged to perform.

\section{Section 2891}

(1) The indemnifying promisor's obligation is created upon the delivery of the indemnifying promisor's declaration to the promisee.

(2) The promisee shall perform the act requested by the indemnifying promisor only if the promisee has undertaken to do so.

\section{Section 2892}

The indemnifying promisor shall reimburse the costs and compensate all damage incurred by the promisee in connection with the act requested by the former.

Section 2893

The promisee shall, in due time, take such measures on the account of the indemnifying promisor so as to reduce the damage to a minimum.

TITLE III

\section{OBLIGATIONS ARISING FROM TORTS}

\section{Chapter 1}

\section{Compensation for pecuniary and non-pecuniary harm}

\section{Division 1}

\section{Basic provisions}

\section{Section 2894 [Recodification]}

(1) The duty to provide compensation to another for harm shall always involve the duty to provide compensation for harm to assets and liabilities (compensation for damage).

(2) If the duty to provide compensation to another for non-pecuniary harm has not been expressly stipulated, it affects the tortfeasor only where specifically provided by a statute. In such cases, the duty to provide compensation for non-pecuniary harm by providing satisfaction is assessed by analogy under the provisions on the duty to provide compensation for damage.

Section 2895

A tortfeasor has the duty to pay damage regardless of his fault in cases specifically provided by a statute.

\section{Section 2896}

If a person declares that he excludes or limits his duty to provide compensation for harm with respect to other persons, it is disregarded. However, if he does so before the harm was incurred, such a declaration may be considered to be a warning against danger.

Section 2897

If a person waives his right to claim compensation for damage caused to a tract of land, and if the waiver is registered in a public register, this shall also have effect against subsequent owners. 
A stipulation which excludes or limits in advance the duty to provide compensation for harm caused to the natural rights of an individual, or caused intentionally or due to gross negligence is disregarded; a stipulation which precludes or limits in advance the right of the weaker party to compensation for any harm is also disregarded. In these cases, the right to compensation may also not be lawfully waived.

\section{Section 2899}

A person who assumed the risk of becoming a victim, whether or not he did so under such circumstances that it could be considered imprudent, did not thereby waive his right to compensation against the person who caused the harm.

\section{Prevention}

\section{Section 2900}

If required by the circumstances of the case or the usages of private life, everyone has the duty to act so as to prevent unreasonable harm to freedom, harm to life, bodily harm or harm to the property of another.

\section{Section 2901 [Recodification]}

If required by the circumstances of the case or the usages of private life, the person who produced a dangerous situation or who has control over it, or where it is justified by the nature of the relationship between the persons, has the duty to intervene to protect another. The person who can, according to his potential and skills, easily avert harm of which he knows or must know that its impending gravity clearly exceeds what must be exerted for the intervention has the same duty.

\section{Section 2902}

A person who has breached a legal duty, or who can and should know that he will breach it, shall, without undue delay, notify the person who may suffer the resulting harm, and warn him of the possible consequences. If he fulfils the duty to notify, the victim shall not have the right to compensation for the harm which he could have prevented after the notification.

\section{Section 2903}

(1) If the person who is at risk of harm fails to act to prevent such harm in a manner appropriate to the circumstances, everything which he could have prevented is borne by the person.

(2) In the case of a serious danger, the endangered person may apply to the court to impose appropriate and reasonable measures to avert the impending harm.

\section{Section 2904}

\section{Accident}

Harm caused by an accident is compensated by the person who was at fault for inducing the accident, in particular by breaching a mandate or causing damage to a device intended to prevent accidental harm.

\section{Section 2905}

\section{Self-defence}

A person who protects himself or another from an imminent or ongoing unlawful attack and, in doing so, causes harm to the attacker, has no duty to provide compensation for such harm. This does not apply if it is clear that, given the circumstances, the attacked person is under the threat of incurring only negligible harm, or the defence is manifestly excessive, especially given the gravity of the harm caused to the attacker by preventing the attack.

\section{Section 2906}

\section{Necessity}

A person who protects himself or another from an imminent risk of harm does not have the duty to provide compensation for the resulting harm if, given the circumstances, the danger could not have been prevented otherwise, or if he does not cause a consequence which is evidently equally serious as, or even more serious than, the imminent harm, unless the property would have decayed in any case even without the act made under necessity. This does not apply if the actor was at fault for inducing the risk.

\section{Section 2907}

In assessing whether or not someone acted in self-defence or under necessity, account is taken of justifiable excitement of mind of the person who prevented the attack or another danger.

\section{Section 2908}

A person who prevented imminent harm is also entitled to the reimbursement of reasonably incurred costs and compensation for the harm suffered in doing so against the person in whose interest he acted, but only to the extent appropriate to the harm which he prevented. 


\title{
Division 2
}

\section{Duty to provide compensation for damage}

\section{Subdivision 1}

\section{General provisions}

\author{
Section 2909 [Recodification]
}

\section{Breach of good morals}

A tortfeasor who causes harm to a victim by an intentional breach of good morals has the duty to provide compensation for it; however, if the tortfeasor was exercising his right, he has the duty to provide compensation for the damage only if his main purpose was to harm another.

\author{
Section 2910 [Recodification]
}

\section{Breach of a statute}

A tortfeasor who is at fault for breaching a statutory duty, thereby interfering with an absolute right of the victim, shall provide compensation to the victim for the harm caused. A tortfeasor also becomes obliged to provide compensation if he interferes with another right of the victim by a culpable breach of a statutory duty enacted to protect such a right.

\section{Presumption of negligence}

Section 2911 [Recodification]

If a tortfeasor causes damage to the victim by breaching a statutory duty, he is presumed to have caused the damage through negligence.

\section{Section 2912 [Recodification]}

(1) If a tortfeasor acts in a manner different from what can be reasonably expected in private dealings from a person of average qualities, he is presumed to be acting negligently.

(2) If a tortfeasor demonstrates special knowledge, skill or diligence, or undertakes to perform an activity for which special knowledge, skill or diligence is required, and fails to apply these special qualities, he is presumed to be acting negligently.

\section{Section 2913 [Recodification]}

\section{Breach of a contractual duty}

(1) If a party breaches a contractual duty, such a party shall provide compensation for the resulting damage to the other party or the person who was evidently intended to benefit from the fulfilment of the stipulated duty.

(2) A tortfeasor is released from the duty to provide compensation if he proves that he was temporarily or permanently prevented from fulfilling his contractual duty due to an extraordinary, unforeseeable and insurmountable obstacle created independently of his will. However, an obstacle arising from the tortfeasor's personal circumstances or arising when the tortfeasor was in default of performing his contractual duty, or an obstacle which the tortfeasor was contractually required to overcome shall not release him from the duty to provide compensation.

\section{Section 2914 [Recodification]}

A person who, in his activities, uses an agent, employee or another helper shall provide compensation for the damage caused by such a person as if he caused it himself. However, if, in the case of a performance provided by another person, someone has undertaken to carry out a particular activity independently, he is not considered to be a helper; however, if such other person has chosen him carelessly or exercised inadequate supervision over him, that other person is liable as a surety for the fulfilment of his duty to provide compensation for damage.

\section{Damage caused by several persons}

\section{Section 2915 [Recodification]}

(1) If several tortfeasors are obliged to provide compensation for damage, they shall do so jointly and severally; if any of the tortfeasors has the duty under another statute to provide compensation only up to a certain limit, he is obliged jointly and severally with the other tortfeasors within that scope. This also applies where several persons have committed separate unlawful acts, each of whom may have caused a harmful consequence with a high degree of certainty, and if the person who caused the damage cannot be ascertained.

(2) Where there are reasons deserving special consideration, a court may decide that the tortfeasor shall provide compensation for the damage in proportion to his participation in the harmful consequences; if the participation cannot be determined accurately, account is taken of the degree of probability. Such a decision may not be made if a tortfeasor knowingly 
participated in causing the damage by another tortfeasor, or instigated or supported it, or if the entire damage can be attributed to each tortfeasor, even where they acted independently, or if the tortfeasor is to pay for the damage caused by a helper where the helper also incurred the duty to provide compensation.

\section{Section 2916}

A person who has the duty to provide compensation for damage jointly and severally with others shall settle with them in proportion to their participation in causing the damage.

\section{Section 2917 [Recodification]}

A person who has the duty to compensate for damage caused by another person is entitled to a penalty against him.

\section{Section 2918 [Recodification]}

If damage has been incurred, or if it has increased also as a result of the circumstances attributable to the victim, the tortfeasor's duty to compensate for damage is proportionately reduced. However, if the circumstances which are to the detriment of one or the other party have contributed to the damage only to a negligible extent, the damage is not divided.

\section{Section 2919}

If the tortfeasor enriched himself at the expense of the victim by an unlawful act or on the basis of another circumstance which caused the damage, the tortfeasor's enrichment is unjust even after the victim's right to compensation for damage has become time-barred. If the victim's right to compensation for damage becomes time-barred, the victim may claim that the tortfeasor give him everything which he acquired, under the provisions on unjust enrichment.

\section{Subdivision 2}

\section{Special provisions}

\section{Damage caused by a person unable to assess the consequences of his acts}

\section{Section 2920 [Recodification]}

(1) A minor who has not yet acquired full legal capacity or a person who suffers from a mental disorder shall provide compensation for the damage caused if he was capable of controlling his behaviour and assessing its consequences; the victim is also entitled to compensation for damage if he did not defend himself against the tortfeasor because of being considerate to him.

(2) If a minor who has not yet acquired full legal capacity or the person who suffers from a mental disorder was incapable of controlling his behaviour and assessing its consequences, the victim is entitled to compensation if it is fair with regard to the property situation of the tortfeasor and victim.

\section{Section 2921}

The person who has neglected to exercise proper supervision over a tortfeasor shall compensate the damage jointly and severally with the tortfeasor. If the tortfeasor does not have the duty to provide compensation for damage, the victim is compensated by the person who neglected to exercise supervision over the tortfeasor.

\section{Section 2922}

A person who induces a self-inflicted condition in which he is unable to control his conduct or assess its consequences shall provide compensation for the damage caused in that condition. The persons who are at fault for inducing that condition upon him shall compensate the damage jointly and severally with him.

\section{Section 2923 [Recodification]}

\section{Damage caused by a person with dangerous qualities}

A person who knowingly assumes care for a person of dangerous qualities by providing him with shelter, although the person does not urgently need one, or entrusting him with a particular activity, whether in the home, establishment or a similar place, shall, jointly and severally with that person, provide compensation for the damage caused to another in such a place or during such activity as a result of the dangerous qualities of such a person.

\section{Section 2924 [Recodification]}

\section{Damage resulting from operating activities}

A person who operates an enterprise or another facility intended for gainful activities shall provide compensation for the damage resulting from the operations, whether it was caused by the actual operating activities, by a thing used in these activities or by the impact of the activities on the environment. The person is released from this duty if he proves that he has exercised all care that can be reasonably requested to prevent the damage.

$$
\text { Section } 2925 \text { [Recodification] }
$$


(1) A person who operates an enterprise or another facility which is particularly hazardous shall compensate the damage caused by the source of the increased danger; an operation is particularly hazardous if the possibility of serious damage cannot be reasonably excluded in advance even by exercising due care. Otherwise, the person is released from the duty if he proves that the damage was externally caused by force majeure or that it was caused by the very acts of the victim or unavoidable acts of a third person; if other grounds for the release from the duty have been stipulated, they are disregarded.

(2) If circumstances clearly indicate that the operation has significantly increased the risk of damage, although it can be legitimately referred to other possible causes, a court shall order the operator to provide compensation for the damage to the extent that corresponds to the probability of the damage having been caused by the operation.

(3) An operation is presumed to be particularly hazardous if it is carried out in a factory-like manner or if explosive or similarly hazardous substances are used or handled therein.

\section{Section 2926 [Recodification]}

\section{Damage to an immovable thing}

A person who, albeit lawfully, performs or provides for work which causes damage to an immovable thing of another or which prevents or substantially hinders the possession of such a thing shall provide compensation for the resulting damage.

\section{Damage caused by the operation of a means of transport}

\section{Section 2927 [Recodification]}

(1) A person who operates transport shall compensate the damage caused by the specific nature of such an operation. Another operator of a vehicle, vessel or aircraft has the same duty, unless such a means of transport is driven by human power.

(2) An operator may not be released from the duty to compensate for the damage if the damage was caused by circumstances originating from the operation. Otherwise, the operator is released from the obligation if he proves that he could not have prevented the damage despite having exerted all the efforts which may have been required.

\section{Section 2928}

If a means of transport is under repair, the person who took over the means of transport for repair is considered to be its operator

\section{Section 2929}

A person who uses a means of transport without the knowledge or against the will of the operator shall provide compensation for the damage instead of the operator. The operator shall provide compensation for the damage jointly and severally with the person in case he allowed such use of the means of transport due to negligence.

\section{Section 2930 [Recodification]} operator.

If the operator cannot be determined, the owner of the means of transport is conclusively presumed to be the

\section{Section 2931}

Where theft or loss of a thing results in damage being caused to a thing, the operator shall provide compensation for the damage only if the victim had no opportunity to keep the thing safe.

\section{Section 2932}

Where the operations of two or more operators collide and in the case of a settlement between the operators, the operators shall settle according to their contribution to the damage caused.

\section{Damage caused by an animal}

\section{Section 2933 [Recodification]}

Where damage is caused by an animal, its owner is to provide compensation for the damage, whether or not the animal was under his supervision or under the supervision of a person to whom the owner entrusted the animal, or whether or not the animal strayed or escaped. A person to whom an animal has been entrusted or who keeps or otherwise uses the animal shall provide compensation for the damage caused by the animal jointly and severally with the owner.

\section{Section 2934 [Recodification]}

If a domesticated animal serves its owner to pursue his profession or another gainful activity or livelihood, or if it serves a disabled person as a helper, the owner is released from the duty to provide compensation if he proves that, in the supervision of the animal, he did not neglect to exercise the necessary care, or that the damage would have also been incurred by exercising the necessary care. Under the same conditions, the person entrusted by the owner with the care of the animal is also released from the duty to provide compensation. 


\section{Section 2935 [Recodification]}

(1) If a third person wilfully took the animal away from the owner or the person entrusted by the owner with the care of the animal, the third person shall provide compensation for the damage caused by the animal himself if the owner or the person entrusted by the owner with the care of the animal proves that he could not have reasonably prevented the animal from being taken away; otherwise, the third person shall provide compensation for the damage jointly and severally with the owner and the person entrusted by the owner.

(2) The person who wilfully took away an animal may not be released from the duty to provide compensation.

\section{Damage caused by a thing}

Section 2936 [Recodification]

The person who is obliged to provide a performance to someone and, in doing so, uses a defective thing shall provide compensation for the damage caused by the defect of the thing. This also applies in the case of the provision of health care, social, veterinary and other biological services.

\section{Section 2937 [Recodification]}

(1) If a thing causes damage by itself, the person who should have had supervision over the thing shall pay compensation for the damage; if such a person cannot be otherwise determined, the owner of the thing is conclusively presumed to be such a person. A person who proves not to have neglected due supervision is released from the duty to provide compensation.

(2) If a thing caused damage by falling, or by being thrown out of a room or similar place, the person who is obliged to provide compensation under Subsection (1) is compensated for the damage jointly and severally with the person who uses such a place, and if the latter cannot be determined, with the owner of the immovable thing.

\section{Section 2938 [Recodification]}

(1) In the case of a building collapsing or its part becoming separated as a result of a defect or lack of maintenance of the building, its owner shall provide compensation for the resulting damage.

(2) The owner shall provide compensation for the damage jointly and severally with the previous owner if the damage was caused by a shortcoming created during the duration of the latter's right of ownership, and the previous owner failed to inform his successor of that shortcoming, and if the damage was incurred within one year after the previous owner's right of ownership was extinguished. This does not apply to a shortcoming of which the successor must have known.

\section{Damage caused by a product defect}

\section{Section 2939}

(1) Compensation for the damage caused by a defect of a movable thing intended to be placed on the market as a product for sale, lease or other use is paid jointly and severally by a person who produced, gained, grew or otherwise acquired the product or its component part, and a person who marked the product or its part with his name, trademark or otherwise.

(2) A person who imported the product for the purpose of marketing it within his business activities shall provide compensation for the damage jointly and severally with the persons under Subsection (1).

(3) Compensation for the damage caused to a thing by a product defect shall only be paid in the amount which exceeds the amount in Czech Crowns calculated from EUR 500 using the exchange rate announced by the Czech National Bank on the date on which the damage was incurred, and if the date is not known, on the date on which the damage was discovered.

\section{Section 2940}

(1) If the producer cannot be determined under Section 2939, compensation for the damage is also provided by any supplier if, within one month, the supplier fails to inform the victim, when the victim asserts the right to compensation for damage, of the identity of the producer or the person who supplied the product to the supplier.

(2) In the case of an imported product, compensation for the damage is paid by any supplier, even where the producer is unknown, if he fails to inform the victim within a specified time limit of the identity of the importer.

\section{Section 2941}

(1) The product is defective within the meaning of Section 2939 if it is not as safe as it can reasonably be expected to be, considering all the circumstances, including, without limitation, the manner in which a product is marketed or offered, the intended purpose of the product, as well as considering the time when the product was placed on the market.

(2) A product cannot be considered defective only because a more advanced product is later placed on the market.

\section{Section 2942 [Recodification]}

(1) A tortfeasor is released from the duty to provide compensation for damage caused by a product defect only if he proves that the damage was caused by the victim or a person for whose act the victim bears liability. 
(2) Such a person is also released from the duty to provide compensation for damage if he proves that:

a) he did not place the product on the market,

b) it can be reasonably assumed, with regard to all the circumstances, that no defect existed at the time when the product was placed on the market, or that it occurred later.

c) he did not produce the product for sale or other manner of use for business purposes, or that he produced or distributed the product in the course of his business activities,

d) the product's defect is due to the fulfilment of the provisions of legal regulations which are binding on the producer, or

e) the state of scientific and technical knowledge at the time when he placed the product on the market did not allow the defect to be discovered.

(3) A person who produced a component of a product is released from the duty to provide compensation for damage if he proves that the defect was caused by the product's structure into which the component was incorporated, or that it was caused by the product's manual.

(4) If the other party waives in advance his right to compensation for damage in whole or in part, it is disregarded.

(5) Stipulations contrary to Subsections (1) to (4) are disregarded.

Section 2943

The provisions of Sections 2939 to 2942 do not apply if the defect caused damage to a defective product, or damage to a thing intended and used primarily for business purposes.

Section 2944

\section{Damage to a thing taken over}

A person who took over from another a thing which is to constitute the subject of his obligation compensates for the damage, loss or destruction of the thing, unless he proves that the damage would have been incurred in any case.

\section{Section 2945 [Recodification]}

\section{Damage to a thing left at a particular place}

(1) If the operation of an activity is typically associated with leaving things at a particular place, and if a thing has been left at a designated place or a place typically used to leave such things, the operator shall provide compensation for the damage to the thing, or loss or destruction of the thing to the person who left it there or, where applicable, to the owner of the thing. Likewise, the operator of a guarded car park or similar type of facility shall provide compensation for the damage caused to means of transport parked in it and their accessories.

(2) If the right to compensation for damage is not asserted against the operator without undue delay, a court shall not grant the right if the operator invokes late assertion of the right. The right to compensation for damage may be asserted within fifteen days from the date on which the victim must have become aware of the damage.

(3) Where damage was caused to a thing left at a particular place in a means of transport used as public transport, compensation of such damage is only paid under the provisions on compensation for damage caused by the operation of a means of transport.

\section{Damage to a thing brought inside}

\section{Section 2946 [Recodification]}

(1) A person who regularly operates accommodation services shall provide compensation for the damage caused to a thing which a guest brought to the premises reserved for accommodation or the storage of things, or to a thing which was taken there for the guest. This also applies where a thing was taken over for that purpose by the accommodation provider.

(2) If the accommodation provider proves that the damage would have been incurred in any case, or that the damage was caused by the guest or a person accompanying the guest of the guest's own will, the accommodation provider is released from the duty to provide compensation for damage. Stipulations of other grounds for the release from such a duty are disregarded.

\section{Section 2947 [Recodification]}

The duty to provide compensation for damage does not apply to vehicles or things left in a vehicle, or to living animals, unless the accommodation provider took them over into deposit.

\section{Section 2948 [Recodification]} one day.

(1) Compensation for damage is to be paid up to the amount of one hundred times the price of accommodation for 
(2) If a thing has been taken over for deposit, if the accommodation provider refused to deposit a thing contrary to a statute or if damage was caused by the accommodation provider or a person who works in the operation, compensation for damage is paid without any limits.

\section{Section 2949 [Recodification]}

(1) If the right to compensation for damage is not asserted against the accommodation provider without undue delay, a court shall not grant the right if the accommodation provider invokes late assertion of the right. The right to compensation for damage may be asserted within fifteen days from the date on which the victim must have become aware of the damage.

(2) The provision of Subsection (1) does not apply if the accommodation provider took over a thing into deposit, if the accommodation provider refused to deposit a thing contrary to a statute or if damage was caused by the accommodation provider or a person who works in the operation.

\section{Section 2950 [Recodification]}

\section{Damage caused by information or advice}

A person who offers professional performance as a member of a vocation or profession, or otherwise acts as an expert, shall provide compensation for damage caused by his provision of incomplete or incorrect information or harmful advice provided for consideration in a matter related to his expertise or skill. Otherwise, only damage intentionally caused by providing information or advice is subject to compensation.

\section{Division 3}

\section{Manner and extent of compensation}

\section{Subdivision 1}

\section{General provisions}

\section{Section 2951 [Recodification]}

(1) Damage is compensated by the restoration to the original state. If this is not reasonably possible, or if so requested by the victim, damage is payable in money.

Non-pecuniary harm is compensated by appropriate satisfaction. Satisfaction must be provided in money unless real and sufficiently effective satisfaction for the harm incurred can provide for satisfaction otherwise.

\section{Section 2952 [Recodification]}

The actual damage and what the victim lost (lost profit) is paid. If the actual damage consists in the creation of a debt, the victim has the right to be released from the debt or provided with compensation by the tortfeasor.

\section{Section 2953 [Recodification]}

\section{Reduction of compensation}

(1) For reasons deserving special consideration, a court shall proportionately reduce the compensation of damage. In doing so, the court shall in particular take into account how the damage occurred, the personal and property situation of the individual who caused and is liable for the damage, as well as the circumstances of the victim. Compensation may not be reduced if the damage was caused intentionally.

(2) Subsection (1) does not apply if the damage was caused by a person who offered to provide professional performance as a member of a particular vocation or occupation, or by a breach of professional care.

\section{Section 2954}

If a tortfeasor caused damage by an intentional criminal offence from which he gained property benefit, a court may, on the application of the victim, decide on satisfaction from the things which the tortfeasor acquired under the property benefit, even if the things are not otherwise subject to enforcement of a decision. Until the right to compensation for damage has been satisfied, the tortfeasor may not dispose of the things specified in the decision.

\section{Section 2955}

If the amount of compensation of damage cannot be accurately determined, it is determined by a court on the basis of a fair consideration of each circumstance.

\section{Subdivision 2}

\section{Compensation for harm to the natural rights of an individual}

\section{General provisions}


Where a tortfeasor incurs a duty to compensate an individual for harm to his natural right protected by the provisions of Book One of this Act, he shall compensate the damage as well as non-pecuniary harm thus caused; compensation of the non-pecuniary harm shall also include mental suffering.

\section{Section 2957 [Recodification]}

The manner and amount of adequate satisfaction must be determined so as to also compensate for the circumstances deserving special consideration. These circumstances shall mean causing intentional harm, including, without limitation, causing harm by trickery, threat, abuse of the victim's dependence on the tortfeasor, multiplying the effects of the interference by making it publicly known or as a result of discriminating the victim with regard to the victim's sex, health condition, ethnicity, creed, or other similarly serious reasons. Account is also taken of the victim's concerns of loss of life or serious damage to health if such concerns were caused by the threat or other causes.

\section{Compensation for bodily harm and death}

Section 2958 [Recodification]

In the case of bodily harm, the tortfeasor shall compensate the victim for such harm in money, fully compensating for the pain and other non-pecuniary harm suffered; if the bodily harm resulted in an impediment to a better future for the victim, the tortfeasor shall also compensate him for the deteriorated social position. Where the amount of compensation cannot be determined in this manner, it is determined according to the principles of decency.

\section{Section 2959 [Recodification]}

In the case of killing or particularly serious bodily harm, the tortfeasor shall compensate the spouse, parent, child or other close person for the mental suffering in money, fully compensating their suffering. Where the amount of compensation cannot be determined in this manner, it is determined according to the principles of decency.

\section{Section 2960 [Recodification]}

\section{Costs associated with health care}

The tortfeasor shall also reimburse reasonably incurred costs associated with the care for the health of the victim, his personal care and his household to the person who incurred these costs; if such a person so requests, the tortfeasor shall provide him with an appropriate advance payment for these costs.

\section{Section 2961 [Recodification]}

\section{Funeral costs}

A tortfeasor shall reimburse the person who incurred reasonable costs associated with the funeral; the reimbursement is provided to the extent in which these costs have not been paid by a public benefit under another legal regulation. In doing so, account is taken of usages as well as of the circumstances of each individual case.

\section{Pecuniary benefits}

\section{Section 2962 [Recodification]}

(1) Compensation for the loss of earnings during the period of the victim's temporary unfitness to work is paid in the form of a pecuniary pension equal to the difference between the victim's average earnings before the occurrence of the harm and the compensation for the amount paid to the victim as a result of an illness or injury under another legal regulation.

(2) A pupil or student is entitled to compensation for loss of earnings from the date on which his compulsory school attendance, study or vocational training should have ended, for a period:

a) by which his compulsory school attendance, study or vocational training was extended as a result of bodily harm,

b) of his incapacity as a result of bodily harm,

c) of the duration of the disability incurred as a result of bodily harm, which usually prevents full involvement in a gainful activity, or

d) of the duration of the disability incurred as a result of bodily harm which partially prevents involvement in a gainful activity, unless he is at fault for missing the opportunity to earn income by carrying out work suitable for him.

\section{Section 2963 [Recodification]}

(1) After the temporary unfitness to work or disability ends, the tortfeasor shall compensate the victim for his loss by a pecuniary pension, which is to be determined with regard to the difference between the earnings which the victim was gaining before the harm arose and the earnings gained after the temporary unfitness to work ended, including, where applicable, any disability pension under another legal regulation. If bodily harm results in a long-term increase in the needs of the victim, these needs are also taken into consideration in determining the amount of the pecuniary pension.

(2) If, after the end of the temporary unfitness to work, the victim gains earnings only by exerting more effort or 
increased strain, which he would otherwise not have had to exert had it not been for the loss event, the increased exertion or effort is compensated to him by a pecuniary pension. In determining the amount of pecuniary pension, account is also taken of any increase in the earnings in the respective field, as well as of any likely increase of the victim's earnings in accordance with rational expectations.

(3) If there are serious reasons, a court may decide whether, how and to what extent the tortfeasor shall secure the victim's claim to pecuniary pension; in doing so, the court is not bound by the motions of the parties.

\section{Section 2964 [Recodification]}

The victim is entitled to compensation for loss of pension in the amount of the difference between the pension to which the victim became entitled, and the pension to which he would have become entitled if the basis used to determine the pension had included the compensation for loss of earnings after the end of the temporary unfitness to work which the victim received at the time decisive for the determination of the pension.

\section{Section 2965 [Recodification]}

If the victim carried out gratuitous work for another person in the person's household or enterprise, the tortfeasor shall provide that other person with pecuniary pension to compensate for the amount the other person lost.

\section{Section 2966 [Recodification]}

(1) In the case of killing, the tortfeasor shall provide a pecuniary pension to reimburse the costs of maintenance for the survivors whom the decedent, on the day of his death, was providing or was obliged to provide maintenance. The survivors are entitled to reimbursement equal to the difference between the pension system benefits provided for the same reason and the amount which the victim could have provided to the survivors from these costs according to reasonable expectations, had he not been injured.

(2) For the sake of decency, a contribution to maintenance and support may also be granted to another person if the killed person provided such a performance to the person without being obliged to do so by a statute.

\section{Section 2967 [Recodification]}

(1) The amount of reimbursement is determined on the basis of the average earnings of the decedent; the total reimbursement of the costs of maintenance to the survivors or other persons may not exceed the amount to which the decedent would have been entitled as compensation for loss of earnings, or pension, where applicable.

(2) In determining the reimbursement to survivors, account is also taken of how long the killed person would likely have lived had it not been for the injury. When determining the reimbursement to other persons, account is taken of how long the killed person would likely have provided the performance.

\section{Section 2968 [Recodification]}

\section{Lump-sum payment}

If justified by an important reason and requested by the victim, a court shall grant the victim a lump-sum payment instead of a pecuniary pension.

\section{Subdivision 3}

\section{Special provisions}

\section{Section 2969 [Recodification]}

\section{Compensation in the case of damage to a thing}

(1) The amount of damage to a thing is determined on the basis of its usual price at the time the damage was incurred, taking into account everything which the victim must efficiently incur to restore or replace the function of the thing.

(2) If the tortfeasor has damaged a thing out of caprice or maliciousness, he shall compensate the victim for the sentimental value.

\section{Section 2970 [Recodification]}

\section{Compensation for an injury of an animal}

In the case of an injury of an animal, the tortfeasor shall provide reimburse the reasonably incurred costs associated with health care of the wounded animal to the person who incurred these costs; if so requested by the person, the tortfeasor shall provide him with a reasonable advance payment for these costs. The costs associated with health care have not been incurred unreasonably even if they substantially exceed the price of the animal, provided that they would be incurred by a reasonable breeder in the position of the victim.

Section 2971 [Recodification] 
If justified by special circumstances under which the tortfeasor caused harm by an unlawful act, including, without limitation, by breaching an important legal duty due to gross negligence, or by causing harm intentionally out of a desire to destroy, hurt or for other especially reprehensible motives, the tortfeasor shall provide compensation for the non-pecuniary harm to everyone who legitimately perceives the harm as a personal misfortune which cannot be undone otherwise.

\section{Chapter 2}

\section{Abuse and restriction of competition}

\section{Division 1}

\section{General provisions}

Section 2972

A person who engages in competition (a competitor) may, in competitive activities or in associating for the purpose of pursuing competitive activities, neither abuse his own engagement in the competition by competing unfairly, nor restrict others in their engagement in the competition.

\section{Section 2973}

The provisions of this Title do not apply to acts to the extent to which the acts have effect abroad, unless otherwise provided by international treaties by which the Czech Republic is bound and which have been published in the Collection of International Treaties.

\section{Section 2974}

In relation to protection against unfair competition, foreign persons who engage in the competition in the Czech Republic are treated as Czech persons. Otherwise, foreign persons may seek protection under international treaties by which the Czech Republic is bound and which have been published in the Collection of International Treaties, and in their absence, on a reciprocal basis.

\section{Section 2975 [Recodification]}

\section{Prohibited non-compete clause}

(1) If a stipulation which prohibits another person to engage in competitive activities does not determine the territory, range of activities or group of persons subject to such a prohibition, the non-compete clause is disregarded.

(2) A non-compete clause stipulated for an indefinite period or for a period longer than five years is prohibited; if the prohibition is breached, the non-compete clause is conclusively presumed to have been negotiated for five years.

(3) A non-compete clause restricting the obligor more than is required by the necessary protection of the obligee is prohibited; if the prohibition is breached, a court may, on the application of the party affected, restrict or cancel the non-compete clause, or declare it invalid.

\section{Division 2}

\section{Unfair competition}

Section 2976

\section{Basic provisions}

(1) If, in business relations, a person gets into conflict with good morals of competition as a result of his conduct capable of causing harm to other competitors or customers, such a person has competed unfairly. Unfair competition is prohibited.

(2) Unfair competition, as referred to under Subsection (1), shall include, without limitation:

a) misleading advertising,

b) misleading identification of goods and services,

c) creating a likelihood of confusion,

d) free-riding on the reputation of an enterprise, product or services of another competitor,

e) bribery,

f) disparaging a competitor,

g) comparative advertising, unless allowed as admissible, 

h) breach of business secrets,
i) unsolicited advertising, and
j) threat to health and the environment.

\section{Section 2977 [Recodification]}

\section{Misleading advertising}

(1) Misleading advertising is advertising which relates to business activities or profession, aims to promote the sales of movable or immovable things or the provision of services, including rights and duties, which misleads or is capable of misleading the persons to whom it is addressed or whom it reaches by its presentation or in any other way, and is thus evidently capable of affecting the economic behaviour of such persons.

(2) In determining whether or not advertising is misleading, account is taken of all its distinctive features. Particular account is taken of the information which the advertising contains regarding:

a) the availability, nature, design, composition, production method, date of production or provision, fitness for the intended purpose, usability, quantity, geographical or commercial origin, as well as a more detailed definition and other features of goods or services, including the expected results of their use or the results and essential features of the tests and checks performed,

b) the price or the method of its determination,

c) the terms under which goods are supplied or service provided, and

d) the nature, characteristicsand rights of an advertiser, including, but not limited to, his identity, property, professional competence, his intellectual property rights or his awards and honours.

Section 2978

\section{Misleading identification of goods and services}

(1) Misleading identification of goods and services is such an identification which, in economic transactions, is capable of causing a misleading assumption that goods or services so identified come from a particular region or place, or from a specific producer, or that they have a particular characteristic feature or a particular quality. It is irrelevant whether the identification was placed directly on the goods, on the packaging, in a commercial document or elsewhere. It is also irrelevant whether the misleading identification was direct or indirect, and what means were used for such identification.

(2) An indication generally established in economic transactions to designate kind or quality is also misleading if it is accompanied by additions capable of misleading, including, without limitation, by using the term "pravý" (genuine), "skutečný" (real) or "původni" (original).

(3) The provisions of the preceding Subsections do not affect other legal regulations on the protection of industrial or other intellectual property.

\section{Section 2979}

\section{Common provisions on misleading advertising and misleading identification of goods and services}

(1) An indication which is correct in itself may also be capable of misleading if it can mislead because of the circumstances and context in which it was provided.

(2) In assessing the misleading nature, account is also taken of additions, including, but not limited to the use of terms such as "druh" (kind), "typ" (type), "způsob" (manner), as well as of omissions, abbreviations and overall external presentation.

\section{Section 2980 [Recodification]}

\section{Comparative advertising}

(1) Comparative advertising directly or indirectly identifies another competitor, or his goods or services.

(2) Comparative advertising is permitted in terms of making comparisons in the following cases:

a) if it is not misleading,

b) if it only compares goods or services which satisfy the same need or which are intended for the same purpose,

c) if it objectively compares one or several relevant, important, verifiable and typical properties of goods or services, including price,

d) if it compares goods with a designation of origin only to goods of the same designation,

e) if it does not disparage a competitor, its position, its activities or its results, or their identification, or unfairly benefits therefrom, and 
f) if it does not offer goods or services as an imitation or copy of goods or services identified by a trademark of a competitor or by the competitor's name.

\section{Section 2981 [Recodification]}

\section{Creating a likelihood of confusion}

(1) A person who uses the name or a special designation of an enterprise which is already lawfully used by another competitor shall cause a likelihood of confusion.

(2) Likelihood of confusion is also caused by a person who uses a special designation of an enterprise or a special designation or presentation of a product, performance or business material of an enterprise which customers consider to be typical for a particular enterprise.

(3) Likelihood of confusion is also caused by a person who imitates a product of another, its packaging or performance, unless it is an imitation of the elements which are functionally, technically or aesthetically predetermined given the nature of the product, and the imitator took all measures which could have been required of him to exclude or at least substantially reduce the likelihood of confusion, if such acts are capable of causing the likelihood of confusion or a false impression of being associated with the competitor, his enterprise, name, special designation, or with a product or performance of another competitor.

\section{Section 2982}

\section{Free-riding on the reputation}

Free-riding consists in the abuse of the reputation of an enterprise, product or service of another competitor which allows a benefit to be gained for the results of one's own or another's business activities, where the competitor would not have gained such a benefit otherwise.

\section{Section 2983}

\section{Bribery}

Bribery within the meaning of this Act is constituted by an act whereby:

a) a competitor directly or indirectly offers, promises or provides any benefit to a person who is the member of a governing body or some other body of another competitor, or is employed by another competitor, in order to obtain, through that person's unfair conduct, priority or some other undue advantage in competition for himself or for some other competitor at the expense of other competitors, or

b) a person under paragraph (a) directly or indirectly requests or accepts any benefit, or has such a benefit promised to him, for the same purpose.

Section 2984

\section{Disparagement of a competitor}

(1) Disparagement is constituted by an act whereby a competitor states or spreads a false statement about the situation, performance or product of another competitor, where such a statement is capable of causing harm to that competitor.

(2) Disparagement is also constituted by stating and spreading a true statement about the situation, performance or product of another competitor if it is capable of causing harm to the competitor. However, if the competitor was forced to perform such acts by the circumstances, it shall not constitute unfair competition (legitimate defence).

\section{Section 2985}

\section{Breach of business secrets}

Breach of business secrets is constituted by an act whereby the person who acts unlawfully discloses or makes available to another person, or uses for himself or for another person, business secrets which can be used in competition and of which the person learned:

a) as a result of having been entrusted with the secrets or as a result of the secrets having been made available to him otherwise under his employment relationship with a competitor, or under another relationship with the competitor, or, where applicable, in the discharge of the office to which he was selected by a court or another body, or

b) by the person's own act or the act of another which is in breach of a statute.

\section{Section 2986 [Recodification]}

\section{Unsolicited advertising}

(1) Unsolicited advertising consists in disclosing information about a competitor, goods or services, as well as in offering goods or services using telephone, fax, electronic mail or similar means where the recipient clearly wishes to be subject 
to no such activity, or in the communication of advertising in which its originator conceals or disguises information which allow for his identification, and does not specify where the recipient can have the advertising ended without incurring extraordinary costs.

(2) Where advertising is sent to an electronic address which an entrepreneur acquired in connection with the sale of goods or provision of services, this does not constitute unsolicited advertising if the entrepreneur uses the address for direct advertising of his own goods or services, and the other party has not prohibited such advertising despite having been clearly informed by the entrepreneur in the acquisition of the address and each time it was used to advertise of the right to have the advertising ended without any additional costs.

Section 2987

\section{Threat to health or the environment}

Threat to health or the environment is constituted by an act whereby a competitor distorts the conditions of competition by operating production, marketing a product or carrying out performance threatening an interest in the protection of health or the environment protected by a statute in order to obtain a benefit for himself or another person at the expense of another competitor or customers.

\section{Protection against unfair competition}

\section{Section 2988}

A person whose right has been jeopardised or violated by unfair competition may request the violator to refrain from competing unfairly or to remove a defective state. He may also request adequate satisfaction, compensation for damage and restitution of unjust enrichment.

\section{Section 2989 [Recodification]}

(1) The right to have the violator refrain from competing unfairly or remove defective state may, in addition to the cases under Sections 2982 to 2985, be also asserted by a legal person entitled to defend the interests of competitors or customers.

(2) If a consumer asserts his right to have a violator refrain from competing unfairly or remove a defective state, and if it is a case provided under Sections 2976 to 2981 or Section 2987, the violator must prove that he did not compete unfairly. If a consumer asserts his right to compensation for damage, the violator must prove that the damage was not caused by unfair competition.

Section 2990

\section{Protection against the restriction of competition}

A person whose right has been jeopardised or violated by an unallowed restriction of competition has the rights provided under Section 2988.

TITLE IV

\section{OBLIGATIONS ARISING FROM OTHER LEGAL CAUSES}

\section{Chapter 1}

\section{Unjust enrichment}

\section{Section 2991 [Recodification]}

(1) A person who is enriched at the expense of another without a just cause must, to the extent of his enrichment, make restitution to the impoverished person.

(2) An unjustly enriched person shall in particular mean a person who acquires a pecuniary benefit by being provided with a performance based on no legal cause, a performance based on a legal cause which expired, by the unlawful use of the value of another or by performance which the unjustly enriched person was lawfully obliged to provide but which was provided in his stead.

\section{Section 2992 [Recodification]}

The duty to make restitution for the enrichment is not created if a debt was discharged, whether or not early, if a right was not asserted although it could have, or if one person did something in his exclusive and personal interest or at his own risk; this also applies where one person enriches another person with the intention to provide the person with a gift or enrich the person with no intention to become legally bound.

\section{Section 2993 [Recodification]}

If a party has provided a performance not based on a valid obligation, the party is entitled to restitution for the performance provided. If both parties provided a performance, either party may request that the other make restitution for the performance acquired; this does not affect the right of the other party to invoke mutual performance. This also applies where the 
obligation was extinguished.

\section{Section 2994}

If someone unlawfully provides a thing to be used or used and enjoyed by another person without such other person being in good faith, the owner or co-owner of the thing is entitled to compensation with respect to such a user or usufructuary.

\section{Section 2995 [Recodification]}

If a performance has resulted in the enrichment of a third person, such a third person shall make restitution to the impoverished person only if the impoverished person was made to provide the performance by trickery, coerced into it under threat or abuse of dependence, or if he lacked legal capacity.

\section{Section 2996}

If a debtor was to provide one of several optional performances and provided more by mistake, he is free to decide what to reclaim. However, if the creditor had the right to choose, the debtor may require that the creditor make the choice; if the creditor fails to do so without undue delay, it may be claimed that the expression of will be made by a court in his stead.

\section{Section 2997 [Recodification]}

(1) A debtor who performed a debt which was not suable or which was time-barred, or one which is invalid due to lack of form, has no right to restitution for the performance he provided. A person who enriched another knowing that he was not required to do so shall also not be entitled to restitution, unless he performed based on a legal cause which later failed to occur or expired.

(2) If a person performed because he was caused to do so by trickery, coerced under threat or abuse of dependence, the provision of Subsection (1) does not apply. This also applies where a performance was provided by a person lacking legal capacity.

\section{Section 2998 [Recodification]}

If a party performed consciously to make the other party do something for a prohibited or completely impossible purpose, the former is not entitled to require that restitution of that performance be made. However, if a person wished to prevent an unlawful act by giving something to the person who wished to commit the act, the former may require restitution.

\section{Section 2999 [Recodification]}

(1) If the restitution of a subject of unjust enrichment is not reasonably possible, the impoverished person has the right to a pecuniary compensation in the amount equal to the usual price. If a performance was provided on the basis of an invalid or cancelled juridical act, the right to pecuniary compensation is not created to the extent to which it is contrary to the purpose of the rule excluding the validity of the juridical act.

(2) If an impoverished person provided a performance for consideration, the compensation is provided in the amount of that consideration; this does not apply if the amount of the consideration establishes grounds for invalidity of the contract or grounds for extinction of the obligation, or if the amount of the consideration was significantly affected by such grounds.

(3) Where no restitution of the subject of unjust enrichment can be made because it decayed, was lost or deteriorated for causes attributable to the impoverished person, the enriched person shall make restitution to the extent of what he saved on his own property.

\section{Section 3000 [Recodification]}

A fair beneficiary shall make restitution of what he acquired to the maximum extent of the scope of enrichment still existing when the right is asserted.

\section{Section 3001 [Recodification]}

(1) If a fair beneficiary alienates the subject of unjust enrichment for consideration, he may choose to make restitution in the form of either pecuniary compensation, or what he gained. If a beneficiary in good faith alienates it gratuitously, the impoverished person is not entitled to compensation from him; however, the impoverished person may claim the compensation from the person who acquired the subject of unjust enrichment from the enriched person and did not act in good faith.

(2) If the enriched person acquires the subject of unjust enrichment in good faith or without his consent, and if its restitution is not reasonably possible, he is not obliged to provide compensation, unless this would result in a situation in clear conflict with good morals.

\section{Section 3002 [Recodification]}

(1) If a party provides a performance under an onerous contract, even where the contract was invalid, his right to pecuniary compensation from the other party is unaffected by the provisions of Sections 3000 and 3001 . This also applies if the obligation arising from such a contract was extinguished.

(2) If a thing acquired under an onerous contract is used by a fair beneficiary and if the contract is invalid, the fair beneficiary shall provide the other party with compensation for the use, but only up to the amount equal to the benefit the beneficiary gained. 
A beneficiary in bad faith shall make restitution of what he gained at the time when he acquired the enrichment.

\section{Section 3004 [Recodification]}

(1) An enriched person who did not act in good faith shall make restitution of the entire enrichment which he acquired, including the fruits and revenues; he shall also compensate for the revenue which the impoverished person would have gained. If he alienated the subject of unjust enrichment for consideration, the impoverished person has the right to demand that he be given, at his choice, either pecuniary compensation, or the amount which the enriched person gained by the alienation.

(2) If unjust enrichment was acquired by interfering with a natural right of an individual protected by the provisions of Book One of this Act, the impoverished person may, as compensation for the unlawful disposal of the values related to his personality rights, demand twice the remuneration usual for the consent to such disposal instead of the performance under Subsection (1). If there is a just cause, a court may appropriately increase the scope of the performance.

\section{Section 3005}

A person who makes restitution of the subject of an unjust enrichment is entitled to reimbursement of the necessary costs which he incurred on the thing, and may separate from the thing everything which he used at his own expense to increase its value, if it is possible without deteriorating the essence of the thing.

\section{Chapter 2}

\section{Agency without mandate and the use of a thing of another for the benefit of another person}

\section{Division 1}

\section{Agency without mandate}

Section 3006 [Recodification]

\section{Basic provisions}

If a person interferes in the matters of another person without being entitled to do so, he bears the resulting consequences.

\section{Section 3007 [Recodification]}

\section{Prevention of damage}

If a person, without being called upon to do so, arranges a matter of another to prevent imminent damage, the person whose matter was arranged shall reimburse the reasonably incurred costs, even where no result was achieved for reasons not attributable to the agent without mandate.

\section{Section 3008 [Recodification]}

\section{Salvaging a thing of another}

A person who salvages a thing of another from an inevitable loss or decay is entitled to adequate remuneration of no more than a tenth of the price of the thing, and to reimbursement of reasonably incurred costs. The owner of the thing is relieved of the duty to provide the payment if he does not reclaim the salvaged thing.

\section{Section 3009 [Recodification]}

\section{Acts for the benefit of another person}

(1) If someone assumes a matter for the benefit of another person without the person's consent, the person shall reimburse him for the reasonably incurred costs if the matter has been arranged for the predominant benefit of the person. Whether a matter has been carried out for the benefit of another is not assessed according to general considerations, but by having regard to his understandable interests and intentions.

(2) If a benefit is not predominant, an agent without mandate is not entitled to reimbursement of costs. The person whose matters the agent without mandate assumed may require the agent without mandate to restore everything to its original state, and where this is not reasonably possible, to compensate for the damage.

\section{Common provisions}

\section{Section 3010}

A person who assumed a matter of another without mandate shall see it through, present the relevant accounts and transfer everything acquired in doing so to the person whose matter was arranged. 
If an agent without mandate is not entitled to reimbursement of costs, he may take what he acquired at his own expense, if it is possible and if it does not deteriorate the essence of the thing or unreasonably hampers its use.

\title{
Division 2
}

\section{Using a thing of another for the benefit of another person}

\author{
Section 3012 [Recodification]
}

\section{Basic provisions}

If someone uses a thing of another for the benefit of another person without the intention to arrange a matter of another, and if it is not reasonably possible to achieve the surrender of the thing, the owner of thing may require him to provide compensation for the value of the thing at the time it was used, even where the benefit was not achieved.

\section{Section 3013 [Recodification]} reimbursement.

A person who incurs a cost for another person which that person was required to incur himself has right to claim

\section{Section 3014 [Recodification]}

If a person in difficulties sacrifices a thing in order to prevent greater damage, each of the persons benefiting from the situation shall provide the victim with a proportionate compensation.

\section{BOOK FIVE}

\section{COMMON, TRANSITIONAL AND FINAL PROVISIONS}

\section{TITLE I}

\section{COMMON PROVISIONS}

\section{Section 3015}

This Act incorporates the relevant legal regulations of the European Union1).

$$
\text { Section } 3016 \text { [Recodification] }
$$

The provisions of this Act do not affect the provisions of other legal regulations on consumer protection.

\section{Section 3017}

The provisions of this Act relating to the assertion of a right in court, or to judicial proceedings and court decisions apply by analogy to the assertion of the right before an arbitrator, to arbitration and arbitration awards.

\section{Section 3018 [Recodification]}

The duty to publish information is fulfilled upon its publication in the Commercial Bulletin, unless otherwise provided by another legal regulation.

\section{Section 3019 [Recodification]}

Information which allows an individual to be identified shall include, without limitation, his name, address of residence and date of birth, or, where applicable, other identifying information under another legal regulation. Identifying information of a legal person or an entrepreneur shall include the person's identification number, if assigned.

\section{Section 3020 [Recodification]}

The provisions of Book One, Book Three and Book Four on marriage and on the rights and duties of spouses apply by analogy to registered partnership and the rights and duties of partners.

\section{Section 3021 [Recodification]}

The provisions of Sections 751 to 753 on domestic violence also apply to cohabitation of persons other than spouses.

\section{Section 3022 [Recodification]} Book Two.

(1) The provisions of this Act on the rights and duties of a legal representative apply by analogy to a guardian under

(2) The provisions of this Act on guardianship council also apply to the appointment of a tutor, but the creation of the board and the election of its members becomes effective only if approved by a court; however, such a measure must be in 
accordance with the interests of the child.

\section{Section 3023 [Recodification]}

The provisions of this Act on an owner of a tract of land apply by analogy to an owner of an immovable thing which does not constitute a component part of a tract of land.

\section{Section 3024 [Recodification]}

(1) A natural person with a residence, or a legal person with a registered office, outside the territory of the Czech Republic is considered to be a foreign person.

(2) If a person other than a foreign natural person has the capacity to acquire rights and assume duties under the legal order under which it was formed, it has the same capacity under the legal order of the Czech Republic. The legal order of the state under which that person was formed shall also govern its internal legal relations and the liability of its members or shareholders for its debts.

\section{Section 3025 [Recodification]}

(1) The provisions of this Act on legal persons and associations apply to trade unions and employers' organisations with the necessary modifications only insofar as they are not contrary to their nature as representatives of employees and employers under international treaties by which the Czech Republic is bound and which govern the freedom of association and the protection of the right to associate freely.

(2) Trade unions, employers' organisations and their subsidiaries are incorporated on the day following the date on which the notice of their formation was delivered to the competent public body.

\section{Section 3026 [Recodification]}

(1) Unless excluded by the nature of the document, the provisions of this Act on instruments also apply by analogy to other documents irrespective of their form.

(2) Where the form of a public instrument is required to make a juridical act, the public instrument is to be understood as a notarial deed; it may be substituted with a decision whereby a public body, within the scope of its powers, approves a settlement or another expression of will whose nature allows it.

\section{Section 3027 [Recodification]}

If this Act creates a creditor's right to sufficient security, and if the creditor and the debtor, or another person providing security, do not stipulate its subject or amount, a court shall decide on sufficient security, having regard to the nature and amount of the claim.

\section{TITLE II}

\section{TRANSITIONAL AND FINAL PROVISIONS}

\section{Chapter 1}

\section{Transitional provisions}

\section{Division 1}

\section{General provisions}

\section{Section 3028}

(1) This Act governs the rights and duties which will arise after its effective date.

(2) Unless otherwise provided below, the provisions of this Act also govern the legal relations regarding personal rights, family rights and rights in rem; however, the creation of these relations, as well as the rights and duties which arose from them before the effective date of this Act are assessed under current legal regulations.

(3) Unless otherwise provided below, other legal transactions created before the effective date of this Act, as well as the rights and duties arising from them, including the rights and duties arising from the breach of contracts concluded before the effective date of this Act, are governed by current legal regulations. This does not prevent the parties from stipulating that their rights and duties will be governed by this Act from its effective date.

\section{Section 3029} their place.

(1) If legal regulations refer to provisions which are repealed by this Act, the corresponding provisions of this Act take

(2) Unless otherwise provided by this Act, the provisions of legal regulations in the field of public law, as well as the provisions of other legal regulations governing special private rights remain unaffected. 

One, Title I.

The rights and duties assessed pursuant to current legal regulations are also governed by the provisions of Book

Section 3031

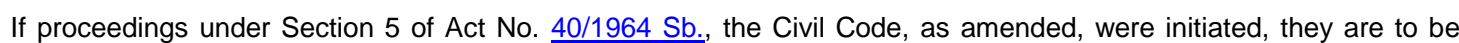
completed in accordance with current legal regulations.

\section{Section 3032 [Recodification]}

(1) A person who has been deprived of legal capacity under current legal regulations shall, from the effective date of this Act, be considered to be a person with limited legal capacity under this Act.

(2) A person whose capacity to make juridical acts has been limited under current legal regulations shall, from the effective date of this Act, be considered to be a person with limited legal capacity under this Act, and shall also henceforth be capable of making juridical acts within the scope provided by current legal regulations, unless otherwise decided by a court on the basis of this Act.

\section{Section 3033 [Recodification]}

(1) Persons who were deprived of the capacity to make juridical acts before the effective date of this Act or whose capacity to make juridical acts was limited before the effective date of this Act acquire full legal capacity no later than three years after the effective date of this Act, unless otherwise decided by a court.

(2) Until otherwise provided by another legal regulation, guardianship under Section 468 passes to the municipality in whose territory the ward resides.

\section{Section 3034 [Recodification]}

If, in anticipation of losing his capacity to make juridical acts, a person with full legal capacity expressed the wish, before the effective date of this Act, to have a particular person as his guardian, the decision-making on the limitation of legal capacity is governed by Section 59 following the effective date of this Act. Section 469 applies to decision-making on guardians of legal persons by analogy.

\section{Section 3035}

If, before the effective date of this Act, adoption proceedings were initiated, they are to be completed under current legal regulations. The acts performed in pre-trial proceedings leading to the adoption is assessed under this Act; this does not apply in the case of granting parental consent to adoption, or in the case of a court decision that such consent is not required.

\section{Division 2}

\section{Time limits and periods}

\section{Section 3036 [Recodification]}

All time limits and periods which commenced before the effective date of this Act, as well as time limits and periods to assert the rights which are governed by current legal regulations, even where they commence after the effective date of this Act, are assessed under current legal regulations until they expire.

\section{Section 3037 [Recodification]}

(1) If, before the effective date of this Act, a person learned of a violation of his right to name, honour or reputation, or of a violation of a similar private relation, and of the identity of the violator, or if he should and could have learned thereof before the effective date of this Act, the time limit for the extinction of the right to its protection commences on the effective date of this Act.

(2) If, following the effective date of this Act, a person learned that his right to name, honour or reputation, or another similar private relation was violated before the effective date of this Act, and he learned of the identity of the violator, or if he should and could have learned thereof, the time limit for the extinction of the right to its protection commences on the effective date of this Act.

\section{Division 3}

\section{Matrimonial property law}

\section{Section 3038 [Recodification]}

Things which belong to the usual equipment of a family household shall cease to be part of community property on the effective date of this Act.

\section{Section 3039 [Recodification]}

Things gratuitously acquired before the effective date of this Act by one of the spouses, or things gratuitously acquired 
before the effective date of this Act by both spouses where such things did not become part of community property, shall continue to be excluded from the community property.

\section{Section 3040 [Recodification]}

Community property shall not include a thing surrendered, under the legal regulations governing the restitution of the title to property, to one of the spouses who owned the thing before entering into marriage or to whom the thing was surrendered as the legal successor of the original owner.

\section{Division 4}

\section{Legal persons}

\section{Section 3041 [Recodification]}

(1) The legal nature of legal persons governed by this Act is governed by the provisions of this Act from its effective date. If proceedings for the registration of a legal person in a public register were initiated before the effective date of this Act, they are completed under current legal regulations; however, if a forming juridical act made before the effective date of this Act is contrary to current legal regulations, it isconsidered valid if it is in accordance with the provisions of this Act.

(2) The provisions of a memorandum of association or the by-laws of the legal persons under Subsection (1) which are contrary to the compelling provisions of this Act cease to have binding effect on the effective date of this Act; a legal person shall, within three years from the effective date of this Act, amend its memorandum of association or by-laws so that they are in accordance with this Act, and deliver them to the public body which maintains the public register in which the legal person is registered. If it fails to do so, the competent public body shall request it to do so, specifying in the request a reasonable additional time limit to fulfil this duty; if the additional time limit expires without the duty being fulfilled, a court shall, on the application of the public body or a person who proves a legal interest therein, dissolve the legal person and order its liquidation.

\section{Section 3042 [Recodification]}

If the name of a legal person is contrary to the provisions of this Act, the legal person shall adapt its name to the requirements of this Act within two years from the effective date of this Act. The legal person is not obliged to do so if there are important reasons for it, especially if the legal person has used its name for a long time and if it is so characteristic for the legal person that it cannot be reasonably expected that the name could be confused or be misleading.

\section{Section 3043 [Recodification]}

(1) If a contract or a decision on the transformation of a legal person made before the effective date of this Act is contrary to current legal regulations, it is considered valid if it is in accordance with the provisions of this Act and if, before the effective date of this Act, the relevant public body did not dismiss the application for the registration of the transformation in a public register, or decide that no transformation occurred.

(2) If, before the effective date of this Act, a decision was made to dissolve or transform a legal person, the dissolution or transformation is governed by current legal regulations, unless the competent body of the legal person decides, within three months from the effective date of this Act, that it is governed by this Act. The provisions of this Act on the protection of creditors also apply to cases where a decision on the dissolution or transformation of a legal person was made before the effective date of this Act and was not yet registered in a public register as of the effective date of this Act.

\section{Section 3044 [Recodification]}

Section 128 also applies to the forming juridical act and transformations of legal persons which occurred before the effective date of this Act.

\section{Section 3045 [Recodification]}

(1) Societies (in Czech: "sdruženi") under Act No. 83/1990 Sb., on the association of citizens, as amended, are considered to be associations (in Czech: "spolky") under this Act. A society has the right to change its legal form to an institute or social cooperative under another statute.

(2) Organisational units of societies having the capacity to act in their own name under Act No. 83/1990 Sb., on the association of citizens, as amended, are considered to be subsidiary associations under this Act. The governing body of the main association shall apply for the registration of the subsidiary association within three years from the effective date of this Act, otherwise the legal personality of the subsidiary association is extinguished on the last day of that time limit.

\section{Section 3046 [Recodification]}

A trade union, employers' organisation, including international organisations, and their organisational units registered under Act No. 83/1990 Sb., on the association of citizens, as amended, are considered to be trade unions, employers' organisations, international trade unions and their subsidiary associations under this Act.

\section{Section 3047 [Recodification]}

If proceedings to declare a decision of a civic association's governing body invalid were initiated before the effective date of this Act, a court shall decide on the application under this Act. 
Until the act on public registers for the registration of associations enters into effect, associations are subject to registration under Act No. 83/1990 Sb., on the association of citizens, as amended.

\section{Section 3049 [Recodification]}

(1) Foundations formed under current legal regulations are considered foundations formed under this Act; if a foundation was formed by a testament, Sections 311 and 312 apply even where a testament was made before the effective date of this Act, if the succession proceedings were not completed by the effective date of this Act. If a foundation was formed otherwise than by the foundation charter, in particular by issuing by-laws, the provisions of this Act on foundation charters apply to such a juridical act and to its amendments within the scope of the elements of a foundation charter provided in Section 310 .

(2) A founder of a foundation may adapt the forming juridical act to the provisions on foundation charters under this Act if he delivers the decision amending the forming juridical act to the person which maintains the public register in which the foundation is registered no later than within two years after the effective date of this Act. If the founder died or terminated before the effective date of this Act, the forming juridical act may be amended by a court on the application of the foundation.

(3) The provisions of Subsections (1) and (2) apply by analogy to endowment funds.

$$
\text { Section } 3050 \text { [Recodification] }
$$

The rights and duties of benevolent associations continue to be governed by current legal regulations. A benevolent association has the right to change its legal form to an institute, foundation or endowment fund in accordance with this Act; the provisions of this Act on the transformation of the legal form of legal persons apply by analogy.

\section{Section 3051 [Recodification]}

Professional associations of legal persons arising from current legal regulations continue to be governed by current legal regulations. A professional association of legal persons has the right to change its legal form to an association under this Act; the provisions of this Act on the transformation of the legal form of legal persons apply by analogy.

\section{Section 3052 [Recodification]}

Legal persons formed under Act No. 42/1980 Sb., on economic relations with foreign countries, as amended, continue to be governed by current legal regulations. This also applies to legal persons incorporated as an association under Section 636 of Act No. 101/1963 Sb., on legal relations in international trade. These legal persons have the right to change their legal form to an association; the provisions of this Act on the transformation of the legal form of legal persons apply by analogy.

\section{Section 3053}

The legal nature and internal legal relations of legal persons pursuing business activities, which are governed, until the effective date of this Act, by previous legal regulations under Section 767(2) of Act No. 513/1991 Sb., the Commercial Code, as amended, remain unchanged and continue to be governed by the legal regulations under which they were established.

\section{Division 5}

\section{Rights in rem}

\section{Tracts of land and buildings}

Section 3054 [Recodification]

A structure which, under current legal regulations, does not constitute a component part of a tract of land on which it has been constructed ceases to be a separate thing and becomes component part of the tract of land on the effective date of this Act, if, on that date, the same person had the right of ownership in the structure and the right of ownership in the tract of land.

\section{Section 3055 [Recodification]}

(1) A structure firmly attached to the tract of land which, under current legal regulations, does not constitute a component part of the tract of land on which it has been constructed and is owned by a person other than the owner of the tract of land as of the effective date of this Act shall not become a component part of the tract of land on that date and constitutes an immovable thing. The same applies to a structure which is co-owned if a co-owner also owns the tract of land, or if at least some of the co-owners of the structure co-own the tract of land.

(2) Subsection (1) applies by analogy to a structure which is to be constructed on the tract of land of another owner on the basis of a right in rem acquired by the builder before the effective date of this Act or under a contract concluded before that date.

\section{Section 3056 [Recodification]}

(1) The owner of the tract of land on which a structure was constructed which, under current legal regulations, does not constitute a component part of the tract of land and did not become a component part of the tract of land on the effective date of this Act has a pre-emptive right to the structure, and the owner of the structure has a pre-emptive right to the tract of land. The pre-emptive right of the owner of land shall also apply to an underground structure on the same land where such a structure is accessory to an aboveground structure. Stipulations excluding or restricting a pre-emptive right are disregarded. 
(2) If a part of a tract of land with a structure can be separated without their use and enjoyment being significantly hampered, the pre-emptive right shall only apply to the part of the land which is essential for the exercise of the right of ownership in the structure.

\section{Section 3057 [Recodification]}

If an owner of land creates a right in rem in favour of a third person who acquires the right in rem in good faith that the structure is a component part of the land, the structure is considered to be a component part of the land with respect to that person. The owner of the structure is entitled to claim compensation for the destruction of his property from the person who created the right in rem; if a structure is encumbered with a pledge, a pledge of claim for such compensation is also created.

\section{Section 3058 [Recodification]}

(1) If the same owner acquires the ownership of land and a structure, the structure shall cease to be a separate thing and becomes a component part of the land on which it has been constructed. This does not apply if the structure is not a component part of the tract of land under this Act.

(2) If the right of ownership in the tract of land has been transferred to a third person that, upon acquisition of the right of ownership, was in good faith that the structure was a component part of the tract of land, the structure shall ceases to be a separate thing and becomes a component part of the tract of land on which it has been constructed. A person who owned the structure shall, on the date of extinction of his the right of ownership, become entitled to compensation from the transferor in the amount of the price of the structure; if the structure was encumbered with a pledge, the pledge of claim passes to the compensation.

\section{Section 3059 [Recodification]}

If a structure has been constructed on several tracts of land, Sections 3056 to 3058 shall only apply in relation to the tract of land on which the dominant part of the structure is located. If the structure becomes a component part of that tract of land, the provisions on property encroachment apply to the tracts of land encroached by parts of the structure.

\section{Section 3060 [Recodification]}

If a structure or tract of land is encumbered with a right in rem, the structure shall not become a component part of the tract of land for the duration of the right in rem, and if it is excluded by its nature.

\section{Section 3061 [Recodification]}

The provisions of this Division do not apply to a structure which does not constitute a component part of the tract of land under this Act, or to an immovable thing under Section 498(1), second sentence.

\section{Co-ownership}

\section{Section 3062 [Recodification]}

A statutory pre-emptive right of co-owners under Section 140 of Act No. 40/1964 Sb., the Civil Code, as amended, is extinguished one year after the effective date of this Act. This does not apply to co-ownership of an agricultural enterprise or family enterprise.

\section{Section 3063 [Recodification]}

If an acquirer acquired the right of ownership in at least one unit in a building with apartments and non-residential premises before the effective date of this Act under Act No. 72/1994 Sb., adapting certain co-ownership relations to buildings and certain ownership relations to apartments and non-residential premises and supplementing certain acts (the Apartment Ownership Act), as amended, the creation of the right of ownership in other units in the same building is governed by current legal regulations even after the effective date of this Act.

\section{Land Registry}

Section 3064 [Recodification]

Regarding the rights registered in the Land Registry before the effective date of this Act, and regarding the rights registered in the Land Registry within one year after the effective date of this Act, the effects under Sections 980 to 986 shall occur after one year from the effective date of this Act. The time limits provided under Sections 983 and 986 commence one year after the effective date of this Act.

\section{Section 3065 [Recodification]}

In the case of a right in rem which was not subject to registration in a public register before the effective date of this Act, the precedence of the registered rights in rem under Section 981 and the order of the rights in rem under Section 982(1) becomes effective in respect of those rights on 1 January 2018.

\section{Section 3066 [Recodification]}

\section{Extraordinary acquisitive prescription}


The period provided under Section 1095 shall also include the period during which the possessor or, where applicable, his legal predecessor had the thing in continuous possession before the effective date of this Act; however, the period ends no earlier than two years after the effective date of this Act with respect to a movable thing, and five years after that date with respect to an immovable thing.

$$
\text { Section } 3067 \text { [Recodification] }
$$

\section{Abandoning an immovable thing} this Act.

If an immovable thing has been abandoned, the period under Section 1050(2) commences on the effective date of

\section{Section 3068 [Recodification]}

If a pledge was created before the effective date of this Act, the owner may assert the right arising from the release of the pledge only with the consent of the pledgee who was registered in an order after the released pledge before the effective date of this Act. This also applies by analogy to a replacement of a pledge.

\section{Division 6}

\section{Law of succession}

Section 3069

In the case of succession, the law valid on the date of the decedent's death applies.

$$
\text { Section } 3070 \text { [Recodification] }
$$

If a decedent died after the effective date of this Act and his disposition mortis causa is contrary to legal regulations effective at the time it was made, it is considered valid if it is in accordance with this Act. The same applies to the testamentary clause on legacy as well as to clauses of lesser importance in the disposition mortis causa if the legal regulations effective at the time the testamentary clause on legacy or disposition mortis causa was made remove their legal consequences or declare them invalid.

\section{Section 3071 [Recodification]}

If the decedent concluded a contract to renounce the inheritance before the effective date of this Act, and if he died after the effective date of this Act, the contract is considered valid.

\section{Section 3072 [Recodification]}

If a decedent died after the effective date of this Act and his declaration of disinheritance is contrary to legal regulations effective at the time the declaration was made, it is considered valid if it is in accordance with this Act.

\section{Division 7}

\section{Rights arising from obligations}

\section{Section 3073 [Recodification]}

The rights arising from securing an obligation created before the effective date of this Act, even where they were created as rights in rem, shall, until their extinction, be assessed under current legal regulations. This does not prevent the parties from stipulating that their rights and duties will be governed by this Act from its effective date.

\section{Section 3074 [Recodification]}

(1) Leases are governed by this Act from its effective date, even where a lease was created before that date; however, the creation of a lease, as well as the rights and duties created before the effective date of this Act are assessed under current legal regulations. This does not apply to the lease of a movable thing or a usufructuary lease.

(2) The provision of Section 2249(1) does not apply where the rent was not determined by a stipulation between the lessor and the lessee or by a court decision, but on the basis of another legal regulation. In that case, the lessor has the right to propose a rent increase to the lessee in writing; Section 2249(3) applies by analogy.

\section{Section 3075}

If, before the effective date of this Act, a special purpose apartment was created and the state fully funded or contributed to its creation, a contract for the lease of such an apartment may only be concluded on the recommendation of the municipal authority of a municipality with extended competence, and the lease may be terminated only with the prior consent of this authority.

\section{Section 3076 [Recodification]}

If, before the effective date of this Act, proceedings were initiated to declare the termination of lease of an apartment invalid, they are to be completed under current legal regulations; the lessee's right to replacement housing or other benefits 
under current legal regulations remain unaffected.

\section{Section 3077 [Recodification]}

(1) Accounts are governed by this Act from its effective date, even where the account contract was concluded before that date; however, the creation of such a contract, as well as the rights and duties which arose thereunder before the effective date of this Act are to be assessed under current legal regulations.

(2) If, before the effective date of this Act, the payment from a savings book was contingent on providing a password, on the permission of a third person or on a fact which is certain to occur, the conditional nature of the payment is governed by current legal regulations.

Section 3078 [Recodification]

If a travel contract concluded before the effective date of this Act is invalid under current legal regulations, but it is in accordance with this Act, it is considered a valid package tour contract with respect to the rights asserted after the effective date of this Act; Section 2542 shall also apply to obligations arising from travel contracts concluded under current legal regulations where the decision on a right being asserted is yet to be made. Where the organiser's or travel agent's duty has been breached, even before the effective date of this Act, Section 2543 applies if no decision on compensation for damage was made before the effective date of this Act.

\section{Section 3079 [Recodification]}

(1) The right to compensation for damage caused by a breach of a statutory duty which occurred before the effective date of this Act are to be assessed under current legal regulations.

(2) If, by the effective date of this Act, a court is yet to decide on the compensation for damage caused by a breach of a duty provided by legal regulations where such a breach occurred before the effective date of this Act, and if there are extraordinary reasons deserving special consideration (Section 2(3)), a court may, on the application of the victim, also grant the victim compensation for non-pecuniary harm under this Act.

\section{Chapter 2}

\section{Final Provisions}

Section 3080

The following is hereby repealed:

1. Act No. $40 / 1964$ Sb., the Civil Code.

2. Act No. 131/1982 Sb., amending and supplementing the Civil Code and regulating certain other property relations.

3. Act No. 188/1988 Sb., amending and supplementing the Labour Code.

4. Act No. $\underline{87 / 1990 \mathrm{Sb}}$, amending and supplementing the Civil Code.

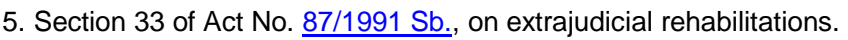

6. Act No. 509/1991 Sb., amending, supplementing and adapting the Civil Code.

7. Article I and IV of Act No. 264/1992 Sb., amending and supplementing the Civil Code, repealing the State Notary's Office Act, and on proceedings before the State Notary's Office (the Rules of Notarial Procedure), and amending and supplementing certain other acts.

8. Act No. 267/1994 Sb., amending and supplementing the Civil Code.

9. Article II of Act No. 104/1995 Sb., amending and supplementing Act No. 634/1992 Sb., on consumer protection, as amended by Act No. 217/1993 Sb. and Act No. 40/1995 Sb., and amending Act No. 40/1964 Sb., the Civil Code, as amended.

10. Article XXIV of Act No. 118/1995 Sb., amending and supplementing certain acts in connection with the adoption of the State Social Support Act.

11. Article II of Act No. 89/1996 Sb., amending and supplementing Act of the Czech National Council No. 344/1992 Sb., on the Land Registry of the Czech Republic (the Land Registry Act) and the Civil Code No. 40/1964 Sb., as amended.

12. Article IV of Act No. 94/1996 Sb., amending and supplementing Act No. 328/1991 Sb., on bankruptcy and settlement, as amended, Act No. 455/1991 Sb., on licensed trades (the Licensed Trades Act), as amended, Act No. 513/1991 Sb., the Commercial Code, as amended, and Act No. 40/1964 Sb., the Civil Code, as amended.

13. Part Two of Act No. $227 / 1997 \mathrm{Sb}$., on foundations and endowment funds and amending and supplementing certain related acts (the Foundations and Endowment Funds Act).

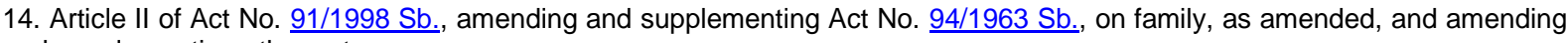
and supplementing other acts. 
15. Article III of Act No. 165/1998 Sb., amending Act No. 21/1992 Sb., on banks, as amended, and certain other acts.

16. Section 12, including the title of Act No. 159/1999 Sb., on certain business conditions and discharge of certain activities in the field of tourism, and amending Act No. 40/1964 Sb., the Civil Code, as amended, and Act No. 455/1991 Sb., on licensed trades (the Licensed Trades Act), as amended.

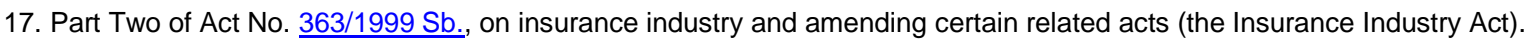

18. Part Six of Act No. $27 / 2000$ Sb., amending certain acts in connection with the adoption of the Public Auctions Act.

19. Part Five of Act No. $103 / 2000$ Sb., amending Act No. $72 / 1994$ Sb., adapting certain co-ownership relations to buildings and certain ownership relations to apartments and non-residential premises and supplementing certain acts (the Apartment Ownership Act), as amended, Act No. 344/1992 Sb., on Land Registry of the Czech Republic (the Land Registry Act), as amended by Act No. 89/1996 Sb., Act No. 586/1992 Sb., on income taxes, as amended, Act No. 549/1991 Sb., on judicial fees, as amended, Act No. 40/1964 Sb., the Civil Code, as amended, and Act No. 357/1992 Sb., on inheritance tax, donation tax and real estate transfer tax, as amended.

20. Part Two of Act No. $\underline{227 / 2000 ~ S b}$, , on electronic signature and amending certain other acts (the Electronic Signature Act).

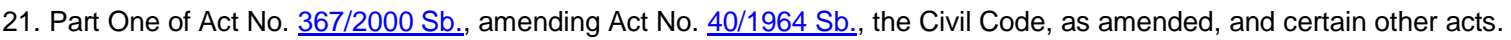

22. Article I of Act No. 317/2001 Sb., amending Act No. 40/1964 Sb., the Civil Code, as amended, and certain other acts.

23. Part Three of Act No. 125/2002 Sb., amending certain acts in connection with the adoption of the Payment Systems Act.

24. Act No. 135/2002 Sb., amending Act No. $40 / 1964$ Sb., the Civil Code, as amended.

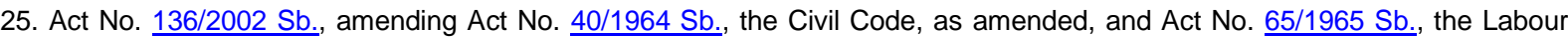
Code, as amended.

26. Part Thirty-Eight of Act No. $\underline{320 / 2002 ~ S b ., ~ a m e n d i n g ~ a n d ~ r e p e a l i n g ~ c e r t a i n ~ a c t s ~ i n ~ c o n n e c t i o n ~ w i t h ~ t h e ~ t e r m i n a t i o n ~ o f ~ t h e ~}$ district offices.

27. Part Two of Act No. $88 / 2003$ Sb., amending Act No. $513 / 1991$ Sb., the Commercial Code, as amended, Act No. $40 / 1964$ Sb., the Civil Code, as amended, Act No. 99/1963 Sb., the Code of Civil Procedure, as amended, Act No. 591/1992 Sb., on securities, as amended, Act No. 358/1992 Sb., on notaries and their activities (the Rules of Notarial Procedure), as amended, Act No. 370/2000 Sb., amending Act No. 513/1991 Sb., The Commercial Code, as amended, Act No. 358/1992 Sb., on notaries and their activities (the Rules of Notarial Procedure), as amended, Act No. 15/1998 Sb., on the Securities and Exchange Commission and amending and supplementing other acts, as amended by Act No. 30/2000 Sb., Act No. 200/1990 Sb., on infractions, as amended, Act No. 99/1963 Sb., the Code of Civil Procedure, as amended, and Act No. 328/1991 Sb., on bankruptcy and settlement, as amended, as amended by Act No. $501 / 2001 \mathrm{Sb}$. and the judgment of the Constitutional Court promulgated under No. 476/2002 Sb., Act No. 219/2000 Sb., on the property of the Czech Republic and its acts in legal relations, as amended, and Act No. 455/1991 Sb., on licensed trades (the Licensed Trade Act), as amended.

28. Part Two of Act No. 37/2004 Sb., on insurance policy and amending related acts (the Insurance Policy Act).

29. Part Four of Act No. 47/2004 Sb., amending Act No. 168/1999 Sb., on liability insurance for damage caused by the operation of vehicles and amending certain related acts (the Insurance of Vehicle Operation Liability Act), as amended, Act No.

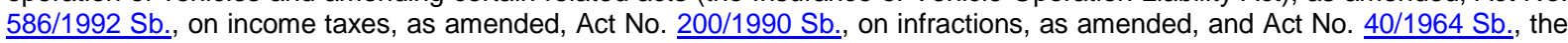
Civil Code, as amended.

30. Part Two of Act No. 480/2004 Sb., on certain information society services and amending certain acts (the Information Society Services Act).

31. Part One of Act No. 554/2004 Sb., amending Act No. 40/1964 Sb., the Civil Code, as amended, Act No. $99 / 1963$ Sb., the Code of Civil Procedure, as amended, Act No. 358/1992 Sb., on notaries and their activities (the Rules of Notarial Procedure), as amended, Act No. 513/1991 Sb., the Commercial Code, as amended, and Act No. 337/1992 Sb., on the administration of taxes and fees, as amended.

32. Part One of Act No. 359/2005 Sb., amending Act No. 40/1964 Sb., the Civil Code, as amended, and certain related acts.

33. Part Four of Act No. 56/2006 Sb., amending Act No. 256/2004 Sb., on business activities on the capital market, as amended, and other related acts.

34. Part Thirty-Three Act No. $\underline{57 / 2006 ~ S b}$, amending certain acts in connection with the integration of financial market supervision.

35. Part Two of Act No. 107/2006 Sb., on unilateral increases in residential rent and amending Act No. 40/1964 Sb., the Civil Code, as amended.

36. Part Six of Act No. 115/2006 Sb., on registered partnership and amending certain related acts.

37. Part Three of Act No. 160/2006 Sb., amending Act No. $82 / 1998$ Sb., on liability for damage caused in the exercise of public authority by decision making or incorrect official procedure and amending Act of the Czech National Council No. 358/1992 Sb., on notaries and their activities (the Rules of Notarial Procedure), as amended, Act No. 201/2002 Sb., the Office of the 
Government Representation in Property Affairs, as amended, and Act No. 40/1964 Sb., the Civil Code, as amended.

38. Part Forty-Three of Act No. 264/2006 Sb., amending certain acts in connection with the adoption of the Labour Code.

39. Part Two of Act No. $\underline{315 / 2006 ~ S b}$., amending Act No. $\underline{26 / 2000 ~ S b}$., on public auctions, as amended, and certain other acts.

40. Part Three of Act No. 443/2006 Sb., amending Act No. 178/2005 Sb., on the abolition of the National Property Fund of the Czech Republic and the competence of the Ministry of Finance in the privatisation of the property of the Czech Republic (the National Property Fund Abolition Act), and Act No. 319/2001 Sb., amending Act No. 21/1992 Sb., on banks, as amended.

41. Part Six of Act No. 296/2007 Sb., amending Act No. 182/2006 Sb., on bankruptcy and settlement (the Insolvency Act), as amended, and certain acts in connection with its adoption.

42. Part Ten of Act No. $230 / 2008$ Sb., amending Act No. $\underline{256 / 2004 ~ S b}$., on business activities on the capital market, as amended, and other related acts.

43. Part Three of Act No. $\underline{306 / 2008 ~ S b}$., amending Act No. 155/1995 Sb., on pension insurance, as amended, Act No. $\underline{582 / 1991}$ $\underline{\mathrm{Sb}}$, on the organisation and implementation of social security, as amended, and certain other acts.

44. Part Six of Act No. $\underline{384 / 2008 ~ S b}$., amending act No. $\underline{155 / 1998 ~ S b}$, on sign language and amending other acts, and other related acts.

45. Part Six of Act No. 215/2009 Sb., amending Act No. 513/1991 Sb., the Commercial Code, as amended, Act No. $\underline{627 / 2004}$ $\underline{\mathrm{Sb}}$., on a European company, as amended, Act No. 21/1992 Sb., on Banks, as amended by Act No. 126/2002 Sb., Act No.

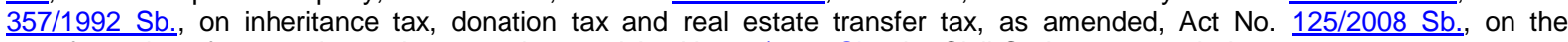
transformation of companies and cooperatives and Act No. 40/1964 Sb., the Civil Code, as amended.

46. Part Three of Act No. 227/2009 Sb., amending certain acts in connection with the adoption of the Basic Registries Act.

47. Part Five of Act No. 285/2009 Sb., amending certain acts in connection with the adoption of the Payment Systems Act.

48. Part Two of Act No. $155 / 2010$ Sb., amending certain acts to improve their application and to reduce the administrative burden on businesses.

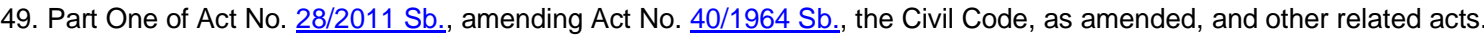

50. Act No. 132/2011 Sb., amending Act No. 40/1964 Sb., the Civil Code, as amended, and Act No. 102/1992 Sb., adapting certain issues related to the issuance of Act No. 509/1991 Sb., amending, supplementing and adapting the Civil Code, as amended.

51. Part Eleven of Act No. 139/2011 Sb., amending Act No. 284/2009 Sb., on payment systems, as amended by Act No. $156 / 2010 \mathrm{Sb}$., and certain other acts.

52. Act No. 116/1990 Sb., on lease and sublease of non-residential premises.

53. Part Five, in terms of Section 24(3) of Act No. $403 / 1990$ Sb., on mitigating the consequences of certain property injustices.

54. Act No. 529/1990 Sb., amending and supplementing Act No. 116/1990 Sb., on lease and sublease of non-residential premises, as amended by Act No. $\underline{403 / 1990 ~ S b}$., on mitigating the consequences of certain property injustices.

55. Section 26(1) of Act No. 229/1991 Sb., on the regulation of the ownership relationships to land and other agricultural property.

56. Act No. 540/1991 Sb., amending and supplementing Act No. 116/1990 Sb., on lease and sublease of non-residential premises, as amended by Act No. $403 / 1990 \mathrm{Sb}$., and Act No. 529/1990 Sb.

57. Act No. 302/1999 Sb., amending Act No. 116/1990 Sb., on lease and sublease of non-residential premises, as amended.

58. Act No. 522/2002 Sb., amending Act No. 116/1990 Sb., on lease and sublease of non-residential premises, as amended, and repealing Act 124/1990 Sb., on the competence of national committees in the implementation of certain provisions of Act on the Lease and Sublease of Non-residential Premises.

59. Act No. $\underline{360 / 2005 ~ S b}$, amending Act No. $116 / 1990$ Sb., on lease and sublease of non-residential premises, as amended.

60. Act No. 72/1994 Sb., adapting certain co-ownership relations to structures and some ownership relations to apartments and non-residential premises, and supplementing certain acts (the Apartment Ownership Act).

61. Act No. $97 / 1999$ Sb., amending Act No. $72 / 1994$ Sb., adapting certain co-ownership relations to structures and certain ownership relations to apartments and non-residential premises, and supplementing certain acts (the Apartment Ownership Act), as amended.

62. Part One of Act No. 103/2000 Sb., amending Act No. 72/1994 Sb., adapting some co-ownership relations to buildings and some ownership relations to apartments and non-residential premises and supplementing certain acts (the Apartment Ownership Act), as amended, Act No. 344/1992 Sb., on Land Registry of the Czech Republic (the Land Registry Act), as amended by Act No. 89/1996 Sb., Act No. 586/1992 Sb., on income taxes, as amended, Act No. 549/1991 Sb., on judicial fees, as amended, Act No. $\underline{40 / 1964 \mathrm{Sb}}$, the Civil Code, as amended, and Act No. 357/1992 Sb., on inheritance tax, donation tax and 
real estate transfer tax, as amended.

63. Part Three of Act No. 229/2001 Sb., amending Act No. 219/2000 Sb., on the property of the Czech Republic and its acts in legal relations, as amended by Act No. $492 / 2000$ Sb., and certain other acts.

64. Part One of Act No. 451/2001 Sb., amending Act No. 72/1994 Sb., adapting certain co-ownership relations to structures and certain ownership relations to apartments and non-residential premises, and supplementing certain acts (the Apartment Ownership Act), as amended, and certain other acts.

65. Part Seventy-One of Act No. $320 / 2002 \mathrm{Sb}$., amending and repealing certain acts in connection with the termination of the district offices.

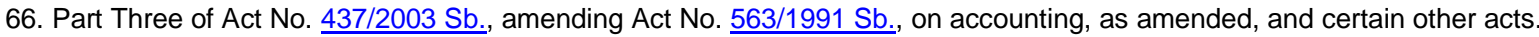

67. Act No. 171/2005 Sb., amending Act No. 72/1994 Sb., adapting certain co-ownership relations to structures and certain ownership relations to apartments and non-residential premises, and supplementing certain acts (the Apartment Ownership Act), as amended.

68. Part Thirty of Act No. 179/2005 Sb., amending certain acts in connection with the adoption of the act on the abolition of the National Property Fund of the Czech Republic.

69. Part Thirty-Four of Act No. 296/2007 Sb., amending Act No. 182/2006 Sb., on bankruptcy and settlement (the Insolvency Act), as amended, and certain acts in connection with its adoption.

70. Part Fifty-One of Act No. 227/2009 Sb., amending certain acts in connection with the adoption of the Basic Registries Act.

71. Part One of Act No. 345/2009 Sb., amending Act No. 72/1994 Sb., adapting certain co-ownership relations to structures and certain ownership relations to apartments and non-residential premises, and supplementing certain acts (the Apartment Ownership Act), as amended, and Act No. 183/2006 Sb., on spatial planning and the construction procedure (the Construction Code), as amended.

72. Act No. $\underline{513 / 1991 ~ S b}$, the Commercial Code.

73. Article VII of Act No. 264/1992 Sb., amending and supplementing the Civil Code, repealing the State Notary's Office Act, and on proceedings before the State Notary's Office (the Rules of Notarial Procedure), and amending and supplementing certain other acts.

74. Article III of Act No. 286/1993 Sb., amending and supplementing Act No. 63/1991 Sb., on protection of competition, as amended by Act No. 495/1992 Sb., and Act No. 513/1991 Sb., the Commercial Code, as amended by Act No. 264/1992 Sb., Act No. 591/1992 Sb. and Act No. 600/1992 Sb.

75. Article II of Act No. 156/1994 Sb., amending and supplementing Act No. 21/1992 Sb., on banks, as amended, supplementing Act No. 513/1991 Sb., the Commercial Code, as amended, and Act No. 328/1991 Sb., on bankruptcy and settlement, as amended.

76. Article II of Act No. 84/1995 Sb., amending and supplementing Act No. 530/1990 Sb., on bonds, as amended, Act No. 513/1991 Sb., the Commercial Code, as amended, Act No. 328/1991 Sb., on bankruptcy and settlement, as amended, Act No. 99/1963 Sb., the Code of Civil Procedure, as amended, and Act No. 21/1992 Sb., on banks, as amended.

77. Article IV of Act No. 94/1996 Sb., amending and supplementing Act No. 328/1991 Sb., on bankruptcy and settlement, as amended, Act No. 455/1991 Sb., on licensed trades (the Licensed Trades Act), as amended, Act No. 513/1991 Sb., the Commercial Code, as amended, and Act No. 40/1964 Sb., the Civil Code, as amended.

78. Article I of Act No. 142/1996 Sb., amending and supplementing Act No. 513/1991 Sb., the Commercial Code, as amended, and amending Act No. 99/1963 Sb., the Code of Civil Procedure, as amended.

79. Part Six of Act No. 15/1998 Sb., on supervision in the area of the capital market and amending and supplementing other acts.

80. Article II of Act No. 165/1998 Sb., amending Act No. 21/1992 Sb., on banks, as amended, and certain other acts.

81. Part Five of Act No. 356/1999 Sb., amending Act No. 455/1991 Sb., on licensed trades (the Licensed Trades Act), as amended, and certain other acts.

82. Part Seven of Act No. $27 / 2000$ Sb., amending certain acts in connection with the adoption of the Public Auctions Act.

83. Part Twelve of Act No. 29/2000 Sb., on postal services and amending certain acts (the Postal Services Act).

84. Part Three of Act No. $30 / 2000$ Sb., amending Act No. 99/1963 Sb., the Code of Civil Procedure, as amended, and certain other acts.

85. Part Five of Act No. 105/2000 Sb., amending Act No. 328/1991 Sb., on bankruptcy and settlement, as amended, and certain other acts.

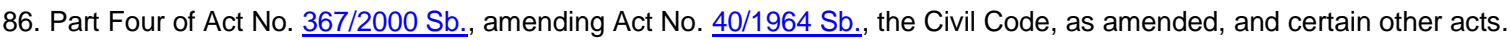


87. Part One of Act No. 370/2000 Sb., amending Act No. 513/1991 Sb., the Commercial Code, as amended, Act No. 358/1992 $\underline{\mathrm{Sb}}$., on notaries and their activities (the Rules of Notarial Procedure), as amended, Act No. 15/1998 Sb., on the Securities Commission and amending and supplementing other acts, as amended by Act No. 30/2000 Sb., Act No. 200/1990 Sb., on infractions, as amended, Act No. 99/1963 Sb., the Code of Civil Procedure, as amended, and Act No. $\underline{328 / 1991 ~ S b}$., on bankruptcy and settlement, as amended.

88. Part Two of Act No. 120/2001 Sb., on private enforcement officers and private enforcement activities (the Rules of Private Enforcement Procedure) and amending other acts.

89. Part Five of Act No. $\underline{353 / 2001 ~ S b}$, amending Act No. $\underline{563 / 1991 ~ S b}$., on accounting, as amended, and certain other acts.

90. Part Five of Act No. 15/2002 Sb., amending Act No. 238/1992 Sb., on some measures related to the protection of public interest and incompatibility of certain offices (the Conflict of Interest Act), as amended, and certain other acts.

91. Part Two of Act No. 125/2002 Sb., amending certain acts in connection with the adoption of the Payment Systems Act.

92. Part Five of Act No. 126/2002 Sb., amending Act No. 21/1992 Sb., on banks, as amended, Act No. 219/1995 Sb., the Foreign Exchange Act, as amended, Act No. 593/1992 Sb., on provisions for determining the tax base, as amended, Act No. 239/2001 Sb., on the Czech Consolidation Agency and amending certain acts (the Czech Consolidation Agency Act), as amended by Act No. 15/2002 Sb., Act No. 513/1991 Sb., the Commercial Code, as amended, and Act No. 363/1999 Sb., on insurance and amending certain related acts (the Insurance Industry Act), as amended.

93. Part Twenty-Two of Act No. 151/2002 Sb., amending certain acts in connection with the adoption of the Code of Administrative Justice.

94. Part Seven of Act No. 308/2002 Sb., amending Act No. 15/1998 Sb., on the Securities and Exchange Commission and amending and supplementing other acts, as amended, and certain other acts.

95. Part Thirty-Seven of Act No. 309/2002 Sb., amending acts related to the adoption of the act on civil service of employees in administrative agencies and on remunerating such employees and other employees in administrative agencies (Civil Service Act).

96. Part Three of Act No. 312/2002 Sb., on the officials of territorial self-governing units and amending certain acts.

97. Part One of Act No. $\underline{88 / 2003 ~ S b .}$, amending Act No. $\underline{513 / 1991 ~ S b ., ~ t h e ~ C o m m e r c i a l ~ C o d e, ~ a s ~ a m e n d e d, ~ A c t ~ N o . ~} \underline{40 / 1964}$ Sb., the Civil Code, as amended, Act No. 99/1963 Sb., the Code of Civil Procedure, as amended, Act No. 591/1992 Sb., on securities, as amended, Act No. 358/1992 Sb., on notaries and their activities (the Rules of Notarial Procedure), as amended, Act No. 370/2000 Sb., amending Act No. 513/1991 Sb., The Commercial Code, as amended, Act No. 358/1992 Sb., on notaries and their activities (the Rules of Notarial Procedure), as amended, Act No. 15/1998 Sb., on the Securities and Exchange Commission and amending and supplementing other acts, as amended by Act No. 30/2000 Sb., Act No. 200/1990 Sb., on infractions, as amended, Act No. 99/1963 Sb., the Code of Civil Procedure, as amended, and Act No. 328/1991 Sb., on bankruptcy and settlement, as amended, as amended by Act No. $501 / 2001 \mathrm{Sb}$. and the judgment of the Constitutional Court promulgated under No. 476/2002 Sb., Act No. 219/2000 Sb., on the property of the Czech Republic and its acts in legal relations, as amended, and Act No. 455/1991 Sb., on licensed trades (the Licensed Trade Act), as amended.

98. Part Two of Act No. 437/2003 Sb., amending Act No. 563/1991 Sb., on accounting, as amended, and certain other acts.

99. Part Three of Act No. 85/2004 Sb., amending Act No. 252/1997 Sb., on agriculture, as amended, and certain other acts.

100. Part Two of Act No. $257 / 2004$ Sb., amending certain acts in connection with the adoption of the act on business activities on the capital market, act on collective investment and act on bonds.

101. Part Two of Act No. 360/2004 Sb., on the European Economic Interest Grouping (EEIG) and amending Act No. 513/1991 Sb., the Commercial Code, as amended, and Act No. 586/1992 Sb., on income taxes, as amended (the European Economic Interest Grouping Act).

102. Part Two of Act No. $484 / 2004$ Sb., amending Act No. $143 / 2001$ Sb., on the protection of competition and amending certain acts (Protection of Competition Act), as amended by Act No. 340/2004 Sb., Act No. 513/1991 Sb., the Commercial Code, as amended, and Act No. $\underline{526 / 1990 ~ S b}$, on prices, as amended.

103. Part Five of Act No. 499/2004 Sb., on archives and the filing service and amending certain acts.

104. Part Four of Act No. 554/2004 Sb., amending Act No. 40/1964 Sb., the Civil Code, as amended, Act No. $99 / 1963$ Sb., the Code of Civil Procedure, as amended, Act No. 358/1992 Sb., on notaries and their activities (the Rules of Notarial Procedure), as amended, Act No. 513/1991 Sb., the Commercial Code, as amended, and Act No. 337/1992 Sb., on the administration of taxes and fees, as amended.

105. Part Five of Act No. 179/2005 Sb., amending certain acts in connection with the adoption of the act on the abolition of the National Property Fund of the Czech Republic.

106. Part One of Act No. $216 / 2005$ Sb., amending Act No. 513/1991 Sb., the Civil Code, as amended, Act No. $99 / 1963$ Sb., the Code of Civil Procedure, as amended, Act No. 189/1994 Sb., on judicial officers, as amended, and Act No. $358 / 1992$ Sb., on notaries and their activities (the Rules of Notarial Procedure, as amended.

107. Part Nine of Act No. $\underline{377 / 2005 ~ S b .}$, on the supplementary supervision of banks, savings and loan cooperatives, insurance companies and securities traders in financial conglomerates, and amending certain other acts (the Financial Conglomerates 
Act).

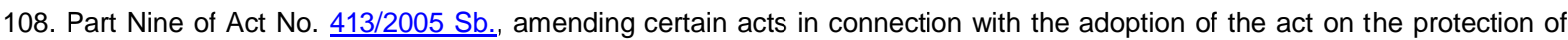
classified information and on security eligibility.

109. Part Twelve of Act No. 56/2006 Sb., amending Act No. 256/2004 Sb., on business activities on the capital market, as amended, and other related acts.

110. Part Twenty-Three Act No. $\underline{57 / 2006 ~ S b ., ~ a m e n d i n g ~ c e r t a i n ~ a c t s ~ i n ~ c o n n e c t i o n ~ w i t h ~ t h e ~ i n t e g r a t i o n ~ o f ~ f i n a n c i a l ~ m a r k e t ~}$ supervision.

111. Part Eleven of Act No. $\underline{79 / 2006 ~ S b}$., amending Act No. $\underline{85 / 1996 \mathrm{Sb}}$., on the legal profession, as amended, and other related acts.

112. Part seven of Act No. $\underline{81 / 2006 ~ S b}$., amending Act No. $\underline{365 / 2000 ~ S b}$, on information systems in public administration and amending certain acts, as amended, and other related acts.

113. Part One of Act No. $308 / 2006$ Sb., amending certain acts in connection with the adoption of the European Cooperative Society Act.

114. Part Three of Act No. $269 / 2007$ Sb., amending Act No. $\underline{365 / 2000 ~ S b}$., on information systems in public administration and amending certain acts, as amended, and other related acts.

115. Part Twelve of Act No. 296/2007 Sb., amending Act No. 182/2006 Sb., on bankruptcy and settlement (the Insolvency Act), as amended, and certain acts in connection with its adoption.

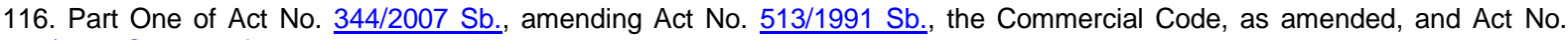
200/1990 Sb., on infractions, as amended.

117. Part Three of Act No. 36/2008 Sb., amending Act No. 634/1992 Sb., on consumer protection, as amended, Act No. $40 / 1995 \mathrm{Sb}$., on the regulation of advertising and amending and supplementing Act No. 468/1991 Sb., on the operation of radio and television broadcasting, as amended, as amended, and Act No. 513/1991 Sb., the Commercial Code, as amended.

118. Part Two of Act No. 104/2008 Sb., on takeover bids and amending some other acts (the Takeover Bid Act).

119. Part Two of Act No. 126/2008 Sb., amending certain acts in connection with the adoption of the act on the transformation of companies and cooperatives.

120. Part Eight of Act No. $130 / 2008$ Sb., amending Act No. $\underline{455 / 1991 ~ S b}$., on licensed trades (the Licensed Trades Act), as amended, and other related acts.

121. Part Five of Act No. $\underline{230 / 2008 ~ S b}$, amending Act No. $\underline{256 / 2004 ~ S b}$., on business activities on the capital market, as amended, and other related acts.

122. Part One of Act No. $\underline{215 / 2009 ~ S b}$, amending Act No. $\underline{513 / 1991 ~ S b}$., the Commercial Code, as amended, Act No. $\underline{627 / 2004}$ Sb., on a European company, as amended, Act No. 21/1992 Sb., on Banks, as amended by Act No. 126/2002 Sb., Act No. 357/1992 Sb., on inheritance tax, donation tax and real estate transfer tax, as amended. Act No. 125/2008 Sb., on the transformation of companies and cooperatives and Act No. 40/1964 Sb., the Civil Code, as amended.

123. Part Three of Act No. 217/2009 Sb., amending Act No. 182/2006 Sb., on bankruptcy and settlement (the Insolvency Act), as amended, and other related acts.

124. Part Twenty-Two of Act No. $227 / 2009$ Sb., amending certain acts in connection with the adoption of the Basic Registries Act.

125. Part Seven of Act No. 230/2009 Sb., amending Act No. 256/2004 Sb., on business activities on the capital market, as amended, and other related acts.

126. Part Six of Act No. 285/2009 Sb., amending certain acts in connection with the adoption of the Payment Systems Act.

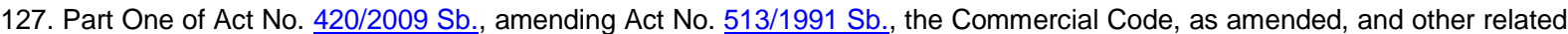
acts.

128. Act No. 152/2010 Sb., amending Act No. 513/1991 Sb., the Commercial Code, as amended.

129. Part Three of Act No. $409 / 2010$ Sb., amending certain acts in connection with the adoption of the act on financial security.

130. Part Thirteen of Act No. 427/2010 Sb., amending Act No. 326/1999 Sb., on the residence of foreigners in the Czech Republic and amending certain acts, as amended, Act No. 325/1999 Sb., on asylum and amending Act No. 283/1991 Sb., on the Police of the Czech Republic, as amended (the Asylum Act), as amended, and other related acts.

131. Part Five of Act No. 188/2011 Sb., amending Act No. 189/2004 Sb., on collective investment, as amended, and other related acts.

132. Act No. $\underline{94 / 1963 \mathrm{Sb}}$, on family. 
133. Act No. $132 / 1982 \mathrm{Sb}$. , amending and supplementing the act on family.

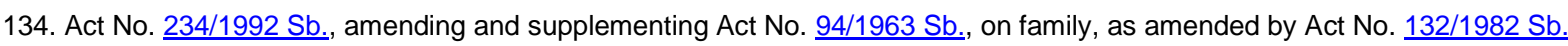

135. Article I of Act No. 91/1998 Sb., amending and supplementing Act No. 94/1963 Sb., on family, as amended, and amending and supplementing other acts.

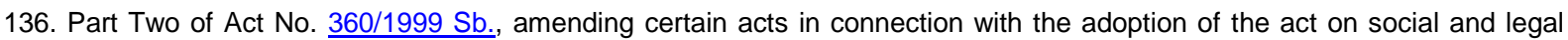
protection of children.

137. Part Two of Act No. $301 / 2000$ Sb., on the registries of births, deaths and marriages, name and surname and amending certain related acts.

138. Part Two of Act No. 109/2002 Sb., on the exercise of institutional and protective upbringing in school facilities and on preventive and upbringing care in school facilities, and amending other acts.

139. Part Forty-Three of Act No. $\underline{320 / 2002 ~ S b}$, amending and repealing certain acts in connection with the termination of the district offices.

140. Act No. $\underline{321 / 2002 ~ S b}$, amending Act No. $\underline{94 / 1963 ~ S b}$., on family, as amended.

141. Part Two of Act No. 315/2004 Sb., amending Act No. 117/1995 Sb., on state social support, as amended, Act No. $\underline{94 / 1963}$ Sb., on family, as amended, and Act No. $359 / 1999 \mathrm{Sb}$. , on the social and legal protection of children, as amended.

142. Part Three of Act No. $383 / 2005$ Sb., amending Act No. $109 / 2002$ Sb., on the exercise of institutional and protective upbringing in school facilities and on preventive and upbringing care in school facilities, and amending other acts, as amended, and other related acts.

143. Part Two of Act No. 112/2006 Sb., amending certain acts in connection with the adoption of the act on minimum living and subsistence level and the act on the assistance in material need.

144. Part Four of Act No. $115 / 2006$ Sb., on registered partnership and amending certain related acts.

145. Part Two of Act No. 134/2006 Sb., amending Act No. 359/1999 Sb., on social and legal protection of children, as amended, Act No. 94/1963 Sb., on family, as amended, Act No. 99/1963 Sb., the Code of Civil Procedure, as amended, Act No. $117 / 1995$ $\underline{\mathrm{Sb}}$., on state social support, as amended, and Act No. 200/1990 Sb., on infractions, as amended.

146. Part Seven of Act No. $227 / 2006$ Sb., on research on human embryonic stem cells and related activities and amending certain related acts.

147. Part Forty-Three of Act No. $342 / 2006$ Sb., amending certain acts related to civil registration, and certain other acts.

148. Part Two of Act No. 259/2008 Sb., amending Act No. 99/1963 Sb., the Code of Civil Procedure, as amended, and certain other acts.

149. Act No. $\underline{42 / 1980 ~ S b}$., on economic relations with foreign countries.

150. Act No. 102/1988 Sb., amending and supplementing Act No. $\underline{42 / 1980 ~ S b}$. , on economic relations with foreign countries.

151. Act No. 113/1990 Sb., amending and supplementing Act No. $42 / 1980 \mathrm{Sb}$. , on economic relations with foreign countries, as amended by Act No. 102/1988 Sb.

152. Part Three, in terms of Section 5, of Act No. 223/1994 Sb., on the merger of the Czechoslovak Chamber of Commerce and Industry with the Chamber of Commerce of the Czech Republic, on some related measures and amending and supplementing Act of the Czech National Council No. 301/1992 Sb., on the Chamber of Commerce of the Czech Republic and Agrarian Chamber of the Czech Republic, as amended by Act No. 121/1993 Sb.

153. Part Six of Act No. $227 / 2009$ Sb., amending certain acts in connection with the adoption of the Basic Registries Act.

154. Act No. $83 / 1990 \mathrm{Sb}$. , on the association of citizens.

155. Act No. $\underline{300 / 1990 ~ S b}$, amending and supplementing Act No. $\underline{83 / 1990 ~ S b}$. , on the association of citizens.

156. Article I of Act No. 68/1993 Sb., amending and supplementing certain acts in the field of general internal administration.

157. Part Eight of Act No. 151/2002 Sb., amending certain acts in connection with the adoption of the Code of Administrative Justice.

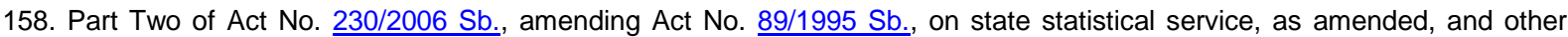
related acts.

159. Part Thirty-Five of Act No. $\underline{342 / 2006 ~ S b}$., amending certain acts related to civil registration, and certain other acts.

160. Act No. $\underline{33 / 2008 \mathrm{Sb}}$, amending Act No. $\underline{83 / 1990 \mathrm{Sb}}$, on the association of citizens, as amended.

161. Part Twelve of Act No. $\underline{227 / 2009 ~ S b}$., amending certain acts in connection with the adoption of the Basic Registries Act. 
162. Part Six of Act No. 424/2010 Sb., amending Act No. 111/2009 Sb., on basic registries, as amended by Act No. $\underline{100 / 2010}$ $\underline{\mathrm{Sb}}$, and other related acts.

163. Act No. 248/1995 Sb., on benevolent associations and amending and supplementing certain acts.

164. Act No. 208/2002 Sb., amending Act No. 248/1995 Sb., on benevolent associations and amending and supplementing certain acts.

165. Part Sixteen of Act No. $\underline{320 / 2002 ~ S b}$., amending and repealing certain acts in connection with the termination of the district offices.

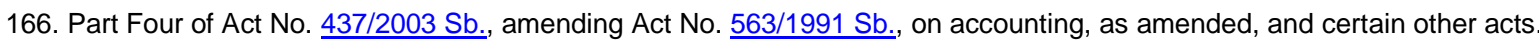

167. Part Forty-Four of Act No. 296/2007 Sb., amending Act No. 182/2006 Sb., on bankruptcy and settlement (the Insolvency Act), as amended, and certain acts in connection with its adoption.

168. Part Eleven of Act No. 126/2008 Sb., amending certain acts in connection with the adoption of the act on the transformation of companies and cooperatives.

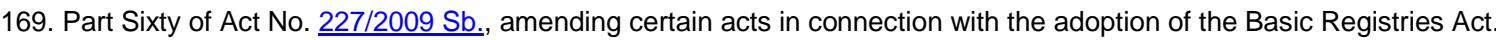

170. Act No. 231/2010 Sb., amending Act No. 248/1995 Sb., on benevolent associations and amending and supplementing certain acts, as amended.

171. Act No. $\underline{59 / 1998 \mathrm{Sb}}$, on product liability.

172. Act No. 209/2000 Sb., amending Act No. $\underline{59 / 1998 ~ S b}$., on product liability.

173. Part One and Sections 35 and 36 of Part Nine of Act No. 227/1997 Sb., on foundations and endowment funds and amending and supplementing certain related acts (the Foundations and Endowment Funds Act).

174. Part One of Act No. 210/2002 Sb., amending Act No. 227/1997 Sb., on foundations and endowment funds and amending certain related acts (the Foundations and Endowment Funds Act), and Act No. 586/1992 Sb., on income taxes, as amended.

175. Part Sixteen of Act No. 257/2004 Sb., amending certain acts in connection with the adoption of the act on business activities on the capital market, act on collective investment and act on bonds.

176. Part Fifty-Two of Act No. 296/2007 Sb., amending Act No. 182/2006 Sb., on bankruptcy and settlement (the Insolvency Act), as amended, and certain acts in connection with its adoption.

177. Part Twenty of Act No. $126 / 2008$ Sb., amending certain acts in connection with the adoption of the act on the transformation of companies and cooperatives.

178. Part Seventy-One of Act No. 227/2009 Sb., amending certain acts in connection with the adoption of the Basic Registries Act.

179. Act No. 158/2010 Sb., amending Act No. 227/1997 Sb., on foundations and endowment funds and amending certain related acts (the Foundations and Endowment Funds Act), as amended.

180. Part Eight of Act No. 160/2010 Sb., amending certain acts in connection with the adoption of the regulation of the European Parliament and of the Council on credit rating agencies.

181. Part Thirteen of Act No. 188/2011 Sb., on collective investment, as amended, and other related acts.

182. Act No. $102 / 1992 \mathrm{Sb}$., adapting some of the issues related to the issuance of Act No. $509 / 1991 \mathrm{Sb}$., amending, supplementing and adapting the Civil Code.

183. Part Eight of Act No. $227 / 1997 \mathrm{Sb}$., on foundations and endowment funds and amending and supplementing certain related acts (the Foundations and Endowment Funds Act).

184. Act No. 126/1998 Sb., amending the Act of the Czech National Council No. 102/1992 Sb., adapting some of the issues related to the issuance of Act No. 509/1991 Sb., amending, supplementing and adapting the Civil Code, as amended by Act No. $227 / 1997 \mathrm{Sb}$.

185. Part Thirty-Nine of Act No. 320/2002 Sb., amending and repealing certain acts in connection with the termination of the district offices.

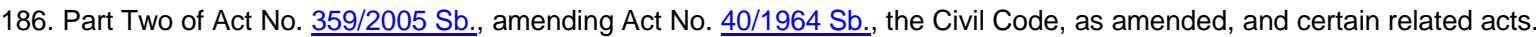

187. Act No. $\underline{591 / 1992 ~ S b ., ~ o n ~ s e c u r i t i e s . ~}$

188. Act No. $89 / 1993$ Sb., amending the Act No. $\underline{591 / 1992 ~ S b}$, of the Czech National Council, on securities.

189. Part Eight of Act No. $331 / 1993 \mathrm{Sb}$., on the state budget of the Czech Republic for the year 1994 and amending and supplementing certain acts. 
190. Article II and Article III, subparagraph 15 of Act No. 259/1994 Sb., amending and supplementing Act No. 586/1992 Sb., of the Czech National Council, on income taxes, as amended, and Act No. 591/1992 Sb., of the Czech National Council, on securities, as amended.

191. Act No. 152/1996 Sb., amending and supplementing Act No. 591/1992 Sb., of the Czech National Council, on securities, as amended, and Act No. 214/1992 Sb., on the stock exchange, as amended.

192. Part Three of Act No. $15 / 1998$ Sb., on supervision in the area of the capital market and amending and supplementing other acts.

193. Article II of Act No. 70/2000 Sb., amending Act No. 229/1992 Sb., on commodity exchanges, as amended, Act No. 591/1992 Sb., on securities, as amended, and Act No. 214/1992 Sb., on the stock exchange, as amended.

194. Part Two of Act No. $\underline{307 / 2000 ~ S b}$, on the agricultural warehouse sheets and public agricultural warehouses and amending certain related acts.

195. Part One of Act No. $\underline{362 / 2000 ~ S b}$., amending Act No. 591/1992 Sb., on securities, as amended, and certain other acts.

196. Part Two of Act No. 259/2001 Sb., on state bond program to cover the losses of the Prague Consolidation Bank, state financial institution, for the year 1999, and amending Act No. $\underline{591 / 1992 ~ S b .}$, on securities, as amended.

197. Part Two of Act No. 308/2002 Sb., amending Act No. 15/1998 Sb., on the Securities and Exchange Commission and amending and supplementing other acts, as amended, and certain other acts.

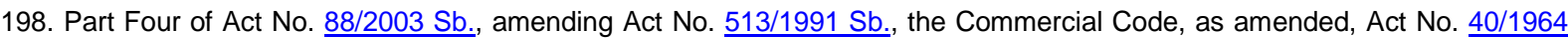

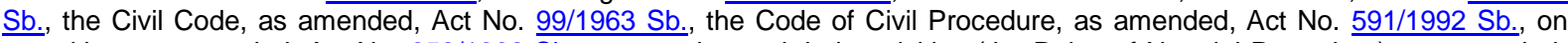
securities, as amended, Act No. 358/1992 Sb., on notaries and their activities (the Rules of Notarial Procedure), as amended, Act No. 370/2000 Sb., amending Act No. 513/1991 Sb., The Commercial Code, as amended, Act No. 358/1992 Sb., on notaries and their activities (the Rules of Notarial Procedure), as amended, Act No. 15/1998 Sb., on the Securities and Exchange Commission and amending and supplementing other acts, as amended by Act No. 30/2000 Sb., Act No. 200/1990 Sb., on infractions, as amended, Act No. 99/1963 Sb., the Code of Civil Procedure, as amended, and Act No. 328/1991 Sb., on bankruptcy and settlement, as amended, as amended by Act No. 501/2001 Sb. and the judgment of the Constitutional Court promulgated under No. 476/2002 Sb., Act No. 219/2000 Sb., on the property of the Czech Republic and its acts in legal relations, as amended, and Act No. $\underline{455 / 1991 \mathrm{Sb} .}$, on licensed trades (the Licensed Trade Act), as amended.

199. Part One of Act No. $257 / 2004$ Sb., amending certain acts in connection with the adoption of the act on business activities on the capital market, act on collective investment and act on bonds.

200. Part Eight of Act No. $\underline{56 / 2006 ~ S b}$, amending Act No. 256/2004 Sb., on business activities on the capital market, as amended, and other related acts.

201. Part Twenty-Seven of Act No. 296/2007 Sb., amending Act No. 182/2006 Sb., on bankruptcy and settlement (the Insolvency Act), as amended, and certain acts in connection with its adoption.

202. Part Six of Act No. 230/2008 Sb., amending Act No. 256/2004 Sb., on business activities on the capital market, as amended, and other related acts.

203. Part Forty of Act No. $\underline{227 / 2009 ~ S b}$., amending certain acts in connection with the adoption of the Basic Registries Act.

204. Part Five of Act No. $\underline{409 / 2010 ~ S b}$, amending certain acts in connection with the adoption of the act on financial security.

205. Part One of Act No. 37/2004 Sb., on insurance policy and amending related acts (the Insurance Policy Act).

206. Part Fourteen of Act No. $377 / 2005$ Sb., on the supplementary supervision of banks, savings and loan cooperatives, insurance companies and securities traders in financial conglomerates, and amending certain other acts (the Financial Conglomerates Act).

207. Part Eleven of Act No. $\underline{57 / 2006 ~ S b}$, amending certain acts in connection with the integration of financial market supervision.

208. Part Five of Act No. 198/2009 Sb., on equal treatment and legal remedies for protection against discrimination and amending certain acts (the Anti-Discrimination Act).

209. Part One Hundred And Forty-Two of Act No. 227/2009 Sb., amending certain acts in connection with the adoption of the Basic Registries Act.

210. Part One of Act No. $\underline{278 / 2009 ~ S b}$, amending certain acts in connection with the adoption of the Insurance Industry Act.

211. Government Decree No. 142/1994 Sb., determining the amount of default interest and late charges under the Civil Code.

212. Government Decree No. $163 / 2005$ Sb., amending Government Regulation No. 142/1994 Sb., determining the amount of default interest and late charges under the Civil Code.

213. Government Decree No. $33 / 2010$ Sb., amending Government Regulation No. 142/1994 Sb., determining the amount of default interest and late charges under the Civil Code, as amended by Government Regulation No. 163/2005 Sb. 
214. Government Decree No. 258/1995 Sb., implementing the Civil Code.

215. Government Decree No. 174/2009 Sb., amending Government Regulation No. 258/1995 Sb., implementing the Civil Code.

216. Government Decree No. 371/2004 Sb., issuing standard by-laws for associations of unit owners.

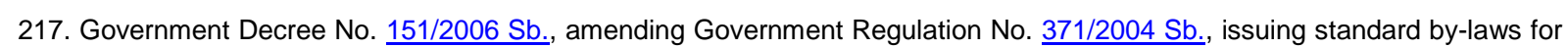
associations of unit owners.

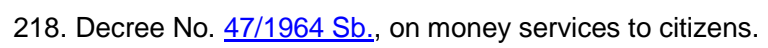

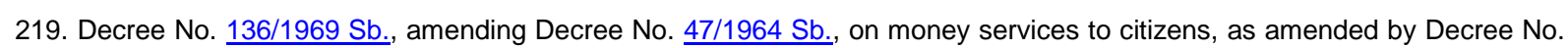
$\underline{45 / 1965 \mathrm{Sb} .}$

220. Decree No. 27/1982 Sb., amending and supplementing Decree No. $47 / 1964$ Sb., of the Ministry of Finance, on money services to citizens, as amended by Decree No. 136/1969 Sb., of the Federal Ministry of Finance.

221. Decree No. 146/1990 Sb., amending and supplementing Decree No. 47/1964 Sb., of the Ministry of Finance, on money services to citizens, as amended.

222. Decree No. $133 / 1964 \mathrm{Sb}$. , on the rules of road carriage.

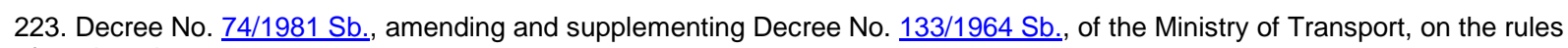
of road carriage.

224. Decree No. 106/1984 Sb., amending and supplementing Decree No. 133/1964 Sb., of the Ministry of Transport, on the rules of road carriage.

225. Decree No. 18/1965 Sb., on conditions for maintenance and repair of road motor vehicles owned by citizens and nonsocialist organisations.

226. Decree No. $17 / 1966 \mathrm{Sb}$., on the rules of air carriage.

227. Decree No. 15/1971 Sb., amending and supplementing Decree No. 17/1966 Sb., of the Ministry of Transport, on the rules of air carriage.

228 Decree No. $121 / 1980$ Sb. , on financial aid in the transfer of collective family houses from cooperative to private ownership.

229. Decree No. 122/1980 Sb., on a one-off contribution to the procurement of new housing for citizens who free up an apartment in a building administered by a state socialist organisation.

230. Decree No. 69/1982 Sb., amending and supplementing Decree No. 122/1980 Sb., of the Federal Ministry of Finance, Ministry of Finance of the Czech Socialist Republic and the Ministry of Finance of the Slovak Socialist Republic, on a one-off contribution to the procurement of new housing for citizens who free up an apartment in a building administered by a state socialist organisation.

231. Decree No. 136/1985 Sb., on financial, credit and other assistance for cooperative and individual housing construction and modernisation of family houses in private ownership.

232. Decree No. 74/1989 Sb., amending and supplementing Decree No. 136/1985 Sb., of the Federal Ministry of Finance, Ministry of Finance of the Czech Socialist Republic, the Ministry of Finance of the Slovak Socialist Republic and the President of the State Bank of Czechoslovakia, on financial, credit and other assistance for cooperative and individual housing construction and modernisation of family houses in private ownership.

233. Decree No. 73/1991 Sb., amending and supplementing Decree No. 136/1985 Sb., of the Federal Ministry of Finance, Ministry of Finance of the Czech Socialist Republic, the Ministry of Finance of the Slovak Socialist Republic and the President of the State Bank of Czechoslovakia, on financial, credit and other assistance for cooperative and individual housing construction and modernisation of family houses in private ownership, as amended by Act no. $\underline{74 / 1989 \mathrm{Sb}}$.

234. Decree No. 398/1992 Sb., amending and supplementing Decree No. 136/1985 Sb., of the Federal Ministry of Finance, Ministry of Finance of the Czech Socialist Republic, the Ministry of Finance of the Slovak Socialist Republic and the President of the State Bank of Czechoslovakia, on financial, credit and other assistance for cooperative and individual housing construction and modernisation of family houses in private ownership, as amended by Act no. $\underline{74 / 1989 \mathrm{Sb}}$, , and Decree $\underline{73 / 1991 \mathrm{Sb}}$.

235. Decree No. 89/1998 Sb., amending Decree No. 136/1985 Sb., of the Federal Ministry of Finance, Ministry of Finance of the Czech Socialist Republic, the Ministry of Finance of the Slovak Socialist Republic and the President of the State Bank of Czechoslovakia, on financial, credit and other assistance for cooperative and individual housing construction and modernisation of family houses in private ownership, as amended.

236. Decree No. 385/2000 Sb., amending Decree No. 136/1985 Sb., of the Federal Ministry of Finance, Ministry of Finance of the Czech Socialist Republic, the Ministry of Finance of the Slovak Socialist Republic and the President of the State Bank of Czechoslovakia, on financial, credit and other assistance for cooperative and individual housing construction and modernisation of family houses in private ownership, as amended.

237. Decree No. 440/2001 Sb., on compensation for pain and deteriorated social position. 
238. Decree No. 50/2003 Sb., amending Decree No. 440/2001 Sb., on compensation for pain and deteriorated social position.

\section{Section 3081}

\section{Effect}

This Act becomes effective on 1 January 2014.

\section{Němcová, signed}

Klaus, signed

Nečas, signed

1) Council Directive of 25 July 1985 on the approximation of the laws, regulations and administrative provisions of the Member States concerning liability for defective products $(85 / 374 / E E C)$.

Council Directive of 20 December 1985 to protect the consumer in respect of contracts negotiated away from business premises (85/577/EEC).

Council Directive of 18 December 1986 on the coordination of the laws of the Member States relating to self-employed commercial agents (86/653/EEC).

Council Directive of 22 June 1987 on the coordination of laws, regulations and administrative provisions relating to legal expenses insurance $(87 / 344 / E E C)$.

Council Directive of 13 June 1990 on package travel, package holidays and package tours (90/314/EEC).

Council Directive of 5 April 1993 on unfair terms in consumer contracts (93/13/EEC).

Directive of the European Parliament and of the Council of 20 May 1997 on the protection of consumers in respect of distance contracts (97/7/EC).

Directive of the European Parliament and of the Council of 6 October 1997 amending Directive 84/450/EEC concerning misleading advertising so as to include comparative advertising (97/55/EC).

Directive of the European Parliament and of the Council of 16 February 1998 on consumer protection in the indication of the prices of products offered to consumers $(98 / 6 / E C)$.

Directive of the European Parliament and of the Council of 25 May 1999 on certain aspects of the sale of consumer goods and associated guarantees $(1999 / 44 / E C)$.

Directive of the European Parliament and of the Council of 29 June 2000 on combating late payment in commercial transactions. (2000/35/EC).

Directive of the European Parliament and of the Council of 12 December 2006 concerning misleading and comparative advertising (2006/114/EC).

Directive of the European Parliament and of the Council of 14 January 2009 on the protection of consumers in respect of certain aspects of timeshare, long-term holiday product, resale and exchange contracts $(2008 / 122 / E C)$.

Directive of the European Parliament and of the Council 2009/101/EC of 16 September 2009 on coordination of safeguards which, for the protection of the interests of members and third parties, are required by Member States of companies within the meaning of the second paragraph of Article 48 of the Treaty, with a view to making such safeguards equivalent. 